\title{
Kapitel V: Arbor-Viren (durch Arthropoden übertragbare Viren)
}

\section{A. Allgemeines}

Die Bezeichnung "Arbor-Virus«" ) ist eine Abkürzung für »arthropod borne« virus, wodurch charakterisiert werden soll, daß diese Viren durch Arthropoden (Gliederfüßler), und zwar durch Insekten und Arachnoidea (Acarina = Milben im weitesten Sinn einschl. Zecken) übertragen werden. Um zu den Arbor-Viren gerechnet zu werden, müssen sie aktiv durch Biß (Blutmahlzeit) von dem betreffenden Gliederfüßler an einem infizierten Individuum während des virämischen Stadiums aufgenommen, später mit dem Speichel des Gliederfüßlers wieder ausgeschieden werden und dann durch einen erneuten $\mathrm{Biß}$ in ein anderes Individuum gelangen. Als Überträger kommen also nur blutsaugende Ektoparasiten in Frage, in deren Geweben das Virus sich konserviert oder vermehrt (s. WHO, 1961 c; KRIEG, 1961; TAYLOR, 1962).

Die bei den Insekten gefundenen Arbor-Viren sind nicht mit echten Insektenviren, d. h. solchen, die bei Insekten Krankheiten hervorrufen, zu verwechseln. Sie sind vielmehr für Insekten nicht pathogen. Thre Entdeckung war mehr oder weniger ein Zufallsbefund bei der Erforschung des Gelbfiebers. Die nach der Entdeckung dieser Viren in den betreffenden Gebieten vorgenommenen epidemiologischen Untersuchungen (Immunitätsnachweise) haben ergeben, daß Infektionen der Menschen mit den Arbor-Viren außerordentlich häufig sind.

Erst wenn ein Arbor-Virus isoliert und charakterisiert worden ist, ist eine Klärung der Ätiologie der durch dieses hervorgerufenen Krankheit oder seines natürlichen Zyklus möglich. Der Ausbruch einer Arbor-Viruskrankheit beim Menschen kann plötzlich im Beginn und beschränkt in seiner Dauer sein. Am Ende des Ausbruches kann das Virus manchmal aus dem betroffenen Gebiet verschwinden (WHO, 1961c).

Das Gelbfieber ist die erste Viruskrankheit, bei der als Überträger eine Mücke (Aedes aegypti) gefunden worden ist (Finlay, 1881 c, REED, 1901, 1911). Auch die Dengue wird durch diese Mücke übertragen. Doerr u. a. (1909a) fanden, daß das Pappataci-Fieber durch eine andere Mücke, den Phlebotomus pappatasii, übertragen wird. Anschließend wurden weitere Insekten als Überträger von Viruskrankheiten aller Arten ermittelt, besonders auch von solchen des ZNS des Menschen und der Tiere (s. Band 2). Die meisten Arbor-Viren stammen von tropischen Mücken in Afrika und Süd- und Mittelamerika; dementsprechend kommen auch die meisten Infektionen von Menschen und anderen Wirbeltieren in den Tropen vor. Bisher sind bereits etwa 120 Arbor-Viren isoliert worden; ihre Zahl dürfte aber noch weiter zunehmen. Etwa die Hälfte dieser Viren erzeugt Infektionen bei Menschen und/oder Tieren. Theiler und CaSals (1959) sowie SAbin (1959 a) nehmen an, daß die durch Arthropoden über-

1) Наммом u. a. (1960a) schlugen vor, besser von »Arbo«-Viren zu sprechen, um Irrtümer mit »arbor" = Baum zu vermeiden. 
tragenen Viren keine völlig verschiedenen Erreger, sondern auf gemeinsame Entwicklungsstufen zurückzuführen sind. Sie weisen auf die Wichtigkeit einer internationalen Zusammenarbeit für die weitere Erforschung dieser Erregergruppe durch Virologen, Epidemiologen, Zoologen, Botaniker, Kliniker und Statistiker hin.

Aus den bisher noch sehr lückenhaften epidemiologischen Untersuchungen geht hervor, daß die Arbor-Virusinfektionen des Menschen und der Haustiere einem Viruskreislauf angehören, der Wirbeltiere und Gliederfüßler (Wirbellose) umfaßt. Allerdings scheinen der Mensch und seine Haustiere keine notwendigen Glieder dieses Viruszyklus zu sein. Vielfach sind die Menscheninfektionen sogar nur zufällige Ereignisse. Um den Menschen zu infizieren, ist für ein "wildes" Arbor-Virus Viscerotropismus erforderlich (Weinbren und Williams, 1958). Nach C.E. G. Sмгтн (1959) kann ihre Epidemiologie nur mittels der quantitativen Ökologie der Wirbeltier-Wirbellose-Virus-Gemeinschaft oder Biozenose (Audy, 1958) verstanden werden. Das Am-Leben-Bleiben eines Arbor-Virus in einem Gebiet beruht also wahrscheinlich immer auf der gesamten Biozenose, innerhalb welcher sowohl das Wirbeltier als auch der Gliederfüßler als Viruswirt oder Reservoir erforderlich sind. Wirbellose Wirte sind besonders wichtig zum "Überwintern" eines Arbor-Virus während der kalten Jahreszeit (ReEves, 1958a, b). Zur Lebenderhaltung des Virus in dieser Biocenose müssen beide Wirtsarten in genügender Zahl und Dichte vorkommen. Wird dieses Verhältnis durch Immunisierung der Säugetierwirte oder durch Vernichtung der Überträger gestört, so kann es zur Ausrottung des betreffenden Virus kommen (s. auch Miles; PavLovsky, zit. WHO, 1961c).

Während transovarielle (germinative) Virusübertragungen bei den Insekten, vor allem Mücken, nicht bekannt sind, kommen solche bei den Arachnoidea (Milben, Zecken) vor: bei letzteren scheint schon dadurch der Fortbestand des Virus ohne andere Zwischenwirte möglich zu sein.

Die Infektion der Menschen und Haustiere erfolgt gewöhnlich durch den Biß der Arthropoden. Durch zahlreiche Laboratoriumsuntersuchungen sind aber auch andere Übertragungsweisen bekannt geworden: Einatmung des Virus oder Berührung des Virus mit der Haut oder Bindehaut (z. B. Rifttal-Fieberinfektionen durch Berührung mit virushaltigen tierischen Geweben) oder Trinken von Milch mit russischen ZeckenKrankheiten infizierter Ziegen.

Klinisch findet man bei Arbor-Viruskrankheiten häufig biphasische Fieberkurven. Gewöhnlich geht das erste Fieber mit der Allgemeininfektion einher, deren wichtigster Ausdruck die Virämie ist. Bei dem 2. Fieber treten die schweren und eigentlichen Leitsymptome der betreffenden Krankheit auf (Hepatitis bei Gelbfieber, Hämorrhagien bei den hämorrhagischen Fiebern und Encephalitis bei verschiedenen Virusinfektionen des ZNS). Während des 1. Fiebers vermehrt sich das Virus im allgemeinen in den Organen, wobei gewöhnlich Leukopenie besteht. Während des 2. Fiebergipfels findet sich dagegen häufig Leukozytose.

Gelegentlich finden sich im Blut von Menschen Viren ohne erkennbare klinische Manifestationen. Infolgedessen ist es schwierig zu entscheiden, ob ein Virus, das im Blut eines Patienten mit Fieber isoliert wird, irgendeine ätiologische Bedeutung hat, insbesondere wenn die Isolierung des betreffenden Virus auf einen Einzelfall beschränkt bleibt, wie dies z. B. bei dem Oropouche-Virus bisher der Fall gewesen ist (ANDERson u. a., 1961).

Eine Einteilung der Arbor-Virusinfektionen nach den klinischen Erscheinungen ist nicht möglich. Verschiedene Stämme desselben Virus können verschiedene Krankheitsbilder, andererseits aber auch ganz verschiedene Viren gleiche Krankheitserscheinungen erzeugen.

CASALs und Brown (1954) nahmen eine Gruppeneinteilung der Arbor-Viren auf Grund von serologisehen Reaktionen (HAHR, KBR und NR) vor. Mittels der HAHR sind zunächst 3 verschiedene immunologische Gruppen A, B, C gefunden worden. Viele noch nicht gruppierte Arbor-Viren, die antigen nicht mit den Gruppen A, B und C verwandt zu sein scheinen, wurden von TheILER und CASALS (1959) zu einer weiteren, aber wahrscheinlich noch nicht vollständigen Gruppe zusammengefaßt. CASALs und WhitmaN (1960) stellten innerhalb dieser Gruppe 4 Viren fest, die eine neue serologische Gruppe 
bilden. Nach ihrem wichtigsten Vertreter wird diese 4. Gruppe als »Bunyamwera-Gruppe» bezeichnet. Als 5. Gruppe bleiben die noch nicht klassifizierten Viren übrig. Zur Identifizierung eines Arbor-Virus ist nach Casals (1961) nicht nur die Bestimmung des ArborVirus-Charakters überhaupt, sondern auch die der Antigengruppe und des Typs innerhalb der Gruppe erforderlich.

Zur Differenzierung der verschiedenen Viren eignet sich oft ihr sehr charakteristisches Verhalten in den verschiedenen Zellkulturarten, im Hühnerembryo und auf der CAM. Nach Taylor (1959) vermehren sich die Viren der Gruppe A von CaSals in Hühnerund Entenembryozellen, Entennieren- und Affennierenzellen in vitro, die der Gruppe B nur in Entennierenzellen, die der Gruppe C nur in Affennierenzellen. Diese Angaben entsprechen allerdings nicht den Beobachtungen anderer Autoren bezügl. der ausschließlichen Vermehrung der B-Viren in Hühnerembryozellkulturen, denn nach Rosenberger und SHAw (1961) übertreffen Hamsternierenzellkulturen alle anderen bisher benutzten Zellstämme auch als Kulturmedium für B-Viren (s. auch Dierks und Hammon, 1957, 1958, 1959; Dierks, 1959; SchMtdт, J. R., 1959).

Nach Kissuing (1960) ist die Infektion in den Amnionsack von Hühnerembryonen zum Nachweis der A-Viren EEE und WEE noch empfindlicher als die von Hamsternierenzellkulturen; sie eignet sich daher auch besser zur Isolierung dieser Viren, wenn nur wenig Material vorhanden ist.

Rosenberger und Shaw (1961) heben hervor, daß die Viren der Gruppe A in Hamsternierenkulturen im allgemeinen einen größeren ZE als Viren der Gruppe B ergeben und auch schneller einen höheren Titer erreichen, sowie daß alle Arbor-Viren bei der Züchtung in Zellkulturen etwas von ihrer Mäusepathogenität verlieren (s. auch KIssLiNG, 1957; 1960). Nach Pattyn u. a., 1960) bildeten unter den von ihnen untersuchten Abor-Viren in primären Menschenamnion- und L-Zellkulturen nur die EEE- und Bunyamwera-Viren einen ZE.

Henderson und Taylor $(1959,1960)$ fanden bei der Züchtung einer Anzahl von Viren der A-, B- und C-Gruppen, daß die Plaquebildungsprobe (PBP) empfindlicher als die Titrierung der Viren in Mäusesäuglingen und auch sicherer als der ZE zur Feststellung der Virusvermehrung ist. Die PBP wurde erstmalig von Dulbecco u. a. (1956) zur Austitrierung des WEEVirus in Hühnerfibroblasten-Einschichtzellkulturen verwandt. Die PB-Endpunkte lagen im allgemeinen höher als die ZE-Endpunkte, gemessen an der $\mathrm{GKID}_{50}$ oder $\mathrm{LD}_{50}$ für Mäuse. Die Differenzierung von Arbor-Viren der Gruppen A, B und C mittels der Plaquegröße oder -form wird allerdings für sehr schwierig und sogar unmöglich gehalten. Unterschiede zwischen diesen Gruppen ließen sich nur durch die Plaquebildung in spezifischen Gewebekultursystemen feststellen. Die Plaquebildung nach der Virusaussaat erforderte im allgemeinen für A-Viren (EEE, Middelburg) 2-3 Tage in Hühnerembryozellkulturen, für B-Viren (WN, SLE) 5-6 Tage in Peking-Entennierenkulturen, für C-Viren (Marituba, Oriboca) 6-7 Tage in Rhesusaffennierenkulturen. Ein ZE trat, wenn überhaupt vorhanden, gewöhnlich in derselben Zeit wie die Plaques auf (s. auch Henderson, 1961). Bei Verwendung von Hühnerfibroblastenkulturen ergab sich nach PoRTerfield (1960) innerhalb der Arbor-Virusgruppe A, daß Größe und Zeit des Auftretens von Plaques unabhängig von der Zugehörigkeit des Virus zu einer serologischen Untergruppe waren. Die beiden WEE- und EEE-Viren bildeten Plaques, welche in 24-36 St. erschienen, nach 48 St. einen Durchmesser von 4-6 mm erreichten und später noch größer wurden. Semlikiwald-Plaques wurden etwas später sichtbar und waren etwas kleiner. Mayaro-Plaques erschienen erst am 3. Tage und wurden nur 2-3 mm groß. Chikungunya-Plaques erschienen ebenfalls am 3 . Tage, blieben aber noch kleiner und weniger deutlich.

Innerhalb der Arbor-Virusgruppe B erschienen Zeit des Auftretens, Größe und Deutlichkeit der Plaques in erheblichem Maße von der Zusammensetzung der Medien abhängig zu sein. Zusatz von 5\% Hühnerembryoextrakt zum Überschichtungsmedium erhöhte die Genauigkeit der Probe erheblich. Die WN-, Uganda S-, JE- und Wesselsbron-Viren erzeugten Plaques, die 
am 2. oder 3. Tage p. i. sichtbar wurden und bis zu $5 \mathrm{~mm}$ Durchmesser erreichten. Das ZikaVirus ähnelte dem Gelbfieber 17D-Virus, indem es nur kleinere Plaques bildete, die erst am 4. oder 5. Tage sichtbar wurden. Das Springkrankheits-Virus (Louping ill) bildete Plaques, die bis zum 7. Tage undeutlich blieben und dann auch nur 2-3 mm groß wurden.

Die Arbor-Viren agglutinieren Erythrozyten von Eintag-Küken, Hähnen und Gänsen. Gänseerythrozyten ergeben im allgemeinen 1-2 Verdünnungen höhere Titer als Hahnerythrozyten (Porterfield, 1957; Salminen, 1959). Hennenerythrozyten werden dagegen meist nicht agglutiniert. Dieser Unterschied tritt besonders deutlich bei mit Zucker-Aceton-extrahierten Mäusegehirn- und Gewebekulturantigenen aus hemmstofffreien Medien hervor (s. später). Durch Behandlung mit Protaminsulfat $(0,75 \mathrm{mg} / \mathrm{ml})$ werden die Antigene aus noch unbekannten Gründen befähigt, auch Hennenzellen zu agglutinieren; d. h. die Geschlechtsunterschiede der Zellen werden verwischt. Da Erythrozyten frisch geschlüpfter Küken beiderlei Geschlechtes ebenfalls agglutinierbar sind, scheinen die Erythrozyten der Weibchen ihre Reaktionsfähigkeit in einem gewissen Lebensalter zu verlieren. Ähnliche Geschlechtsunterschiede wurden auch bei Truthühnererythrozyten, nicht dagegen bei Gänseerythrozyten beobachtet. Nach Salminen (1962a, b, d) fällt dieser Zeitpunkt mit dem Erreichen der Geschlechtsreife der Hennen (4-5 Monate) zusammen. Hieraus wird geschlossen, daß die weiblichen Geschlechtshormone eine Rolle beim Verschwinden der Agglutinierbarkeit spielen könnten. Aus Versuchen in dieser Richtung scheint hervorzugehen, daß Vorbehandlung junger Hähne mit Progesteron oder Testosteronpropionat die Agglutinierbarkeit ihrer Erythrozyten in einem $\mathrm{p}_{\mathrm{H}}$-Bereich von 5,8-6,8 bei Zimmertemperatur durch verschiedene A- und B-Viren (Sindbis, EEE, WEE, Semlikiwald, Gelbfieber, Uganda S, JE, zentraleuropäische ZME, WN) nicht beeinflußt. Dagegen führen Östradiolbenzoat und Diäthylstilbestrol bei jungen und erwachsenen Hähnen zu einem vollständigen oder fast vollständigen Verlust der Agglutinierbarkeit. Diese Veränderung ist allerdings nur vorübergehend; 5-7 Tage nach Beendigung der Hormonbehandlung erscheint sie nach und nach wieder. Möglicherweise beruht die Wirkung der östrogenen Hormone auf die Agglutinierbarkeit darauf, daß die Virusrezeptoren auf der Erythrozytenoberfläche von hyperlipämischem Plasmamaterial eingehüllt werden, denn Versuche von EnTenman u. a. (1940) hatten gezeigt, daß Östrogene im Hühnerplasma eine Hyperlipämie erzeugen. Die Hormone könnten aber auch die Zahl der Arbor-Virus-Rezeptoren auf den Zellen herabsetzen (Salminen, $1962 \mathrm{a}, \mathrm{b}, \mathrm{d}$ ).

Untersuchungen von ANGiLillo und MASCA (1959) über das HA-Vermögen (Kükenerythrozyten) ergaben, daß die B-Stämme Ilhéus, Ntaya, Uganda $S$ bei verschiedenem $p_{H}$ und verschiedener Temperatur agglutinierten, während der A-Stamm Sindbis mit höchsten Titern nur bei $\mathrm{p}_{\mathrm{H}} 6,4-6,7$ und $4^{\circ} \mathrm{C}$ sowie bei $\mathrm{p}_{\mathrm{H}} 6,0-6,7$ und $37^{\circ} \mathrm{C}$ agglutinierte.

Hämagglutinierende Antigene von Arbor-Viren werden gewöhnlich aus infektiösen Mäusesäuglingsgehirnen gewonnen (Clarke und Casals, 1958). Porterfield und Rowe (1960) extrahierten aus den Gehirnen i. cer. infizierter 4 Tage alter Mäusesäuglinge mit Fluorkohlenstoff wirksame Hämagglutinine der A-Viren EEE, WEE, Chikungunya, Semlikiwald und der B-Viren Gelbfieber (französischer neurotroper Stamm), Uganda S, WN, Zika, Ntaya, Dengue, Louping ill. Besonders deutliche HA wurde mit Aceton-extrahierten Hämagglutininen aus Louping ill- und Chikungunya-Viren erhalten.

Über Versuche, HA-Aktivität in Arbor-Virus-infizierter Zellkulturflüssigkeit nachzuweisen, liegen zahlreiche Veröffentlichungen vor (s. auch Daniels, 1958; Clarke, 1960a). So wiesen Kundin und Dierks (1960) sowie Dierks u. a. (1961) Hämagglutinine einer Reihe von ArborViren in Hamsternierenkulturen nach, deren Medium $4 \%$ Pferdeserum enthielt. Salminen (1960) erhielt einen hohen HA-Titer eines ZME-Virus in stabilisierten (kontinuierlichen) Menschen-Amnionzellkulturen in einem Medium, das anstatt Serum Rinderplasmaalbumin enthielt. Dieses Medium bestand aus:

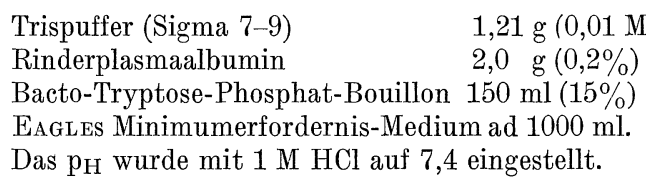


Salminen (1962a, b, c) erhielt auf diese Weise Hämagglutinine der A-Viren Sindbis, WEE, EEE, Semlikiwald und der B-Viren Gelbfieber, JE, Uganda S, ZME, WN. Das A-Virus Chikungunya und die B-Viren Ntaya und Dengue 2 bildeten dagegen unter diesen Bedingungen kein Hämagglutinin.

Die Viren wurden in der Kulturflüssigkeit durch Erwärmen $\left(37^{\circ} \mathrm{C}\right)$ abgetötet (s. auch NIR und Goldwasser, 1961; Rosenberg und Shaw, 1961), ohne daß das HA-Vermögen geschädigt wurde. Der HA-Titer zeigte also die Gesamtmenge an totem und lebendem Virus in der Kulturflüssigkeit an. Das HA-Vermögen der Kulturflüssigkeit konnte durch Behandlung mit Protaminsulfat $(0,75 \mathrm{mg} / \mathrm{ml})$ gesteigert werden. Nach dieser Behandlung ließen sich die Viren bei $\mathrm{p}_{\mathrm{H}} 9,0$ durch Wärme $\left(30^{\circ} \mathrm{C}, 4\right.$ Wochen oder $37^{\circ} \mathrm{C} 2$ Wochen je nach Virusart) abtöten, ohne daß ihr HA-Vermögen geschädigt wurde. Die mit Protamin behandelten, durch Erwärmung inaktivierten Hämagglutinine wurden durch spezifische und Über-Kreuzreagierende Immunseren in gleicher Weise wie die Mäusegehirnantigene gehemmt. Außerdem hatten sie Immunisierungsvermögen, wie Schutzversuche an Mäusen und Immunisierungsversuche an Meerschweinchen zeigten.

Die A- und B-Viren haben 2 Hämagglutinine, von denen das eine der El. K. selbst ist (s. auch Mussgay, 1957; Cheng, 1959). Das andere ist in seiner Natur noch unbekannt, kleiner oder weniger dicht sowie durch Protaminsulfat präzipitierbar; es scheint ein Oberflächenbestandteil des Virus zu sein. Beide haben verschiedene Sedimentierungsmerkmale (Sмiтн und Holt, 1961).

Porterfield und Rowe (1960) stellten fest, daß die $H A$ sämtlicher B-Viren durch rohe $\alpha$ - und $\beta$-Lipoproteinextrakte und rohe Menschen-Erythrozytenextrakte gehemmt wird, die des A-Virus WEE dagegen nicht. Ei-Lecithin hemmte in der gewählten Konzentration 8 untersuchte B-Viren nicht, dagegen 4 untersuchte A-Viren. Auch in Gewebekulturen von Arbor-Viren, deren Nährflüssigkeit normale Menschen- oder Tierseren enthält, kann das HAVermögen durch in diesen Seren enthaltene unspezifische Hemmstoffe "maskiert" werden. Eine chemische Analyse dieser Hemmer ergab Gemische von Palmitinsäure und Cholesterin sowie von Lecithin und Cholesterin, d. h. Cholesterin mit einem Phospholipid oder einer freien Fettsäure (Salminen, 1962e). Die erforderliche Menge des Hemmstoffes beträgt etwa $4 \times 10^{-10} \mathrm{Mol}$. Diese Hemmstoffe können durch Aceton-Extraktion oder Kaolin-Adsorption aus den Seren entfernt werden (Clarke und CASALS, 1958). Durch Aceton-Extraktion können auch die maskierten Hämagglutinine aus den serumhaltigen Nährmedien wiedergewonnen werden (Salminen, 1962 b, c). Chemisch definierte Hemmstoffe können also unter Umständen zur Klassifizierung der Arbor-Viren brauchbar sein.

Theiler (1957) stellte fest, daß ein gemeinsames Merkmal aller Arbor-Viren ihre große Empfindlichkeit gegen $\mathrm{Na}$ desoxycholat ist. Sie werden durch Verdünnungen zerstört, gegen welche zahlreiche andere Viren, z. B. Polio, Coxsackie, Mäuse-EM, Columbia-SK, unempfindlich sind (s. auch BURNET und Lush, 1940). Nach diesen Autoren wirken auch die oberflächenaktiven Verbindungen Saponin und Na laurylsulfat virusinaktivierend (Louping ill). Thre Wirkung scheint auf dem Abbau der El.K. infolge Entfernung von Strukturlipiden zu beruhen, wobei RNS abgegeben wird (ANDERson und Ada, 1959). Sunaga u. a. (1960) beobachteten, daß außer Na desoxycholat auch Äther die A-Viren EEE, Sindbis, Semlikiwald, die B-Viren Ilhéus, WN, JE, die C-Viren Marituba, Oriboca sowie die Bunyamwera-Viren Bunyamwera, California inaktiviert (s. auch Birch, 1941; Sulkin und ZARAFonetis, 1947; Hotta und Evans, 1956). Die Empfindlichkeit der Arbor-Viren gegen Äther und Na desoxycholat ist also ein wichtiger Anhalt für die Charakterisierung eines noch unbekannten Virusisolats als Arbor-Virus, da sie gestattet, eine Reihe anderer Viren, die im entnommenen Material (Entero-Viren) oder in den beimpften Tieren (z. B. Mäuse-EM) vorhanden sein könnten, auszuschlieBen (CaSals, 1961b; s. auch Hardy und Scherer, 1961).

Cheng (1958b) fand, daß das HA-Vermögen und die Infektiosität der B-Viren REFSE, Zika, Dengue, Ilhéus, JE, SLE, Ntaya, SAH 366, WN, Gelbfieber (französ. neurotroper Stamm) durch Trypsin, Chymotrypsin und Papain inaktiviert werden, der A-Viren WEE, EEE, VEE, Sindbis, Semlikiwald dagegen nicht. Die inaktivierende Wirkung der Enzyme scheint auf 
einer unmittelbaren proteolytischen Wirkung auf die El. K. zu beruhen. Der Unterschied der Viren in ihrer Proteaseempfindlichkeit gestattet vielleicht eine chemische Differenzierung der beiden serologischen Gruppen A und B. Ferner könnte eine Bestimmung der NS-Natur der B-Viren möglich sein (s. auch Cheng, 1956). Nach Anderson und Ada (1960) wird das B-Virus Murray-Tal durch Phospholipase A inaktiviert. Hieraus scheint hervorzugehen, daß Phospholipid für die Erhaltung der Virusteilchenstruktur und damit für die biologische Aktivität des Virus erforderlich ist.

Nach Allison u. a. (1962) sind die A-Viren vollständig resistent gegen Sulfhydrylverbindungen, andere Arbor-Viren dagegen nicht.

Nach PoRTERFIELd (1959b, d) kann man die Wirkung von Interferon (aus Hühnerembryooder Kaninchenzellkulturen) mit Hilfe der Plaquehemmungsprobe (PHP) in Einschichtzellkulturen von 10 tägigen Hühnerembryonen feststellen (s. auch Porterfield u. a., 1960). In Kulturen, die mit Gelbfiebervirus infiziert waren, erreichten die Hemmungszonen einen Durchmesser von 20-30 mm. Das Interferon wirkte noch hemmend, wenn es erst 18-24 St. p.i. den Kulturen zugesetzt wurde. Die Grenze zwischen der Plaquehemmungszone und dem Gebiet normaler Plaques war allerdings nicht sehr scharf. Größere Hemmungszonen wurden bei den beiden sich langsam vermehrenden Arbor-Viren WN und Bunyamwera im Vergleich zu dem sich schneller vermehrenden WEE-Virus beobachtet. Besonders klare und scharfe Hemmungszonen traten in den mit Bunyamwera-Virus infizierten Kulturen auf. Der Durchmesser der Hemmungszone stand im umgekehrten Verhältnis zur Virusdosis, aber im direkten Verhältnis zur Interferonkonzentration. Allerdings hatte eine Verdünnung von 1:125 auf das Bunyamwera-Virus keine Hemmwirkung mehr.

Eins der wichtigsten Merkmale vieler Arbor-Virusinfektionen ist die häufige Immunität in einem Gebiet ohne hohe Erkrankungsziffer.Vielfach wird sie im Kindesalter erworben, ohne daß die Infektion zu einer schweren oder sogar erkennbaren Erkrankung führt. Die Infektionen bleiben anscheinend auf die blutbildenden und Jymphatischen Systeme beschränkt, von denen die Virämie ausgeht, die wiederum Voraussetzung für die Virusaufnahme durch Biß der Arthropoden ist. Die Arbor-Virusinfektionen führen gewöhnlich zu einer dauernden Immunität. TheILER und CASALS (1959) unterscheiden grundsätzlich 2 verschiedene Arten der Seroreaktionen:

1. der Wirt ist zum erstenmal mit dem Virus einer Gruppe infiziert worden: Einzel- oder Erst(Primär-)infektion,

2. der Wirt ist früher schon einmal mit einem Virus derselben Gruppe infiziert worden: Doppel- oder Superinfektion.

Der Nachweis von AK (HAHR, KBR, NR) gestattet die spezifische Diagnose der Infektion. Die HAHR eignet sich zur Bestimmung der Viren der A- und B-Gruppen besser als die KBR, während für die Viren der C-Gruppe (Casals und Whitman, 1961) und der Bunyamwera-Gruppe (Casals und Whitman, 1960) die KBR besser geeignet ist. In allen 4 Hauptgruppen ist die Mäuseschutzprobe (i.cer. NR) im allgemeinen spezifischer als die HAHR oder die KBR. Andererseits greift die Mäuse-NR erheblich über, und zwar oft mehr als die HAHR und KBR. Es ist aber zu bedenken, daß die Infektionen mit einem Virus auch zur AK-Bildung gegen andere Viren derselben Gruppe führt.

Die Plaque-Hemmungsprobe ist ein genauer qualitativer Test für $N$-AK gegen ein bekanntes plaquebildendes Virus. Versuche mit dem Gelbfiebervirus und einer Reihe verschiedener Antiseren haben eine hohe Spezifität ergeben. Die Hemmungszone in der Einschichtzellkultur ist direkt proportional zum Logarithmus der im Agar enthaltenen AK-Konzentration.

Die Erstinfektion mit einem Virus der Gruppe A erzeugt sehr schnell homologe $H A H-A K$. Derartige AK gegen ein anderes Virus der Gruppe können entstehen oder auch nicht; sie zeigen aber fast immer einen niedrigeren Titer als die homologen AK. Die Erstinfektion mit einem Virus der Gruppe B führt dagegen sehr schnell auch zur Bildung von HAH-AK gegen andere Virusarten der Gruppe, und zwar in derselben Höhe wie gegen das infizierende Virus. Dies macht eine Diagnose schwierig oder unmöglich. 
Die $K B-A K$ nach Erstinfektion mit einem Virus der Gruppen A oder B sind außerordentlich spezifisch: Heterologe AK fehlen entweder oder weisen einen viel niedrigeren Titer auf als die homologen.

Die $N-A K$ sind nach einer Primärinfektion oft spezifisch (i.cer. Mäuseschutzversuch). Kreuzreaktionen kommen aber vor. Besonders im Schutzversuch an jungen Mäusen läßt sich die Bildung heterologer AK nachweisen. So ergeben Dengue-, WN-, JE- und Ilhéus-Virusinfektionen Gelbfieber-N-AK. Hieraus wird nach Infektion mit einem Virus der Gruppe B auf eine relative Immunität auch gegen ein anderes Virus dieser Gruppe geschlossen.

Die AK-Bildung bei einer Superinfektion unterscheidet sich grundsätzlich von jener der Einzelinfektion. Soweit bei B-Infektionen bekannt ist, werden die AK sehr schnell gebildet. Die HAHR und KBR ergeben zwar hohe Titer, sind aber nicht spezifisch wie bei einer Erstinfektion. Meist werden höhere heterologe als homologe AK-Titer gefunden. Auch die Bildung heterologer N-AK kann nach einer Superinfektion sehr bedeutend sein, so daß die spezifische Serodiagnose sehr schwierig oder sogar unmöglich wird. In diesem Fall führt nur der Erregernachweis zu einer spezifischen Diagnose. Wahrscheinlich treffen die bei Gruppe B-Infektionen gemachten serologischen Beobachtungen auch für die Gruppe A zu.

Die Untersuchung der Seren von Bewohnern 15 verschiedener Ortschaften im AmazonasTal auf AK gegen 14 Arbor-Viren mit der NR an der Maus, die am spezifischsten zu sein scheint (Causey und Theiler, 1958), ergab einen hohen Prozentsatz von Seren mit AK gegen Gelbfieber (44,7\%), Ilhéus (36,2\%), VEE $(16,7 \%)$ und Semlikiwald $(13,9 \%)$, einen geringeren Prozentsatz von Seren mit AK gegen Dengue $1(9,6 \%)$, WN $(6,1 \%)$, SLE $(5,5 \%)$, Bunyamwera $(4,7 \%)$, EEE $(4,1 \%)$, Zika $(4 \%)$, Uganda S $(2,1 \%)$, Dengue $2(2 \%)$ und WEE $(1,6 \%)$. Nur gegen Bwamba-Virus wurden keine AK gefunden. Die serologischen Untersuchungen gegen Uganda S, Zika, WN, SLE, Dengue 2 und WEE waren nicht so eindeutig, daß sie auf das Vorhandensein dieser Viren im Amazonas-Gebiet mit Sicherheit hinweisen (s. auch SweEt u. a., 1962; Wisseman u. a., 1962; Wisseman und Sweet, 1962).

Im Tierversuch ist eine Kreuzimmunität zwischen verschiedenen Viren festgestellt worden, so z. B. zwischen der Springkrankheit (louping ill) und der REFSE (CASALS, 1944,) zwischen WN-, Murray-Tal-, SLE und JE (Hammon und Sather, 1956) sowie zwischen Semlikiwald und Chikungunya (CASALS, 1957). Küken, die mit dem JE-Virus infiziert wurden, wiesen einen gewissen Schutz gegen WN-Virus auf. Auch die Virämie war bei ihnen geringer als bei nicht zuvor heterolog infizierten Küken. Mücken, die ihre Blutmahlzeit bei nur mit WN-Virus infizierten Vögeln genommen haben, sollen die Infektion leichter bekommen und weiter übertragen als Mücken, die Blut von Vögeln aufnahmen, welche vor der WN-Infektion mit JE-Virus immunisiert worden waren (PRICE, 1956).

Allen bisher isolierten Arbor-Viren ist gemeinsam, daß sie i.cer. auf Mäusesäuglinge und junge Mäuse, vielfach aber auch auf erwachsene Mäuse übertragbar sind. Sie vermehren sich außer in Säugetieren auch in Vögeln.

GARD (1958) hat die Merkmale der nach seiner Ansicht wichtigsten Vertreter der ArborViren wie folgt zusammengestellt: 
Tabelle 31

Nach GARD (1958)

\begin{tabular}{|c|c|c|c|c|c|c|c|c|c|}
\hline $\begin{array}{l}\text { Unter- } \\
\text { gruppe }\end{array}$ & Virus & Ref. & & $\begin{array}{l}\text { IA* } \\
\text { Temp }\end{array}$ & & $\mathrm{H}^{*}$ & $\begin{array}{l}\mathrm{KB} * \\
\mathrm{~A}\end{array}$ & $\begin{array}{l}\text { Kanin- } \\
\text { chenpa- } \\
\text { thoge- } \\
\text { nität }\end{array}$ & Vektoren \\
\hline \multirow{3}{*}{ A } & & $\begin{array}{l}\text { Ten Broeeck } \\
\& \text { MerriLl }\end{array}$ & 6.4 & 37 & & - & - & & \\
\hline & WEE & Mey er \& Mitarb. & 6.5 & 37 & $(+)$ & - & - & + & Stechmücken \\
\hline & VEE & Веск \& WускоғF & 6.4 & 37 & $(+)$ & - & -- & + & Stechmücken \\
\hline \multirow{7}{*}{ B } & SLE & $\begin{array}{l}\text { MUCKENFuss } \\
\text { \& Mitarb. }\end{array}$ & 6.8 & 37 & - & + & -+ & - & Stechmücken \\
\hline & $\mathrm{JE}$ & HAYASHI & 7.0 & 37 & - & + & -+ & - & Stechmücken \\
\hline & $\begin{array}{l}\text { Murray } \\
\text { Valley }\end{array}$ & $\begin{array}{l}\text { Cleeland } \\
\text { CAMPB ELL }\end{array}$ & 6.4 & 37 & - & + & -+ & - & Stechmücken \\
\hline & Louping IIl & Pool \& Mitarb. & 6.8 & 4 & - & + & -+ & - & Zecken \\
\hline & REFSE & SMORODINTSEFF & 6.8 & 4 & - & + & -+ & - & Zecken \\
\hline & Gelbfieber & & 6.4 & 37 & - & + & -+ & - & Stechmücken \\
\hline & Dengue & & 6.8 & 4 & - & + & -+ & - & Stechmücken \\
\hline
\end{tabular}

EEE, WEE und VEE = Östliche, Westliche und Venezolanische Equine Encephalitis, REFSE $=$ Russische epidemische Frühjahr-Sommer-Encephalitis. * Hämagglutination (HA) und Hämagglutinationshemmung (HAH) nach CASALS: $(+)$ und + geben übergreifende Gruppenreaktionen an. ** Komplementbindung (KB) gekreuzte (Gruppen-)Reaktionen.

Rhodes und van Rooyen (1958) stellten die wichtigsten Eigenschaften einiger ArborViren in Tabelle 32 (S. 587) zusammen.

\section{Weitere Literatur:}

Hoogstraal (1958), Darlington (1960), Mattingly (1960), Smith (1960).

\section{B. Arbor-Viren, Gruppe A}

Die zur Gruppe A gehörenden Arbor-Viren sind in der Tabelle 33 aufgeführt.

BARON u. a. (1961) sahen in überschichteten Hühnerembryozellkulturen nach Infektion mit A-Viren Plaquebildung nur bis zu einer gewissen Tiefe. Sie führten dies auf die mit zunehmender Tiefe geringer werdende O-Spannung zurück. Aber selbst bei eng verwandten Viren (Chikungunya, Semlikiwald einschließlich Kumba und O'nyong-nyong) ergaben sich Unterschiede im 0-Bedarf, der also keine Gruppengemeinsamkeit ist.

IsaAcs u. a. (1961b) fanden Übereinstimmung zwischen der Tiefe der Virusvermehrung in agargefüllten Röhrchen und der Empfindlichkeit dieser Viren gegen die hemmende Wirkung des Interferons. Viren mit Interferonempfindlichkeit zeigten einen großen O-Bedarf. Interferonzusatz verringerte die Tiefenvermehrung der Viren. Das Interferon schien stärker in den O-ärmeren Schichten der Röhrchen zu hemmen. Herabsetzung des verfügbaren $\mathrm{O}$ durch 


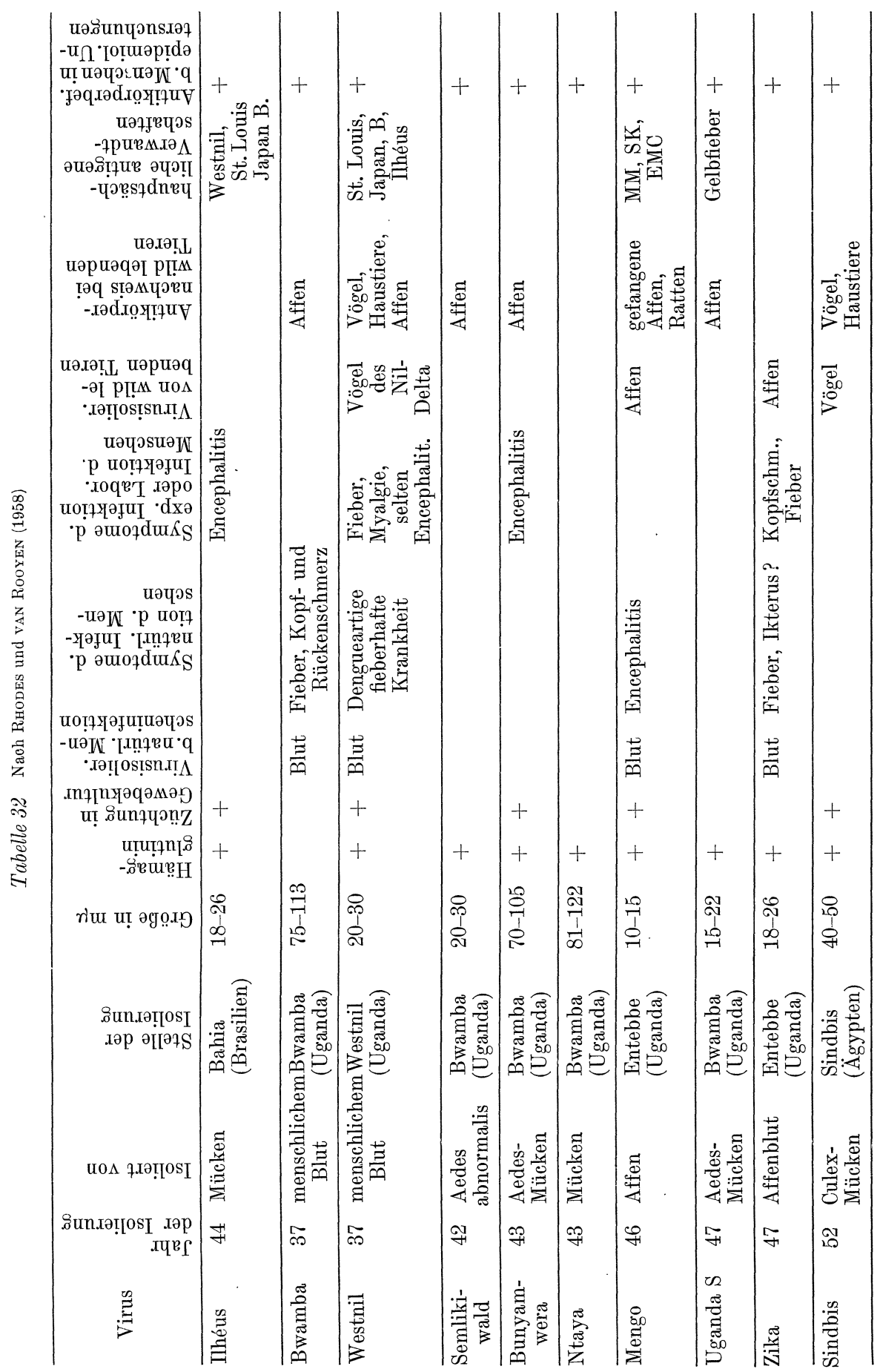




\begin{tabular}{|c|c|c|c|c|c|c|c|c|c|c|c|c|}
\hline 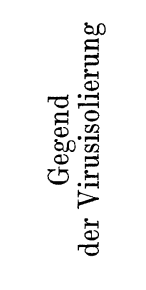 & 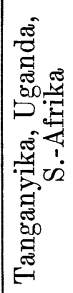 & 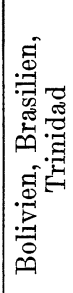 & 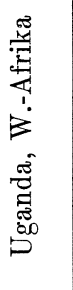 & 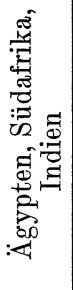 & 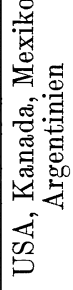 & 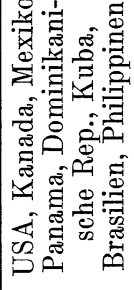 & 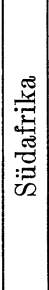 & 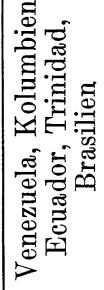 & 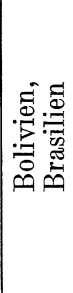 & 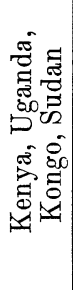 & 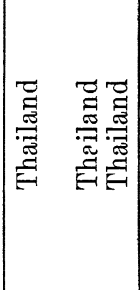 & 宽 \\
\hline 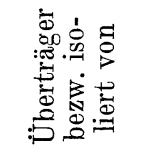 & 总 & 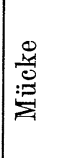 & 总 & 总 & 总 & 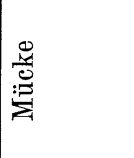 & 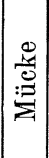 & 总 & & 总 & & \\
\hline 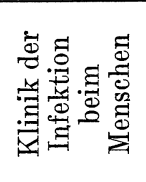 & 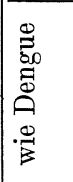 & 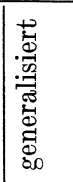 & & & 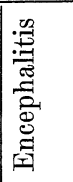 & 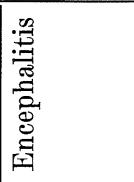 & & 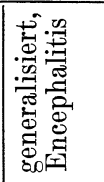 & 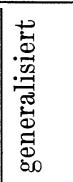 & 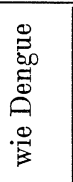 & 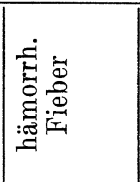 & \\
\hline 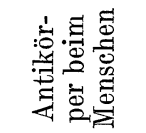 & + & + & + & + & + & + & + & + & + & + & & + \\
\hline 总总 & + & + & + & + & + & + & + & + & & + & ++ & + \\
\hline 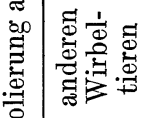 & & & & + & + & + & & + & & & & + \\
\hline 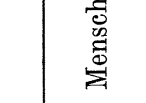 & + & + & & & + & + & & + & + & + & $+\quad++$ & \\
\hline 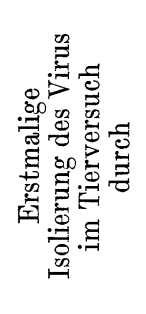 & $\begin{array}{l}0 \\
0 \\
0 \\
\overrightarrow{1} \\
w \\
0 \\
0 \\
0 \\
0\end{array}$ & 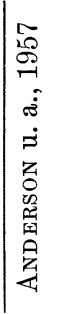 & 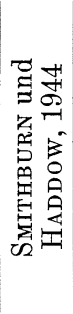 & 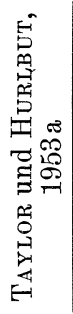 & 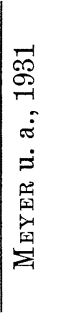 & 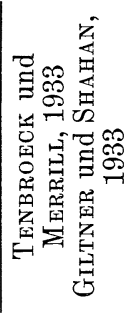 & 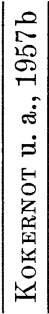 & 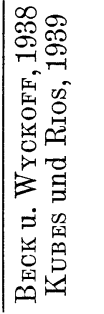 & 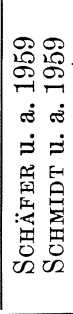 & 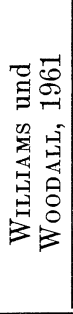 & 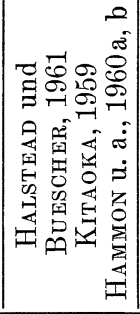 & \\
\hline 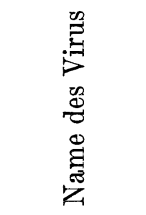 & 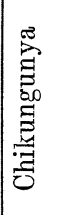 & 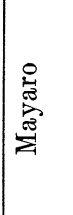 & 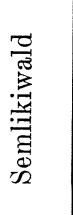 & 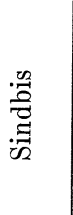 & 岳 & 空 & 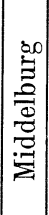 & 絰 & 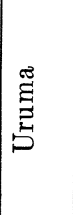 & $\begin{array}{l}\infty \\
5 \\
0 \\
0 \\
0 \\
80 \\
0 \\
0 \\
\vdots \\
0 \\
0\end{array}$ & 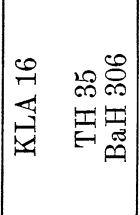 & 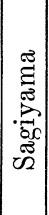 \\
\hline
\end{tabular}


Zusatz von Na thioglycolat oder durch Vergrößerung der Tiefe oder Konzentration der Agarschicht führte zu einer Zunahme der Interferonwirkung. Steigerung der verfügbaren OMenge entweder durch Bebrütung der Kulturen in O-reicher Atmosphäre oder durch Verminderung der Agarschichtdicke bedingte eine Abnahme der Interferonwirkung. Diese Beobachtungen entsprechen der Hypothese, daß Interferon den Oxydationsprozeß, der die für die Virussynthese benötigte Energie liefert, hemmt. Nach IsaAcs u. a. (1961a) wirkt es durch Auskupplung einer oxydativen Phosphorylation, vielleicht im Kern (s. auch Ho und Enders, 1959 b; Chany, 1960; Isaacs und Baron, 1960; Canteli, 1961).

Milanovic u. a. (1957) hatten anläßlich der Züchtung des Sindbis-Virus in primären menschlichen Amnionzellkulturen das Ausbleiben des üblichen ZE festgestellt, wenn diese Kulturen mit einem Corynebacterium verunreinigt waren. CARver und NAFICY (1962) fanden in einem unidentifiziert gebliebenen Corynebacterium einen Faktor, der die beiden Gruppe A-Viren Sindbis und Chikungunya in Kulturen von menschlichen Amnionzellen und Hühnerembryozellen hemmte. Der ZE von 7 anderen verwandten Viren wurde dagegen nicht gehemmt. Die Interferenz beruht auf einer Hemmung der Neubildung dieser Viren, nachdem sie in die Zellen eingedrungen sind. Der Hemmfaktor scheint ein Protein zu sein. Es wird darauf hingewiesen, daß die bisher bekannten Virushemmer mit Ausnahme von Interferon keine Proteine sind. Der hier beschriebene Faktor "BIF« ist nicht mit Interferon identisch. Seine Aktivität wird durch Säure zerstört, während Interferon unbeschädigt bleibt. Interferon reduziert die Virusvermehrung, während BIF sie ganz unterdrückt.

Porterfield (1961b) stellte mit der PHP fest, daß Sindbis- und WEE-Viren nur einwegig verwandt sind, sowie daß Middelburg- und EEE-Viren keine Verwandtschaft mit anderen Viren der Gruppe haben. Die übrigen Viren haben gemeinsame Komponenten, welche mit Kaninchenhyperimmunseren gegen Semlikiwald-Virus reagieren. Bei Benutzung von Einzeldosen-Kaninchenseren oder spezifischen Mäuseimmunseren können 4 Serotypen unterschieden werden:

1. Chikungunya-Virus und seine Unterstämme (Vereeniging. TH 35

2. Mayaro- und Uruma-Virus

3. Semlikiwald-Virus

4. O'nyong-nyong-Virus

Tabelle 34

Gruppenimmunitätsreaktionen (HAHR) bei Meerschweinchen, die nacheinander mit 2 verschiedenen Viren der Gruppe A infiziert wurden.

(Nach Casals, 1961 b)

\begin{tabular}{l|c|c|c}
\hline \multirow{2}{*}{ Antigen (8 Einheiten) } & \multicolumn{2}{|c}{ Titer der Meerschweinchenseren nach Infektion mit } \\
\cline { 2 - 4 } & Mayaro & Mayaro + Sindbis & Sindbis \\
\hline Mayaro & $2560 / 20480$ & $5120 / 10240$ & 0 \\
Chikungunya & $80 / 40$ & $320 / 1280$ & 0 \\
Semlikiwald & $160 / 80$ & $1280 / 1280$ & 0 \\
AMM 2021 & $320 / 80$ & $1280 / 2560$ & 0 \\
AMM 2354 & $20 / 40$ & $640 / 640$ & 0 \\
Sindbis & $0 / 20$ & $640 / 1280$ & 640 \\
WEE & $20 / 80$ & $1280 / 2560$ & 320 \\
Aura (Ar 10315) & $0 / 0$ & $160 / 1280$ & - \\
Middelburg & $0 / 20$ & $320 / 1280$ & 0 \\
EEE & $0 / 0$ & $160 / 1280$ & 0 \\
VEE & $0 / 0$ & & 0 \\
\hline
\end{tabular}

Für die Doppelinfektion (zuerst Mayaro, dann Sindbis) wurden 2 Meerschweinchen verwandt; das 3. Tier wurde nur mit Sindbis infiziert.

$0=$ keine Reaktion mit der niedrigsten Verdünnung von $1: 20$ 
Auf die Pferde-EM-Viren wird hier nicht eingegangen, da bei ihnen das klinisch dominierende Syndrom die EM ist (siehe 2. Band). Es sollen hier also nur folgende Viren und die durch sie hervorgerufenen Infektionen besprochen werden: Chikungunya, Mayaro, Uruma, O'nyongnyong, KLA16, Semlikiwald, Sindbis, Middelburg und Sagiyama. Weitere Viren der Gruppe A sind Aura (BeAr 10315), Una (BeAr 13136), beide in Belém, Brasilien, isoliert, sowie AMM 2021 und AMM 2354, beide in Malaya isoliert (CASALS, 1961b). Alle bisher bekannten AViren werden durch Mücken übertragen und agglutinieren Gänseerythrozyten.

\section{B I. Chikungunya-Virusinfektionen}

Seit dem Jahre 1952 wird im südlichen Tanganyika-Territorium (Newala-Distrikt) eine anscheinend neue epidemisch auftretende dengue-artige Krankheit beobachtet, deren Bezeichnung bei den Eingeborenen "Chikungunya" ist, was etwa "Krankheit, welche die Gelenke spannt« bedeutet. Die erste Epidemie wurde von RoBinson (1955) und Lumsden (1955b) studiert und beschrieben (s. auch HADDow, 1953, Ross, 1953). Inzwischen trat die Krankheit auch in Uganda, Portug.-Ostafrika, im ehemaligen Belgisch-Kongo, in der Südafrikanischen Union, Nordrhodesien und Bangkok auf. AK gegen das Virus wurden in Nigeria und sogar in Malaya angetroffen. Auch bei Schimpansen (Pan troglodytes) sind AK nachgewiesen worden (Osterrieth und Delaplaque-Liegeols, $1961 \mathrm{a}$; s. auch Ross, 1956). Die Verbreitung scheint sich demnach über verschiedene Kontinente zu erstrecken (CASALS, 1957: Olitsky und CaSALS, 1959).

Ross (1956) isolierte das Virus aus dem Blut akut Kranker und aus Aedes aegypti-Suspensionen. Hammon u. a. (1960; s. auch Rudnick und Hammon, 1960) isolierten bei einem Kranken mit hämorrhagischem Fieber aus dem Blut sowie aus einem A.aegypti ein mit dem Chikungunya-Virus identisches Virus.

Zur i.cer. oder i.p. Infektion dienten Mäusesäuglinge. Im Gegensatz zum Dengue-Virus läßt sich das Chikungunya-Virus erstaunlich leicht auf Mäusesäuglinge übertragen .(s. auch Gear und Reid, 1957; Mason und Haddow, 1957; Osterrieth und Blanes-Ridaura, 1960; Osterrieth u. a., 1960). McIntosh (1961) fand verschiedene wilde Nagetierarten (Mystromys, Arvicanthis, Mastomys, Saccostomus, Aethomys, Tatera) für das Virus empfänglich. Diese bekamen mitunter eine stärkere Virämie und bildeten AK.

Ross (1956) stellte 2 Virustypen mit verschiedener Gehirnpathogenität für Mäusesäuglinge fest. Der eine Typ „Chikungunya-Virus« umfaßt Stämme mit kurzer Inkubationszeit, hoher Letalität und leichter Passagierbarkeit von Gehirn zu Gehirn unter Auslösung charakteristischer Symptome (Streckkrämpfe des Kopfes und der Beine, spastischer Tremor). Die Infektiositätstiter der Mäusegehirne für 6 Tage alte Tiere betrug $10^{-6}$ bis $10^{-8}$, die mittlere Sterbezeit 4 Tage. Junge erwachsene Mäuse (28 Tage) sind weniger empfänglich. Das im Mäusesäuglingsgehirn adaptierte Virus erzeugte erst nach 160 Passagen eine tödliche Infektion bei erwachsenen Mäusen, aber nur bis zu einem Titer von $10^{-6}$. Die Inkubationszeit betrug hier 4-8 Tage. Der Tod trat nach 3-5 Tagen ein. Die Mäuse erkrankten an Encephalitis, Myositis und Myokarditis (Weinbren, 1958; Weinbren u. a., 1958a, b). Bei 38 Tage alten Mäusen trat der Tod nur gelegentlich ein. Der andere Typ »Makonde-Virus" umfaßt Virusstämme, die eine lange Inkubationszeit bei Mäusen haben. Die Viren töteten im Gegensatz zum ersten Typ auch regelmäßig über 14 Tage alte Mäuse. Beide Typen waren im Kreuzimmunisierungsversuch unterscheidbar. Ross (1956) ist der Ansicht, daß nur das Chikungunya-Virus die Menschenkrankheit erzeugt, während die Bedeutung des MakondeVirus in der Humanpathologie noch ungeklärt ist.

Weinbren (1958) sowie Weinbren u. a. (1958a, b) sahen einen Affen, der mit Mückensuspensionen infiziert worden war, an Fieber, Reizbarkeit und Gesichtsblässe erkranken. Virämie und N-AK wurden nachgewiesen.

Meerschweinchen und Kaninchen scheinen nicht empfänglich zu sein.

Eine Zü̈htung des Virus gelang Spence und Thomas (zit. Buckley, 1959) in Hühnerembryozellkulturen, ohne daß es zu ZE kam, während BuckLey (1959) das Virus in HeLaZellkulturen fortlaufend züchten konnte, in denen schwere Zellzerstörungen auftraten. Diese 
begannen mit herdförmiger Zellnekrose (Mikroplaques) und setzten sich über die ganze Einschichtzellkultur fort.

Nach Baron und Isaacs (1961) nahm die Sterblichkeit der Hühnerembryonen nach Verimpfung von Chikungunya-Virus $\left(10^{4}-10^{5} \mathrm{ID} / 0,5 \mathrm{ml}\right)$ in den Dottersack mit zunehmendem Alter ab. Sie war bei den 4-7 Tage alten Embryonen hoch, bei den 10-13 Tage alten aber fast ebenso niedrig wie bei den normalen Kontrollen. Aus diesen Beobachtungen scheint hervorzugehen, daß das Überleben der Embryonen bei Vorhandensein eines funktionierenden Interferonmechanismus auch ohne AK möglich ist (s. auch IsaACs und BARoN, 1960). Dieser beginnt vom 8. Lebenstag des Embryos an aktiv zu werden (IsaAcs und Нттснсоск, 1960).

Das Virus bildet ein Hämagglutinin, zu dessen Nachweis Gänseerythrozyten geeignet sind (Porterfield, 1957).

Nach Mason und Haddow (1957) ist das Virus in infektiösem Menschenserum bei - $20^{\circ} \mathrm{C}$ aufbewahrt mindestens $2^{1} / 2$ Jahre haltbar. In Glycerin bei $-20^{\circ} \mathrm{C}$ aufbewahrt bleiben die isolierten Virusstämme 43 Tage am Leben; in infektiösen Mückenpools, die mit Glycerin versetzt waren, hielt sich das Virus 47 Tage (Ross, 1956).

Das Virus ist ätherempfindlich (WeInBREN, 1958; WeINBRen u. a., 1958a, b).

Die Chikungunya-Krankheit wird offenbar durch Mücken von Mensch zu Mensch übertragen. Der Hauptüberträger scheint der A.aegypti zu sein (Haddow, 1953; Ross, 1956). Außerdem kommen als natürliche Überträger noch A.africanus (gefangen im Zikawald) und Culex fatigans in Frage (Lumsden, 1955b; Rodger, 1961). Mücken, welche Kranke im akuten Stadium beißen, sind noch 33 Tage später virushaltig (Ross, 1956). Das Virus vermehrt sich im Mückenkörper; es läßt sich von Mücke zu Mücke (A.aegypti) mit Speicheldrüsengewebe passagieren (Whitman, 1956, zit. Olitsky und Casals, 1959). Da für jede Passage eine Speicheldrüsenverdünnung von $10^{-5}$ verwandt werden konnte, muß in der Mücke eine starke Virusvermehrung stattfinden.

Die Ausbreitung durch die Mücken scheint sehr leicht und schnell zu erfolgen. Innerhalb kurzer Zeit werden alle Bewohner einer Hütte befallen; nach 2-3 Wochen können schon 60-80\% der Bevölkerung einer Ortschaft erkrankt sein (Lumsden, 1955 b; RoBinson, 1955).

Ross (1956) fand das Virus auch in Bettwanzen, welche in den Betten von kürzlich erkrankt Gewesenen gesammelt worden waren.

Afrikanische Eingeborene, Europäer und Asiaten scheinen gleich empfänglich zu sein. Über 45 Jahre alte Menschen waren in manchen Gegenden der Epidemiegebiete resistent.

Die Inkubationszeit scheint 2-6 Tage zu betragen (GEAR und REID, 1957). RoBINson (1955) hat folgende Beschreibung der Krankheit gegeben: Sie beginnt plötzlich mit allgemeinem Unbehagen und Fieber von $38-40^{\circ} \mathrm{C}$, das 1-6 Tage anhält; nach einer fieberfreien Periode von 1-3 Tagen kommt es meist zu einer 2. Fieberphase, die aber nur 1-2 Tage anhält, weniger hoch ist und von einem makulopapulösen Ausschlag in etwa $80 \%$ der Fälle begleitet ist. Auffallend sind die von Beginn sehr schweren Gelenkschmerzen, die gelegentlich mit Schwellungen einhergehen. Fieberlose Erkrankungen kommen vor. Infolge der Schmerzen liegen die Kranken mit allen Gelenken in Beugestellung. Gewöhnlich besteht auch leichter Kopfschmerz. Lichtscheu wird beobachtet. Die Symptome können so schlagartig einsetzen, daß die Kranken schon innerhalb weniger Minuten völlig unbeweglich sind (RoBIsson, 1956). Die Erkrankung scheint nur eine Woche zu dauern. Die Gelenkschmerzen können jedoch noch monatelang weiterbestehen. Drüsenschwellungen fehlen. Gewöhnlich tritt Leukopenie auf. Der Puls kann im Vergleich zur Fieberhöhe verlangsamt sein. Gear und ReID (1957) sahen lokalisierte Neuritiden und arthritische Knötchen. Tödliche Krankheitsverläufe sind nicht beobachtet worden. RODGER (1961) beschrieb einen Ausbruch verdächtiger Chikungunya-Infektionen; 3 von 13 Fällen verliefen mit Pneumonie.

Über die pathologische Anatomie und Histologie der Krankheit ist noch nichts bekannt.

Die klinische Diagnose erstreckt sich im wesentlichen auf eine Abgrenzung gegen Dengue und WN-Fieber. Bei der Chikungunya-Krankheit fehlen die Lymphdrüsenschwellungen; die Kopfschmerzen bleiben gering oder fehlen ganz. Ebenso fehlen die retrobulbären Augenmuskelschmerzen; dagegen ist der chronische Verlauf der Gelenkschmerzen charakteristisch. Wichtig ist die Laboratoriumsdiagnose. Sie erstreckt sich auf den Virusnachweis im Mäuseversuch. Ist dieser gelungen, so muß das Virus noch serologisch identifiziert werden, und zwar 
zur Abgrenzung gegen die Dengue-, Mayaro- und Semlikiwald-Viren. Zur Diagnose gehört auch der Nachweis von N-AK. Serumpaare aus der akuten Krankheitsphase und der Rekonvaleszenz ergeben einen Anstieg der AK für das Chikungunya-Virus.

Bei der Leichtigkeit des Verlaufs und dem Fehlen von tödlichen Ausgängen ist die Prognose als durchaus gut zu bezeichnen.

Die Behandlung ist rein symptomatisch und beschränkt sich auf die Schmerzbekämpfung, welche allerdings unter Umständen die Anwendung von Opiaten erfordert.

Bisher sind außer N-AK auch KB-AK und HAH-AK nachgewiesen worden. Die NR wird als Schutzprobe an der Maus angestellt. Mason und HadDow (1957) fanden eine Vermehrung der N-AK von der akuten Phase bis zur Rekonvaleszenz von 0,6 auf 2,2 log. 32 von 44 Rekonvaleszentenseren, für die keine entsprechenden Seren aus der akuten Phase zum Vergleich zur Verfügung standen, neutralisierten 400 Mäuse- $\mathrm{LD}_{50}$ des Chikungunya-Virus.

Immunologisch bildet das Chikungunya-Virus mit den Mayaro-, Semlikiwald- und O'nyongnyong-Viren eine Untergruppe der Arbor-Virusgruppe A (Spence und Thomas, 1956). Die 4 Viren lassen sich durch ihre HAH-AK unterscheiden, da die Titer gegen das homologe Virus höher als gegen die heterologen Viren sind, während ihre antigene Verwandtschaft besonders in der NR hervortritt. Chikungunya-Antiseren neutralisieren sowohl Semlikiwaldals auch Mayaro-Virus, letzteres stärker (s. auch McIntosh u. a., 1961).

HadDow (1953) unterschied 2 antigen verschiedene Typen a und $b$, wobei letzterer dem "Chikungunya-Typ" von Ross (1956) entsprach, der eine kreuzweise NR mit dem DengueVirus Neuguinea B und dem Sindbis-Virus ergab. Der a-Typ wies keine serologische Verwandtschaft mit einem bekannten Virus auf.

Die Prophylaxe beschränkt sich auf die Sanierung durch Mückenbekämpfung und entspricht hierin dem Vorgehen bei Gelbfieber und Dengue.

\section{B II. Mayaro-Fieber}

ANderson u. a. (1957) isolierten 1954 in Trinidad bei 5 Fällen einer leicht fieberhaften Erkrankung in der akuten Phase aus dem Serum ein Virus durch i.cer. Verimpfung auf Mäusesäuglinge. CASals und Whitman (1957) bezeichneten das Virus als "Mayaro-Virus" nach dem Gebiet, wo der erste Fall beobachtet wurde. Aтtкen u. a. (1960) konnten das Virus in Trinidad erstmalig von in der Wildnis natürlich infiziert gewesenen Mücken (Mansonia venezuelensis) isolieren. Grooт u. a. (1961) fanden 4 Stämme von Mayaro-Virus in der Waldmücke Psorophora in Kolumbien.

ANderson u. a. (1957) gelang eine i.cer. und i.p. Fortzüchtung des Virus auf 2 Tage alten Mäusesäuglingen (s. auch AтtKen u. a. 1960). Die $\mathrm{LD}_{50}$ für diese betrug etwa 10-7. Mit zunehmender Passagenzahl wurde die Inkubationszeit kürzer (2-5 Tage). Die Mäuse starben dann nach 1-3 Tagen unter Erscheinungen wie Schwäche, Reizbarkeit, Freßunlust. Sie zeigten gelegentlich in den ersten Passagen auch schlaffe Lähmungen. Erwachsene Mäuse erkrankten meist nicht erkennbar. Nach AItKen u. a. (1960) war der Virusstamm TR 4675 für erwachsene Mäuse nach i.cer. Verimpfung nicht pathogen, während der Stamm TR 15536 mäßig pathogen war.

Das mäuseadaptierte Virus ließ sich auf Meerschweinchen übertragen, welche gelegentlich unter nervösen Erscheinungen erkrankten und starben.

Bei der Züchtung in Hühnerembryozellkulturen beobachtete BUCKLEY (1959) keinen ZE (s. auch Aitken u. a., 1960); ein solcher trat aber in HeLa-Zellen auf: die Einschichtzellkultur wurde vollständig zerstört. AItKen u. a. (1960) gelang auch eine Züchtung in Hamsternierenkulturen. Porterfield (1960) beobachtete in Einschichtzellkulturen von Hühnerembryofibroblasten, die mit Agar überschichtet waren, Plaquebildung. Diese wurde durch Zusatz von spezifischem Antiserum durch Neutralisation des Virus gehemmt.

In primären Hühnerembryozellkulturen fand zwischen dem Mayaro- und dem SindbisVirus infolge der Infektionsmultiplizität des interferierenden Mayaro-Virus eine Infektionsinterferenz und infolge der Bildung eines Hemmers in den mit Mayaro-Virus infizierten Zellen eine Hemmerinterferenz statt (HEND ERSON und TAYLOR, 1961). Erstere war nur nachweisbar, 
wenn vollinfektiöses Mayaro-Virus oder RN-ase-empfindliche Komponenten, die durch 2\%ige $\mathrm{Na}$ desoxycholat-Behandlung gewonnen worden waren, verwandt wurden. Sie trat nicht auf, wenn das Mayaro-Virus durch Immunserum, Erhitzen oder UV-Licht inaktiviert worden war. Nach Zusatz von mit Na desoxycholat behandeltem Mayaro-Virus konnte kein infektiöses Virus zurückgewonnen werden; die Zellen waren aber trotzdem gegen eine nachfolgende Sindbis-Infektion resistent. Wahrscheinlich handelte es sich bei der aktiven interferierenden Einheit um die Virus-NS selbst (s. auch Ho und Enders, 1959a; Henderson und Taylor, 1960a, b; Hitchcock und Isaacs, 1960; Wagner, 1960). Der Hemmer, der in den mit Mayaro-Virus infizierten Zellkulturen 72-96 St. p. i. erschien, interferierte mit der Plaquebildung durch das Sindbis-Virus. Er hatte viele Eigenschaften, die bei den durch Influenzaund anderen Viren hervorgerufenen interferonartigen Substanzen beschrieben worden sind. Der nach der Behandlung des Mayaro-Virus mit Na desoxycholat erhaltene Anteil hemmte etwa $10^{2}$ bis $10^{4} \mathrm{PBE}$ des Sindbis-Virus.

Zur HA eigneten sich am besten Gänseerythrozyten (Porterfield, 1957). Casals und Whitman (1957) konnten mittels Aceton-Ätherextraktion aus dem Virus (Tr-4675) ein brauchbares Hämagglutinin herstellen, während AтткеN u. a. (1960) dies nur durch ZuckerAcetonextraktion gelang. Es agglutinierte Hühnererythrozyten bei Temperaturen von $4^{\circ}$, $22^{\circ}$ und $37^{\circ} \mathrm{C}$ und in einem optimalen $\mathrm{p}_{\mathrm{H}}$ von 6,4 .

Das Mayaro-Virus ist bisher außer in Trinidad in Kolumbien durch AK-Nachweis bei der Bevölkerung festgestellt worden (Buescher, 1955; SAnMartin-Barberi, 1956; zit. Olitski und Casals, 1959). In Pará (Brasilien) brach 1955 eine umschriebene Epidemie aus, welche 50 Erkrankte umfaßte (Causey und Maroja, 1957).

Die Virämie und die sonstigen Umstände lassen eine Insektenübertragung vermuten. Whitman (zit. Anderson u. a., 1957) stellte fest, daß der Stamm Tr-4675 sich nach experimenteller Infektion Jeicht sowohl in A.aegypti als auch in Anopheles quadrimaculatus vermehrt.

Die Infektion des Menschen verläuft mit leichtem Fieber, schwerem Stirnkopfschmerz, gelegentlichem epigastrischem Schmerz, Rückenschmerzen und leichter Gelbsucht. Die Krankheitsdauer beträgt 2-6 Tage (OLItsky und CaSals, 1959).

Da noch keine Todesfälle aufgetreten zu sein scheinen, ist über die pathologischen Prozesse im einzelnen noch nichts bekannt.

Die Diagnose erfordert die Virusisolierung und die serologische Untersuchung zur Identifizierung des Erregertypes.

Bei dem leichten Verlauf scheint die Prognose durchaus gut zu sein.

Die Behandlung beschränkt sich auf symptomatische Maßnahmen.

ANDERSON u. a. (1957) untersuchten 2 der 5 von ihnen isolierten Virusstämme auf ihre antigenen Eigenschaften mittels der NR, KBR und HAHR. Beide Stämme waren serologisch nicht von einander zu trennen und enger mit dem Chikungunya-Virus als mit den anderen Viren der Gruppe A verwandt, so daß das Mayaro-Virus auch zu dieser Untergruppe gehört. McInтosн u. a. (1960) bestätigten die antigene Verwandtschaft des Mayaro-Virus mit den Chikungunya- und Semlikiwald-Viren durch serologische Untersuchungen bei Bewohnern von Natal und Portugisisch-Ostafrika (s. auch Sanna und Angelillo, 1959).

In kreuzweisen i.p. Schutzversuchen an Mäusesäuglingen neutralisierten Mäuseimmunseren gegen Mayaro (Tr-4675)- und Semlikiwald-Virus beide in hohen Konzentrationen (CAUSEY und Maroja (1957). Quantitative Unterschiede scheinen nicht zu bestehen. Auch Mäuseimmunserum gegen WEE-Virus neutralisierte Mayaro (Tr-4675)- und Semlikiwald-Virus in erheblichem Maße. Casals und Whitman (1957) glauben auf Grund dieser Untersuchungen, daß die im Amazonas-Tal als Semlikiwald-positiv angesehenen Antiseren in Wirklichkeit Mayaro-Antiseren waren (s. auch CAUSeY und TheILeR, 1958).

In kreuzweisen KB-Versuchen mit Mayaro- und Semlikiwald-Viren und ihren Immunseren (Maus) ergab sich folgendes: Semlikiwald-Immunserum reagierte mit homologem Virus mit einem Titer von 1: 256, mit Mayaro-Virus dagegen nur von 1:32, d. h. Semlikiwald-Immunserum reagierte mit homologem Virus 8 mal stärker. Wurden dagegen beide Immunseren gegen Mayaro-Virus geprüft, so ergab sich, daß Semlikiwald-Immunserum mit heterologem Virus 16 mal schwächer reagierte. Auch in Serumpaaren von Kranken und Rekonvaleszenten 
wurde eine stärkere Zunahme der HAH-Titer gegen homologes als gegen Semlikiwald-Virus festgestellt.

Die serologischen Unterschiede in der KBR und HAHR sind groß genug, um das MayaroVirus als selbständigen Erreger vom Semlikiwald-Virus zu trennen.

Die Prophylaxe scheint bei der Leichtigkeit der Krankheit bedeutungslos zu sein. Soweit eine Mückenbekämpfung in Frage kommt, richtet sich diese gegen A.aegypti und Anopheles quadrimaculatus mit denselben Mitteln wie bei Gelbfieber und Dengue.

\section{B III. Uruma-Dschungelfieber}

Von 400 Okinawa-Pionieren, welche sich im Regenwald in der Tiefebene Boliviens in der Nachbarschaft des Matto Grosso (Brasilien) angesiedelt hatten, erkrankte fast die Hälfte an einem fieberhaften Syndrom ohne besondere pathognomonische Erscheinungen. Die Krankheit wurde als »Uruma-Dschungelfieber" bezeichnet.

Schaeffer u. a. (1959) sowie Schmidt u. a. (1959) isolierten aus dem Blut von 2 Patienten ein Virus, das i.cer. und i.p. auf eintägige Mäusesäuglinge übertragbar war. Diese erkrankten an Lähmungen und starben nach 2-6 Tagen. 3-4 Tage alte Mäuse waren schon weniger empfänglich. 10 tägige Mäuse überlebten eine i.cer. Infektion mit $10^{7}$ Mäusesäuglings- $\mathrm{LD}_{50}$ des Virus ohne Krankheitssymptome. Meerschweinchen und neugeborene Hamster waren ebenfalls hochempfänglich, erwachsene Hamster dagegen nur wenig. Junge erwachsene Kaninchen erkrankten zwar nicht nach i.p. Infektion, entwickelten aber N-AK.

Das Virus ließ sich in Zellkulturen von Hamsterniere, KB-Karzinom des Menschen, Menschenleber und Affenniere züchten. In der Reihenfolge dieser Zellarten nahm der ZE ab. Vollständige Zellzerstörung trat nach 3-4, 4-6, 5-9 bzw. 8-9 Tagen ein. In 7-8tägigen Hühnerembryonen war nach Impfung in den Dottersack eine Züchtung des Virus möglich. In der 7. Passage tötete eine 10\% ige Virussuspension die Embryonen nach durchschnittlich 3,6 Tagen.

Die Epidemie unter den Okinawa-Pionieren dauerte von Oktober 1954 bis Februar 1955. Von den insgesamt 403 Siedlern erkrankten 192 (47,6\%), wobei es sich um eine Mindestzahl handelt, da ganz leichte und klinisch inapparent verlaufende Fälle wahrscheinlich nicht erfaßt wurden. 132 Fälle betrafen das männliche, 60 das weibliche Geschlecht. 15 Kranke, davon 3 Kinder, starben.

Das Uruma-Dschungelfieber wird offenbar wie die anderen Arbor-Viren durch Insekten übertragen. Welche Species in Frage kommt, wurde noch nicht ermittelt. SchaEFFER u. a. (1959) weisen darauf hin, daß es nicht möglich ist, bei den im Dschungel vorkommenden Fieberformen den ökologischen Zykluskomplex (Säugetier, Vögel, Insektenüberträger), der jeweils in Frage kommt, festzustellen.

Als typisch wird folgender Krankheitsverlauf geschildert: plötzlicher Fieberanstieg, unbestimmte Muskelschmerzen, Schlaflosigkeit, leichte Ermüdbarkeit, geringer Appetit, meist Schüttelfrost beim Temperaturanstieg. Das Fieber, das am 2.-3. Tag $39^{\circ}-40,5^{\circ} \mathrm{C}$ erreichte, war außerdem von Stirnkopfschmerz, Glieder- und Rückenschmerzen, besonders in der Lendengegend, und allgemeinem Krankheitsgefühl begleitet. In 10\% der Fälle bestanden Übelkeit und Erbrechen; Schluckauf gilt als bedenkliches Zeichen. Lichtscheu, Nackensteifigkeit, Bewußtseinstrübungen, Krämpfe, Gelbsucht und andere spezifische Hauterscheinungen fehlten; dagegen wiesen 3-4\% einen leichten flüchtigen makulo-erythematösen Ausschlag zwischen dem 3. und 6. Krankheitstage auf. Bereits frühzeitig trat Polyurie auf, die 3 Liter täglich erreichen konnte. Gelegentlich bestand vorübergehende Albuminurie. Manchmal war der Blutdruck herabgesetzt. Der Puls pflegte schneller zu sein, als dem Fieber entsprach. Leichte nichteitrige Konjunktivitis und leichte generalisierte nicht schmerzhafte Lymphdrüsenschwellung kamen vor. Bauchschmerzen und Diarrhöen waren selten; Leber und Milz waren gewöhnlich nicht vergrößert oder druckempfindlich. Manche Kranke bekamen Bronchitis oder sogar Pneumonie. Das Fieber fiel vom 3. Tag lytisch ab. Die durchschnittliche .Krankheitsdauer betrug etwa 1 Woche, die Rekonvaleszenz etwa 10 Tage (3 Tage bis 1 Monat), während Schwäche und Schlaflosigkeit weiter bestehen konnten. Bei 
tödlichem Ausgang starben die Patienten zwischen dem 3. und 8. Krankheitstag ohne vorausgehendes Koma, Bewußtseinstrübungen oder Krämpfe.

Ein genaues pathologisch-anatomisches und -histologisches Bild ist noch nicht bekannt. Die mit dem Viscerotom gewonnenen Leberstückchen ergaben keine charakteristischen Befunde.

Das beschriebene klinische Bild des Uruma-Dschungelfiebers glich dem von vielen anderen klinisch unspezifischen Fiebern, wie sie bei den mit Rodungsarbeiten im Urwald beschäftigten Menschen gefunden werden. Die Differentialdiagnose konnte daher nur im Laboratorium gestellt werden.

Die Sterblichkeit war erheblich. Von 15 Gestorbenen hatten 6 an Schluckauf gelitten.

Eine Behandlung mit Antibiotika, Sulfonamiden und anderen Chemotherapeutika hatte keine erkennbare Wirkung.

Immunbiologische Untersuchungen ergaben, daß eine Infektion mit dem Uruma-Virus oder einem serologisch verwandten Erreger endemisch in der Eingeborenenbevölkerung vorkommt, denn 38\% derselben hatten AK. Das Serum von 10-15\% der Rekonvaleszenten neutralisierte das isolierte Uruma-Virus.

Eine enge serologische Verwandtschaft wurde mit dem Mayaro-Virus festgestellt, so daB das Uruma-Virus unter Umständen ein Stamm dieses Virus sein könnte. Es gehört zu derselben Untergruppe wie das Chikungunya-Virus der Gruppe A der Arbor-Viren.

Hyperimmunseren von Semlikiwald- und Sindbis-Viren neutralisierten das Uruma-Virus, zahlreiche andere Arbor-Virus-Immunseren dagegen nicht.

\section{B IV. 0’Nyong-nyong-Fieber}

Im Jahre 1959 trat in Afrika eine neue Virusinfektion in einer großen dramatischen Epidemie auf, die anscheinend in Nord-Uganda begonnen hatte und dann stetig nach SO wanderte (GILlet, 1961). Sie breitete sich auch in Kenya, Belgisch-Kongo und Sudan aus. Die Krankheit ist seitdem nicht mehr erloschen. Nach SHore (1961) ist der Ursprung der Epidemie im Obongo-Gebiet am Albert-Nil zu suchen. Alle Altersklassen waren beteiligt. Im allgemeinen waren $50-75 \%$ der Gesamtbevölkerung erkrankt. Innerhalb von 2 Jahren dürften etwa 1 Million Fälle aufgetreten sein. Direkte Todesfälle schienen nicht vorgekommen zu sein. Die Krankheit trat mit Gelenkschmerzen und allgemeiner Schwäche auf und wurde O'Nyong-nyong (Gelenkbrecher)-Fieber genannt.

Die Krankheit hat klinisch Ähnlichkeit mit Dengue. Sie verläuft gewöhnlich mit Fieber, Kopfschmerz, schweren Gelenk- und Rückenschmerzen, juckendem Ausschlag und in vielen Fällen mit Lymphadenitis, häufig auch mit retroorbitalem Schmerz (SHore, 1961). Differentialdiagnostisch ist leicht eine Verwechslung mit Röteln, Masern, Malaria und vor allem Dengue möglich. Eine gewisse Ähnlichkeit besteht auch mit der Chikungunya-Infektion, bei der aber die Lymphadenitis und der Kopfschmerz fehlen, sowie manohmal Bradykardie in der 2. Phase vorhanden ist.

Das Virus wird durch Anopheles-Mücken, hauptsächlich A.funestus und A.gambiae verbreitet (CoRBET u. a., 1961). Damit sind zum ersten Mal auch Malaria-Mücken als Überträger einer menschlichen epidemischen Viruskrankheit bekannt geworden. Das Virus vermehrt sich in A.funestus, nicht dagegen in Aedes aegypti und anderen Arthropoden.

Porterfield u. a. (1960) isolierten ein Virus aus dem Serum eines Kranken durch Verimpfung auf 1-2 Tage alte Mäusesäuglinge (s. auch Williams und Woodall, 1961). Die Adaptierung an die Mäuse fand nur langsam statt und erforderte mehr als 15 Gehirnpassagen. Nach einigen i.cer. Passagen erkrankten die Tiere, bei denen eine fleckige Alopecia auffiel, die noch nach 15 Passagen ein Indikator für das Vorhandensein des Virus war. Die Mäuse zeigten außerdem Wachstumsstörungen und starben. Eine Adaptierung an erwachsene Mäuse gelang nicht.

Die Identifizierung des Virus wurde dadurch erschwert, daß gleichzeitig, wenn auch örtlich getrennt, eine durch das verwandte Chikungunya-Virus verursachte Epidemie herrschte. Die 
Schwierigkeiten wurden außerdem noch dadurch größer, daß das Chikungunya-Virus sich viel leichter als das O'Nyong-nyong-Virus isolieren ließ (Haddow u. a., 1960; Porterfield, 1961 b, c). Ein Virusstamm, der aus einem Pol von Anopheles gambiae-Mücken durch Mäusesäuglingspassagen isoliert werden konnte, erzeugte in Einschichtzellkulturen von Hühnerfibroblasten unter Agar bei $35^{\circ} \mathrm{C}$ nach 48 St. Plaques, die nach 5-6 Tagen 5-10 mm Durchmesser erreichten (s. auch BARON u. a., 1961; ISAACS u. a., 1961 b).

Mittels der PHP wurde das Virus als Arbor-Virus der Gruppe A klassifiziert (s. auch Williams und Woodall, 1961). Eine Plaquehemmung fand mit homologen Kaninchen- und Mäuseantiseren und den Antiseren der A-Viren Chikungunya und Semlikiwald statt. Das O'Nyong-nyong-Virus bildet also mit diesen Viren eine Untergruppe der Gruppe A. Es wird vermutet, daß es eine antigene Mutante des Chikungunya-Virus ist.

Das O'Nyong-nyong-Virus ist filtrierbar und ätherempfindlich. Aceton-Äther- und ZuckerAceton-Extraktionen von infektiösem Gehirnmaterial infizierter Mäusesäuglinge ergaben ein Hämagglutinin, das bei $\mathrm{p}_{\mathrm{H}}$ von 7,3-7,4 reagierte.

Das Virus (Osege-Stamm) bildet in Mäusegehirnen ein Interferon (Нітснсоск und PorterFIELD, 1961). Der Interferonnachweis in den Gehirnextrakten erfolgte nach der Methode von IsaAcs und Нiтchсоск (1960). Die durch Dialyse gegen einen $\mathrm{p}_{\mathrm{H}}$ 2- Puffer von lebendem Virus freigemachten Extrakte wurden auf Einschichtzellkulturen sekundärer Mäuseembryofibroblasten gebracht. Nach Über-Nacht-Bebrütung bei $37^{\circ} \mathrm{C}$ in $3 \% \mathrm{CO}_{2}$-haltiger Luft wurden die Gehirnextrakte entfernt und die Zellkulturen mit EMC-Virus infiziert. Die Kulturen wurden dann mit agarhaltigem Nährmedium $(0,7 \%)$ überschichtet und 48 St. bei $37^{\circ} \mathrm{C}$ bebrütet. Nach 2 Tagen wurde der gegen das EMC-Virus gerichtete, durch O'Nyong-nyongVirus-Interferon bedingte Prozeß sichtbar, indem die PB herabgesetzt blieb. Diese Wirkung wurde durch die Gegenwart eines kräftigen O'Nyong-nyong-Mäuseimmunserums nicht beeinträchtigt. Versuche mit ultrazentrifugiertem Gehirnmaterial (4 St. mit 100000 U/Min) ergaben, daß das interferierende Agens in der überstehenden Flüssigkeit zurückblieb. Das so gewonnene Interferon interferierte in Hühnerfibroblastenkulturen nicht mit SemlikiwaldVirus. Die vorliegenden Beobachtungen weisen darauf hin, daß der auffallende Virustiterabfall in den Gehirnen erwachsener Mäuse am 3. und 4. Tag p. i. nicht auf eine Neutralisierung durch AK im Gehirn zurückzuführen ist, sondern auf der Interferonbildung beruht. Der Gleichgewichtszustand zwischen der Vermehrung von infektiösem Virus und der Interferonbildung könnte ein Faktor sein, der die Geschwindigkeit der Virusadaptierung an eine neue Gewebs- oder Wirtsart beeinflußt.

Williams u. a. (1962) benutzten die PHP für epidemiologische Untersuchungen in einem Gebiet Ugandas, in dem kurz zuvor eine O'Nyong-nyong-Epidemie abgelaufen war. Gleichzeitig wurden die Mäuseschutzprobe und HAHR zum Nachweis von AK gegen O'Nyongnyong-, Chikungunya, -Semlikiwald-, Sindbis- und WN-Viren ausgeführt. Die PHP eignete sich ebenso gut wie die beiden anderen Proben zum Nachweis von AK. Es wurden hohe AKTiter sowohl gegen O'Nyong-nyong- als auch gegen Chikungunya-Virus gefunden. Die Ergebnisse zeigten aber an, daß O'Nyong-nyong-Virus das infizierende Agens war und die Chikungunya-AK-Titer auf antigenes Übergreifen mit dem O'Nyong-nyong-Virus beruhten. Inapparente Infektionen wurden angetroffen. Aus den serologischen Untersuchungen wird geschlossen, daß etwa $90 \%$ der Bevölkerung mit O'Nyong-nyong-Virus infiziert worden waren. Die anderen genannten Viren ergaben keine AK-Reaktionen mit den betreffenden Seren, konnten also als Erreger der Epidemie ausgeschlossen werden. Positive Resultate mit WN-Virus und Sindbis-Virus dürften auf gelegentliche Infektionen mit diesen Viren oder nahe verwandten Erregern in dieser Gegend zurückzuführen sein. Von 14 anderen Gruppe-A-Viren unterscheidet sich das O'Nyong-nyong-Virus deutlich (s. auch OsterRieth u. a., 1960).

\section{B V. KLA 16-Virus-Infektionen (Hämorrhagisches Fieber von Thailand).}

Halstead und Buescher (1961) isolierten in Bangkok (Thailand) von einem Kind mit hämorrhagischem Fieber am 2. Krankheitstag aus dem Blut ein Virus durch Übertragung auf 1-2 Tage alte Mäusesäuglinge und trypsinierte Hamster- und Affennierenzellkulturen. Dieses 
"KLA 16-Virus» erzeugte bei Mäuse-, Hamster- und Rattensäuglingen eine Krankheit, die durch spontane Blutungen an verschiedenen Körperstellen, insbesondere im Verdauungstrakt, sowie durch ausgesprochene Schädigungen des hämostatischen Mechanismus gekennzeichnet war. I.cer. Passagen von infektiösen Mäusegehirnen und Zellkulturen führten bei etwa 20\% der Mäuse zu subkutanen und intestinalen Blutungen. Hämorrhagien traten aber nur bei Mäusen auf, die vor dem 7. Lebenstag infiziert wurden. Bei Mäusen von 7-21 Tagen wurden nur gelegentlich Todesfälle beobachtet. Die i.cer. Infektion war 100 mal empfindlicher als die s.c. oder i.p. Infektionen. Bei den beiden letzteren kam es nur selten und mit großen Virusmengen zu Blutungen. Durch 3 malige Gehirnpassage wurde die Häufigkeit offener Blutungen von 20 auf $90 \%$ gesteigert. $10-100 \mathrm{LD}_{50}$ waren für $24-48$ St., alte Mäuse optimale Virusmengen, um eine hämorrhagische Krankheit zu erhalten. Mäuse mit Hämorrhagien starben gewöhnlich innerhalb von 24. St. Die Entstehung der Blutungen schien mit einer Verminderung der Plättchenzahl von $920000 / \mathrm{mml}$ bei 4-5 Tage alten normalen Mäusen auf 220000 bei infizierten Mäusen einherzugehen. Letztere zeigten ferner eine Leukozytose mit absoluter Vermehrung der Polymorphkernigen (65-90\%). Die Blutungs- und Gerinnungszeiten waren immer verlängert. Bei den infizierten Hamstersäuglingen waren die intestinalen Blutungen geringer als bei den Mäusen; dagegen waren sie bei den Ratten etwa gleich stark oder sogar noch schwerer. Erwachsene Mäuse, Hamster, Ratten und Kaninchen waren refraktär.

Das KLA 16-Virus ist immunologisch identisch mit dem TH 35-Virus von KiтAoKa (1959) sowie mit dem BaH 306-Virus von Hammon u. a. $(1960 \mathrm{a}$, b), das diese Autoren in Thailand von Kranken und Aedes aegypti-Mücken isoliert hatten. Es wurde ebenfalls als Arbor-Virus der Gruppe A identifiziert und erwies sich immunologisch eng verwandt mit dem Chikungunya-Virus (s. auch Piyaratn, 1961).

Die durch KLA 16-Virus hervorgerufene akute Infektion der Kinder ist charakterisiert durch Fieber, petechiale Blutungen, Purpura, gastrointestinale Blutungen und Schock. Die klinischen Erscheinungen beim Menschen ähneln also jenen der Versuchstiere.

NeLSON (1960) berichtete über 60 Fälle einschl. 5 Obduktionen von hämorrhagischem Fieber in Thailand. Piyaratn (1961) beschrieb 22 Autopsien bei Kindern von $1 / 2-9$ Jahren. Die hauptsächlichsten pathologisch-anatomischen und histologischen Veränderungen waren Gefäßerweiterungen, Ödem und Hämorrhagien, ferner Zellproliferationen des retikuloendothelialen Gewebes. Die Proliferation unreifer und reifer großer Mononukleärer war auffallend. Sie trat besonders in der Milz und den Lymphknoten, weniger stark in den Lungen und im interstitiellen Bindegewebe anderer Organe in Erscheinung. Die beobachteten Gefäßveränderungen wiesen auf eine direkte Schädigung der Endothel- und Nervenzellen durch das Virus hin. Es könnte sich um eine biochemische hämodynamische Reaktion wie beim Schock handeln.

\section{B VI. Semlikiwald-Virus}

Smithburn und Haddow (1944) isolierten in Uganda in der Gegend des Semlikiwaldes aus Mücken der Aedes (Aedimorphus)-abnormalis-Gruppe ein Virus durch i.cer. Injektion auf Mäuse. McIntosh u. a. (1961b) fanden Aedes argenteopunctatus in Portugisisch-Ostafrika in Küstennähe infiziert.

Beim Menschen scheint es zu keiner manifesten Erkrankung, wohl aber zu AK-Bildung zu kommen. Urwaldaffen (Cercopithecus nictitans) dürften als Wirtstiere dieses als »Semlikiwald-Virus" bezeichneten Erregers in Frage kommen. Das "Kumba-Virus» ist nach KERR (1952) und TAYlor (1952) mit dem Semlikiwald-Virus identisch (s. auch Cheng, 1961 b).

Das Virus läßt sich durch i.cer. und i.p. Übertragungen auf Mäusen weiterzüchten. Bereits adaptiertes Virus infiziert 3 Tage alte Mäusesäuglinge i.cer. mit 0,02 ml einer 10-4-Verdünnung (Gehirnsuspension). Cheng (1961c) erhielt bei i.cer. Infektion 3 Tage alter Mäusesäuglinge mit etwa $10^{5}$ Virusteilchen nach 26 St. $3 \times 10^{10}$ Teilchen. Die Infektiositätsendpunkte liegen 
nach i.cer. Impfung bei $10^{-10}$, nach i.p. und s.c. Impfung bei $10^{-9}$. Das Semlikiwald-Virus ist auch hochpathogen für erwachsene Mäuse bei i.cer. Infektion (s. auch Aıtken u. a., 1960). Es vermehrt sich im Mäusegehirn mit den höchsten Titern unter allen Arbor-Viren (Cheng, 1961b). Unabhängig von der Infektionsweise kommt es zu einer Virämie. Die Mäuse erkranken an einer Encephalitis mit Lähmungen der Hinterbeine; der Tod tritt häufig während eines Krampfes ein. Große Virusmengen töten bereits innerhalb von 48 St., kleinere Mengen erst nach 5-7 Tagen. Die Gehirnveränderungen ähneln jenen der experimentellen PferdeEM: Hyperämie mit kleinen Blutungsherden, perivaskuläre Lymphozytenmanschetten, manchmal Lymphozyteninfiltrationen in der Meningea und Choroidea. Nekrotische Nervenzellen, besonders in der Medulla, sind von mikroskopisch kleinen Infiltrationsherden umgeben. Die Nieren weisen unter allen Organen des Bauches und Thorax die größten Viruskonzentrationen auf. REAGAN a. u. (1953d) führten einen Virusstamm durch 5 rektale Passagen bei abgestillten Mäusen, die an ähnlichen nervösen Erscheinungen wie nach i.cer. Infektion erkrankten.

In der Leber von Mäusen, die eine sonst tödliche Dosis des Virus überstanden haben, findet sich eine Substanz, welche neue Mäuse gegen eine Infektion zu schützen vermag. Über die Natur dieses Hemmstoffes ist noch nichts bekannt; es könnte sich um ein Interferon oder eine ähnliche Substanz handeln. Sie scheint nicht im Gehirn, Muskel oder in der Milz vorzukommen (Shоре, 1961).

Benzimidazol, 2,6-Diaminopurin und andere Purinabkömmlinge scheinen die Empfänglichkeit der Mäuse für das Semlikiwald-Virus zu steigern. Dagegen scheint Ethionin sowohl verfüttert als auch i.p. eingespritzt die Überlebensżeit i.p. infizierter Mäuse zu verlängern. I.cer. injiziert ist es wirkungslos. Methionin hemmt die Ethioninwirkung nicht. Ähnlich wie letzteres wirken Dichlorphenoxythiouracil und verwandte Verbindungen (ТномРson und LAVENDER, 1953).

Durch Acrolein, einen ungesättigten Aldehyd, inaktiviertes Virus schützt Mäuse, i.p. injiziert, gegen eine spätere i.cer. Infektion mit lebendem Virus (KameN, 1961).

Das aus Penicillium funiculum gewonnene Helenin übt eine therapeutische Wirkung auf die Infektion der Mäuse aus (Shope, 1953). Auch Kulturfiltrate von Penicillium stoloniferum (M 8450) hemmen das Virus (Powell u. a., 1952).

Meerschweinchen und Kaninchen erkranken nach i.cer. Infektion an einer tödlichen Encephalitis. Mit Mäusegehirn infizierte Affen (Rhesus, Cercopithecus nictitans, C.mitis, C.griseoviridis) erkrankten nach s.c. und i.cer. Infektion an Virämie und starben an Encephalitis (Smithburn und Haddow, 1944). Nach Reagan u. a. (1954c) lassen sich syrische Hamster i.cer., i.n., intralingual, i.d., rektal, intrakardial und i.m. infizieren. Goldhamster (Mesocricetus aureus) sind nach Davies u. a. (1955) i.cer., i.p., i.m. und s.c. infizierbar. Der Virustiter im Blut erreichte sein Maximum 24 St. nach i.p. und 3-6 Tage nach i.cer. Infektion. 25\% der Tiere bekamen am 5.-6. Tage Lähmungen. Virus konnte nach 4 Tagen nicht mehr im Blut und nach 9 Tagen nicht mehr im Gehirn nachgewiesen werden.

REAGAN u. a. (1954f) übertrugen das Virus außerdem auf 1 tägige Küken, und zwar i.cer., i.p., i.d., i.m. intrakardial, intralingual, intraokulär und rektal. 2 tägige Küken zeigten nach i.m. Infektion Virämie, aber keine Krankheitserscheinungen. Bei älteren Hühnern fehlte auch die Virämie. AK schienen nicht zu entstehen (MacNamara, 1953a).

Junge Hunde lassen sich mit einem mäuseadaptierten Virusstamm i.p. und i.cer. infizieren. Es kam zu nervösen Erscheinungen. Durch Rückverimpfung auf Mäuse konnte das Virus in den Hundegehirnen nachgewiesen werden (REAGAN u. a., 1953c).

Nach Infektion auf verschiedenen Wegen erkrankten Höhlenfledermäuse (Myotus lucifugus) an nervösen Erscheinungen.

Rattensäuglinge von Müttern, die am Ende der Trächtigkeit mit Semlikiwald-Virus infiziert worden waren, wurden in utero infiziert. Sie ergaben aber erst im Durchschnittsalter von 14 Wochen eine normale Antigen-AK-Reaktion. Wurden diese Tiere im Alter der normalen maximalen Empfänglichkeit reinfiziert, so kam es zu einer erheblich lange dauernden Virämie. Die Rattensäuglinge schienen demnach infolge der intrauterinen Infektion eine gewisse Toleranz für das Virus erworben zu haben, das dadurch länger als normalerweise zu kreisen vermochte. Solche Tiere wurden also besonders gute Virusreservoire. 
Nach i.m. Injektion von Kaninchen, die gleichzeitig oder 2 Tage zuvor mit dem Kaninchenfibrom (Shope) geimpft worden waren, führte das Semlikiwald-Virus schnell zu Nekrosen des Tumorgewebes (GINDER und FrIEDEwald, 1951). Nach gleichzeitiger i.m. Infektion von Kaninchen mit Semlikiwald-Virus und i.d. Infektion mit Myxomvirus, das normalerweise die Kaninchen in 100\% tötet, betrug die Letalität nur noch 62\%. Gleichzeitige i.m. Injektion beider. Viren setzte die Letalität sogar auf $25 \%$ herab. Wurde das Semlikiwaid-Virus erst 24 St. nach dem Myxom-Virus eingespritzt, so betrug die Letalität 50\% (GINder und FrieDEWALD, 1952).

Das Semlikiwald-Virus vermehrt sich schnell in Gewebekulturen von Gehirn und Muskel 8-16tägiger Hühnerembryonen. Nach BuckLex (1959) ist in Hühnerembryozellkulturen keine Adaptierung des Virus erforderlich, sondern es bilden sich sofort Plaques und ein ZE (s. auch Aitken, u. a. 1960). Die Plaquebildung wird durch spezifische Antiseren infolge Neutralisation des Virus gehemmt (Porterfield, 1960). Virusvermehrung findet auch in Gewebekulturen junger Kaninchen (16, 30 und 90 Tage), nicht dagegen in solchen erwachsener Kaninchen statt. Ginder und Friedewald (1951) sahen eine starke Vermehrung des Virus in Kulturen des Kaninchenfibroms, in denen es zu einem ZE kam, sowie in Kaninchenmyxomkulturen mit Titern bis zu 106,5 $\mathrm{LD}_{50}$ nach $48-96 \mathrm{St}$. (GIND er und FriedewaLd, 1952). Fulton züchtete das Semlikiwald-Virus für Untersuchungen im Phasenmikroskop auf Polythenmembranen. In den Zellen wurde ein kräftiger ZE erkannt.

Interferon, das in Hühnerfibroblasten-Einschichtzellkulturen durch inaktiviertes InfluenzaVirus gebildet worden war, interferierte in der Zellkultur mit dem Semlikiwald-Virus (STRANDsтRöм u. a., 1962). Auch mit aktivem Coxsackie-Virus (Typ A, Stamm 10) und mit durch UV-Licht inaktiviertem Influenza-Virus wurde Interferenz beobachtet.

Smithburn (1946) kultivierte das Semlikiwald-Virus durch 33 Passagen in 7-9 Tage embryonierten Hühnereiern. Die Anzüchtung erfolgte mit einem virushaltigen Mäusegehirnfiltrat. Das Virus vermehrte sich schnell; die Embryonen starben schon 11-24 St. p. i. Der Virustiter im Embryogewebe schwankte zwischen 1:3,65 Millionen und 1:210 Millionen. Die infizierten Embryonen wiesen Hyperämie und Blutungen auf. Die histologische Untersuchung ergab Erweiterung und Blutüberfüllung der Gefäße mit Blutaustritt, besonders in der Unterhaut, sowie geringfügige Zellnekrose. Auch Filtrate der infektiösen Embryonen konnten serienweise übertragen werden. Nach TAYLOR (1952) waren die besten Infektionsorte Dottersack und Amnionsack. Nach 3-10 Tagen tötete das Virus auch in hohen Verdünnungen regelmäBig die Embryonen, für die es pantrop zu sein schien. Nach CheNG (1961c) vermehrt sich das Semlikiwald-Virus im Hühnerembryo mit den höchsten Titern unter allen Arbor-Viren.

Das Virus agglutiniert Gänseerythrozyten (Porterfield, 1957). Clarke und Theiler (1955) stellten aus infizierten Mäusesäuglingsgehirnen ein Hämagglutinin her, das sich auch für die HAHR eignete (s. auch ArtKen u. a., 1960). Salminen (1962b) stellte ein Hämagglutinin aus menschlicher Amnionzellkultur -Flüssigkeit her.

Das Hämagglutinin wurde im Gegensatz zu dem der Enteroviren nicht durch Parachlormercuribenzoat inaktiviert, was auf grundlegende Strukturunterschiede zwischen den verschiedenen Virusgruppen hinweist (Buckland, 1960). Protaminsulfat erhöht die HA-Aktivität einer Virussuspension, setzt aber die KB-Aktivität herab. Dies weist darauf hin, daß entweder die funktionellen Strukturen beider Antigenarten nicht identisch sind oder die KBAktivität durch andere Teilchen als die des Virus selbst hervorgerufen wird (Cheng, 1961c).

Das Virus läßt sich im gefrorenen Zustand trocknen und aufbewahren. Im Serum suspendiert bleibt es im Kühlschrank mehrere Wochen am Leben. In NaCl-Lösung verliert es bei niedriger Temperatur zunehmend seine Wirksamkeit. Das Virus widersteht einer 60 Min.Erhitzung auf $60^{\circ} \mathrm{C}$, wird aber bei $62^{\circ} \mathrm{C}$ in $30 \mathrm{Min}$. zerstört. Seine Thermostabilität ist also erheblich. Es hält sich am besten bei niedriger relativer Luftfeuchtigkeit (BUCKLAND und TYRRELL, 1962).

Nach Cheng (1961b, c, 1962b) ist das Semlikiwald-Virus ätherempfindlich.

Das Virus ist durch Seitz- und Berkefeld-Filter aller Porenweiten filtrierbar. Kollodiummembranfiltrationen ergaben eine Teilchengröße von 15-30 mu. Elektronenmikroskopische Aufnahmen von infizierten Mäusegehirnen sowie der Oberfläche von Erythrozyten i.m. infizierter Mäuse zeigten sphärische Teilchen von etwa 20-30 m $\mu$ Durchmesser. Solche fehlten in normalen Präparaten gleicher Art (REAGAN und Brueckner, $1953 \mathrm{a}, \mathrm{e}$ ). 
Aus Verreibungen infektiöser Mäusegehirne wurden durch Phenolextraktion und $65 \%$ Alkoholpräzipitation sowie 0,1 M NaCl-Ausfällung RNS-Präparationen gewonnen. Sie waren infektiös, so daß daran gedacht werden kann, daß die Infektiosität des Virus ebenso wie die anderer Viren auf die RNS selbst zurückzuführen ist. Mäusegehirne, die mit einer $10^{-3}$-Verdünnung der RNS geimpft worden waren, ergaben KB mit Semlikiwald-Antiserum, woraus auf eine Vermehrung des Inoculums im Gehirn geschlossen wird. Für die Infektiosität der RNS spricht außerdem die Tatsache, daß normalerweise bei der Zentrifugation 99\% der ursprünglichen Infektiosität des Virus entfernt wurden, während die Infektiosität der RNS nur um $50 \%$ herabgesetzt wurde, und weiterhin, daß durch Desoxycholatbehandlung $99 \%$ des Gesamtvirus zerstört wurde, die Infektiosität der RNS aber unverändert blieb (Cheng, 1958; s. auch Theiler, 1957). Das Semlikiwald-Virus gehört also zu den RNS-Viren.

Cheng (1962a) fand den RNS-Gehalt mit Semlikiwald-Virus infizierter HeLa-Zellen (Klon $\mathrm{S}_{3}$ ) 2-3 St. p. i. 10-15\% niedriger als jenen nicht infizierter Zellen. Er weist darauf hin, daß radioaktive Kern-RNS als Träger ("messenger") der genetischen Information von Genom $\mathrm{zu}$ einer Zytoplasmastruktur gilt, auf der spezifische Proteine oder besser das komplette Virus synthetisiert werden (Cheng, 1961a). Die Markierungsgeschwindigkeit wird durch die Einführung eines fremden Genoms, wie z. B. eines RNS-haltigen Virus, modifiziert. Diese Modifikation geht wahrscheinlich mit einer leichten Beschleunigung der RNS-Synthese einher. HeLa-Zellen, die zu verschiedenen Zeiten nach der Infektion mit trituriertem Cytidin, Adenosin oder Thymidin 15 Min lang behandelt wurden, ergaben mittels der Autoradiographie folgendes: Der Titer des intrazellulären Virus begann ungefähr 4 St. p. i. zu steigen. 7 St. p. i. wurde kein morphologischer Unterschied zwischen infizierten und nicht infizierten Zellen gefunden. Wurde ${ }^{3} \mathrm{H}$ Cytidin verwandt, so zeigte sich, daß die Markierung der Kern-RNS (ohne Kernkörper-RNS) 2 St.p.i. um das 3fache gesteigert war. Eine ähnliche Zunahme wurde in der Markierung der Kernkörper-RNS beobachtet (CHENG, 1962b). Dagegen wurde keine Zunahme der Zytoplasma-RNS während der $7 \mathrm{St}$. Beobachtungsdauer festgestellt. Fand die Markierung erst 4 St. p. i. statt, so blieb diese in den infizierten Zellen gegenüber jener der Kontrollen um etwa $24 \%$ geringer. Zu diesem Zeitpunkt dürfte neues intrazelluläres Virus erscheinen.

Die epidemiologischen Untersuchungen können sich nur auf den Nachweis von AK stützen, da bisher das Virus nicht von Menschen isoliert worden ist. N-AK wurden bei Menschen (47 von 313) in Uganda, Tanganyika und Nigerien, außerdem auch in den Seren von 6 unter 12 Affen (Cercopithecus nictitans) nachgewiesen. In den Affen dürften wahrscheinlich die natürlichen Virusreservoire zu suchen sein. Bei anderen wild lebenden Tierarten gelang der AK-Nachweis nicht (Smithburn u. a., 1944; Smithburn, 1952b). Smitburn (1953, 1954a) sowie Sмitнburn u. a. (1955a) fanden auch in Indien, Malaya und Borneo, КокеRnot u. a. (1956) in Südafrika sowie Causey und Theiler (1958) in Brasilien bei Menschen N-AK. Serologische Untersuchungen bei den Bewohnern der Philippinen ergaben, daß auch dort neben zahlreichen anderen Arbor-Viren Semlikiwald-Virus vorkommt (Hammon u. a., 1958).

Nach Davies und Yoshpe $(1954 \mathrm{a}, \mathrm{b})$ ist der A. aegypti als Überträger anzusehen. Das Virus vermag sich in den Mücken zu vermehren, aber eine serienweise Passagierung von Mücke zu Mücke war nicht möglich. Transovarielle Fortpflanzung fand nicht statt. Dagegen konnte das Virus mit A. aegypti von Maus zu Maus übertragen werden (s. auch SмiтhBuRN und Haddow, 1944; Dick, 1953b; Goldwasser und Davies, 1953; Woodall und Bertram, 1959; Nye und Lien, 1960). Nach Boorman (1960) ist das Virus in der Hämolymphe der A. aegypti nach Verfütterung von infektiösem Mäuseblut nachweisbar. Auch Ny e (1961) gelang eine künstliche Infektion von Aedes aegypti durch intrahämocölische Verimpfung von infektiösem Mäusegehirn. In 24 St. fand eine erhebliche Virusvermehrung statt. Nach NyE und B ERTram (1960) ergibt die künstliche Mückeninfektion anfänglich dieselben Infektiositätstiter für Mäusesäuglinge wie die natürliche Infektion. In den experimentell infizierten Mücken war aber der Titerabfall um etwa 1,5 log größer. Dieser Unterschied wird auf eine Schädigung des Virus bei der Herstellung der Mäusegehirnsuspension zurückgeführt.

Nye und Lien (1960) übertrugen das Virus von Maus zu Maus durch Blutmahlzeiten mit Aedes togoi; eine transovarielle Virusübertragung wurde aber auch bei dieser Mückenart nicht beobachtet. Die A.togoi zeigten hohe Virustiter während mindestens 31 Tagen. Es wird 
angenommen, daß diese Mückenart als potentieller Überträger des Semlikiwald-Virus sowie anderer Gruppe A-Viren in Frage kommt.

Das Semlikiwald-Virus läßt sich immunbiologisch von den Viren des Gelbfiebers, der JE, SLE, des WN-Fiebers, des Bwamba-Fiebers, dem Bunyamwera-Virus und den Viren der EEE und WEE unterscheiden (SmithburN u. a., 1944, 1946; Smithburn, 1952a).

Nach Infektion von Menschen mit Mayaro-Virus kommt es auch zur Bildung von N-AK gegen Semlikiwald-Virus (CAusey und Maroja, 1957). In Afrika und Malaya gaben Menschenseren mit N-AK gegen Semlikiwald-Virus in der HAHR erheblich höhere Titer gegen Chikungunya -Virus (s. dort) als gegen Semlikiwald-Virus.

Das Semlikiwald-Virus ist mit Chikungunya- und Mayaro-Virus so eng verwandt, daß es ebenfalls zu derselben Untergruppe der Gruppe A gehört (CaSals und Whitman, 1957; McIntosh u. a. 1961b). Die 3 Viren können durch die HAHR und im Tierversuch unterschieden werden. Der Titer der HAH-AK ist gegen das homologe Virus immer höher als gegen die beiden andern.

\section{B VII. Sagiyama-Virus}

Von erwachsenen Mückenweibchen (Culex tritaeniorhynchus und Aedes vexans) wurde in der Nähe von Tokio 1956-57 das erste in Japan bekannt gewordene Arbor-Virus der Gruppe A isoliert. Zunächst (Anfang Juli 1956) waren offenbar nur die Mücken infiziert, Ende Juli auch Schweine. Menscheninfektionen erfolgten im August und September, als diese Mückenarten ihre größte Dichte erreicht hatten. Die etwaige Bedeutung des Sagiyama-Virus als Krankheitserreger beim Menschen ist jedoch noch nicht geklärt (SCHERER u. a., 1962a).

Das Virus kreist offenbar zwischen Mücke als Überträger und Wirbeltieren einschl. Wildvögeln als Wirten. Über das Spektrum der in der Natur empfänglichen Tiere ist noch nichts bekannt. Das Virus wurde bisher außer bei Schweinen, die nicht manifest zu erkranken scheinen (ScHERER u. a., 1962b), auch bei Pferden und Reihern gefunden. Erwachsene Menschen auf Höfen in der Nähe infizierter Schweine wiesen einen N-AKIndex des Sagiyama-Virus von 0,18 auf, während dieser in der gesamten Stadt- und Landbevölkerung nur 0,09 betrug. Die Übertragungsweise des Virus auf den Menschen ist noch ungeklärt geblieben.

In verschiedenen Gegenden wurde das Virus zusammen mit dem JE-Virus gefunden. Gelegentlich wurden Doppelinfektionen auch bei Schweinen nachgewiesen. Die Ökologie beider Viren ist recht ähnlich, aber mit der Ausnahme, daß das Sagiyama-Virus auch in Aedes vexans vorkommt und das JE-Virus viel weiter unter Culex tritaeniorhynchus, Schweinen, Reihern und Menschen verbreitet ist.

2-12 Tage alte Mäusesäuglinge lassen sich i.cer. infizieren. Die bei ihnen auftretenden pathologischen Prozesse, welche zu Lähmungen der hinteren Gliedmaßen führen und nach 2-5 Tagen tödlich enden, sind Myositis, Degeneration der Nervenzellen im Gehirn und Rückenmark sowie Nekrose des braunen Fettes. Die Titer der Mäusegehirnsuspensionen schwanken zwischen $10^{7,5}$ und $10^{8,5} / 0,01 \mathrm{ml}$ Gehirn. In den Beinmuskeln findet man etwa denselben Titer. 3-4 Wochen alte Mäuse bleiben nach i.cer. Infektion mit $10^{4,8}$ bis $10^{6,9} \mathrm{LD}_{50}$ des Virus gesund. Die histopathologischen Veränderungen ähneln wie auch die bei Sindbis-Virusinfektionen jenen bei Coxsackie B-Infektionen, so daß diese nicht länger als pathognomonisch für letztere gelten können (SCHERER, 1961).

Kaninchen und Meerschweinchen erkranken nach verschiedenen Infektionsweisen nicht, bilden aber AK. Schweine erkranken nach s.c. Infektion ebenfalls nicht, bekommen aber eine Virämie und bilden ebenfalls AK.

Küken ließen sich i.v. und s.c. (3.-10. Mäusepassagevirus) infizieren, bekamen eine 
Virämie und starben unregelmäßig. Ein Teil der Küken erkrankte; andere wurden nur stumm infiziert. Virus wurde im Gehirn, in der Leber und Milz gefunden.

In primären Schweine- und Hamsternierenzellkulturen kam es zu einer vollständigen Degeneration der Zellen nach 2-4 Tagen. Das Virus wurde durch 12 Passagen gezüchtet. In primären Kälbernierenzellkulturen wurden 50-70\% der Zellen bis zum 4. Tage zerstört. In Hühnerembryozellku?turen unter Agar entstanden kleine Plaques. In L-Zellkulturen kam es auch bei serienweiser Passage zu keinem ZE. Primäre Affennierenzellkulturen zeigten ebenfalls keinen ZE. In Kulturen menschlicher Zellen [Amnion, KB, Konjunktiva, Leber (Chang), Knochenmark (Det 6 und 98), leukämisches Blut (J 111) und Pleuralymphosarkom (116 P)] entstanden keine ZE, die passagenweise fortgeführt werden konnten. HeLa-Zellen wurden innerhalb von 7 Tagen zu 80\% zerstört, enthielten aber kein für Mäusesäuglinge pathogenes Virus.

Infektion embryonierter Hühnereier führte zum Tod der Embryonen und Hämorrhagien der Haut. Das Virus ließ sich durch Dottersackinfektion 15 Passagen lang züchten. Beimpfung der CAM tötete die Embryonen ebenfalls.

Filtration (Cellulosemembranen mit durchschnittlichem Porendurchmesser von $50 \mathrm{~m} \mu$ ) ergab eine Teilchengröße des Virus von 15-25 m $\mu$, während für das JE-Virus nur 3-5 m $\mu$ ermittelt wurden. Da letzteres nach Filtration (Elford) eine Größe von 15-30 m $\mu$ hat, dürfte das Sagiyama-Virus erheblich größer sein.

Das Virus ist wie die meisten Arbor-Viren bei $37^{\circ} \mathrm{C}$ stabil. Es wird durch $\mathrm{Na}$ des-

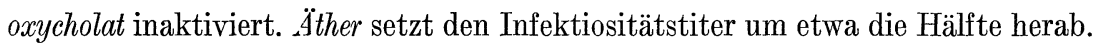

Durch Zucker-Aceton-Extraktion infizierter Mäusegehirnsuspensionen wurden Hämagglutinine für erwachsene Gänse- und Kükenerythrozyten erhalten, die in einem $\mathrm{p}_{\mathrm{H}^{-}}$ Bereich von 6,0-6,6 (Optimum 6,2-6,4) wirksam waren. Es ergaben sich keine Unterschiede der HA bei $25^{\circ}$ und $37^{\circ} \mathrm{C}$. Durch Protaminsulfatbehandlung wurde die HA um das 16 fache gesteigert.

Durch scharfe Zentrifugation sowie Zucker-Äther-Extraktion wurde ein hochwirksames $K B$-Antigen erhalten.

Das Virus erzeugte bei Kaninchen, Meerschweinchen und abgestillten Mäusen N-AK-, HAH-AK und KB-AK. Bei Schweinen bestanden Stammunterschiede, indem ein Virus $\mathrm{N}$-AK, HAH-AK und KB-AK, ein anderer Stamm nur N-AK erzeugte. Außerdem erwiesen sich die N-AK als labil gegen Erhitzen ( $56^{\circ}$ C, 30 Min). Das Fehlen nachweisbarer KB-AK könnte auf einer prokomplementären Wirkung des Schweineserums beruhen.

Das Sagiyama-Virus wird durch Immunserum gegen Semlikiwald-Virus neutralisiert und ergibt KB mit Semlikiwald-, Sindbis- und Chikungunya-Antiseren.

\section{B VIII. Sindbis -Virus}

Das Sindbis-Virus ist 1952 im Sindbis-Distrikt des Nildeltas in den Mücken Culex pipiens und C. univittatus sowie einmal in einer Nebelkrähe nachgewiesen worden (TAYLor und HurLBUt, $1953 \mathrm{~b}$; TAYLOR u. a., $1955 \mathrm{~b}$; s. auch TAYLOR, $1953 \mathrm{a}$ ).

Sнан и. а. (1960a) isolierten weitere Virusstämme in verschiedenen Gegenden Indiens aus einem Pool von Culex-Mücken (einschl. C. bitaeniorhynchus) und Milben (Bdellonyssus bursa) sowie aus Milzpools weißer Bachstelzen (Motacilla alba) und von Staren (Gracula reliogiosa). RudNick u. a. (1962) gelang in Indien die Isolierung eines Virusstammes (P-886) aus Culex bitaeniorhynchus, der aber gegenüber dem ägyptischen Stamm (Ar 339) und südafrikanịschen Stämmen antigene Unterschiede in der HAHR, NR und KBR zeigte.

Menschliche Erkrankungen sind bisher nicht bekannt geworden; auch ist das Virus noch nicht bei Menschen isoliert worden. Dagegen sind AK bei Bewohnern des Nildeltas gefunden worden. 
Die Isolierung des Virus (Stamm Ar 339) erfolgte durchi.p. und i.cer. Verimpfung von Mückenbrei auf 3tägige Mäusesäuglinge (TAY LOR u. a., 1955b). Diese erkrankten innerhalb von 2-5 Tagen an Lähmungen und starben. Der Virustiter in den Gehirnen erreichte $10^{-6}$ bis 10-7,5. Er war nach i.cer. Infektion gewöhnlich 0,1-1,0 log höher als nach i.p. Infektion. Mit zunehmendem Alter der Mäuse nahm ihre Empfänglichkeit ab. Nur 10 Tage alte Tiere zeigten bereits eine verlängerte Inkubationszeit und längere Lebensdauer. Die histopathologischen Veränderungen in den Mäusegehirnen waren encephalitische Prozesse eigener Art: hauptsächlich herdförmige kystische Degeneration, Ganglienzellendegeneration (Neurolyse) ohne Ödem oder perivaskuläre Infiltrationen. Auch das Rückenmark wies Neurolyse auf. Im Skelettmuskel fanden sich ähnlich wie bei der Coxsackie-Infektion Verlust der Streifung der Myofibrillen und Kerndegeneration sowie Gebiete herdförmiger Nekrosen mit Entzündungsreaktion vom mononukleären Typ. Interstitielle myokardiale Infiltrationen waren selten. Leber und Lungen waren hyperämisch. Ein Virusstamm ließ sich durch Gehirnpassagen auch auf erwachsene Mäuse adaptieren (WeINBReN u. a., 1956).

Hamstersäuglinge und Höhlenfledermäuse (Myotis lucifugus) erkrankten nach Infektion auf verschiedenen Wegen (REAGAN u. a., 1956b). Bei beiden Tierarten traten nervöse Erscheinungen auf. Infektionsversuche an Affen (M. mulatta und Cercopithecus aethiops aethiops), Hühnern, Ibissen, Nebelkrähen und Tauben ergaben bei allen Tieren Virämie sowie N-AK. Beim Schaf wurden keine AK erhalten (TAYLOR u. a., 1955b).

In Gewebekulturen von Hühnerembryozellen in Plasma fand eine schnelle Virusvermehrung mit erheblichem ZE auf die fibroblastenartigen Zellen statt, während ein ZE auf die anderen Zellen fehlte. In Kulturen von menschlichem Uterusgewebe traten ähnliche Veränderungen auf; sie fehlten aber in HeLa-Zellkulturen und Fibroblastenkulturen aus menschlichem Embryohautmuskelgewebe.

In jungen Amnionzellkulturen ist der ZE häufig herabgesetzt oder fehlt; in älteren Kulturen ist die Virusvermehrung größer und auch der ZE viel stärker (Frothingham, 1959). Nach GRESSER ünd ENDERs (1962) findet in primären Menschenamnionzellkulturen immer Vermehrung des Virus mit vollständiger Zellzerstörung statt, während in stabilisierten (kontinuierlichen) Amnionzellkulturen ZE nur nach Verimpfung hoher Viruskonzentrationen eintrat. Wurden zu den primären Amnionzellen kleine Mengen stabilisierter Amnionzellen zugesetzt, so zerstörte das Sindbis-Virus ebenfalls die primären Amnionzellen. Die stabilisierten Amnionzellkulturen in Reinkultur oder mit primären Amnionzellen gemischt veranlaßten das Virus dagegen zur Bildung großer Mengen von Interferon, so daß der ZE des Virus in primären Amnionzellkulturen gehemmt wurde. Wurden zu wenig stabilisierte Zellen verwandt, so wurden sowohl diese Zellen als auch ein Teil der primären Amnionzellen zerstört. Wahrscheinlich werden unter diesen Bedingungen große Virusmengen durch die primären Amnionzellen gebildet, bevor genügend Interferon entsteht, um völligen Schutz zu verleihen (s. auch GrEssER, 1961).

Ho $(1961 \mathrm{a}, 1962)$ sowie Ho und Breining (1962) gewannen aus mit Sindbis-Virus infizierten Hühnerembryozellkulturen ein Interferon. Die Bildung dieses Hemmers wurde durch Vorbebrütung der Zellkulturen mit Hitze-inaktiviertem Virus, das allein keinen Hemmer bildet, gefördert. Die Interferonbildung erfolgte zusammen mit der Virusvermehrung offenbar in denselben Zellen. Die Hemmwirkung wurde jedoch erst etwas später als die Infektion nachweisbar. Der gebildete Interferontyp genügte aber nicht, um die schnelle Sindbis-Virusvermehrung und eine etwaige Zellzerstörung zu verhindern. Das Sindbis-Virus erzeugte auch in hoher Verdünnung einen vollständigen ZE in 24-48 St. und ergab eine Virusernte mit Titern von $10^{9}$ bis $10^{10} \mathrm{PBE} / \mathrm{ml}$.

Die Bildung von Interferon scheint ein allgemeines Phänomen der Virusinfektionen zu sein. Seine optimale Bildung scheint aber teilweise durch die auslösende Wirkung von inaktivierten oder anderen nichtinfektiösen Virusteilchen bestimmt zu sein. Da der Schutz der Zellen durch das Interferon gegen die Sindbis-Virusinfektion durch zuneh- 
mende Virusmultiplizität überwunden werden kann, ist er bis zu einem gewissen Grad reversibel. Die Hemmung schwankt von einer Verhütung der Zellinfektion bis zu einer teilweisen Hemmung der Virussynthese. Beide Beobachtungen weisen darauf hin, daß das Interferon kein Hemmer der Virussynthese ist, der einen notwendigen Schritt im Infektionszyklus spezifisch schädigt. Es könnte vielmehr in den Zellhaushalt eingreifen, wodurch erst indirekt die Virussynthese geschädigt würde. Diese Auffassung würde nicht im Widerspruch zu der Theorie stehen, daß die chemische Stelle der Interferonwirkung die Auslösung einer oxydativen Phosphorylierung ist, besonders da noch wirksamere Auslöser als das Interferon die Virus-Aktivitäten nicht vollständig schädigen (IsAacs u. a., 1961a).

Nach Ho (1961b) hemmt das Sindbis-Interferon die Infektiosität der Polio-RNS, da eine Verzögerung der Zellinfektion und der Gesamtproduktion an Polio-Virus eintrat. Die Plaquebildung von Stomatitis vesicularis-Virus wurde auch, und zwar optimal, gehemmt, wenn die Zellkulturen vorher mit einem Gemisch von infektiösem und hitzeinaktiviertem Sindbis-Virus infiziert worden waren.

Wurde mit $2 \%$ igem Na desoxycholat behandeltes Mayaro-Virus auf Hühnerembryozellkulturen übertragen, so bildeten die Zellen ein Interferon, wodurch sie gegen eine nachfolgende Sindbis-Virusinfektion resistent wurden. Der Hemmer trat in der Kulturflüssigkeit 72-96 St. p. i auf (HENDERSON und TAYLOR, 1961).

In Menschenamnion- und Hühnerembryozellkulturen, die mit Masern-Virus infiziert worden waren, wurde ein Interferon gebildet, das das Sindbis-Virus in HeLa-Zellkulturen hemmte (De Mayer und Enders, 1961).

Das Virus ließ sich in der Zellkultur mittels der Hämadsorptionsreaktion von Shelokov u. a. (1958) nachweisen (Frothinham, 1955; s. auch Buckley, 1959).

TAYLOR u. a. (1955b) fanden das Virus nach Dottersackbeimpfung hochpathogen für 7tägige Hühnerembryonen. Diese erkrankten an allgemeiner Hyperämie, petechialen Blutungen des Integumentums und der Membran und starben nach Beimpfung mit Verdünnungen bis zu 10-7 nach 24-72 St. In den Allantoissack infizierte Embryonen bekamen in der Allantoisflüssigkeit keine Agglutinine für Hühnererythrozyten. Aus infektiösen Gehirnen neugeborener Mäuse wurde dagegen ein Hämagglutinin isoliert, das bei $37^{\circ}$ Hühnerzellen mit einem Titer von 1: 64 agglutinierte (CASALS und BRown, 1954). Gänseerythrozyten wurden ebenfalls agglutiniert (PorTerfield, 1957). Salminen (1962b) stellte ein Hämagglutinin aus infizierter menschlicher Amnionzellkulturflüssigkeit her.

Mittels der Collodiummembranfiltration wurde eine Teilchengröße des Virus von 40-48 m $\mu$ ermittelt (TAYLoR u. a., 1955b).

Das Virus widerstand der Einwirkung von $20 \%$ igem Äther bei $4^{\circ} \mathrm{C}$ über Nacht und Desoxycholat $1: 1000$ bei $37^{\circ} \mathrm{C}$ etwa 1 St. In gereinigtem Zustand war es empfindlicher.

In einer 10\%igen infektiösen Mäusemuskelsuspension bei $0^{\circ} \mathrm{C}$ aufbewahrt blieb der Titer des Virus etwa 40 Tage unverändert (7,6-7,7 log); am 79. Tage betrug er noch 7,6 log. Der durchschnittliche Titerabfall bei der Gefriertrocknung in 50\% igem normalem Kaninchenserum betrug $0,9 \log$.

Obwohl menschliche Erkrankungen noch nicht bekannt geworden sind, weisen die AK-Befunde in Seren von Eingeborenen nicht nur in verschiedenen Stellen des Nildeltas und des anglo-ägyptischen Sudans, sondern auch in anderen Teilen der Südafrikanischen Union (KoKeRNot u. a., 1956) auf eine Durchseuchung der Bevölkerung hin. Es dürfte mit einem noch unbekannten tierischen Viruswirt zu rechnen sein, von dem aus die Übertragung auf den Menschen durch Vermittlung von Mücken - in Transvaal wurde das Virus in Culicinen isoliert -, vielleicht auch durch Zeckenarten erfolgen kann. Die Zecke Ornithodorus savignyi ist für experimentel]e Infektionen empfänglich (TAYLOR u. a., 1955b).

Im Nildelta besaßen von 400 Personen $27 \% A K$; diese kamen öfter bei Personen über 15 Jahren (34\%) als bei jüngeren Menschen (14\%) vor (TAÝLOR u. a., 1955b). WeInBREN u. a. (1956) fanden in Südafrika bei 9\% von 160 untersuchten Nichteuropäern N-AK. Für die NR 
war die Zellkultur besser geeignet als der Mäusesäugling (Frothingham, 1955). Sanna und ANGelillo (1961) wiesen Sindbis-Infektionen in Sardinien nach.

Ein serologisch mit den Sindbis- und WEE-Viren verwandtes Virus wurde von BRunoLово и. а. (1961) im Blut und Nervensystem eines Rennpferdes gefunden. Homologe AK wurden in den Seren von Personen festgestellt, die das kranke Tier gepflegt hatten. Der Nachweis dieses Virus in 700 Culex-Mücken, die 1 Monat nach dem Tod des Pferdes in der Umgebung gesammelt worden waren, gelang nicht.

Die HAHR mit Äther-Acetonextrakten aus infektiösen Mäusesäuglingsgehirnen als Antigen, verschiedenen Immunseren und Hühnererythrozyten ergab, daß das Sindbisvirus zur Gruppe A der Arbor-Viren gehört (CASALS und Brown, 1954, CASALS, 1957). Es läßt sich von den anderen Angehörigen dieser Gruppe durch NR differenzieren. Mit Meerschweinchenhyperimmunseren ergab sich eine Kreuzneutralisation zwischen Sindbis- und WEE-Virus. Hühner und Hamster, die parenteral mit Sindbis-Virus infiziert wurden, waren gegen eine periphere Infektion mit dem WEE-Virus geschützt. Umgekehrt waren diese Tiere, wenn sie s.c. mit WEE-Virus infiziert wurden, anschließend gegen eine periphere Infektion mit dem Sindbis-Virus geschützt (Parks und PrICe, 1958; s. auch Willifams und Woodall, 1961). Mit Sindbis-Virus immunisierte Mäuse erwarben einen signifikanten Schutz gegen Semlikiwald-Virus (Sanna und ANgelillo, 1959).

\section{B IX. Middelburg -Virus}

Ein weiterer Angehöriger der Arbor-Virusgruppe A ist das Middelburg-Virus. Es wurde von Kokernot u. a. (1957b) aus wild lebenden Aedes caballus- und Aedes sp. BanksienellaMücken im Middelburg-Distrikt der Östlichen Kapprovinz (Südafrika) isoliert. Es ist experimentell durch A. caballus übertragbar. Mäusesäuglinge können i.p. und i.cer. infiziert werden. Experimentell infizierte wilde Nagetiere (Mystromys, Mastomys, Aethomys, Lemniscomys, Arvicanthis, Saccostomus, Tatera) bekamen eine Virämie und entwickelten AK. Lämmer erkrankten nach experimenteller Infektion schnell mit hohem Fieber, genasen aber wieder. N-AK wurden bei 2 von 9 untersuchten Personen und bei 10 von 13 Mutterschafen sowie bei Rindern und Ziegen (КокевNот u. a., 1961 a) gefunden. Man muß also mit natürlichen Menschen- und Säugetierinfektionen rechnen.

\section{Arbor-Viren, Gruppe B}

Die Angehörigen der Arbor-Virusgruppe B sind serologisch einander ähnlicher als die der Gruppe A, wie aus der HAHR deutlich hervorgeht. Nach Sмiтн und HoLt (1961) haben die B-Viren im Gegensatz zu den A-Viren 2 KB-Antigene mit verschiedenen Sedimentierungseigenschaften. Das eine Antigen ist der El.K. selbst, das andere ist eine kleine Komponente, die sich aber vom Hämagglutinin unterscheidet, das möglicherweise ein Oberflächenbestandteil ist. (s. Tabelle 34 a).

Olitsky und Clarke (1959) nehmen als wahrscheinlich an, daß alle Viren der Gruppe B ihren Ursprung von einem Elternstamm haben, aus dem sie als Mutanten mit veränderlichen antigenen und pathogenen Eigenschaften infolge verschiedener Umwelteinflüsse (z. B. Wirtwechsel), denen sie im Verlauf ihrer Evolution ausgesetzt waren, hervorgegangen sind. Die Viren stimmen darin überein, daß ihre Vermehrung durch einen genetisch kontrollierten Faktor, der sich im PRI-Mäusestamm befindet, unterdrückt wird (SABIN, 1952c), und sie durch einen Menschen-Milchfaktor, der kein Virus-AK ist, inaktiviert werden (SABIN, 1953). Die meisten Viren der Gruppe B werden durch Mücken, 5 Viren durch Zecken übertragen bzw. sind sie aus ihnen isoliert worden. Die Zeckenviren sind immunologisch eng verwandt oder sogar identisch.

Ebenso wie die Infektionen der Gruppe A-Viren sind auch die der Gruppe B-Viren gewöhnlich nur Gelegenheitsbefunde und das End- oder Nebenglied einer Infektkette 


\section{Tabelle $34 a$}

Gruppenimmunitätsreaktionen (HAHR) bei Meerschweinchen, die nacheinander mit 2 verschiedenen Viren der Gruppe B infiziert wurden

(Nach Casals, 1961 b)

\begin{tabular}{l|c|c}
\hline \multirow{2}{*}{ Antigen (8 Einheiten) } & Titer der Meerschweinchenseren nach Infektion mit \\
& $\mathrm{JE}$ & $\mathrm{JE}+\mathrm{SAH} 336$ \\
\hline JE & $640 / 640$ & $5120 / 5120$ \\
SAH 336 & $80 / 80$ & $1280 / 1280$ \\
REFSE & $40 / 40$ & $1280 / 1280$ \\
Powassan & $20 / 0$ & $640 / 640$ \\
Gelbfieber & $80 / 160$ & $2560 / 2560$ \\
Zika & $320 / 320$ & $10240 / 10240$ \\
Dengue 1 & $40 / 40$ & $1280 / 1280$ \\
Dengue 2 & $80 / 40$ & $2560 / 1280$ \\
Dengue 3 & $80 / 40$ & $2560 / 1280$ \\
Spondweni & $20 / 40$ & $640 / 640$ \\
Bussaquara & $320 / 320$ & $10240 / 10240$ \\
\hline
\end{tabular}

Für die Doppelinfektionen (zuerst JE, dann SAH 336) wurden 2 Meerschweinchen verwandt. $0=$ keine Reaktion mit der niedrigsten Verdünnung von $1: 20$

innerhalb tierischer Wirte. Die zur Gruppe B gehörenden Viren sind in Tabelle $35 \mathrm{zu-}$ sammengefaßt.

Die durch die Viren dieser Gruppe verursachten Krankheiten nehmen keinen einheitlichen Verlauf. Er kann sehr leicht, aber auch schwer und sogar tödlich sein. Fast alle B-Viren sind menschenpathogen; die Infektionen können aber klinisch stumm oder latent bleiben, so daß sie nur durch die Isolierung des Virus oder den Nachweis der AK diagnostizierbar sind. Nichtpathogen für den Menschen sind das Fledermausspeicheldrüsen- und das Bussaquara-Virus; letzteres wurde aus dem Blut eines Sentinel-Affen im Amazonas-Tal isoliert. Bei Menschen sind N-AK gegen das Ntaya-Virus gefunden worden, gewöhnlich aber zusammen mit AK gegen WN-, JE- oder Dengue-Viren. Es wird vermutet, daß diese AK durch die immunologische Verwandtschaft aller dieser Erreger zu erklären sind. Auch in der Gruppe B lassen sich verschiedene Untergruppen feststellen:

I. Dengue 1-, 2-, 3- und 4-Viren,

II. WN-, JE-, SLE-, Ilhéus- und Murrayvalley-Viren,

III. Gelbfieber-, Uganda S-, SAH 336-, evtl. auch Zika-Viren.

Die neurotropen Viren der Gruppe B werden wie die der Gruppe A im Band 2 besprochen. Das SAH 336-Virus ist nicht besprochen, da bisher keine Literatur vorzuliegen scheint. Von den noch verbleibenden Viren der Gruppe sollen hier nur die behandelt werden, die eine menschliche Erkrankung hervorrufen oder gegen die bei Menschen AK gefunden worden sind: Dengue, Ilhéus, Gelbfieber, Zika, Kyasanurwald, Omsker und argentinisches hämorrhagisches Fieber, Wesselsbron, Uganda S, Ntaya und Spondweni. 


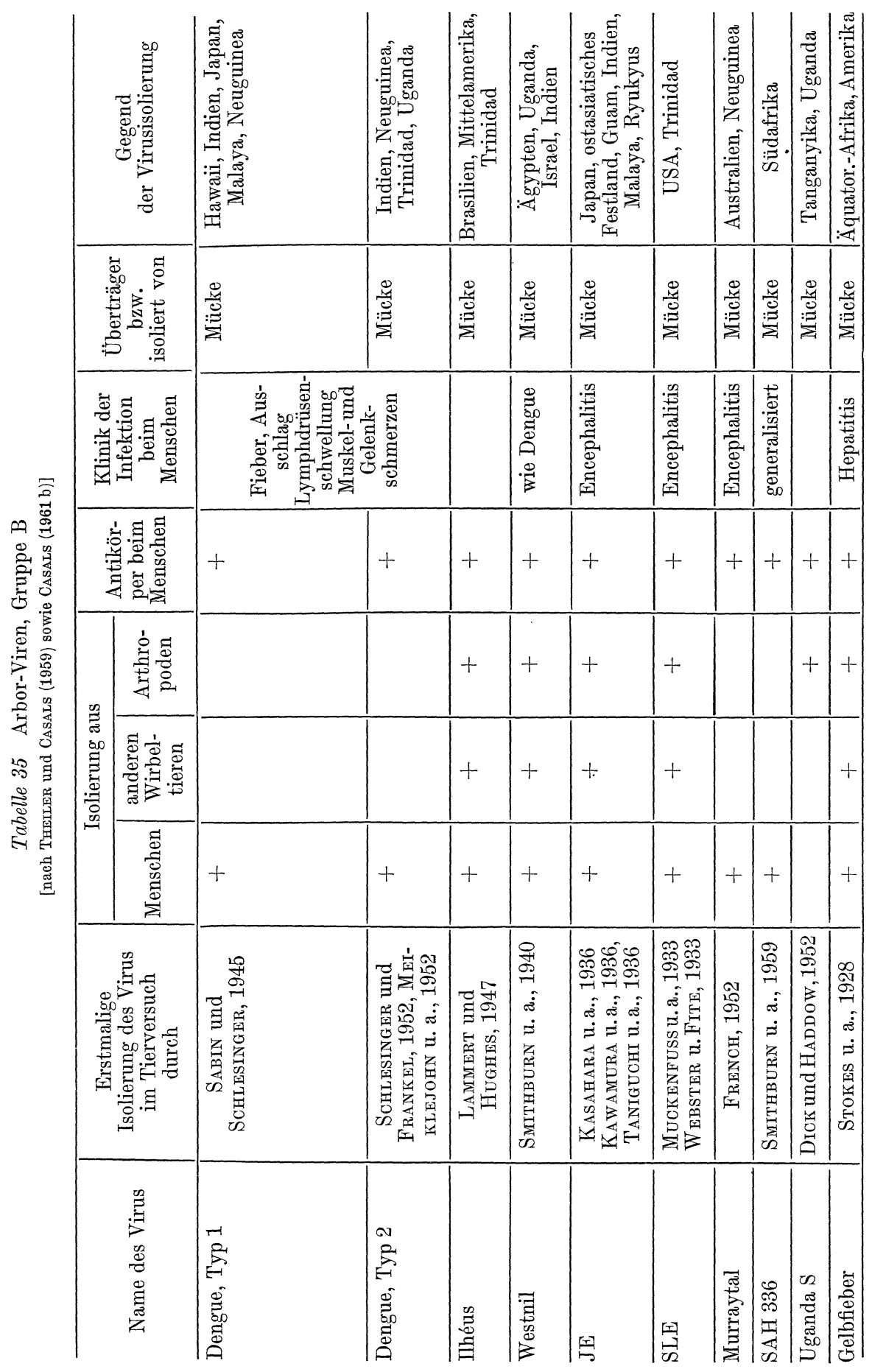




\begin{tabular}{|c|c|c|c|c|c|c|c|c|c|c|c|c|c|}
\hline 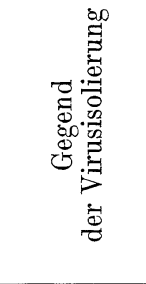 & 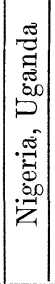 & 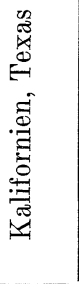 & 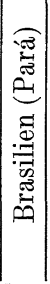 & & 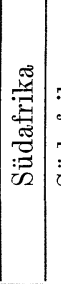 & 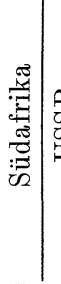 & $\begin{array}{l}x_{12} \\
02 \\
0 \\
0\end{array}$ & 苞 & 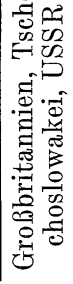 & 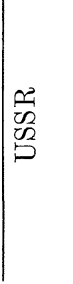 & 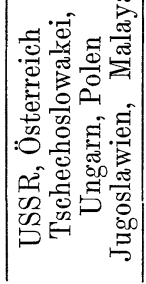 & 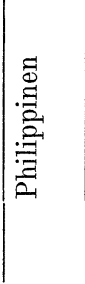 & 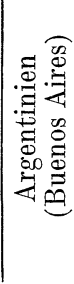 \\
\hline 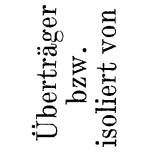 & 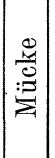 & & & 总 & 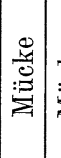 & . & $\begin{array}{l}\frac{\mathscr{g}}{0} \\
\stackrel{d}{J} \\
\text { N }\end{array}$ & 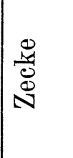 & 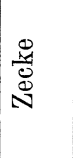 & 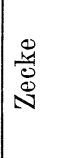 & 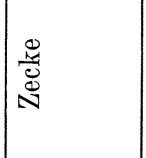 & & \\
\hline 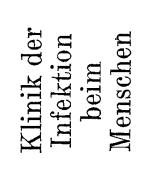 & 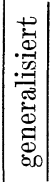 & & & & & 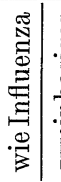 & 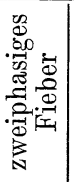 & 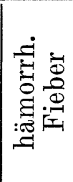 & 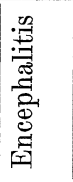 & 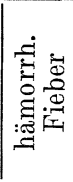 & 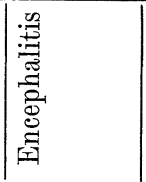 & 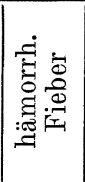 & 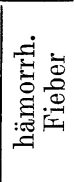 \\
\hline 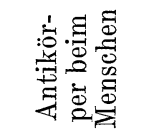 & + & & & + & + & + & + & + & + & + & + & & + \\
\hline 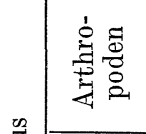 & + & & & + & + & + & + & + & + & + & + & + & \\
\hline 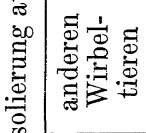 & + & + & + & & & + & + & + & + & & & & \\
\hline 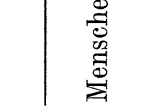 & + & & & & & + & + & + & + & + & + & + & + \\
\hline 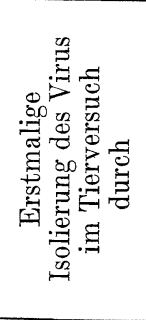 & 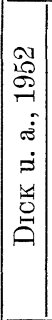 & 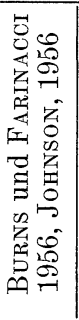 & 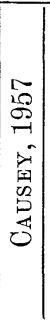 & 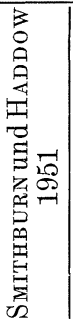 & 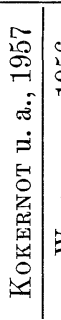 & 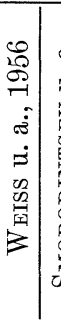 & 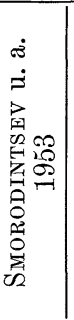 & 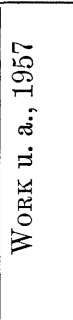 & 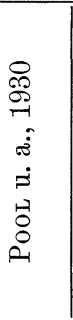 & 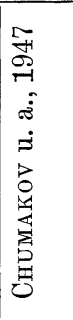 & 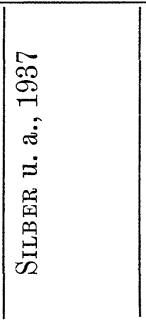 & 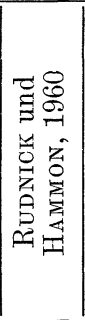 & 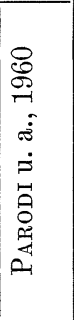 \\
\hline 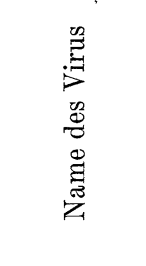 & 㞼 & 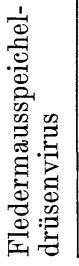 & 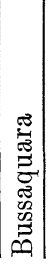 & 茎 & 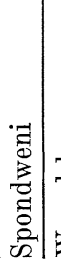 & 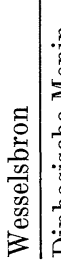 & 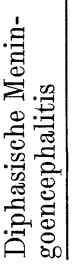 & 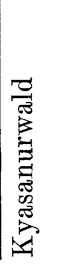 & 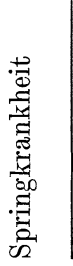 & 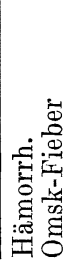 & 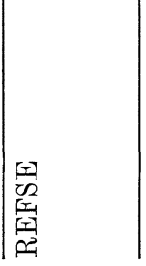 & 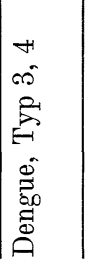 & 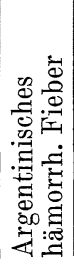 \\
\hline
\end{tabular}




\section{I. Dengue}

(Denguefieber, Denguero, Break-bone Fever, Dandy Fever, Siebentagefieber)

\section{Einleitung}

Die Dengue ist wahrscheinlich schon im Altertum bekannt gewesen. Sie scheint bereits im 2. Jahrhundert nach Chr. epidemiehaft und mit hoher Letalität im Mittelmeerraum gewütet zu haben. Eine als »Antoniusfeuer" beschriebene Krankheit, die seit 165 nach Chr. jahrelang im Römischen Reich unter Marc Aurel herrschte, spricht dafür. Sie soll bis nach Gallien und Germanien vorgedrungen sein und ganze Heere und Städte zerstört haben (BARRAUd, 1954). Die frühesten zuverlässigen Beschreibungen der Dengue gehen aber erst auf GALBERT (1779) in Ägypten und auf Bylon (1780) in Batavia zurück (zit. Hirsch, 1881; s. auch PEPPER, 1941). Rush (1809, zit. Hirsch, 1881) beschrieb eine als »biliöses remittierendes Fieber» bezeichnete Krankheit, die 1780 epidemisch in Philadelphia auftrat und wahrscheinlich Dengue war. Zu Beginn des 19. Jahrhunderts herrschte Dengue epidemisch in Bogotá (Kolumbien) und in Lima (Peru). Von den 70000 Einwohnern Limas sollen praktisch alle befallen gewesen sein (Hirsch, 1881, s. auch Zülzer, 1874). Anschließend breitete sich die Dengue über die Westindischen Inseln, Nord- und Südamerika sowie gleichzeitig über Indien und den Fernen Osten aus (Shattuck, 1951).

Die Dengue ist heute ein in den tropischen und subtropischen Gebieten vorkommendes, bis in die gemäßigten Breitengrade der ganzen Welt sich ausbreitendes, leicht verlaufendes Sommerfieber, das epidemisch und pandemisch auftritt. Die Bezeichnung geht offenbar auf den durch die Muskelschmerzen (Lendenmuskulatur) bedingten steifen, gezierten Gang (Dengue = Ziererei) zurück. Nach ihrem seuchenhaften Auftreten in Texas (1922) und in Griechenland (1928) hat die Krankheit wieder größeres allgemeines Interesse bekommen (s. auch Hoffmann, 1931).

Im 2. Weltkrieg wurden ausgedehnte Epidemien in Japan und im Pazifik beobachtet. Diese ermöglichten eine gründliche Erforschung von Ursache, Epidemiologie, Immunbiologie und Prophylaxe. Sabin $(1950,1952 \mathrm{a}, \mathrm{d}, 1955)$ gelang die Adaptierung eines Virusstammes auf Mäusen (Typ 1/Hawaii) sowie die Erzeugung einer abgeschwächten Variante oder Mutante durch Züchtung im embryonierten Ei, welche bei Versuchspersonen nur noch eine modifizierte milde Erkrankung mit Bildung von N-AK hervorrief.

Das Dengue-Virus tritt mindestens in 2 immunologisch verschiedenen Typen auf, die trotz antigenerVerwandtschaft eine langdauernde Immunität nur gegen das homologe Virus, gegen Reinfektion mit dem heterologen Virus aber nur eine kurzdauernde Immunität erzeugen. Zu den bedeutsamen Ergebnissen der Arbeiten der SabIN-Gruppe gehört ferner die Entwicklung serologischer Methoden, die sowohl epidemiologische als auch diagnostische Bedeutung haben.

Die Dengue wird wie das Gelbfieber durch Aedes aegypti und verwandte Mücken von Nensch zu Mensch übertragen (Graham, 1903; Bancroft, 1906; Cleland u. a. 1916b, 1918, 1919; SILER u. a. 1925a, b, 1926)

Ashburn und Cratg (1907a) wiesen bereits nach, daß der Erreger ein filtrierbares Virus ist.

HöRIng (1950) rechnet die Dengue ebenso wie das Gelbfieber zu den viscerotropen zyklischen Allgemeininfektionen (s. auch Doerr, 1944).

Bei Epidemien eines hämorrhagisch verlaufenden Fiebers während der Regenzeit in Manila 1956 und in Bangkok (Thailand), in denen meist Kinder unter 5 Jahren erkrankt waren, wurden als Erreger 2 neue Dengue-Virustypen $» 3 «$ und »4« ermittelt. Die Infektion wurde durch Aedes aegypti übertragen (Rudnick und Hаммом, 1960; Наммом, 1961). 
Die Sterblichkeit betrug 10\%. Chew u. a. (1961) beobachteten von Juni bis Oktober 1960 in Singapore eine Epidemie von hämorrhagischem Fieber, dessen Übertragung vermutlich durch Anophelesbisse stattfand. Der Erreger schien ebenfalls ein neues Virus der Dengue-Gruppe zu sein.

\section{2. Ätiologie}

\section{2-1. Übertragungsversuche}

Bis zur Entdeckung der Empfänglichkeit der Mäusesäuglinge für das Dengue-Virus konnten zuverlässige experimentelle Infektionen nur am Menschen ausgeführt werden (s. auch Doerr, 1930; Schilling, 1939a; Blanc, 1948; van Rooyen und Rhodes, 1948).

Daß das Dengue-Virus im Krankenblut kreist und durch i.v. Verimpfung des Blutes oder Serums Kranker auf gesunde Versuchspersonen übertragen werden kann, ist schon lange bekannt (s. auch Ashburn und Craig, 1907a, b, c; Koizumi u. a., 1917a, b; Cleland u. a., 1919). Pontano (1930) führte eine experimentelle Übertragung mit infektiösem Serum durch 11 Menschenpassagen aus. Das Virus wurde in Erythrozyten, Serum und Plasma, Lymphdrüsen, Cerebrospinalflüssigkeit, nicht dagegen im Nasenschleim und Urin gefunden. Nach SiLER u. a. (1925a, b, 1926) ist das meiste Virus bei Fieberbeginn, aber auch schon einige Stunden vorher im Blut nachweisbar. Wenn es nach der Infektion zu einer inapparent bleibenden Krankheit kommt, wird das Blut genau so schnell virushaltig wie bei einer manifesten Erkrankung (BLANC und CaMinopetros, 1928a).

Nach i. d. Einspritzung von 0,1-0,2 ml Menschenserum, das mindestens 10 Menschen-MID enthielt, kam es bei Versuchspersonen nach 3-5 Tagen zu einer Hautreaktion in Form von Ödem und Rötung mit 1-4 cm Durchmesser. Diese Reaktion beruht nach SABIN (1944, zit. 1952 d) auf einer lokalen Virusvermehrung. Innerhalb von 24 St. nach dem ersten Fieberanstieg entnommenes Blut enthielt bereits 1 Million MID/ml. Anschließend kam es immer zu einer schweren typischen Erkrankung. Schon 1 MID erzeugte entweder eine typische Erkrankung, einen milden Anfall mit vollständiger Immunität oder keine manifeste Erkrankung mit nur teilweiser Immunität. Verreibung infektiösen Serums in die skarifizierte Haut führte ebenfalls zu einer typischen Dengue. I.n. Verimpfung von 100000 MID bedingte eine milde bis schwere typische Erkrankung, während nur 10000 MID weder eine Erkrankung noch eine Immunität erzeugten.

Nach Infektion der Konjunktiva durch Instillation von 200000 MID in den Bindehautsack kam es zu einer typischen Dengue, während 10000 MID unwirksam blieben.

Manoussakis $(1928 \mathrm{a}, \mathrm{b}, \mathrm{c})$ wies darauf hin, daß sich die experimentelle Erkrankung von der natürlichen nicht unterscheidet. Durch wiederholte Mensch-zu-Mensch-Passage fand keine Pathogenitätszunahme des Virus statt, auch nicht durch Zwischenschaltung von Mücken (Cleland u. a., 1919; Chandeler und Rice, 1923, 1925; Blanc und Caminopetros, 1928d, e; Simmons, 1931; Simmons u. a., 1931b).

Sabin und Schlesinger (1945) gelang es, Mäuse i.cer. zu infizieren (Stamm Hawaii). Während der ersten Passagen erkrankte nur ein Teil der Tiere nach einer Inkubationszeit von bis zu 5 Wochen klinisch sichtbar an motorischer Schwäche und schlaffer Lähmung einer oder mehrerer Extremitäten mit oder ohne encephalitische Erscheinungen. Es waren 15 Mäusegehirnpassagen erforderlich, um das Virus so weit zu adaptieren, daß alle infizierten Mäuse an schlaffen Lähmungen erkrankten und starben. Im Verlauf von 40 Passagen stiegen die Infektiositätstiter von $10^{-1}$ auf $10^{-5}$ bis $10^{-6}$, wobei die Inkubationszeit zunehmend kürzer wurde (s. auch Hотta, 1947; Taniguchi u. a., 1951; Meiklejohn u. a., 1949). Die Gehirne von Mäusesäuglingen, die zwischen 1 und 7 Tagen infiziert wurden, ergaben bei 3 Wochen alten Mäusen einen i.cer. Infektiositätstiter von $10^{-7}$ bis $10^{-8}$. SABIN (1950) fand, daß diese hohen Titer serienweise nur in den Gehirnen neugeborener Mäuse gewährleistet waren; sie fielen bereits nach einer Passage in 14 Tage alten Mäusen auf $10^{-5}$ bis $10^{-6}$. HоттА (1952) isolierte 3 biologisch und immunologisch identische Dengue-Stämme durch i.cer. Infektion von Krankenblut auf Mäusesäuglinge (s. auch Krmura und Hotтa, 1943). Das Virus wurde auch 
im Blut der Mäuse nachgewiesen. Die Blutveränderungen bei den infizierten Tieren entsprachen jenen bei der experimentellen Dengue-Infektion des Menschen (Hотта und Sнiомi, 1952).

Die pathologischen Veränderungen bei den Mäusen bestanden makroskopisch in Hyperämie des Gehirns und der Lungen, manchmal auch kleinen Petechien in den Meningen und auf der Lungenoberfläche, ferner Blutungsneigung in anderen Organen, die aber mit zunehmender Passagenzahl geringer wurde. Histologisch ergaben sich im ZNS Zellinfiltrationen und Gliaproliferationen sowie Degenerationen der Nervenzellen, in den Lungen Hyperämie der Kapillargefäße und Zellinfiltrationen im interstitiellen Gewebe. Auch in den anderen Organen bestanden Gefäßwandschädigungen. Aus der verschiedenen Infektiosität der einzelnen Virusstämme für Mäuse schlossen Sabin und Schlesinger (1945) auf mehrere Virustypen (s. auch Holt und KLintarer, 1931 b).

Schlesinger und Frankel (1952) sahen, daß die Anpassungsfähigkeit des Virus (Neuguinea B) in den verschiedenen Mäusestämmen verschieden war. Nach 8 Gehirnpassagen in Mäusen des dba-Stammes, bei denen in etwa 50\% Lähmungen und Schwäche eintraten, übertrugen sie das Virus auf 1-7 Tage alte Mäuse des Schweizer Stammes. Bereits nach 2 Passagen betrug der tödliche Titer der Mäusesäuglingsgehirne $10^{-7}$ bis $10^{-8}$. Nach fortlaufenden Passagen gelang es auch, bei erwachsenen Mäusen Lähmungen und Tod hervorzurufen. Nach insgesamt 26 Passagen war das Virus so abgewandelt, daß es regelmäßig pathogen für Mäuse des Stammes Schweiz war. Der Infektiositätstiter war bei diesen Tieren etwa ebenso hoch wie bei Mäusesäuglingen.

Schlesinger und Frankel vermuten, daß das in den frühen Mäusesäuglingspassagen gebildete Virus aus 2 Teilchentypen besteht, von denen der eine nur für Mäusesäuglinge, der andere für Mäuse jeglichen Alters pathogen ist und den ersteren während der fortlaufenden Adaptierung im Mäusegehirn nach und nach verdrängt. Der Erwachsenentyp wird also mit zunehmender Passagenzahl prädominierend.

Meiklejohn u. a. (1952a) gelang es nur schwer, an erwachsene Mäuse anpaßbare Stämme (Neuguinea C und D) durch eine verhältnismäßig kleine Anzahl von Gehirnpassagen in 2-4 Tagen alten Mäusesäuglingen zu adaptieren und in diesen eine große Gleichmäßigkeit des Verhaltens von 5 Stämmen zu erzielen, die sich in 3-6 Wochen alten Mäusen scharf unterschieden.

Die zwar nur schwachen, Kreuzneutralisationen erlaubten eine klare Trennung der Stämme in 2 Typen (s. auch Smithburn, 1954b; Sмiтн, 1956a). Zum Typ 1 gehören die Stämme Hawaii, Neuguinea A2, indische Stämme und 3 japanische Stämme, unter ihnen der Stamm Mochizuki. Zum Typ 2 gehören die Stämme Neuguinea B, C und D. Außer mit den bisher bekannten beiden Typen muß noch mit weiteren antigenen bzw. immunologisch verschiedenartigen Typen gerechnet werden. Anderson u. a. (1956b) isolierten einen Virusstamm, der immunologisch mit beiden Typen verwandt, aber eher zum Typ 2 als zu 1 zu gehören schien. Hаммом (1958) sowie Hammon u. a. (1960) scheint es gelungen zu sein, in Thailand und den Philippinen neue Dengue-Virustypen aus Menschenseren und A.aegypti zu isolieren, die als Typ 3 und 4 bezeichnet werden und eine hämorrhagische Krankheit erzeugen. Sie sind mit den klassischen Dengue-Viren antigen eng verwandt und werden offenbar auch durch A. aegypti übertragen. Sie ließen sich auf Mäusesäuglinge übertragen. Die Infektiositätstiter stiegen während der Passagen von $10^{\circ}$ auf $10^{6} \mathrm{LD}_{50}$. Bei weiteren angeblichen Dengue-Stämmen aus Japan handelte es sich teils um Rifttal-Fiebervirus (IsHII,1948), teils um Tollwutvirus fixe (Yaoi und Arakawa, 1948).

Cortisonbehandlung erwachsener Mäuse steigerte deren Empfänglichkeit für eine DengueInfektion nicht (SмIтн, 1956a). Durch Hydroxylamin-Einspritzungen wurde die Katalase der Mäuse herabgesetzt, wodurch diese Tiere auch für an sich nicht mäusepathogene Stämme empfänglich wurden (YAMAFUGI und UEDA, 1950).

YaOI und ARAKAWa (1948) konnten Mäuse durch Injektion von Kaninchenimmunserum gegen eine i.cer. Infektion schützen, und zwar auch noch dann, wenn es erst 4 Tage nach der Infektion verabfolgt wurde (s. auch INoki u. a., 1952).

Sabin und Schlesinger (1945) sowie Sabin (1950) kontrollierten die Pathogenität des neurotropen murinen Virus für den Menschen durch s.c. oder i.d. Injektion bei 60 Personen. Die 2.-10. Gehirnpassagen ergaben noch typische Dengue-Erkrankungen mit normaler 
Inkubationszeit zwischen 3 und 9 Tagen. Von der 7. Mäusepassage an verlor der HawaiiStamm zunehmend seine Menschenpathogenität, so daß er schließ]ich nur noch einen masernartigen Ausschlag und eine kräftige Immunität gegen unmodifiziertes Virus hervorrief. Neurologische Symptome traten nicht mehr auf. Blut dieser nur Leichtkranken erzeugte bei weiteren Versuchspersonen wieder eine modifizierte Erkrankung. A. aegypti, welche bei infizierten Personen (10. Mäusegehirnpassage) eine Blutmahlzeit bekamen, vermochten die Infektion nur wieder in der modifizierten Form zu übertragen. Eine Reversion des Virus fand also in den Mücken nicht statt. Ein gleicher Versuch, in welchem die Mücken ihre Blutmahlzeit an Personen nach Infektion mit der 15. Mäusegehirnpassage bekamen, verlief negativ. Alle obigen 60 Versuchspersonen wurden einer Kontrollinfektion mit Bissen hochinfektiöser Mücken unterworfen; sie wiesen eine vollständige Immunität auf, während 4 normale Personen an Dengue erkrankten. SABIN (1952a) hält die mäuseadaptierten Virusstämme, die nur wenig menschenpathogen sind, aber volle Immunisierungsfähigkeit besitzen, für Impfstoffe verwendbar.

Der japanische Mochizuki-Stamm zeigte während der Züchtung in Mäusegehirnen die gleiche Abwandlung seiner Pathogenität für den Menschen (Нотта, 1952). Menschen, die mit dem mäuseadaptierten Typ 2-Neuguinea "B«-Stamm s.c. infiziert worden waren, erkrankten auch nur leicht; es trat nur der makulopapulöse Ausschlag in Erscheinung. Das Typ 2-Virus schien also eine ähnliche Abschwächung wie die Typ-1-Viren erfahren zu haben (Schlesinger u. a., 1956).

Ebenso wie in Gelbfieber-infizierten Mäusegehirnen kommt es auch in Dengue-infizierten Mäusegehirnen zu einer Zunahme der Xanthin-Oxydase-Aktivität (BAUER, D. J. und Bradley, 1959). Das Enzym wird offenbar auch durch eine I.-Ordnung-Reaktion mit derselben Geschwindigkeitskonstante, mit der die Virusneubildung erfolgt, gebildet, vorausgesetzt, daß es einen exponentiellen Zerfallsprozeß durchmacht, der ebenso schnell stattfindet wie die Enzymbildung. Diese nimmt von dem Augenblick ab, in dem der Virusvermehrungsprozeß beendet ist. Es kann angenommen werden, daß das Enzym immer in solchen Zellen auftreten muß, in denen sich auch das Virus vermehrt. Seine Bildung scheint aufs engste mit dem Prozeß der Virusvermehrung verbunden zu sein, für den es offenbar von fundamentaler Bedeutung ist (s. auch Bauer, D. J., 1947; Bauer und Bradley, 1956).

Blanc u. a. (1928a, 1929a) infizierten verschiedene Affenarten (Macacus cynomolgus, sinicus und fascicularis, Cercopithecus callithrichus, C. aethiops und Papio papio) mit Krankenblut. Alle Tiere blieben fieberfrei; sie schienen nur latent infiziert zu werden, da ihr Blut vom 5.-8. Tage für den Menschen infektiös war (s. auch Nicolle, 1928; SABIN und Theirer, zit. SABIN, 1952a). Kuigler (1930) sah, daß der Cercopithecus nach experimenteller Infektion vom 6.-12. Tage p. i. dieselben Veränderungen in der absoluten und relativen Lymphozytenzahl wie der mit Dengue infizierte Mensch aufwies. Übertragungen von Affe zu Affe mißlangen. Weitere Beobachtungen ergaben fieberhafte Erkrankungen bei einem japanischen Macacus fuscatus (Simmons, 1931; Simmons u. a., 1931b) und bei M. philippinensis, Cebus fatuellus, Cebus chrysops, Hapale jacchus und Hapale penicillata (Findlay, 1932) und bei 1 von 9 Schimpansen (Pan satyricus) (PAUl u. a., 1948). Alle Schimpansen wiesen N-AK mit hohen Titern auf. Rosen (1958a, b) fand in Panama die Affen Cebus capucinus, Ateles geoffroyi, Ateles fusciceps, Saimiri orstedii, Aotus trivirgatus, Marikina geoffroyi und Alouatta palliata für eine Infektion mit unmodifizierten Dengue-Virusstämmen (Typ 1 und 2) aus Seren experimentell infizierter Menschen empfänglich. Bei den Affen wurde nach 4-6 Tagen eine Virämie festgestellt. Alle entwickelten N-AK, einige auch HAH-AK, ohne manifest zu erkranken. Die mit Typ 1 infizierten Affen entwickelten mehr heterologe AK als jene mit Typ 2. Dingler und Snijders (1931) infizierten Macacus rhesus und cynomolgus nicht nur mit Virus von Menschen, sondern auch mit solchem von experimentell infizierten A. aegypti (s. auch Taniguchi u. a., 1951). Rosen u. a. (1954) konnten von einem experimentell mit Krankenblut i.p. infizierten M.irus durch Mückenbisse (Aedes polynesiensis) weitere Affen (M. mulatta) infizieren. Im Blut dieser Tiere wurden HAH-AK nachgewiesen. Die Titer der meisten Affen waren ebenso hoch wie von Menschen nach experimenteller Infektion (SwEET und SABIN, 1954b). Nach SABIN (1959b) erzeugten unmodifiziertes Menschenvirus sowie Frühpassagen von mäuseadaptiertem Virus nach i.cer. Injektion bei Rhesus- und Cynomolgus- 
Affen eine latente Infektion mit nur herdförmigen infiltrativen Veränderungen vorwiegend im Hirnstamm und Rückenmark. Während fortgesetzter Mäusepassagen entwickelten sich Virusteilchen mit erhöhtem Affenneurotropismus, so daß es nach i.cer. Infektion mit höheren Mäusegehirnpassagen häufig zu einer schweren Lähmungskrankheit kam. 4 von 15 Affen, die mit 400-40000 Mäuse- $\mathrm{LD}_{50}$ der 118. Mäusepassage des Typ 1 (Hawaii)-Virus infiziert wurden, erkrankten mit Lähmungen. Bei einer großen Anzahl von Affen, die mit 80 Millionen Mäuse$\mathrm{LD}_{50}$ der 18.-26. Mäusegehirnpassage des Typ 2 (Neuguinea C) infiziert wurden, kam es nicht zu Lähmungen. Nach zusätzlicher Züchtung des Virus in Affennierenzellkulturen durch weitere 13 Passagen erzeugte auch dieses Virus Lähmungen bei Affen, welche mit ausgedehnten neuronalen Schädigungen im Hirnstamm und Rückenmark einhergingen (s. auch SABIN, 1950, SABIN, 1955).

Die Dengue-Stämme Hawaii und Neuguinea C ließen sich auf 2-5 Tage alte syrische Hamstersäuglinge (Cricetus auratus) übertragen und sich in diesen adaptieren (MEIKLEJoHN u. a., 1952a). REAGAN u. a. (1956a) übertrugen den mäuseadaptierten Hawaii-Stamm auf laktierende Hamsterweibchen; sie beobachteten, daß die Infektion auf die Säuglinge übertragen wurde. Die Hamstermütter, die i.p. infiziert worden waren, zeigten noch nach 21 Tagen keine Beteiligung des ZNS und nach i.cer. Infektion kein Virus im Gehirn. Von 32 Hamstersäuglingen erkrankten 4 mit nervösen Erscheinungen. Ihre Gehirne enthielten Dengue-Virus, wie durch den Mäusegehirn-Neutralisationstest festgestellt wurde.

Von 2 jungen Hunden, die i.cer. mit einem mäuseadaptierten Virus infiziert wurden, erkrankte einer an encephalitischen Erscheinungen. Andere Infektionsweisen bei Hunden blieben erfolglos (REAGAN und BRUECKNER, 1953c).

REagan und Brueckner (1952 b) fanden die Höhlenfledermaus (Myotus lucifugus) empfänglich für eine i.cer. Infektion mit dem Dengue-Virus (mäuseadaptierter Hawaii-Stamm). Dieses Virus wurde durch 6 Fledermauspassagen gezüchtet. Die Spezifität der Infektion wurde durch die i.cer. Mäuseinfektion jeder Fledermauspassage und durch die NR (i.cer. Mäuseschutzprobe) bestätigt.

Blanc u. a. (1928b) fanden Meerschweinchen nur bis zu einem gewissen Grad empfänglich. 5 Tage nach Einspritzung des infektiösen Menschenblutes entnommenes Meerschweinchenblut erzeugte bei Versuchspersonen typische Dengue. Eine Passagierung des Virus gelang nicht; man kann also nur von einer einmaligen latenten Infektion sprechen, die zu keiner Adaptierung führte. Die Beobachtungen von Harris und Duval (1924a, b), daß es bei Meerschweinchen zu charakteristischen Fieberreaktionen mit Leukopenie kommt, konnte nicht bestätigt werden.

Weitere Übertragungsversuche wurden auf Kaninchen, Ratten, Ferkel, Hühner und Tauben von verschiedenen Autoren unternommen (Doerr und Russ, 1914; Siler u. a., 1926; Blanc und Caminopetros, 1930; Simmons, 1931; Нотta, 1952). Soweit diese als positiv verlaufen bezeichnet wurden, müssen sie mit größter Vorsicht beurteilt werden, da es sich in vielen Fällen wahrscheinlich gar nicht um Dengue gehandelt hatte (s. auch DoERR, 1930).

\section{2-2. Züchtungsversuche}

Hotta und Evans (1956a) sowie Hotta (1959) hielten das Typ 1 (Mochizuki)-Virus in Rollröhrchen- und Plasmatropfenkulturen von Affenhodengewebe in Hühnerplasma bei $35^{\circ} \mathrm{C}$ mindestens 11. Wochen am Leben; eine passagenweise Züchtung war nicht möglich. In Affennierenzellkulturen wurde der Mochizuki-Stamm durch 31 Passagen und der Hawaii-Stamm durch über 10 Passagen gezüchtet. Die Kulturen blieben mäusepathogen und wiesen einen ZE auf, der wie die Pathogenität durch spezifische Kaninchenimmunseren neutralisiert wurde. Нотта und Evans (1956b) züchteten außerdem den mäuseadaptierten Typ 2-Stamm Neuguinea $\mathrm{C}$ in Affennierenzellkulturen bei $35^{\circ} \mathrm{C}$ durch 18 Passagen. Die infizierten Zellen wiesen einen ZE auf, der denen der Typ 1-Viren glich. Die Zellinfektiosität wurde durch homologes Kaninchenimmunserum neutralisiert. Mit heterologem (Typ 1) Antiserum fand keine Neutralisation statt. Es wurde aber eine gewisse Hemmung gefunden, indem die mit Typ 2-Virus und Typ 1-Antiserum beimpften Zellkulturen eine geringere Degeneration als die nur mit Typ 2-Virus infizierten Kulturen aufwiesen. Nach HоттA (1959) erreichte die 
Virusvermehrung Titer bis zu $10^{-4,7}$ am 7. Tag p. i. Der Virustyp 1 wurde durch 40 Passagen mit Titern von $10^{-5}$ gezüchtet. Mit dem Virustyp 2 wurden weniger regelmäßige Resultate erhalten. In den Affennierenkulturen traten Degenerationen vom 5.-7. Tag p. i. auf. Nach 10 Tagen war die Zellpopulation auf etwa die Hälfte verringert und nach 3 Wochen waren nur noch spärlich Zellen vorhanden, welche dichte Massen im Zytoplasma enthielten. Auch SABIN (1955) erzielte gute Vermehrung der beiden Typen (1-Hawaii, 2-Neuguinea C) in Affennierenzellkulturen, allerdings ohne erkennbaren ZE. In der 3. Kulturpassage betrug der Mäuse$\mathrm{LD}_{50}$-Titer des Typ 2-Virus (Kulturflüssigkeit) $10^{6,2} / \mathrm{ml}$. Das Typ 1-Virus vermehrte sich erheblich schlechter; die Kulturflüssigkeit enthielt nur $10^{3,3}$ bis $10^{3,8}$ Mäuse- $-D_{50} / \mathrm{ml}$. Durch Auswahl von Varianten während der Züchtung konnte die Vermehrung in der Zellkultur gesteigert werden, ohne aber auch hier einen ZE zu beobachten: Der Typ 1 ergab einen Mäuse-LD $\mathrm{D}_{50}$-Titer von $10^{6}$ bis $10^{6,5}$ und der Typ 2 einer solchen von $10^{6,8}$ bis $10^{7,4} / \mathrm{ml}$ Kulturflüssigkeit (SWEET und SABIN, zit. SABIN, 1955). Die größte Virusernte wurde nach 4 Tagen erhalten (s. auch BANTA, 1957).

Hamsternierenzellkulturen erwiesen sich ebenfalls gut zur Züchtung beider Virustypen geeignet (Dierks und Hammon, 1958, 1959). Die Empfindlichkeit dieser Zellart entsprach oder übertraf sogar jene der Mäusesäuglinge. Sie war auch zur unmittelbaren Isolierung des Dengue-Virus aus dem Krankenblut in der akuten Phase geeignet. Ein Typ 2-Stamm (Serum), der bereits $12 \mathrm{Jahre}$ in $\mathrm{CO}_{2}$-Eis aufbewahrt worden war, konnte auf diese Weise isoliert werden (Diercks, 1959). Нотта u. a. (1961) fanden ebenfalls gute Vermehrung in Hamsternierenzellkulturen. Nach 23 Passagen mit dem Typ 1-Virus und 10 Passagen mit dem Typ 2-Virus hatten sich die Mäusetiter nicht verändert. Ein ZE wurde nach etwa 1 Woche sichtbar und war nach etwa 3 Wochen vollständig. Nach 7 Hamsternierenkulturpassagen ergab der Trinidad-Stamm 1751 einen höheren Titer als nach Mäusepassagen.

Eine gute Virusvermehrung (Typ 1) ohne ZE fand auch in Meerschweinchen- und Schweinenierenzellkulturen statt, während in Hühner-, Mäuse-, Kaninchen- und Rindernierenzellkulturen nur eine geringe Vermehrung erfolgte (Нотта u. a., 1961). In Menschennierenzellkulturen fand keine deutliche Virusvermehrung statt (Нотта, 1959). In Plasmakulturen von Menschenlungen-, lymphknotenmilz- und Schilddrüsenzellen (Нотта u. a., 1961) vermehrte sich Typ 1-Virus (Stamm Mochizuki) nur langsam. Es hielt sich etwa 1 Monat in Menschengehirnkulturen, verschwand aber schon nach 48 St. aus Nebennierenkulturen.

Banta (1957) züchtete Typ 1-Virus (Stamm Perry u. a., 1958) in Zellkulturen menschlicher Haut ohne ZE.

WieB ENGa $(1961 \mathrm{a}, \mathrm{b})$ erhielt nach Infektion menschlicher Hautzellkulturen (Stamm HuS 2806) mit mäuseadaptiertem Typ 1-Virus (Stamm Hawaii) Virusträgerkulturen, in denen eine fortlaufende Vermehrung der Zellen während 4 Wochen in Gegenwart von Virus stattfand. Das Virus blieb in vitro latent bzw. maskiert, da es keine erkennbare Wirkung wie einen ZE auf die Wirtszelle ausübte. Es ließ sich aber im Mäusesäuglingsgehirn nachweisen. Wurde das Pferdeserum im Medium durch Rinderserum-Ultrafiltrat ersetzt, so kam es zu morphologischen Veränderungen, die sich allerdings von jenen in Affennierenzellkulturen unterschieden. Während dieser ruhenden Infektion schien ein stabiles Wirts-Parasiten-Gleichgewicht zu bestehen. Solche chronisch infizierten Zellpopulationen konnten 2 Jahre lang am Leben erhalten bleiben. Mittels der Immunofluorescenzmethode wurde nachgewiesen, daß mindestens 10\% der Zellen der Virusträgerkulturen Antigen enthielten. Nach 15 Monate langer Züchtung des Virus war ein neuer Virusunterstamm entstanden, der nach Übertragung auf frische HuS 2806- oder Affennierenzellkulturen einen, vollständigen ZE ergab, der sich durch 5 Passagen weiterführen ließ. Entsprechend der Entwicklung des ZE in beiden Zellarten (GKZED ${ }_{50}$ ) wurde in HuS-2086-Kulturen als höchster Titer nach 78 St. Bebrütung $10^{4} \mathrm{LD}_{50} /$ Maus und in Affennierenzellkulturen nach $125 \mathrm{St}$. Bebrütung $10^{5} \mathrm{LD}_{50} /$ Maus erhalten. Die Titrationsendpunkte der ZE in den Kulturen entsprachen etwa der Mäuse- $\mathrm{LD}_{50}$. Der ZE in beiden Kulturarten wurde spezifisch durch Dengue-Antiserumzusatz neutralisiert. Der Neutralisationsindex in den Kulturen entsprach jenem in Mäusesäuglingen.

BANTA (1957) konnte bei der Züchtung in HeLa-Zellkulturen keinen ZE feststellen, während Buckley (1961) bei der Züchtung von 4 immunologisch verschiedenartigen Dengue-Virustypen (Mäusesäuglingspassagen von Typ 1/Hawaii, Typ 2/Neuguinea, Typ 3 und 4) in 
HeLa-Zellkulturen mit Tryptose-Phosphat-Bouillon ZE erhielt, die für alle 4 Typen gleich erschienen. Nach 5-7 Tagen traten Herde von runden und granulierten Zellen in Form von Mikroplaques auf, die zahlreicher wurden und während der 2. Woche konfluierten. Während der 3. Woche waren 50-70\% der Zellen von der Glasfläche abgelöst. Die Kulturflüssigkeit tötete 2 tägige Mäusesäuglinge, die i.cer. infiziert worden waren, nach 6-7 Tagen. Die Entwicklung des ZE, der jenem der Typen 1 und 2 von Hotтa und Evans $(1956 \mathrm{a}, \mathrm{b})$ in Affennierenzellkulturen glich. wurde durch typenspezifisches Kaninchenimmunserum gehemmt.

Schulze und Schlesinger (1962) beobachteten, daß der Dengue-Virustyp 2 in KB-Einschichtzellkulturen in flüssigem Medium einen starken ZE erzeugte. Kulturen, die bereits fast vollständig zerstört waren, wechselten in einen chronischen Virusträgerzustand über, der $21 /{ }_{2} \mathrm{Jahre}$ anhielt. Durch Zusatz von Agar oder wäßrigem Agarextrakt wurden der ZE und die Virusvermehrung gehemmt. Das mit wäßrigem Agarextrakt behandelte Virus hatte eine herabgesetzte Mäuseinfektiosität und verringerte HA-Fähigkeit. In mit Agar überschichteten KB-Zellkulturen traten keine ZE auf. Die Hemmung des ZE wurde teilweise durch Verdünnung des Virus aufgehoben. Durch Diäthylaminoäthyl-Cellulose wurde die Hemmung ebenfalls aufgehoben. Ersatz der Agardeckschicht durch 2\%ige Methyl-Cellulose gestattete eine genaue Beobachtung der Plaquebildung. Die Virusträgerzellen verklumpten in Gegenwart von spezifischem Immunserum (BeAsley und Sigel, 1961; s. auch Sigel u. a., 1961).

Beasley u. a. (1961) hatten eine Vermehrung des Typ 2-Virus in KB-Zellkulturen ohne ZE beobachtet. Längere Behandlung der Kulturen mit Dengue-Immunserum führte zu keiner "Heilung", d. h. zu keiner Hemmung der Dengue-Infektion in vitro. Die Kulturen zeigten aber eine verlangsamte Wachstumsspitze und Herabsetzung der Fähigkeit, bei Ratten nach i.cer. Impfung Tumoren zu erzeugen. Die Menge des für Mäusesäuglinge infektiösen Virus blieb relativ gering, gewöhnlich geringer als 1 IE je Zelle.

Die Dengue-infizierten Zellkulturen wiesen eine herabgesetzte Empfänglichkeit für PolioVirus auf. Auch chronisch (latent) mit Dengue infizierte Zellkulturen zeigten eine verstärkte Interferenz mit dem Polio-Virus, die allerdings nur vorübergehend war, während in diesen Kulturen die erhaltenen Dengue-Virusmengen herabgesetzt waren.

Sновтт u. a. (1936b) übertrugen Serum oder Plasma aus Dengue-Krankenblut vom 1. Fiebertag auf die CAM embryonierter Hühnereier. In 15 Fällen entstanden Herde auf den Membranen, welche Ähnlichkeit mit Veränderungen hatten, wie sie auch durch PappataciFieber-Virus erzeugt werden; sie waren aber zarter als bei letzteren und wurden niemals nach Verimpfung von normalem Serum beobachtet. $\mathrm{Ob}$ es sich allerdings um eine Kultur des Dengue-Virus gehandelt hat, ist unbestätigt geblieben, zumal Übertragungen vom Ei auf Versuchspersonen nicht vorgenommen worden sind (s. auch Kawamura u. a., 1943; Kimura u. a., 1944). SABIN und Schlesinger (zit. Sabin, 1952d) versuchten vergeblich, unmodifiziertes Menschen-Virus im Ei zu züchten. Erst ein durch 16 oder 18 Mäusegehirnpassagen adaptiertes Virus konnte in 5tägigen Embryonen bei $35^{\circ} \mathrm{C}$ während 8-10 Tagen am Leben erhalten werden. Mit zunehmender Mäusegehirnpassage ließ sich das Virus auch im embryonierten Ei passagenweise kultivieren. Schlesinger (1950) erhielt die besten Züchtungsergebnisse mit der 101. Mäusepassage des Typ 1-Virus Hawaii. Die größte Vermehrung fand im Nervensystem des Embryos statt; sie war 100-1000 mal größer als in den anderen Geweben. In den extraembryonalen Membranen und Flüssigkeiten war sie nur minimal. Die Titer des ZNS des Embryos im Mäusegehirn erreichten 105, und zwar noch in der 88. Embryopassage. Die Virusmenge entsprach aber nur 1\% jener im Gehirn infizierter neugeborener Mäuse. Wachstum und Entwicklung der Hühnerembryonen wurden nicht gestört. Das Virus blieb im Gehirn ohne Veränderungen desselben mindestens 10 Tage nach dem Schlüpfen der Küken nachweisbar, in ihrem Blut dagegen nur 2 Tage. Die Unmöglichkeit, das Virus in geschlüpften Küken nach i.cer. Impfung zur Vermehrung zu bringen, beruht auf der abnehmenden Empfänglichkeit der Embryonen mit zunehmendem Alter. Mäusepathogenität, Affenneurotropismus und serologische Spezifität des Virus blieben während der in ovo-Züchtung unverändert. Nach der 38. Eipassage erzeugte das Virus beim Menschen eine modifizierte Dengueform, die durch nur leichten makulopapulösen Ausschlag und 2tägiges niedriges Fieber ohne weitere Erscheinungen sowie Bildung von N-AK gegen den mäuseadaptierten Hawaii-Stamm gekennzeichnet war (SABIN, 1955). 


\section{2-3. Eigenschaften des Virus}

Das Dengue-Virus läßt sich durch Chamberland-Kerzen $\mathrm{L}_{2}, \mathrm{~L}_{3}, \mathrm{~L}_{7}, \mathrm{~L}_{8}, \mathrm{~L}_{11}$ (Ashburn und Craig, 1907a, b, c; Cleland u. a., 1919; Blanc u. a., 1928b; Blanc und Caminopetros, 1928d, 1929b) sowie durch Berkefeld N- und V-Kerzen (KuigLer und Aschner, 1928; Simmons u. a., 1931b) filtrieren, wie die Infektiosität der Filtrate in Menschenversuchen zeigte.

Die Teilchengröße des Virus beträgt nach SABIN (1952d) 17-25 mu, nach Toda und NAGaWa (1944) 15-23 mu. Das Virus wird aus infektiösem Menschenserum durch 90 Min. Zentrifugieren mit $24000 \mathrm{U} / \mathrm{Min}$ sedimentiert.

SABIN u. a. (1945, zit. SABIN, 1952 d) fanden in elektronenmikroskopischen Aufnahmen von Präparationen aus hochinfektiösem Menschenserum nach Reinigung und Differentialzentrifugierung hantelförmige Strukturen von $700 \times 20-40 \mathrm{~m} \mu$. REAGAN und BRUECKNER (1952a) sahen dagegen in chrombeschatteten infektiösen Mäusegehirnpräparationen (mäuseadaptiertes Typ 1 Hawaii-Virus) Stäbchenformen von 24-46 m $\mu$ Dicke und 175-220 m $\mu$ Länge. НоттA $(1950,1953 a)$ fand kuglige Körper mit einem Durchmesser von etwa 20 m $\mu$. OzAWA (1954) gab kuglige Teilchen mit einem mittleren Durchmesser von 34,2 $\pm 2,8 \mathrm{~m} \mu$ in durch Methanolpräzipitation von infizierten Mäusegehirnen gewonnenen Präparationen an (s. auch YAor u. a., 1954).

Нотта (1953c) behandelte den mäuseadaptierten Mochizuki-Stamm mit Protaminsulfat und stellte fest, daß dieses Virus zur Gruppe der nicht durch Protamin präzipitierbaren Viren gehört, was auch seiner Kleinheit entspricht. Durch Adsorption an Kaolin bei saurer Reaktion und anschließender Elution bei alkalischer Reaktion war eine teilweise Reinigung des Virus möglich. Die Aktivität dieser Präparation blieb bei $47^{\circ} \mathrm{C}$ mindestens 20 Min erhalten, ging bei $54^{\circ} \mathrm{C}$ in 5 Min zum größten Teil und in 10 Min ganz verloren (s. auch НоттA, 1948). TaKahara und Hotta (1961) reinigten Typ 1-Virus (Stamm Mochizuki) durch Adsorption an ECTEOLA-Cellulose-Säulen und anschließende Elution.

Bei der Untersuchung physikalischer Einflüsse ergab sich, daß das Dengue-Virus in getrocknetem Zustand lange am Leben bleibt (FindLay, 1932). In gefrorenem Zustand getrocknet (infektiöses Menschenserum) blieb es bei $5^{\circ} \mathrm{C}$ oder $-70^{\circ} \mathrm{C}$ mindestens 8 Jahre wirksam (SABIN, 1950). Zusatz von 5\% menschlichem Albumin bei der Gefriertrocknung wird empfohlen (SABIN, 1959b). 48 St. langes Gefrieren von Krankenserum bei $-7^{\circ} \mathrm{C}$ zerstörte oder schwächte das Virus nicht (HoLT und Kintner, 1931b). Da das Virus bei tiefen Temperaturen aber recht labil ist, sollte es mit einem geeigneten Stabilisator, z. B. mit bei $56^{\circ} \mathrm{C} 30 \mathrm{Min}$ erhitztem Kaninchenserum, das mit gleicher Menge NaCl-Lösung verdünnt ist, versetzt werden. Mäusegehirnsuspensionen mit mäuseadaptiertem Virus erhielten durch Zusatz von $10 \%$ dieser Serumverdünnung ihre optimale Konservierbarkeit bei $-60^{\circ} \mathrm{C}$. Bei $0^{\circ} \mathrm{C}$ hielt sich infektiöses Menschenserum etwa 2 Monate (Blanc u. a., 1928a, b), im gewöhnlichen Kühlschrank einige Wochen (Schlesinger und Frankel, 1952). Bei $12-15^{\circ} \mathrm{C}$ sowie bei Zimmertemperatur blieb es 8 Tage wirksam (Pontano, 1930). Durch Erhitzen auf $50^{\circ} \mathrm{C}$ wurde es in 30 Min zerstört (Manoussakis, 1928a, b).

Während HoLt u. a. (1931) glaubten, daß UV-Bestrahlung keine Wirkung auf das DengueVirus hätte, stellte SABIN $(1950,1952$ d) fest, daß das Virus in Menschenserum oder Mückenverreibungen durch 0,47 Sek. dauernde Behandlung im Oppenheimer-Levison-Gerät inaktiviert wird und sogar seine Immunisierungsfähigkeit verliert. HoLt u. a. (1931) beobachteten, daß Röntgenbestrahlung (Erythemdosen) infizierter Aedes-Mücken das Virus nicht zerstört, denn der Krankheitsverlauf bei experimentell mit bestrahltem Virus durch Mückenbiß infizierter Menschen änderte sich nicht.

Durch Behandlung mit Rindergalle wird das Mäusepassagevirus abgeschwächt, ohne seine Immunogenität zu verlieren (BLANC und Caminopetros, 1930; HotTa, 1954). Nach TAKaHARA und Hотта (1961) wird die Infektiosität des Typ 1-Virus (Mochizuki) durch Trypsin und Pankreaslipase herabgesetzt oder vollständig zerstört. Ähnlich wirken Bakterienproteinase und -lipase. Das Virus widersteht einer Formolverdünnung von 1: 8005 St. (s. auch Нотта, 1954), einer 0,5\% igen Cholesterinlösung 15 Min, Neutralrotverdünnungen von 1: 5007 St., 95\% igem Alkohol und 0,1\% iger Adrenalinlösung nur kurze Zeit (Blanc und Caminopetros, 1930). In 
Affennierenzellkulturen gezüchtetes Virus der Typen 1 und 2 wird durch Schütteln mit Äthyläther inaktiviert. Hier ergibt sich eine Verwandtschaft dieses Virus mit den Gelbfieberund verschiedenen durch Arthropoden übertragbaren Encephalitis-Viren, die auch ätherempfindlich sind (Нотta und Evans, 1956 a, c; s. auch Andrewes und Horstmann, 1949). Bei der Verwendung von Mäusen zur Isolierung von Dengue-Virus ist die Ätherempfindlichkeitsprüfung wichtig, um auszuschließen, daß ein etwa isoliertes Virus ein Theiler-Mäuse-EMVirusstamm ist, der ätherresistent ist. Das Virus wird durch schwache Lösungen von $\mathrm{MgCl}_{2}$, 0,1\% ige Olein-Buttersäure, Gentianaviolett 1:500 und Chinin in verschiedenen Zeiten (BLaNC und Caminopetros, 1930) abgetötet.

Нотта (1953d) prüfte die etwaige chemotherapeutische Wirkung 28 chemischer Verbindungen an infizierten Mäusesäuglingen: Arsen-, Antimon-, Vanadium-, Guanidin-, Diphenylätherverbindungen, Atebrin, Sulfonamide u. a.; keine dieser Substanzen setzte die Sterblichkeit herab. In nur wenigen Fällen wurde eine Verlängerung der Überlebenszeit beobachtet.

SweEt und Sabin (1954b) konnten aus Mäusesäuglingsgehirnen, die mit den. Viren Typ 1 Hawaii und Typ 2 Neuguinea C infiziert worden waren, durch Extraktion mit 0,016 M BoratKCl-Puffer ( $\mathrm{p}_{\mathrm{H}}$ 9) Hämagglutinine gewinnen, die bei einem $\mathrm{p}_{\mathrm{H}}$ von 6,7 schnell zerstört wurden. Tiefgefrieren bei $-80^{\circ} \mathrm{C}\left(\mathrm{p}_{\mathrm{H}} 7,9\right)$ und Wiederauftauen führten zu einer völligen Zerstörung des Hämagglutinins. Nach Aufbewahrung bei $4^{\circ} \mathrm{C}\left(\mathrm{p}_{\mathrm{H}} 7,9\right)$ blieben die Hämagglutinine wenigstens 4 Monate stabil. Auch bei $25^{\circ} \mathrm{C}\left(\mathrm{p}_{\mathrm{H}} 7-7,9\right)$ bestand eine erhebliche Stabilität. Bei $37^{\circ} \mathrm{C}$ blieben die Hämagglutinine der 19. Mäusepassage des Typs 2 und der 7. Mäusepassage der Typs 1 mindestens 18 St. stabil, während das der 118. Mäusepassage des Typs 1 fast seine ganze Wirksamkeit schon in 1 St. verlor (s. auch SweEt u. a., 1953; CASALS und Brown, 1954; SABIN, 1955). Die Hämagglutinine beider Typen sind sowohl antigen verschieden als gleichzeitig auch antigen verwandt. Sie konnten mittels ihrer $\mathrm{p}_{\mathrm{H}^{-}}$und Temperaturerfordernisse für eine maximale $\mathrm{HA}$ unterschieden werden. Die Typ 1-HA war bei $4^{\circ} \mathrm{C}$ und $25^{\circ} \mathrm{C}$ in einer breiten $\mathrm{p}_{\mathrm{H}}$-Zone $(6,2-7,5)$ mit maximalen Titern bei 6,7 nachweisbar. Die Typ 2-HA fand nur bei $4^{\circ} \mathrm{C}$ bei einem $\mathrm{p}_{\mathrm{H}}$ von nur $6,5-6,6$ statt. Die HA erfolgte am besten mit Hühnererythrozyten. NaKagawa und Shingu (1955) fanden in den Gehirnen 2-4 Tage alter Mäusesäuglinge, die mit Dengue infiziert worden waren, ein spezifisches Hämagglutinin für Pferdeerythrozyten. Die optimale HA-Temperatur lag bei $4^{\circ} \mathrm{C}$.

NAKAmURa (1961) isolierte aus infizierten Mäusesäuglingsgehirnen (Typ 1-Virus Hawaii) eine infektiöse RNS. Nach Auftreten von Krankheitserscheinungen wurde aus den Gehirnen eine $10 \%$ ige Suspension in destilliertem Wasser hergestellt, die langsam zentrifugiert wurde. Die überstehende Flüssigkeit wurde $3 \mathrm{mal} 3$ Min mit der gleichen Menge 80\% igem Phenol bei $4^{\circ} \mathrm{C}$ (nach Gierer und Schramm, 1956) oder 3 Min mit der gleichen Menge geschmolzenem Phenol bei $50^{\circ} \mathrm{C}$ (nach WeCKeR, 1959) unter Schütteln extrahiert. Nach 3 solchen Extraktionen wurde die wäßrige Phase $5 \mathrm{mal}$ mit peroxydfreiem Äther geschüttelt und der überschüssige Äther durch N-Durchströmung entfernt; dann wurde mit sterilem destilliertem Wasser das Ausgangsvolumen wieder hergestellt. Die Kälte- und Hitze-Phenolextraktionen ergaben keine Unterschiede. Die UV-Absorptionsspectra dieser Präparationen waren typisch für NS. Durch 10 Min Behandlung mit $50 \mu \mathrm{g} / \mathrm{ml}$ RN-ase bei Zimmertemperatur vor der Beimpfung von Mäusen wurde die Infektiosität vollständig zerstört, während die gleiche Behandlung der Virusrohsuspension keine Wirkung auf die Infektiosität hatte. Die Ausbeute an infektiöser RNS war etwa $0,01-0,1 \%$ der Virusrohpräparation. Die Infektiositätstiter wurden als $\mathrm{LD}_{50}$ durch i.cer. Impfung $(0,02 \mathrm{ml}$ bei $3-4$ Tage alten und $0,03 \mathrm{ml}$ bei 3 Wochen alten Mäusen) in serienweiser 10 facher Verdünnung bestimmt. Es bestand kein Unterschied in der RNS-Infektiosität für Mäusesäuglinge und erwachsene Mäuse, während die rohe Virussuspension für erwachsene Mäuse einen 100 mal geringeren Infektiositätstiter hatte. Das Verhältnis von Virus : RNS lag für erwachsene Mäuse viel näher bei 1 als für Mäusesäuglinge. Die RNSPräparationen hatten kein HA-Vermögen. 


\section{Epidemiologie und Übertragung}

Die Dengue gehört zu der größten Gruppe der durch Arthropoden übertragenen Viruskrankheiten und kommt vorwiegend in den Tropen und Subtropen vor, und zwar wie das Gelbfieber nur dort, wo A. aegypti-Mücken vorhanden sind. Im Gegensatz zum Gelbfieber ist aber der Dengue-Gürtel, der sich um den ganzen Erdball erstreckt, erheblich breiter (s. auch DeRRICK und BICKs, 1958). Dies beruht darauf, daß das Dengue-Virus in den Mücken noch in Breitengraden aktiv bleibt, wo das temperaturempfindlichere Gelbfiebervirus keine Existenz- bzw. Vermehrungsmöglichkeiten mehr findet. Epidemien kommen besonders in Küstengegenden vor.

Zureisende aus denguefreien Gebieten werden leicht befallen, ebenso Menschen aus Gebirgsgegenden oberhalb verseuchter Gebiete, soweit sie aus Höhen stammen, in denen Aedes nicht mehr existieren. BLANC (1948) charakterisierte die Dengue als »eine Infektionskrankheit, deren Bedeutung erst zu Zeiten schneller und brutaler Ausbreitung an Orten, wo sie noch nicht einheimisch war, hervortritt. Wenn sie für den einzelnen Menschen auch immer gutartig ist, so wird sie durch ihr Massenauftreten schwer».

Während des 2. Weltkrieges stellte die Dengue für die Truppen besonders im pazifischen Raum und im Fernen Osten ein ernstes Problem dar. Es kam besonders in militärischen Einheiten, welche aus nicht verseuchten Ländern in endemische Dengue-Gebiete verlegt wurden, schnell zu Massenausbrüchen (s. auch Theiler und CASALS, 1959). Diese Beobachtung wurde bereits um die Jahrhundertwende während des spanisch-amerikanischen Krieges auf den Philippinen gemacht. Нотта (1953b) wies auf eine Epidemie in Japan 1942-1945 hin, welche mindestens 200000 Personen umfaßt haben und die größte jemals in gemäßigten Zonen beobachtete Epidemie gewesen sein dürfte (s. auch Sabin, 1952a; Rosen u. a., 1954). Rowan (1959) beschrieb eine Dengue-1-Epidemie in Nord-Queensland 1954. Nach MacLeaN und Margrath (1959) kommen seit 1920 Dengue-1-Epidemien von Zeit zu Zeit in Australien und benachbarten Inseln vor. Downs u. a. (1956b) stellten endemisches Vorkommen der Dengue in Trinidad fest.

In verseuchten Gebieten wird die Infektion im allgemeinen schon im Kindesalter durchgemacht, wodurch die ortsansässige Bevölkerung eine erhebliche Resistenz erwirbt. Findet trotzdem im späteren Alter eine Infektion statt, insbesondere mit einem anderen Virustyp, so verläuft die Krankheit meistens so leicht, daß sie nicht diagnostiziert wird (SiLER u. a. 1926). Unterschiede der Empfänglichkeit von Alter, Geschlecht und Rasse scheinen nicht vorhanden zu sein.

Die wichtigste Dengue-Mücke ist der A. aegypti (Stegomyia fasciata) (Näheres s. Gelbfieber). Ihre Bedeutung als Überträger der Dengue von Mensch zu Mensch wurde bereits von BanCRoft (1906), welchem es gelungen war, 2 Menschen durch Biß dieser Mücke zu infizieren, sowie auch von LeGENDRE $(1911,1929)$ erkannt, aber erst von CleLAND u. a. (1916a, 1918, 1919) und Siler u. a. (1925a, b) in Menschenversuchen bestätigt. Auf der westlichen Halbkugel scheint nur A. aegypti als Überträger in Frage zu kommen (Rosen, 1958a). Cleland u. a. $(1916$ a , 1918, 1919) schlossen gleichzeitig aus, daß Culex fatigans Dengue übertragen könnte (s. auch Kligler, 1928; Kligler und Aschner, 1928; Blanc und Caminopetros, 1928 b, c, d). Die minimale extrinsische Inkubationszeit des A. aegypti, d. h. die Zeit von der virushaltigen Blutmahlzeit bis zum Infektiöswerden der Mücke, beträgt 7-8 Tage (KamaL, 1928; Schule, 1928; Blanc und Caminopetros, 1929a; Blanc, 1948). Die Durchschnittszeit liegt jedoch zwischen 11 und 14 Tagen (Apostolopoulos, 1930). Die Dauer der extrinsischen Inkubationszeit hängt außer vom Virusstamm und der Virusdosis (Siler u. a., 1926) vor allem von der Umgebungstemperatur ab. Durch Abkühlung wird sie verlängert, durch Erwärmung verkürzt. Die infizierten Mücken behalten ihre Infektiosität bei über $18^{\circ} \mathrm{C}$, verlieren sie aber, wenn die mittlere Temperatur unter $18^{\circ} \mathrm{C}$ fällt. Das Virus bleibt jedoch auch dann noch am Leben, da die Mücken wieder infektionstüchtig werden. wenn die mittlere 
Temperatur über $18^{\circ} \mathrm{C}$ steigt. Bei dauernd tiefen Temperaturen $\left(16^{\circ} \mathrm{C}\right)$ bleibt das Infektionsvermögen mindestens 104 Tage erhalten, während die Mücken sonst lebenslänglich infektiös bleiben (Blanc und Caminopetros, 1929a, 1930).

Aus den Versuchen von Holt und KintneR (1931a) geht hervor, daß die Infektion sich im Mückenkörper generalisiert und septikämischen Charakter hat. Unter Versuchsbedingungen ist die Übertragung des Virus von einer infizierten auf eine nichtinfizierte Mücke möglich (Sт. Јоно u. a., 1930a; Simmons u. a., 1931a). Dies trifft auch für die Kopulation zu. Nach Simmons u. a. (1931a) findet diese Übertragungsart aber in der Natur nicht statt. Damit entfällt auch die Übertragung vom erwachsenen Mückenweibchen auf ihre Eier. SABIN (1944, zit. 1952 d) fand Larven unfähig, sich in virushaltigem Menschenserum zu infizieren.

Neben A. aegypti kommt dem A. albopictus in manchen Gegenden des Dengue-Gürtels wie in Australien und besonders Japan, wo er in den Monaten Juni-September schwärmt (IsHII u. a., 1954) größte Bedeutung zu. Simmons u. a. (1930a, b) gelang in Manila mit A. albopictus Skuse eine experimentelle Übertragung auf Menschen (s. auch Sт. Joнn u. a., 1930b). SNiJders (1931) sowie SNIJDERS u. a. (1931a, b) fanden in Sumatra auch A. albopictus neben A.aegypti als natürlichen Dengue-Überträger und konnten mịt ihm - nach Amsterdam gebracht - bei Versuchspersonen Dengue erzeugen (s. auch Dinger und SNIJDERs, 1931). Während der A. aegypti an die menschliche Behausung gebunden ist, vermag A. albopictus auch im Urwald zu leben, wo er sehr wohl die Dengue-Infektion unter den empfänglichen Affenarten aufrecht erhalten kann, so daß es zu demselben Dschungeltyp kommt wie beim Gelbfieber, was auch für die Epidemiologie der menschlichen Dengue von größter Bedeutung ist (s. auch KoIzumi u. a., 1917a, b, 1918; Morishita, 1925). Ishir u. a. (1954) haben eine genaue Beschreibung der Biologie dieser Mücke einschließlich A.togoi gegeben (s. auch HALCROW, 1955).

Als weitere Überträger kommen in Frage: in Formosa Armigeres Walk (Desvoidera obturbans), ein partieller Hausbrüter, und Aedes scutellaris Walk (Korzumi u. a., 1917, a, b, 1918; Morishita, 1925) sowie in Polynesien A. polynesiensis Marks, eine Untergattung von A. scutellaris, was in Affenversuchen bestätigt wurde (Rosen u. a., 1954), außerdem A. hebridus, eine Waldmücke, mit welcher experimentelle Infektionen bei Menschen gelungen sind (UsingER, 1944), in Neuguinea (Mackerras, 1946) und auf den Neuen Hebriden (Daggr, 1944). Perrr (1948) sprach sich jedoch gegen eine natürliche Übertragung der Dengue durch A. hebridus aus.

In Texas (USA) konnten Chandler und Rice (1923) die Dengue mit Aedes argenteus übertragen (s. auch HaMlin und HarRis, 1931). In Panama kann Dengue möglicherweise auch durch Haemagogus-Mücken, welche für das Dschungelgelbfieber so wichtig sind, übertragen werden (SABIN, 1952a). SABIN und JAHNES (1944, zit, SABIN, 1952 d) stellten in Nordamerika fest, daß unter denselben Bedingungen, unter denen A. aegypti die Dengue übertrug, folgende Mücken dazu nicht in der Lage waren: Aedes vexans, A. taeniorhynchus, A.sollicitans, A.cantator, Anopheles punctipennis, Anopheles quadrimaculatus und Culex pipiens. In Australien kommen nach O'Gower (1960) 5 Mückenarten als mögliche Überträger der Dengue von den angenommenen Reservoiren auf den Menschen in Frage: Taeniorhynchus = Mansonia uniformis, A. vigilax, Culex annulirostris, C. fatigans und C. sitiens; in erster Linie verdächtigt sind A. vigilax und $\mathrm{C}$. sitiens.

Unter natürlichen Bedingungen kommt eine Dengue-Epidemie beim Eintritt von Frost sehr schnell zum Erlöschen (ARMstrong, 1923), da infolge der Notwendigkeit von Mindesttemperaturen für ein Infektiöswerden des A. aegypti (s. oben) die Dengue eine stark saisongebundene Krankheit ist.

Schon Blanc und Caminopetros (1929a) hatten festgestellt, daß infizierte A. aegypti während der Monate Januar, Februar und März nicht infektiös sind und dies erst ab April wieder werden. Manoussakis (1931) fand, daß in einem endemischen Gebiet mit Einsetzen der warmen Witterung zunächst nur einige wenige sporadische Fälle nach Aedesbissen auftreten. Durch die Blutmahlzeit an diesen wird gleichzeitig eine große Zahl von Mücken infektiös, worauf es dann plötzlich zu einem größeren Ausbruch kommt. Auf der Höhe des 
Sommers ist die maximale Zahl infektiöser Mücken erreicht. Anschließend ist die Ausweitung der Epidemie ganz von der Zahl empfänglicher Menschen im befallenen Gebiet abhängig. Nach Hanson (1936) sind in einer Gemeinde weniger Mücken für einen Dengue-Ausbruch als wie für einen Gelbfieberausbruch erforderlich. Aber nur dort, wo die Virusvermehrung und -ausscheidung der Mücken am günstigsten sind, d. h., wo die Mücken ganzjährig überleben, vermag auch die Dengue ununterbrochen zu bestehen; dies ist offenbar nur in Äquatornähe der Fall (Rogers und Megaw, 1942). Hier scheint der neugeborene Nachwuchs in der Bevölkerung zu genügen, um die ganzjährige Permanenz der Infektion zu gewährleisten.

Ebenso wie das Gelbfieber kann die Dengue primär als eine Zoonose aufgefaßt werden, die durch gemeinsame Blutsauger (Mücken) auch auf den Menschen oder direkt von Mensch zu Mensch übertragen wird, so daß auch hier eine Zoo-Anthroponose vorliegt.

Das Dengue-Virus wird beim Menschen normalerweise nicht auf natürlichen Wegen ausgeschieden und aufgenommen. Die Dengue ist daher keine kontagiöse Krankheit. Allerdings haben Laboratoriumsinfektionen gezeigt, daß unter besonderen Umständen eine Infektion auch durch die Konjunktiva erfolgen kann (MeLnick u. a., 1948). Das Virus kreist, wie schon erwähnt, nur während der Fieberperiode und vornehmlich nur während der ersten 4-5 Krankheitstage im Blut; eine Virämie kann aber auch bereits 1 Tag vor Fieberausbruch bestehen. Eine Infektion der Mücken kann also nur bei einer Blutmahlzeit innerhalb dieser Zeit stattfinden. Nach Simmons u. a. (1931b) genügt ein einziger Biß einer Mücke, nach SiLer u. a. (1926) sind 2 Bisse erforderlich, um eine experimentelle Infektion bei Menschen zu erzeugen. Der wichtigste Viruswirt ist der Mensch selbst, aber auch verschiedene Affenarten kommen in endemischen Gebieten als Virusreservoire in Frage. BRuMpt (1949) nimmt an, daß die Affen spontan erkranken können, was auch aus der Beobachtung hervorgeht, daß sie sich häufig gegen eine experimentelle Infektion unempfänglich erweisen. M.fuscatus, M.philippinensis sowie M. mulatta gelten heute in erster Linie als Viruswirte unter den Affen. Obwohl Rosen (1958a, b) die Affen in den Wäldern Panamas empfänglich für eine experimentelle DengueInfektion fand, konnte er keinen Anhalt für natürliches Dengue-Vorkommen unter diesen Tieren feststellen. Er glaubte im übrigen nicht an Dschungelviruswirte, da unter den Randbewohnern der Wälder N-AK nur ganz selten angetroffen wurden. Dagegen schrieben Simmons u. a. (1931b) den Affen eine wichtige Rolle bei der Ausbreitung der Dengue in den Philippinen zu. Osterrieth u. a. (1961b) wiesen bei Schimpansen (Pan troglodytes) AK nach. Bei einer erheblichen Anzahl in Baumwipfeln lebender Tierarten (außer Affen), wie z. B. Eichhörnchen und Zibets, aber nur bei wenigen auf dem Waldboden lebenden Tierarten Malayas wurden Dengue-Infektionen festgestellt. In Australien wurden fiegende Füchse (Genus: Pteropus scapulatus und P. Gouldi) als Träger von N-AK gefunden; ob sie als Virusreservoire in Frage kommen, ist noch unbekannt (O'ConNoR u. a., 1955; O'Gower, 1960). Sie könnten für das endemische Fortbestehen der Dengue in Nordaustralien, den FidschiInseln und Samoa, wo die menschliche Bevölkerung gering, die Zahl der früchtefressenden Fledermäuse dagegen sehr groß ist, in Frage kommen. Ebenfalls in Australien wurden bei einer Reihe von Wildvögeln N-AK gefunden, und zwar gegen den Typ 1 bei Strandläufern (Heteroscelus brevipes) und Silbermöven (Larus novaehollandiae) (Rowan und O'Connor, 1957; O'Gow ER, 1960).

Sмгтн (1956c) glaubt an das Vorkommen von Dengue in Wäldern, wo das Bestehen durch Mücken, die nur in den Baumwipfeln beißen, gewährleistet wird. Von diesen Waldreservoiren wird das Virus durch A. albopictus auf die außerhalb der Wälder lebende Landbevölkerung übertragen, in welcher sie aber nur endemisch vorkommt. A. albopictus bildet also das Verbindungsglied zwischen der Wald- und übrigen Bevölkerung.

In den Städten ist nur der A. aegypti Überträger von Mensch zu Mensch. Bemerkenswert ist, daß bis Ende des 19. Jahrhunderts die Dengue nur in den Städten und nicht auf dem Lande vorgekommen zu sein schien. Wahrscheinlich wurde das Virus aber trotzdem vom Lande durch A. aegypti in die Städte eingeschleppt, wo es dann unter der empfänglichen Bevölkerung Epidemien hervorrief. War der A. aegypti in den Städten seßhaft geworden, so konnte die Dengue endemisch bestehen bleiben und von Zeit zu Zeit zu lokalisierten Ausbrüchen 
unter den inzwischen eingewanderten empfänglichen Menschen führen (s. auch SigeL und Beasley, 1959). Sмith (1956c) nimmt diese Verhältnisse für das ganze tropische Asien an.

Durch die Vervollkommnung der serologischen Untersuchungsmethoden ist es möglich, ähnlich wie beim Gelbfieber, genaue geographische Bestimmungen des Dengue-Vorkommens in der Vergangenheit und der Gegenwart vorzunehmen. Rückblickend wurde durch diese Untersuchungen festgestellt, daß Typ 1-Epidemien 1920/22 in Durban, Südafrika (KoKeRNot u. a., 1956), 1927-1928 in Griechenland (Theiler u. a., 1960), 1943 in Malaya (Sмiтh, 1956 c), 1943/44 in Hawaii (SABIN, 1952a) und in Französisch-Ozeanien (Rosen, 1958a, b) bestanden haben, während eine ausgedehnte Typ 2-Epidemie 1941/42 in Panama geherrscht hat (Rosen, 1958a, b). Bemerkenswert ist, daß in dieser Gegend Dengue nicht mehr endemisch bestand und auch nicht mehr von außen eingeschleppt worden ist, da die nach 1942 geborenen Kinder keine Dengue-AK aufwiesen. Ähnliches stellte Rosen (1958b) auf den Gesellschaftsinseln fest (s. auch Lumsden, 1958; Downs und Anderson, 1959; Doherty und Carley, 1961).

Nach Smithburn (1954a), Sabin (1955) und Smith (1956a, b) kommen in Malaya, Borneo sowie Indien beide Virustypen vor. In der malayischen Bevölkerung wurden bei etwa $25 \%$ der Kinder unter 11 Jahren, bei 50\% der Altersgruppe 11-20 Jahre und bei fast 100\% jener über 30 Jahre N-AK gegen Typ 1 und bei 18 Personen unter 15 Jahren einmal, sowie bei 81 Erwachsenen 36 mal (44\%) N-AK gegen Typ 2 gefunden (Sмiтн, 1958). Viele Seren besaßen gleichzeitig N-AK gegen beide Virustypen. Auch SABIN (1952a) fand im 2. Weltkrieg in Neuguinea beide Virustypen gleichzeitig.

Aus der Geschichte der Dengue- und Gelbfieberepidemien schließt Frederiksen (1955), daß jede dieser beiden Krankheiten die Neigung hat, die andere auszuschließen. In Gegenden, wo beide heimisch sind, pflegt gewöhnlich zuerst eine Gelbfieberepidemie aufzutreten, der anschließend eine Dengue-Epidemie folgt. Während der Dengue-Pandemie in den USA 1950/51 trat Gelbfieber in den befallen gewesenen Gebieten während der folgenden Jahre praktisch überhaupt nicht auf. Die Ursache für diese Ausschließlichkeit könnte durch Interferenzvorgänge beider Viren in den Aedes-Mücken erklärt werden, wie solche von SABIN (1952a) experimentell festgestellt worden sind.

\section{Klinik}

Die Inkubationszeit beträgt 3-15, im Durchschnitt etwa 5-8 Tage. Simmons u. a. (1931b) fanden bei 80 Versuchspersonen einen Durchschnitt von 5,66 Tagen (vorwiegend nach Mückenübertragung), Fontano (1930) nach i.m. und i.v. Injektion von Krankenserum im Mittel 6-7 Tage. Die Krankheit beginnt mit plötzlichem Fieberanstieg. Zu den üblichen Symptomen der Allgemeininfektion gehören schweres Krankheitsgefühl mit Frösteln, später Schüttelfrost (Invasionsstadium mit Virusnachweis im Blut; "Generalisierungsstadium" von HöRING, 1950), Schlaflosigkeit, Kopf-, Rücken-, Gelenk- und Gliederschmerzen, fast immer Schmerzen im Retroorbitalraum (Schlesinger, 1949); Augapfel und Augenmuskeln sind druckschmerzhaft; Augenbewegungen sind ebenfalls schmerzhaft. Krankheitsgefühl und Schmerzen nehmen im Verlauf der nächsten Tage zu. Es bestehen erhebliche Schwäche, Mattigkeit und Schwindelgefühl. Ein objektiver klinischer Befall der Gelenke selbst liegt nicht vor, sondern es handelt sich um Schmerzen an den Sehnen- und Muskelansätzen (NAUcK, 1956).

Gewöhnlich dauert die Krankheit nur 5-6 Tage. Simmons u. a. (1931b) beobachteten bei ihren Versuchspersonen Fieberperioden von 1-9 Tagen. Das Fieber, daß auf 39-40 $\mathrm{C}$ und mehr steigt, fällt oft schon nach 2-3 Tagen wieder ab, um nicht wieder anzusteigen; es bleibt dann also monophasisch. Es kann jedoch auch zu einem erneuten Fieber kommen, das aber nur 1-2 Tage anzuhalten pflegt. Damit ergibt sich eine diphasische oder sattelförmige Fieberkurve, die zu den Merkmalen der Dengue gehört.

Mit dem endgültigen kritischen Fieberabfall verschwinden die Krankheitserscheinungen unter gleichzeitigem Schweißausbruch. Der Schweiß hat einen eigenartig faulen Geruch. 
Inkubation

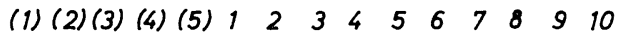

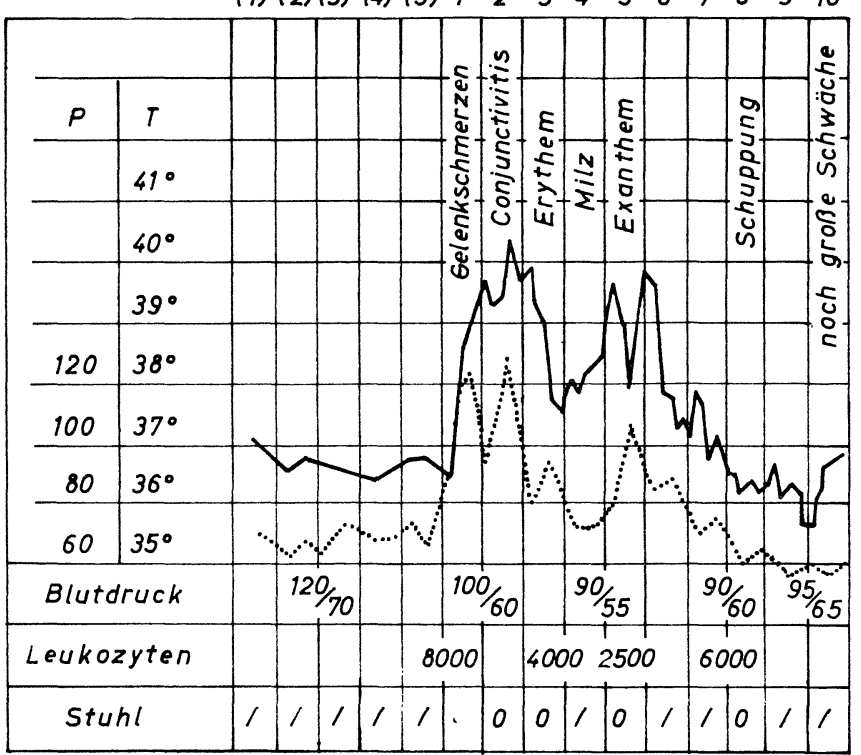

Abb. 26a. Typische Dengue (nach HöRING, 1950)

Der Puls ist gewöhnlich nur mäßig beschleunigt und entspricht nicht dem hohen Fieber (bei $40^{\circ} \mathrm{C}$ nur 80-100 Schläge). Vom 3. Tage an kann es zu' einer relativen Pulsverlangsamung (bis zu 40 Schlägen) kommen, die bis in die Rekonvaleszenz anhält. Als weiteres Zeichen von Kreislaufschwäche findet man erhebliche Blutdrucksenkung; wie bei anderen Viruskrankheiten wird eine Beteiligung des Mykoards im EKG erkennbar. Verlauf von Puls- und Fieberkurven kann das Fagetsche Zeichen des Gelbfiebers vortäuschen.

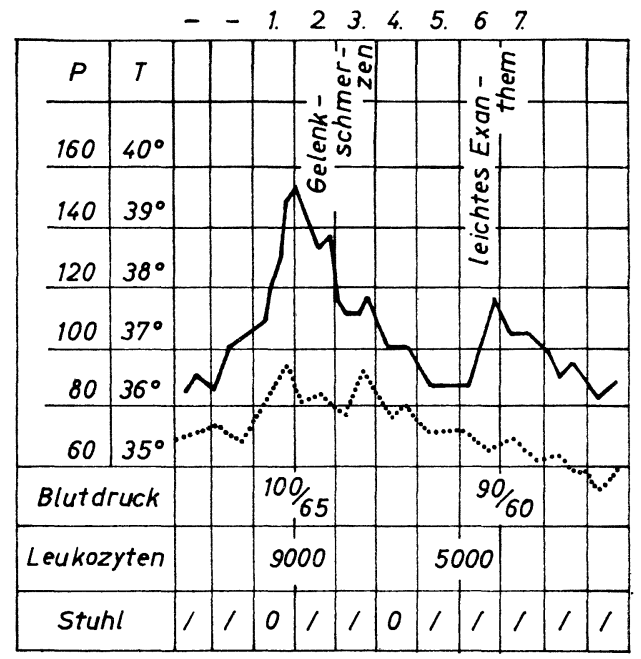

$A b b .26 b$. Leichte Dengue (nach HöRING, 1950) 
Schon am 1. oder 2. Krankheitstag entwickelt sich in etwa $50 \%$ der Fälle oder häufiger ein Erythem am Gesicht, Hals, an der Brust und den Armen, so daß die Haut mäßig gerötet aussieht. Dieses Erythem ist nur flüchtig und verschwindet wieder nach 1-2 Tagen; gleichzeitig können auch alle anderen Erscheinungen zurückgehen, womit die Krankheit schon beendet sein kann, abgesehen davon, daß es höchstens noch zu einem schwachen DengueExanthem ohne Fieber kommt (HöRING, 1950). In typischen Fällen entwickelt sich aber nach 2-3 weiteren Tagen, also am 5.-6. Krankheitstag, unter erneutem Fieberanstieg das eigentliche Dengue-Exanthem, das makulopapulös ist und höchstens 3-4 Tage anhält. Es wechselt in Ausdehnung und Stärke erheblich und erstreckt sich besonders auf Gesicht, Stirn, Hals, Arme, Hände, Brust, Schulter, Rücken, Unterschenkel und Füße einschließlich Handflächen und Fußsohlen. Oft besteht Juckreiz; die Kranken klagen über Ameisenlaufen auf der Haut und kratzen sich dauernd, was schon die Schlaflosigkeit erklärt und zu Sekundärinfektionen führen kann. Das Exanthem kann röteln-, scharlach-, masern- oder urtikariaartig, manchmal aber auch petechial werden; es geht mitunter in kleieförmige Schuppung über. Der Charakter des Exanthems ist in den einzelnen Epidemien verschieden; es tritt auch verschieden häufig auf (s. auch Armstrong, 1923; Siler u. a., 1926; Stewart, 1944).

Im Verlauf der Erkrankung kommen häufig Verdauungsstörungen vor: Appetitlosigkeit, Erbrechen, mitunter Blutbrechen infolge kleiner Darmblutungen sowie Verstopfung und unangenehmer Foetor ex ore. Ferner bestehen manchmal Schnupfen, Husten und Halsschmerzen. Als auffallend werden in vielen Fällen Geschmackstörungen beobachtet; EreK (1944, zit. Sнаттиск, 1951) fand solche in $86 \%$ von 154 Fällen in Neuguinea. Die Milz ist im allgemeinen nicht, die Leber gelegentlich vergrößert; Ikterus kann vorkommen. Die in manchen Epidemien beobachteten Lymphdrüsenschwellungen, die nicht schmerzhaft sind, werden von Nauck (1956) nicht als typisches Dengue-Symptom gewertet (s. auch Findlay und BroorFIELD, 1944).

Die Blutsenkung ist nicht spezifisch verändert. Das Blutbild entspricht dem einer Viruskrankheit: während der ersten Tage eine deutliche Leukopenie mit Verminderung der weißen Blutkörperchen (vorwiegend Polynukleäre) auf 2000 und weniger mit relativer Lymphozytose (60-65\%) und bald anschließender Leukozytose mit Linksverschiebung, Eosinophilie und Monozytose (s. auch Srmmons u. a., 1931 b; Misao, 1944; Hotтa und Shiomi, 1952; Sabin, 1952 d).

Ein hämorrhagischer Verlauf fällt besonders bei Kindern auf; er ist vom infizierenden Virustyp unabhängig. Zu den hämorrhagischen Symptomen gehören Blutungen aus Nase, Zahnfleisch, Darm- und Harnwegen, ferner Netzhaut-, Nieren-, Lungen- und meningeale Blutungen. Das Rumpel-Leed esche Phänomen pflegt positiv zu sein. Sabin (1952a) beobachtete bei Versuchspersonen gelegentlich Petechien. Das »hämorrhagische Fieber « der Philippinen, das von Hammon u. a. (1960) beschrieben worden ist, ist eine Form der Dengue, die vor allem bei Kindern und jungen Erwachsenen vorkommt. Sie verläuft in leichteren Fällen mit geringem Temperaturanstieg, Blutungsneigung der Haut und Schleimhaut, in schweren Fällen mit ausgedehnten Hämorrhagien vor allem im Verdauungstrakt und schweren Schockzuständen. Die Sterblichkeit erreichte hier 10\% (Rudnick und Hammon, 1960). Chew u. a. (1961) beschrieben als besonderes klinisches Syndrom das »hämorrhagische Fieber von Singapore", das in 6-7 Tagen nach plötzlichem Beginn meist akut und hochfieberhaft verlief. Das Fieber fiel nach einer Kontinua kritisch ab. Es bestanden Kopf- und Gliederschmerzen, Appetitlosigkeit, Übelkeit, Verstopfung oder Durchfall und Hustenreiz. Am Rumpf und an den Extremitäten fiel als besonderes klinisches Symptom ein Erythem mit petechialen Blutungen auf. Bei fast allen Patienten war das Rumpel-Leede'sche Zeichen positiv. Ungewöhnliche Symptome waren ferner Milzvergrößerung in 40\%, Lymphadenopathie in 20\% sowie häufige falsch-positive Widal- und Weil-Felix-Agglutinationen.

Im Urin findet man kein oder wenig Eiweiß (meist nicht über $1 \%$ ) sowie manchmal Harnzylinder. Andere Zeichen von Nierenschädigungen fehlen.

Die Beteiligung des ZNS kommt außer durch Kopfschmerzen durch Erregungszustände und anhaltende Schlaflosigkeit oder auch Somnolenz und Bewußtseinsstörungen zum Ausdruck. Dazu treten Angstgefühl und Depressionen. Auch meningeale, encephalitische, myelitische und polyneuritische Erscheinungen, ferner Singultus als zentrales Symptom 
können auftreten (s. auch Kaplan und Lindgren, 1945). Legac und Servant (1939) fanden in allen von ihnen untersuchten 6 Fällen Erhöhungen des Liquordrucks, Eiweiß- und Zuckervermehrung sowie normale oder leicht erhöhte Zellzahl bei klarer Flüssigkeit.

Komplikationen, die den Verlauf der Dengue beeinflussen, sind Herzinsuffizienz, Meningitis, ruhrähnliche blutig-schleimige Durchfälle, Konjunktivitis mit Tränenfluß und Lichtscheu, Keratitis, Thrombophlebitis, gelegentlich Parotitis und Orchitis oder Oophoritis. Die Gelenkbeschwerden können den Charakter einer Periarthritis an den Knien und Handgelenken annehmen. Ob es sich hier aber in der Tat um echte Komplikationen oder um doch wenigstens zum Teil durch das Dengue-Virus bedingte Erscheinungen handelt, ist noch unentschieden; zum Teil liegen aber bakterielle Sekundärinfektionen vor.

Rückfälle werden verschieden häufig angegeben (bis zu 30\%); es ist jedoch nicht immer leicht, zu entscheiden, ob echte Rückfälle oder neue Infektionen im späteren Verlauf einer Epidemie vorliegen. Reinfektionen pflegen aber atypisch mit nur leichten Fieberschüben zu verlaufen. Menschenversuche von SABIN (1952a) haben gezeigt, daß die Immunität gegen den heterologen Virustyp nur etwa 2 Monate anhält und eine anschließende Infektion mit einem solchen dann nur zu einer leichten modifizierten Erkrankung ohne Ausschlag führt.

Die Rekonvaleszenz dauert bei älteren Personen länger als bei jüngeren, und zwar kann sie sich mit Schwäche, Appetitlosigkeit, Akkomodationsstörungen der Augen, Schlafstörungen, Depressionen und rheumatischen Schmerzen wochenlang hinziehen. Die während der akuten Phase bis in die Rekonvaleszenz bestehenden vasomotorischen Störungen dürften auf eine selektive toxische Wirkung des Virus auf die glatten Muskelfasern zurückzuführen sein, worauf bereits von GILL (1928) hingewiesen worden ist.

\section{Pathologie}

Infolge des im allgemeinen gutartigen Verlaufs kommt es nur selten zu tödlichen Ausgängen und damit zur Möglichkeit pathologisch-anatomischer und -histologischer Untersuchungen. Die allgemeinen Organveränderungen weisen auf toxische Reaktionen hin, welche zu degenerativen Veränderungen besonders der parenchymatösen Organe (Leber, Nieren, Herz, Gehirn) führen und sich auf die Blutkapillarwände fortsetzen; diese werden für die Blutkörperchen durchlässig. Das allgemeine pathologische Bild ist aber das von exsudativentzündlichen Vorgängen des Endothels, der Gelenkserosa und Meningen mit perivaskulärer hämorrhagischer Diathese und mehr oder weniger ausgedehnten Hämorrhagien im Endound Perikard, in der Pleura, im Peritoneum, in den Muskeln, der Haut und dem ZNS. In den Verdauungswegen sieht man Stauungserscheinungen mit Schleimhautblutungen. SABIN (1952d) fand bei histologischen Untersuchungen der Haut nach i.d. Infektion und beim Auftreten des Exanthems oder petechialer Blutungen weder Epithelveränderungen noch Einschlüsse in den Epithelzellen. Insgesamt sind die pathologischen Veränderungen bei der Dengue nicht hinreichend charakteristisch, um diagnostische Bedeutung zu haben (s. auch Рhotakis, 1929; Catsaras, 1931).

Aus einer Beobachtung von Thalmammer (1953) scheint hervorzugehen, daß das DengueVirus embryopathische Eigenschaften hat: eine Mutter, welche im 2. Schwangerschaftsmonat an Dengue erkrankt war, gebar ein Kind mit autistischer Idiotie. Ophthalmologisch bestanden beiderseitige Mikrophthalmie und Optikusatrophie, am rechten Auge Mikrokornea mit Trübungen und Residuen einer fötalen Iridozyklitis.

\section{Diagnose}

Die Symptomatologie der Dengue schwankt erheblich von Fall zu Fall, aber auch von Epidemie zu Epidemie. Die Unterschiede beruhen u. a. auf der biologischen Verschiedenheit der infizierenden Virustypen bzw. -stämme. 
Während die Diagnose in Epidemiezeiten leicht ist, bereitet sie bei sporadischen und atypischen Einzelfällen Schwierigkeiten, insbes. gegen Gelbfieber.

\section{6-1. Klinische Diagnose}

Für die klinische Diagnose sind folgende Symptome wichtig: plötzlicher Beginn, retroorbitaler Schmerz, Hyperämie der Bindehäute und Nn. optici mit Lichtscheu, heftige Rücken- und Gliederschmerzen, diphasische Fieberkurve, leichte Bradykardie, makulopapulöses Exanthem und Leukopenie mit Linksverschiebung (s. auch Mıмs und Mason, 1956).

Für die Frühdiagnose sollen das von Castellani angegebene Zeichen (punktförmiges Erythem auf der Gaumenschleimhaut) sowie die Vergrößerung und Schmerzhaftigkeit der seitlichen Halsdrüsen von größter Wichtigkeit sein. Allerdings kommt ein derartiges Rachenerythem u.a. auch bei Pappataci-Fieber vor (Guiseppe, 1937).

Bei sonst ähnlichen Allgemeinerscheinungen, besonders im Beginn, spricht Geringbleiben der Eiweißmenge im Urin für Dengue, während Hämorrhagien und besonders Ikterus an Gelbfieber denken lassen könnten. Letzteres ist aber durch die verschiedenen Laboratoriumsverfahren sowie durch das Fehlen des Syndroms Gelbsucht-Nephrose auszuschließen. Im Beginn hat die klinische Differentialdiagnose auch Influenza, Pappataci-Fieber, Malaria, WN-Fieber und Fleckfieber zu berücksichtigen. Ferner kommen bei stärkerem Ausschlag auch Röteln, Masern und Scharlach in Frage. Außerdem ist an Dreitagefieber, Abdominaltyphus, Paratyphus, Maltafieber und Gelenkrheumatismus zu denken. Von der Influenza unterscheidet sich die Dengue durch das Fehlen typischer katarrhalischer Erscheinungen der oberen Luftwege, von den Masern ebenfalls durch das Fehlen solcher sowie durch die negative Diazoreaktion. Gegenüber Gelenkrheumatismus fehlt bei Dengue die entzündliche Schwellung der Gelenke und lokalisieren sich die Schmerzen an den Muskel bzw. Sehnenansätzen sowie in den Knochen. Weniger schwierig ist die Abgrenzung gegen Bauchtyphus und Brucellosen. Die Weilsche Krankheit weist außer dem häufigen Ikterus Nephritis auf, welche bei Dengue fehlt. Gegenüber Feldfieber entscheidet gegebenenfalls die Agglutinationsreaktion.

Neuerdings kommen differentialdiagnostisch ECHO-Viruserkrankungen hinzu, welche überall auftreten, ferner dengue-artige Erkrankungen in Afrika, deren Erreger mit den DengueTypen auch antigen eng verwandt sind, wie z. B. die Chikungunya-Infektion, die allerdings zur Arbor-Gruppe A gehört (Theiler und Casals, zit. Sabin, 1959 b; Bernkopf u. a., 1953).

\section{6-2. Laboratoriumsdiagnose}

Um in Zweifelsfällen Irrtümer zu vermeiden, müssen zur Klärung alle für die genannten Krankheiten zur Verfügung stehenden diagnostischen Hilfsmittel, insbes. die Laboratoriumsuntersuchungen erschöpft werden.

Die Virusisolierung aus dem Blut hat nach SchlesInger (1949) an sich keine praktische diagnostische Bedeutung, da sie sehr lange Zeit benötigt und nicht immer gelingt. Sie sollte aber zur Sicherstellung der Ätiologie in dengue-artigen Epidemien nicht unterlassen werden. SABIN (1959b) empfiehlt daher Blut innerhalb von 24-48 St. nach Krankheitsbeginn zu entnehmen; wenn es nicht sofort verarbeitet wird, muß es entweder im Kühlschrank (nicht länger als 2 Wochen) oder in $\mathrm{CO}_{2}$-Trockeneis eingefroren gehalten werden. Die Verimpfung von Serum (konzentriert und 1: 100 verdünnt) erfolgt i.cer. und i.p. auf höchstens 3 Tage alte Mäuse eines dengue-empfänglichen Stammes, z. B. »Schweiz». Manche Virusstämme weisen für Mäuse sofort einen starken Neurotropismus auf, indem ein großer Teil der Tiere in 9-21 Tagen gelähmt wird, während andere Stämme kaum oder gar nicht neurotrop sind und die i.cer. infizierten Mäuse kaum oder gar nicht krank machen. Ein unbekannter Virusstamm kann als verdächtig gelten, wenn die i.cer. geimpften, nicht dagegen die i.p. geimpften Mäuse sterben. Die Sicherstellung der Virusart muß aber noch in der NR mit typenspezifischen Antiseren oder in der HAHR erfolgen. Wenn keine der i.cer. geimpften Mäuse stirbt, läßt sich das 
Vorhandensein einer Dengue noch dadurch nachweisen, daß die Mäuse nach 4-6 Wochen eine i.cer. Kontrollinfektion mit $100 \mathrm{LD}_{50}$ eines mäuseadaptierten Virus erhalten (SABIN, 1956; s. auch Anderson u. a., 1956 b; SMith, 1956a; Hammon u. a., 1958).

Für die serologischen Teste benutzt man am besten Serumpaare (Entnahme in der akuten Phase und Rekonvaleszenz). Der Titeranstieg ist dann ausschlaggebend.

Die NR (Mäuseschutzprobe) ermöglicht die Dengue-Diagnose auch stumm verlaufender Infektionen. Sie hat nicht nur klinischen, sondern auch epidemiologischen Wert und kann zur unmittelbaren Virustypbestimmung des einzelnen Falles wie der Epidemie dienen. Die homologen N-AK erscheinen innerhalb von 7 Tagen nach Fieberbeginn (Sмiтh, 1956a; Sabin, $1959 \mathrm{~b})$.

SABIN (1959b) bezeichnet die $H A H R$ als die diagnostische Laboratoriumsmethode der Wahl, da Rekonvaleszentenseren bereits 1-2 Tage nach Entfieberung einen AK-Anstieg gegenüber der akuten Phase zeigen. Beide Typenantigene müssen aber verwandt werden, da die heterotypische Reaktion verspätet sein oder einen niedrigen Titer haben kann. In Gebieten, in denen WN-Fieber oder JE herrschen, müssen allerdings Kreuzreaktionen angestellt werden, um diese Krankheiten auszuschließen.

Die KBR (Sabin und Young, 1948; Sweet und Sabin, 1954a) ist die am wenigsten spezifische der Seroreaktionen und wird auch erst später positiv.

Zur Ergänzung der Serodiagnostik dient schließlich noch der Intrakutantest mit Antigenen aus infektiösen Mäusegehirnen (Нотта, 1952). Bei Dengue kommt es zu Rötung, Verhärtung, Bläschenbildung und sogar Nekrose an der Injektionsstelle. Die Reaktion ist vom 3. Krankheitstag ab regelmäßig positiv und nach 48 St. voll entwickelt. Die Spezifität der Probe wird durch Neutralisierung mit homologem Rekonvaleszentenserum bestätigt. Sie läßt auch die Unterscheidung der beiden Virustypen zu.

\section{Prognose}

Die Sterblichkeit der Dengue ist im allgemeinen so gering, daß sie praktisch gleich O ist; man rechnet mit kaum 1\%. In der großen Epidemie in Griechenland 1928 betrug sie unter etwa 960000 Erkrankten 1,5\% (CARdamatis, 1929). NaUCK (1956) gibt 3 Todesfälle auf 10000 Erkrankungen an. Wenn keine Komplikationen besonderer Art eintreten, kann die Prognose also stets als gut bezeichnet werden, obwohl Kinder und ältere Menschen schwerer erkranken. Die Rekonvaleszenz kann langwierig sein, pflegt aber zu vollständiger Heilung zu führen. FEGALI (1951) wies aber auch auf einen bösartigen Verlauf der Dengue in einer Epidemie im Libanon hin, in der die Kinder mit viel zahlreicheren Komplikationen als gewöhnlich erkrankten, so daß es zu einer erheblichen Letalität kam. Aus unbekannten Gründen hatte das Virus hier von Anfang an eine hohe Toxizität. Von 10 Säuglingen mit cerebralen Symptomen starben 4. Bei der auf den Philippinen festgestellten Fieberform der Dengue scheint die Letalität offenbar infolge schwerer Schockwirkung ungewöhnlich hoch gewesen zu sein. Hammon u. a. (1958) fanden bei 750 Fällen eine Letalität von $15 \%$.

Die Dengue scheint eine geringere Lungentuberkulose auslösende Wirkung als z. B. Masern, Influenza, Keuchhusten, Pneumonie oder Typhus abdominalis zu haben. Bei einer bereits bestehenden Tuberkulose wird allerdings fast immer eine Verschlimmerung beachtet (Papanicolau, 1929; Chaniotis und Scordombelis, 1929). Nach Marselos (1930) hat Dengue häufig Gonorrhöerezidive zur Folge, und zwar auch, wenn diese Infektion schon mehrere Jahre zurücklag und geheilt gewesen zu sein schien. Bei einer noch florierenden Gonorrhöe kann es zu einer akuten Verschlimmerung oder genorrhoischen Komplikationen kommen.

MAGARA (1942) beobachtete bei Dengue-kranken Schwangeren zahlreiche Aborte.

\section{Behandlung}

Eine spezifische Chemotherapie der Dengue gibt es nicht. Infolge des gewöhnlich harmlosen Verlaufs genügt eine symptomatische Behandlung, die sich hauptsächlich auf die Be- 
kämpfung der zu Beginn bestehenden Obstipation mit Abführmitteln oder Einläufen ererstreckt. Sonst beschränken sich die Maßnahmen auf Bettruhe, Fieberkost, Antihistaminika, Antirheumatika und Antineuralgika. Im Fall von Lichtempfindlichkeit wird der Krankenraum verdunkelt. Bei anhaltenden unerträglichen Schmerzen und Unruhe können Morphium, bei Schlaflosigkeit Barbitursäurepräparate erforderlich sein. Zur Stützung des Kreislaufs kommen Sympatol, Ephetonin, Hexeton u. a.m. in Frage. Auf Mund- und Hautpflege ist zu achten. Behandlung mit Rekonvaleszentenserum scheint wirkungslos zu sein, ebenso unspezifische Eiweißtherapie. Legac (1947, s. auch Legac und Servant, 1939) hält die Entnahme von Lumbalflüssigkeit für ein schnell wirkendes Mittel zur Erleichterung besonders der zentralnervös bedingten Beschwerden.

\section{Immunbiologie}

\section{9-1. Allgemeines}

Über eine Immunität bei Dengue und ihre Dauer gingen die Ansichten früher sehr auseinander. Legendre (1929) z. B. lehnte eine Immunität überhaupt ab. Nach Schilling (1939a) spricht die Tatsache, daß Epidemien, in denen ein großer Teil der Bevölkerung erkrankt war, sich im folgenden Jahr nicht wiederholen, für eine Immunität. Siler u. a. (1925a, b; 1926) schlossen auf einen gewissen Schutz, da erkrankt gewesene Versuchspersonen bei Reinfektionen 32-94 Tage nach der Entfieberung nicht erkrankten und nach 53-121 Tagen nur milde Krankheitserscheinungen auftraten (s. auch Cleland, 1928, 1930). Blanc und Caminopetros (1929c) sahen einen Schutz noch nach 10 Monaten (s. auch Simmons u. a., 1931a, b; LuMLey, 1943).

Holt und Krntner (1931b) beobachteten, daß eine Versuchsperson, welche von infektiösen Aedes-Mücken gebissen worden war und nicht erkrankte, also offenbar immun war, auch gegen eine Nachinfektion mit infektiösen Mücken geschützt war. Bei Verlegung in eine Gegend, wo Dengue bestand, erkrankte diese Person jedoch nach 14 Tagen an typischer Dengue (s. auch Holt u. a., 1931). SniJders u. a. (1934a, b) stellten in dem Dengue-freien Holland mit 2 Virusstämmen verschiedener Herkunft Menschenversuche an, in denen eine Infektion mit einem Virusstamm keinen Schutz gegen eine nach wenigen Monaten vorgenommene Reinfektion mit einem anderen Stamm erzeugte. Diese Beobachtungen wiesen auf das Vorhandensein von 2 immunologisch verschiedenen Virustypen hin (s. auch SHARP und Hollar, 1935).

Untersuchungen von SABIN (1950) bestätigten, daß die Dengue eine sowohl langdauernde als auch kräftige Immunität erzeugt. SNIJDERS u. a. (1934a) konnten einen 30 jährigen Schutz feststellen. Allerdings ist zu berücksichtigen, daß dieser Schutz nur für das homotypische Virus gilt und es eine ganze Reihe immunologisch verschiedener Stämme gibt, die zu wiederholten Erkrankungen führen und das Fehlen einer Immunität vortäuschen können. Andererseits vermag die Infektion vielfach mit einem Virusstamm auch zu einer Immunität gegen andere Stämme zu führen. So wurde beobachtet, daß Personen, welche eine Typ 1-HawaiiInfektion durchgemacht hatten und mehrere Monate später einer Reinfektion mit einem heterotypischen Virus (Typ 2-Neuguinea B, C oder D) ausgesetzt wurden, erneut, allerdings nur leicht und 3 Tage lang sowie ohne Ausschlag, erkrankten.

\section{9-2. Antikörperbildung und Immunitätsreaktionen}

CAusey und Theiler (1958) fanden bei serologischen Untersuchungen in 15 Gemeinden des Amazonas-Tales in Brasilien bei 15\% der Bewohner N-AK. Gegen das Typ-1-HawaiiVirus treten sie bereits 7 Tage nach Fieberbeginn in Erscheinung und bleiben mindestens 4 Jahre bestehen (SABIN, 1950; Sмiтн, 1956a, 1957a). In Menschenversuchen konnten Sabin und Schlesinger (1945) mit Mäusegehirnvirus, Typ-1-Hawaii, Schlesinger (1950) mit Hühnerei-adaptiertem Virus und Schlesinger u. a. (1956) mit mäuseadaptiertem Typ-2Neuguinea-Virus N-AK erzeugen. 
Die N-AK sind typenspezifisch. Die meisten Rekonvaleszentenseren von Menschen und Rhesus-Affen, die mit den Typ 2-Stämmen Neuguinea B, C oder D infiziert worden waren, enthielten keine signifikanten AK-Titer gegen den mäuseadaptierten Typ 1-Hawaii-Stamm (SABIN, 1950). Es gibt allerdings auch einen gruppenspezifischen AK, der nur gelegentlich mit niedrigem Titer bei Menschen und Affen vorkommt, insbesondere nach Typ 2-Infektionen. Die Titer bleiben zwischen $1: 50$ und 1:500. Blanc und Caminopetros (1929 c, d) sowie Holt u. a. (1931b) wiesen in Menschenversuchen mit Menschenvirus keine N-AK nach. Dagegen erzielte Pontano (1930), wenn er Rekonvaleszentenserum und infektiöses Serum mischte und dieses Gemisch Versuchspersonen einimpfte, eine Neutralisation des Erregers.

Mit mäuseadaptiertem Virus läßt sich eine zuverlässige Neutralisation an der Maus (Mäuseschutzversuch) erreichen. MеIкLеJонn u. a. (1952 a) fanden, daß Mäusesäuglinge sich für die Reaktion am besten eignen. Die Neutralisierung des mäuseadaptierten Virus beruht nach SABIN (1959b) auf 2 Faktoren: 1. einem spezifischen AK, der hitzeresistent ist, d. h. erst nach 30 Min Erhitzung bei $56^{\circ} \mathrm{C}$ zerstört wird, und 2. einer nichtspezifischen komplementartigen, hitzelabilen, bei $56^{\circ} \mathrm{C}$ zerstörbaren akzessorischen Substanz, die die größte Inaktivierung des sensibilisierten Virus nach 2 St. Bebrütung bei $37^{\circ} \mathrm{C}$ herbeiführt. Bei Verwendung von sowohl frischem als auch gefrorenem Antiserum und Bebrütung der Serum-Virusgemische bei $37^{\circ} \mathrm{C}$ schwankten die Neutralisationsindices mit der i.cer. Mäusepathogenität des verwandten Virus. Die Indices betrugen im allgemeinen nur 100-300 mit Mäusevirus, das einen Titer von $10^{3}-10^{4}$ hatte, aber $10000-100000$ mit Viren, die i.cer. Titer von etwa $10^{7}$ hatten. Mit Virus höherer Wirksamkeit kann auch bei $56^{\circ} \mathrm{C}$ inaktiviertes Dengue-Antiserum Neutralisationsindices von 100-500 ergeben. Wird zu einem Gemisch von Virus und inaktiviertem Antiserum ein akzessorischer Faktor in Form von frischem oder gefrorenem normalem unverdünntem Menschen- oder Meerschweinchenserum zugegeben, so steigen die Neutralisationsindices auf 50000 (s. auch SABIN, 1950).

Sмrтн $(1956 \mathrm{a}, 1957 \mathrm{a})$ fand 30 Wochen nach der Erkrankung $K B$ - $A K$. Dоновту (1954) stellte während einer großen Dengue-Epidemie in Queensland bei $1 / 3$ bis $1 / 2$ der Patienten einen erheblichen Anstieg der KB-AK fest. Bei Personen, die noch nicht mit einem der antigen verwandten Viren infiziert waren, ist der Titer gewöhnlich höher als die Titer der heterotypischen AK; er bleibt auch länger erhalten. Der homotypische AK ist mindestens 4 Jahre nachweisbar (SabiN, 1959b). Die Seren experimentell mit humanen Dengue-Stämmen der Typen 1 (Hawaii) oder 2 (Neuguinea B, C, D) infizierter Menschen wurden nach 2 Monaten mit einem Antigen aus dem Typ 1-Virus untersucht: die homologen Seren wiesen einen KBAK-Titer von 1:64 bis 1:256, die heterologen Seren einen solchen von nur $1: 4$ bis $1: 16$ auf. Nach 6 Monaten waren die AK gegen das heterologe Virus bereits verschwunden, während die gegen das homologe Virus noch nach 3 Jahren mit Titern von $1: 2$ bis $1: 128$ positiv waren. Rhesus-Affen, die mit Menschenvirus infiziert worden waren, zeigten die höchsten Titer (bis 1: 256) für die typenspezifischen KB-AK nach 3-4 Wochen, während sie bei manchen Tieren nach 5 Wochen bereits verschwunden waren, bei anderen dagegen länger bestanden (Sabin, 1950). Aus Mäusesäuglingsgehirnen kann ein wirksames Antigen gewonnen werden. (Sabin und Young, 1948). Das Antigen der Wahl ist nach Sabin (1952d) ein Benzolextrakt aus den Gehirnen neugeborener Mäuse, welche mit dem mäuseadaptierten Typ 1-HawaiiVirus infiziert worden waren.

Nach Sмiтн (1956a, 1957a) sind die $H A H-A K$ noch 30 Wochen nach der Erkrankung nachweisbar. Sмгтн sieht den Hauptwert dieser Reaktion in der Feststellung neuer Fälle in Ausbrüchen, deren Virustyp bereits ermittelt wurde. Nach SABIN (1959b) ist die HAHR heute nicht nur die Methode der Wahl zur Bestätigung der Diagnose eines Einzelfalles, sondern auch von Bedeutung für experimentelle Reihenuntersuchungen. Hämagglutinierendes Virus, das durch Antiseren gegen beide Dengue-Typen gehemmt, nicht dagegen durch beide oder nur leicht durch das eine neutralisiert wird, könnte ein neuer Dengue-Typ sein. Bei der Ausführung der $H A H R$ ist zu beachten, daß höhere Titer erzielt werden, wenn $\mathrm{AK}$ und Hämagglutinin in einem $p_{\mathrm{H}}$ von 7,2 $2 \mathrm{St}$. bei $22^{\circ} \mathrm{C}$ gehalten werden, bevor die Erythrozyten (Suspension in Pufferlösung von $\mathrm{p}_{\mathrm{H}} 5,6$, um das Gemisch auf $\mathrm{p}_{\mathrm{H}}$ von $6,7 \mathrm{zu}$ bringen, welches optimal für das Hämagglutinin ist) zugesetzt werden. Seren, welche in der NR streng homotypisch sind, reagieren mit verschiedenen Titern auf heterotypische Dengue-Hämagglutinine 
unter Verwendung von Hühnererythrozyten. NaKagawa und Shingu (1955) fanden, daß die spezifische Dengue-HA von Pferdeerythrozyten nur durch Dengue-Immunserum (Mäuse, Kaninchen), nicht aber durch Antiseren gegen andere Viren der Gruppe gehemmt wird, so daß diese Reaktion spezifisch ist. Der HAH-AK ist leicht von den normalen Hemmstoffen in Menschen-, Affen- und Kaninchenseren durch Acetonpräzipitation der Seren und nachfolgende Aufnahme in geeigneten Puffern trennbar (SweEt und Sabin, 1954b).

\section{9-3. Gruppenverwandtschaft mit anderen Viren}

Menschen, die mit einem Dengue-Virustyp infiziert sind, entwickeln KB-AK nicht nur gegen andere Dengue-Typen, sondern häufig auch gegen die WN-Fieber-, JE- und Gelbfieber-Viren (SABIN, 1952d, 1959b; O'Connor, 1955). Personen, welche noch keine Infektion mit einem der antigen verwandten Viren durchgemacht haben, weisen gewöhnlich einen höheren AK-Titer gegen das homotypische als gegen das heterotypische oder die heterologen Viren auf. SABIN (1950) betonte, daß eine Gruppenverwandtschaft in der KBR nur dann in Erscheinung tritt, wenn die stärksten 20\% igen Gehirnantigene (Benzolextrakte) verwandt wurden, d. h., daß die gemeinsamen Antigengruppen in viel geringerer Konzentration als die typenspezifischen Antigenkomponenten vorhanden waren. Auch die HAHR ergab eine antigene Verwandtschaft mit den Gelbfieber-, WN-Fieber-, SLEund JE-Viren, nicht dagegen mit Pappataci-, Rifttal-Fieber- und WEE-Viren. Zwischen Dengue- und Colorado-Zecken-Fieber besteht in Menschenversuchen keine kreuzweise Immunität. Dies steht im Widerspruch zu der Annahme mancher Autoren, daß das Colorado-Zecken-Fieber mit der Dengue identisch oder doch eng verwandt sei (Pollard, u. a., 1946b; Florio u. a., 1946 a; Koprowski und Cox, 1947 a).

Bei Menschen führt eine Dengue-Infektion manchmal auch zur Bildung von N-AK, welche Mäuse gegen Uganda S-Virus schützen. Grossberg und Scherer (1959) berichteten über eine Laboratoriumsinfektion mit Typ 1-Virus bei einer Person, die vorher bereits AK gegen JE-Virus hatte. Demnach scheint keine heterologe Immunität zwischen diesen beiden Viren zu bestehen. Die klinische Dengue-Erkrankung blieb durch die Gegenwart der JE-AK unbeeinflußt. Die Mäusepathogenität des Dengue-Virus war ebenfalls unverändert nach der Menschenpassage. Die N-AK-Bildung war normal; es wurden aber keine KB-AK nachweisbar.

SABIN (1955) fand bei Affen, die mit Dengue-Virus i.cer. infiziert worden waren, KB-AK gegen Gelbfieber, WN-Fieber und JE mit Titern von 1:16 bis 1:64, nicht aber gegen St. Louis-Encephalitis, WEE und Rifttal-Fieber. Nach TheILer und CASals (1959) schützen Seren von Dengue-immunen Affen gegen das SLE-Virus. FindLay (1932) konnte bei RhesusAffen und Mäusen keine Kreuzimmunität zwischen Dengue- und Rifttal-Fieber feststellen.

Schon seit langem sind zahlreiche Untersuchungen insbesondere über die etwaige antigene Verwandtschaft der Dengue- und Gelbfieber -Viren angestellt worden. Sie haben allerdings bisher zu recht widersprechenden Ergebnissen geführt. Stefanopoulo (1929), Stefanopoulo und Callinicos (1932) sowie Dinger und Snijders (1931) fanden im Serum von Dengue-Genesenen keine N-AK gegen Gelbfiebervirus. Blanc und Caminopetros $(1929 \mathrm{c}$, d) sowie Blanc u. a. (1929b) hatten beobachtet, daß Gelbfieber-Antiserum keine Wirkung auf das DengueVirus auszuüben schien. SnIJders u. a. (1934a. b) hielten die Annahme, daß Dengue unter bestimmten Umständen eine gewisse Immunität gegen Gelbfieber erzeugen kann, für unbewiesen. Sie fanden, daß Seren von 20 Fällen experimenteller Dengue im Mäuseschutzversuch keine neutralisierende Wirkung auf das Gelbfiebervirus ausübten, die Überlebenszeit der Mäuse allerdings etwas verlängert war (s. auch Stefanopoulo und Callinicos, 1932; Theiler, 1951, zit. Smithburn, 1951).

Schlesinger u. a. (1956) injizierten abgeschwächtes Dengue-Virus Typ 2 (Neuguinea B) zusammen mit Gelbfieberimpfstoff oder zusammen mit diesem und gleichzeitig Typ 1-Virus. Es ergab sich ein Dominieren von AK gegen Typ 2, was auf eine Unterdrückung der anderen Antigene wahrscheinlich infolge von Interferenz hinweist. Dagegen kam es bei Personen, welche einige Jahre vorher gegen Gelbfieber geimpft worden waren, zur Bildung von AK in gleicher Menge sowohl gegen beide Dengue-Virustypen als auch gegen 17D-Gelbfiebervirus (s. auch Sabin und Schlesinger, 1945). Nach Sabin (1949) wurde die Inkubationszeit der 
Dengue verlängert und die Dauer der Erkrankung erheblich herabgesetzt, wenn Gelbfiebervirus $17 \mathrm{D}$ einige Tage vorher oder gleichzeitig mit humanem Dengue-Virus injiziert wurde. Es kam auch zu keiner Entwicklung des Dengue-Ausschlages. Betrug das Intervall zwischen Injektion beider Viren dagegen 35 Tage, so fand keine Interferenz mehr statt, d. h. die gegen Gelbfieber geschützten Personen wiesen keine Immunität gegen Dengue-Virus bis herab zu 10 MID auf. Ähnliche Ergebnisse bezüglich der Interferenz wurden zwischen viscerotropen Gelbfiebervirusstämmen und Dengue-Virus bei Rhesus-Affen und A. aegypti erzielt. Nach Stefanopoulo (1929) sowie Stefanopoulo und Callinicos (1932) behielt ein mit Dengue geimpfter Affe seine Gelbfieberempfänglichkeit, während DiNGER und SNIJDERs (1931) 8 von 26 Affen, die mit Dengue infiziert worden waren, gegen eine Gelbfieberinfektion resistent fanden. SABIN (1949) stellte fest, daß 6 von 12 Affengelbfieberimmunseren KB-AK gegen Dengue-Virus mit einem Titer von 1:4 bis 1:16, gegen das eigene Virus dagegen solche von $1: 32$ bis $1: 128$ aufwiesen. Rhesus-Affen, welche i.cer. mit Dengue-Typ 1-Virus (Hawaii) ode Typ 2-Virus (Neuguinea) infiziert worden waren, zeigten 3-4 Wochen p. i. KB-AK mit Titern von $1: 8$ bis $1: 32$ gegen Gelbfieberantigen und von $1: 128$ gegen Dengue-(Hawaii-)Antigen (s. auch SABIN, 1950, 1956, 1959 b); sie entwickelten aber keine N-AK gegen Gelbfieber. Rosen (1958b) stellte fest, daß mit Dengue-Typ 2-Virus infizierte Affen gegen Dengue-Typ 1Virus und Gelbfiebervirus gleich hohe HAH-AK-Titer entwickeln. Von 7 Affen, die mit dem Gelbfiebervirus 17D infiziert worden waren, bildeten 1 und von 7 mit dem Gelbfiebervirus "Trinidad" infizierten Affen 6 höhere HAH-AK-Titer gegen das Dengue-Typ 2-Virus als gegen das Dengue-Typ 1-Virus (s. auch Sabin, 1955). Dinger (1954) fand, daß 3 i.p. Injektionen von Dengue-Typ 1-(Hawaii-) Virus bei Mäusen einen teilweisen Schutz gegen eine i.p. Gelbfieberinfektion, welche mit einer i.cer. Stärkereizung verbunden war, erzeugten.

\section{Prophylaxe}

\section{0-1. Mückenbekämpfung}

Die vorbeugenden Maßnahmen zur Verhütung der Dengue erstrecken sich in erster Linie auf die Vernichtung der die Krankheit übertragenden Aedes-Arten sowie auf deren Fernhaltung aus Wohn- und Krankenräumen durch mückensichere Gaze oder Netze, Beseitigung aller überflüssigen Wasserbehälter und Mückenkontrolle auf Schiffen und Flugzeugen. Allerdings sind Mückennetze insofern unwirksam, als die Aedes auch bei Tage, besonders wenn Bewölkung besteht, beißen. Ebensowie zur Gelbfieberbekämpfung wird auch hier DDT zur Vernichtung der Larven an den Brutplätzen sowie der erwachsenen Mücken in Häusern, aber auch im Freien verwandt, letzteres besonders in Gebieten, wo der A. albopictus vorkommt. Bailey und Bohart (1952) fanden als beste Methode zur Vernichtung der AedesBrutstätten Bedeckung von Trinkwasser- und ähnlichen Gefäßen mit Sackstoff, der mit 5\% DDT-haltigem Xylen getränkt wird. Die kleinen DDT-Mengen, die ins Wasser fallen oder durch Regen ausgewaschen werden, unterbrechen das Brüten der Mücken wirksam während 3-5 Monate. Zur Großraumbekämpfung können Flugzeuge mit Erfolg eingesetzt werden. Wo gleichzeitig A. aegypti und A. albopictus vorkommen, wie dies z. B. in Hawaii der Fall ist, gestaltet sich die Mückenbekämpfung besonders schwierig, da sie gleichzeitig in und außer dem Hause erfolgen, ja sogar sich auf das offene Land und die Wälder erstrecken muß. Bei der Dengue-Verhütung ist ferner zu bedenken, daß zur Aufrechterhaltung einer Epidemie weniger Mücken erforderlich sind als beim Gelbfieber (Hanson, 1936; WALKER u. a., 1942; Usinger, 1944; Gilbertson, 1945; News und Comment, 1945; Sabin, 1952 d). McCarthy und Wilson (1949) haben auf Madagaskar festgestellt, daß eine Verringerung des Aedes-Index von $27 \%$ auf $2 \%$ erforderlich ist, um die Dengue zum Erlöschen zu bringen. Da in der westlichen Hemisphäre nưr der A. aegypti als Überträger der Dengue in Frage zu kommen scheint, richtet sich die Mückenbekämpfung in erster Linie gegen diesen. Hier fällt also die Gelbfieber- und Denguebekämpfung zusammen. 


\section{0-2. Schutzimpfung}

Sabin empfiehlt die Vornahme von Schutzimpfungen: 1. wenn die Gefahr ausgedehnter Dengue-Epidemien besteht, 2. wenn ungeschützte Personen sich in hochendemische Gebiete begeben, 3. vor allen Dingen bei Tuberkulosekranken, um sie vor der ungünstigen Wirkung einer Dengue-Infektion zu schützen.

Da bereits Blanc (1932) festgestellt hatte, daß auf physikalischem oder chemischem Wege abgetötetes Dengue-Virus nicht mehr immunisiert, muß man mit lebendem Virus schutzimpfen. Blanc und Caminopetros $(1929$ e, 1930) empfahlen als Impfstoff pathogenes Virus enthaltendes Krankenserum, das mit 1/20 Rindergalle 5 Min Kontakt hatte und dann sofort eingespritzt wurde. Bei diesem Vorgehen kommt es nach Ansicht dieser Autoren nicht zu einer Abschwächung, sondern zu einer Umhüllung des Virus, wodurch eine zu schnelle Ausbreitung der Impfstoffe in den Organismus verhindert wird. Die nur allmählich frei werdenden kleinen Virusmengen immunisieren, ohne pathogen $: \boldsymbol{\tau}$ wirken. Mit diesen "Depotimpfstoffen" wurde eine gute Immunität erzielt. Teils verliefen die Impfungen ohne Reaktionen; ein Teil der Geimpften bekam aber Fieber oder sogar Dengue. Stärkere Gallekonzentrationen oder längere Einwirkungsdauer töteten das Virus ab. Eine Doppelimpfung zunächst mit inaktiviertem Gallevirus (1/15) und 2 Wochen später mit aktivem Gallevirus $(1 / 20)$ erzeugte Schutz gegen eine Kontrollinfektion mit sehr aktivem Virus (Krankenserum) (s. auch Blanc, 1948, Нотта, 1954).

Simmons u. a. (1931b) haben vergeblich versucht,. mit Impfstoffen aus virushaltigem Menschenblut und infizierten Mücken zu immunisieren. Sт. Јонм und Hоцт (1931) stellten aus Leber und Milz von Affen (M. philippinensis), welche durch Mückenbiß infiziert worden waren und deren Blut Virus aufwies, einen Impfstoff her, der 2mal im Abstand von 1 Woche eingespritzt zwar keinen absoluten Schutz gegen eine Infektion erzeugte, aber eine experimentelle Infektion nur leicht verlaufen ließ.

Mit der Gewinnung eines durch Mäusegehirnpassagen abgeschwächten Dengue-Virus, das beim Menschen nur noch eine milde Erkrankung mit leichtem Ausschlag und geringem Fieber, dabei aber eine kräftige Immunität gegen das natürliche Virus erzeugt (SaBIN und SCHLesinger, 1945), konnte an eine zuverlässige Schutzimpfung gedacht werden. Das modifizierte abgeschwächte Virus gewann offenbar infolge Mutation auch durch erneute Menschenpassagen seine ursprüngliche Pathogenität nicht wieder. Dies kam auch dadurch zum Ausdruck, daß Aedes aegypti-Mücken nach einer Blutmahlzeit bei Menschen, welche mit der 10. Mäusepassage infiziert worden waren, auch nur ein Virus weiter übertrugen, das eine modifizierte milde Erkrankung hervorrief. Aedes aegypti, welche Blutmahlzeiten an mit der 15. Mäusepassage infizierten Personen erhielten, vermochten keine Infektion bei weiteren Versuchspersonen mehr zu erzeugen.

Ein einzelnes Mäusegehirn mit einem i.cer Infektiositätstiter von nur $10^{2}$ enthielt mindestens 10000 immunisierende Einheiten für den Menschen. SabIN (1952 a) nahm bei einer Reihe von Versuchspersonen Schutzimpfungen vor, wobei er als Impfstoff Frühpassagen des Typ 1-Virus (2-3 Wochen alte Mäuse) benutzte, welche höchstens 100 Mäuse-PD 50 oder Mäuse$\mathrm{LD}_{50}$ enthielten. Die Impflinge bekamen keine oder eine ganz milde Allgemeinerkrankung mit makulopapulösem Exanthem und entwickelten eine Immunität gegen einen infektiọ̈sen Mückenbiß mit großen Mengen unmodifiziertem Virus.

Auch die Typ 2-Viren (Neuguinea B und C) erfuhren in Mäusesäuglingsgehirnpassagen eine Mutation im Sinne einer Abschwächung, so daß sie als Impfstoffe benutzt werden konnten.

Bei der Herstellung von Impfstoffen und der Impfung ist nach SABIN (1959b) folgendes zu beachten: Nur Frühpassagen der Viren sollen benutzt werden, da nach längerer Passagierung für Affen stärker neurotrope Varianten entstehen. Die Impfstoffe sollen nur aus Mäusesäuglingsgehirnen gewonnen werden, da im Hühnerembryo keine oder nur eine geringe Vermehrung stattfindet und in Affennierenzellkulturen ebenfalls ein erhöhter Affenneurotropismus erscheint. Es ist zu beachten, daß Impfung mit $10^{4}$ oder mehr Mäuse- $\mathrm{LD}_{50}$ des Virustyps 1 häufig vorübergehende Störungen des Allgemein- 
befindens und leichte Fieberreaktionen herbeiführt. Der Impfstoff wird deshalb besser in einer Dosis von etwa $10^{3} \mathrm{LD}_{50}$ gegeben. Nach der Impfung dürfte eine langdauernde Immunität gegen Typ 1-Virus, aber auch eine zeitweilige Immunität gegen Typ 2Virus erzielt werden, die etwa 8 Wochen anhält. Der Typ 2-Impfstoff (nicht mehr als $10^{4}$ $\mathrm{LD}_{50}$ ) kann anschließend injiziert werden, aber nicht früher als nach 8-10 Wochen. Wird Typ 1-Impfstoff 6 Wochen nach Typ 2-Impfstoff verabfolgt, so entstehen keine Typ 1-AK. Handelt es sich vorwiegend um Typ 2-Epidemien, wird natürlich Typ 2Impfstoff verwandt. Getrockneter Impfstoff soll zur Verwendung in 5\% iger Menschenalbuminlösung ( $\mathrm{pH}$ 8) verdünnt und im gewöhnlichen Kühlschrank nur wenige Stunden, aufbewahrt werden, da das Virus schnell zerstört wird. Die HAHR ist ein schnelles, sicheres und einfaches Verfahren, um die Impfreaktion zu kontrollieren.

\section{II. Ilhéus-Infektion}

Das Ilhéus -Virus wurde im Verlauf von epidemiologischen Gelbfieberuntersuchungen zum ersten Mal von Laemmert und Hughes (1947) in einem waldreichen Gebiet in der Gegend von Ilhéus (Provinz Bahia, Brasilien) aus einem Pool dort gefangener Mücken der AedesPsorophora-Gruppe, der insbes. P. ferox, A. aegypti und A.serratus enthielt, isoliert, indem eine Suspension dieser Mücken einem Rhesus-Affen täglich 8 Tage lang eingespritzt wurde. Mit dem Serum dieses Affen i.cer. infizierte Mäuse erkrankten; mit ihren Gehirnen wurden weitere Mäusepassagen (insgesamt 50) angelegt. Während das Serum des Affen vor der Impfung keine N-AK enthielt, wurden solche 10 Wochen später gefunden. Ein weiterer Rhesus-Affe, der später mit einer anderen ähnlichen Mückensuspension geimpft wurde, wies nach 21 Tagen N-AK auf. De Rhodaniche (1956b) isolierte das Virus aus PsorophoraMücken (P. ferox, P. lutzii, P. varipes) in Honduras und anschließend stellten De Rodaniche und Galindo (1957b) das Vorkommen des Virus in einem Pool von Sabethes chloropterusMücken aus dem Motagua-Tal in Guatemala fest. Anderson u. a. (1956a) isolierten das Virus in Trinidad aus Waldmücken durch Verimpfung einer Mückensuspension (P.ferox, P. albipes, P. cingulata, Aedes serratus, A. scapularis und Culex candelli) auf 2 Tage alte Mäusesäuglinge (s. auch Aitken, 1953). De Rodaniche und Galindo (1961) gelang in Panama die Virusisolierung aus Haemagogus spegazzinii falco und Trichoprosopon spp., Groot u. a. (1961) aus P.ferox in Kolumbien. Er fand außerdem unter den Bewohnern der Gebiete mit infizierten Mücken auch AK.

Galindo und De Rodaniche (1961) isolierten das Ilhéus-Virus erstmalig von Vögeln in Zentralamerika. Das Virus wurde bei einem kleinen blauen Reiher (Florida caerulea) und einem rotbäuchigen Tukan (Pfefferfresser = Rhamphastos sulfuratus), außerdem N-AK in verschiedenen Vogelseren gefunden.

In Trinidad wurde das Virus zum ersten Mal im Menschenblut nachgewiesen (Dowss u. a., 1956b). Aus den bisher nur spärlichen klinischen Befunden bei Menschen geht hervor, daß die natürliche Infektion zu einer Encephalitis führen kann. Nach dem ersten Fundort Ilhéus im Staate Bahia, Brasilien, und dem erstmalig beobachteten Krankheitsbild ist das Virus von Laemmert und Hughes (1947) ursprünglich "Ilhéus-Encephalitis-Virus" genannt worden. Southam und Moore (1951) infizierten 19 Versuchspersonen mit fortgeschrittenen bösartigen Geschwülsten aus therapeutischer Indikation s.c. mit mäuseadaptiertem Ilhéus-Virus (s. auch Klinik). 9 von ihnen entwickelten eine Infektion. Bei 3 Patienten wurde das Virus mindestens 3 Tage lang nach Aufhören der Virämie nachgewiesen. In je 1 Fall wurde es auch in Rachenwaschungen und in der Spinalflüssigkeit während der Virämie gefunden. Eine Hemmung des Tumorwachstums trat nicht ein.

Affen (M. rhesus) ließen sich infizieren. Bei M. mulatta bestand 3-6 Tage nach i.cer. Impfung Virämie. Ein Affe erkrankte nach 12 tägiger Inkubationszeit an Lähmungen, ohne daß das Gehirn besondere pathologische Veränderungen erkennen ließ; es enthielt aber Virus. Die beiden Affenarten Callithrix jacchus und C.penicillata erwiesen sich so empfänglich, daß sie einer Infektion erliegen konnten. Ihr Gehirn war virushaltig. Nach i.p. Impfung kam es zu 
einer 5 Tage währenden Virämie. Bei C.penicillata traten nach i.cer. und s.c. Infektion nach etwa 1 Monat AK auf. Cebus versutus ließ sich i.cer. infizieren, ohne manifest zu erkranken. Er entwickelte ebenfalls spezifische AK (Koprowsis und Hughes, 1946; Laemmert und Hughes, 1947).

Koprowski und Hughes (1946) züchteten das Ilhéus-Virus auf Mäusen. In der 40. i.cer. Passage hatte die Inkubationszeit von 6 auf 4 Tage abgenommen. Junge Mäuse waren empfänglicher als alte. Nach i.p. und i.n. Impfung lokalisierte sich das Virus im Mäusegehirn, mitunter auch in Lunge, Leber, Niere, Milz, Darm und Nebennieren, obwohl es bereits nach 3 Tagen aus dem Blut verschwunden war, während gleichzeitig im Gehirn eine schnelle Vermehrung stattfand. Unmittelbare Kontaktinfektionen in den Käfigen schienen nicht stattzufinden; eine Infektion über die Verdauungswege schien möglich zu sein, da solche nach Kannibalismus auftraten. Laemmert und Hughes (1947) fanden 3 Tage alte Mäusesäuglinge für s.c. Infektion besonders empfänglich. REAGAN u. a. (1954e) konnten die Mäuse auch rektal infizieren; sie entwickelten dieselben nervösen Erscheinungen wie nach i.cer. Impfung. Das Virus ist also ausgesprochen neurotrop für Mäuse. Die Mäuse weisen nach jeder Infektionsweise encephalitische Veränderungen auf: Hyperämie, kleine Blutungsherde und monozytäre Infiltrationen. Große Cortisondosen erhöhen die Empfänglichkeit der Mäuse für eine tödliche Infektion erheblich (Southam und Baвсоск, 1951).

Koprowski und NorTon (1950) beobachteten einen onkolytischen Effekt des Virus auf das Methylcholanthren-Sarkom der Maus, das Mäusesarkom 180 und das Mäusesarkom E0-771. Southam u. a. (1951) fanden, daß die Blastosezellproliferation der AK4-Mäuseleukämie durch das Virus gehemmt wird und die Hepatosplenomegalie ausbleibt. Ähnliche Beobachtungen wurden an anderen Leukämiestämmen gemacht. Das Théus -Virus scheint sich in den Zellen des Ehrlichschen Asciteskarzinoms der Maus zu vermehren, aber auch einen hemmenden Einfluß auf den Tumor auszuüben (Koprowska und Koprowski, 1952).

Weiße Ratten, Meerschweinchen und Kaninchen sowie verschiedene kleine Nager (Oryzomys ratticeps, Proechimys dimidiatus) lassen sich i.cer. und s.c. infizieren, ohne allerdings manifest zu erkranken; 2-5 Tage p. i. findet sich aber Virus in ihrem Blut (Koprowski und Hughes, 1946). KERR (1952) beobachtete bei einem von 2 i.cer. infizierten Meerschweinchen eine tödliche Encephalitis, während i.p. Infektionen erfolglos blieben. ANderson u. a. (1956a) bestätigten die Empfänglichkeit von Kaninchen, die sie mit dem brasilianischen Originalstamm und 2 Trinidad-Viren i.p. infizieren konnten; die Identität der 3 Stämme wurde durch kreuzweise Neutralisierung mit den erhaltenen Immunseren bewiesen. Ähnlich verhalten sich verschiedene Beuteltierarten: Caluromys philander und Metachirus medicaudatus ließen sich i.cer. und s.c. infizieren; sie wiesen nach 3 bzw. 8 und 9 Tagen Virus im Blut auf; bei einem gestorbenen Tier fand sich Virus auch im Gehirn. Schwerer infizierbar waren Metachirus opossum und Didelphis marsupialis. KerR (1952) konnte Hamster i.cer. infizieren; ein Teil der Tiere starb an Encephalitis. Junge Tiere waren besonders empfänglich. Eine s.c. Infektion gelang nicht. REAGAN u. a. (1954c) fanden den syrischen Hamster ebenfalls sehr empfänglich. Nach ReAGan u. a. (1954a) sind junge Hunde für das Ilhéus-Virus empfänglich. Die Fledermaus Carollia perspicillata bekam nach i.cer. Infektion eine 6 Tage, die Vampirfledermaus Desmodus rotundus nach s.c. Infektion eine 3 Tage anhaltende Virämie (Koprowski und Hughes, 1946). Hühner, Tauben und Kanarien scheinen gegen das Ilhéus-Virus refraktär zu sein; nur bei einigen Kanarien wurde Virus noch nach 30 Tagen nachgewiesen (Koprowski und Hughes, 1946).

Das Ilhéus-Virus läßt sich leicht in Zellkulturen des zerkleinerten Hühnerembryos ohne ZNS in Serum-Tyrode-Lösung nach dem Maitland-Verfahren züchten (Koprowski und Hughes, 1946, s. auch Koprowski, 1956). Kissling (1957) stellte in Affennierenzellkulturen und Moore (1957) in Zellkulturen der verschiedensten Gewebe einen ZE fest.

Auf der $C A M$ des embryonierten Hühnereies findet eine Vermehrung des Virus statt, das in den Embryo eindringt und diesen in genügend hoher Konzentration tötet (Koprowski und Hughes, 1946). Taylor (1952) züchtete das Virus passagenweise im Dottersack, wobei Gehirn oder Rumpf des Embryos als Passagenmaterial dienten. Nach einigen Passagen konnten die Eier mit Virusverdünnungen, die höher waren als sie für eine tödliche Mäuseinfektion erforderlich sind, infiziert werden. Die Embryonen starben noch nach Infektion mit 
den höchsten Verdünnungen. Das Ilhéus-Virus kann als pantrop gelten, da es nicht nur im Gehirn, sondern auch in anderen Körperstellen in gleichen oder sogar höheren Konzentrationen vorkam.

Das Ilhéus-Virus passiert Seitz- und Berkefeld-W-Filter. Seine Größe beträgt 18-26 m $\mu$ (Sмithburn und Bugher, 1953). Es läßt sich in getrocknetem Zustand gut, in Glycerin weniger gut aufbewahren. Es hält sich gut bei Zimmertemperatur, wird aber bei Erhitzen auf $60^{\circ} \mathrm{C}$ zerstört.

CASALS und BROWN (1953) stellten aus infektiösen Mäusesäuglingsgehirnen ein hochkonzentriertes stabiles Hämagglutinin für Hühnererythrozyten her, indem sie aus dem Gehirn die nichtspezifischen Komponenten durch Aceton- und Ätherextraktion entfernten. Für die $H A$ war eine Temperatur von $4^{\circ}$ oder $22^{\circ} \mathrm{C}$ erforderlich. Durch Behandlung mit Protaminsulfat, welches weder die Infektiosität noch das Hämagglutinin präzipitierte, wurde das Ergebnis noch verbessert (Clarke, 1959 zit. Olitsky und Clarke, 1959; s. auch Casals und Brown, 1954). Clarke und Casals (1958) wiesen darauf hin, daß Protamin selbst eine hämagglutinierende Wirkung hat, die am stärksten bei niedrigem $\mathrm{p}_{\mathrm{H}}(6-6,4)$ und niedriger Temperatur $\left(4^{\circ} \mathrm{C}\right)$ ist. Dieser Protamineffekt kann aber verhältnismäßig leicht durch Zusatz von geringen Mengen Rinderplasmaalbumins gehemmt werden. HA, die erst nach Protaminbehandlung und bei niedrigem $\mathrm{p}_{\mathrm{H}}$ auftritt, muß daher mit Vorsicht beurteilt werden, wenn nicht ihre Virusnatur feststeht. Porterfield (1957) fand Gänseerythrozyten für die HA durch Thhéus -Virus geeignet.

Nach den bisher bekannt gewordenen Fundstellen (s. oben) des Ilhéus-Virus scheint es unter den Mücken weitverbreitet zu sein und diese scheinen eine wesentliche epidemische Bedeutung für die Infektionsverbreitung zu haben, wobei P.ferox die wichtigste Mücke zu sein scheint. Da sie eine Urwaldmücke ist, haben bereits Koprowski und Hughes (1946) angenommen, daß die im Wald lebenden Callithrichus-Affen die natürlichen Virusreservoire sein könnten, zumal der Erreger bei ihnen länger im Blut kreist als bei anderen Affenarten. Der natürliche Infektionszyklus wäre dann Affe-Mücke-Affe, vielleicht mit gelegentlicher Zwischenschaltung von Beuteltieren und Nagern. Bereits Laemmert und Hughes (1947) hatten festgestellt, daß außer Psorophora ferox auch A. aegypti und A. serratus das Virus von Mäusesäugling zu Mäusesäugling übertragen können, so daß auch in der Natur mit einer Ausbreitung der Infektion durch diese Mückenarten zu rechnen wäre. Während Aitken (1957) zunächst vergeblich versuchte, das Ilhéus-Virus mit A.serratus oder P.ferox durch Fütterungsinfektion zu übertragen, konnten AItKeN und ANDERSon (1959) später feststellen, daß A.aegypti, A.scapularis, A.serratus, Culex quinquefasciatus, P.albipes und P.ferox nach intrathorakaler Infektion Überträger, d. h. Virusausscheider werden (s. auch AiтkeN, u. a., 1960).

Aitken u. a. (1958) fanden ferner, daß die parasitischen Philornisfliegen (Anthomidae), welche Nestvögel befallen, sich mit Ilhéus-Virus infizieren lassen. Die experimentelle Infektion kann schon im Larvenstadium erfolgen und im Erwachsenenstadium bestehen bleiben. Ob diese Fliegenart eine Rolle in der Epidemiologie der Ilhéus-Infektion spielt, ist noch ungeklärt. Die Bedeutung der Infektion für den Menschen geht aus der Häufigkeit des AK-Nachweises bei ihnen hervor (Laemmert und Hughes, 1947; Anderson u. a., 1956a; De RodaNiche, 1956a, b; Downs u. a., 1956a, b; De Rodaniche und Galindo, 1957a, b).

Hammon u. a. (1958) wiesen bei der Bevölkerung der Philippinen AK nach. Causey und Theiler (1958) stellten im Amazonas-Tal bei 7 von 150 Kindern von 4-14 Jahren und in $36,2 \%$ von 359 Personen im Alter über 15 Jahren AK fest. Der höhere Anteil der Männer wird durch berufliche Gründe erklärt.

Aus den von Southam und Moore (1951) vorgenommenen experimentellen Infektionen bei 10 Krebskranken, von denen allerdings nur 6 klinisch verwertbar waren, geht folgendes hervor: 3 Patienten bekamen keine klinischen Erscheinungen, die anderen 3 erkrankten nach einer Inkubationszeit von 6-16 Tagen an Fieber, das 3-8 Tage anhielt. Dromedarkurven wurden nicht beobachtet. Ein Patient klagte nur über allgemeine Schmerzen und Krankheitsgefühl während der Fieberperiode, 2 Patienten wiesen Zeichen einer kurzdauernden Encephalitis auf. In einem Fall bestanden Schüttelfrost und Schläfrigkeit. Am 9. Tag fiel das Fehlen er tiefen Sehnenreflexe auf; es kam zu einem Dämmerzustand ohne Verlust der Orientierung, 
nach 2 weiteren Tagen zu Desorientierung, Lethargie und Sprachstörungen. Am 11. Tage fiel die Temperatur schnell zur Norm; die encephalitischen Symptome wurden aber noch ausgeprägter. Die Lumbalflüssigkeit war getrübt. Am 15. Tage setzte Besserung des Geisteszustandes ein und die Lumbalflüssigkeit wurde wieder klar. Am 19. Tage bestanden keine Symptome einer Virusinfektion mehr. Bei einem anderen Patienten waren die encephalitischen Erscheinungen noch ausgeprägter. Bei allen 3 Kranken bestand am 3. und 4. Tag Virämie, die in einem Fall 9 Tage anhielt.

Bisher sind nur 2 natürliche Infektionen von Menschen bekannt geworden, von denen die eine mit Encephalitis, die andere symptomlos verlief.

Bei den Versuchspersonen, die an einer anderen Ursache gestorben waren (Geschwülste), wurden keine pathologischen Veränderungen gefunden, welche auf die Viruswirkung zurückzuführen waren (Southam und Moore, 1951).

Die Diagnose beruht in erster Linie auf ätiologischen und serologischen Untersuchungen: Virusnachweis und antigene Differenzierung des Virus gegen andere Viren der Gruppe. In Gebieten, in denen verschiedene B-Infektionen gleichzeitig eine hohe Endemizität erreichen, so daß die Bewohner schon früher mit verschiedenen Viren der Gruppe infiziert worden waren, kann die serologische Diagnose der neuen Infektion infolge des breiten gemeinsamen antigenen Spektrums sehr schwierig, ja sogar unmöglich sein, wenn es sich um einen Einzelfall handelt.

Die antigene Verwandtschaft des Ilhéus-Virus besonders zum SLE-Virus, aber auch zum WN- und JE-Virus wurde in der KBR u. a. von Hughes und Perlowagora (1950b) mit Mäusegehirnantigen und Mäuseimmunserum festgestellt. KeRR (1952) fand eine kreuzweise KBR zwischen Ilhéus- und Ntaya-Virus.

Rhesus-Affen, die mit virushaltigen Mückensuspensionen infiziert werden, bilden N-AK, welche durch die Mäuseschutzprobe ermittelt werden können. Die zum Nachweis der AK an 22 Tage alten Mäusen i.cer. ausgeführte Schutzprobe ist weniger empfindlich als die s.c. Probe an 3 tägigen Mäusesäuglingen. Mittels der Neutralisation läßt sich das Ilhéus-Virus von folgenden Arbor-Viren unterscheiden: Gelbfieber, EEE, WEE, VEE, REFSE, Louping ill, lymphozytäre Choriomeningitis (Laemmert und Hughes, 1947).

CASALS und Brown (1953) konnten mit der HAHR mit hochgereinigten Hämagglutininen aus Mäusegehirnen feststellen, daß das Ilhéus -Virusantigen sehr stark mit homologen Immunseren, aber weniger stark, wenn auch noch deutlich mit anderen Immunseren der Gruppe B reagiert.

Bei den von Southam und Moore (1954b) infizierten Versuchspersonen bildeten sich nach etwa 3-4 Wochen AK. Die N-AK-Titer blieben mindestens 6 Monate gleich hoch, während die KB-AK nach 3-4 Monaten abfielen.

\section{III. Gelbfieber}

Gelbfiebervirus $=$ Charon evagatus spec. nov. (Holmes, 1948).

\section{Einleitung}

Das Gelbfieber ist eine in Afrika, Mittel- und Südamerika endemisch und epidemisch auftretende Krankheit, die durch Mücken übertragen wird, was bereits von NoTt (1848) angenommen worden war. Es scheint den zivilisierten Völkern des Altertums nicht bekannt gewesen zu sein, denn zweifellos wäre es der Aufmerksamkeit der damaligen Ärzte infolge seines auffallenden klinischen Charakters nicht entgangen. Der Eingeborenen-Geschichtsforschung Afrikas dürfte es schwierig sein, dokumentarische Beweise dafür zu finden, wann das Vorkommen der Krankheit zum erstenmal als gesichert gelten kann. Euton (1956) weist auf vorkolumbische Bücher aus Chilam und Belam hin, in welchen Angaben über eine 1484 im Maya-Reich wütende "Blutbrechen-Epidemie» 
gemacht wurde, bei der es sich um Dschungelgelbfieber gehandelt haben kann (s. auch Bustamente, 1958b). Die ersten klinisch brauchbaren Beschreibungen der Krankheit in Amerika gehen nach Mollaret (1948) auf Du Tertre in Guadeloupe (1635), Lopes Cogolludo in Yukatan (1648), wo auch die erste Epidemie beobachtet worden sein soll, und De La Martinière in Martinique (1703) zurück.

Nach HörING (1948) gehört das Gelbfieber zu den zyklischen Infektionskrankheiten mit teils virämischem, teils toxischem Verlauf, der im wesentlichen durch die degenerativen Veränderungen in verschiedenen Organen bestimmt ist. Unter ihnen stehen an erster Stelle die Leberveränderungen, welche auch die Ursache für den Ikterus, das charakteristische Symptom des Gelbfiebers sind.

Die Frage, ob das Gelbfieber ursprünglich in Afrika vorkam und - wie vielfach angenommen wird - durch den Sklavenhandel nach Amerika zusammen mit der Mücke Aedes aegypti vom Golf von Guinea an die Küste des Karibischen Meers verschleppt worden ist, konnte noch nicht eindeutig beantwortet werden. Das Umgekehrte kann auch der Fall sein. Aus den historischen Untersuchungen von CARTER (1931), welcher ebenfalls annimmt, daß die Krankheit zuerst in Afrika beheimatet war, geht hervor, daß sich die Bezeichnung "Gelbfieber" zum ersten Mal in dem Werk "Natural History of Barbados" von Hughes (1750) findet. BerengerFeraud (1890, zit. Mollaret, 1948) gibt 73 Synonyme für Gelbfieber an. Mathis (1948) und Mollaret (1948) sehen nach wie vor die wahrscheinliche Wiege der Krankheit im Golf von Mexiko, wo die Begleiter von Columbus die ersten europäischen Opfer dieser Seuche geworden sein sollen. In Haiti scheint das Fieber 1502 unter den dort gelandeten Truppen gewütet zu haben.

Man unterscheidet heute 2 Gelbfieberformen: das klassische Gelbfieber und das Dschungelgelbfieber. Nach BuRnet (1955) ist das Gelbfieber von Afrika nach Amerika gebracht worden, wo sich die sekundäre Dschungelphase entwickelt hat. Hierfür spricht, daß man wohl amerikanische Affen, nicht aber afrikanische Urwaldaffen an Gelbfieber sterben sah. Auf die etwaige Bedeutung von Affen für die Gelbfieberepidemiologie ist bereits von Mánson (1905, zit. Bugher, 1955) hingewiesen worden. Die Tatsache, daß die Krankheit in der Dschungelphase als epidemiologisch ganz neue Form auftritt, daß sie unter den Urwaldaffen seuchenartig vorkommt und daß der Erreger im Blut vieler anderer Waldtiere vorhanden ist, erlaubt es nicht mehr, das Gelbfieber als eine nur unter den Menschen verbreitete Krankheit zu betrachten; es ist vielmehr eine Menschen- und Tierseuche. Wahrscheinlich ist in der Dschungelphase der Tiere sogar die primäre Gelbfieberform zu sehen; dann wäre die menschliche Form in der Naturgeschichte dieser Krankheit nur ein seitlicher oder sekundärer Abkömmling in der normalen tierischen Infektkette. Man muß daher das Gelbfieber als eine Zoo-Anthroponose bezeichnen.

Durch gründliche Selbstversuche mit allen denkbaren Übertragungsweisen kam bereits der amerikanische Arzt Firтн (1804) zu der Auffassung, daß das Gelbfieber weder durch Kontakt noch durch Sekrete oder Exkrete übertragen wird. Peller (1919) weist aber darauf hin, daß schon vor ihm Cathrall (1794). ähnliche negativ gebliebene Versuche angestellt hat (s. auch ScotT, 1939).

Mit den ebenso grundlegenden wie denkwürdigen Arbeiten von Finlay in Havana (1881a, b, c, 1886) begann die moderne Gelbfieberforschung. Es gelang ihm, die Krankheit durch Bisse von A. aegypti-(früher Culex fasciatus-) Mücken, die er in der Natur gefangen hatte, auf gesunde Versuchspersonen zu übertragen. Nach Montestruc (1956) soll aus Mitteilungen eines Arztes namens BEAUPERTHUI hervorgehen, daß dieser bereits 30 Jahre vor FinLAY auf den Antillen den A. aegypti als Überträger des Gelbfiebers bezeichnet hat.

SOPER u. a. (1933) machten in einem ländlichen A. aegypti-freien Gebiet in Brasilien 
(Chanaan-Tal im Staate Esperito Santo) die Beobachtung, daß es Gelbfieberübertragungen und -epidemien auch ohne diese "Gelbfiebermücke« gibt. Sie fanden außerdem, daß nicht die Menschen, sondern Affen die primären Virusreservoire waren. Das Virus wurde durch baumbrïtende Aedes- und Haemagogusarten übertragen. Die Mücken übertrugen nur gelegentlich die Infektion von Affen auf Menschen. Anläßlich dieser für die ganze Gelbfieberepidemiologie überaus wichtigen Feststellung erinnert Soper (1935b) daran, daß bereits Franco (1907) in Munzo (Columbien) das Dschungelgelbfieber und seine Übertragung beschrieben hatte.

Die Übertragung des Gelbfiebers auf den Menschen erfolgt fast nur durch AedesMücken. Da die meisten Arten in tropischen Gebieten vorkommen, unterliegt damit auch die Ausbreitung der Krankheit einer Begrenzung, die normalerweise etwa zwischen dem 30. und 40. Grad nördl. und südl. Breite zu suchen ist.

REED und CARRoll (1902) stellten durch Filtrationsversuche den Viruscharakter des Erregers sicher. STоKеs u. a. (1928) fanden das erste für Gelbfieber empfängliche Laboratoriumstier im Rhesus-Affen. Theiler $(1930 \mathrm{a}, \mathrm{b})$ entdeckte die große Empfänglichkeit der Mäuse. HaAGen (1933a, 1934a) züchtete das Gelbfiebervirus zum erstenmal dauernd in der Gewebekultur.

Mit der Auffindung empfänglicher Laboratoriumstiere und der Schaffung von Methoden zur Dauerzüchtung des Virus in vitro war die Möglichkeit einer systematischen Erforschung der Krankheit und ihres Erregers möglich geworden. Das wichtigste Ergebnis war die Entwicklung wirksamer lebender Impfstoffe, die sich in ihrer Bedeutung für die Seuchenbekämpfung neben Jenners Entdeckung der Pockenschutzimpfung reihen.

\section{2. Ätiologie}

Durch die Entdeckung der Filtrierbarkeit des Gelbfiebererregers durch Reed und CarRoll (1902) mußte dessen Virusnatur als gesichert gelten. Damit war zunächst die Auffassung widerlegt, daß ein Bacillus, wie ihn SANARELLI (1897) im B.icteroides entdeckt zu haben glaubte, die Ursache wäre. Die Entdeckung von REED und CARRoll geriet aber wieder in Vergessenheit, so daß die Ansicht der Spirochätennatur des Erregers (Schaudins, 1904; Novy und Knapp, 1906; Stimson, 1907; NoGuchi, 1919-1921) in den Vordergrund treten konnte. Die irrtümlichen Befunde von NoGUchI sind nur so zu erklären, daß sich unter den von ihm untersuchten Gelbfieberkranken eine Anzahl von Kranken mit WeILschem Ikterus befand. Im übrigen gelang es auch NoGUcHI selbst später nicht mehr, den Spirochätennachweis an der Westküste Afrikas zu führen. Die erste Ablehnung erfuhr die Hypothese durch Hofrmanv (1920). Außerdem konnte beobachtet werden, daß die Spirochäten überhaupt nicht durch Aedes aegypti übertragbar waren (Theiler und Sellards, 1926; Schüffner u. a., 1927).

\section{2-1. Übertragungsversuche}

Die moderne experimentelle Aera der Gelbfieberforschung wurde durch FinLay (1881a, b, c) eingeleitet, der in Menschenversuchen A.aegypti an Gelbfieberkranken Blut saugen ließ und diese nach einer Reihe von Tagen zu einer erneuten Blutmahlzeit Gesunden ansetzte. Auf diese Weise konnte er experimentell Gelbfieber erzeugen. Aus Finlays Versuchen ergab sich, daß der Erreger des Gelbfiebers zeitweise im Krankenblut kreisen und sich im Organismus der Mücke vermehren müßte, damit letztere beim Biß einen gesunden Menschen infizieren kann. Es erscheint heute unverständlich, daß die Entdeckung Finlays in ihrem vollen Wert erst 20 Jahre später erkannt wurde, als die amerikanische Gelbfieberkommission in Havana von REED u. a. (1900) diese Versuche wiederholte und vollständig bestätigte. $\mathrm{Zu}$ denselben Ergebnissen kamen die Mit- 
glieder einer französischen Gelbfieberkommission in Brasilien (Marchoux u. a. 1903; 1906 a, b, c; s. auch Dominguez, 1938).

Thomas (1907) in Manos (Brasilien) dürfte als erster einen Affen (Pan troglodytes troglodytes) den Bissen von Aedes aegypti ausgesetzt haben, welche 3 Wochen vorher eine Blutmahlzeit bei 2 Gelbfieberkranken bekommen hatten. Nach 3 Tagen erkrankte der Affe an Fieber und dem menschlichen Gelbfieber ähnlichen Symptomen. Nach der Genesung konnte er nicht noch einmal infiziert werden. Erst 20 Jahre später übertrugen Mahaffy und BaUer (1927, zit. WarRen, 1951) in Accra (Westafrika) Blut von 2 Gelbfieberkranken auf einen Rhesus-Affen, der nach 4 Tagen fieberhaft erkrankte und am folgenden Tag starb. Der auf diese Weise isolierte viscerotrope Gelbfiebervirusstamm wurde nach dem Blutspender »Asibi« genannt. Er konnte von STокеs u. a. (1928b) passagenweise auf Affen auch durch $\mathrm{BiB}$ von A.aegypti weitergezüchtet werden. Mathis u. a. (1928) ließen in Dakar (Senegal) A. aegypti 24 St. nach einer Blutmahlzeit bei einem Kranken ebenfalls an einem Rhesus-Affen saugen und konnten von diesem Affen einen zweiten allerdings neurotropen Virusstamm, den sogenannten "französischen Stamm Dakar isolieren (s. auch Aragao de Beaurepaire, 1928b; Davis und Burke, 1929; Davis und Shannon, 1929a).

Zur erfolgreichen Übertragung der Gelbfieberinfektion auf den von allen untersuchten Affen am gleichmäßigsten empfänglichen M.rhesus genügen minimalste Virusmengen aus Blutverdünnungen (Lewis, 1930; Bauer, 1931). Aragao De Beaurepaire und Da Costa Lima (1929a, b , c, d, e, f, g) infizierten Rhesus -Affen, indem sie Ausscheidungen infizierter A. aegypti auf die Haut und Konjunktiva brachten (s. auch Bauer und Hudson, 1928a, b). Die Affen können auch durch Instillation des Virus in die Nase infiziert werden (Findlay und Clarke, 1935a); das Virus breitet sich dann über den N. olfactorius in das Gehirn aus. Unter Versuchsbedingungen sind Affen auch oral infizierbar, wenn das Virus mittels Magensonde in die Verdauungswege gebracht wird. Diese Möglichkeit würde das Zustandekommen verschiedener Käfiginfektionen von Affen erklären (Findlay und Maccallum, 1939). Das Virus wurde im Blut nachweisbar. Bei den Affen, die nicht an visceralem Gelbfieber starben, kamen AK vor. Nach i.cer. Infektion der Rhesus-Affen traten mehr oder weniger schwere Encephalomyelitiden auf (Goodpasture, 1932; Nicolau u. a., 1934a). Stefanopoulo (1932), Findlay und Maccallum (1938a) sowie van Den Berghe (1940) fanden bei Affen nach i.cer. Injektion von neurotropem Virus Leberschädigungen. Meers (1959) sah bei Rhesus-Affen, die i.cer. mit mäusegehirnadaptiertem $17 \mathrm{D}$-Virus (5000-16000 Mäuse $\mathrm{LD}_{50}$ ) infiziert wurden, eine schwache Virämie. Die Inkubationszeit betrug 6, 8 Tage nach Infektion mit der 17. Gehirnpassage. Die Encephalitishäufigkeit stieg bei den Affen von 0 mit dem Ausgangsvirus auf 1:6 mit der 1. Mäusegehirnpassage, auf $2: 3$ mit der 3 . und auf $6: 6$ mit der 17. Passage.

Außer M.rhesus lassen sich auch andere Makaken wie M. sinicus, M.cynomolgus, M.nemestrinus und M.inuus experimentell infizieren (Ретtit u. a., 1928b; Рettit und Stefanopoulo, 1929, 1930).

Von afrikanischen Affen konnten Angehörige der Cercopithecidae (Cercopithecus aethiops aethiops, C.mona, C.tantalus, Cercocebus torquatus sowie Erythrocebus patas) durch Verimpfung von virushaltigem Rhesusblut oder Biß infizierter Mücken infiziert werden. Sie erkrankten nicht, wiesen aber Virämie und N-AK auf (BAUER und MAHAFFY, 1930). Lasiopyga callitrichus (verwandt mit C.tantalus) zeigte nach i.p. Infektion ebenfalls Virämie und N-AK, während i.cer. Infektion zu einer tödlichen Encephalitis führte. Dasselbe traf für zahlreiche andere afrikanische Affenarten zu. Manchmal wurde Fieber beobachtet. Bei jungen Tieren traten mitunter Leberveränderungen auf (Theiler und Hughes, 1935; Hughes, 1943; Smithburn und Haddow, 1949; Bugher, $1951 \mathrm{a}$; Williams, 1956; Bearcroft, $1960 \mathrm{~b}$, 1962).

Über die Empfänglichkeit südamerikanischer Affen gibt folgende Tabelle Auskunft: 
Tabelle 36

Empfänglichkeit verschiedener südamerikanischer Affenarten im Versuch (Nach van Rooyen und RHodes, 1948)

\begin{tabular}{|c|c|c|c|c|c|c|}
\hline Autor & $\begin{array}{l}\text { Affenart und } \\
\text { Anzahl } \\
\text { der Tiere }\end{array}$ & $\begin{array}{l}\text { Art der } \\
\text { Infektion }\end{array}$ & $\begin{array}{l}\text { Sym- } \\
\text { ptome }\end{array}$ & Tote & $\begin{array}{l}\text { Leber- } \\
\text { verän- } \\
\text { derung }\end{array}$ & $\begin{array}{l}\text { Schutz } \\
\text { nach } \\
\text { Infektion }\end{array}$ \\
\hline Davis, 1931 & $\begin{array}{l}\text { Alouatta } \\
\text { caraya (2) }\end{array}$ & Blutinjektion & - & $\cdot$ & $\because$ & 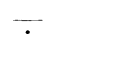 \\
\hline DAvis, 1931 & $\begin{array}{l}\text { Alouatta } \\
\text { seniculus (4) }\end{array}$ & Mückenbiß & + & 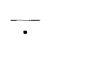 & - & + \\
\hline Davis, 1931 & $\begin{array}{l}\text { Aotus trivirgatus } \\
(1)\end{array}$ & Mückenbiß & - & - & 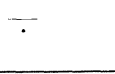 & + \\
\hline DAvIS, 1930/1931 & Ateles ater (5) & $\begin{array}{l}\text { Mückenbiß und } \\
\text { Injektion }\end{array}$ & + & - & - & + \\
\hline $\begin{array}{l}\text { Lloyd und Penna, } \\
1933\end{array}$ & $\begin{array}{l}\text { Ateles paniscus } \\
\text { (1) }\end{array}$ & Injektion & + & + & + & $\div$ \\
\hline $\begin{array}{l}\text { Lloyd und Penna, } \\
1933\end{array}$ & $\begin{array}{l}\text { Ateles variegatus } \\
\text { (1) }\end{array}$ & Injektion & + & + & + & $\because$ \\
\hline Davis, 1931 & $\begin{array}{l}\text { Cacajao } \\
\text { rubicundus (3) }\end{array}$ & $\begin{array}{l}\text { Biß und } \\
\text { Injektion }\end{array}$ & - & - & $\div$ & + \\
\hline Davis, 1931 & $\begin{array}{l}\text { Callicebus } \\
\text { moloch (2) }\end{array}$ & Injektion & + & . & + & + \\
\hline $\begin{array}{c}\text { Davis, } 1930, \text { Lloyd } \\
\text { und Penna, } 1933\end{array}$ & $\begin{array}{l}\text { Callithrix } \\
\quad \text { albicollis (26) }\end{array}$ & $\begin{array}{l}\text { Biß und } \\
\text { Injektion }\end{array}$ & + & + & - & + \\
\hline $\begin{array}{l}\text { Davis, } 1930, \text { Davis } \\
\text { und Shannon, } \\
1929\end{array}$ & $\begin{array}{l}\text { Cebus frontatus } \\
\text { (77) }\end{array}$ & $\begin{array}{l}\text { Biß und } \\
\text { Injektion }\end{array}$ & + & \pm & \pm & + \\
\hline $\begin{array}{l}\text { Davis, 1931, Lloyd } \\
\text { und Penna, } 1933\end{array}$ & $\begin{array}{l}\text { Cebus variegatus } \\
\text { (2) }\end{array}$ & $\begin{array}{l}\text { Biß und } \\
\text { Injektion }\end{array}$ & \pm & - & - & + \\
\hline Davis, 1930 & Lagothrix (12) & Injektion & + & - & - & + \\
\hline $\begin{array}{l}\text { Davis, 1930, Lloyd } \\
\text { und Penna, } 1933\end{array}$ & $\begin{array}{l}\text { Leontocebus } \\
\text { ursulus }(10) \\
\text { (Cercopithecus } \\
\text { ursulus) }\end{array}$ & $\begin{array}{l}\text { Biß und } \\
\text { Injektion }\end{array}$ & + & + & + & 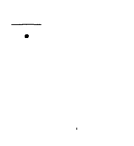 \\
\hline Davis, 1931 & $\begin{array}{l}\text { Pithecia } \\
\text { monachus (2) }\end{array}$ & $\begin{array}{l}\text { Biß und } \\
\text { Injektion }\end{array}$ & + & - & 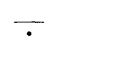 & - \\
\hline $\begin{array}{l}\text { ARAGAO } \\
\text { DE BEAUREPAIRE } \\
1929\end{array}$ & $\begin{array}{l}\text { Pseudocebus } \\
\text { azarae (2) }\end{array}$ & Injektion & + & - & - & 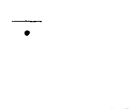 \\
\hline $\begin{array}{l}\text { Davis, 1930, Lloyd } \\
\text { und PenNa, } 1933\end{array}$ & $\begin{array}{l}\text { Saimiri } \\
\text { sciureus (34) }\end{array}$ & $\begin{array}{l}\text { Biß und } \\
\text { Injektion }\end{array}$ & + & + & + & + \\
\hline
\end{tabular}


Bugher (1951a) teilt die südamerikanischen Affen, die für Gelbfieber empfänglich sind, in die beiden Familien Callitrichidae und Cebidae.

$\mathrm{Zu}$ den Callitrichidae gehören Leontocebus ursulus: die Tiere starben nach i.cer. Infektion mit dem »Dakar«-Stamm an Encephalitis (Lloyd und MaHAFFy, 1936 s. auch Tabelle 36). Leontocebus rosalia: die Tiere zeigten auffallende Unterschiede in der Sterblichkeit nach Infektion mit afrikanischen und südamerikanischen Virusstämmen. Mit letzteren starben alle Affen, während erstere Affen nicht töteten. Oedipomidas oedipus (Seidenäffchenart): die Tiere bekamen hochgradige Virämie (bis $10^{-10}$ ); sie starben zum Teil an der Infektion und zeigten Lebernekrose (Bates und RocA-Garcia, 1946a). Oedipomidas geoffroyi reagierte ähnlich und entwickelte Schutzkörper. Callithrix jacchus (gewöhnliches Seidenäffchen): die Tiere zeigten nach s.c. Infektion, daß alle Stämme eine etwa gleich große Pathogenität hatten. Die Sterblichkeit nach Infektion mit afrikanischen Virusstämmen war jedoch erheblich geringer als jene der Rhesus-Affen. Durch Mückenpassagen von Tier zu Tier erfuhr das Virus keine Abwandlung (Lammmert, 1944). Callithrix aurita: diese Affen konnten passagenweise durch A. aegypti infiziert werden und zeigten regelmäßig Virämie $\left(10^{-7}\right)$. 15 von 17 Tiere starben, die beiden überlebenden wiesen AK auf. Eine Infektion gelang auch durch Biß von Haemagogus equinus und H.spegazzinii. Hieraus ergibt sich, wie leicht eine Infektkette zwischen diesen Affen durch Stadt- und Dschungelmücken wechselseitig aufrecht erhalten werden kann (WADdell und TAYLOR, 1945, 1946, 1947). Callithrix penicillata: diese Affen waren sehr empfänglich mit sțarker Virämie $\left(10^{-7}\right)$. Von 8 durch A. aegypti infizierten Tieren starben 6. 1 Tier zeigte typische Leberveränderungen, die übrigen Tiere wiesen AK auf (WADDELL und TAYLOR, 1946). Von 10 infizierten Callithrix leucocephalia-Affen starben 9 an Gelbfieber. Die Empfänglichkeit von Callithrix ornatus schien nicht groß zu sein. Der Virustiter im Blut erreichte nur 10-2 (Bates und Roca Garcia, 1946a; Kerr und Bosheld, zit. BUGHER, 1951). (Callithrix albicollis und Callithrix molloch, s. Tab. 36).

$\mathrm{Zu}$ den Cebicidae gehören die 4 Unterfamilien Alouatta, Pithecinae, Aotinae und Cebinae.

Die Brüllaffen (Alouatta) haben neuerdings eine zunehmende epidemiologische Bedeutung für das Gelbfieber bekommen. Man findet sie weit verbreitet von Mexiko bis Argentinien. Alouatta seniculus wurde bereits von BALfour (1914) und DAvis (1931b) als Gelbfieberreservoire verdächtigt. Whitman (zit. Bugher, 1951) infizierte 4 Brüllaffen mit AsibiVirus; 2 Affen starben. Der Virustiter im Blut erreichte 10-5. Auch Alouatta caraya und A.guariba clamitans waren leicht infizierbar und starben an Gelbfieber. Das Virus kreiste in so großen Mengen im Blut, daß zyklische Übertragungen mit A. aegypti, A.scapularis und A.leucocelaenus möglich waren (Laemmert und Kumm, 1950, s. auch Tab. 36).

Bereits Aragao de Beaurepaire (1929a) hatten die Empfänglichkeit des zu den Pithecinae gehörenden Saimiri sciureus, der in Südamerika unter den Saimiri-Affen am weitesten verbreitet ist, festgestellt. Nach Davis $(1930 \mathrm{~b})$ starben 10 von 15 infizierten Tieren mit typischen Leberveränderungen; weitere 15 Tiere ließen sich durch Biß und i.cer. mit neurotropem Virus infizieren. Sie erkrankten an einer tödlichen Encephalitis, die sich passagen weise mit Gehirnfiltraten übertragen ließ (Lloyd und Penna, 1933b). Bates (1944a) beobachtete bei Saimiri sciureus caquetensis einen Blutvirustiter von 1:1 Million. Von 14 Tieren, die erkrankten, starben 5 (ca. 33\%). BughER (1951) erzielte keine klinisch erkennbare Erkrankung, obwohl Virus mit einem Titer von 10-3 im Blut kreiste.

Whitman (zit. Bugher, 1951) infizierte 4 Aotinae (Nachtaffen) mit Asibi-Virus; 2 Tiere starben. Alle bekamen eine Virämie. Ein Aotus wurde durch A. aegypti-Biß infiziert und starb ebenfalls mit starker Virämie und typischen Leberveränderungen. Bates und Roca-GaRcia (1945) führten einen Infektionszyklus von Affe zu Affe mit Haemagogus-Mücken als Überträger durch; alle 4 Affen bekamen Fieber sowie starke Virämie und starben bereits nach 4 oder 5 Tagen mit schweren Leberveränderungen und Magenblutungen. Ein Aotus trivirgatus wurde von Davis (1931b) infiziert (s. Tabelle 36 ).

Von den Cebinae sind verschiedene Ateles- und Cebus-Arten experimentell infizierbar: Ateles ater, Ateles paniscus (s. Tabelle 36). Die Empfänglichkeit von Lagothrix lagothricha wurde von Davis (1930b) untersucht (s. Tabelle 36). Nach i.cer. Infektion mit neurotropem Virus erkrankten die Tiere an einer tödlichen Encephalitis (Lloyd und Penna, 1933b, s. auch Bugher, 1951). Der Kapuzineraffe Cebus azarae konnte von Aragao de Beaurepaire 
(1929b) nicht infiziert werden; dagegen gelang es Davis und Shannon (1929a), Cebus macrocephalus durch A. aegypti-Biß zu infizieren; es kam zu mehrtägiger Virämie, aber nicht zu Erkrankungen. Davis (1930c) konnte Cebus albifrons passagenweise mit Asibi-Virus durch Injektion und Mückenbiß infizieren; es kam zu leichter Erkrankung mit Virämie und einem Todesfall. Cebus frontatus und Cebus variegatus konnten ebenfalls infiziert werden (s. Tab. 36). Bugher (1951) gelang es, Cebus fatuellus zu infizieren, wobei es zu Virämie mit Titern bis zu $10^{-3}$ und AK-Bildung kam. Passagenweise Infektion von Affe zu Affe durch Mücken (A. aegypti) nahmen W ADDELL und TAYLOR (1945) vor; alle 13 Tiere wiesen vom 3. bis 7. Tage Virus im Blut mit Titern bis zu $10^{-6}$ auf.

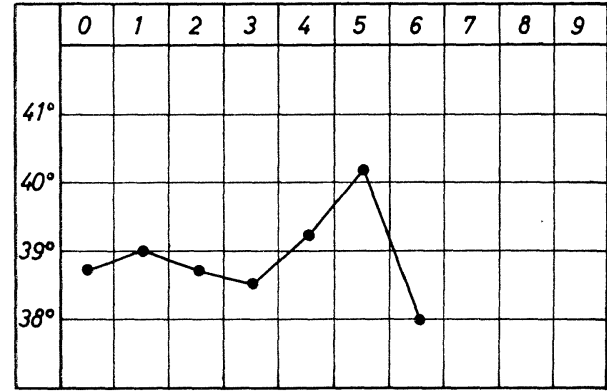

Abb. $27 a$. (nach MATHIS, 1948)

Temperaturverlauf bei einem infizierten Rhesusaffen (gewöhnliches Virus)

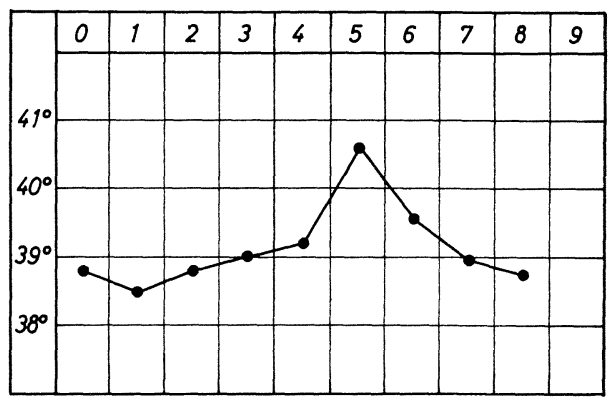

$A b b .2 \% b . \quad$ (nach Mathis, 1948)

Temperaturverlauf bei einem infizierten Rhesusaffen (französ. Stamm, 2 Jahre gezüchtet)

Die experimentell infizierten Affen zeigen dieselben klinischen Erscheinungen wie gelbfieberkranke Menschen. Die Inkubationszeit beträgt 2-6 Tage; nach weiteren 1-5 Tagen pflegen die Tiere bereits zu sterben. Bei typischer Infektion mit dem Asibi-Stamm und normalem Krankheitsverlauf beträgt die Letalität der Rhesus-Affen mindestens 95\%. Bei Infektion mit geringen Virusmengen sind Inkubationszeit und Krankheitsdauer verlängert; man findet beim Tod dieser Tiere im Blut N-AK (BAUER, 1931). Zwischen den in Afrika und Südamerika isolierten Virusstämmen bestehen erhebliche Pathogenitätsunterschiede für Affen, wobei die Schwere der menschlichen Erkrankungen offenbar ohne Beziehung ist (Davis und Burke, 1929; Sawyer u. a., 1930; Laemmert, 1944). Der Urin enthält Eiweiß und Galle; er ist dunkel- oder grünlichgelb. Kurz vor dem Tode findet man hyaline und granulierte Zylinder. Das Serum enthält ebenfalls Galle. Die Leberfunktionsprüfung mit Bromsulphalein hat prognostischen Wert: Farbretention von $10 \%$ und mehr am 2.Tag und von $15 \%$ am 3. Tag läßt tödlichen Ausgang erwarten (KERR, 1931); ein Ikterusindex des Serums von mehr als $10 \mathrm{E}$ am 2 . Fiebertag und $15 \mathrm{E}$ am 3. und 4. Fiebertag ist ebenfalls prognostisch ungünstig; bei niedrigem Index besteht dagegen Genesungsaussicht bei $75 \%$ der Tiere. (s. auch Wakeman und Morrell (1932).

Davon ausgehend, daß Tetrachlorkohlenstoff ähnlich wie Gelbfieber Leberzirrhose verursacht, welche über Störung des Kreatininstoffwechsels zu einem Guanidinüberschuß führt, verglichen Findlay und Hindle (1930) den Guanidinspiegel im Blut bei normalen und gelbfieberinfizierten Affen. Sie fanden ihn bei letzteren gegenüber der Norm erhöht $(0,498$; $0,148 \mathrm{mg}$ ). Dieselbe Beobachtung machten BerRy und KITCHen (1931) bei einem gelbfieberkranken Menschen. Man könnte also in den guanidinartigen Stoffen die möglichen toxischen Substanzen sehen, die zu den gastrointestinalen Blutungen führen.

Theiler (1951) untersuchte den Infektionsablauf und die Gewebsaffinität eines noch nicht modifizierten viscerotropen Virusstammes (F.B.) bei Rhesus-Affen, für welche dieser Stamm relativ apathogen war. Nach i.d. Infektion mit etwa 100 Mäuse- $\mathrm{LD}_{50}$ fanden sich nur in den lokalen Lymphdrüsen Spuren von Virus; alle Organe und das Blut waren virusfrei. Erst am 5. Tag, wenn das Blut einen Virustiter von 1: 50 aufwies, wurde auch in den Organen 
Virus gefunden, und zwar in den Mesenteriallymphknoten mit einem Titer von 1:3200, im Knochenmark 1:760, in den Nebennieren 1: 430, in den Leistendrüsen 1:200, in der Leber 1:160, in der Milz 1: 135 und in den Nieren 1:10. Am 7. Tag war das Virus bereits fast ganz aus dem Blut verschwunden; die Titer in den Organen waren: Knochenmark 1: 720, Nebennieren 1: 500, Leber 1:450, Milz 1:60, Nieren 1:30, Mesenteriallymphknoten 1:32, Leistendrüsen 1:17. Der letzte Affe, der 3 Tage nach Verschwinden des Virus aus dem Blut getötet wurde, hatte nur noch Spuren von Virus in den lokalen Lymphknoten und der Leber, dagegen bereits AK im Blut. Modifiziertes (adaptiertes) neurotropes Virus ergab nach i.d. Infektion ähnliche Resultate: der 1 Tag p. i. getötete Rhesus-Affe wies Virus nur in der Haut an der Impfstelle und den lokalen Lymphknoten auf. Bei einem nach 3 Tagen getöteten Affen fand sich der Erreger in der Haut, den lokalen Lymphknoten, dem Serum, der Milz und den Mesenterialdrüsen, aber nur in den lokalen Lymphknoten in hinreichender Menge, um auf eine Vermehrung hinzuweisen. Der am 5. Tag getötete Affe hatte Virus in mäßiger Menge im Blut und allen Organen. Eine Virusvermehrung fiel in den lokalen Lymphdrüsen, der Milz, Leber, den Nebennieren und Mesenterialdrüsen auf; virusfrei waren dagegen Nieren und Gehirn. TheILer (1951) folgerte aus diesen Versuchen: das i.d. injizierte Virus wird auf den Lymphbahnen in die lokalen Lymphdrüsen gebracht, wo es sich vermehrt; von hier gelangt es wieder in den ganzen Körper und damit auch in die Leber, Nebennieren und andere Lymphdrüsen, wo es sich vermehrt. Der höchste Titer des französischen neurotropen Virus (Dakar) in der Affenleber war allerdings nur 1:20000, während der Asibi-Stamm einen solchen von 1:10 Millionen erreichte.

TigGert u. a. (1960) fanden nach i.p. Infektion von M. mulatta-Affen mit dem Asibi-Virus das meiste Virus in Blut und Leber, aber schon nach 4 Tagen p. i. AK im Blut (KB-AK, HAHAK) und infolgedessen nach 6 Tagen keine Virämie mehr. Mittels der fluorescierenden AKMethode wurde zu dieser Zeit in den Kupfferschen Sternzellen Antigen nachweisbar. Mit dieser Methode ist vielleicht noch vor dem Auftreten histologischer Leberveränderungen eine Gelbfieberdiagnose möglich.

Bearcroft $(1960 \mathrm{~b}, 1962)$ beobachtete, daß die afrikanischen Affen Cercopithecus aethiops tantalus und Erythrocebus patas 2 Tage nach s. c. Infektion mit dem Asibi-Virus eine Virämie bekamen, die 5 Tage anhielt und am 4. Tag ihr Maximum erreichte. In der Leber wurde das Virus vom 2.-3. Tag p. i. mit Maximum am 3.-5. Tag gefunden, am 10. Tag jedoch nicht mehr. Während der Virämie und frühen Leberbeteiligung bestand mildes Fieber.

Die pathologischen Veränderungen des Affengelbfiebers gleichen jenen des Menschen: Ikterus und Blutungen im Magen, in den Lungen, Nieren und anderen Organen. Die Malpighischen Körperchen in der Milz sind klein und wenig ausgeprägt. In den mikroskopischen Leberherden finden sich die polymorphkernigen Leukozyten und Endothelzellen in größerer Zahl als beim Menschen; umgekehrt sind in den Nieren Hyperämie der Glomerulusgefäße weniger ausgeprägt und granuläre, hyaline und Kalk-Zylinder weniger häufig (HINdLe, 1930). Councilmansche Körperchen in den Leberzellen werden offenbar wegen der Schnelligkeit des Verlaufs der Prozesse beim Rhesus-Affen weniger häufig als beim Menschen gefunden (Hudson, 1928b). Kerneinschlüsse sind fast regelmäßig und in großer Zahl in der Leber vorhanden, nach Cowdry und Kitchen (1930) zahlreicher als beim Menschen (s. auch Pettit, 1929). Bugher (1951) hebt die Schwere der pathologischen Veränderungen bei den verschiedenen untersuchten südamerikanischen Affenarten hervor: sie gleichen dem durch das Asibi-Virus hervorgerufenen Gelbfieber mit ausgebreiteter Koagulationsnekrose der Leberzellen und Councilman'schen Körper, gleichmäßigem Befall der Leberläppchen in allen Zonen, starker fettiger Degeneration, gewöhnlich Gelbfärbung. Die Feinstruktur der Councilman'schen Körper in der Leber von Alouatta seniculus seniculus L. wurde von BARUCH (1962) untersucht. Die Nieren weisen ebenfalls starke Degenerationserscheinungen mit anschließender Nekrose des Tubulusepithels, hyalinen und granulierten Zylindern sowie Gelbfärbung auf. Manchmal ist die Milz vergrößert und zeigt Vermehrung der großen Mononukleären.

Durch Leberbiopsie mit dem Roholm-Iversen-Trokar stellte BeARcroft (1957) fest, daß die ersten Leberveränderungen etwa 3-4 Tage p. i. erkennbar werden: Nekrose der Leberzellen vorwiegend der Mittelzone und herdförmige entzündliche Monozytenreaktion; noch keine Kerneinschlüsse. Letztere treten in den 36 St. vor dem Tod auf, in denen auch schnelle 
strahlenförmige Ausbreitung der Nekroseherde erfolgt; mitunter findet man auch unregelmäßige nekrotische Bezirke; in der Umgebung der Portalgebiete und Zentralvenen bestehen Zonen überlebender Zellen. Lymphozyteninfiltrationen treten erst spät im Bindegewebe des Portalgebietes und um größere Lebervenen auf.

Zytochemische Untersuchungen der Leberzellen von BEARCROFT (1960) ergaben als erstes Kernvergrößerung sowie vermehrte RNS-Proteinsynthese im Kern und anschließend im Zytoplasma, wo sie an der Virusproduktion beteiligt sein könnte. Die im Kern stattfindenden degenerativen Veränderungen führten zu Chromatinzerfall und DNS-Ansammlung an der Kernmembran, wobei ein hellgefärbter Hof um das Kernkörperchen hinterlassen wurde. Die präzipitierenden Proteine bildeten die Torres-Einschlüsse, die kein Virus zu enthalten und auch nicht an der Virusvermehrung beteiligt zu sein schienen; sie enthielten Histone, Lipoproteine und verschiedene Aminosäuren, aber weder NS, Kohlenhydrate noch freie Fette. Die Zytoplasmadegeneration bestand in Verlust des Golgi-Apparates, fortschreitender Degeneration der Mitochondrien, schnellem Glykogenverlust, Vermehrung der Neutralfette und schließlich Verlust der RNS. Gleichzeitig wurde das Retikulum des Zytoplasmas feingranuliert oder homogen. Manchmal wurde eine vorübergehende Vakuolisierung des Zytoplasmas, die auf Lipidtröpfchen hinwies, festgestellt (s. auch BEARCROFT, 1962).

Ebenso wie beim Menschen kommt es auch beim Rhesus-Affen mit der Genesung zu einer vollständigen Wiederherstellung des Leber- und Nierengewebes. Nach Kцotz und BetT (1930 a, b, c) weist das Fehlen einer Fibrose in diesen Organen auf eine besondere Widerstandsfähigkeit des Stromagewebes gegen das Virus hin. Es handelt sich beim Gelbfieber im wesentlichen um nichtentzündliche und nichtautolytische Vorgänge, die insbesondere nicht das Bindegewebe während des akuten Krankheitsstadiums befallen. Die Entzündungszellen sind nicht vermehrt. Die schnell vor sich gehende Gewebswiederherstellung geht von den restlichen Parenchyminseln aus. Die normale Leberarchitektur wird schon innerhalb von 14 Tagen $\mathrm{p}$. i. sichtbar. Soweit es zu Gehirnprozessen, insbesondere nach unmittelbarer i.cer. Infektion der Affen kommt, handelt es sich im wesentlichen um eine akute disseminierte Encephalomyelitis mit ausgebreiteten Nekrosen der motorischen und sensorischen Ganglienzellen, in denen auch Kerneinschlüsse gefunden werden (Goodpasture, 1932; Findaly und Stern, 1935a, b; BeARKroft, 1962).

Theiler $(1930 \mathrm{a}, \mathrm{b})$ gelang es, auf Rhesus-Affen adaptiertes Gelbfiebervirus (französischer neurotroper Stamm Dakar), auf Mäuse zu übertragen. Nach i.cer. Injektion von Affenvirus (Blut) erkrankten die Mäuse nach wenigen Tagen an einer charakteristischen tödlichen Encephalitis mit Lähmungen der Extremitäten als Hauptsymptomen (s. auch SAwY ER u. a., 1931, 1932; Dinger, 1931; u. a. m.). Durch fortlaufende i.cer. Weiterverimpfung des Virus von Mäusegehirn zu Mäusegehirn fand eine zunehmende Adaptierung des Affenvirus in der Maus statt, bis ein »Virus fixe« für Mäuse entstanden. war, das sich im Nervengewebe schneller als unmodifiziertes Virus vermehrte. Viscerotrope Eigenschaften für die Mäuse erwarb das Virus jedoch nicht. Das adaptierte Virus hatte seine ursprüngliche Affenpathogenität verloren, denn nach subkutaner Infektion wurden Affen nicht mehr getötet. Es trat nur eine milde oder stumm bleibende Infektion mit dauernder Immunität ein. Später fanden M. Mathis, (1936 b, 1937) und SOPER (1936a) unabhängig voneinander, daß auch unmittelbar vom Menschen (Blut) stammendes Virus Mäuse i.cer. zu infizieren vermag (s. auch Stef.ınopovlo, 1934a; Sellards, 1935; Durieux, 1937).

Fox (1943) beobachtete, daß Mäuse nach Infektion mit virushaltigem Menschenblut nicht immer sterben. Thre Empfänglichkeit ist also für frisch isoliertes unmodifiziertes Virus verschieden. Die einzelnen Virusstämme werden auch verschieden schnell im Mäusegehirn adaptiert; sie lassen sich nach ihrer Gehirnfixierung durch den Grad ihrer Mäusepathogenität unterscheiden (s. auch Collier, 1958). Collier u. a. (1959a) beobachteten, daß auch mit 17 D-Virus infizierte Mäuse Infektiositätsschwankungen der Gehirnpassagen von $10^{\circ}$ bis 10-5,5 zeigten. Coldier und De Wit (1961b) fanden in den Gehirnen infizierter Mäuse »Immunsubstanzen«, welche die Mäusepathogenität des Virus herabsetzten (s. auch CoLlier u. a., 1959).

Durch passagenweise i.cer. Verimpfung von 17D-Kulturvirus (aus dem Asibi-Virus entwickelter Kulturstamm) auf Mäuse erfährt die Überlebenszeit der Tiere eine Verkürzung von etwa 11 Tagen in den ersten Passagen auf 7 Tage in den 11.-20. Passagen und auf 6,5 Tage in 
den 47.-65. Passagen. Die Virulenz des mäuseadaptierten 17D-Virus scheint zwischen jener des 17D- und des neurotropen Asibi-Virus zu liegen (Collier u. a., 1959a).

Zwischen den einzelnen Mäusestämmen bestehen aber auch Empfänglichkeitsunterschiede (Sawyer und Lloyd, 1931). Nach Lynch und Hughes (1936) spielen Erbfaktoren hierbei eine Rolle. SabiN (1952b) fand den Mäusestamm "Swiss" (Schweiz) 100\%ig empfänglich für i.cer. injiziertes $17 \mathrm{D}$-Kulturvirus, den PRI-Stamm dagegen vollständig unempfänglich. Die Empfänglichkeit der Tiere scheint auf den Eigenschaften eines einzigen Gens zu beruhen. Während die $\mathrm{F}_{1}$-Generation vollständig unempfänglich war, zeigte die $\mathrm{F}_{2}$-Generation eine Sterblichkeit von etwa $25 \%$ und die Rückkreuzung $\mathrm{F}_{1} \times \mathrm{S}$ eine solche von $50 \%$. Nach Goodman und Koprowski (1962) ergaben Untersuchungen des Mechanismus, der das Gen für die Resistenz gegen Gelbfiebervirus in 2 Mäuseinzuchtstämmen bestimmt, daß das Vererbungsmuster, welches den Resistenzcharakter anzeigt, dominant, infektorisch und autosomal ist. Das Abwehrsystem, das zur Resistenz gegen Arbor-B-Virusinfektionen führt, scheint auf der Zellebene in einem als Makrophagen bezeichneten Zelltyp ausgedrückt zu sein. Diese Zellen sind offenbar der Ausdruck des dominanten Gens für die Virusresistenz in resistenten Mäusen, während die regressive Allele ihren Ausdruck in morphologisch ähnlichen Zellen findet, die in empfänglichen Mäusen die Virusvermehrung unterstützen und die Virusinfektion erleichtern.

Bates und Roca Garcia $(1945,1946)$ fanden, daß neugeborene Mäuse sich leichter i.cer. mit verschiedenen Virusstämmen infizieren lassen. SABIN (1952b) stellte fest, daß Mäusesäuglinge des PRI-Stammes nach i.cer. Infektion tödlich erkranken, während 3-4 Wochen alte Tiere bereits unempfänglich sind, obwohl auch bei ihnen Virusvermehrung stattfindet.

Die Gehirne der an Gelbfieberencephalitis gestorbenen Mäuse weisen ein charakteristisches Bild auf: man findet neben perivaskulären Rundzelleninfiltrationen azidophile Kernveränderungen in den Ganglienzellen. Diese können verschiedenste Größe haben und von einer Granulaform beginnend unter Verdrängung von Kernkörperchen und Kernchromatin größere Schollen bilden, um schließlich als amorphe Massen sogar den ganzen Kern auszufüllen. Es ist nicht immer ganz leicht, zu unterscheiden, wann es sich bei diesen azidophilen Körperchen schon um pathologische Gebilde handelt oder wann sie noch als normal zu gelten haben, denn schon im normalen Zustand findet man in den Kernen der Nervenzellen einen gewissen Gehalt an azidophilem Material. Hier dürften aber die besondere Anordnung und der Umfang der Gebilde den Ausschlag geben. Findlay und Stern (1935a) beschrieben 2 Arten von Kerneinschlüssen: die einen sind verhältnismäßig groß und kommen nur spärlich vor, die anderen sind verschieden in Form und Größe sowie auch zahlreicher (s. auch LAIGRET, 1933c; NicolaU u. a., 1934b, c, d, e; Stefanopoulo, 1934b).

21 Tage alte Mäuse sind für eine i.n. Infektion mit dem französischen neurotropen (Dakar), dem Asibi- und dem 17D-Virus empfänglich: die Tiere starben an einer Encephalitis oder erwarben Immunität (Linhares, 1943a). Instillation dieser Virusstämme in den Gehörgang führte ebenfalls zu Infektion und Immunität. Eine Infektion durch Skarifikation der Kornea war möglich, nicht aber durch die intakte Kornea (s. auch Theiler, 1930a; Findlay und Clarke, 1935a). Auch durch Einführung des Virus in den Magen gelang eine Infektion, die entweder zu einer tödlichen Encephalitis oder Immunität führte. Schließlich konnte LinHARES (1943a) sogar durch einfache Aufbringung von Virus auf die intakte oder skarifizierte Haut bei 6 Tage alten Mäusen eine Infektion erzeugen. Lennetrte und Koprowski (1946) stellten Pathogenität des ursprünglichen Asibi-Virus-Stammes, nicht aber des 17D-Kulturvirus für Mäusesäuglinge nach s.c. Infektion fèst. Nach TheILeR (1930a) lassen sich weniger als 2 Wochen alte Mäuse auch s.c. und i.p. infizieren. I.p. injiziertes Asibi-Virus führt nach 2 tägiger visceraler Vermehrung bei kleinen Mäusen zum Auftreten von Virus im Gehirn, nicht dagegen in Leber, Nieren und Blut. Nach direkter i.cer. Infektion tritt das Virus 1 Tag früher auf und die Tiere sterben auch 1 Tag früher. Es wird angenommen, daß das Virus nach visceraler Vermehrung von der Peripherie her durch anschließende Vermehrung in den Blutkapillaren im ZNS das Gehirn erreicht. Findlay und MAHAFFy (1936) wiesen nach i.p. Infektion von Mäusesäuglingen das Virus auch im Blut nach. Sie glauben, daß es mit letzterem in die Nasenschleimhaut und von dieser dann auf den Nervenbahnen (N. olfactorius) ins Gehirn gelangt. Denn durch Verätzung mit Pikrinsäure wird die Nasenschleimhaut so weit für das Virus undurchdringlich, daß es nicht mehr über diesen Weg in das ZNS zu gelangen ver- 
mag. Mit zunehmendem Alter nimmt die Empfänglichkeit der Mäuse für eine i.p. Infektion ab (Whitman, 1943). I.p. zugeführte Virusmengen erzeugen bei erwachsenen Mäusen nur eine Encephalitis, wenn im Gehirn künstlich ein Trauma, z. B. durch i.cer. Injektion einer hämorrhagieerzeugenden Substanz gesetzt wird (Sawy er und Lloyd, 1931). Das Gelbfiebervirus läßt sich passagenweise im Mäusehoden züchten (Lloyd und Mahaffy, 1933; Lloyd u. a., 1936; H. H. Sмгтн, 1938). I.v. zugeführtes Virus verschwindet sehr schnell aus dem Blutstrom erwachsener Mäuse (Mıms, 1957b). Bugher (1941) fand, daß Mäusesäuglinge sich durch den Biß von A.aegypti mit dem neurotropen Dakar-Stamm infizieren lassen (s. auch Davis u. a., 1932).

Ionisierende Strahlen (75-500r) heben die natürliche Resistenz der Mäuse gegen Gelbfiebervirus bei i.p., i.cer. und i.v. Impfung auf. Bestrahlung 3-7 und 12 Tage vor der i.cer. Infektion steigert dagegen die Empfänglichkeit nicht, verkürzt aber die Inkubationszeit und führt zu schwerem klinischem Verlauf (SKLjamkaja, 1957).

Nach D. J. BAUER (1947) kommt es bei i.cer. mit dem 17 D-Virus infizierten Mäusen zu einem Anstieg der Xanthin-Oxydase-Reaktivität des Gehirns, die bei Einsetzen der Symptome um das 7 fache der Norm gestiegen war. BAuer und Bradley (1956) vermuteten, daß der Xanthin-Oxydase-Anstieg eine allgemeine Erscheinung bei der Virusvermehrung ist. Sie stellten ihn bei 47 verschiedenen neurotropen Viren fest (s. auch BAUER und BRADLEY, 1959).

Nach BAUer (1951) ist die Aktivität verschiedener Enzyme, die an dem NS-Stoffwechsel beteiligt sind, im infizierten Mäusegehirn gest eigert.

Die Entdeckung der Empfänglichkeit der Mäuse für Gelbfieber ist von größter praktischer Bedeutung geworden. Sie ermöglichte nämlich die Ausarbeitung von Laboratoriumsmethoden, zum Nachweis überstandenen Gelbfiebers (Schutzprobe und Bestimmung des Gehaltes an $\mathrm{N}-\mathrm{AK}$ ). Infolge seiner verhältnismäßig geringen Menschenpathogenität konnte das Mäusevirus außerdem zur Herstellung von Impfstoffen verwandt werden.

Bemerkenswert erscheint die hohe Affinität des Gelbfiebervirus für Geschwulstzellen, die später auch bei anderen Virusarten festgestellt werden konnte. Findlay und Maccallum (1937c) sahen bei der Züchtung eines neurotropen Virus durch Passagen im Mäusekarzinom 63 keine Pathogenitätsveränderung auftreten. Ein zuvor in Gewebekulturen abgeschwächtes Virus erfuhr durch 60 »Krebspassagen« in vivo eine leichte Zunahme seines Neurotropismus. Ein unmodifizierter französischer Virusstamm zeigte nach 65 Krebspassagen eine erhebliche Abschwächung seiner Pathogenität für Affen und Igel. Beide Tierarten wurden nicht mehr getötet. Es trat keine Zunahme des Neurotropismus auf. In dem transplantablen Mäusesarkom 37 konnte keine Vermehrung des Gelbfiebervirus erzielt werden. Es übte eine nekrotisierende Wirkung auf das Sarkomgewebe aus, ohne daß $B$ aber charakteristische zytologische Veränderungen entstanden. Nach i.p. und s.c. Infektion der Mäuse hielt sich das Virus im Tumorgewebe noch lange Zeit nach Aufhören der Virämie. Koprowski und NorTon (1950) fanden das Virus ohne Wirkung auf 5 verschiedene übertragbare Mäusetumoren. ColLIER und DE WIт $(1959,1961)$ züchteten den 17D-Stamm in vivo in der Ascitesflüssigkeit des Krebs-2Mäuseascitescarcinoms über 1 Jahr lang, wobei es im Verlauf von mehr als 39 i.p. Passagen zu einer Abschwächung des Virus kam, die im i.cer. Mäusetest ihren Ausdruck fand. Collier und DE WIT (1959b) sahen, daß nach Adsorption des Asibi-Virus an die Asciteszellen in vitro die Flüssigkeit einen stärkeren Titerabfall erfuhr, während in den Zellen nach anfänglichem Titerverlust nach 24 St. ein Anstieg von 2,5 log auf 3,7 log stattfand. Die immunisierende Eigenschaft schien aber unverändert geblieben zu sein. Ähnliche Beobachtungen wurden mit dem neurotropen Asibi-Stamm gemacht (s. auch Moore, 1954).

Die in Nordafrika wild vorkommenden grauen Mäuse (Mus musculus, M.gentilis und M. musculus azoricus) sind Gelbfieber-empfänglich. Während die beiden ersten Arten nur nach i.cer. Infektion starben, erkrankte M.musculus azoricus auch nach i.p. Infektion an einer tödlichen Encephalitis (Laigret, 1933c; s. auch Stefanopoulo, 1934b; Mathis, 1936a). Die Wühlmaus (Microtus agrestis, Findlay, 1934a) und die südnigerische Spitzmaus (Croccidua manni,S. C. Sмттн, 1936) starben nach Infektion mit neurotropem Virus ebenfalls an Encephalitis.

Meerschweinchen erkranken nach i.cer. Infektion mit neurotropem Mäusevirus in 100\% an einer charakteristischen Encephalitis (Sawyer und Frobisher, 1930; Dinger u. a., 1930, 
1931; Dinger, 1931; Lloyd u. a., 1933; Stefanopoulo und Wassermann, 1933; Stefanopoulo, 1934b; Nicolau u. a., 1934b, c). Eine Verkürzung der Inkubationszeit im Verlauf der Meerschweinchenpassage findet nicht statt. Sie schwankt zwischen 4 und 14 Tagen. Das Krankheitsbild entspricht etwa jenem der Mäuse: schnell fortschreitende Paralyse der Gliedmaßen, welche in 1-2 Tagen zum Tode führt (s. auch Nicolau u. a., 1934f, 1936). Nach TheIler (1951) ändert das durch eine große Zahl von Meerschweinchengehirnpassagen gezüchtete Virus seine Mäusepathogenität nicht. Das Virus fixe für Mäuse scheint auch ein solches für Meerschweinchen zu sein. Theiler nimmt auch für das Meerschweinchen an, daß das Virus nach i.cer. Injektion zentrifugal im Nervengewebe wandert, wobei das Blut allerdings keine Rolle spielen soll. Die Virusverteilung in den Meerschweinchenorganen entspricht etwa jener bei der Maus: Gehirn, Rückenmark, N.ischiadicus. Das Virus fehlt dagegen in Leber, Milz, Nebenniere und Blut. Es breitet sich aber im Nervengewebe des Meerschweinchens viel langsamer als in jenem der Mäuse aus. Die Meerschweinchenencephalitis ist ein oft nur auf kleine Gefäßgebiete beschränkter Prozeß. Ausgedehnte Nekrosen des Hippokampus wie bei der Maus werden nicht gefunden. Im wesentlichen beschränken sie sich auf perivaskuläre Infiltrationen mononukleärer Leukozyten, während z. B. die bei der Maus so auffallenden azidophilen Kernveränderungen (Einschlüsse) der Ganglienzellen bei den Meerschweinchen im allgemeinen fehlen (s. auch Theiler, 1933a). Mathis (1948) weist allerdings auf "Gelbfiebereinschlüsse» in den Neuronen, Gliazellen und Gefäßendothelien hin. Er fand die pathologischen Veränderungen im ZNS dieser Tiere nicht nur auf das Gehirn beschränkt, sondern auch im Rückenmark, so daß man eher von einer EM sprechen sollte (s. auch FindLAY und Stern, 1935a). Mit noch nicht auf Mäusegehirn adaptiertem Virus (z. B. Affenvirus) bekommen die Meerschweinchen keine ausgesprochenen cerebralen Erscheinungen; sie bilden aber N-AK. Fortlaufende Meerschweinchenpassagen von nichtmodifiziertem Virus gelingen nicht. Der Asibi-Stamm ließ sich erst nach 45 Mäusegehirnpassagen auf Meerschweinchen weiterzüchten.

Stefanopoulo und Duvolon (1947b) fanden, daß das abgeschwächte 17D-Virus nach i.cer. Infektion etwa $40 \%$ der Meerschweinchen tötet. Tiere unter $350 \mathrm{~g}$ Gewicht waren empfänglicher als schwerere. Durch 10 vorausgegangene Mäusegehirnpassagen und folgende 7-16 Hühnerembryopassagen fand keine Pathogenitätszunahme für die Meerschweinchen statt. Es wurden nicht nur tödliche Erkrankungen, sondern auch solche mit Lähmungen, die wieder zurückgingen, sowie latent bleibende Infektionen gesehen. Die histologischen Gehirnveränderungen, die das 17D-Virus erzeugte, entsprachen etwa jenen des neurotropen Virusstammes, der aber eine größere Pathogenität hat und die Meerschweinchen in 100\% tötet. Diese Tiere scheinen demnach zur Feststellung etwaiger neurotroper Komponenten des 17D-Impfstoffes geeignet zu sein.

Dinger u. a. (1930, 1931), Sellards (1930) sowie Sawyer und Frobisher (1930) erzielten auch nach i.p. Infektion eine Erkrankung der Meerschweinchen, die mit Peritonitis oder Hämorrhagien im Magen und in der Lunge verlief. TheiLer (1951) bezweifelt allerdings, daß es sich bei den beobachteten Erkrankungen um Gelbfieber gehandelt hat. Er konnte mit dem aus dem Asibi-Virus entwickelten 17D-Kulturstamm bei Meerschweinchen nach i.p. Infektion keine Erkrankung erzeugen, wohl aber eine Immunität, die allerdings mit zunehmender Passagenzahl abnahm, was auf eine weitgehende Modifizierung des Asibi-Virus im Verlauf der Zü̈chtung schließen läßt. Auch Borron und Camain $(1957,1958)$ erzielten nach i.p. und s.c. Infektion von Meerschweinchen mit großen Mengen eines neurotropen Gelbfiebervirusstammes keine Krankheitserscheinungen. Virus im Blut und in Organen sowie AK-Bildung wurden nachgewiesen. Es hat also eine inapparente Infektion stattgefunden.

Eine Hodeninfektion der Meerschweinchen mit Mäusevirus scheint möglich zu sein. FonseCA (1938b) konnte noch 43 Tage p. i. Virus im Hodengewebe nachweisen.

Eine Immunisierung von Meerschweinchen mit neurotropem Virus und 17D-Kulturvirus durch Skarifikation der Haut ist von FAvEReL (1945) angegeben worden.

Wilde Meerschweinchen (Cavia anolaima und aperea) zeigten sich ebenfalls empfänglich (Bugher u. a., 1944; Laemmert, 1948).

Der gewöhnliche europäische Igel (Erinaceus europaeus) ist für eine experimentelle Gelbfieberinfektion besonders empfänglich (Findlay und Clarke, 1935b, c). Findlay u. a. (1935) 
fanden auch den sudanesischen Igel (E.pruni = Atelerix albiventris) empfänglich E. C. SмIтн (1936) fanden denselben Igel, aber nordnigerischer Herkunft, hochempfänglich für eine i.cer. Infektion mit neurotropem Virus, während Findlay und MAHAFFy (1936) bei dem nordnigerischen Igel im Gegensatz zu dem aus dem Sudan stammenden eine erhebliche Resistenz gegen diesen Virusstamm fanden. Neurotropes Virus tötet empfängliche Igel nicht nur nach i.cer., sondern auch nach i.p. und s.c. Infektion. Es führt zu herdförmigen Lebernekrosen. Man findet es in größerer Menge im Gehirn, ferner in der Leber, Milz und den Nieren in geringerer Menge, im Blut dagegen nur selten. Der viscerotrope Asibi-Stamm führt nach s.c. oder i.p. Einspritzung nach 4-7 Tagen zum Tod. Die pathologisch-histologischen Organveränderungen entsprechen etwa jenen bei Affen. E. C. Sмттн (1936) beschrieb folgende histologischen Veränderungen beim Igel: fettige Degeneration, Pigmentierung der Kupfferschen Sternzellen, diffuse Infiltration des Lebergewebes mit Lymphozyten besonders unter der GuIsonschen Kapsel, später Lebernekrose, Councilmansche Körperchen und Hyperchromasie der Kerne. Giemsa-Färbung ergab feine azidophile Granulierung des Parenchyms. Das Virus fand sich im Blut, in der Leber, den Nieren, der Milz und im Gehirn. Die Affenpathogenität des viscerotropen Virus ging durch Igelpassagen nicht verloren.

Bei Ratten wurde von Findlay und Howard (1951) eine erhebliche Empfänglichkeit für das neurotrope Virus und das 17D -Virus festgestellt; nach i.cer. Infektion starben die jungen Tiere regelmäßig an einer EM. Je älter die Ratten wurden, desto langsamer verlief die Krankheit. Mehr als 20 Tage alte Tiere erkrankten nicht. Eine i.p. Infektion blieb auch bei jungen Ratten symptomlos.

Nach Bates und WeIr (1944) sterben i.cer. mit neurotropem Virus infizierte kolumbianische Schilfrohrratten (Zygodontomys microtinus $=$ stella) an Encephalomyelitis.

Bei Untersuchungen über die Virusreservoire des Busch- oder Dschungelgelbfiebers spielen die Beutelratten (Familie der Didelphidae) eine wichtige Rolle. Meist handelt es sich um Opossumarten. BUGHER u. a. (1941, 1944) prüften Didelphis marsupialis (gemeines Opossum), Didelphis paraguayensis (gemeines Weißohropossum), Metachirus opossum (Graumaskenopossum), M.nudicaudatus (Braunmaskenopossum), Caluromys philander (Wollopossum), Marmosa (Rattenopossum = M. cinerea und M.incana). Zwischen den einzelnen Arten bestehen offenbar Empfänglichkeitsunterschiede, die auch gegen die jeweils verwandten Virusstämme gerichtet sind. Nach s.c. Infektion mit kleinen Virusmengen wurden bei einem Teil der Tiere Virämie und immer AK-Bildung festgestellt. (Bates, 1944b; Bates und Roca Garcia, 1946 a; Laemmert u. a., 1946; Laemmert, 1946; Taylor und Fonseca da Cunha, 1946; Anderson und Roca Garcia, 1947; Waddell und Taylor, 1948; Bugher, 1951).

Außerdem wurden folgende in Südamerika vorkommenden wilden Nagetiere empfänglich gefunden: Hydrochoerus capybara, Proechimys chrysaeolus und P.cayennensis (BugHer u. a., 1944; LaEMmert, 1948). Es handelt sich hier um Rattenarten.

Kaninchen scheinen nur eine geringe Empfänglichkeit für den Gelbfiebererreger zu haben, da weder viscerotropes noch neurotropes Virus zu Krankheitserscheinungen führen. Eine Virusvermehrung in den Organen ist mit Sicherheit nicht nachzuweisen; es kommt aber zu einer vorübergehenden Bildung von N-AK (SAWY ER und Frobisher, 1930; Findlay, 1934a; Whitman, 1935). Empfänglich zeigen sich die wilden südamerikanischen Kaninchen (Cuniculus paca). In ihnen kreist das Virus bis zu 9 Tagen im Blut; es werden N-AK gebildet (BugheR u. a., 1944; Laemmert, 1948).

Nach i.cer. Infektion mit neurotropem Virus starben an einer Encephalitis das Steißtier (Agouti = Dasyprocta agouti) (Lloyd u. a., 1933; Bugher, 1951), das Eichhörnchen (Sciurus vulgaris) und der brasilianische Nager Ctemomys (DA FonseCA, 1938a).

Kumm (1932) sowie Hughes und Perlowagora (1948) versuchten F'ledermäuse durch Biß infektiöser A. aegypti zu infizieren. Virämie wurde nicht festgestellt. Die bei 254 Tieren ausgeführte NR blieb negativ. Nach RodHAin (1936) soll die Fledermausart Epomorphorus wahlbergi haldemani jedoch nach i.cer. Infektion mit neurotropem Virus an Encephalitis mit Virämie erkranken.

Whitman (zit. Bugher, 1951) sowie Bugher u. a. (1941) untersuchten die Empfänglichkeit verschiedener Angehöriger der Ordnung Edentata: brasilianische Gürteltiere (Dasypus novemcinctus und D.kappleri), südamerikanische Ameisenbären (Tamandua tetradactyla und 
Mymcophaga tridactyla) sowie das Faultier (Choloepus didactylus). Nach s.c. Infektion wurde das Gelbfiebervirus zum Teil mehrere Tage nachgewiesen; später traten N-AK auf. Unter den Fleischfressern, die im allgemeinen als resistent gegen alle Gelbfiebervirusstämme gelten, führt Bugher (1951) als Ausnahme den kleinen indianischen Wickelbären (Kinkajou = Potos flavus) an; er läßt sich leicht infizieren und weist oft mehrere Tage im Blut einen Virustiter von $10^{-2}$ bis $10^{-3}$ sowie später eine ausgesprochene Immunität mit reichlichen AK auf.

Nach Linhares (1943b) lassen sich Katzen i.cer. und i.p. infizieren. Sie erkrankten zwar nicht manifest, ergaben aber Immunitätsreaktionen.

Bei Untersuchungen über die Empfänglichkeit afrikanischer Wildtiere fand Dick (1952 b), daß bei experimentell infizierten Ginsterkatzen und Zibetkatzen Virämie und vorübergehende AK auftreten.

Das Pferd reagiert auf eine Gelbfieberinfektion nur mit Bildung von N-AK (Pеттiт u. a., 1928a), ohne zu erkranken.

Stefanopoulo u. a. (1934) beobachteten beim Schwein nach i.cer. Infektion Zeichen einer EM, welche nach 7 Tagen zum Tode führte und histologisch bestätigt werden konnte. BugHER u. a. (1941) infizierten junge Hausschweine und Nabelschweine (Tagassu tajacu und T.pecari) mit Asibi-Virus; in ihrem Blut wurden Virus und später N-AK nachweisbar.

Nach Stefanopoulo und Nagano (1937) verhalten sich folgende Tiere gegen Gelbfieberinfektionen refraktär: Zieselmaus (Citellus citellus), Goldhamster (Cricetus auratus), Frettchen (Putorius faetidus) und der Fuchs (Vulpes vulpes) nach i.cer. und i.p. Injektion von viscerotropem und neurotropem Virus, die Gazelle (Cephalopus leucogaster und C.nigrifrons) nach s.c. Injektion von viscerotropem Virus.

Erwachsene Hühner reagieren auf eine Infektion mit großen Mengen von Asibi-Virus mit der Bildung von AK (SAWYER und Frobisher, 1930). Geschlüpfte Küken sind i.cer., i.p. und i.d. mit dem französischen neurotropen Dakar-Stamm und dem Asibi-Virus infizierbar; sie erkranken zwar nicht, aber das Virus kreist im Blut und führt zur Bildung von AK. Die größte Virusmenge im Blut findet man bei 1-tägigen Küken. Linhares (1943d) gelangen 60. Passagen. Die AK traten 10-11 Tage p. i. auf, d. h. zu einer Zeit, wenn noch Virus im Gehirn vorhanden ist. LaEmmert und Moussatché (1943) züchteten den Asibi-Stamm durch 102 Kükenpassagen, ohne daß die Tiere sichtbar erkrankten. Der Erreger war in den Gehirnen bis zu 14 Tage nachweisbar; bei den meisten Küken bestand Virämie zwischen dem 1. und 6. Tage; AK-Bildung fand statt. Im Verlauf der Gehirnpassagen erfolgte eine Modifikation des Virus; es verlor seine Fähigkeit, Affen durch visceralen Befall zu töten, behielt aber im wesentlichen seine Mäusepathogenität und seinen Encephalotropismus für Affen.

Eine große Anzahl von Kaltblüterarten wurde von verschiedenen Autoren auf ihre Empfänglichkeit für den Gelbfiebererreger untersucht: Frösche und Kröten (Sawy er, 1931b), Frösche, Kröten, Eidechsen, Schlangen, Schildkröten (Bugher u. a., 1941), Leguane, Eidechsen, Schildkröten, Boa constrictor, Kröten und Frösche Südamerikas (LaEmmert, 1943, 1944, 1946, 1948), Frösche, Eidechsen, Schlangen, Schildkröten (Sмiтнвurn u. a., 1951). Eine Infektion scheint in keinem Fall gelungen zu sein.

Die Entscheidung, welche Tierarten unter natürlichen Bedingungen gelbfieberempfänglich sind und damit u. U. als Virusreservoire in Frage kommen, ist auf Grund der Laboratoriumsinfektionsversuche allein nicht möglich. Letztere haben aber gezeigt, daß eine große Anzahl von Tierarten passagenweise Virusübertragungen gestattet, was wiederum auf eine erhebliche Virusvermehrung in den betreffenden Wirten schließen läßt, sowie daß es während einer Phase des Infektionsablaufs auch zu einer Virämie kommt.

\section{2-2. Verhalten der viscerotropen (pantropen) und neurotropen Virusstämme; Interferenz.}

Bei den Gelbfiebervirusstämmen lassen sich 2 Formen unterscheiden, die viscerotropen und neurotropen Stämme.

Man hat versucht, die Bezeichnung "viscertropes« Virus aufzugeben und mehr von einem "natürlichen" oder "pantropen" Virus zu sprechen. Wie die Untersuchungen von PenNa (1936) sowie Findlay und Stern (1935b) ergeben haben, hat das natürliche Virus nämlich zwar eine überwiegende Affinität für die mesodermalen und entodermalen Organe, aber 
trotzdem auch noch eine solche für das Ektoderm (Gehirn). Die neurotrope Komponente ist allerdings durch die übrigen Komponenten zunächst unterdrückt und kommt erst durch unmittelbare Übertragung in das Gehirn zur Geltung, indem dafür die viscerotropen Anteile mehr und mehr zurücktreten und erst durch geeignete Versuchsanordnung wieder zur Manifestation gebracht werden können. Findlay und Clarke (1935a, d) nahmen an, daß die beiden Extreme, die viscerotropen und die sogenannten fixen neurotropen Stämme eine Reihe von Zwischenformen bilden, bei denen entweder die viscerotrope oder die neurotrope Komponente je nach der Tierart und den Geweben, in welche sie verimpft werden, dominieren. LLoyD u. a. (1933) beobachteten, daß das sogenannte Virus fixe im Verlauf zunehmender Mäusegehirnpassagen eine Steigerung seines Neurotropismus erfuhr. Die Virus fixe-Natur des neurotropen Virus geht auch aus den Beobachtungen hervor, daß das Virus durch Mückenpassagen nicht wieder in ein viscerotropes Virus zurückverwandelt werden kann (DAvis u. a., 1932; Roubaud und Stefanopoulo, 1933). Das neurotrope Mäusevirus ist aber nur für die Maus ein Virus fixe, denn Findlay und Clarke (1935a, d) fanden, daß es nach unmittelbarer Einspritzung des Mäusegehirns in die Leber von Rhesus-Affen in dieser zu Veränderungen führt, wie sie mit dem viscerotropen Virus erzeugt werden. Nach anschließender s.c. Verimpfung dieses auf Affenleber gebrachten neurotropen Virus erkranken die Affen wieder an typischem Gelbfieber mit den bekannten Veränderungen in Leber, Nieren, Herz und Magen. In der Folge verhält sich das "rekonvertierte" Virus wie ein typisches viscerotropes Virus bei Affen, Mäusen und Igeln. Nach abermaliger Rückverimpfung auf Mäusegehirne geht der wiedererlangte Viscerotropismus erneut verloren und es entwickelt sich wieder das neurotrope Virus fixe.

Hoskins (1935) beobachtete, daß die meisten Rhesus-Affen, die gleichzeitig parenteral mit dem viscerotropen unmodifizierten Asibi-Stamm und dem französischen neurotropen Dakar-Stamm infiziert wurden, am Leben blieben. Das neurotrope Virus übte eine deutliche Schutzwirkung gegen das viscerotrope Virus aus. Diese blieb noch erkennbar, wenn ersteres 24 St. nach dem Asibi-Virus injiziert wurde, fehlte aber, wenn das Intervall 48 St. betrug, was der kurzen Inkubation des Asibi-Virus entspricht. Findlay und Maccallum (1937b) bestätigten diese Beobachtungen, sahen aber, daß Affen nach i.cer. Infektion mit einem Gemisch beider Viren nicht an Lebernekrose, sondern an Encephalitis starben. Dieses weist darauf hin, daß im ZNS keine Interferenz stattfindet. Auch im Mäusegehirn ergab sich keine Interferenz zwischen dem viscerotropen und neurotropen Virus. Igel, die mit einem Gemisch beider Virusstämme infiziert worden waren, erwiesen sich gegen das viscerotrope Virus geschützt; sie starben an einer Encephalitis. Die Lebernekrose war nur gering. Virus im Blut fehlte. Nach TheILERs Ansicht (1951) fallen bei der Erklärung der Interferenz 2 Faktoren auf: 1. beide Virusstämme müssen im richtigen Verhältnis, und zwar das neurotrope in viel gröBerer Menge als das viscerotrope Virus injiziert werden; 2. beide Viren vermehren sich in den Leberzellen, wobei das neurotrope Virus allerdings keine Lebernekrose erzeugt. Der Interferenzvorgang selbst scheint in der Verhütung des Befalls einer hinreichend großen Zahl von Leberzellen zu bestehen, um das Tier gegen Lebernekrose und Tod zu schützen. Theiler nimmt an, daß der Virusstamm, der die Zelle zuerst erreicht, diese vor dem Befall mit dem anderen Virus bewahrt, $d . h$. eine Leberzelle, in die bereits neurotropes Virus gelangt ist, ist gegen die Infektion mit einem viscerotropen Virusteilchen geschützt. Werden mehrere Leberzellen jeweils nur mit dem einen Virusstamm infiziert, der sich in ihnen vermehrt und dann von ihnen nach einer gewissen Zeit wieder abgegeben wird, so kommt es zu einem ununterbrochenen Wettkampf zwischen beiden Viren. Vermag das neurotrope Virus genügend Leberzellen zu schützen, bis der Immunisierungsvorgang einsetzt, und bleiben die Tiere dann am Leben, so soll dies auf die stattgefundene Interferenz zurückzuführen sein. Hierfür spricht auch, daß zwischen dem 17D-Kulturvirus und dem Asibi-Virus im Rhesus-Affen keine Interferenz stattfindet, denn infolge des Verlusts eines großen Teils seiner Infektiosität für Leberzellen und seines Vermehrungsvermögens in diesen kommt das 17D-Virus in der Affenleber nur in minimalen Mengen vor. Immunitätsvorgänge spielen für die Interferenz keine Rolle. FindLAY und Maccallum (1937b) konnten zeigen, daß eine Interferenz zwischen Gelbfieber- und Rifttal-Fieber-Virus stattfindet. TheiLer (1951) wies Interferenz auch zwischen Gelbfieberund Dengue-Virus am Affen nach. 
Nicht nur im Tier, sondern auch in der Gewebekultur kommt es zu Interferenzvorgängen zwischen Gelbfieber- und anderen Viren. Nach DонеRту (1958) weisen mit 17D-Kulturvirus infizierte menschliche Appendixzellen eine vollständige Resistenz gegen den ZE des WNVirus auf. Die mit 17D-Virus infizierten Appendixzellkulturen, welche mit großen Dosen WN-Virus nachinfiziert wurden, gaben dann letzteres in die Flüssigkeit ab, wobei der 17DTiter abnahm. Mit 17D-Virus infizierte Kulturen wiesen außerdem eine teilweise Resistenz gegen Herpes-, Polio 1- und 3-Viren, aber keine solche gegen Vaccinia-Virus auf.

In Hühnerembryo- und Kaninchenzellkulturen gewonnenes Interferon hemmte die Plaquebildung in Gelbfieber-infizierten Hühnerembryo-Einschichtzellkulturen, wobei Hemmungszonen von 2-3 mm Durchmesser mit unscharfen Grenzen gegen das Gebiet normaler Plaques entstanden (Porterfield, 1959 d). Das Interferon hemmte auch, wenn es erst 18-24 St. p. i. den Kulturen zugesetzt wurde.

\section{2-3. Züchtungsversuche}

Die Kultivierung des Gelbfiebervirus gelang erstmalig HaAgen (1933a, 1934, 1937, s. auch HaAgen und Theiler, $1932 \mathrm{a}, \mathrm{b}$ ).

Bei der Züchtung des neurotropen Mäusevirus (Stamm Dakar) erzielte HaAGen die besten Ergebnisse in einem flüssigen Nährmedium, das aus $10 \mathrm{fach}$ mit Tyrode-Lösung verdünntem Affenserum und einer geringen Menge frischen zerkleinerten Hühnerembryogewebes bestand und ein $\mathrm{p}_{\mathrm{H}}$ von 7,6 hatte. Auf diese Weise gelang eine Kultivierung durch mehr als 100 Passagen ohne Veränderung der Pathogenität oder anderer Eigenschaften des Ausgangsvirus. Nach i.cer. Injektion des Kulturvirus starben die Mäuse in 100\% nach etwa 6 Tagen. Nach Einspritzung des Kulturvirus in den Vorderteil einer Großhirnhälfte erkrankten Affen an typischer Gelbfieberencephalitis. Das Kulturvirus ließ sich nach Trocknung in gefrorenem Zustand eingeschmolzen mindestens $1 / 2 \quad \mathrm{Jahr}$ ohne Virulenzverlust aufheben. Lloyd u. a. (1936) setzten diese Versuche fort und züchteten einen weiteren Stamm (305. Mäusegehirnpassage) in Gesamthühnerembryogewebe durch 46 Subkulturen und dann durch weitere 27 Passagen in Gesamtembryo ohne Gehirn und Rückenmark. Es ergab sich kein Unterschied zwischen beiden Kulturstämmen in ihrer Mäusepathogenität. Auch bei Züchtung des Dakar-Stammes (305. Mäusegehirnpassage) durch 55 Gewebekulturpassagen in Gesamtmäuseembryo in Serum-Tyrode-Lösung trat keine Modifizierung dieses neurotropen Virusstammes bezüglich seiner Mäusepathogenität ein. Lloyd u. a. (1936) gelang es, auch das unmodifizierte Asibi-Virus zunächst durch 150 Passagen in vitro zu züchten. Da dieser Stamm nicht in Gegenwart von Hühnerembryogewebe angezüchtet werden konnte, diente hierzu zunächst Mäuseembryogewebe. Nach 3jähriger Kultivierung durch 240 Passagen mit 10\% Affenserum-Tyrode-Lösung erhielt der Stamm die Bezeichnung "17 E " (Theiler und Smith, 1937). Während der Züchtung trat ein Verlust des Viscerotropismus für Affen ein, während der Neurotropismus unverändert blieb. Aus dem 17E-Stamm wurde nach 27 Subkulturen in zerkleinertem Mäusehoden der Stamm "17 AT erhalten. Im Verlauf der Passagen im Mäusehodengewebe wurde der Neurotropismus erheblich geringer als der des Asibi-Elternstammes. Nach 70 Subkulturen in Mäusehoden gelang auch eine Kultivierung in Meerschweinchenhoden.

Nachdem das Asibi-Virus durch 18 Passagen in Gegenwart von Mäuseembryogewebe gezüchtet worden war, gelang auch eine Kultivierung mit Gesamthühnerembryo. Nach 58 Passagen in diesem Medium wurden 2 verschiedene Subkulturen angelegt: eine Serie enthielt Hühnerembryogewebe ohne Gehirn und Rückenmark; das so gezüchtete Virus erhielt die Bezeichnung $" 17$ " $D$. Die andere Serie enthielt nur Hühnerembryogehirn; das in ihm gezüchtete Virus erhielt die Bezeichnung »17D(CEB)«. Der im Gesamthühnerembryogewebe gezüchtete Virusstamm wurde "17 $D(W C)$ ) genannt.

Im Verlauf der in vitro-Züchtung des Asibi-Virus trat eine erhebliche Wandlung seines Charakters ein. Mit zunehmender Kulturdauer verlor dieses pantrope Virus mehr und mehr die Fähigkeit, bei Rhesus-Affen wieder typisches Gelbfieber zu erzeugen. Es trat 
also zumindest eine teilweise Abschwächung des Virus ein, die man aus der größeren Labilität der viscerotropen Komponente des Virus erklären könnte.

Für den Virusstamm 17 D ergab sich im einzelnen folgendes: größerer Verlust seines Neurotropismus für die Maus als bei anderen Kulturstämmen, fast völliger Verlust der Fähigkeit, bei Affen nach i.cer. Infektion eine tödliche Encephalitis zu erzeugen, wobei die Häufigkeit tödlicher Erkrankungen der Affen nur noch 5-10\% betrug. Nach extraneuraler Infektion kam es in der Regel bei Affen nicht mehr zu Fieber oder anderen Krankheitserscheinungen; im Blut wurden nur minimale Virusmengen nachweisbar. Das Virus verlieh aber den Affen eine kräftige Immunität gegen hochpathogenes AsibiVirus. Die minimale infektiöse Dosis für Affen entsprach einer minimalen tödlichen Dosis für Mäuse. Im Gegensatz zu allen anderen Gelbfieberstämmen erzeugte das 17D-Virus bei Affen eine Infektion, welche ausschließlich auf die lymphatisches Gewebe enthaltenden Organe und das Knochenmark beschränkt blieb. Eine erhebliche Abnahme der Igelpathogenität trat ebenfalls ein, ohne daß das Immunisierungsvermögen verloren ging. Durch länger anhaltende Mäusegehirnpassagen wurde ein neurotropes Virus fixe erhalten, das auch bei Affen eine tödliche Encephalitis erzeugte. Außerdem erwarb der 17D-Stamm im Verlauf der Mäusepassagen einen stärkeren Viscerotropismus, wie aus der starken Virämie bei den Affen hervorging, die der 17D-Kulturstamm nicht hervorrief.

Die beiden anderen Kulturstämme $17 D(W C)$ und $17 D(C E B)$ zeigten keine so ausgeprägte Abschwächung: noch nach mehreren hundert Kulturpassagen riefen sie bei Affen eine tödliche Encephalitis und eine ziemlich schwere viscerale Infektion mit erheblicher Virämie hervor. Theiler (1951) führte diese Unterschiede darauf zurück, daß die Menge des Nervengewebes im Kulturmedium den Grad des Neurotropismus des gezüchteten Virus bestimmt, da ein Verlust desselben nur in Kulturen eintrat, die nur noch minimale Mengen von Nervengewebe enthielten. Theiler glaubte, daß der Stamm 17D durch eine Mutation hervorgegangen sei, woraus die relative Stabilität zu erklären wäre. Die Gründe für diese Mutation oder vielleicht auch nur Modifikation des Asibi-Virus in der Gewebekultur sind im wesentlichen noch unbekannt und nicht allein durch die Zusammensetzung des Gewebes und insbesondere durch das Fehlen von Nervengewebe im Medium zu erklären.

Das abgeschwächte 17D-Kulturvirus wurde von Fox (1947) in zerkleinerten 10tägigen Hühnergesamtembryonen gezüchtet; dabei fand die stärkste Virusvermehrung während der 2. und 3. Bebrütungstage statt, d. h. zu einer Zeit, in welcher das Zellwachstum maximal und das $\mathrm{p}_{\mathrm{H}}$ am niedrigsten war. In 50\% igem Serum fand Verlangsamung der Zell- und damit auch Virusvermehrung statt. Die beste Vermehrungstemperatur war $32,5-35^{\circ} \mathrm{C}$.

Die Kultivierung weiterer unmodifizierter Virusstämme gelang zunächst nicht. H. H. Sмiтн und Theiler (1937) nahmen an, daß im Mäuseembryo bestimmte Zellgruppen besonders geeignet zur Virusvermehrung sind, ihre Zahl aber - gemessen an der nur geringen Virusernte - relativ klein im Verhältnis zum Gesamtembryo sein muß. Diese Autoren stellten außerdem fest, daß das Gehirn des in utero infizierten Mäuseembryos bei weitem mehr Virus als die anderen Organe enthält. Sie züchteten daher unmodifizierte Virusstämme in einem nur zerkleinertes Mäuseembryogehirn enthaltendem Nährmedium mit gutem Erfolg. Eine Zunahme des Neurotropismus für erwachsene Mäuse wurde dabei beobachtet. Nach 20-25 Passagen mit Mäuseembryogehirn konnten die Stämme leichter mit Gesamtembryogewebe gezüchtet werden. Schließlich gelang auch die Züchtung der neuen Kulturstämme in einem Medium, das gehirn- und rückenmarkfreies Hühnerembryogewebe enthielt. Zusatz kleinster Mengen von Nervengewebe genügte, um eine Zunahme des Neurotropismus zu erzielen. So wurde der unmodifizierte Virusstamm »J. S. S. in 3 Serien durch über 300 Passagen gezüchtet. Mit zunehmender Kulturdauer wurde eine leichte Abnahme des Neurotropismus für Affen beobachtet. Während der Züchtung mit Gesamthühnerembryogewebe fand eine so weitgehende Abschwächung des Viscerotropismus statt, daß das Virus auch nach s.c. Injektion verhältnismäßig großer Dosen nicht mehr zu einer Erkrankung führte, während es in Gehirn eingespritzt Affen noch zu töten vermochte. THeiler (1951) bezeichnete die Abwandlung des 
Virusstammes J.S.S. als die erheblichste, die bisher in der Gewebekultur gelungen ist. Diese Beobachtungen (s. auch Llołd, 1935; Findlay und MacCallum, 1937 c, 1940; Stefanopoulo, 1937; Whitman, 1939; Stefanopoulo und Duvolon, 1943) wiesen darauf hin, daß das pantrope Gelbfiebervirus während der Züchtung in vitro eine Abschwächung gewisser pathogener Eigenschaften erfuhr, die es zur Schutzimpfung beim Menschen als besonders geeignet erscheinen ließ.

In Einschichtzellkulturen von Hühnerembryofibroblasten unter Agarschutz ist eine genaue Austitrierung des Virus selbst und der N-AK mittels der Plaque-Technik von Dulbecco (1952) möglich (s. auch Immunbiologie). Am 4. Tage p. i. sieht man kleine Plaques von 2-3 mm Durchmesser. Der französische neurotrope Gelbfiebervirusstamm (Mäusegehirnpassagen), der noch nicht in Gewebekulturen gezüchtet worden war, erzeugte größere Plaques als der 17D-Stamm. Die Plaques sind nach Dulbecco das Ergebnis einer Infektion mit einem einzelnen Virusteilchen (Porterfield, 1959a, b, 1960).

Hannoun und Panthier (1960) errechneten, daß in Hühnerembryo-Einschichtzellkulturen in Hanks-Lösung gezüchtetes Virus mit 6,5-7,1 $\log \mathrm{PBE} / \mathrm{mJ}$ für Mäuse 8,8 $\log \mathrm{LD}_{50}$ enthielt. Die höchsten Mäusetiter wurden am 4. und 5. Tag p. i. beobachtet, worauf Titerabnahme stattfand.

SAINZ u. a. (1960) züchteten das neurotrope Dakar-Virus in Primärkulturen von Affenund Kaninchennierenzellen. Nach 3 tägiger Züchtung waren $10^{5} \mathrm{LD}_{50} /$ Maus erreicht. Ein ZE wurde nicht beobachtet. Hотта u. a. (1962) stellten eine Vermehrung des 17 D-Virus in primären trypsinierten Nierenkulturen vom Huhn, Meerschweinchen, Hamster, Schwein und japanischen Affen (Macaca fuscata) fest, nicht aber vom Kaninchen. Die längste Bebrütungsdauer mit Virusnachweis und der höchste Titer (i.cer. Mäuse- $\mathrm{LD}_{50} / 0,02 \mathrm{ml}$ ) waren folgende: für Hühnerniere 30 Tage und 103,5, für Meerschweinchenniere 14 Tage und $10^{3,25}$, für Hamsterniere 36 Tage und 104,25, für Schweineniere 50 Tage und $10^{3,75}$ und für Affenniere 43 Tage und 103,5. Hamster- und Affennierenkulturen zeigten Degenerationserscheinungen, die durch spezifisches Kaninchenantiserum gehemmt wurden. Die in vitro-NR entsprach in ihrer Empfindlichkeit der Mäuseschutzprobe. In Hamsternierenkulturen war eine passagenweise Züchtung möglich. In der 44. Passage betrug die Virusvermehrung in der Kulturflüssigkeit gegenüber dem Ausgangstiter 10-8,8. Die Mäusepathogenität war erhalten geblieben.

Die ersten Versuche, das Gelbfiebervirus in Zellkulturen menschlicher Gewebe in vitro zu züchten, scheinen auf EAGLE u. a. (1956) zurückzugehen, welche in KB-(Menschenkarzinom)Zellenkulturen einen partiellen ZE zwischen dem 5. und 7. Bebrütungstag beobachteten. In der 2. Kulturpassage wurden aber nur noch geringe Virusmengen nachgewiesen. Hallauer (1959) züchtete das Gelbfiebervirus (17D-Kulturstamm, neurotroper Dakar-Stamm, AsibiStamm) in $K B$ - und HeLa-Zellkulturen in Dauerpassagen, während eine Züchtung im Karzinomzellenstamm Detroit 6 nicht gelang. Ein wesentliches Ergebnis der Dauerpassagen in den KB-Zellen war, daß der 17D-Stamm seine Mäusepathogenität und der Asibi-Stamm seine viscerotropen Eigenschaften für den Affen verloren. In HeLa-Zellkulturen erfolgte der Virusnachweis schon in der Ausgangskultur. Ein ZE trat frühestens am 3. Tag auf, beginnend mit fortschreitender Nekrotisierung. Die Spezifität des ZE wurde im Hemmungsversuch mit spezifischem Immunserum bewiesen. Die Infektiositätstiter für Kulturen und Mäuse betrugen $10^{5}$ bis $10^{6} \mathrm{ID}_{50}$. Der KB-Zellstamm hatte eine besondere Empfänglichkeit für néue Virusstämme. In dieser Zellart traten neben ZE auch Plaques auf. In den KB-Zellen schien im Gegensatz zu den HeLa-Zellen der Zellstoffwechsel in der Regel bis zur völligen Zerstörung der Kultur erhalten zu sein. Es ergaben sich Infektiositätstiter von $\log 5-7 \mathrm{ID}_{50} 4-6$ Tage p.i. Die Kultivierung des Gelbfiebervirus in KB- und HeLa-Zellkulturen gestattet eine genaue Titrierung der Infektiosität: der Endtiter in den Kulturen entspricht etwa jenem im Mäusegehirn. Die Menschenzellkulturen dürften auch zur Auswertung von Immunserum brauchbar sein. SAINZ u. a. (1960) sahen bei der Kultivierung des Dakar-Stammes in HeLa-Zellen keinen ZE.

De Groot u. a. (1960) züchteten das 17 D-Virus in menschlichen Embryo- und Amnion (FL)Zellen sowie in Changs' Leberzellen. Das Virus wurde mit fluorescierendem Kaninchenantiserum (Fluorescein isothiocyanat) nachgewiesen. 48 St. p. i. begann die spezifische Fluorescenz in der perinukleären Region und 96 St. p. i. zeigten viele Zellen eine solche. Sie wurde durch Zusatz von Immunserum gehemmt. 
DoHerty (1958) gelang es, das Gelbfiebervirus 17D in menschlichen Konjunktiva- und Appendixzellen zur Vermehrung zu bringen. Die Appendixzellkulturen zeigten einen charakteristischen ZE in Form einer Zelldegeneration und Umbildung der normalen Zellschicht, welche Virus abgab. Diese Versuche stellen eine Bestätigung der Beobachtung von HaAGeN (1934a) dar, welcher einen ZE des Gelbfiebervirus in Kaninchenkornea- und -hodenexplantaten sah: zuerst Proliferation, dann Degeneration der Zellen. DoherTy (1958) fand, daß durch Menschen- und Kaninchenimmunserum der ZE des Virus neutralisiert wurde, aber auch in Gegenwart von Immunserum die Infektiosität der Zellen bestehen blieb, was auch von $\mathrm{H}_{\mathrm{AA}}$ GEN (1933a, b) beobachtet worden war (s. auch Bugher und Sмттн, 1944).

ElmendoRf und Sмiтн (1937) kultivierten verschiedene Gelbfiebervirusstämme in 7 Tage embryonierten Hühnereiern, die durch ein kleines Loch der sonst ungeöffnet bleibenden Eischale infiziert wurden. Die Bebrütung fand bei $37^{\circ} \mathrm{C}$ statt. Die Eipassagen erfolgten in Abständen von 2-8 Tagen unter Verwendung der CAM, der Embryoflüssigkeiten oder des Zentrifugenüberstandes von 50\%igen Embryoemulsionen in NaCl-Lösung. Mit der 165. Hühnerembryogewebekulturpassage des $17 \mathrm{D}$-Virus wurden über 60 Eipassagen ausgeführt. Die Anzüchtung dieses Virusstammes wie auch die eines in Mäuseembryogewebekulturen adaptierten Virus gelang ohne weiteres. Der 17D-Stamm erreichte in der Eikultur einen Titeranstieg von $2 \times 10^{-3}$ vor der Züchtung auf $2 \times 10^{-4}$ in der 6 . Passage und $2 \times 10^{-5}$ in der 12 . Passage. Infektionsversuche mit der 18. Eipassage an Rhesus-Affen ergaben, daß während der Ei- zu Ei-Passagen das Virus keine Abwandlung seiner Eigenschaften erfahren hatte. 4 noch nicht modifizierte, d. h. nicht in Gewebekulturen gezüchtete Virusstämme wurden nach Überwindung anfänglicher Schwierigkeiten ebenfalls im Ei gezüchtet (s. auch JADIN, 1937).

Fox und Laemmert (1947) beobachteten, daß die größte Empfänglichkeit der embryonierten Eier für das 17D-Virus nach unmittelbarer Beimpfung der CAM oder Anstechen des Embryos bestand. Als weniger wirksam erwies sich die Infektion in den Dottersack oder die Allantoishöhle. Nach Infektion der CAM fand erst nach Virusvermehrung an Ort und Stelle Übertritt des Erregers in das Blut und damit Infektion des Embryos statt. Das Virus schien sich in allen Embryoorganen zu vermehren; die größte Viruskonzentration zeigten Gehirn und Muskulatur. Der höchste Titer wurde nach 3-4 Tagen beobachtet. Die Viruskonzentration im Gewebeanteil des Mediums war 100 mal größer als in der überstehenden Flüssigkeit. Durch Erniedrigung der Bebrütungstemperatur auf $27^{\circ} \mathrm{C}$ trat die größte Virusvermehrung erst am 8. Kulturtag auf. O-Mangel beeinträchtigte die Vermehrung. Die Hälfte der geschlüpften Küken wies Virämie und später AK auf. Erfolgte die Infektion bei unter 11 Tage alten Embryonen, so starben fast alle zwischen dem 4. und 7. Tage. p. i.; waren die Embryonen bereits über 13 Tage alt, so schlüpften die Küken in normaler Zahl, wobei die Brutzeit allerdings um einige Tage verlängert war. Fox und Laemmert (1947) sahen wie Elmendorf und Smith (1937) auch nach längeren Hühnereipassagen keine erhebliche Abwandlung der Eigenschaften des unmodifizierten Virus (französischer Stamm) eintreten. Zur Infektion der Eier mit letzterem war allerdings im Gegensatz zur Züchtung von bereits in Gewebekulturen kultiviertem Virus eine sehr viel größere Virusmenge erforderlich.

Penna und Moussatché (1939) erzielten im Verlauf der Eipassagen eine bemerkenswerte Abwandlung des Asibi-Virus, dessen Anzüchtung im Hühnerembryo erst gelang, nachdem es in vitro durch 19 Passagen in einem zerkleinerte Mäuseembryonen enthaltendem Medium gezüchtet worden war. Die 19. Mäuseembryopassage zeigte keine Pathogenitätsabschwächung für Affen. Nach Übertragung auf das Hühnerei erfolgten Pathogenitätsprüfungen der 19., 29., 39., 47. und 63. Passagen durch i.cer. Verimpfung auf Rhesus-Affen. Während der mit der 19. Eipassage infizierte Affe noch an visceralen Erscheinungen starb, fehlten diese in der 29. Passage, wobei der Neurotropismus noch erhalten war; der an Encephalitis erkrankte Affe genas. Von der 39. Eipassage ab erkrankten die Affen überhaupt nicht mehr. Das Eikulturvirus scheint demnach eine ähnliche Abwandlung erfahren zu haben wie das 17DVirus. In 3 weiteren Kulturserien wurde derselbe Verlust des Viscerotropismus beobachtet; der Encephalo (Neuro)-tropismus für Rhesus-Affen ging jedoch nur in einer Serie verloren. 


\section{2-4. Eigenschaften des Virus}

ReED und CARRolL (1902) stellten die Fittrierbarkeit des Gelbfiebererregers durch bakteriendichte Filter fest. Nachdem LöFFLER und Frosch bereits 1898 entdeckt hatten, daß die MKS durch ein filtrierbares Virus verursacht wird, hatten nunmehr REED und CARROLL das erste filtrierbare Virus als Erreger einer menschlichen Infektionskrankheit isoliert. Über diesen klassischen Versuch der beiden Amerikaner schreibt WARREN (1951): "Am 15. Oktober 1901 spritzten REED und CARRoll $3 \mathrm{ccm}$ verdünnten und filtrierten Serums eines experimentell mit Gelbfieber infizierten Patienten 3 nichtimmunen Personen subkutan ein. 2 von diesen entwickelten klinisches Gelbfieber (Reed und Carroll 1902). Walter Reed gab an: ... die Experimente scheinen anzuzeigen, daß Gelbfieber ... durch einen in seiner Größe so winzigen Mikroorganismus verursacht wird, daß er als ultramikroskopisch bezeichnet werden kann!«

Diese Beobachtungen wurden von Marchoux u. a. (1903) sowie Rosenau (1905) ebenfalls in Menschenversuchen bestätigt. SToKes u. a. (1928a) isolierten erstmalig das Virus aus dem Blut infizierter Affen mittels Filtration durch Berkefeld-V- und N-Kerzen sowie Seitz-Asbest(EK)-Scheiben bei einem negativen Druck von $400 \mathrm{~mm} \mathrm{Hg.} \mathrm{Dagegen} \mathrm{wurde} \mathrm{der} \mathrm{Erreger} \mathrm{von}$ Berkefeld-W-Kerzen auch noch bei einem Druck von $720 \mathrm{~mm} \mathrm{Hg}$ zurückgehalten.

Sawyer und Frobisher (1929) wiesen nach, daß das in A. aegypti befindliche Virus sowohl im infektiösen als auch im Inkubationsstadium durch Berkefeld-N-Kerzen filtrierbar ist, wenn eine Suspension in einem $\mathrm{NaCl}$-Affenserumgemisch zu gleichen Teilen verwandt wird. In weiteren Versuchen filtrierten BAUER und MAHAFFY (1930) das Virus (infektiöses Affenblut und infizierte Mücken) durch Berkefeld-V-, N-. und W-, sowie durch die sehr engporigen Chamberland-Kerzen $\mathrm{L}_{11}$. Auch hier zeigte sich die günstige Wirkung des Serumzusatzes auf die Filtrierbarkeit. Sie dürfte dadurch zu erklären sein, daß das Serumeiweiß auf die NaClLösung entgiftend bzw. puffernd einwirkt, so daß das Virus nunmehr lange genug am Leben bleibt. In Gegenwart von Serum läßt es sich in einer $\mathrm{p}_{\mathrm{H}}$-Breite zwischen 4,8 und 7,8 erhalten. Schließlich gelang es FroBIsher (1929) auch, Mückenvirus in reinem dest. Wasser $\left(p_{H} 6,4\right)$, in NaCl-Lösung $\left(p_{H} 6,2\right)$ und Phosphatpufferlösung $\left(p_{H} 7,1\right)$ durch Berkefeld-VKerzen zu filtrieren. Die virushaltigen Mückensuspensionen mußten aber spätestens $10 \mathrm{Min}$ nach Herstellung filtriert sein.

In einem Serum-NaCl-Gemisch ist auch das im Mäusegehirn befindliche neurotrope Virus leicht filtrierbar. Kotter und van den Berghe (1935) filtrierten infektiöses Mäusegehirn in einer 1\% igen Verdünnung durch Seitz-Filter.

Aus der Filtrierbarkeit durch engporige Filter ging bereits hervor, daß der Gelbfiebererreger ein sehr kleines Virus sein müßte. Filtrationen von Findlay und Вroom (1933) durch graduierte Kollodiummembranen ergaben Teilchendurchmesser zwischen 18 und $27 \mathrm{~m} \mu$. Bauer und Hughes $(1934,1935)$ bestätigten diese Befunde bei Filtrationen des viscerotropen Asibi-Stammes und des neurotropen französischen Stammes; sie erhielten Teilchendurchmesser zwischen 17 und $25 \mathrm{~m} \mu$.

Die nur geringfügig niedrigeren Werte werden dadurch erklärt, daß ein anderes Verdünnungsmittel verwandt wurde, das die Filtration erleichtert haben könnte. Es bestand aus Ascitesflüssigkeit, Hormonbrühe, Phosphatpuffer und dest. Wasser. Pickels und Bauer (1940) fanden bei der Ultrazentrifugation von infektiösem Affenserum ein Absorptionsband im Spektrum zwischen 320 und $440 \mathrm{~m} \mu$ des Quecksilberlichtes, was durchschnittlich einer Wellenlänge von $365 \mathrm{~m} \mu$ entspricht. Davon ausgehend, daß die E. K. sphärisch sind und eine Dichte von 1,33 g/ml ähnlich wie die meisten Proteine haben, wurde ein Teilchendurchmesser von etwa $12 \mathrm{~m} \mu$ errechnet. Bei einer Dichte von $1,5 \mathrm{~g} / \mathrm{ml}$ würde er nur $10 \mathrm{~m} \mu$, bei einer solchen von $1,15 \mathrm{ml}$ dagegen $19 \mathrm{~m} \mu$ betragen. Die mittels derSedimentation erhaltenen Größen decken sich also im wesentlichen mit jenen durch Ultrafiltration gewonnenen Werten. Polson (1954) benutzte zur Bestimmung der Teilchengröße mittels Ultrazentrifugation infizierte Mäusegehirne (17D-Virus), die zunächst in Serum-NaCl-Lösung verrieben und mit 
2700 U/Min in der Kälte zentrifugiert wurden. Die überstehende Flüssigkeit wurde zu gleichen Teilen mit $2 \%$ igem Hämozyanin zur Vermeidung von Sedimentationsunregelmäßigkeiten versetzt und $100 \mathrm{Min}$ in der Spinco-Zentrifuge zentrifugiert. Mit 20000 U/Min wurde eine Sed.-Konstante ermittelt, die einer Teijchengröße von 19,2-31,4 m $\mu$ entspricht.

Reagan und Brueckner (1953b) sowie ReAgan u. a. (1953a, 1955a) versuchten die Abbildung des Gelbfieber-Virus mittels des Elektronenmikroskops. Sie fanden das 17D-Virus im Gehirn infizierter Mäuse und nach i.p. Infektion von Höhlenfledermäusen im virämischen Stadium an die Erythrozytenoberfläche adsorbiert, als sphärische Gebilde, die der durch Ultrazentrifugation und Ultrafiltration bestimmten Teilchengröße des Erregers entsprachen. Sie beschrieben das Virus als 50-55 m $\mu$ große runde Körperchen mit leicht unregelmäßiger Kontur. Es sollte dem Masernvirus ähneln.

BeARCROFT (1960) fand in den Lebern gelbfieberkranker Tiere elektronenoptisch und histochemisch eine zunehmende Vergrößerung der Kerne mit Steigerung der Kern-RNS und -Proteinsynthese in den Nukleolen der Leberzellen sowie gleichzeitig eine Vermehrung des basophilen Materials im Zytoplasma. Es handelte sich offenbar um das im Kern neugebildete RN-Proteinmaterial, das durch die Poren der Kernmembran in das Zytoplasma eindringt, sich bis in die Zellperipherie ausbreitet und im Zytoplasma zur Virussynthese dient. Die RNProteingranula bildeten Rosetten, aus denen runde Teilchen von 55-61 m $\mu$ Durchmesser hervorgingen, deren Größe allerdings im Widerspruch zu den mittels Filtration und Zentrifugation gefundenen Werten zwischen nur 12 und $31 \mathrm{~m} \mu$ des extrazellulären El.K. stand. Die Mitochondrien und Fett-Tröpfchen im Zytoplasma sollen kein Virus enthalten haben. Auch die azidophilen Torres-Körper schienen frei von NS und damit von Virus zu sein. Die als Virus gedeuteten Teilchen waren anfänglich im perinukleären Gebiet gelagert, später aber über das ganze Zytoplasma verteilt. BeArCroft (1960 b) sah in Ultradünnschnitten Osmiumfixierter Leberstückchen infizierter Rhesus-Affen (Asibi-Virus) die Entwicklung der mit einer Innenstruktur versehenen Teilchen. BAYER und NIELSEN (1961) beobachteten in KMNO fixierten Ultradünnschnitten von KB-Zellkulturen nach 18-48 St. Bebrütung mit AsibiVirus neben primär auftretenden Kernveränderungen (granuläres, sehr elektronendichtes Material, Kernzerstörung) sehr charakteristische Zytoplasmareaktionen: in meist größeren "Vakuolen" (stark erweiterte Innenräume zwischen den Lamellen des deutlich vermehrten endoplasmatischen Retikulums), die später entleert zu sein schienen, runde $25-27 \mathrm{~m} \mu$ große Teilchen ohne auffällige Innenstruktur. Diese Teilchen traten besonders reichlich in den späteren Infektionsstadien im peripheren Zytoplasmabereich auf. Gleichartige Teilchen wurden außerdem extrazellulär angetroffen, und zwar meist in kleineren Aggregaten an KBZellen oder im HA-Versuch an Gänseerythrozyten adsorbiert. Die immunofluorescenzmikroskopische Darstellung intrazellulärer AK-bindender Herde stimmte mit den elektronenoptisch nachgewiesenen Fundstellen im Zytoplasma überein; außerdem waren RNS-haltige Bezirke gleicher Lagerung zytochemisch darstellbar. Asibi-Antiserum (Affe) und D 17Antiserum (Kaninchen) in hohen Verdünnungen neutralisierten das Virus und verhinderten Virusvermehrung und Zellreaktionen. Bereits De Groot u. a. (1960) hatten in infizierten menschlichen Leberzellen, die mit fluorescierendem Gelbfieber-Immunserum behandelt worden waren, Virusantigen in den perinukleären Regionen von 48 St. p. i. ab gefunden.

Bergold und Weibel (1962) wiesen in infizierten Mäusegehirnen und -lebern, in KB-, HeLa- und Hühnerembryo-Zellkultursuspensionen, in erwachsenen infizierten Aedes aegypti sowie in gereinigten KB-Zellsuspensionen gleichartige runde Teilchen von etwa $35 \pm 5 \mathrm{~m} \mu$ Durchmesser nach, welche ein dichtes Zentrum und eine Membran hatten. Sie glauben, daß es sich hier um das Gelbfiebervirus handelt, da ähnliche Teilchen nicht in normalen Zellen nachweisbar waren. Die von BAY ER und NIELSEN (1961) beschriebenen Teilchen halten sie dagegen nicht für das Virus, da sie diese niemals in den infizierten Gehirnzellen, dagegen aber in normalen Leberzellen fanden. In den untersuchten Lebern der infizierten Mäuse wurden allerdings nur wenige oder gar keine Virusteilchen gesehen. BERGOLD und WEIBEL nahmen deshalb an, daß die schweren pathologischen Leberveränderungen wie die Councrumanschen Körper nicht auf der Gegenwart von Virusteilchen (EI.K.) beruhen, da auch BARUCH (1962) in diesen Gebilden keine Virusteilchen fand.

Von chemisch-physikalischen Methoden zur Reindarstellung des Virus sind in erster Linie 
die Untersuchungen von Hughes (1934) zu erwähnen; es handelte sich hier im wesentlichen um eine partielle Reinigung des Virus durch Adsorption an Kaolin, wie sie von WiLlstäTteR und WALDSCHмIDT-LEITZ erstmalig zur Konzentration von Enzymen benutzt worden ist, und anschließende Auswaschung des Virus und Kaolins mit verdünntem Ammoniak. Diese Methode ist bereits mit Erfolg zur Reinigung anderer Viruasarten benutzt worden. HugHeS versetzte virushaltige Seitz- oder Berkefeld-N-Filtrate infektiöser Mäusegehirnemulsionen in dest. Wasser mit einer $40 \%$ igen Kaolinsuspension in dest. Wasser; nach ]ängerem Stehen und Schütteln bei Zimmertemperatur wurde das Kaolin-Virusgemisch zentrifugiert und die überstehende Flüssigkeit wieder durch ein Seitz- oder Berkefeld-N-Filter geschickt. Der Kaolinrückstand wurde mit Ammoniak ausgewaschen. Es ergab sich, daß eine vollständige Adsorption des Virus erfolgt war, und daß mit zunehmenden $\mathrm{p}_{\mathrm{H}}$-Werten eine Abnahme der adsorbierten Proteinmengen eintrat. Auf diese Weise kann eine Aufschwemmung von aktivem Gelbfiebervirus erreicht werden, die nur noch Spuren von Protein enthält. Hughes gibt diesen Proteingehalt mit $50 \mathrm{mal}$ niedriger an, als überhaupt mit chemischen Proben nachgewiesen werden kann. Aus diesen Versuchen geht weiterhin hervor, daß sich die Virusteilchen gegenüber dem Kaolin anders als Serumproteine oder sonst im Serum oder Gehirn vorkommende Substanzen verhalten. Das Gelbfiebervirus wird nämlich schneller und vollständiger adsorbiert, aber gleichzeitig auch schon durch sehr niedrige Ammoniakkonzentrationen wieder vom Kaolin gelöst. Dies mag seinen Grund in der verhältnismäßig hohen elektrischen Ladung des Virus haben, wie eine solche aus der schnellen Wanderung der Virusteilchen in einem elektrischen Feld angenommen werden kann. Die optimale Konzentration des Eluens, welche zur Gewinnung der größten Menge freien Virus erforderlich ist, dabei aber gleichzeitig die geringste Menge unspezifischen Eiweißes abgibt, wurde in $\mathrm{N} / 100 \mathrm{NH}_{4} \mathrm{OH}$ gefunden; sie ergab $80 \%$ des ursprünglichen Virusgehalts mit nur 3\% Begleiteiweiß. In 2 Min war die Viruselution bereits beendet.

Takahara und Hotta (1961) reinigten die Kulturflüssigkeit von in Hamsternierenzellen gezüchtetem 17 D-Virus durch 15 Min langes Zentrifugieren mit 3000 U/Min, Adsorption an ECTEOLA-Cellulosesäulen und Elution mit 0,07 M Phosphatpuffer $\left(\mathrm{p}_{\mathrm{H}} 7,2\right)$ oder durch Behandlung mit Fluorkohlenstoff (s. auch StansLY und Ramsey, 1960). Mit beiden Verfahren wurden über $90 \%$ des $\mathrm{N}$ des Ausgangsmaterials und praktisch $100 \%$ des Virus selbst gewonnen. Der N-Gehalt der gereinigten Virussuspensionen (gemessen mit der Mikro-Kjeldahl-Methode) schwankte zwischen 0,1 und $0,2 \mathrm{mg} / \mathrm{ml}$. Die Virussuspensionen wurden mit den Enzymen Trypsin, Papain, Bakterienproteinase, Pankreaslipase, Weizenkeimlipase, $\alpha$-Amylase, RN-ase und Lysozym gemischt bei $37^{\circ} \mathrm{C}$ und mit Bakterienlipase gemischt bei $30^{\circ} \mathrm{C} 1-2$ St. bebrütet und nach Verdünnung auf aktives Virus in Mäusen und Röhrchenzellkulturen geprüft. Trypsin und Pankreaslipase setzten die Infektiosität des Gelbfiebervirus herab oder zerstörten sie vollständig; sie scheinen auf Virussubstanzen zu wirken, welche die Infektiosität und Immunogenität kontrollieren. Dagegen scheint die RNS in den infektiösen El.K. gegen RNase resistent zu sein.

Nielsen und Marquardt (1962) stellten aus Gelbfieber-infizierten Mäusegehirnen (AsibiStamm) durch Phenolextraktion eine proteinfreie Fraktion her, die für NS charakteristische UV-Absorption zeigte und deren Infektiosität $0,03 \%$ des Ausgangsmaterials ausmachte. Diese beobachteten Titerdifferenzen zwischen der NS-Fraktion und dem Ausgangsvirus waren bereits von Colter und ELLEM $(1961 \mathrm{a}, \mathrm{b})$ festgestellt und damit begründet worden, daß nur ein Anteil der infektiösen RNS zur Wirkung gelangte. RN-ase, Trypsin und Serumprotein hemmten die Infektiosität, nicht dagegen DN-ase und Chymotrypsin. Die RNS-Inaktivierung durch Trypsin wurde nicht auf eine proteolytische Wirkung des Trypsins zurückgeführt. Hierfür sprach u. a. auch, daß Chymotrypsin die RNS nicht hemmte. Während die infektiöse RNS durch Äthanol nicht beeinflußt wurde, wurde das Virus vollständig inaktiviert. Die Infektiosität der RNS wurde durch Normal- und Immunglobulin, die des intakten Virus nur durch Immunglobulin inaktiviert. Die vorliegenden Untersuchungen haben nicht gezeigt, ob die infektiöse RNS dem Virus selbst oder seiner vegetativen Vorstufe in der Wirtszelle entstammte. Die RNS blieb erst bei $-70^{\circ} \mathrm{C}$ mehrere Wochen stabil.

Hindle und Findlay (1930) fanden auf elektrophoretischem Wege für das viscerotrope Virus in zell- und hämoglobinfreiem Serum im saurem $\mathrm{p}_{\mathrm{H}}$-Bereich von 5,2-7 eine negative Ladung, 
während es im leicht alkalischen Bereich von 7,2-8 zum negativen Pol wanderte, also positiv geladen war. In etwa neutralem Medium $\left(\mathrm{p}_{\mathrm{H}} 6,9-7,2\right)$ wanderte das Virus nicht; es schien in diesem Bereich seinen isoelektrischen Punkt zu haben. Das neurotrope Virus verhielt sich im elektrischen Feld anders als das viscerotrope (Frobisher, 1933); es wies 2 breite isoelektrische Zonen auf, die eine im sauren Bereich über einem $p_{H}$ von 7,2. In der Zwischenzone von 6,9 bis 7,2, welche dem isoelektrischen Punkt des viscerotropen Virus entspricht, wanderte das neurotrope Virus zu beiden Polen (Frobisher, 1933). Die N-AK haben nach Frobisher (1931 c) eine höhere elektronegative Ladung $\left(p_{H} 7,4\right)$ als das Virus selbst. Hindle und Findlay (1930) stellten außerdem fest, daß das viscerotrope Virus im sauren $p_{H}$-Bereich von 3-4 zerstört wird, während es im Bereich von 5,2-7 (Hindle, 1929) bzw. 4,8-8,1 (Frobisher, 1931 c) am Leben bleibt. Frobisher (1933) fand, daß das neurotrope Virus in Serumverdünnungen in einem $\mathrm{p}_{\mathrm{H}}$-Bereich von 5,7-9,2 $3 \mathrm{St}$. am Leben bleibt, während es bei einem $\mathrm{p}_{\mathrm{H}}$ von 5 in $3 \mathrm{St}$. unwirksam wird. JACOBS (1944) ermittelte als $\mathrm{p}_{\mathrm{H}}$-Optimum für das Virus den sauren Bereich zwischen 6,3 und 6,5 .

In destilliertem Wasser, physiologischer NaCl-Lösung, Ringer-Lösung, Locke-Lösung und Hormonbrühe wird das Virus schnell abgetötet (BAUER und MAHAFFY, 1930). Zusatz von 1\% Ammoniumsulfat nimmt der physiol. NaCl-Lösung die toxische Wirkung; das Virus hält sich in dieser Lösung im Dunkeln aufbewahrt bei $22-25^{\circ}$ C 20 Tage lang (JACoBs, 1944). Auch Zusatz von normalem Serum, am besten 10\% Affenserum, hebt die abtötende Wirkung dieser Medien auf. Collier u. a. (1959) weisen darauf hin, daß Gelbfiebervirus nur in einer Verdünnungsflüssigkeit aktiv bleibt, welche Protein enthält, was für genaue Titrationsversuche wichtig ist, die nur exakt ausfallen können, wenn innerhalb der Vorbereitungszeit des Versuchs nur eine möglichst minimale Virusinaktivierung stattfindet. Geeignet sind Verdünnungsflüssigkeiten, welche 10\% normales Menschen-, Affen-, Kaninchen- oder Pferdeserum, 20\% Ascites oder Pleuraflüssigkeit, alle in physiol. Na-Cl-Lösung, oder $0,2-0,75 \%$ Rinderalbumin in gepufferter isotonischer NaCl-Lösung enthalten (s. auch Dick und TAYLoR, 1949).

Trotz der an sich großen Labilität vermag das Virus in infektiösem Affengewebe bei Zimmertemperatur lange am Leben zu bleiben, selbst wenn letzteres sich bereits im fortgeschrittenen Fäulniszustand befindet (BAUER, 1931): noch 9 St. nach dem Tod des Affen genügte 0,01 ml Blut, um bei einem normalen Affen eine tödliche Infektion zu erzeugen. Hier kam gleichzeitig eine erhebliche Resistenz des Virus gegen die Wirkung postmortal in die Gewebe eingedrungener Bakterien zum Ausdruck. Collier u. a. (1959b) fanden außerdem, daß auch 10\% ige normale Mäusegehirnsuspensionen außerordentlich gut als Verdünnungsflüssigkeit geeignet sind. In diesem Medium behält das Virus bei $10^{\circ} \mathrm{C}$ mindestens 24 St. lang seine ursprüngliche Infektiosität. De Roever-Bonnet und Hoekstra (1961) verwandten anstelle von normalem Menschenserum zur Herstellung von Verdünnungen für die Titrierung des 17 D-Impfstoffvirus sterilisierte Milch, welche die Ergebnisse nicht beeinträchtigen soll.

Mit dem für Viren klassischen Konservierungsmittel Glycerin versetzt kann das Gelbfiebervirus gewöhnlich 60-100 Tage im Eisschrank wirksam gehalten werden; später kommt es zu einer erheblichen Virulenzabschwächung (SAWYER u. a., 1929). Ein Gemisch von 60\% Glycerin und $0,5 \%$ Phenol tötet das Virus bei $0^{\circ} \mathrm{C}$ während 5 Tagen nicht, bei $16^{\circ} \mathrm{C}$ dagegen in 48 St. ab (HINDLe, 1929).

Sellards und Hindle (1928) stellten anläßlich des Versandes von infektiösen Affenorganen und -blut in gefrorenem Zustand fest, daß Kälte ein gutes Konservierungsmittel ist. HindLE (1929, 1930) sowie Peтtiт u. a. (1929) gaben die Konservierung des Virus durch Trocknung im Vakuum und Aufbewahrung in der Kälte an. Burruss und Hargett (1947) empfahlen, das getrocknete Virus $(17 \mathrm{D})$ bei $-20^{\circ}$ bis $-25^{\circ} \mathrm{C}$ aufzubewahren. Bei $-9^{\circ}$ bis $-32^{\circ} \mathrm{C}$ hielt es sich $3 \mathrm{Jahre}$, aber schon bei $-5^{\circ}$ bis $-7^{\circ} \mathrm{C}$ trat innerhalb von 2 Jahren ein erheblicher Virulenzverlust ein. Die Haltbarkeit des getrockneten Virus in Gegenwart von Luft bei $37,5^{\circ} \mathrm{C}$ ist von der Luftfeuchtigkeit in den zugeschmolzenen Röhrchen abhängig: das Virus wird bereits in 24 St. unwirksam, wenn letztere über $6 \%$ beträgt. Zum Teil wurde das Virus auch durch Oxydation zerstört.

Durch die Untersuchungen von SAwyer u. a. (1929) wurde bestätigt, daß die beste Konservierungsmethode die Trocknung von virushaltigem Material (Blut, Organe) in 
gefrorenem Zustand ist, worauf die Aufbewahrung des getrockneten Materials in zugeschmolzenen luftleeren Röhrchen im Eisschrank erfolgt. Obwohl im Lauf der Zeit eine allmähliche Virulenzabnahme stattfindet, bleibt das Virus doch außerordentlich lange wirksam.

SchüFFnER u. a. (1939) hielten getrocknetes Virus in luftleeren Röhrchen 5 Jahre unverändert wirksam (s. auch HaAGeN und GRAEFE, 1943). Fox und GARP (1940) bestätigten, daß das getrocknete Virus in luftleeren oder stickstoffhaltigen zugeschmolzenen Röhrchen viel länger virulent bleibt als in Gegenwart von Luft. Nach Theiler (1951) enthielt das getrocknete Blut eines mit Asibi-Virus infiziert gewesenen Affen noch nach 10 jähriger Aufbewahrung im Kühlschrank aktives Virus.

Reed und Carroll (1902) hatten bereits die Hitzeempfindlichkeit des Erregers untersucht. Sie sahen, daß infektiöses Menschenserum durch 10 Min Erhitzen auf $55^{\circ} \mathrm{C}$ abgetötet wird. Marchoux u. a. (1903) fanden hierfür 5 Min ausreichend. Nach Hindle (1930) wird das Virus erst nach 10 Min Erhitzung auf $65^{\circ} \mathrm{C}$ abgetötet. Frobisher $(1930,1933)$ sah, daß neurotropes und viscerotropes Virus bei $60^{\circ} \mathrm{C}$ in 10 Min inaktiviert werden. In getrocknetem Zustand hat das Virus eine verlängerte Hitzewiderstandsfähigkeit. Er stellte außerdem fest, daß viscerotropes Virus durch 30 Min lange Einwirkung von 6,7\% igem Äthylalkohol, 0,3\% igem Phenol und Sublimat 1: 7500 bei $3^{\circ} \mathrm{C}$ nicht abgetötet wird. Neurotropes Virus scheint gegen Alkohol noch etwas widerstandsfähiger zu sein. Wegen ihrer Giftigkeit für Mäusegehirn konnten andere Substanzen bezüglich ihrer Wirkung auf neurotropes Virus nicht geprüft werden. Formol (1:1000) tötet das Virus bei Zimmertemperatur schnell, bei $0^{\circ} \mathrm{C}$ in $48 \mathrm{St}$. ab. Nach Coldier und DE WIT (1960) ließ Formolbehandlung des 17D-Virus eine geringe immunisierende Wirkung für Mäuse zurück, während durch Behandlung mit Formol oder $\beta$-Propiolacton und 1 St. Erhitzen auf $56^{\circ} \mathrm{C}$ die immunisierende Wirkung vollständig zerstört wurde. Das Virus wird durch Methylenblau (1:100000) in Gegenwart von Licht innerhalb von 20 Min soweit zerstört, daß auch seine antigenen Eigenschaften verloren gehen (FIndLay, 1934a, b). Nach Frobisher (1933) scheint aber das neurotrope Virus etwas widerstandsfähiger gegen diese photodynamische Wirkung des Methylenblaus zu sein als der viscerotrope Stamm. Gegen Eosin scheint das Virus (viscerotroper Stamm) eine größere Resistenz zu haben (Frobisher, 1930).

Eine konzentrierte Harnstofflösung tötet das Virus in 20\%iger Suspension fast sofort ab, während eine nur 10\% ige Lösung hierzu 1 St. erfordert. Die normalerweise im Blut vorkommende Harnstoffmenge von 0,2-0,4 g/Liter dürfte daher nicht ausreichen, um kreisendes Virus zu vernichten (HöRING, 1939). Galle scheint in vitro eine gewisse hemmende Wirkung auf neurotropes Virus auszuüben (PeLtier u. a., 1937). Von 8 mit französischem Virus infizierten Affen blieben nach Verfütterung von Cholinchlorhydrat 3 am Leben, während alle unbehandelten Kontrolltiere starben (Sellards und MaccanN, 1944).

Die Sulfonamide Sulfathiazol und Sulfapyridin erwiesen sich in der Gewebekultur auch in großen Mengen ohne Wirkung auf die Vermehrung des 17D-Virus. Erst wenn das Medium eine Konzentration von $20 \times 10^{-4}$ enthielt, wurde eine leichte Wachstumshemmung beobachtet (Koprowski und Lennette, $1944 \mathrm{a}, \mathrm{b}$ ).

Hallauer (1946, zit. 1950) erzielte Agglutination von Hühnererythrozyten mit hohen Titern mit 17D-, pantropem und neurotropem Virus. Nach Porterfield (1957) werden auch Gänseblutzellen agglutiniert. Die HA erwies sich allerdings nicht als spezifisch, sondern ergab weitgehendes Übergreifen auf andere Viren der Arbor-Gruppe. (s. auch McCollum und Foley, 1957; Daniels, 1958).

Nach HalLaUer (1946, zit. 1950) findet HAH nicht nur mit Immunseren, sondern auch mit normalem Kaninchenserum statt. Auch Phospholipide aus dem menschlichen Blut hemmen die HA durch das Gelbfiebervirus (Porterfield und Rowe, 1960). Nach Salminen (1962 c) handelt es sich bei den HA-Hemmern um ein Gemisch zweier Lipide, von denen das eine ein Cholesterin, das andere entweder Phospholipid oder freie Fettsäure ist.

CASAlS und BRown $(1953,1954)$ konnten durch Aceton-Äther-Extraktion nichtspezifische Faktoren aus infizierten Mäusesäuglingsgehirnen entfernen und dadurch so- 
wohl aus dem Asibi-Stamm als auch aus dem neurotropen Virus ein Hämagglutinin für Hühnerblutzellen gewinnen. Die HAH durch beide Viren lief am besten bei $4^{\circ}$ und $22^{\circ} \mathrm{C}$ und einem $p_{H}$ von etwa 7 ab. Hallauer und Kronauer (1960) wiesen in infizierten KB-, FL- und HeLa-Zellkulturen spezifisches Hämagglutinin für Gänseerythrozyten sowohl im Gewebe durch alkalische Extraktion mit Boratpuffer als auch in der Kulturflüssigkeit nach Entfernung unspezifischer Hemmstoffe durch Freon (Fluorkohlenstoff) nach. Das Hämagglutinin, das nur in gerollten Kulturen auftrat, wird schon vor dem ZE nachweisbar und hat seinen höchsten Titer mit dem höchsten Infektiositätstiter. Die Abgabe von Hämagglutinin in das Medium findet mit zunehmendem ZE statt; sie war vom $p_{H}$ und den Elektrolyten der Extraktionsflüssigkeit unabhängig. Eine enzymatische Zellrezeptorzerstörung wurde nicht beobachtet. Die Stabilität des Hämagglutinins scheint nur in alkalischem Milieu gewährleistet zu sein. Die Hämagglutininbildung kann im Verlauf der Züchtung verloren gehen. SALminen (1962 c) gewann aus menschlichen Amnionzellkulturen (Passageklon in Hemmstoff-freiem Medium), die mit 17 D-Virus infiziert waren, am 3. Tag p. i. ein Hämagglutinin, dessen Titer die Gesamtmenge an lebendem und totem Virus in der Kulturflüssigkeit anzeigte. Ein ZE wurde nicht beobachtet. Protaminsulfatbehandlung der infektiösen Kulturflüssigkeit steigerte das HA-Vermögen. Das Virus konnte bei $37^{\circ} \mathrm{C}$ und einem $p_{H}$ von 9,0 ohne Verlust seines HA-Vermögens inaktiviert werden.

Auf das Hämagglutinin wirken hemmend: am stärksten Kongorot, ein Diazofarbstoff und 3 andere Diazoverbindungen (Biebrichs Scharlach, Azoblau, Trypanrot), 2 Monoazoverbindungen (Chlorazo fast pink-Orange G), ein Phenylmethanfarbstoff (Schnellgrün FCF), und nur schwach Malachitgrün. Dagegen führen Surinam- und Trypanblau zu spontaner HA. Die Farbstoffwirkung scheint sich mehr gegen das Virus als die Erythrozyten zu richten (Mercado und Sмiтн, 1960).

Das Gelbfiebervirus hat sich im Verlauf der jahrzehntelangen Erforschung als antigen stabil erwiesen. Allerdings unterscheiden sich die afrikanischen und amerikanischen Virustypen darin, daß letzteren ein Antigen fehlt, das in den afrikanischen Stämmen vorkommt (Clarke, 1960b). Das abgeschwächte 17D-Virus hat während der Züchtung ein zusätzliches Antigen erworben, das weder in dem nichtadaptierten Elternstamm noch in anderen Stämmen nachweisbar war. Eine etwaige Pathogenitätsänderung für den Menschen wurde jedoch nicht durch eine antigene Modifikation erworben, wie die antigene Identität des französischen neurotropen Impfstoffstammes mit seinem pantropen Elternstamm ergab.

\section{Epidemiologie; Übertragung}

\section{3-1. Allgemeines}

Das Gelbfieber bedarf zu seinem Fortbestehen einer Kombination von Faktoren, die im einzelnen durchaus noch nicht vollständig bekannt sind. Die Epidemiologie des Gelbfiebers ist durch folgende Tatsachen charakterisiert:

Das Virus ist ein obligater Zellparasit, der unter normalen Umweltsbedingungen außerhalb des Organismus schon in kürzester Zeit zugrunde geht. Die Wirtstiere oder natürlichen Reservoire des Erregers sind offenbar nur Warmblüter. In ihnen kreist das Virus während einer verhältnismäßig kurzen Zeit des Infektionsablaufs; es ist das virämische Stadium. Um in ein neues Individuum zu gelangen, muß das Virus den Blutkreislauf seines Wirts verlassen und durch die Körperhülle nach außen, aber auch wieder durch die Körperhülle des zu Infizierenden in dessen Blut gelangen. Das virämische Stadium wird, falls nicht vorzeitig der Tod eintritt, von dem Immunitätsstadium abgelöst. Die Kontinuität des Viruslebens ist also nur gewährleistet, wenn durch einen mechanischtraumatischen Vorgang der Erreger aus dem Blut des Infizierten in das Blut eines gesunden, jedenfalls nicht immunen Individuums gelangt. 
Der Gelbfiebererreger wird nicht mit den Körperausscheidungen an die Außenwelt abgegeben; das bedeutet, daß keine Aufnahme des Virus durch Inhalations-, Tröpfchenoder Schmierinfektion bzw. Lebensmittel-, Wasser -oder Kontaktinfektion stattfindet. Die Übertragung erfolgt nur durch den Biß bestimmter Mückenarten, die nicht zu erkranken scheinen. Das Virus vermehrt sich in den Mücken. Aber auch in den Mücken ist die Kontinuität des Erregers nicht gewährleistet, selbst wenn - im Gegensatz zu den Wirbeltieren - die Mücken für die Dauer ihres Lebens infektiös bleiben.

Die Temperatur ist ein wesentlicher physikalischer Umweltsfaktor, der auf die Vermehrung im Mückenkörper von entscheidendem Einfluß ist, während bei infizierten Warmb]ütern die Außentemperatur ohne Einfluß auf den Infektionsablauf ist. Auch die Luftfeuchtigkeit gehört zu den wichtigsten Umweltsfaktoren des Mückenlebens und damit des Fortbestehens des Virus.

Low und FARLEY (1931) haben auf "Kontaktinfektionen « mit infektiösem Blut hingewiesen, bei denen das Blut durch die intakte Haut eingedrungen zu sein scheint. Sie haben aber keinerlei praktische Bedeutung. BeRRY und KITCHEN (1931) stellten 32 Laboratoriumsinfektionen zusammen, von denen 30 offenbar durch Kontakt der Haut bzw. Schleimhaut, letztere durch Inhalation mit virushaltigem Material zustandegekommen waren. Ob die Kontaktinfektion hier durch eine mikroskopisch intakte Haut oder Schleimhaut stattgefunden hat, darf stark bezweifelt werden, wenn auch Bauer und Hudson (1928a) den Durchtritt des Virus durch die intakte Haut und Findlay und Clarke (1935a) sowie Findlay und Maccallum (1937b) eine solche durch die Schleimhäute und auch den Magen empfänglicher Tiere annehmen. Eine rein mechanische Übertragung des Erregers durch Insekten, die unempfindlich für eine Infektion sind und in denen das Virus sich nicht vermehrt, scheint praktisch nicht vorzukommen (PнiцIP, 1930 b, Kuмm, 1932). So wurde festgestellt, daß z. B. Taeniorhynchus fasciolata das Virus für lange Zeit beherbergt, ohne es aber durch $\mathrm{Bi} \beta \mathrm{zu}$ übertragen.

Man unterscheidet heute in Afrika und Amerika 2 epidemiologische Formen des Gelbfiebers, die in ganz verschiedenen Milieus vorkommen (MaHafFy, 1955). Die eine Form, das klassische oder Stadtgelbfieber ist eine Menschenkrankheit, die vorwiegend in städtischen Zentren auftritt und durch die Hausmücke Aedes aegypti übertragen wird. Die andere Form, das Dschungel-(Urwald-, Busch-)gelbfieber ist eine Krankheit vorwiegend der Waldtiere und wird durch Waldmücken übertragen. Das Dschungelgelbfieber scheint die Urform zu sein, die sich von Zeit zu Zeit in die Städte erstrecken kann. Die Ausrottung des städtischen Überträgers ist ohne Einfluß auf die in den Wäldern lebenden Virusreservoire. Beide Formen unterscheiden sich durch ihren Infektionszyklus: MenschMücke-Mensch-Zyklus oder Tier-Mücke-Tier-Zyklus (Waldzyklus). In letzterem tritt die menschliche Infektion nur als Nebenform auf.

BRumpt (1949) hat folgendes Schema beider Infektionen mit ihrem Verbindungsglied angegeben.

BuRnet (1955) bezeichnete das Gelbfieber als ein Beispiel dafür, daß eine menschliche Krankheit aus einer solchen hervorgehen kann, die primär bei Tieren vorkam.

Auf den Streit der Kontinente um die Priorität sei hier nicht noch einmal eingegangen. Grundsätzlich ist festzustellen: In Afrika und in Amerika gibt es trotz gewisser epidemiologischer Unterschiede ätiologisch, immunbiologisch, klinisch und pathologisch nur eine Gelbfieberform. Ferner: Die ursprüngliche Form dürfte eine Zoonose sein, die menschliche Krankheit dagegen nur eine sekundäre oder Nebenform dieser Zoonose, also eine Zoo-Anthroponose.

Überall, wo das Gelbfieber bisher aufgetreten ist, hat es mindestens einmal epidemische Ausbreitung erfahren. Zu den schwersten Epidemien des vorigen Jahrhunderts gehört jene von Rio de Janeiro, wo im Jahre 1850 etwa 80000 Einwohner erkrankt waren. Die Zahl der 
Tedesopfer von 1851-1883 wird auf 23000 geschätzt. In den USA trat die letzte Epidemie 1905 in New Orleans auf, während in Mexiko die letzte Epidemie im Jahre 1920 herrschte.

Von den westindischen Inseln wurde das Gelbfieber zeitweilig nach Südeuropa gebracht. In Antigua, Westindien, ist es seit 1857 bekannt (UtтLey, 1960). Als wichtigstes Gelbfiebergebiet Afrikas galt bis vor kurzem Westafrika. Die Krankheit kommt heute aber auch in Ostafrika vor. So brach 1940 im englisch-ägyptischen Sudan eine große Epidemie aus, in welcher die Sterblichkeit 10\% betrug. Nach Panthier u. a. (1962) kommt Gelbfieber wahscheinlich auch dauernd im Gebiet des Oubangui-Flusses in Zentralafrika vor.

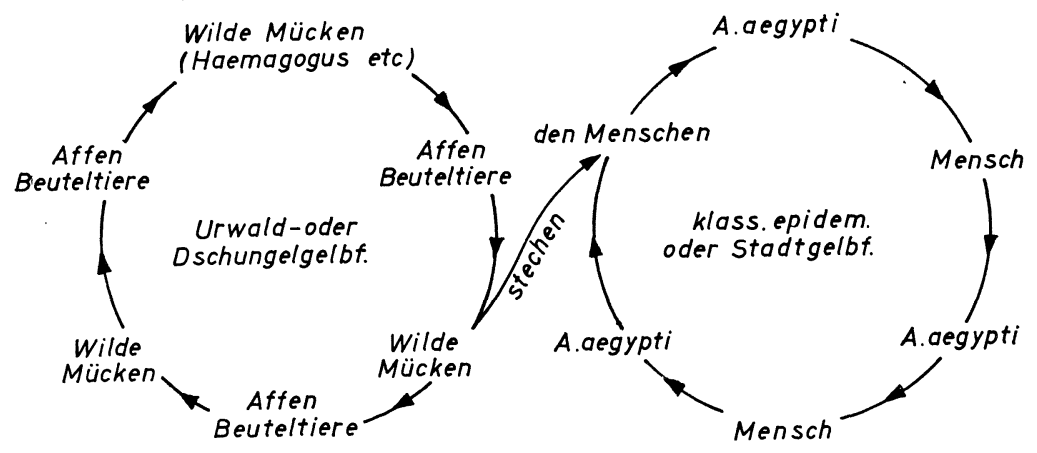

Abb.28. links: Primärzyklus des Dschungelgelbfiebers rechts: Stadtepidemie, hervorgegangen aus Dschungelgelbfieber (nach BRUMPT, 1949)

Kuмm (1952) weist auf das Vorwiegen 6 jähriger Intervalle in den letzten 50 Jahren hin; sonst ist aber weder in Afrika noch in Südamerika eine Periodizität des menschlichen Gelbfiebers festgestellt worden.

Unter den Primaten tritt die Krankheit als Waldzyklus gebietsmäßig enzootisch oder in periodischen Epizootien auf. Nach TAY LOR (1951) wäre es allerdings richtiger, nicht von gebietsmäßigen Enzootien zu sprechen, da anzunehmen ist, daß das Virus durch kontinuierlich wandernde Epizootien in dem betreffenden Gebiet verbleibt. Allerdings "brennt" das Virus in verhältnismäßig kurzer Zeit in einem umschriebenen Teil des Urwalds "aus", indem die dortigen empfänglichen Tiere immunisiert werden und das Virus in andere Teile des Urwalds wandert. Die von enzootischen Herden ausgehenden epizootischen Wellen können ziemlich schnell wandern. Man hat für eine solche Welle, die vom Osten Panamas westlich nach Costa Rica wanderte, eine Geschwindigkeit von 12-15 Meilen monatlich festgestellt (Clark, 1952; Elton, 1952a-d, 1955b). Das Wandern des Gelbfiebers über große Entfernungen innerhalb verhältnismäßig kurzer Zeit scheint weniger durch Überwechseln infizierter Affen von einem Waldgebiet in ein anderes zustandezukommen (CAuseY, u. a., 1948, 1950), sondern beruht offenbar auf einer Verschleppung der Überträger (Stechmücken) auf größere Entfernungen. Die zurückgelegten Strecken hängen von den Windverhältnissen, dem Klima u. a.m. ab.

Wie aus dem Virusnachweis bei Affen, die an Gelbfieber gestorben waren, hervorgeht, herrscht seit 1952 in verschiedenen Gegenden von Honduras (Trapido und Galindo, 1955) sowie in Guatemala bis an die Grenze von Mexiko Gelbfieber in epizootischer Form (Euton, 1955a, 1956; Boshell und Bevier, 1958). Menschliche Erkrankungen scheinen bisher nicht festgestellt worden zu sein. ELton sieht aber in dem ständigen nordwärts gerichteten Vordringen des Dschungelgelbfiebers jetzt schon eine unmittelbare Gefahr für das Wiederauftreten auch des Stadtgelbfiebers nicht nur in Mexiko, sondern auch in Nordamerika. Diese Gefahr erneuter Gelbfieberepidemien in den Südstaaten der USA kann einerseits infolge der Gegenwart von Haemagogus equinus in Texas (Dschungelgelbfieber), andererseits durch die 
Einwanderung infizierter Personen, Säugetiere oder Mücken in Gebiete, in denen gleichzeitig A. aegypti-Mücken vorkommen (Stadtgelbfieber), akut werden (HAY ES und Tink ER, 1958). Jedenfalls muß die lange gehegteHoffnung, das Gelbfieber in absehbarer Zeit so weit einschränken zu können, daß es keine Gefahr mehr für die Weltgesundheit bedeutet, aufgegeben werden.

Das Gelbfieber scheint aber nicht nur infolge selektiver Epizootien der Waldprimaten, sondern auch der Beuteltiere nordwärts zu wandern (Aldichieri, 1954; Sautet, 19555; Groot u. a., 1959a).

Ebenso wie in Südamerika bleiben auch in Afrika die Waldepizootien nicht an Ort und Stelle. Das Virus hält sich auch hier nicht in einem enzootischen Gebiet während einer gegebenen Zeit an einer bestimmten Stelle, sondern überlebt nur infolge der wandernden Epizootien (Haddow u. a., 1947; SmithburN u. a., 1949b). Taylor (1951) geht sogar so weit, anzunehmen, daß auch in Afrika Epizootien sich periodisch über die enzootischen Zonen hinaus ausdehnen, um dort jahreszeitlich gebundenen Charakter zu tragen.

Über die geographische Ausbreitung des Waldzyklus in Afrika ist aber bisher nur sehr wenig bekannt. Nach TAYLOR (1951) ist im Gegensatz zu Südamerika die menschliche Erkrankung kein zuverlässiger Index, da es in großen Teilen Afrikas Hausüberträger gibt, so daß es unmöglich ist, zwischen dem im Walde erworbenen Gelbfieber und dem "klassischen" aus dem Mensch-Mücke-Mensch-Zyklus hervorgehenden Gelbfieber zu unterscheiden. Soweit

Die Grenzen der endemischen Gelbfiebergebiete in Afrika und Südamerika sind in den beiden Karten Abb. 29 u. 30 wiedergegeben:

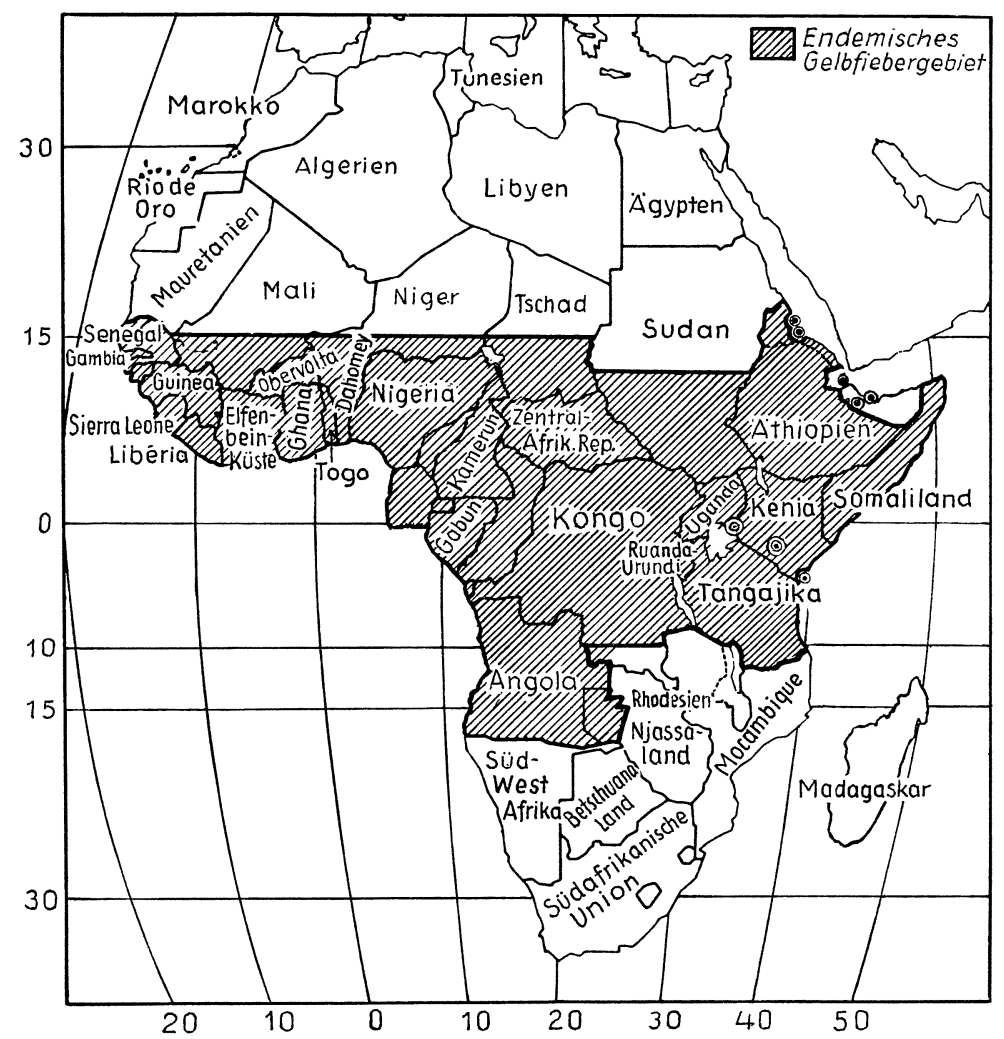

Abb.29. Endemische Gelbfiebergebiete in Afrika nach dem Stand von 1961 (nach WHO, 1961b) 
der Waldzyklus bisher geographisch erforscht worden ist, liegen positive serologische Ergebnisse an Affen von der Westküste Afrikas nördlich bis Senegal und südlich bis BelgischKongo, von Ostafrika im englisch-ägyptischen Sudan und Uganda, in Zentralkenyia und im Gedeur-Wald am Indischen Ozean vor (Findlay u. a., 1936; Findlay und Maccallum, 1938b; Berghe, 1939; Haddow, 1945c; Durieux u. a., 1947; Smithburn und Haddow, 1949).

Die Immunitätsprobe ermöglicht eingehende Untersuchungen über die Epidemiologie des Gelbfiebers in Gegenden, wo wohl Verdacht endemischen Vorkommens besteht, ohne daß aber klinische Fälle bekannt geworden sind. Genaue Immunitätsprüfungen in großen Teilen Afrikas und Südamerikas sowohl der Bevölkerung als auch der Primaten haben im Laufe der Jahre eine genaue Topographie des Gelbfiebers in diesen Gebieten gegeben. Die Enzootie in einem Gebiet, das durch die Immunität der untersuchten Primaten erkennbar ist, entspricht dem Auftreten des Gelbfiebers in der dort ansässigen ländlichen Bevölkerung, deren Immunität mit dem Alter zunimmt (Soper, 1937b; Smith u. a., 1943; SNIJders u. a., 1947).

In nichtepidemischen oder nichtepizootischen Gebieten ]äßt sich die Feststellung des Vorhandenseins von Gelbfieber aber nur durch den Viscerotomgebrauch erwarten. Bereits die ersten Massenuntersuchungen mit dem Viscerotom in Südamerika durch Soper u. a. (1934) an 28000 Leberpräparaten ergaben die histologische Gelbfieberdiagnose in 43 Gebieten, in denen Gelbfieber klinisch noch nicht festgestellt worden war. Histologische Untersuchungen

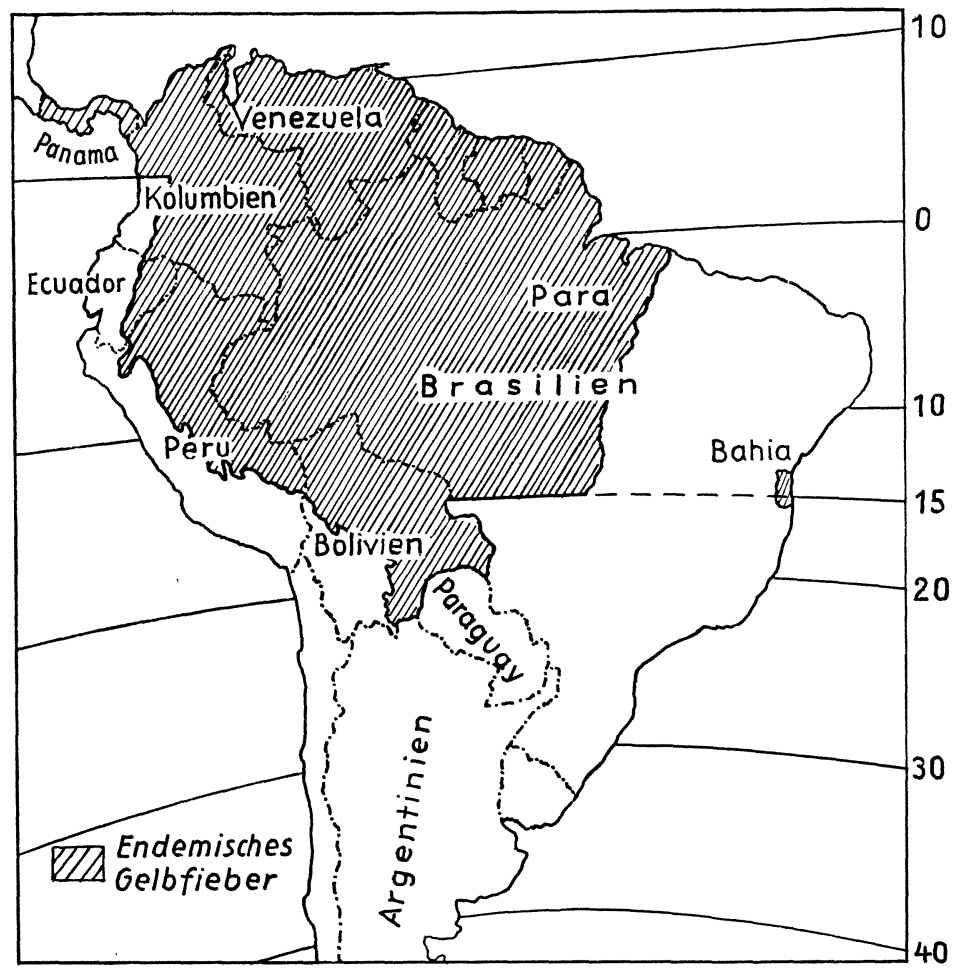

Abb. 30. Endemische Gelbfiebergebiete in Südamerika nach dem Stand von 1961 (nach WHO, 1961b) 
von Affen, die in Costa Rica gelbfieberkrank, sterbend oder tot aufgefunden wurden, zeigten, daß die Epizootie im Dschungel sich parallel mit der menschlichen Erkrankung entwickelt hatte. Deshalb glauben Vargas-Mendes und Elton (1953), daß sich die Wanderung einer Gelbfieberwelle durch die Untersuchungen der Affenlebern im Dschungel ebensogut verfolgen läßt wie durch die Leberuntersuchungen bei den Menschen (s. auch Galindo und Trapido, 1956). Die Viscerotomie vermittelt also einen Eindruck über das augenblickliche Vorkommen von Erkrankungen in den betreffenden Gebieten, während die Mäuseschutzprobe durch Ermittlung der Immunität den Aufschluß über zurückliegende Erkrankungen, also ein postepidemische Diagnose gestattet.

Wie Gast-Galvis und Bates (1945) feststellten, bestehen Beziehungen zwischen der Häufigkeit menschlicher Erkrankungen und der Jahreszeit in der epidemischen Zone. Die meisten Fälle treten während der Regenzeit, die wenigsten während der Trockenheit auf. In den endemischen Zonen findet man dagegen Erkrankungen während des ganzen Jahres. Ausschlaggebend für die jahreszeitliche Häufigkeit ist natürlich das Vorkommen des Überträgers.

Unter Zugrundelegung des Säugetierreservoirs, der Überträgerart und des Fortdauerns der Infektion lassen sich folgende Gelbfiebergebiete unterscheiden.

1. Enzootische Gelbfiebergebiete, die frei von A. aegypti sind, und in denen das Virus unter den Tieren lange Zeit vorhanden ist, wobei es zu gelegentlichen menschlichen Infektionen (Holzfäller, Jäger u. a.) kommt.

2. Epizootische Gelbfiebergebiete, die frei von A. aegypti sind und in denen die Krankheit periodisch für kurze Zeit unter den Tieren vorkommt.

3. Endemische Gelbfiebergebiete mit A.aegypti und langdauerndem Vorkommen des Virus unter den Tieren.

4. Epidemische Gelbfiebergebiete, in welchen Erkrankungsfälle infolge Übertragung des Virus durch A. aegypti auftreten.

Über die von 1946-1955 in Afrika gemeldeten Gelbfieberfälle gibt die Karte, Abb. 31, Auskunft.

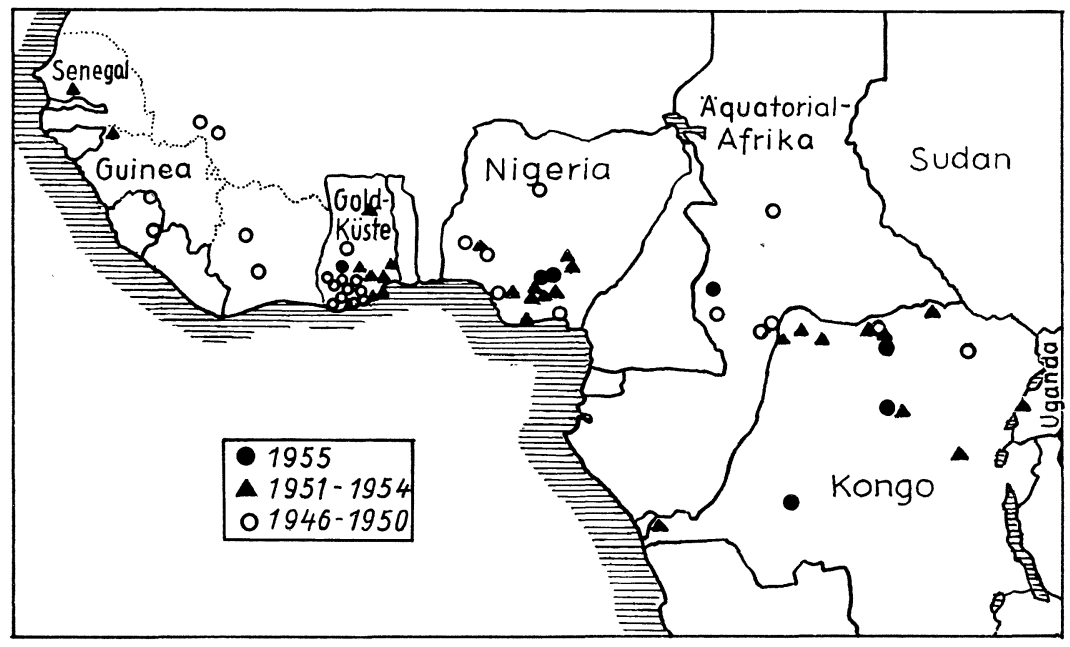

Abb. 31. Gemeldete Gelbfieberfälle in Afrika 1946-1955 (nach WHO, 1956a) 
Die Karte, Abb. 32 a, enthält die 1954 in Zentral- und Mittelamerika gemeldeten Gelbfiebererkrankungen (einschl. Dschungelgelbfieber).

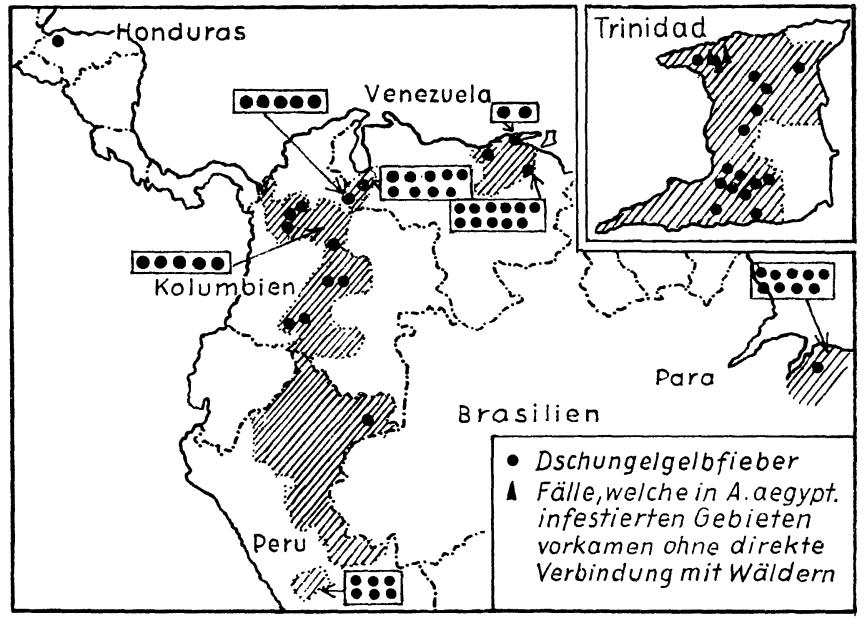

Abb. 32a. (nach WHO, 1956b)

Die Karte, Abb. 32 b, enthält nur die Dschungelgelbfieberfälle, die 1955 in Zentralund Südamerika gemeldet worden sind.

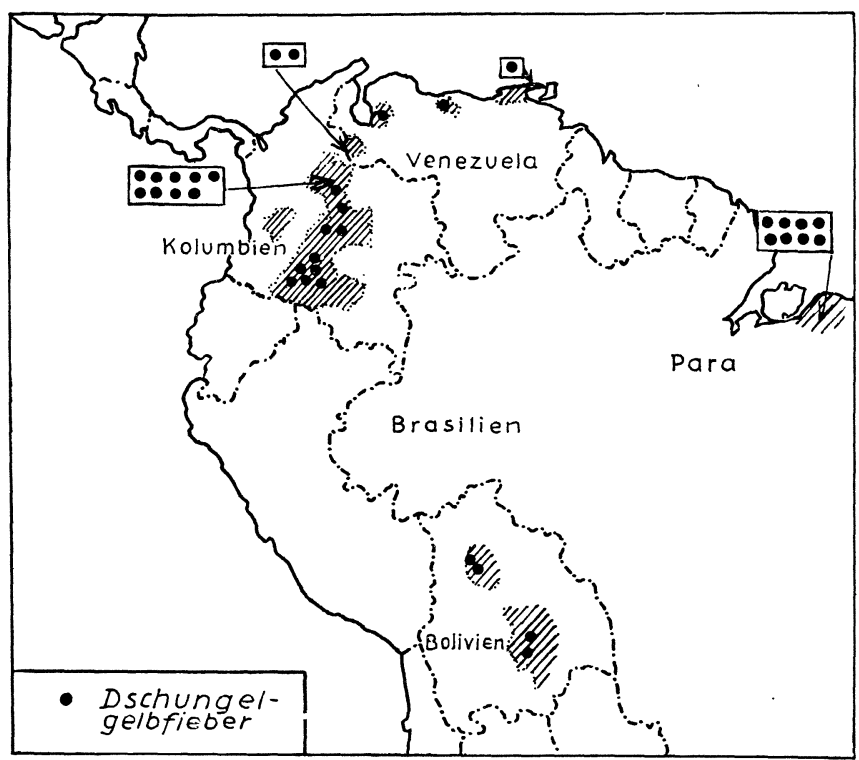

$A b b .32 b . \quad$ (nach WHO, 1956b) 
Der Wно wurden 1961 aus der ganzen Welt 3103 Gelbfiebererkrankungen mit 3073 Todesfolgen gemeldet. Wahrscheinlich lagen aber die tatsächlichen Zahlen, insbesondere die der Erkrankungen erheblich höher. In einer Epidemie in Äthiopien wurden allein 3021 Erkrankungen mit 3011 Todesfolgen gemeldet. Sonst waren in Afrika nur noch im Kongo 4 Erkrankungen mit 1 Todesfall bekannt geworden. Die übrigen Fälle betrafen Südamerika, wo die meisten Fälle in Peru (54 Erkrankungen mit 34 Todesfolgen) vorkamen (Weekly Epid. Rep., 1962; s. auch Bd. Gsh. Bl., 1962).

Zusammentassend ergibt sich: Für die Übertragung und das Fortbestehen des Gelbfiebers in den Städten wie auch in den Urwäldern spielen nur Stechmücken eine wichtige Rolle, da sie sowohl infizierbar sind als auch den Erreger durch Biß auf Wirbeltiere übertragen. Ihrer geographischen Ausbreitung und Ökologie entsprechend kommen verschiedene dieser Arten gleichzeitig mit Urwaldaffen und Menschen in Berührung, was die Übertragung von einer Wirtsart auf eine andere erleichtert. Das Stadtgelbfieber wird fast nur von A. aegypti übertragen; nur gelegentlich scheinen auch A. scapularis, A. fluviatilis und verschiedene Haemagogusarten in Frage zu kommen; letztere vermögen aber nicht zum Fortbestehen des Stadtgelbfiebers beizutragen. In Afrika sind neuerdings als Menschzu-Mensch-Überträger noch A.vittatus, A.metallicus und A.taylori hinzugetreten.

Auf die besondere epidemiologische Situation in Bwamba (Uganda) sei hingewiesen. In diesem Gebiet kommen sowohl epidemisches als auch endemisches Gelbfieber vor. Die größte Infektionshäufigkeit findet sich in der Bevölkerung, die in der Nachbarschaft des Urwalds lebt.

MacDonald (1956a, b) fand in Malaya eine Ausbreitung des A.aegypti von der Küste in die ländlichen Gebiete. Die Gegenwart dieser Mücke in Malaya stellt eine dauernde und erhebliche Gefahr für eine Einschleppung und Ausbreitung des Gelbfiebers in diesem bisher frei gebliebenen Gebiet dar.

Während das epidemische »menschliche« Stadtgelbfieber noch vor einigen Jahrzehnten im Vordergrund aller epidemiologischen und prophylaktischen Bemühungen stand, tritt es für den Menschen heute mehr und mehr zurück. Durch die A. aegypti-Vernichtung in urbanen Gebieten ist es sogar schon weitgehend ausgerottet worden. Dafür tritt das sporadische Gelbfieber in den Vordergrund, und zwar nicht so sehr, weil es innerhalb der menschlichen Wohnstätten ständige Infektionsherde bedingt, sondern mehr noch, weil es der wichtigste Indikator für das »tierische« Gelbfieber ist, dem heute alle Bekämpfungsmaßnahmen zugewandt sind.

Schon Soper (1936a) sowie Walcott u. a. (1937) wiesen darauf hin, daß das Dschungelgelbfiebervirus in die Stadt gelangen kann, um dort eine klassische Stadtgelbfieberepidemie zu verursachen. Nach TAYLOR (1951) ist anzunehmen, daß viele plötzlich ausbrechende Epidemien in den Städten, welche lange gelbfieberfrei waren, aber Wäldern benachbart sind, durch Einschleppung des Waldvirus zustande gekommen und nicht von einem in der Stadt befindlichen stummen Herd ausgegangen sind (s. auch Dick, 1953a). Das menschliche Dschungelgelbfieber, dessen Bezeichnung Soper (1935a, b) geprägt hat, um das aus dem Waldzyklus abgezweigte, durch andere Mückenarten als A. aegypti übertragene Gelbfieber des Menschen zu unterscheiden, ist in Amerika seit vielen Jahren wahrscheinlich die einzige noch vorkommende epidemische Erkrankungsform. Nach TAYLOR (1951) soll der letzte offenbar durch A. aegypti übertragen gewesene Fall 1942 in Peru vorgekommen sein. Das menschliche Dschungelbfieber tritt meist in ländlichen, häufig abgelegenen Gebieten auf, in denen ärztliche Versorgung fehlt. Hier können Ausbrüche schweren Epidemiecharakter annehmen. Durch den behördlichen Meldedienst wird zweifellos nur ein kleiner Teil der vorkommenden Erkrankungen bekannt. Viele Epidemien bleiben sogar völlig unbemerkt und werden erst bei Immunitätsprüfungen nachträglich festgestellt (H. Н. Змттн, 1951).

Als Überträger des Dschungelgelbfiebers in Mittel- und Südamerika von Affe zu Affe und von Affe zu Mensch sind bekannt geworden: Aedes leucocelaenus, Haemagogus spegazzinii 
falco, H.capricornii, H.equinus, H.splendens. Kомp (1955) hält jede Haemaggogusart, welche Menschen in Erdbodennähe anfällt, für mögliche Dschungelgelbfieberüberträger. So sind auch die periodisch vom Amazonas in Zentral- und Südbrasilien einwandernden Gelbfieberepizootien zu erklären, denn in Brasilien sind seit 1955 keine Aedes aegypti-Herde mehr gefunden worden (Franco, 1957). Wahrscheinlich hat es sich auch bei 100 an einem Fieber unbekannter Ursache gestorbenen Eingeborenen Panamas 1952 um Gelbfieber gehandelt, da in der Nähe des Ausbruchs Haemagogus Boshelli-Osorno-Mesa gefunden worden ist.

Mit Überschreiten der Grenze zwischen Honduras und Guatemala Ende 1955 ist das epizootische Gelbfieber in ein. ganz neues ökologisches Gebiet mit zunächst unbekannten Überträgern eingedrungen. De Rodaniche und Galindo (1957a) und Boshell-ManRique und Bevier (1958) isolierten das Virus unter den bisher angetroffenen Mückenarten dieses Gebietes in Haemagogus mesodentatus, H. equinus und Sabethes chloropterus; sie halten die beiden ersten Arten für primäre und die letztere für eine etwaige sekundäre Überträgerart. Alle 3 sind Baumkronenbewohner; in Bodennähe werden sie nur unter ungewöhnlichen Bedingungen gefunden, z. B. beim Abbrechen der Baumkronen und dadurch Eindringen des Sonnenlichts in die Tiefe des Waldes. In den großen Regenwaldgebieten ist das Dschungelgelbfieber geradezu eine Krankheit des Walddaches, unter dessen Bewohnern die Baumkronenmücken und -affen betroffen sind. Diese Feststellungen in Guatemale entsprechen weitgehend jenen in Nikaragua und Panama, obwohl in diesen beiden Staaten andere Überträger gefunden worden sind (Galindo u. a., 1950, 1951, 1956a, b; Galindo und Trapido, 1955, 1956, 1957; s. auch Boshell-Manrique, 1955; Trapido und Galindo, 1956; BoshellMANRIQUE und GROOT, 1957).

Patino Camargo (1933) hatte schon 1933 mittels der Mäuseschutzprobe eine starke latente Gelbfieberdurchseuchung der Stadt Muzo in Kolumbien gefunden, obwohl niemals A. aegyptiMücken festgestellt worden waren. $47 \%$ der Bewohner hatten N-AK. Weitere Untersuchungen von Kerr u. a. (1960) ergaben, daß es sich hier um Dschungelgelbfieber gehandelt hat. Bei $70 \%$ der Männer und 60\% der Frauen wurden N-AK nachgewiesen. Als Viruswirte werden Opossums, als Überträger von diesen auf Menschen und vielleicht von Mensch zu Mensch Haemagogus-Mücken vermutet.

Auch in Argentinien kommt Dschungelgelbfieber vor, wo es durch Haemagogus- und nichtdomestizierte Aedesarten übertragen wird und auch beim Menschen auftritt. Demnach erstreckt sich das Gelbfieber in Südamerika bis $31^{\circ} 20^{\prime}$ südlich (Bejarono, 1956a, b). Ander son u. a. (1954) beschrieben den ersten menschlichen Dschungelgelbfieberfall auf Trinidad.

Im afrikanischen Urwald kommen als Überträger in erster Linie in Frage: Aedes africanus, A. luteocephalus, der allerdings in der Natur noch nicht infiziert gefunden worden ist, ferner unter Umständen noch Eretmapodites chrysogaster, Taeniorhynchus africanus für die TierMücke-Tierinfektion, A.simpsoni, der sich seinerseits an den Urwaldaffen infiziert, für die Mensch-Mücke-Menschinfektion. Über die Ökologie dieser Mückenart außerhalb Ugandas ist noch wenig bekannt geworden. Über die Art und Weise des Fortbestehens des Dschungelfiebers in Afrika, insbesondere, ob es direkt als Tier(Affe-)Mücke-Tier-Zyklus fortbesteht oder nur das Endglied eines noch anderen unbekannt gebliebenen Zyklus ist, ist noch nichts bekannt.

Das Dschungelgelbfieber wird oft eine Berufskrankheit genannt. Dies ist richtig, wenn man den Begriff auf jede Beschäftigung im Urwald ausdehnt (TAYlor, 1951), also Holzfällen, Urbarmachung von Waldrändern, Wegebau durch den Urwald u. ä., welche durch Fällen von Bäumen die Haemagogen aus der Wipfelhöhe auf die Erde und damit in Kontakt mit den Menschen bringt. Häufig genug werden aber auch Kinder und Farmarbeiter in der Umgebung infiziert.

Beim Dschungelgelbfieber ist die Letalität unter den kleinen Kindern verhältnismäßig niedrig, in der Altersgruppe 15-40 Jahre am höchsten. TAYlor und Fonseca DA CunHA (1946) fanden vom 15. Lebensjahr ab einen plötzlichen Anstieg der Immunitätshäufigkeit, und zwar vorwiegend bei männlichen Personen, was wiederum mit dem engeren Dschungelkontakt der männlichen Bevölkerung in Zusammenhang gebracht werden kann. Auch der seit Jahren in Brasilien und Kolumbien durchgeführte Viscerotomiedienst hat ein Überwiegen der Gelbfiebertodesfälle im männlichen Geschlecht ergeben, und zwar verhältnis- 
mäßig wenig Todesfälle im Alter unter 14 Jahren und mit einem Höhepunkt in der Altersgruppe von $20-30$ Jahren.

\section{3-2. Überträger}

Lange Zeit wurde angenommen, daß der Aedes aegypti Linn (= Stegomyia fasciata Theobald $=$ Culex fasciatus $=$ Aedes fasciatus Meigen) unter natürlichen Bedingungen der einzige Überträger des Gelbfiebers von Mensch zu Mensch wäre. Schon 1911 war aber FraNCo bei einer Gelbfieberepidemie aufgefallen, daß die Ansteckung nicht in der Umgebung der Wohnungen, sondern im Walde erfolgt zu sein schien, und nicht nur A. aegypti, sondern offenbar auch andere Mücken als Überträger in Frage zu kommen schienen. SopER u. a. (1933) stellten während einer im Jahre $1932 \mathrm{im}$ Channaan-Tal (Brasilien) wütenden ländlichen Epidemie fest, daß als Überträger A. aegypti fehlte, dafür aber A.scapularis in Frage zu kommen schien (s. auch Soper, 1934a, b). 1934 wurde eine Epidemie in einem ländlichen Gebiet der Hochebene von Matto Grosso (Brasilien) beobachtet, wo ebenfalls keine A. aegypti existieren (BURKe, 1937). Spätere Übertragungsversuche verschiedener Autoren mit weiteren Mückenarten ergaben, daß auch andere Mücken als Überträger in Frage kommen. So infizierten Shannon u. a. (1938b) Affen durch Biß in der Wildnis gefangener Mücken (s. auch Woodall und Bertram, 1960; Bertram u. a., 1960; Lamotte, 1960; Bertram und Bird, $1961 \mathrm{a}, \mathrm{b}$; Chamberlain und Sudia, 1961; Ogden, 1961).

\section{Aedes-Arten}

Als Heimat des Aedes aegypti gilt Afrika. Whitman (1951) nimmt an, daß er ursprünglich eine Waldmückenart, ein Baumhöhlenbrüter und Tierblutsauger war. Es gab aber Stämme, welche Domestikationsneigung hatten und in Ost-West-Richtung gewandert sind, wobei Wasserbehälter als Transportmittel gedient haben mögen. Auf solche Weise ist diese Mücke schließlich nach Westafrika und von dort als Hausbrüter nach Südamerika gelangt. Aus Untersuchungen von Tinker und Hayes (1958) über das Vorkommen des A.aegypti in den USA geht hervor, daß diese Mückenart in einem ausgedehnten Gebiet des Südostens der USA beheimatet ist und es daher hier zu gefährlichen städtischen Gelbfieberepidemien kommen könnte, wenn das Virus in Ortschaften besonders in Texas, Alabama, Georgia und Südcarolina eingeschleppt würde. In Amerika findet man eine vorwiegend in Häusern und sonstigen Räumen lebende Form, die ihre Lebensbedingungen weitgehend an das menschliche Leben anpaßt, fast nur in künstlichen Wasserbehältern in menschlichen Wohnstätten und deren unmittelbarer Nachbarschaft brütet und fast nur Menschenblut saugt. Übergangsformen zwischen beiden Extremen kommen vor. Die Brut- und Lebensgewohnheiten des A.aegypti in Afrika und Amerika sind also nicht die gleichen.

Auch in Westafrika ist der A. aegypti vorwiegend ein Menschenblutsauger (GILletr, 1951) und Hausbrüter, aber in der Auswahl der Brutplätze weniger domestiziert. Eiablagen und Larven finden sich nicht nur in künstlichen Wasserbehältern der menschlichen Wohnstätten, sondern auch bis zu einigen 100 Metern von letzteren entfernt im Wald und in den Bambusbüschen. Der A. aegypti brütet hier in Baumhöhlen und Wasserpfützen (Duns, 1927a, b, c) und scheint nach wie vor als einziger Überträger von Mensch zu Mensch in Frage zu kommen (Beeuwkes und Hayne, 1932; Beeuwhes und Mahaffy, 1935; Bugher, zit. Whitman, 1951). In Uganda ist die Mücke vorwiegend ein Waldbewohner und Tierblutsauger und kommt daher nur selten in Städten und Dörfern vor (HADDow, 1945a, c). Die außerordentliche Wandlungsfähigkeit der Lebensgewohnheiten bzw. der Ökologie des A. aegypti in Afrika gestaltet in diesem Kontinent die Gelbfieberbekämpfung schwierig oder macht sie vielleicht sogar unmöglich, da die Ausrottung nicht auf die menschlichen Wohnstätten und ihre nähere Umgebung beschränkt bleibt (Whitмan, 1951; Thомas, 1960).

Die A. aegypti-Variante Queenslandensis dürfte Überträger von Stadtgelbfieber außerhalb von Afrika sein. In Afrika kommen als Überträger im Inland auch domestizierte Stämme von A. aegypti formosus in Frage (Mattingly, 1958). Alle A. aegypti-Stämme scheinen in gleicher Weise Virusträger sein zu können, ob sie nun von Amerika, Afrika oder Niederländisch-Indien sind (Dinger u. a., 1929; Hindle, 1930; Lewis u. a., 1942). 
Morphologie, Entwicklung und Lebensweise des Aedes aegypti sind besonders von Brumpt (1949) und Piekarski (1954) beschrieben worden. Die relativ kleine Mücke besitzt alle typischen Kennzeichen der Culicinae, ist dunkelbraun, aber besonders durch 2 kräftige gebogene weiße Linien auf der Rückseite des Thorax ausgezeichnet, zwischen denen sich in der Mitte längs verlaufend 2 feinere, mehr goldige saitenartige Linien befinden. Aus dieser Linienanordnung ergibt sich die charakteristische "Leierzeichnung", die man bei keiner anderen Stechmücke findet. Weitere Merkmale sind schneeweiße Flecke breiter Schuppen auf dem Scutellum und im Nacken, schneeweiBe seitliche Schuppenflecke am Thorax und Hinterleib, dessen Querbänder ein mattes und unreines Weiß zeigen, weiße Ringel am Grunde der Fußglieder, besonders an den Hinterbeinen ausgebildet, an den Tastern einige Flecke heller Schuppen, ganz schwarzer Rüssel, ungefleckte, klar durchsichtige Flügel mit feinen fast haarartigen Schuppen an den Adern entlang dem Saum (siehe Abb. 33).
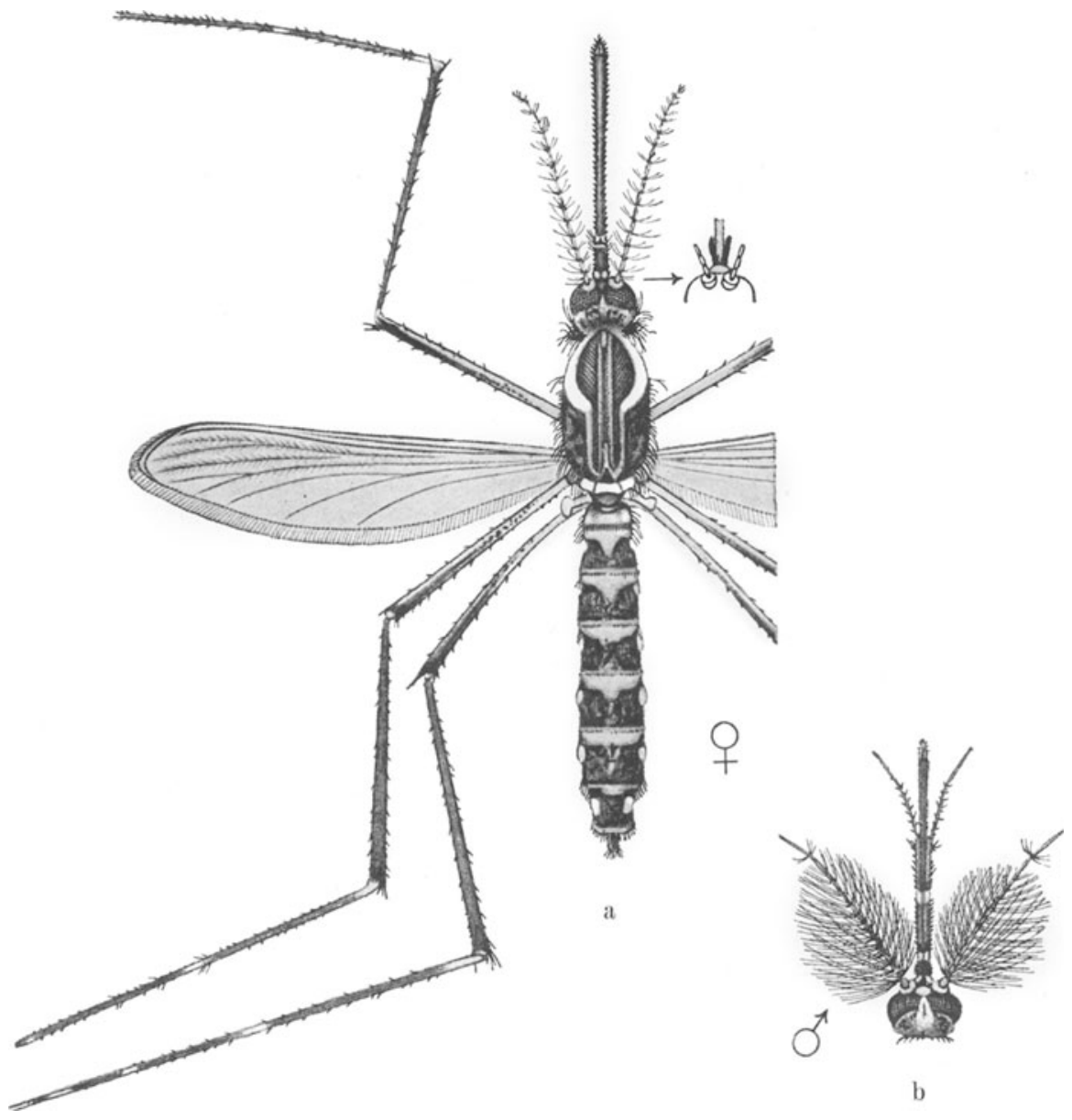

Abb. 33. Aedes aegypti. a) Imago, Weibchen. Am Kopf weist der Pfeil auf die kurzen, in der Nebenabbildung schwarz dargestellten Maxillarpalpen. b) Kopf eines Männchens, mit buschigen Fühlern und langen Maxillarpalpen (nach Piekarski, 1954) 
Die erwachsenen Mücken finden sich während der Ruhestunden in den dunkelsten Ecken der Räume, hinter Kleidungsstücken, Möbeln und Bildern, unter Betten usw. Zu ihrer normalen Ernährung ist eine Temperatur von mindestens $23^{\circ} \mathrm{C}$ erforderlich, zu ihrer vollen Aktivität 23 bis $28^{\circ} \mathrm{C}$; unter $17^{\circ} \mathrm{C}$ wird die Mücke träge oder starr und vermag nicht mehr zu saugen, unter $6^{\circ} \mathrm{C}$ stirbt sie in kurzer Zeit. Ihr Flug ist geräuschlos und schnell, geht aber nur über kurze Entfernungen. Sie wandert nicht und wird auch nicht vom Winde verschleppt. Thre größte Flugweite soll normalerweise nur $300 \mathrm{~m}$ betragen. Von ankernden Schiffen vermag sie aber größere Strecken über Wasser an Land zu fliegen, was für die Einschleppung des Gelbfiebers in Häfen und Flußufergebiete von Bedeutung ist (Shannon und Davis, 1930; Shannon u. a., 1930). Sie bedarf großer Iuftfeuchtigkeit. Eine Anpassung an große Trockenheit und große Höhe findet nicht statt.

Die Mücke beißt mit Vorliebe in den frühen Morgenstunden und in der Abenddämmerung, aber auch sonst zu jeder Tageszeit, wenn sie hungrig ist (s. auch McClelland, 1959). Nur das Weibchen saugt Blut, um seine Eier zu ernähren und ausreifen zu können. Eiablage erfolgt nur bei Temperaturen über $20^{\circ} \mathrm{C}$. Oft genügt für ihr Zustandekommen nicht nur 1 Blutmahlzeit, sondern es sind mehrere erforderlich. Bei jeder Blutmahlzeit besteht die Möglichkeit der Gelbfieberübertragung.

Nach Wore (1937) ist zum Zustandekommen der Eiablage nicht das Gesamtblut erforderlich, sondern jeweils nur einer der folgenden Bestandteile: Erythrozyten, Hämoglobin, Serum oder Plasma. Die Weibchen leben unter Versuchsbedingungen bis zu etwa 150 Tagen; während dieser Zeit kommt es unter günstigen Bedingungen zu zahlreichen Eiablagen. Jedes Gelege zählt 70 bis 150 Eier.

Die Eier sind länglich, schwarz gekörnelt; sie haben eine flachere Ober- und eine gewölbte Unterseite. Sie werden meistens am Rande wasserhaltiger Behälter, nur selten dagegen an offenem Wasser abgelegt. Da die Mücke auch in Baum- und Bambushöhlen, Blattachseln, Bütten, Fässern, Kanistern, Zisternen, Konservendosen, Flaschenböden, Eimern, Muschelschalen, Kokosnußschalen u. a. im Hause, Stall und in unmittelbarer Nachbarschaft ja sogar in Weihwasserbecken brütet und selbst die kleinsten Wasserstellen nicht verschmäht, ergibt sich eine Vielfaltigkeit der Eiablage, welche schon die Gefährlichkeit der Mücke als Überträger des Gelbfiebers erklärt. Die Eiablage erfolgt meistens über dem Wasserspiegel am Rande der Behälter. Regenwasser wird bevorzugt. Im Notfall erfolgt die Eiablage auch in nur feuchter Umgebung. Die Eier vermögen Trockenperioden zu überleben und dann erst in der nächsten Regenzeit zu schlüpfen. Die Luftfeuchtigkeit darf aber nicht 70\% unterschreiten. Sauerstoffreichtum des Wassers verhütet das Schlüpfen; durch Zusatz reduzierender Stoffe (Pyrogallol, Hydrochinon, Vitamin C u. a.) wird ein Schlüpfen in 10-20 Min möglich (Roubaud, zit. Joyeux und SicÉ, 1950). Bei tiefen Temperaturen (unter $0^{\circ}$ C) sterben die Eier in wenigen Tagen (Davis, 1932 b; HadDow u. a., 1959a).

Die Larven, welche sich schnell entwickeln, bevorzugen das Halbdunkel und scheinen sich in dem verunreinigten Wasser von Bakterien zu ernähren. Werden sie gestört, lassen sie sich auf den Boden des Gefäßes sinken; sie können lange unter Wasser aushalten und werden dann leicht übersehen. Die Puppe reift an der Stelle, an der sich die Larve entwickelt.

Bei der Larve folgen auf den einheitlichen breiten Brustabschnitt 9 Hinterleibsegmente; das 8. Segment trägt das Atemrohr und den sogenannten "Striegel", d. i. eine Reihe mehrspitziger Schuppen. Das Atemrohr hat eine Reihe von Zähnen mit Nebenzähnchen, den sogenannten »Kamm». Hinter diesem steht jederseits ein mehrteiliges Haar. Das ziemlich kurze Atemrohr ist an der Spitze mit Klappen versehen, die beim Tauchen eine Luftblase festhalten. Am Ende des 9. Segmentes, das nicht ganz von einem derberen braunen Chitinsattel umgriffen wird, befinden sich 4 große glasklare "Kiemen", unter diesen ein aus geteilten Borsten gebildetes Ruder und über ihnen die sogenannten Schwanzhaare. Der Larvenkopf trägt kleine, ganz glatte Fühler mit einem winzigen ungeteilten Fühlerschafthaar, welche die A. aegyptiLarve so gut wie eindeutig von anderen Stechmückenlarven unterscheiden (siehe Abb. 34). Die Entwicklung einer Generation von Ei bis Mücke dauert bei günstigen Ernährungs- und Temperaturverhältnissen $\left(23-25^{\circ} \mathrm{C}\right)$ etwa 10-11 Tage, hiervon 2 Tage im Ei, 6 Tage der Larve, 2 Tage der Puppe; nach BRUMPT 11-18 Tage.

Mücken, Larven und Eier gelangen leicht auf Schiffe und andere Verkehrsmittel, so daß 
sie über große Entfernungen verschleppt werden. Auf langsam fahrenden Schiffen können sich ganze Generationen entwickeln.

Man findet A. aegypti heute in allen tropischen Breitengraden.

Soweit die Gelbfieberverbreitung an Aedes geknüpft ist, beschränkt sie sich nicht nur auf deren geographisches Vorkommen überhaupt, sondern auf die Zonen, innerhalb welcher die Mücke noch beißt. Diese liegen zwischen dem 30 . und $40^{\circ}$ nördlicher und südlicher Breite. In Eurona findet man A. aegypti z. B. in Griechenland und in Konstantinopel.

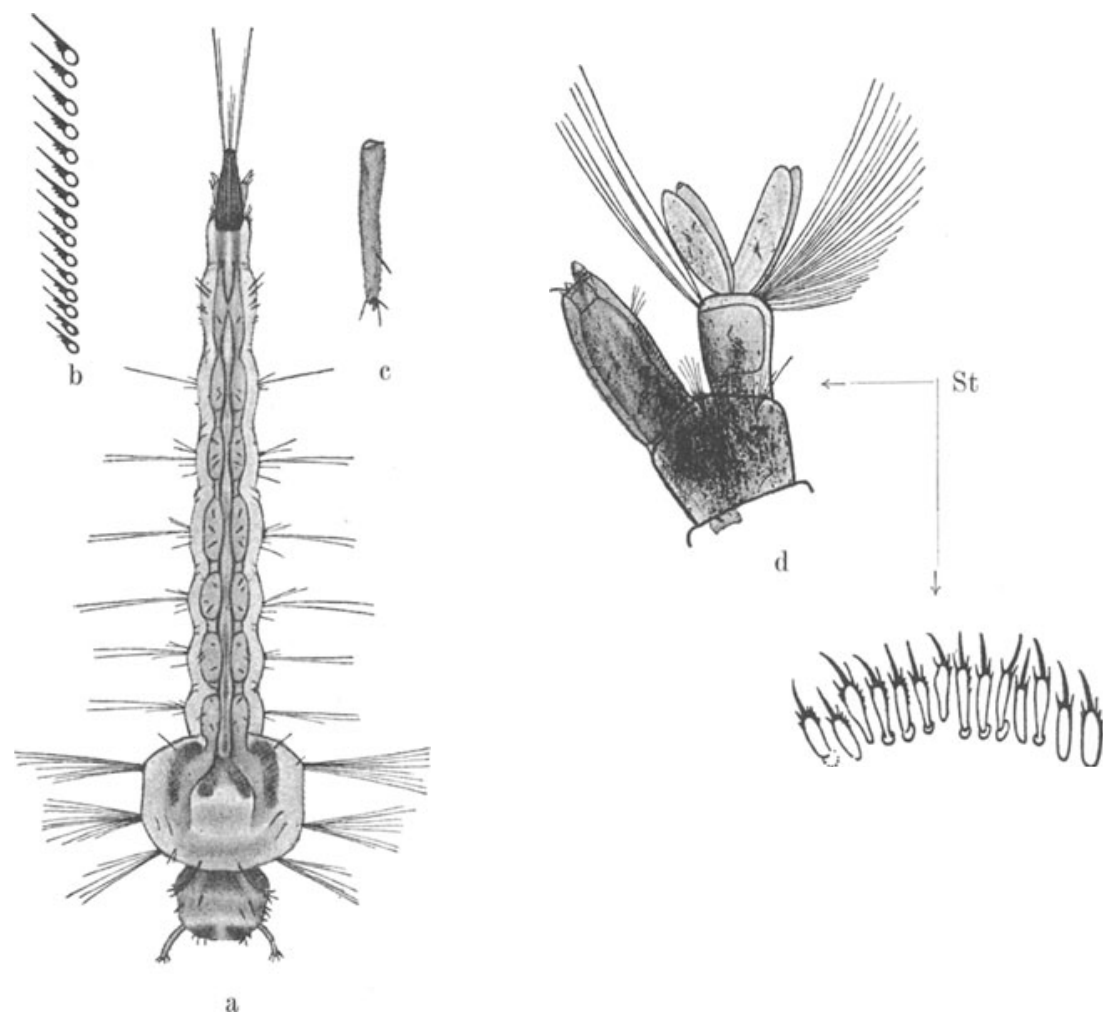

Abb. 34. Aedes aegypti. Larve a) dorsal gesehen b) der "Kamm" des Atmungsrohres c) ein Fühler (stärker vergrößert) d) 8. und 9. Segment der "Striegel " (St) (a etwa 10×)

(nach Piekarski, 1954)

Es ist noch nicht bekannt, warum in Malaya, wie überhaupt fast überall in Südostasien, wo die A.aegypti-Mücken günstige Lebensbedingungen finden und empfängliche Affen reichlich vorhanden sind, bisher kein Gelbfieber aufgetreten ist (Gillett und Ross, 1955). Denn der A. aegypti vermag auch hier unter Laboratoriumsbedingungen das Gelbfieber von Affe zu Affe (Macaca mulatta) durch Biß zu übertragen. Die Geschichte des Gelbfiebers und der Dengue weist aber darauf hin, daß beide Krankheiten sich ausschließen (s. auch FrEDRIKSEN, 1955)

Nach Whitman (1951) beruht die Fähigkeit der Mücken, Gelbfieber zu übertragen, auf dem Grad des Kontaktes zwischen Mücken und Mensch bzw. Tier, und auf dem Schicksal des aufgenommenen Virus. Das Mückenweibchen wird nur nach einer Blutmahlzeit an einem Kranken 
oder Infizierten, der sich im virämischen Stadium befindet, infektiös. Für das Zustandekommen einer Mückeninfektion scheint maßgebend zu sein, zu welchem Zeitpunkt der Inkubation des Menschen die Blutmahlzeit erfolgt. Schon Bauer und Hudson (1928a) sowie Bauer und MaHAFFy (1930) hatten beobachtet, daß mitunter trotz starker Virämie des Blutspenders die Mücken nicht infektiös waren. Hinde (1930) führt dies auf das gleichzeitige Vorhandensein von AK im Blut zurück, welche das Virus erst im Mückenmagen neutralisieren (s. auch BATES und Roca Garcia, 1946b; Waddell und Taylor, 1947). Voraussetzung für die neutralisierende Wirkung im Blut befindlicher AK auf das Virus im Mückenmagen scheint zu sein, daß die AK nicht erst nachträglich durch eine weitere Blutmahlzeit aufgenommen werden. Eine Sterilisierung bereits infizierter Mücken durch Ansetzen an Immuntiere scheint also nicht möglich zu sein (Dinger u. a., 1929; Hindle, 1930; Davis, 1931a). Nach Davis (1934a) scheinen durch einen Mückenstich 100 Affen-ID in den Affen zu gelangen. Wнгтмал (1937) infizierte Mücken mit dem Blut von Affen, deren Serum 570 bzw. 1800 Mäuse-MID (AsibiVirus) enthielt, d. h. die aufgenommene Virusmenge im Blut wurde auf 14,25-28,5 MID geschätzt. Diese Werte liegen weit unter jenen, wie sie von Davis u. a. (1933) angegeben worden sind; im Affentest fanden sie, daß eine Mücke im Durchschnitt 1-2 Millionen LD aufnimmt. Aragao de Beaurepaire und da Costa Lima (1930) errechneten, daß eine Suspension von, 3 infizierten A. aegypti noch in einer Verdünnung von über 1:1 Million Rhesus-Affen zu infizieren vermag.

Die »extrinsische Inkubationszeit», d.h. die Zeit zwischen Blutmahlzeit und Infektiöswerden der Mücke, ist auch beim Gelbfieber von der Umweltstemperatur abhängig. Nach Hindle (1930) sowie Davis (1931 c, $1932 \mathrm{a}, \mathrm{b})$ wird die Mücke bei $37^{\circ} \mathrm{C}$ bereits nach 4 tägiger, bei $36^{\circ} \mathrm{C}$ nach 5 tägiger, bei $31^{\circ} \mathrm{C}$ nach 6 tägiger, bei $23,4^{\circ} \mathrm{C}$ aber erst nach 11 tägiger Inkubation des Virus ansteckungsfähig (s. auch Carter, 1900, $1901 \mathrm{a}, \mathrm{b}$; Whitman und ANTUNEs, 1938a). Bei 10-18 ${ }^{\circ} \mathrm{C}$ werden die Mücken überhaupt nicht mehr infektiös; sie vermögen aber den Erreger zu konservieren; auf eine Temperatur von $36^{\circ} \mathrm{C}$ gebracht, tritt Infektiosität wieder nach 6 Tagen ein. Bei nur $8^{\circ} \mathrm{C} 4$ Wochen aufbewahrt, ist eine Temperatur von $36^{\circ} \mathrm{C}$ 6 Tage lang erforderlich, um die Mücken wieder infektiös zu machen. Temperatur von $40^{\circ} \mathrm{C}$ (7 St.) führt zu einer Pathogenitätsabnahme des Virus. Um dauernd infektiös zu bleiben, bedarf die Mücke aber Temperaturen zwischen 26 und $32^{\circ} \mathrm{C}$.

Die Beobachtungen von Frobisher u. a. (1931) weisen darauf hin, daß das Virus innerhalb einer Mückenkolonie so lange zu bestehen vermag, wie die durchschnittliche Lebensdauer der Mücke selbst beträgt. Die einzelnen Mücken scheinen demnach dauernd infektionsfähig zu sein (ARagao de Beaurepaire, 1929b). Während der extrinsischen Inkubationszeit ist das Virus durch Verimpfung des Mückenleibes auf Tiere nachweisbar (BAUER und Hudson, 1928b). Das Virus ist in der Mücke weit verbreitet. Man findet es in besonders großen Mengen in der Speicheldrüse und im Kot (Gay und Sellards, 1927; Aragao de Beaurepaire und Costa Lima, 1929 a-g; Hindle, 1929; Davis und Shannon, 1930). In der Hämolymphe macht es im allgemeinen $0 ; 1-1 \%$ der Gesamtvirusmenge aus (Boorman, $1960 \mathrm{a}, \mathrm{b}$ ).

Bereits Gay und Sellards (1927) sowie Seldards (1935) schlossen aus den Beziehungen zwischen Temperatur und Inkubationszeit auf eine Virusvermehrung im Mückenleib, während Russeld (1932) sowie Davis u. a. (1933) eine solche ablehnten. Nach Sellards (1935) wird ein großer Teil des mit der Blutmahlzeit aufgenommenen Virus von den Mückengeweben zerstört, und erst dann setzen Virusvermehrung und Infektiöswerden des Mückenbisses ein (s. auch Kumm und Laemmert, 1950). Whitman (1937) führte den endgültigen Beweis der Virusvermehrung. Er fand auch, daß das Virus während der ersten Inkubationstage in der Mücke schnell abnahm, um sich vom 7. Tage ab zu vermehren. Boorman (1960a, b) stellte fest, daß das Virus 10 Min nach der infizierenden Blutmahlzeit in der Hämolymphe erscheint, nach 3 St. wieder verschwindet, um nach 48 St. erneut zu erscheinen.

Bates und Roca Garcia $(1945,1946 \mathrm{a}, \mathrm{b}, \mathrm{c})$ beobachteten, daß die Übertragungsfähigkeit der Mücken in Beziehung zu der Gesamtvirusmenge im Organismus steht, nicht aber auf einer Infektion der Speicheldrüsenzellen beruht. In stark infizierten Mücken bleibt das Virus nach einer Bebrütung bei $30^{\circ} \mathrm{C}$ anschließend 32 Tage bei $1-4^{\circ} \mathrm{C}$ am Leben; bei einer mittleren oder schwachen Infektion verkürzt sich die Lebensdauer auf 5-12 Tage (Ross, 1950). Das Gelbfiebervirus vermag in toten Mücken bei $26-30^{\circ} \mathrm{C}$ bis zu $72 \mathrm{St}$ am Leben zu bleiben. Um das 
Virus in den Mücken möglichst nicht zu schädigen, empfiehlt es sich, sie mit Äther zu töten (WADDELL, 1945).

Eine erbliche Übertragung des Erregers von Generation zu Generation findet nicht statt; weder die Eier infizierter Mücken noch die aus solchen Eiern hervorgegangenen Mücken sind infektiös (Stokes u. a., 1928a; Philip, 1929; Davis und Shannon, 1930; Frobisher u. a., 1931; Kerr und Hayne, 1932; Whitman und Antunes, 1938b). Die frühere Behauptung von Marchoux und Simond (1906 a, b), daß sie einen Menschen experimentell durch den Biß einer Mücke, welche aus dem Ei einer infizierten Mücke geschlüpft war, infiziert hätten, ist damit widerlegt. Eine Infektion von Mückenmännchen durch Mückenweibchen ist wahrscheinlich nur eine äußere mechanische durch Verschmierung von Kot des letzteren (Aragao de Beaurepatre, 1929; Hindle, 1930). Auch Kerr und Hayne (1932) sowie Whitman (1937) gelang keine Kopulationsinfektion. Während Davis und Shannon (1929a, b, 1930) Larven nicht experimentell infizieren konnten, gelang dies Whitman und Antunes (1938b) mit genügend konzentrierten Virussuspensionen; die aus diesen Larven hervorgehenden Puppen und erwachsenen Mücken behielten die Infektion (s. auch Christopher, 1960; KrIEG, 1961).

Außer A. aegypti werden folgende Aedesarten in Südamerika gefunden:

Aedes (Ochlerotatus) scapularis ist eine in Mittel- und Südamerika zwischen Westindien bzw. Mexiko und Argentinien weit verbreitete Aedine, die sich leicht experimentell infizieren läßt und durch Biß leicht die Infektion weiter überträgt. Die extrinsische Inkubationszeit beträgt 16-23 Tage (Davis und Shannon, 1929a, b; Whitman und Antunes, 1937). Ob sie aber in Brasilien an der Verbreitung des epidemischen Dschungelgelbfiebers beteiligt ist, ist noch unbekannt (Soper u. a., 1933, Whitman, 1951). Natürlich infizierte A. scapularis sind niemals gefunden worden (La EMmerT u. a., 1946). Sie gelten mehr als fakultative Vorstadtmücken denn als reine Waldmücken (Shannon, 1931; Shannon u. a., 1938b; Bates, 1944c).

Aedes (Taeniorhynchus) fluviatilis kommt in Brasilien, Guyana und Mittelamerika von Mexiko bis südlich von Panama und Kolumbien vor. Diese Mücke gilt als Vorstadtbrüter; sie ]äßt sich experimentell infizieren und überträgt durch Biß das Virus nach einer extrinsischen Inkubationszeit von 16 Tagen (Davis und Shannon, $1931 \mathrm{a}, \mathrm{b}$; Whitman und Antunes, 1937).

Aedes (Taeniorhynchus) taeniorhynchus kommt längs der nord- und südatlantischen Küste von New-England bis Argentinien vor und dringt zur Blutmahlzeit häufig in die Häuser ein. Nach experimenteller Infektion wird das Virus nach 19 tägiger Inkubationszeit durch Biß übertragen. Körperemulsionen sind noch nach 24 Tagen virushaltig (Davis und Shannon, $1929 \mathrm{~b} ; 1931 \mathrm{a} \mathrm{b}$; Whitman und Antunes, 1937).

Aedes (Conopostegus) leucocelaenus ist in ganz Südamerika von Panama bis Argentinien, besonders in Brasilien weit verbreitet (Kumm und CerqueIra, 1951). Natürlich infizierte Mücken werden in Kolumbien gefunden (Bugher u. a., 1944; Boshell-Manrique und Osorno Mesa, 1944). Sie kommen auch ziemlich häufig in Panama dort vor, wo 1949 menschliches Gelbfieber aufgetreten ist (Countney, 1950; Galino, u. a., 1950). Der A.leucocelaenus ist eine Waldmücke, die als einer der Hauptüberträger des Dschungelgelbfiebers in Südamerika in Frage kommt. Die Mücke hat ähnliche Lebensgewohnheiten wie die Haemagogusarten, brütet allerdings nicht in Baumkronen und ist auch nicht überall dort häufig, wo Dschungelgelbfieber auftritt (Laemmert u. a. 1946; Kumm, 1950). Galindo u. a. (1952) unterscheiden innerhalb der Gruppe: A.leucocelaenus (Dyer und Shannon), A.leucocelaenus darki, A.leucophoebus und A.leucotaeniatus.

In Afrika werden folgende Aedes-Arten gefunden:

Aedes (Stegomyia) africanus (Theobald), die mit A.luteocephalus eng verwandt, wenn nicht sogar identisch ist, ist im tropischen Afrika weit verbreitet (Lewis, 1943; Meillon, 1946). Beide Arten leben vorwiegend in Baumkronen (Mattingly, 1949) und sind meistens Baumhöhlenbrüter (DunN, 1926, 1937 a, b; PHILIP, 1933); sie werden nur äußerst selten in Häusern gefunden (KERR, 1933). Sie beißen vorwiegend Affen in der Abenddämmerung, wenn diese zur Ruhe gegangen sind (HADDow, $1945 \mathrm{a}, \mathrm{b}$, c; HadDow und MaHAFFY, 1949).

Aus epidemiologischen Gründen wird vermutet, daß A. africanus einer der natürlichen Überträger des Dschungelgelbfiebers von Affe zu Affe in Uganda ist (SмiтнBuRN und HadDow, 1946; Haddow u. a., 1946, 1947). Ross und Gillett (1950) bestätigten den Wald- 
zyklus (Affen-Mücke-Affe) und stellten eine extrinische Inkubationszeit des Virus in der Mücke von 13-39 Tagen fest. PHililp (1929, 1930a) fand bei A. africanus eine Inkubationszeit von 12 Tagen. BÁuer (1928) hatte beobachtet, daß A.luteocephalus das Virus nach einer extrinsischen Inkubationszeit von 15-33 Tagen durch Biß auf Rhesus-Affen überträgt.

Haddow u. a. (1948) sowie Smithburn u. a. (1949a) infizierten Rhesus-Affen mit einer Verreibung von wilden A.africanus aus der Umgebung von Schildwacht-Affen; die Affen erkrankten an Gelbfieber.

Gelegentlich werden auch Menschen in den Anpflanzungen und auf dem Waldboden gebissen (Haddow und Dick, 1948; Gillett, 1951). A. africanus dürfte für die sporadischen Gelbfieberinfektionen bei Menschen verantwortlich sein, welche in nächster Nachbarschaft von Wäldern wohnen, in denen enzootisches Affen-Gelbfieber besteht, wo aber anderseits A. simpsoni die Menschen nicht beißen (Dick, 1953b).

Die von Chwatt (1949) sowie Bruce-Chwatt (1950) von A.africanus abgetrennte neue Art »Aedes pseudoafricanus" vermag den Gelbfiebererreger ebenfalls durch Biß zu übertragen.

Da das Erwachsenenstadium die trockene Jahreszeit überlebt (RoBınson, 1950), kann das Mückenweibchen Virusüberträger von einer feuchten zur anderen feuchten Jahreszeit sein. (s. auch Gillett u. a., 1950).

Aedes (Stegomyia) simpsoni (Theobald) ist eine in Afrika zwischen dem Sudan und Natal weit verbreitete Mücke. Sie hat in verschiedenen Gegenden verschiedene Lebensgewohnheiten. In vielen Gebieten, z. B. Nigeria, ist sie ein Baumhöhlenbrüter (Duns, 1926, 1927a; KeRR, 1933; PhILIP, 1933). In Bwamba (Uganda) ist sie dagegen ein Blattachselbrüter in der Umgebung der Häuser, Bananen-und Colocasia-Anpflanzungen (Haddow, 1945b). A. simpsoni ist eine Mücke, die Menschenblut anderem Warmblüterblut vorzieht. Bereits PHILIP (1929) fand, daß dieser Aedes das Virus experimentell durch Biß zu übertragen vermag, wobei die extrinsische Inkubationszeit 19 Tage beträgt. Aber erst MaHAFFy u. a. (1943) wiesen das Gelbfiebervirus bei in der Wildnis gefangenen Mücken nach, und zwar zu einer Zeit, als dieses sich auch in einer menschlichen Bevölkerung der Gegend angesiedelt hatte. Später wiesen SmithbuRn und Haddow (1946) den Erreger in Mücken nach, auch ohne daß er in der benachbarten Bevölkerung vorzukommen schien. Dies weist darauf hin, daß A.simpsoni nicht nur das Stadtgelbfieber überträgt (GibBins, 1942; Lumsden, 1951a), sondern sich auch durch Blutmahlzeiten an anderen Wirten als Menschen zu infizieren vermag (s. auch GiLLETt, 1951). Haddow u. a. (1948), Haddow (1950) sowie Mahaffy (1949) nahmen an, daß A.simpsoni besonders als Überträger des Virus von Affen (z. B. Colobus und Cercocebus) auf den Menschen im Dschungel in Frage kommt.

Aedes strelitziae (Muspratt) ist in Natal (Südafrika) in waldigen Tälern und Schluchten sehr reichlich verbreitet. Er kommt in Gesellschaft mit A.simpsoni in Bananenkulturen vor und beißt den Menschen sehr gern. Er vermag sich an intraperitoneal mit Gelbfieber infizierten Rhesus-Affen durch eine Blutmahlzeit anzustecken und 14-18 Tage später einen weiteren Affen zu infizieren. Über die praktische Bedeutung dieses Aedes als Gelbfieberüberträger in der Natur ist noch nichts bekannt (GILlETt und Ross, 1953).

Aedes (Stegomyia) vittatus (Bigot) $=$ A.sugens (Theobald) ist eine nicht nur in ganz Afrika außerordentlich verbreitete, sondern auch in Korsika, Arabien und Indien vorkommende Mücke. PHILIP (1929) beschreibt sie als eine schnell reifende halbdomestizierte Mücke, welche Regenpfützen in Gestein und Mauern zum Brüten bevorzugt. Kuмм (1931 b) sah sie in Nigeria auch in Wassertöpfen brüten. Sie brütet manchmal in Häusern. Nach Lewis (1943) ist A. vittatus wahrscheinlich die im Regen am häufigsten blutsaugende Mücke. Sie beißt den Menschen während des ganzen Tages im Freien; ihre Hauptblutmahlzeit liegt aber in der ersten Stunde nach Sonnenuntergang (s. auch KERR, 1933). Die Mücke wird nach einer infektiösen Blutmahlzeit 11 Tage später infektiös (Philip, 1929; Johnson, 1932).

Aedes (Stegomyia) metallicus (Edwards) ist ein in Afrika ziemlich verbreiteter Baumhöhlenbrüter, der auch im Gelbfiebergebiet der Nuba-Berge im Sudan gefunden wird; er beißt häufig den Menschen (Lewis, 1943). In der Natur wurde diese Mücke noch nicht infiziert gefunden; sie überträgt aber experimentell infiziert das Gelbfiebervirus durch Biß nach einer 10 tägigen extrinsischen Inkubationszeit (LewIs u. a., 1942).

Aedes (Diceromyia) tayloris (Edwards) und A. (Diceromyia furcifer (Edwards) werden von 
LewIS (1943) als eine Gruppe betrachtet, deren Weibchen manchmal nur schwer unterscheidbar sind. A.taylori ist bisher nur in Nigeria und Tanganjika gefunden worden, dürfte aber weiter verbreitet sein. A.furcifer wird dagegen in Westafrika, Sudan, Uganda bis nach Transvaal in Südafrika angetroffen. Man schreibt beiden Arten eine Bedeutung bei der Gelbfieberepidemie in den Nuba-Bergen zu. Beide sind Baumhöhlenbrüter, aber sie legen größere Entfernungen als z. B. A.metallicus zurück, um Menschen zu beißen. Bisher beschränkt sich die Kenntnis der Fähigkeit, das Gelbfieber zu übertragen, lediglich auf Laboratoriumsversuche mit A.taylori, der nach einer extrinsischen Inkubationszeit von 12 Tagen das Virus beim Biß überträgt (Lewis u. a., 1942).

Aedes (Aedimorphus) stokesi (Evans) $=$ A. apicoannulatus (Edwards) ist bereits von BAUER (1928) als möglicher Gelbfieberüberträger angegeben worden. Diese Mücke kommt am häufigsten in Westafrika vor, wird aber auch in Transvaal (Kumm, 1931a, b) und Uganda (EDwards, 1941) beobachtet. Die Mücke ist ein Baumhöhlenbrüter und wird nicht in Häusern gefunden. KeRR (1933) nimmt an, daß sie ihre Blutmahlzeiten normalerweise nicht beim Menschen nimmt. Sie überträgt das Virus im Versuch durch Biß nach einer extrinsischen Inkubationszeit von 19 Tagen.

In anderen Erdteilen wurden folgende Aedesarten beschrieben:

Aedes (Stegomyia) albopictus (Skuse) ist in Java zu Hause. Er läßt sich im Laboratorium infizieren und scheidet das Virus beim Biß aus. Emulsionen der Mückenleiber sind ebenfalls infektiös (DINGER u. a., 1929).

Aedes (Stegomyia) variegatus (Walker) ist eine Mücke des Fernen Ostens. Sie läßt sich ebenfalls experimentell infizieren und scheidet das Virus später beim Biß aus (DE VogEL, 1930).

Aedes (Stegomyia) aegypti kommt auch in Indien vor und verhält sich im Laboratoriumsversuch wie die Gelbfiebermücken in Afrika und Amerika (Hindle, 1929).

Aedes geniculatus (Oliv.) ist eine in Frankreich beheimatete Mückenart, die sich experimentell mit dem Gelbfiebervirus infizieren läßt und dieses nach einer extrinsischen Inkubationszeit von 14 Tagen wieder beim Biß ausscheidet; Emulsionen der Mückenleiber sind ebenfalls infektiös (Roubaud u. a., 1937, 1938).

Aedes triseriatus ist eine nordamerikanische Mücke, die sich experimentell wie A. geniculatus verhält (Bennetт u. a., 1939). Die beiden letztgenannten Mückenarten leben außerhalb des tropischen Gelbfiebergürtels und haben daher keine praktische epidemiologische Bedeutung.

\section{Häemagogus-Arten}

Das Vorkommen von Gelbfieber beim Menschen ohne A. aegypti als Überträger wurde in den großen Urwaldgebieten (Dschungelgelbfieber) in Brasilien festgestellt. Die Überträger gehören hier zu den Haemagogusarten (Kumm 1950).

Während der A. aegypti in gleicher Weise in Afrika und Südamerika eine hervorragende Rolle in der Gelbfieberepidemiologie spielt, gehören die Haemagogus-Arten auf dem südamerikanischen Kontinent zu den am weitesten verbreiteten Mücken. Nach Kumm und CerqueIra (1951) kommen sie in ganz Brasilien bis nach Argentinien im Süden und nach der Insel Trinidad im Norden vor. Ihr Ausbreitungsgebiet reicht auch bis an die Kanalzone von Panama, wo seit einiger Zeit ebenfalls Gelbfieber beobachtet wird (Courtney, 1950; Galindo u. a., 1950; Trapido und Galindo, 1956 b, 1957). Da sie die Trockenheitsperiode gut überstehen, stellen sie gute natürliche Virusreservoire dar (Bugher u. a., 1944).

Die für die Gelbfieberübertragung in Frage kommenden Hämagogusarten scheinen vorwiegend Waldmücken zu sein, die aber gelegentlich auch in den Höhlen der Parkbäume brüten und in die Häuser eindringen. Im Walde ziehen sie Baumwipfel vor. Die bevorzugte Tageszeit für die Blutmahlzeit ist der Mittag (Kumm und Novis, 1938).

Der wichtigste Virusüberträger unter den Haemagogi ist der H.spegazzinii falco = capricornii (Cerqueira und Boshell Manrique 1949; Manso Soto u. a., 1953; Soper, 1958). (Siehe Abb. 35). 
Galindo und Trapido (1955) fanden diese Mücke in 2 Gebieten Costa Ricas mit Dschungelgelbfieber relativ häufig, und zwar normalerweise als Baumkronenbrüter. Sie greift aber auch die Menschen am Boden an, wenn kleine Lichtungen vorhanden sind (s. auch Комг, 1936, 1952).

Abb. 35. Haemagogus spegazzinii (nach Whitman, 1951)

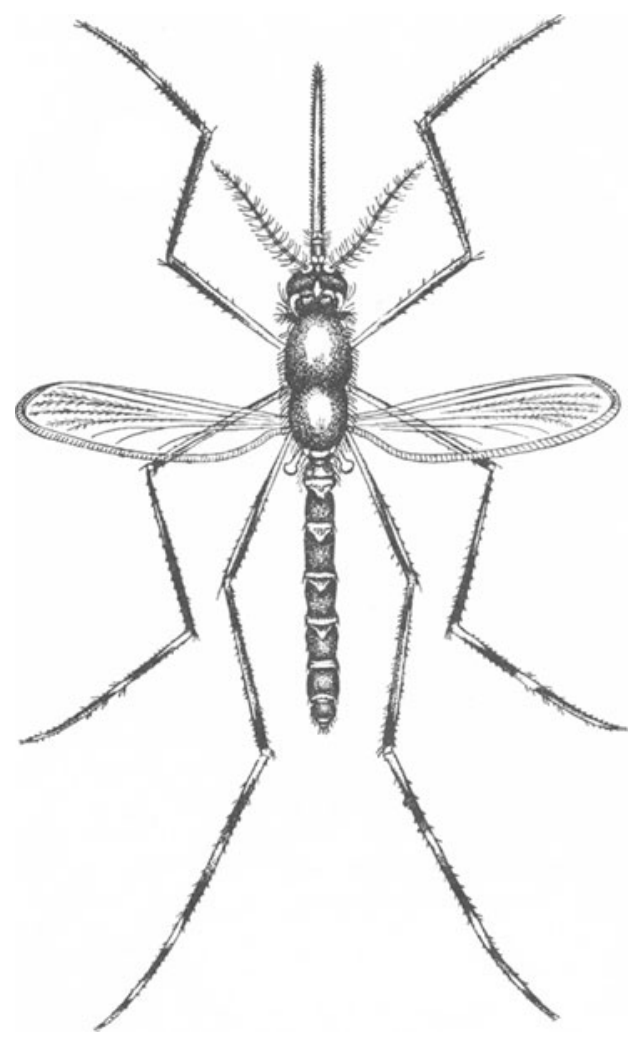

Shannon u. a. (1938b) isolierten zum ersten Mal Gelbfiebervirus im Dschungelgelbfiebergebiet Brasiliens durch den Bißversuch bei gefangenen H.capricornii. Später fanden auch Bugher u. a. (1944) sowie Laemmert u. a. (1946) infizierte Mückenweibchen in der Wildnis.

Anderson und Downs (1955) sowie Downs u. a. (1955a) wiesen das Gelbfiebervirus 21 mal in Pools von H. spegazzinii und einmal in einem Pool von 17 verschiedenen Mückenarten, die in den verseuchten Wäldern Trinidads nach einem Affensterben gefangen worden waren, nach.

Bates und Roca Garcia $(1945,1946$ a) sowie Bates (1947) fanden auch bei H.spegazzinii eine weitgehende Abhängigkeit der extrinsischen Inkubationszeit von der Temperatur. Bei $20^{\circ} \mathrm{C}$ trat nach einer großen Blutmahlzeit sofort eine Virusabnahme ein, die bis zum 5. Tage andauerte; nach einer nur kleinen Blutmahlzeit kam es zu keiner Infektion der Mücke. Bei $25^{\circ} \mathrm{C}$ war das Virusminimum nach 4 Tagen und bei $30^{\circ} \mathrm{C}$ nach 2 Tagen erreicht. War dies der Fall, so begann eine zunehmende Virusvermehrung. Ausreichendes Virus, um Affen zu infizieren, enthielten die Mücken bei $35^{\circ} \mathrm{C}$ nach 10 Tagen, bei $25-35^{\circ} \mathrm{C}$ nach 12 Tagen und bei $25^{\circ} \mathrm{C}$ nach 28 Tagen. Bei wiederholt wechselnden Temperaturen $\left(25^{\circ} \mathrm{C}\right.$ je $10 \mathrm{St}$. und $30^{\circ} \mathrm{C}$ je 4 St. täglich) betrug die extrinsische Inkubationszeit 23 Tage. Weitere Beobachtungen ergaben extrinsische Inkubationszeiten von $13-15$ Tagen bei $30^{\circ} \mathrm{C}$ und von $22-27$ Tagen bei $27^{\circ} \mathrm{C}$. Bemerkenswert erscheinen die erheblichen individuellen Schwankungen bei sonst gleichbleibenden äußeren Bedingungen. 
Anderson und Osorno Mesa (1946) übertrugen die Infektion zwischen 2 Nachtaffen (Aotus trivirgatus) mittels H.splendens, bei dem die extrinsische Inkubationszeit bei $30^{\circ} \mathrm{C}$ 14-16 Tage betrug. Die Infektionsfähigkeit ist aber viel geringer als die von A. aegypti (WADDELL, 1949).

Antunes und Whitman (1937) fanden H.uriartei für eine experimentelle Infektion empfänglich.

Für einen experimentellen Tier-(Seidenäffchen $=$ Callithrix penicillata)-Mücke-Tier-Zyklus eignet sich H.equinus (WADDELL und TAYLOR, 1945, 1947).

GaLindo u. a. (1956a) übertrugen das Gelbfiebervirus erfolgreich von Affe zu Affe (RhesusAffen, rote und schwarze Spinnenaffen = Ateles geoffroyi robustus und panameensis) durch Biß von H.equinus, H.mesodentatus mesodentatus, H.mesodentatus gorgasi (s. auch BosHeLL Manrique und Osorno Mesa, 1944; Waddell und Kumm, 1948). Alle diese Mücken sowie H.lucifer und H.spegazzinii enthielten Gelbfiebervirus (i.cer. Mäuseversuch) 1-4 Wochen nach der infektiösen Blutmahlzeit.

Levi-Castillo (1954/55b) fand in H. soperi $n$.sp. einen weiteren Überträger des Dschungelgelbfiebers (s. auch Martinez u.a., 1960).

\section{Weitere südamerikanische Stechmückenarten}

Psorophora ferox kommt in Nord- und Südamerika von Kanada bis Südargentinien vor. Davis und Shannon (1931b) übertrugen das Gelbfiebervirus durch Biß bzw. Injektion zerriebener Mückenleiber, welche nach 35 Tagen infektiös waren.

Shannon u. a. (1938b) isolierten bei einem Fang verschiedener Sabethini Gelbfiebervirus, ohne eine Bestimmung im einzelnen vorzunehmen, in welcher Mückenart es vorkam. Trichoprosopon frontosus, der im tropischen Amerika (Ostbrasilien, Britisch-Guyana, Trinidad) weit verbreitet ist, übertrug das Virus experimentell durch Biß. Die Mücke konserviert den Erreger lange Zeit in ihrem Körper (Whitman u. a., zit. Whitman, 1951; s. auch Waddell, 1949).

De Rodaniche u. a. $(1957,1959)$, de Rodaniche und Galindo (1957a) und Galindo (1958) isolierten in Guatemala und Panama das Gelbfiebervirus von in der Wildnis gefangenen Weibchen des Sabethes chloropterus. Galindo u. a. (1956a) sowie de Rodaniche u. a. (1959) konnten das Gelbfieber außerdem von Affe zu Affe durch Biß des S.chloropterus übertragen (s. auch Galindo und Trapido, 1955; T'rapido u. a., 1955). Diese Mücke ist aber kein so guter Überträger wie der Haemagogus; sie erfordert einen geeigneten Virusstamm, eine lange extrinsische Inkubationszeit und einen hochempfänglichen Wirt.

Culex fatigans vermag das Gelbfiebervirus nach einer Blutmahlzeit eine gewisse Zeit zu konservieren (39 Tage) und sogar durch Biß zu übertragen. Im allgemeinen scheinen aber die Culex-Mücken in der Natur nicht an der Gelbfieberübertragung beteiligt zu sein (Davis, 1933b). DAvis fand bei 2 Affe-Mücke-Affe-Passagen (M.rhesus) eine extrinsische Inkubationszeit von 17 bzw. 23 Tagen).

\section{Weitere afrikanische Stechmückenarten}

Taeniorhynchus (Mansonides) africanus (Theobald), eine zu den Culiciden gehörende Mücke, überträgt unter experimentellen Bedingungen das Gelbfieber (Philip, 1930 a; Beeuwkes u. a. 1933) durch Biß und Einspritzung von Mückenbrei nach 16 tägiger extrinsischer Inkubationszeit. Welche Rolle diese Mücke in der Natur als Gelbfieberüberträger spielt, ist noch unbekannt (Smithburn u. a., 1949a). Sie kommt vor allem in Nigeria sowie im Gebiet zwischen der Sahara und dem Südteil der Südafrikanischen Union vor. Die Mücke ist ein Baumkronenbrüter, dringt aber in Scharen in die Wohnstätten ein und beißt den Menschen vorzugsweise in der Nacht. Haddow u. a. (1948) sowie MaHAFFy (1949) vermuten auch im Taeniorhynchus einen Überträger innerhalb des Waldzyklus.

Eretmapodites chrysogaster (Graham) ist eine Sabethinenart, die in ganz Afrika südlich der Sahara weit verbreitet ist; sie kommt nur im Wald oder in dichten Anpflanzungen (z. B. Bananenplantagen) vor. Sie beißt am Tage, besonders nachmittags (HaDDow, 1945 b, 1946) und wird selten hoch über dem Erdboden gefangen. Das Gelbfiebervirus ist niemals in wild 
Tabelle 37

Verhalten südamerikanischer Stechmücken unter Laboratoriumsbedingungen

(Nach WhiтмıN, 1951)

\begin{tabular}{|c|c|c|}
\hline Mückenart & angegeben bei & Ergebnis \\
\hline Aedes aegypti & U.S.61. Kongreß »Gelbfieber 1911" & $\mathrm{B}$ \\
\hline Aedes scapularis & Davis und Shannon 1929 & B \\
\hline Aedes serratus & Davis und Shannon 1929 & $\mathrm{E}$ \\
\hline Aedes terrens & Davis und Shannon 1931 & $\mathrm{E}$ \\
\hline Aedes nubilus & Whitman und Antunes, 1937 & $\mathrm{E}$ \\
\hline Aedes fulvithorax & Davis, zit. Whitman und Antunes, 1937 & $\mathrm{E}$ \\
\hline Aedes fluviatilis & Davis und Shannon, 1931 & $\mathrm{E}$ \\
\hline Aedes taeniorhynchus & $\begin{array}{l}\text { Davis und ShanNon, } 1931 \\
\text { Whithman und Antunes, } 1937\end{array}$ & $\mathrm{E}$ \\
\hline Aedes leucocelaenus & $\begin{array}{l}\text { Shannon, Whitman und Franca, } 1938 \\
\text { WaddeLL, } 1949\end{array}$ & $\mathrm{~B}+$ \\
\hline Haemagogus capricornii & $\begin{array}{l}\text { Shannon, Whitman und Franca, } 1938 \\
\text { Waddell und Kumm, } 1948\end{array}$ & $\mathrm{~B}+$ \\
\hline Haemagogus equinus & WADDELL Und TAYLOR, 1945 & $\mathrm{~B}$ \\
\hline Haemagogus spegazzinii & $\begin{array}{l}\text { Antunes und Whitman, } 1937 \\
\text { LaEmmert, De Castro FerReira } \\
\text { und TaYlor, } 1946\end{array}$ & $\mathrm{~B}+$ \\
\hline Haemagogus spegazzinii falco & $\begin{array}{l}\text { Bugher, Boshell Manrique u. a., } 1942 \\
\text { Bates und Roca Garcia, } 1945,1946\end{array}$ & $B+$ \\
\hline Haemagogus splendens & ANDERSON und Osorno, 1946 & $\mathrm{~B}$ \\
\hline Haemagogus uriartei & Antunes und Whitman, 1937 & $\mathrm{E}$ \\
\hline Psorophora ferox & $\begin{array}{l}\text { Davis und Shannon, } 1931 \\
\text { Whitman und Antunes, } 1937\end{array}$ & B \\
\hline Psorophora cingulata & Davis und Shannon, 1931 & $\mathrm{E}$ \\
\hline Taeniorhynchus albicosta & Davis und Shannon, 1931 & $\mathrm{E}$ \\
\hline Taeniorhynchus chrysonotum & Davis und Shannon, 1931 & $\mathrm{E}$ \\
\hline Taeniorhynchus fasciolata & Davis und Shannon, 1931 & $\mathrm{E}$ \\
\hline Taeniorhynchus juxtamansonia & Whitman und Antunes, 1937 & $\mathrm{E}$ \\
\hline Taeniorhynchus titillans & Kumm und Frobisher, 1932 & $\mathrm{E}$ \\
\hline Trichoprosopon digitatum & $\begin{array}{l}\text { Davis und Shannon, } 1931 \\
\text { Kumm und Frobisher, } 1932\end{array}$ & $\mathrm{~N}$ \\
\hline Trichoprosopon frontosus & $\begin{array}{l}\text { Whitman, Tulloch und Waddell, } \\
\text { zit. WADDELL, } 1949\end{array}$ & $\mathrm{~B}$ \\
\hline Wyeomyia bromeliarum & Davis und Shannon, 1931 & $\mathrm{~N}$ \\
\hline Wyeomyia oblita & Davis und Shannon, 1931 & $\mathrm{~N}$ \\
\hline Limatus durhami & Davis und Shannon, 1931 & $\mathrm{~N}$ \\
\hline Culex fatigans & $\begin{array}{l}\text { Davis und Shannon, } 1929,1931 \\
\text { Davis, } 1933\end{array}$ & B \\
\hline Culex nigripalpus & Davis, zit. Whitman und Antunes, 1937 & $\mathrm{E}$ \\
\hline Anopheles albitarsis & Davis und Shannon, 1931 & $\mathrm{~N}$ \\
\hline Anopheles tarsimaculatus & Davis und Shannon, 1931 & $\mathrm{~N}$ \\
\hline
\end{tabular}

$\mathrm{B}=$ Ausscheidung des Virus durch Biß

$\mathrm{E}=$ empfänglich; Virusnachweis durch Verimpfung des Gesamtorganismus möglich

$+=$ in der Natur infiziert gefunden

$\mathrm{N}=$ nicht empfänglich; Virus verschwindet schnell nach der experimentellen Infektion 
gefangenen Mücken dieser Art nachgewiesen worden. Daß E. chrysogaster als Gelbfiebermücke in Frage kommt, geht aber aus Beobachtungen von BAUER (1928) hervor, daß diese Mücke sich künstlich infizieren läßt. Nach einer extrinsischen Inkubationszeit von 16 Tagen wird ihr Biß infektiös. Mückenverreibungen sind nach 24 Tagen virushaltig.

Culex thalassius (Theobald) kommt an beiden Küsten des tropischen Afrikas vor, fehlt aber im Inneren des Kontinents. Die Mücke brütet häufig im Brackwasser der Lagunen. Sie scheint die einzige afrikanische Culexart zu sein, die als Gelbfieberüberträger in Frage kommt. Natürlich infizierte Mücken sind allerdings noch nicht gefunden worden. Nach Laboratoriumsinfektion bleibt die Mücke (Zerreibung) bis zu 49 Tage infektiös. Die Inkubationszeit beträgt bis zur Virusausscheidung durch Biß 12-27 Tage (KERR, 1932).

In den Tabellen 37 und 38 sind die wichtigsten Stechmückenarten Südamerikas und Afrikas zusammengestellt (s. auch AitKen u. a. 1960; Omardeen, 1961).

\section{Tabelle 38}

Verhalten afrikanischer Stechmücken unter Laboratoriumsbedingungen

(Nach WhitMan, 1951)

\begin{tabular}{|c|c|c|}
\hline Mückenart & angegeben bei & Ergebnis \\
\hline Anopheles gambiae & Philip, 1930 & $\mathrm{~N}$ \\
\hline Taeniorhynchus africanus & Philip, 1930 & $\mathrm{~B}$ \\
\hline Taeniorhynchus uniformis & KERR, 1932 & $\mathrm{E}$ \\
\hline Aedes aegypti & U.S.61. Kongreß »Gelbfieber« 1911 & $\mathrm{~B}+$ \\
\hline Aedes africanus & Philip, 1929 & $\mathrm{~B}+$ \\
\hline Aedes apicoargenteus & Bauer, 1928, Kitchen, Haddow, Smithburn & $\mathrm{E}$ \\
\hline Aedes luteocephalus & BAUER, 1928 & $\mathrm{~B}$ \\
\hline Aedes metallicus & Lewis, Hughes und Mahaffy, 1942 & $\mathrm{~B}$ \\
\hline Aedes simpsoni & Philip, 1929 & $\mathrm{~B}+$ \\
\hline Aedes vittatus & Philiт, 1929 & B \\
\hline Aedes cumminsi & Kitchen, Haddow und Smithburn & $\mathrm{E}$ \\
\hline Aedes irritans & Philip, 1930 & $\mathrm{E}$ \\
\hline Aedes nigricephalus & PhILIP, 1930 & $\mathrm{E}$ \\
\hline Aedes stokesi (= apicoannulatus) & BAUER, 1928 & $\mathrm{~B}$ \\
\hline Aedes lineatopennis & KERR, 1933 & $\mathrm{E}$ \\
\hline Aedes punctocostalis & PhILIP, 1930 & $\mathrm{E}$ \\
\hline Aedes taylori & Lewis, Hughes und Mahaffy, 1942 & $\mathrm{~B}$ \\
\hline Aedes grahami & Kitchen, Haddow und Smithiburn & $\mathrm{N}$ \\
\hline Eretmapodites chrysogaster & BAUER, 1928 & $\mathrm{~B}$ \\
\hline Culex thalassius & KERR, 1932 & $\mathrm{~B}$ \\
\hline
\end{tabular}

$\mathrm{B}=$ Ausscheidung des Virus durch Biß

$\mathrm{E}=$ empfänglich; Virusnachweis durch Verimpfung des Gesamtorganismus möglich

$+=$ in der Natur infiziert gefunden

$\mathrm{N}=$ nicht empfänglich

\section{Andere Insekten}

Außer Stechmücken spielen als natürliche Überträger des Gelbfiebers andere Insekten offenbar keine Rolle. Allerdings gelang es SмгтнвurN u. a. (1949 b) einmal unter besonderen Umständen mit in der Wildnis gefangenen Phlebotomen Affen zu infizieren. Unter experimentellen Bedingungen lassen sich folgende Arthropoden infizieren: 
Bettwanzen (Cimex hemipterus, C.lectularius. Nach Lemos Monteiro (1929, 1930) scheiden sie das Virus nach Biß an einem infizierten Affen bis zu 15 Tage mit dem Kot aus; nach Kumm und Frobisher (1932) tritt Virus nur 2 Tage in den Faeces auf; Philip (1930b) war dagegen keine Infektion dieser Wanzen gelungen.

Raubwanzen (Triatoma megista). Nach Davis und Shannon (1931b) und Davis (1932c) vermag das Virus 7 Tage in den Larven und 10 Tage in den Erwachsenen zu überleben.

Hundeföhe (Ctenocephalides canis). In ihnen überlebt das Virus nur wenige Stunden; eine Übertragung von infizierten auf gesunde Affen gelang nicht (Hoskins, 1934b).

Stallfiegen (Stomoxys calcitrans). Sie konservieren das Virus bis zu 42 St. (Hoskins, 1934b); eine Übertragung von Affe zu Affe war nur bis zu 6 St. nach der Infektion der Fliegen möglich.

Tsetsefliegen (Glossina morsitans). Sie konservieren das Virus nicht (Findlay, 1942).

Zecken (Acarinae). Aragao de Beaurepaire (1933c) übertrug Gelbfieber durch den Biß von Amblyomma cayennense und Ornithodorus rostratus 14 bzw. 4 Tage nach der infektiösen Blutmahlzeit sowie durch Injektion verriebener infektiöser Zecken (Ornithodorus moubata) auf Affen. Er glaubte auch eine Vererbung der Infektion über die Eier auf die nächste Zeckengeneration beobachtet zu haben. Die Zeckenbißübertragungen wurden von DAvIs (1933a) nicht bestätigt; DAvIS fand aber auch Zeckenverreibungen virushaltig, und zwar bis zu 23 Tage nach der infektiösen Blutmahlzeit (A.cayennense, Argas persicus, Rhipicephalus sanguineus, Boophilus = Margoropus annulatus microplus). Auch Zecken, die aus 2 Monate zuvor infizierten Larven geschlüpft waren, erwiesen sich noch virushaltig.

Hühnermilben. DAvis (1933a) konnte aus einer Anzahl nicht näher angegebener Hühnermilben 1 Woche nach der infektiösen Blutmahlzeit das Virus zurückgewinnen.

Wie aus Fütterungsversuchen mit infizierten Mücken hervorgeht, scheinen Spinnen und Wanzen aus dem Zika-Wald (Uganda) nicht als Überträger des Gelbfiebers in Frage zu kommen (Gillett, 1958).

Nicht blutsaugende Insekten können auch als langdauernde Erhaltungswirte in kleinen isolierten Waldgebieten mit nur wenig Affen in Frage kommen. Findlay und Maccallum (1939) hatten beobachtet, daß das Gelbfiebervirus z. B. in Küchenschaben zu existieren vermag. Solche infizierten Arthropoden können von Wirbeltieren wie Affen gefressen werden und diese infizieren, was experimentell bewiesen wurde.

\section{3-3. Wirtstiere (Virusreservoire)}

Zur Bedeutung der Affen bemerkt TAYLOR (1951): "Experimentell sind sie ausgesprochen empfänglich; sie können durch den Mückenbiß infiziert werden; sie lassen das Virus in hohem Titer kreisen; Mücken können von ihnen infiziert werden, und das Virus kann durch abwechselnde Passagen durch sie und einen geeigneten Mückenüberträger am Leben erhalten werden. Immunität durch natürlich erworbene Infektion ist verschiedentlich nachgewiesen worden, und das Virus selbst ist bei wild gefangenen Exemplaren (Seidenäffchen) isoliert worden. Ökologisch gesehen passen sie in das Bild des bekannten Waldzyklus des Virus. Sie sind weit über das Gebiet verbreitet, wo Wald-Kontaktinfektionen des Menschen bekanntermaßen vorkommen, und es besteht eine Wechselbeziehung zwischen der Immunität der Waldaffen und jener der Menschen, welche Kontakt mit den Wäldern haben. Ihre Lebensgewohnheiten bringen die Affen mit den bekannten Überträgern in Berührung. Sie sind Baumtiere und verbringen den größten Teil ihrer Zeit noch in den Wäldern in der Nähe der Baumkronen oder in diesen selbst. Dies ist auch die Schicht, in der sich die größte Menge der wichtigsten Überträger, Mücken der Haemagogusgattung, findet. Gewöhnlich sind Affen sehr wachsam und daher keine leichte Beute für die Mücken, aber es ist bekannt, daß Affen die Gewohnheit haben, ein Schläfchen in den Mittagsstunden abzuhalten, welche die Zeit der aktivsten Nahrungsaufnahme der Überträger sind. Es ist jedoch fraglich, ob die Gewohnheiten der Nachtarten (Aotinae) die Mahlzeiten der Haemagogusarten leichter gestalten, denn während des Tages sollen sich diese kleinen Tiere in die Baumhöhlen zurückziehen. Soviel man über die Gewohnheiten der Haemagogusmücken weiß, erscheint es zweifelhaft, ob sie zur Nahrungsaufnahme in die Baumhöhlen eindringen... Wenn aber diese Nacht- 
affen zufällig an exponierten Stellen schlafen, wie z. B. in einem dichten Rankengewirr in den Baumspitzen (ENDERs, 1935) oder einer Astgabelung, so sind sie auch besonders den Überträgern ausgesetzt."

BALfour $(1914,1915)$ wies darauf hin, daß wilde Affen die eigentlichen Virusreservoire des Gelbfiebers sein könnten, da er kurz vor einer Epidemie unter der Bevölkerung von Trinidad eine große Anzahl von Brüllaffen tot oder sterbend in den Wäldern fand. KINGSLAY (1871) hatte bereits das Sterben von Affen an Gelbfieber in Trinidad im Jahre 1869 während einer Gelbfieberepidemie beobachtet. Aber erst nachdem die Affen als hochempfängliche Versuchstiere erkannt worden waren, gewannen diese Beobachtungen eine feste Grundlage. Nach Courtney (1950) scheint der weiße Brüllaffe (Alouatta palliata) eine Rolle in der Epidemiologie des Dschungelgelbfiebers zu spielen (s. auch Bugher, 1951). ANderson und Downs (1955) sowie Downs u. a. (1955a) beobachteten in Trinidad kurz vor einer Gelbfieberepidemie ein großes Affensterben in den Wäldern. Bei 7 toten Brüllaffen (Alouatta seniculus insulanus) wurde Virus in der Leber und in 2 Fällen auch im Blut gefunden. Bei 19 von 61 Brüllaffen sowie bei 7 von 12 Cebus apella-Affen wurden Schutzstoffe (N-AK) im Serum gefunden. Auch in Venezuela wurde bei einem Alouatta seniculus seniculus Virus insoliert (Briceno Rossi, 1960). Soper (1943) war der Ansicht, daß z. B. Cebus-Affen, in denen das Gelbfiebervirus nach experimenteller Infektion im Blut kreist, leicht als Virusquellen in Frage kommen könnten (s. auch Soper, 1935b). Laemmert und Ferreira de Castro (1945) sowie Waddell und Taylor (1946) wiesen den Erreger bei in der Wildnis gefangenen Seidenäffchen (Callithrix penicillata) nach (s. auch La emmert u. a., 1946).

Nur wenige Affenarten sterben in Afrika und Südamerika unter natürlichen Bedingungen an der Gelbfieberinfektion. Soweit sie erkranken, geschieht dies nur für wenige Tage. Infolgedessen findet man in der Wildnis auch nur selten an Gelbfieber gestorbene Affen. Dagegen weisen viele wild lebende Affen in bekannten Gelbfiebergebieten spezifische AK auf (SOPER, 1936 a). Bugher (1940) hat in postepidemischen bzw. postepizootischen Perioden bei Affen in Kolumbien in $67 \mathrm{bzw}$. 70\% der Tiere AK gefunden. Kumm und Laemmert (1950) ermittelten in Brasilien nach einer Epizootie ähnliche Werte (s. auch Lazmmert u. a., 1949). Diese Zahlen geben aber keinen absoluten Anhalt für die Häufigkeit des Gelbfiebers unter den Affen, da nicht bekannt ist, wie viele Tiere vorher an der Infektion gestorben sind (s. auch Hughes und Perlowagora, 1950a). De Rodaniche (1957) fand in Panama bei einer erheblichen Zahl von Seidenäffchen (Marikina geoffroyi) und schwarzen Spinnenaffen (Ateles geoffroyi panamensis und robustus) N-AK. In Afrika sind spontan infizierte Affen noch nicht angetroffen worden, was aber bei der außerordentlich kurzen virämischen Phase nicht so sehr verwunderlich sein sollte (TAYLOR, 1951). Die Primaten scheinen aber auch im afrikanischen Waldzyklus die wichtigsten Virusreservoire zu sein, da bei verschiedenen Arten natürlicherweise AK gefunden wurden (Findlay u. a., 1936; Findlay und Maccallum, 1938b; Berghe, 1939; Hughes, 1943; Haddow u. a., 1947; Smithburn und Haddow, 1949; BUGHER, 1951 a ; HADDOw u. a., 1951). Untersuchungen von TAYLOR u. a. (1955a) im Sudan, wo das Gelbfieber unter den Menschen endemisch vorkommt, ergaben einen sehr hohen Prozentsatz von N-AK bei Pavianen (94\%) und Cercopithecidae (77\%).

Aus Untersuchungen von Spence u. a. (1960) über die Affenerkrankungs- und Sterbeziffern in Ost-Trinidad geht hervor, daß das Gelbfieber dort 6 Jahre lang bis 1959 aktiv gewesen sein muß. Die Zahl der Affen in diesem Sumpfgebiet ist aber an sich zu klein, um einen fortlaufenden Jahr-zu-Jahr-Zyklus zwischen Affen und Hämagogen zu gewährleisten. Infolgedessen wird in Übereinstimmung mit anderen Autoren angenommen, $\mathrm{da} ß$ es noch einen anderen Zyklus für den Bestand des Gelbfiebers in einem endemischen Gebiet geben muß, der sogar von noch größerer Bedeutung als der Affe-Haemagogus-Affe-Zyklus ist.

$\mathrm{Zu}$ den empfänglichsten afrikanischen Wildtieren gehören - nach dem häufigen AK-Befund zu schließen - auch verschiedene Lemuridenarten (Halbaffen) wie Galago demidovii demidovii und Pottos (Perodicticus potto) sowie Potos flavus (Wickelbär oder Buschbaby) und Olyngos (Bassaricyon) (Smithburn, 1949a; Bugher, 1951a; Dick, 1953a). Aus Untersuchungen von HaDDow (1952) geht hervor, daß in Kenyia und den trockenen Gebieten Ugandas die Halbaffen die hauptsächlichsten Wirte des Gelbfiebererregers zu sein scheinen. Er fand unter 103 untersuchten Galagos 14\% immun, während unter den Galagos (G. senega- 
lensis) im Sudan nur selten (1 unter 56 Seren) Schutzkörper gefunden wurden (TAYLOR u. a., 1955a).

Aus Untersuchungen an Beuteltieren geht hervor, daß sie neben den Primaten in manchen Gebieten Südamerikas als natürliche Virusreservoire für den Waldzyklus in Frage kommen könnten. Nach TAYLoR (1951) ist allerdings die Rolle der Beuteltiere (Oppossums) als natürliche Virusreservoire in der Wildnis Südamerikas noch ungeklärt, um so mehr, als auch die Tierversuche keine eindeutigen Ergebnisse bzgl. der Empfänglichkeit geliefert haben. Eine gewisse Immunität bei Opossums (Didelphis marsupialis) hatte Whitмan (1943) in Waldgebieten festgestellt, in denen unter den Affen eine Epizootie geherrscht hatte, während sie bei Opossums aus epizootiefreien Waldgebieten fehlten. Bugher u. a. $(1941,1944)$ untersuchten ebenfalls 55 Didelphis marsupialis-Exemplare eines kolumbianischen Bezirks, in dem virushaltige Mücken gefunden worden waren; 15 dieser Tiere besaßen AK; 4 weitere wurden in der Gefangenschaft immun. Laemmert u. a. (1946) fanden beim Metachirus nudicaudatus in Brasilien nur selten Immunität (1 unter 246 Tieren); unter verschiedenen Marmosa-Arten wiesen auch nur 7\% N-AK auf, wobei die Spezifität der Reaktion in allen Fällen noch bezweifelt wird. Außerdem fanden sie bei zahlreichen Opossums dieser Art aus einem endemischen Gebiet mit immunen Affen und virustragenden Seidenäffchen und Mücken keine AK.

De Assumpcao (1940) wies in einem Gebiet von Brasilien im Anschluß an eine Dschungelgelbfieberepidemie bei 50\% der Hausratten (Camondongos-Ratten) N-AK nach.

Von großer Wichtigkeit für das dauernde Fortbestehen enzootischer Gelbfieberherde in Gebieten, in denen Affeninfektionen selten oder Affenvölker nur klein sind, sind die AKBefunde bei diesen Tieren. Für sie könnte auch die an Ratten gemachte Beobachtung Bedeutung haben, daß nach intrauteriner Infektion mit dem Semlikiwald-Virus eine bemerkenswerte Toleranz für Gelbfiebervirus erworben wird.

Findlay u. a. (1936) konnten in pflanzenfressenden Fledermäusen (Epomophorus sp.), die in Gambia (Afrika) gefangen worden waren, keine N-AK nachweisen. Diese Beobachtungen und erfolglos gebliebene Infektionsversuche an verschiedenen Fledermausarten lassen vermuten, daß diese Tiere keine Rolle als Virusreservoire spielen.

TeEsdale (1955), welcher eine eingehende Beschreibung der Lebensgewohnheiten des A.aegypti in Kenyia gibt, fand bei Präzipitationsuntersuchungen der Mageninhalte dieser Mücken, daß es in dem Gebiete ihres Vorkommens einen noch unbekannt gebliebenen, aber wichtigen anderen Blutspender als den Menschen gibt, der allerdings nicht unter den gewöhnlichen Haustieren zu suchen sein dürfte; es wird vermutet, daß es sich um Eidechsen handelt.

Findlay und Cockburn (1943) fanden in allerdings noch unbestätigt gebliebenen Schutzversuchen N-AK im Blut wilder Vögel an der Goldküste.

\section{Weitere Literatur zu Epidemiologie:}

Soper (1937a, 1938, 1939), Antunes und Castro (1945), Garnham u. a. (1946), Azevedo u. a. (1947), Lewis (1947), Causey und Kumm (1948), Liegois u. a. (1948), Taylor und Theiler (1948), Herrera u. a. (1949a, b), Dick (1950), Buxton (1951), Garcia (1951) Levi Castillo (1951), Lumsden (1951b, c), Pinto (1951), Raynal (1952), Soper (1952), Floch (1953) Floch u. a. (1953), Kirk und Haseeb (1953), Levi Castillo (1953), Lewis (1953), Bonnel und Deutschmann (1954), Mahaffy (1954), Meillon (1954) Cambournac u. a. (1955), Lippi (1955), Lumsden (1955a), Soper (1955), Darns u. a. (1956), Gilette (1956), Johnson und Farnworth (1956), Rodaniche (1956a), Boorman und Porterfield (1957), Baroian und Lozinskaia (1958), Bustamente (1957, 1958), Chabaud und Ovazza (1958); Gast Galvis (1958), Kuyp (1958), Laake (1958), WolfF u. a. (1958), Causey und Maroja (1959), Schulz (1959), Courtois u. a. (1960), Berdonneau u. a. (1961).

\section{Klinik}

Das klassische epidemische Stadtgelbfieber und das Dschungelgelbfieber sind nicht nur ätiologisch, sondern auch klinisch identisch. Der Verlauf ist immer akut und verhältnismäßig kurz, aber äußerst wechselvoll in seiner Schwere. Hierauf wurde bereits 
von Nотт (1848) hingewiesen. Viele Fälle verlaufen so leicht oder uncharakteristisch, daß sie weder diagnostiziert noch behandelt werden. KERR unterscheidet 4 Schweregrade:

1. Die sehr milden Formen haben als einziges Symptom vorübergehendes Fieber und Kopfschmerzen von nur wenigen Stunden bis 1-2 Tage Dauer. Die Infektion kann sogar klinisch vollständig stumm (inapparent) bleiben. Dies soll in endemischen Gebieten nach langem Kontakt mit dem Virus der Fall sein, u. a. bei Säuglingen, die ihre von der Mutter passiv übernommene Leihimmunität verlieren und "gerade mit der Virusmenge infiziert werden, welche sie ohne Symptome schutzimpft."

2. Die milden Formen haben Fieber und Kopfschmerzen ausgeprägter; sie beginnen meistens plötzlich. Dazu treten Übelkeit, Nasenbluten, FAGETsches Zeichen, leichte Albuminurie und Subikterus. Die Krankheit dauert auch nur 2-3 Tage und wird nur während einer Epidemie diagnostiziert.

3. Die mittelschweren Formen sind klinisch erkennbar an dem Auftreten eines oder mehrerer klassischer Symptome: höheres Fieber von 5-7 tägiger Dauer, stärkeres FAG ETsches Zeichen, schwerere Kopf- und Rückenschmerzen, schwerere Übelkeit und Erbrechen, sogar schwarzes Erbrechen, uterine Blutungen, deutliche Gelbsucht und Albuminurie. Hier kommen abortive Verläufe mit schwerem Beginn, aber schneller Genesung nach etwa 3-4 Tagen vor.

4. Die malignen Formen weisen neben allen klassischen Symptomen noch andere verschiedener Art auf. Es gibt einen hyperakuten fulminanten Verlauf mit Hämorrhagien, manchmal Delirien und Tod am 3. oder 4. Tage.

Die Inkubationszeit, hier die Zeit vom Augenblick der Ansteckung durch den Biß der infektiösen Mücke bis zum Ausbruch der Krankheit, beträgt gewöhnlich 3-10 Tage und ist erscheinungslos. Die Krankheit beginnt sehr häufig in der Nacht.

Die mittelschweren und schweren Formen verlaufen mit 3 klinisch unterscheidbaren Phasen:

1. Die Phase der Infektion oder des initialen Fiebers (virämische Phase),

2. Die Phase der nicht immer vorhandenen und nur kurzen Remission,

3. Die Phase der Intoxikation und Organschädigungen.

Van Rooyen und Rhodes (1948) heben 3 Krankheitsstadien hervor: 1. Initialfieber, 2. Ruhestadium, 3. Reaktionsstadium, falls die Erkrankung schwer verläuft. Diese Einteilung entspricht der HöRINGschen zyklischen Verlaufsform (1948).

1. Die Phase der Infektion dauert etwa 3 Tage. Das plötzlich mit Schüttelfrost einsetzende Fieber bleibt 39-40 $\mathrm{C}$ hoch oder höher (s. Abb. 36). Es besteht schweres Krankheitsgefühl mit Allgemeinerscheinungen wie Mattigkeit, Rücken-, Lenden-, Glieder-, Kopf- und Muskelschmerzen, ferner Trockenheit, Hitzegefühl und Rötung der Haut sowie Konjunktivitis als äußere Zeichen einer allgemeinen Hyperämie, Appetitlosigkeit, quälender Durst, Übelkeit und Erbrechen, die manchmal schwer sind, und Verstopfung, ferner gewöhnlich Reizbarkeit, Schlaflosigkeit und Überwachheit. Die besonders retrofrontalen und retroorbitalen Kopfschmerzen und Lichtscheu können sehr stark sein. NAUcK (1952a) weist darauf hin, daß Rücken- und Kreuzschmerzen sowie nach den Beinen ausstrahlende ziehende Schmerzen mit gleicher Heftigkeit auftreten wie zu Beginn der Pocken, sowie daß zuweilen ein epigastrischer Druckschmerz besteht.

Der Puls ist entsprechend der Fieberhöhe mehr oder weniger beschleunigt, bis 120, kräftig, hüpfend, später weicher und langsamer werdend. Häufig kennzeichnend ist das schnelle Absinken des beschleunigt gewesenen Pulses bei weiter hoch bleibendem Fieber; dieses Fagetsche Zeichen hat diagnostischen Wert (s. Abb. 37). Der Blutdruck ist zunächst normal oder erhöht. Die Zunge wird ziemlich charakteristisch verändert: sie wird klein, spitz, pelzig, belegt und trocken mit hellroten Rändern; Gaumen und Zahnfleisch werden hyperämisch geschwollen 


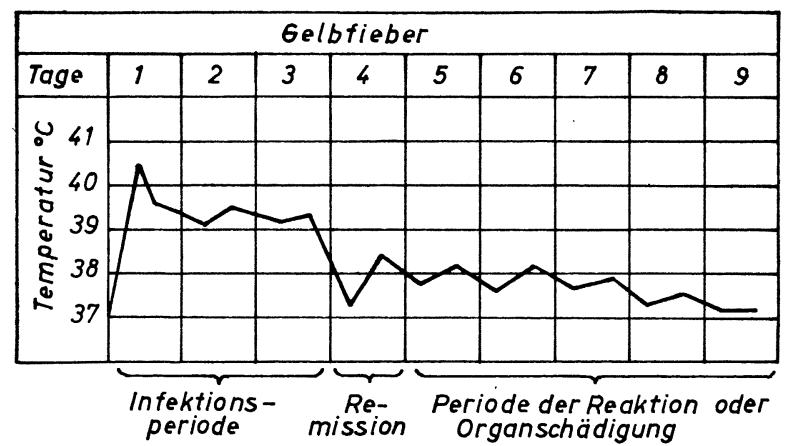

Abb. 36. Schematische Fieberkurve bei Gelbfieber (nach NAUCK, 1956)

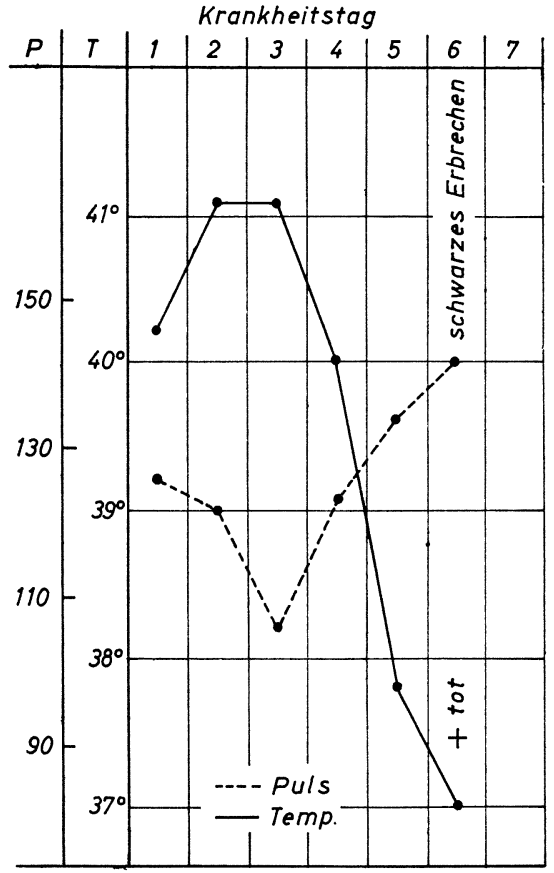

Abb. 3\%. Schweres Gelbfieber mit Fagetschem Zeichen (nach Lavier und Stefanopoulo, 1946) 
und neigen zu Blutungen. Während die Haut meistens heiß und trocken bleibt, kann die Gesichtsrötung in Zyanose übergehen. Bei drohendem Kollaps treten Schweißausbrüche auf. Das Aussehen des Gesichtes ist ebenfalls recht charakteristisch: es ist gerötet und geschwollen, đie Lippen sind rot und dick, die Augen feucht glänzend und injiziert.

Mathis (1948) führt die Erscheinungen der ersten Phase auf einen Meningo-Neurotropismus des Erregers zurück und möchte daher diese auch als »nervöse Phase« der Krankheit bezeichnen. Infolge des Überwiegens der entzündlich-hyperämischen Erscheinungen wird aber auch von einer "roten Phase» (Dutrouleau) gesprochen (Joyeux und SicÉ, 1950).

Während dieses nur wenige Tage dauernden ersten Abschnittes der Krankheit wie auch schon während der Inkubationszeit kreist das Virus im Blute, so daß der Kranke während dieser virämischen oder septikämischen Phase für blutsaugende Insekten ansteckungsfähig ist.

2. Die Phase der Remission setzt nach etwa 3-4 Tagen mit schnellem Fieberabfall zur Norm und ebenfalls schneller Genesung ein. Sie kann aber auch nur kurz, manchmal Stunden, dauern, worauf das Fieber wieder auf $39-40^{\circ} \mathrm{C}$ ansteigt und nun erst das charakteristische "Gelbfieber" ausbricht.

3. Die Phase der Intoxikationen betrifft vor allem Leber-, Nieren- und Kreislaufschädigungen. Im Anschluß an das Zurückgehen der Allgemeinerscheinungen treten die degenerativen Veränderungen der Leber und Nieren hervor. Die Leber ist meistens vergrößert und druckempfindlich. Zunächst verfärben sich die Skleren, dann die Haut gelblich. Je früher der Ikterus einsetzt, desto schwerer pflegt er zu werden. Er ist allerdings häufig weder ein frühes noch ein hervortretendes Symptom und bleibt manchmal sogar bei tödlichem Ausgang schwach. Manchmal wird er erst nach längerem Krankheitsverlauf oder sogar erst nach dem Tode sichtbar. Gelegentlich treten erythematöse oder petechiale Hautausschläge auf. Die Haut riecht nach fauligem Fleisch oder »schlecht gelüftetem Fleischerladen« (NAUCK, 1952).

Die Nierenschädigung bedingt Harnverminderung, Oligurie, die in malignen Fällen schon am 4. Tage zu vol]ständiger Anurie führen kann. Eiweiß im Urin tritt selten vor dem 3. Krankheitstage auf; in leichten. Fällen kann es auf Spuren beschränkt bleiben; in schweren Fällen nimmt die Albuminurie dagegen schnell zu, von $0,5 \%$ bis zu $2-12 \%$. Schon nach 12 Stunden kann die Eiweißausscheidung so stark sein, daß der Harn bei der Eiweißprobe im Röhrchen gerinnt (KerR, 1951). Die Chloride und Phosphate nehmen ab, die Reaktion ist sauer, die Diazoreaktion negativ. Der Chloridgehalt kann auf O sinken. Genaue Harnanalysen liegen vor von Penido (1928), Lins (1929) und Berry und Kitchen (1931).

Das Erbrechen von schwarzem Blut ("Vomito negro" = Verfärbung des in den Magen ausgetretenen Blutes durch den Magensaft) ist ein charakteristisches, sehr ernstes Symptom. Der Magen verweigert dann oft alle Nahrung, auch flüssige. Infolge toxischer Gefäßwandschädigungen kommt es auch zu Darmblutungen mit schwarzen diarrhöischen Stühlen (Melaena) oder frischem Blut, sowie zu hämorrhagischen Diathesen auch in anderen Körperstellen (Nasen- und Zahnfleischblutungen, ziemlich häufig Metrorrhagien, seltener Blutungen der Harnwege). Die hämorrhagischen Manifestationen gehören zu den konstantesten Symptomen des Gelbfiebers.

Die Toxikamie, welche die Virämie ablöst, erfaßt nicht nur Nieren, Leber und Herz sowie die Blutgefäße überhaupt, sondern auch die kleinen Gefäße lebenswichtiger Zentren des Gehirns (KerR, 1951). Schließlich reicht die natürliche Abwehr des Körpers nicht mehr aus und der Tod tritt ein. Die Dauer der toxischen Phase schwankt. In leichten Fällen tritt sie überhaupt nicht hervor; gewöhnlich dauert sie 3-4 Tage, manchmal aber auch bis zu2 Wochen. Der Puls bleibt im Verhältnis zur Temperatur langsam und weich; kurz vor dem Tode wird er aber tachykardisch. Oft besteht eine echte Bradykardie, ebenso sind Extrasystolen häufig. Die Herztöne sind gedämpft; verschiedenartige Geräusche können sich entwickeln. Die toxische Herzschädigung wird elektrokardiographisch erkennbar (Chagas und Freitas, 1929; Lins, 1929; Berry und Kitchen, 1931). Die Veränderungen, welche schon zu Beginn der Erkrankung erscheinen, sind zwar nicht für Gelbfieber charakteristisch, scheinen aber doch eine gewisse prognostische Bedeutung zu haben.

Bei bösartigem Verlauf kommt es häufig 2-3 Tage vor dem Tode zu Koma, von dem die Kranken aber auch noch genesen können. Das Koma kann seinen Ursprung in der Leber 
haben, wenn die Nieren noch ausreichend arbeiten. Meistens ist aber wegen der schweren Nierenschädigung nicht zu entscheiden, ob ein urämisches oder hepatisches Koma vorliegt (Kerr, 1951). Nach Mollaret (1948) gleicht die Gelbfiebernephritis weitgehend verschiedenen anderen superakuten toxisch-infektiösen Nephritiden, z. B. der akuten Quecksilbernephritis. Zu den schweren Symptomen gehört ferner der Singultus. Meistens bleibt jedoch das Bewußtsein erhalten, und erst kurz vor dem Tode wird der Kranke delirös, wild erregt und sogar maniakalisch. Zuweilen treten epigastrisches Angstgefühl und Krämpfe auf. Diese Erscheinungen dürften auf kleinste perivaskuläre Blutungen im Gehirn zurückzuführen sein (Stevenson, 1939).

$\mathrm{Zu}$ Beginn der Erkrankung setzt gewöhnlich eine zunehmende Leukopenie ein, welche am 5. Tage 2500 bis herab zu 1500 Leukozyten erreicht, wobei die großen Mononukleären gleichzeitig vermehrt sein können (bis zu 20\%) und die Eosinophilen völlig verschwinden. Dieser Leukozytensturz ist aber nur kurze Zeit nachweisbar. Am 10. Tage ist die Zellzahl wieder etwa normal, um während der Rekonvaleszenz Neigung zu Vermehrung zu zeigen. BERRY und Kitchen (1931) denken an eine Störung der myelogenen Funktionen des Knochenmarks. Bei Eindickung des Blutes, was besonders im Endstadium der Fall ist, sind Hämoglobin und Erythrozyten vermehrt; Lins (1929) fand Werte von über 6 Millionen. Die Gerinnungszeit ist verlangsamt, das Komplement (Alexin) vermindert (da Costa Cruz, 1930a, b, c), die Senkung beschleunigt (Bugher, zit. KERR, 1951). Der Blutharnstoff kann auf $3 \mathrm{~g}$ und mehr erhöht sein. Das Blutbilirubin wird bei normalem $\mathrm{p}_{H}$ stark vermehrt gefunden, desgleichen das Blutkalium, während das Calcium eine starke Abnahme aufweist. Oft besteht Hypoglykämie. SoPER (1943) sah eine Erhöhung des Blutguanidinspiegels beim menschlichen Gelbfieber, welche Findlay und Hinde (1930) bereits beim experimentell infizierten Rhesus-Affen gefunden hatten. Über das Verhalten anderer Blutbestandteile liegen noch keine übereinstimmenden Ergebnisse vor. Trejos und Romero (1954) fanden keine abnorme Kapillarfragilität, keine konstante Änderung der Koagulations- und Blutungszeiten oder der Plättchenzahl und Gerinnselretraktion; die Fibrinogenbestimmung verlief gewöhnlich normal. Dagegen scheinen die Veränderungen des Plasmathrombinspiegels in deutlicher Beziehung zur Schwere der Erkrankung zu stehen. Trejos und Romero fanden bei 24 Personen, welche starben, einen durchschnittlichen Thrombinspiegel von $20,25 \%$, bei Patienten, die genasen, dagegen einen solchen von $66,7 \%$. Weniger als $25 \%$ wurden gewöhnlich nur bei tödlichem Ausgang beobachtet. Der Grad der Prothrombinabnahme ist proportional der Schwere der Leberveränderungen und der klinischen Erscheinungen (s. Abb. 38).

Der Liquor cerebrospinalis ist vermehrt, manchmal hämorrhagisch; sein Druck ist erhöht (Lacorte und Villela, 1928); die Zellzahl ist normal, das Eiweiß vermehrt (25-55 mg \%). Die Pandy-Reaktion ist immer negativ, die Nonne-Apelt-Reaktion dagegen immer schwach bis stark positiv (s. auch Mollaret und Stefanopoulo, 1934).

Der Tod tritt meistens zwischen dem 6. und 10. Tage, bei ganz schwerem Verlauf schon, am 4. Tage ein; er steht im Zeichen schwerer Intoxikationen infolge des Versagens von Leber, Nieren und Nebennieren, einer Myokarditis oder einer schweren Hämorrhagie. Bei Genesung gehen die Erscheinungen dagegen sehr schnell zurück; die Heilung pflegt vollständig zu sein. Rezidive sind aber ziemlich häufig.

$\mathrm{Zu}$ den Komplikationen gehören. Lungenentzündungen, subkutane und intramuskuläre Hämatome, eitrige Speicheldrüsenentzündungen, Abszesse, Gangräne und verschiedene Sekundärinfektionen. Die Komplikationen treten häufig erst in der Rekonvaleszenz auf (Mollaret, 1948).

\section{Pathologie}

Für die Entstehung der pathologischen Veränderungen in den befallenen Geweben sowie der Funktionsstörungen der Organe ist wesentlich, daß sich der Gelbfiebererreger in zahlreichen Zellarten ansiedelt und vermehrt, und zwar primär in solchen, welche sich in unmittelbarer Berührung mit dem Blut- und Lymphstrom befinden, sekundär in der Leber, Niere und anderen Organen. Nach BuRnet (1955) werden große Mengen von 
$\begin{array}{llllllllllll}12 & 3 & 4 & 5 & 6 & 7 & 8 & 9 & 1011 & 1213 & 14\end{array}$

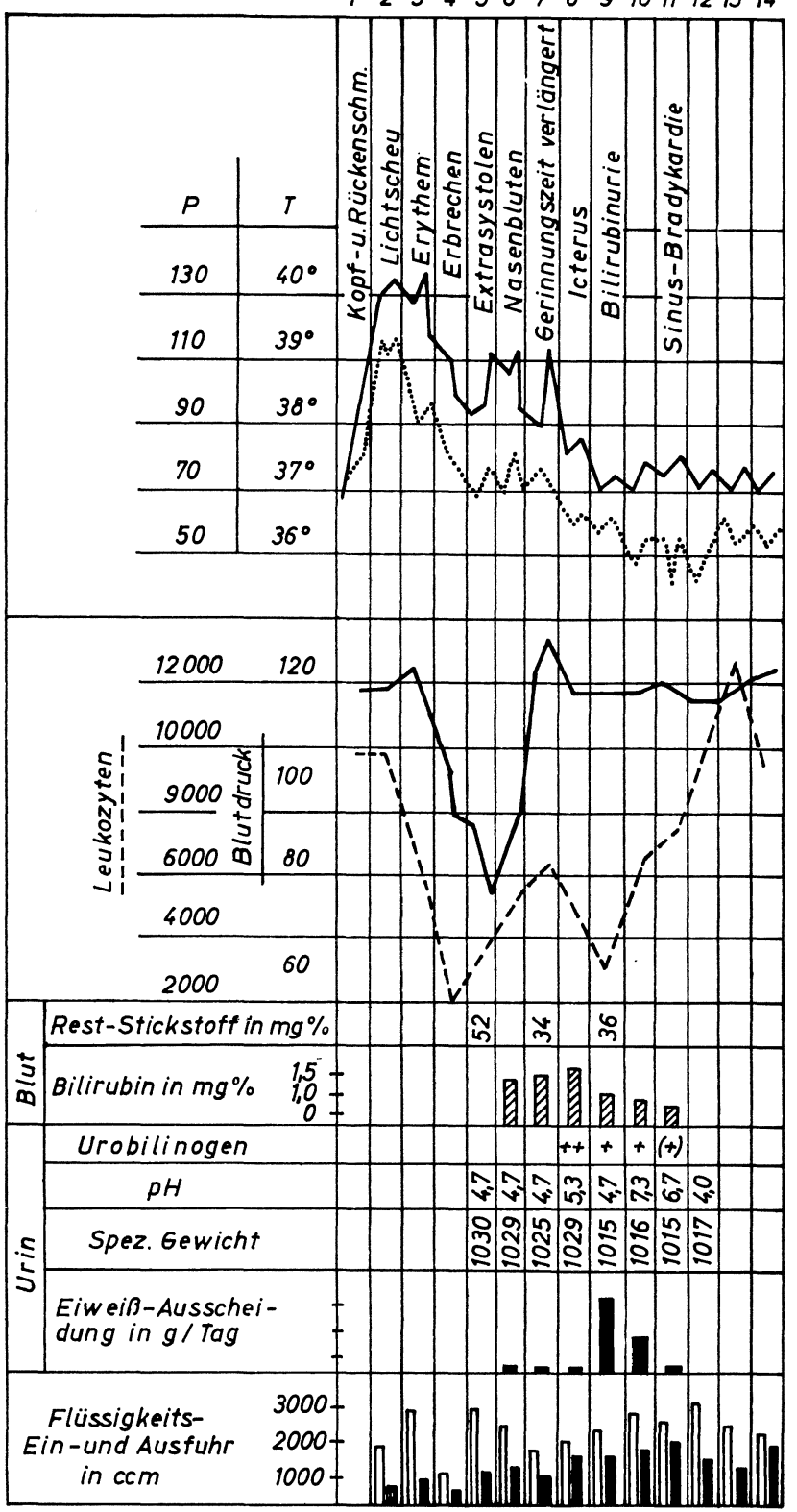

Abb. 38. Gelbfieber mit Heilung (nach HöRING, 1950) 
Virus, löslichem Antigen und Zellabbauprodukten in den Kreislauf abgegeben, welche unmittelbar an dem Zustandekommen der toxischen Erscheinungen beteiligt sind.

Der Ikterus der Haut und Schleimhaut tritt an der Leiche stärker hervor als am Lebenden und wird oft sogar erst post mortem deutlich erkennbar. Die Haut ist zitronengelb; sie ist mit petechialen Blutungen und lividen Flecken durchsetzt. Multiple Blutungen finden sich häufig auch in den Schleimhäuten des Mundes, der Nase und praktisch allen Eingeweideorganen als Zeichen des ausgesprochenen gefäßtoxischen Charakters der Krankheit. Außerdem fällt makroskopisch die fettige Verfärbung vieler Organe und Gewebe auf. Hier handelt es sich um eine fettige Degeneration als Folge der schweren Störungen des Gesamtstoffwechsels. In erster Linie sind Leber und Nieren befallen. Noch nach dem Tode findet sich Virus in der Leber (ANDERson und WattLey, 1955). In leichten, nicht tödlichen Fällen dürften die histopathologischen Veränderungen nur leicht sein und sich auf eine milde trübe Schwellung des Nierenepithels und leichte generalisierte Hyperämie beschränken. Bei schweren Verläufen sind aber ausgedehnte pathologische Prozesse zu erwarten, wobei fast alle Organe und Gewebe betroffen sind (BUGHER, 1951a).

Im Vordergrunde des pathologischen Geschehens steht die Leber. Im Gegensatz zur akuten gelben Leberatrophie ist sie jedoch nicht verkJeinert, eher sogar vergrößert. Sie ist gewöhnlich weich, spröde, stark fettig degeneriert und nekrotisch. Die anatomische Betrachtung allein genügt jedoch häufig nicht zur Erkennung der schweren Schäden des Lebergewebes, die erst bei mikroskopischer Untersuchung hervortreten. Zur histologischen Untersuchung wird Formolfixierung und Färbung mit Hämatoxylin-Eosin oder Mann empfohlen (s. auch BABLET und Bloch, 1937; Bugher, 1951a) (s. Abb 39)..

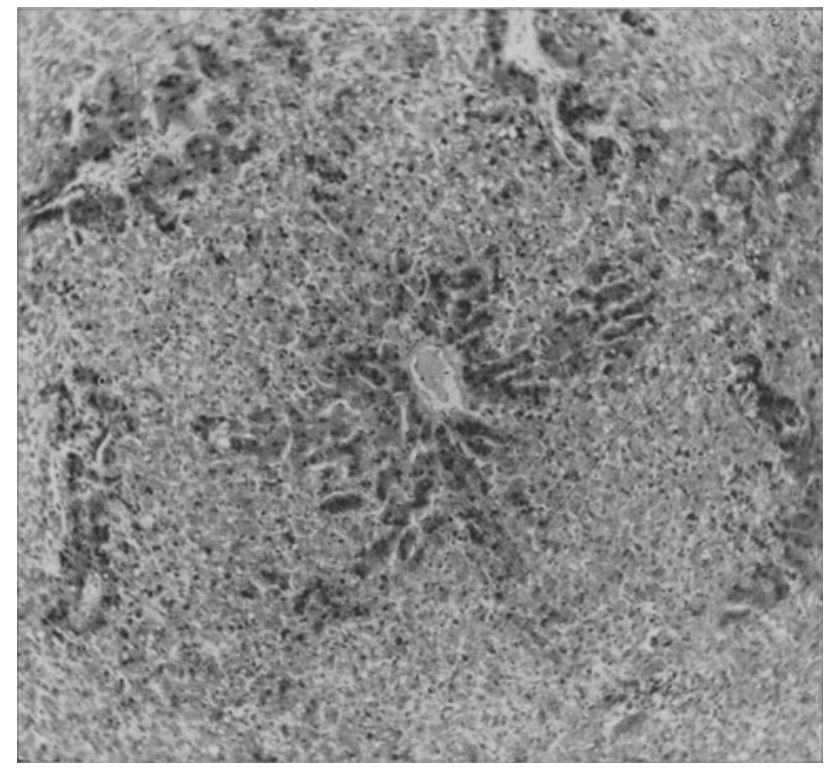

Abb.39. Gelbfieberleber: Ausgedehnte versprengte Nekrosen und Verfettung. In der Umgebung der Zentralvene und an der Peripherie des Leberläppchens relativ gut erhaltene Leberzellen (nach NAUCK, 1959)

Außer einer ausgedehnten Koagulationsnekrose sowie fettigen Degeneration und Schwellung findet man als besondere Degenerationsform des Parenchyms die von Councilman 
(1890) beschriebene irreversible »hyaline Degeneration« der Leberzellen, die sich zunächst in dem Auftreten abgerundeter Körperchen im Zytoplasma der Leberzellen („CouncILmansche Körperchen «) äußert, schließlich aber auch den ganzen Zelleib zu einer einzigen hyalinen Masse machen kann.

Die Councilmanschen Körperchen lassen sich leicht von der hyalinen Struktur der Alkoholzirrhose (MaLLORY) unterscheiden; erstere sind rund, vakuolisiert und kommen auch außerhalb der Zellen im parenchymalen Maschenwerk und den Sinusoiden vor; letztere bleiben dagegen vakuolenfrei und neigen dazu, sich zu verzweigen und den Zellkern zu umlagern (Ash, 1950). Man findet diese hyalin-nekrotischen Zellen unregelmäßig, besonders in der Mittelzone der Leberläppchen verstreut ("versprengte Nekrosen«), (s. auch BABLET, $1936 \mathrm{a}-\mathrm{e}$, 1937a, b, 1945; BABLET und BLOCH, 1937). In ihnen kommt es außerdem zu einer von Da Rocha Lima beschriebenen Nekrose, die gegen Peripherie und Zentrum abgegrenzt und an sich recht charakteristisch ist, aber zur histologischen Gelbfieberdiagnose allein nicht ausreicht. Im Gegensatz zu anderen Leberkrankheiten bleibt aber immer ein Kranz von überlebenden Zellen um die Zentralvene erhalten, was schon einen gewissen diagnostischen Anhalt ergibt.

Nach ANGulo u. a. (1949) ist die Spezifität der Councilmanschen Körperchen in der Leber für Gelbfieber etwas dadurch erschüttert, daß auch bei einem Falle von generalisiertem Herpes simplex in der Leber derartige Councilmansche Körperchen gefunden wurden.

Zahlreiche Autoren, unter ihnen Da Rocha Lima (1912a, b, 1926, 1937), Hoffmann (1928a, b, c, 1929, 1930a, b, 1931a, b, 1932, 1937), ToRRes (1926, 1928a-h, 1929a-e, 1930 a, b, 1931), Hudson (1928a), Stokes u. a. (1928a), Hindle (1929), Cowd RY und Kitchen (1929, 1930), Penna und Figueiredo (1929), Klotz und Belt (1930d), Cowd Ry (1933), Nicolau u. a. (1934a), beobachteten in den Kernen der Leberparenchymzellen Veränderungen, die entsprechend den Befunden bei anderen Viruskrankheiten als Kerneinschlüsse bezeichnet werden können. Sie wurden zuerst von Torres (1930) in den Leberzellen infiziert gewesener Affen beschrieben. Sie lassen sich mit den z. B. bei Herpes- und Virus-III-Infektionen vorkommenden Kernveränderungen vergleichen. Durch ihre deutliche Azido-(Eosino-)philie sind sie von dem übrigen basophilen Kernchromatin und den Kernkörperchen deutlich unterscheidbar.

Sie sind am besten mit Giemsa, Phloxin oder Eosin darstellbar; man bezeichnet sie daher auch als oxychromatische Kerndegeneration. Je nach ihrem Umfang bilden diese Veränderungen einzelne Körnchen oder kleinere umschriebene Körperchen, oder sie können auch als ziemlich amorphe Massen den ganzen Kern ausfüllen. Nach Nicolau u. a. (1934b, d) scheint eine Innenstruktur zu fehlen. Manchmal sind sie von einem farblosen Hof umgeben. Obwohl die Kerneinschlüsse für die Gelbfieberhistologie an sich pathognomonisch sind, so haben sie doch für die postmortale Gelbfieberdiagnostik beim Menschen keine praktische Bedeutung, denn in der menschlichen Leber werden sie nur selten gefunden. Mit dem Virus selbst haben diese Gebilde nichts zu tun. Es handelt sich bei ihnen vielmehr um Reaktionsprodukte der Zellen, die von diesen unter dem Einfluß des Virus gebildet werden.

Einschlußkörperchen lassen sich auch in ungefärbten Schnitten mit dem Phasenkontrastmikroskop sichtbar machen (Angulo u. a., 1949).

Die Kupfferschen Sternzellen werden gewöhnlich ebenfalls schwer in Mitleidenschaft gezogen. Sie sind geschwollen, trübe, vakuolisiert und vielfach vermehrt. Sie enthalten oft große Mengen von Gallenpigment, gelegentlich vorwiegend Fetttröpfchen, niemals dagegen hyaline Substanz. Hyperplastische Sternzellen werden besonders im Spätstadium weniger schwerer Fälle gefunden (Klotz und Simpson, 1927). Villeda (1941) hat im Zellzytoplasma vorwiegend in Makrophagen und KupfFERschen Sternzellen, aber auch frei liegend hell-ockerfarbene granuläre Körperchen beschrieben, welche er für zerfallene mit Galle durchsetzte Councilmansche Körperchen und bei Fehlen letzterer für die Gelbfieberdiagnose brauchbar hält. Bei schwerem Verlauf weisen die Retikuloendothelzellen pyknotische und karrhyorektische Kerne auf. Sonst bleibt das Gefäßsystem ebenso wie Stroma und Gallengänge gewöhnlich unbeschädigt. 
Die Verminderung des Leberglykogens scheint proportional zu der Schwere der Leberschädigung zu sein (Kцотz und Belt, 1930b, c). Nach diesen Autoren können alle Leberläppchen am Nekroseprozeß beteiligt sein, doch ist die intermediäre Zone besonders betroffen, während in der Läppchenperipherie und in der Umgebung der Zentralvene intakte Leberzellen gefunden werden. Bemerkenswert ist das Fehlen nennenswerter entzündlicher Vorgänge. Charakteristisch sind aber die Leukozyten-(Rundzellen- und Polynukleären)-Infiltrate, welche in der Mittelzone der Läppchen besonders ausgeprägt sind. Sie weisen auf den toxoinfektiösen Vorgang bei der Hepatitis hin. Die Leberveränderungen sind am 5. und 6. Tage am schwersten. Die Wiederherstellung des zerstörten Leberparenchyms geht schnell und vollständig vor sich; dies konnten KLotz und BeLt auch beim experimentell infizierten Affen feststellen. Erleichtert wird der Regenerationsvorgang dadurch, daß das Leberstroma erhalten geblieben ist. Nach van Rooyen und Rhodes (1948) besteht zwischen den Leberveränderungen des Gelbfiebers und der akuten gelben Leberatrophie große Ähnlichkeit.

Ein wichtiges Gerät zur schnellen histologischen Gelbfieberdiagnostik der Leber ohne Leicheneröffnung ist das Viscerotom. Dieses ist ein von Biao angegebenes vierkantiges, hohlsondenartiges Instrument, das im wesentlichen aus 4 Messern besteht, von denen das eine gegen das gegenüberliegende Messer verschoben werden kann. Dieses bewegliche Messer läuft in einer Führung und schließt, nach vorwärts gestoßen, den Sondenhohlraum. Die Sonde wird in geschlossenem Zustand durch die Bauchwand in die Leber der Leiche gestoßen, das bewegliche Blatt zurückgezogen und die Sonde noch tiefer in die Leber gepreßt, so daß sie ein Stück Leber aufnimmt. Dann wird die Sonde wieder geschlossen und zurückgezogen. Die Viscerotomie ist schnell und einfach durchzuführen und vermag für diagnostische Zwecke die zeitraubenden und kostspieligen Sektionen an Ort und Stelle zu ersetzen (Rickard, 1931, 1937; s. auch Para und Aviles Nugue, 1953).

Die Nieren erscheinen bei tödlich verlaufendem Gelbfieber geschwollen und mehr oder weniger ikterisch verfärbt. Subkapsuläre Blutungen kommen vor. Im Schnitt ist die Nierensubstanz trübe, geschwollen, graurötlich verfärbt und mit mehr oder weniger zahlreichen gelben Streifen im Nierenmark und Teilen der Rinde durchsetzt (Bugher, 1951a). Mikroskopisch findet man in den Nieren schwere Veränderungen vom Typus der toxoinfektiösen Nephritis bzw. Nephrose, neben Hyperämie und Hämorrhagien eine parenchymatöse Degeneration in Gestalt von trüber Schwellung, Nekrose und Verfettung der Epithelien in Nierenkanälchen, weniger dagegen in den Glomeruli, in denen nur Hyperämie und Ödem vorkommen, aber keine Hämorrhagien oder Leukozyteninfiltrationen gefunden werden. Die in den Tubulizellen befindlichen Massen sind mit den CounciLmanschen Körperchen zu vergleichen. Die Nierenkanälchen können hyaline, granuläre und Kalkzylinder enthalten; die Entstehung der letzteren wird auf die schwere toxische Wirkung zurückgeführt; ihr Nachweis wird von manchen Autoren als wichtig für die histologische Diagnostik bezeichnet (Da Rocha Lima, 1912a, b; Torres, 1926, 1928a-h, 1929a-d; Hoffmann, 1937.) Außerdem ist bei $60 \%$ der Fälle in den die Tubuli ausfüllenden Massen eine erhebliche Eisenmenge vorhanden (MagalHaes, 1931).

Echte Einschlußkörperchen in den Kernen der Nierentubuli sind nicht nachgewiesen worden (Cowdry und Kitchen, 1929, 1930). Magalhaes beschrieb azidophile Körperchen, welche aber unspezifischen nekrotischen Ursprunges gewesen sein dürften. Eine nennenswerte Stromabeteiligung in den Nieren fehlt; die Zellinfiltrationen bleiben nur geringfügig. Auch die Nieren machen bei Genesung einen recht vollständigen Wiederherstellungsvorgang durch. Bugher (1951a) hält die Nekrose in diesen Fällen für nur gering und glaubt an einen Ersatz der Gewebedefekte durch Hypertrophie der verbliebenen Zellen, aber auch durch Regeneration durch Zellvermehrung, so daß die Nieren dann mikroskopisch wieder normal erscheinen. Nach Ast (1950) steht noch keineswegs fest, daß die Nierenveränderungen durch eine spezifische Wirkung des Gelbfiebererregers auf die Nierenepithelzellen zustandekommen; die fettigen und hyalinen Degenerationen lassen sich vielmehr durchaus sekundär aus der schnellen und schweren Leberschädigung (Cholinmangel) oder durch allgemeine toxische Wirkung erklären. AsH weist überdies darauf hin, daß ähnliche kristallinische stärkeartige 
Körperchen in den Tubuli auch bei anderen pathologischen Vorgängen, wie z. B. Tetrachlorkohlenstoffvergiftung gesehen werden (SMETANA, 1939). BARBARESCHI (1957) spricht von einer toxischen Glomerulose, die im Verlaufe des Gelbfiebers mit hepatorenalem Syndrom auftritt und zu einer akuten Nephrose mit veränderter Permeabilität für Proteine mit Infiltration (Proteinurie) führt.

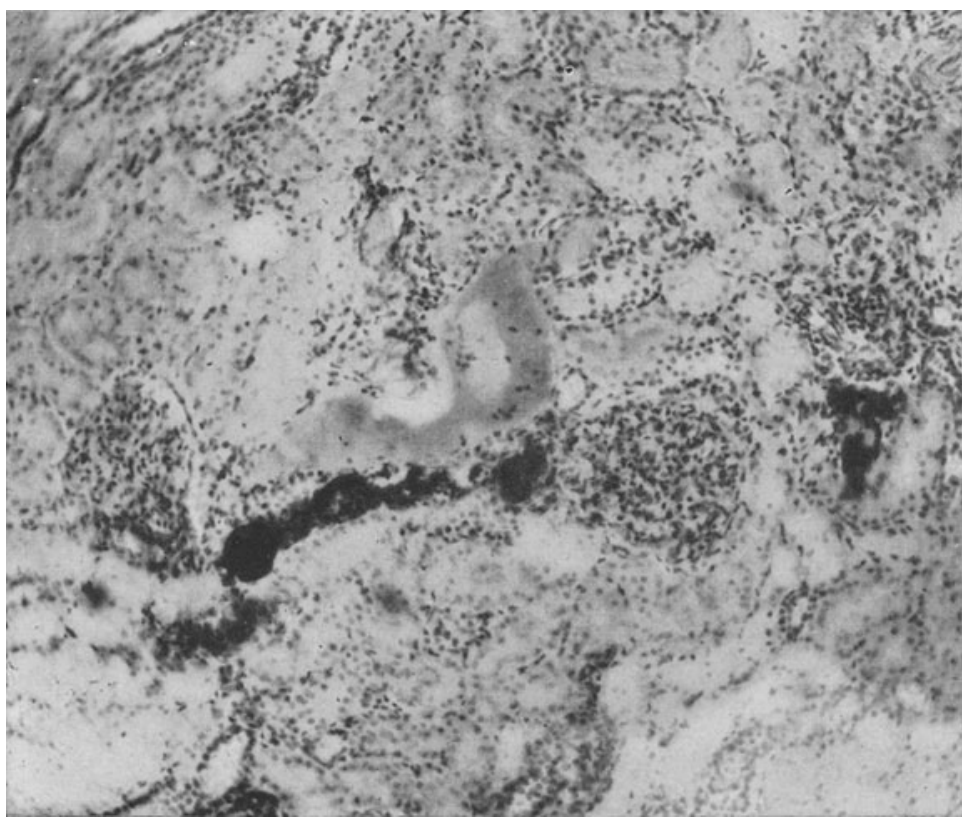

Abb. 40. Gelbfieberniere: Kalkzylinder, Degeneration der Epithelen der gewundenen Harnkanälchen (nach NAUCK, 1952a)

Die Milz zeigt meistens keine auffallenden makroskopischen Veränderungen. Eine leichte Vergrößerung kann bestehen, doch erscheint es in den Tropen, wo Malaria vorherrscht, schwierig, eine solche auf das Gelbfieber zurückzuführen (BugHer, 1951a). Die Milzsinus sind erweitert und stark hyperämisch. Veränderungen an den Malipighischen Körperchen stehen im Vordergrunde (KLotz und BeLt, 1930b). Zunächst treten Monozyten in und um die Follikel auf. Mit Zunahme der großen Mononukleären nehmen die Lymphozyten ab; später vermindern sich auch erstere wieder, so daß das Bild einer deutlichen retikuloendothelialen Hyperplasie entsteht. Die Keimzentren degenerieren gewöhnlich. Die Nekrose der Lymphfollikel ist beim Menschen jedoch verhältnismäßig selten, häufig dagegen beim Affen. Die Milz ist im allgemeinen weniger befallen als die Leber (KLotz und Simpson, 1927).

Die Nebennieren werden von einer starken fettigen Degeneration der Rinde beherrscht; dieser wurde bereits von Marchoux und Simond (1906a, b, c,), später auch von Hudson (1928a), Torres (1928a-h) sowie Torres und Penna-Azevedo (1928) beobachtet. Außerdem besteht eine erhebliche Rindenzellennekrose; ferner werden Eosinophilie, Kernpyknose und Hämorrhagien angetroffen.

Das Pankreas erscheint vergrößert und weist Gallenfärbung sowie fleckige Blutungen auf. Mikroskopisch finden sich diffuse Erythrozytenaustritte in das Stroma sowie kleine fettige Degenerationen der Acini und Langerhansschen Inseln. Dagegen scheint eine Nekrose der sekretorischen Zellen infolge der Viruseinwirkung zu fehlen und der Prozeß auf Veränderungen der Gefäßendothelien und Blutungsneigung beschränkt zu sein. 
Am Herzen steht eine Myodegeneration mit unregelmäßiger fleckiger Trübung im Vordergrund. Auch hier handelt es sich um trübe Schwellung und fettige Degeneration der Muskelfasern (Отто und Neumann, 1905; da Rocha Lima, 1912 b; Klotz, 1927; Cannell, 1928). Auch die Muskelzellkerne degenerieren. Diese Prozesse können sich in den Sinoaurikularknoten und das His-sche Bündel erstrecken (LLOYd, 1931). Hierdurch wie auch durch die Nebennierenfunktionsstörungen ist die Bradykardie zu erklären. Zellinfiltrationen und Bindegewebsproliferationen, primäre Entzündungsvorgänge und interstitielle Reaktionen fehlen (Bugher, 1951a). Ash (1950) weist am Herzen auf charakteristische Hämorrhagien besonders im hinteren Subepikard nahe der Aurikuloventrikularverbindung hin.

Der Magen kann größere Mengen verdauten und frischen Blutes enthalten, die Schleimhaut zahlreiche petechiale Blutungen und Infiltrationen polynukleärer Leukozyten und Lymphozyten in der Submukosa aufweisen (BUGHeR, 1951a). Die Hämorrhagien setzen sich in den Darm fort, und zwar in das Duodenum und manchmal Jejunum; in den unteren Darmabschnitten werden die Blutungen seltener. Im lymphatischen Gewebe des Darmes treten ähnliche Veränderungen wie in der Milz auf: Zunahme der großen Rundzellen und Abnahme der Lymphozyten; erstere erfahren später wieder eine Verminderung. Keimzentren können ganz verschwinden. Die beim Kranken gefundene Leukopenie scheint auf den weitverbreiteten Prozessen im lymphatischen Apparat zu beruhen. Im Lymphgewebe ist außerdem Virus vorhanden. Dieses scheint sich überall im retikuloendothelialen Apparat zu vermehren; trotzdem bleibt es in so geringen Mengen, daß es kaum nachweisbar wird (Bugher, 1951a).

Die makroskopische Betrachtung des Zentralnervensystems ergibt eine Hyperämie und unter Umständen punktförmige Blutungen in Brücke und verlängertem Mark. Die Meningen erscheinen spezifisch nicht beteiligt. Während im Tierexperiment das i.cer. injizierte Virus einen ausgesprochenen Neutropismus aufweist, scheint normalerweise die Blut-GehirnSchranke dem im Kreislauf befindlichen Virus den Eintritt in das Gehirngewebe zu versperren. Kleinkinder machen allerdings eine Ausnahme und können eine Gelbfieberencephalitis bekommen. Beim Erwachsenen bleiben die Gehirnveränderungen nur unbedeutend und scheinen unspezifisch zu sein (Nicolau u. a., 1937); es handelt sich um perivaskuläre Blutungen, vor allem im Hypothalamus, aber manchmal auch in den Gehirnhemisphären und im Kleinhirn. Selten sind perivaskuläre Rundzelleninfiltrationen und Proliferation der Gliazellen. Eine Beteiligung der Nervenzellen kommt dagegen kaum vor (Stevenson, 1939; Ash, 1950; Nauck, 1952a). Während Stevenson annimmt, daß die an sich geringfügigen Gehirnprozesse allein schon ausreichen, um den Tod herbeizuführen, glauben Findlay und Stern (1935b), daß die von ihnen beobachteten nervösen Komplikationen (Facialisparese und Augenlidptose) zentral bedingt sind.

Die neuere Auffassung über die Pathologie des Gelbfiebers geht dahin, daß die als spezifisch anzusehenden Veränderungen in den Organen erheblich eingeschränkt werden müssen. Bugher (1951 a) stellt die selektive Nekrobiose, die nur hochentwickelte Epithel- oder Herzmuskelzellen befällt, in den Vordergrund, während Stromazellen nicht ergriffen werden und Entzündungsreaktionen fehlen. Die prädominierende spezifische Lokalisation ist das Leberparenchym (AsH, 1950); die überwiegend parenchymale fettige Degeneration besonders der Leber, Nieren und des Herzmuskels bezeichnet Asн nur als zufällige Erscheinungen. Die schwere hyaline Degeneration weist dagegen auf einen gemeinsamen ursächlichen Faktor hin, welcher nur in der unmittelbaren Viruswirkung gesucht werden kann. In einer ganz neuen Darstellung der klinischen Pathologie des Gelbfiebers beschreiben Elton u. a. (1955) die azidophile Nekrose des Zytoplasmas der polygonalen Leberzellen als die gewöhnlichen Leberveränderungen.

Weitere Literatur

Elton und Johnson (1950), Martinez Baez (1958). 


\section{Diagnose}

\section{6-1. Klinische Diagnose}

Wie HöRING (1950) mit Recht hervorhebt, ist das Gelbfieber heute gar nicht mehr »eine mit Gelbsucht und Albuminurie einhergehende schwere Krankheit mit hoher Letalität». Zu Beginn ist das Gelbfieber oft nur schwer zu erkennen; die charakteristischen Symptome fehlen. Dies trifft besonders bei Einzelfällen zu. Leichte Fälle können mit Influenza und Dengue verwechselt werden. Auch die Differentialdiagnose zwischen Gelbfieber und Schwarzwasserfieber, Rückfallfieber, Leberlues oder WEILscher Krankheit ist nicht immer ganz leicht. Bezüglich der Differentialdiagnose ist darauf hinzuweisen, daß das Gelbfieber gewöhnlich in Ländern vorkommt, in denen auch Malaria heimisch ist. Die Blutuntersuchung muß daher die letztere ausschließen.

Die Gelbfieberinfektion äußert sich in folgenden Verlaufsformen (s. auch Klinik):

1. die latent bleibende klinische Form, die nicht über das Generalisierungsstadium herauskommt, aber doch zu einer wirksamen Immunität führt. Man spricht von einer "stillen Feiung", die offenbar bei Kindern die häufigste Infektionsform ist.

2. die fieberhafte Erkrankung, die bereits nach 2 Tagen zu Abheilung kommt, ohne daß sich typische Symptome entwickeln.

3. das vollentwickelte Gelbfieber mit Organbefall und funktionellen Störungen.

Couto und Da Rocha Lima (1935) unterscheiden je nach dem stärkeren Befall des einen oder anderen Organsystems folgende Formen:

1. die acholische oder hepatische Form,

2. die anurische oder renale Form,

3. die hämorrhagische oder vaskuläre Form,

4. die kardio-asthenische oder kardiale Form,

5. die ataktische oder cerebrale Form,

6. die Mischform, welche die häufigste ist.

Bei einigermaßen typischem Verlauf ist die Diagnose durch das gleichzeitige Auftreten von Gelbsucht, Hämorrhagien und Nierenstörungen ziemlich leicht zu sichern, besonders in Epidemien. Diese klassische Trias wird aber nur in schweren Fällen angetroffen. Einzelfälle sind schwerer zu erkennen, zumal wenn das äußere Hauptsymptom, der Ikterus, fehlt. Die Leukopenie gibt schon einen gewissen Hinweis auf Gelbfieber, ebenso die schnell zunehmende Albuminurie und Verminderung der Hämolyse bereits in den ersten Krankheitstagen. Relative Bradykardie und Leukopenie können auch den Verdacht eines Abdominaltyphus aufkommen lassen. KERR (1951) gibt für die klinische Diagnose folgendes an:

"Je milder der Anfall, desto schwieriger ist es, die Diagnose zu stellen. Diagnostizierbare Anfälle von Gelbfieber sind charakterisiert durch plötzlichen Beginn mit Kopfschmerzen und schnell auf $39-40^{\circ} \mathrm{C}$ ansteigende Temperatur, Rückenschmerzen und allgemeinen Muskelschmerzen, Schwindel, Erbrechen von Nahrung, Hyperämie im Gesicht, in den Konjunktiven und im Gaumen; der Puls ist voll und hüpfend; das FAGETsche Zeichen entwickelt sich; die Zunge nimmt bald ein recht charakteristisches Aussehen an; sie wird in der Mitte pelzig mit hellroten Rändern und Spitze. Während der ersten 3 Tage der Krankheit, der Infektionsperiode, ist der Allgemeinzustand des Patienten gut, obwohl er sich selbst sehr unbehaglich fühlt. Am 1. Tage vermag leichte Leukopenie zu bestehen, aber weder Gelbsucht noch Albuminurie. Ein charakteristisches Zeichen für Gelbfieber ist das plötzliche Auftreten von großen Eiweißmengen im Harn am 3. oder 4. Tage und eines Subikterus der Skleren etwa am 3. Tage. Schwarzes Erbrechen kommt dagegen selten vor dem 4. Tage vor. Mit 
der Remissionsperiode findet ein Blutdruckabfall statt, aber der Patient fühlt sich gewöhnlich besser. Wenn sich die Periode der Intoxikation mit typischem schwarzem Erbrechen und deutlicher Oligurie entwickelt, sind alle klassischen Krankheitssymptome vorhanden."

HöRING (1950) gibt zur Differentialdiagnose folgende Zusammenstellung:

\begin{tabular}{|c|c|c|c|}
\hline & Gelbfieber & $\begin{array}{l}\text { Weilsche } \\
\text { Krankheit }\end{array}$ & $\begin{array}{c}\text { Schwarzwasser- } \\
\text { fieber }\end{array}$ \\
\hline $\begin{array}{l}\text { Puls } \\
\text { Erbrechen } \\
\text { Stuhl } \\
\text { Urin: Eiweiß } \\
\\
\text { Bilirubin }\end{array}$ & $\begin{array}{c}\text { langsam } \\
\text { vomito negro } \\
\text { Melaena } \\
+++ \\
+\end{array}$ & $\begin{array}{c}\text { schnell } \\
\text { schleimig } \\
\text { farblos } \\
++ \\
++\end{array}$ & $\begin{array}{c}\text { schnell } \\
\text { grau } \\
\text { blaurot } \\
+ \\
\frac{-}{\text { (Hämoglobinurie) }}\end{array}$ \\
\hline
\end{tabular}

In den Gelbfieberepidemien von 1951-1954 in Ostnigeria wurden von MacNamara (1957) leichte Gelbfieberfälle gefunden, in denen Gelbsucht, Lebervergrößerung sowie Bradykardie fehlten und nur eine leichte AJbuminurie bestand. Sie wurden nur durch Laboratoriumsmethoden diagnostiziert. Macnamara sah außerdem Fälle mit verlängertem Verlauf, welche klinisch der infektiösen Hepatitis ähnelten. Die höchsten Virustiter im Blut bestanden in den 2-3 ersten Krankheitstagen.

\section{6-2. Laboratoriumsdiagnose}

Sie erstreckt sich auf die histologische Diagnostik, den Virusnachweis und die serologischen Reaktionen.

Zur Entnahme von Leberproben kann eine Biopsie vorgenommen werden. Herrera und Pardo (1947) bezeichnen das Trauma, das durch die Einführung des Trokars in die Leber ausgeübt wird, als minimal; sie führten 72 Biopsien aus, ohne daß es zu einer einzigen Hämorrhagie oder anderen Komplikation kam (s. auch KalK und WiLdHIRT, 1958).

Zur Laboratoriumsdiagnostik am Krankenbett kommt nur der Virusnachweis im Blut durch den Tierversuch in Frage. Das Blut muß so früh wie möglich entnommen werden, am besten innerhalb der ersten 3 Tage nach Fieberbeginn, aber auch bis zum 7. Tage ist mitunter noch Virus im Blute vorhanden (Bugher, 1951a; Macnamara, 1954a). Downs u. a. (1955b) wiesen in einem Falle den Erreger im Blute noch am 12. Krankheitstage nach; dieser Patient war gleichzeitig ein schlechter Antikörperbildner. Wenn das Blut nicht sofort verarbeitet werden kann oder versandt werden muß, ist es möglichst kühl ( $4^{\circ} \mathrm{C}$ oder darunter), aber nicht gefroren aufzubewahren, falls es nicht zuvor zentrifugiert und der Blutkuchen entfernt wird. In hämoglobinfreiem Serum hält sich der Erreger am besten. Als Testtiere eignen sich Affen und Mäuse.

Rhesus-Affen sind zu bevorzugen; falls nicht vorhanden, sind auch. M.inuus und M.sinicus brauchbar. Das Gesamtblut oder Serum wird subkutan oder noch besser intraperitoneal eingespritzt. Im positiven Falle kommt es am 3. oder 4. Tage zu Fieber und Tod vom 5. Tage ab. Die Affenleber ist histologisch auf spezifische Veränderungen zu untersuchen. Da die Affen aber auch fieberlos bleiben können, empfiehlt es sich, ihnen täglich Blut zu entnehmen und das Serum Mäusen intraperitoneal zu injizieren. Bei Überleben der Tiere ist nach einiger Zeit das Blut auf die Bildung von N-AK zu prüfen. Die histologische Leberdiagnose wird durch die positive NR wertvoll ergänzt.

Der Mäuseinfektionsversuch wird vielfach vorgezogen: konzentriertes, $1: 10,1: 100$ und mehr verdünntes Krankenserum wird je 6 Mäusen i.cer. injiziert (s. Theiler, 1930a). Die Mäuse werden mindestens 2 und bis zu 4 Wochen auf encephalitische Symptome beobachtet; verdünntes Serum führt mitunter zum Erfolg, wo konzentriertes Serum infolge frühzeitiger 
Entstehung von N-AK nicht mehr brauchbar ist. Je nach der Viruskonzentration der Serumproben erkranken die Mäuse gewöhnlich vom 8. bis 10. Tage ab an einer tödlichen Encephalitis. Die Spezifität dieser Encephalitis wird durch i.cer. Weiterverimpfung des Gehirns auf gesunde Mäuse und mikroskopisch durch den Nachweis der charakteristischen Veränderungen (Kerneinschlüsse in den Nervenzellen und perivaskuläre Rundzelleninfiltrationen) sowie durch die Neutralisation des im Mäusegehirn vorhandenen Virus mit bekanntem Gelbfieberimmunserum gesichert.

Von Immunitätsreaktionen kommt für die Diagnostik nur die Mäuseschutzprobe (SerumNeutralisationsreaktion) in Frage. In Zweifelsfällen, wo die anderen Hilfsmittel versagen, läßt sich mit dieser Probe die Diagnose etwa von der 3. oder 4. Krankheitswoche an sichern. Sie ist dann aber schon retrospektiv und ohne klinische Bedeutung. Für die diagnostische Beurteilung, ob es sich in der Tat um Gelbfieber gehandeJt hat, ist eine mehrmalige Blutentnahme im Verlauf der Erkrankung bis zur Rekonvaleszenz erforderlich. Enthält die in der Rekonvaleszenz entnommene Blutprobe N-AK, die zu Beginn der Erkrankung entnommene Probe dagegen nicht, oder zeigen die entnommenen Proben einen deutlichen Titeranstieg, so kann die Gelbfieberdiagnose als gesichert gelten. Gleichbleibende Titer zweier Proben schließen Gelbfieber während dieser Zeit aus und zeigen nur eine Immunität infolge früherer Erkrankung oder Schutzimpfung an. Die N-AK bleiben bis zu lebenslänglich nachweisbar. Auf die Durchführung des Mäuseschutzversuchs wird später eingegangen. Die Komplementbindungsreaktion ist viel weniger empfindlich als die Mäuseschutzprobe und daher ohne praktische diagnostische Bedeutung (s. Immunität); sie wird überdies nur in schweren Fällen positiv. KERR (1951) sieht den Wert der Reaktion in der Unterscheidungsmöglichkeit zwischen einer alten und neu erworbenen natürlichen Immunität sowie einer solchen zwischen einer natürlichen und durch Impfung erworbenen Immunität. PANthier und Hannoun (1960) schreiben der KBR diagnostische Bedeutung zu, wenn der Tod schon früh eintritt.

Die von Hughes $(1933,1934)$ ausgearbeitete Präzipitationsreaktion hat keine diagnostische Bedeutung bekommen.

Weitere Literatur zu Diagnostik:

Nauck (1953), Torres (1953).

\section{Prognose}

In Anbetracht der vielen unerkannt bleibenden (stummen und ambulant verlaufenden) Infektionen ist es schwer, die absolute Letalität des Gelbfiebers zu bestimmen. Je nach der Schwere der jeweiligen Epidemie sterben 0,5 bis 95\% der Erkrankten. Es kann aber angenommen werden, daß durchschnittlich etwa ${ }^{2} / 3$ aller diagnostizierten klassischen Erkrankungen zum Tode führen, und zwar bereits zwischen dem 6. und 10. Krankheitstage; nach dem 10. Tage ist die kritische Zeit überstanden und der Kranke befindet sich außer Gefahr. Kinder pflegen leichter zu erkranken als Erwachsene; die Heilung verläuft meistens schnell und trotz schwerster Organveränderungen gewöhnlich vollständig. Bei Erwachsenen erstreckt sich die Rekonvaleszenz dagegen oft über einen längeren Zeitraum. Wenn es auch bei Überstehen des Gelbfiebers zu einer überraschend schnellen und vollständigen Regeneration der hepatorenalen Schäden kommt, so erfordert die Überwindung der Kreislaufinsuffizienz und des allgemeinen Schwächezustandes doch längere Zeit. Bei alten Leuten ist die Sterblichkeit besonders hoch.

Die Prognose ist durch die Widerstandsfähigkeit der Leber, Nieren und des Kreislaufes bestimmt. Todesursachen sind Kreislaufschwäche, Leber- und vor allem Niereninsuffizienz. Eine sichere Prognose im Einzelfall ist kaum möglich; auch bei schwersten hoffnungslos erscheinenden Verläufen kommt es manchmal wie durch ein Wunder noch zu Genesung. Bei hyperakutem foudroyantem Verlauf kann es bereits am 1. Krankheitstage zum exitus letalis kommen; im allgemeinen tritt der Tod aber nicht während der ersten 3-4 Tage, also während der Infektionsphase, ein. Der Grad des Ikterus allein ist für den Ausgang weniger bedeutsam; aber je höher das Fieber ist und je früher die Gelbsucht und Albuminurie ausbrechen, desto 
schlechter wird die Voraussage (KeRR, 1951). KLotz und Simpson (1927) halten eine in ihrer Schwere zunehmende Gelbsucht eher für ein günstiges Zeichen. Die subjektive Besserung während der ersten beiden Tage der Remissionsphase ist ohne prognostische Bedeutung; bleiben anschließend Symptome der Intoxikation aus, kann der Patient als gerettet gelten; kommt es dagegen zu einer ausgesprochenen Intoxikationsphase mit erneutem Fieberanstieg (zyklischer Verlauf), so muß die Prognose sehr ernst gestellt werden. Etwa die Hälfte dieser Kranken stirbt. Puls über 100 in dieser Phase ist als ernstes Zeichen, über 120 als sehr bedenklich anzusehen. Plötzlicher Temperaturabfall muß schlecht beurteilt werden. Schluckauf im Koma ist äußerst bedenklich. Mit tödlichem Ausgang muß bei völligem Versagen des Magens, anhaltender Anurie, wiederholten schweren Blutungen, schweren Muskelkrämpfen gerechnet werden.

Das Schicksal der Kranken entscheidet sich also schon innerhalb weniger Tage. Ebenso schnell kann auch der Heilungsprozeß einsetzen.

Prognostisch günstig sind ausreichend bleibende Harnmenge bzw. Wiedereinsetzen der Harnentleerung, Abnahme der Albuminurie, frühzeitiges Erscheinen von Gallenpigmenten und klar bleibendes Bewußtsein. Einsetzen von Leukozytose mit Linksverschiebung und Mononukleose ist ebenfalls ein günstiges Zeichen. Trejos und Romero (1954) halten einen Prothrombinspiegel unter $25 \%$ zwischen dem 4 . und 9. Krankheitstage für prognostisch viel schlechter als einen solchen über $35 \%$. Bei Genesenden wird ein schneller und manchmal früher Anstieg des Prothrombinspiegels gesehen, was auf eine schnelle Wiederherstellung der Leber hinweist.

\section{Behandlung}

Eine spezifische Chemo- oder Serotherapie des Gelbfiebers gibt es nicht. Versuche, die Krankheit durch Rekonvaleszentenserum oder Pferdeserum zu beeinflussen, sind ohne Erfolg geblieben, obwohl diese Seren bei Laboratioriumstieren eine Schutzwirkung ausüben. KERR (1951) schreibt:

»Die meisten Patienten genesen schnell und vollständig, ganz gleichgültig, was für sie getan wurde oder nicht. Andererseits scheint nichts von dem, was der Kliniker tun kann, bei den meisten der schweren Infektionen merklich zu helfen. Es bleibt nur ein kleiner Bruchteil aller Fälle übrig, bei denen unterstützende Behandlung mit sorgfältiger Pflege verbunden vielleicht das Leben des Patienten retten konnte."

Die allgemein anerkannte symptomatische Behandlung, deren Möglichkeiten an sich auch nur beschränkt sind, erstreckt sich hauptsächlich auf Entlastung und Unterstützung von Leber, Nieren, Herz und, Kreislauf. Hierzu gehört völlige Bettruhe. Es wird daher vielfach empfohlen, einen Gelbfieberkranken an Ort und Stelle zu belassen, wenn die Pflegemöglichkeiten es gestatten, um die Kräfte des Patienten nicht vorzeitig zu erschöpfen, da auch der Stoffwechsel aufs äußerste angespannt ist. Auf sorgfältige Pflege des Kranken ist besonderes Gewicht zu legen; er soll möglichst wenig bewegt werden und in einem völlig ruhigen und sehr gut gelüfteten Raum liegen. Bettruhe ist auch in leichten Fällen noch etwa 1 Woche nach der Entfieberung erforderlich.

Bei frühzeitig einsetzenden Stauungssymptomen wird immer noch ein Aderlaß empfohlen (etwa $200 \mathrm{ml}$ bei größeren Menschen werden angeraten). Da diese Blutentnahme für den Arzt infektiös sein kann, sind alle Vorsichtsmaßnahmen gegen eine Selbstinfektion erforderlich. Das Blut ist sofort durch ein kräftig wirkendes Desinfektionsmittel unschädlich zu machen. Durch Senffußbäder, die im Bett ausgeführt werden, erzielt man eine Ableitung der Blutüberfüllung der Organe. Die Herztätigkeit wird durch Tonika sowie unter Umständen täglich mehrmalige i.v. Injektionen von $20 \mathrm{ml} 40 \%$ iger Traubenzuckerlösung angeregt. Im Kollaps kommen Bluttransfusionen in Frage. Abwaschungen mit kaltem Wasser setzen das Fieber herab und wirken lindernd auf Schmerzen und Erbrechen; die Verstopfung wird durch milde wirkende Abführmittel und Einläufe angegangen; heftiger wirkende Mittel sind wegen der Hämorrhagiegefahr zu vermeiden. Jedes Brechmittel ist aus dem gleichen Grunde unbedingt 
zu vermeiden. Während der 3 ersten Krankheitstage oder länger wird Fasten angeraten. Der Brechreiz wird durch Eisbeutel auf die Magengegend, Schlucken kleiner Eisstückchen und kleine Kokain- oder Kodeinmengen (kein Morphium!) bekämpft. Zur Behebung der Azidose gibt man schluckweise alkalisiertes Wasser, ferner Frucht-(Zitrus)-säfte und überhaupt viel Flüssigkeit, um den Wasserhaushalt möglichst im Gleichgewicht zu halten und die Diurese anzuregen. Hierzu dienen auch NaCl-Infusionen. Blutbrechen erfordert Ernährung vom Darm her und besonders Styptika (Adrenalin, Ergotin, Bleiacetat). Durch Verabfolgung von Ca-Salzen - täglich mehrere g per os oder injiziert - werden der Ca-Spiegel des Blutes gehoben sowie Blutungsneignung und Guanidinerhöhung bekämpft; Findlay und Hindle (1930) empfehlen Einspritzungen von $5 \mathrm{ml}$ einer 5\% igen Ca lactat-Lösung alle 4-6 St. Dem Versagen der Leber begegnet man durch Injektion von Leberextrakten und kleinen Insulindosen. Die Zuckerverarmung und Leberintoxikation werden durch Verabfolgung großer Kohlenhydratmengen, bei Brechreiz durch Tropfinfusionen oder i.v. Injektionen von Traubenzucker bekämpft. Die Nierentätigkeit wird durch 2 mal tägliche s.c. oder rektale Verabfolgung von je $0,4 \mathrm{~g}$ Harnstoff angeregt; bei trockener Haut und spärlichem Harn wird außer Flüssigkeitszufuhr Pilokarpin in kleinen Mengen empfohlen. (NАUck, 1952a).

KERR (1951) weist noch auf folgende unterstützende Behandlungsversuche während der Infektionsphase hin: Fleischbrühe, Huhn und Käse; frühzeitig und laufend Kaseinhydrolysat oder Hydrolysate anderer guter Eiweiße i.v., falls der Kranke nicht genug Nahrung per os aufnimmt. Cholin und Methionin sollen dem Kaseinhydrolysat nicht überlegen sein, Ca glukonat kann i.v. gegeben werden, wenn das Blut-Ca zu niedrig ist oder Guanidin bzw. guanidinartige Substanzen vermehrt im Blute gefunden werden.

Nach Einsetzen der Besserung geht man schrittweise zu leichter Kost über. Schonkost ist aber bis in die Rekonvaleszenz fortzusetzen, um sogenannte "Rückfälle", welche in nachträglichen Darm- und Leberschäden bestehen und tödliche Folge haben können, zu verhüten. HöRING (1950) empfiehlt außer Breikost geeiste Milch, geschlagenes Ei und dergleichen, zunächst 1-2 mal stündlich in kleinen Mengen, und erst vom 12. Tage an wieder langsam aufbauende feste Kost.

\section{Immunbiologie}

\section{9-1. Allgemeines}

Das Gelbfieber gehört zu den immunbiologisch am besten erforschten Krankheiten. Die Ergebnisse, die hier gefunden worden sind, haben wesentlich zur Erweiterung der Kenntnisse aller Immunitätsvorgänge auch anderer Viruskrankheiten beigetragen.

Auf Grund der großen Erfahrungen kann heute angenommen werden, daß das Überstehen einer Gelbfieberinfektion, sei es einer natürlichen Infektion mit oder ohne Erkrankung, sei es durch Schutzimpfung, eine lange, bis zu lebenslängliche Immunität herbeiführt. Zweiterkrankungen scheinen nicht vorzukommen.

Neugeborene können von den immunen Müttern eine passive Leihimmunität aufweisen, welche zwar nur kurze Zeit vorhält, aber offenbar genügt, um eine in dieser Zeit stattfindende natürliche Infektion stumm oder ganz leicht verlaufen zu lassen und dabei eine kräftige aktive Immunität zu erwerben (REed u. a., 1900; Marchoux u. a., 1903). Dies konnte auch experimentell an Affen festgestellt werden (Hoskins, 1934a). Alle Neugeborenen von gelbfieberimmunen Affenmüttern hatten anfänglich Schutzkörper im Serum, aber nur solange, wie sie von der Mutter gesäugt wurden. An die Möglichkeit einer Übertragung der Immunität mit der Muttermilch wurde gedacht. Stefanopoulo (1936) sowie Stefanopoulo u. a. (1936) fanden bei sowohl durch Erkrankung als auch durch Schutzimpfung immunisierten Frauen AK in der Milch. Weitere Untersuchungen dieser und anderer Autoren (Soper u. a., 1938) wiesen auch auf eine transplazentare Übertragung spezifischer Schutzstoffe hin. Die längste Zeit des nachweislichen Fortbestehens einer solchen Leihimmunität betrug bei Kindern 6 Monate und bei Affen $5^{1 / 2}$ Monate. 
Stefanopoulo und Nagano (1937) nahmen eine passive Immunisierung von Mäusen mit Pferdeantiserum vor und stellten ebenfalls eine Übertragung der AK auf die Jungen beim Säugen mit der Milch fest. Linhares (1943a, c) immunisierte trächtige Mäuse aktiv und passiv; er fand bei den Abkömmlingen der Weibchen eine passive Immunität. Auch hier erfolgte die Immunisierung der Jungen teils durch die Plazenta, teils mit der Muttermilch. Die transplazentare Immunität verschwand schneller als der Milchschutz.

Die Gelbfieber-AK lassen sich durch radioaktives Jod markieren (Clarke und Black, 1955).

\section{9-2. Antikörperbildung und Immunitätsreaktionen}

Beim Gelbfieber findet man N-AK, KB-AK, HAH-AK und präzipitierende AK.

Der Nachweis der neutralisierenden Antikörper ist für die Immunbiologie von besonderer Wichtigkeit. N-AK treten etwa vom 5. Krankheitstag auf, finden sich aber erst nach 2-3 Wochen in einer hinreichenden Menge im Serum, um in der Schutzprobe zuverlässig nachgewiesen werden zu können. Sie bestehen dann jahre- bis jahrzehntelang. Ihr Verschwinden aus dem Blut bedeutet aber noch keineswegs das Erlöschen der Immunität. Der AK-Titer nach Schutzimpfung mit dem 17D-Virus wird im allgemeinen nicht so hoch wie nach einer natürlichen Infektion.

Bei immunologischen Untersuchungen von Sмітн (1958) in 5 Gemeinden in verschiedenen Gegenden von Malaya ergab die NR bei etwa $1 / 3$ der Seren AK gegen Gelbfiebervirus. Es wird angenommen, daß es sich hier aber um Kreuzreaktionen mit anderen in Malaya vorkommenden Arbor-B-Viren handelt. Sonst müßte ja mit einer erheblichen Gelbfieberdurchseuchung gerechnet werden, während bisher kein einziger Fall bekannt geworden ist. MACNAMARA u. a. (1959) stellten NR bei 97 Schulkindern einer größeren Stadt und bei 207 Personen aller Altersklassen eines Dorfes in Südwestnigeria an. Sie fanden N-AK mit hohen Titern gegen verschiedene Arbor-B-Viren: in der städtischen Schulkindergruppe hatten $77 \%$ AK gegen Bwamba-Virus und etwa 50\% gegen Uganda-S-, Gelbfieber- und Zika-Virus. In der dörflichen Bevölkerung zwischen 10 und 20 Jahren bestanden bei etwa der Hälfte AK gegen Dengue-, Uganda-S, Zika- und Gelbfieber-Virus sowie bei der Hälfte der 20-29jährigen solche gegen Bwamba-Virus. Es wird angenommen, daß auch hier das Bestehen von Kreuzreaktionen zwischen den einzelnen B-Viren der wahrscheinliche Grund für das verbreitete AK-Vorkommen in der Bevölkerung gegen Gelbfieber ist, da in diesen Gebieten noch keine Gelbfieberepidemien beobachtet worden sind. Nach Wisseman u. a. (1962) beeinflußt ein vorausgegangener Kontakt mit dem JE-Virus nicht die Bildung von N-AK gegen Gelbfiebervirus bezgl. ihres Erscheinens und ihrer Titerhöhe; ebenso bedingt Impfung mit dem Gelbfiebervirus (17 D) keine nennenswerte Veränderung des N-AK-Titers gegen JE-Virus. Dagegen entwickelten Personen, welche infolge einer Schutzimpfung JE-AK hatten, nach Gelbfieberschutzimpfung (17 D) N-AK hauptsächlich gegen Dengue Typ 1- und WN-Virus. Wisseman und Sweet (1962) stellten außerdem fest, daß Personen ohne frühere ArborVirus-Infektionen, die mit $17 \mathrm{D}$-Virus primär und 14 Monate später mit demselben Virus nachgeimpft wurden, mit einem Anstieg der N-AK gegen $17 \mathrm{D}$-Virus reagierten. Der Titer war 3 Wochen nach der Wiederimpfung durchschnittlich 4,7 mal höher als nach der Erstimpfung. Sowohl nach der Erst- als auch nach der Wiederimpfung waren keine heterologen AK gegen WN- und Dengue 1- und 2-Virus nachweisbar.

Die ersten Immunitätsprüfungen wurden von BeEuwkes u. a. (1930) in 2 Gemeinden Nigerias mittels der Affenschutzprobe (Sток es u. a., 1928a) vorgenommen. Für jedes zu prüfende Serum wurden 2 Affen (M.rhesus) verwandt. Jedes Tier erhielt 5,0 ml Serum und 3-24 St. später virushaltiges Affenblut (0,1-1,0 ml) i.p. oder s.c. Zur Kontrolle wurde derselbe Versuch mit bekanntem Normalblut gemacht. Die Kontrolltiere starben regelmäßig. Enthielt das Serum der Testgruppe AK, so blieben diese Tiere am Leben. Immunserum von Rhesus-Affen schützte die Tiere, auch wenn es bis zu 6 Wochen vor der Infektion infiziert wurde. Menschenserum wirkte jedoch nur bis zu 1 Woche vor der Infektion schützend. Eine gewisse Schutzwirkung wurde auch noch beobachtet, wenn das Immunserum bis zu $48 \mathrm{St}$. 
p.i. eingespritzt wurde, keine dagegen mehr, wenn das Fieber bereits ausgebrochen war (DAvis, 1934b). Wurde aber das Virus zuerst i.cer. injiziert und nachträglich Immunserum i. p. zugeführt, so erkrankten die Affen an Encephalitis (PenNa, 1936).

Mit der Affenschutzprobe wurde die Identität des afrikanischen und amerikanischen Gelbfiebervirus bewiesen sowie eine Abgrenzung der Leptospirengelbsucht gegen das echte Gelbfieber möglich (Aragao de Beaurepaire, 1928b; Hudson u. a., 1929a, b; Davis, 1929; Sawyer u. a., 1930). Beeuwkes u. a. (1930) bestimmten in Afrika und Soper u. a. (1932) in Amerika das Vorkommen des Gelbfiebers geographisch. Bauer und Hudson (1930) fanden N-AK noch 10 Jahre sowie SAWYER (1931b) noch bis zu 78 Jahre p. i. (s. auch Hudson und Kitchen, 1930; Davis, 1931c). Eine größere Anwendungsbreite hat die Affenschutzprobe infolge ihrer Kostspieligkeit nicht bekommen.

Lloyd u. a. (1933) sowie Lloyd und MaHAFFy (1935) gaben eine i.cer. Schutzprobe am Meerschweinchen an. Für jedes Serum wurden 2 Tiere gebraucht; infolgedessen waren nur $0,3 \mathrm{ml}$ Serum zur Untersuchung erforderlich. Die mit dieser Probe erzielten Ergebnisse stimmten in $95 \%$ mit der i.cer. Mäuseschutzprobe überein.

Die Mäuseprobe ist die praktischste und zugleich zuverlässigste, daher wichtigste Immunitätsreaktion überhaupt. Sie geht auf die Arbeiten von TheIler (1930a) zurück, der bei gleichzeitiger i.cer. Einspritzung von Virus und Immunserum die Mäuse vor einer Encephalitis schützen konnte. Die Dauer des Kontakts zwischen Virus und Serum vor der Injektion spielte dabei keine Rolle. Um zuverlässige und vergleichbare Ergebnisse zu erhalten, müssen die Mäuse von großer und gleichmäßiger Empfänglichkeit sein, die bei den einzelnen Mäusestämmen sehr verschieden ist.

Gleiche Teile Serum und Virussuspension (100 $\mathrm{LD}_{50} \mathrm{im}$ Gemisch) wurden den Mäusen i.cer. injiziert (je Maus $0,03 \mathrm{ml}$ ).

An N-AK reiches Serum schützt alle, weniger AK enthaltendes Serum einen Teil der Mäuse, während AK-freies Serum überhaupt nicht schützt, so daß alle Mäuse dieser Gruppe nach 4-10 Tagen an Gelbfieberencephalitis sterben. DINGER (1931) bestätigte als erster diese Beobachtungen. Junge Mäuse sind empfänglicher als erwachsene (TheILeR, 1933b).

SAWYer und Lloyd (1931) stellten fest, daß nach i.p. Infektion eines Gemischs von neurotropem Mäusevirus und Immunserum sowie einer gleichzeitigen unspezifischen Schädigung des Gehirns der Mäuse durch Einspritzung kleiner Mengen von Stärke- oder $\mathrm{MgCl}_{2}$ Lösung die Mäuse im Gegensatz zu den Kontrolltieren ohne Immunserum gesund blieben. Während bei einem Test mit erwachsenen Mäusen $3 \mathrm{ml}$ Serum erforderlich sind, werden bei jungen Tieren nur 0,4 ml benötigt. Nach Whitman (1943) ist auch die Probe mit 18-21 Tage alten Mäusen so empfindlich, daß noch der Nachweis ganz kleiner AK-Mengen möglich ist (s. auch Sмiтhвurn, 1945).

Aus diesen Erkenntnissen entwickelten sich die direkte i.cer. und die indirekte i.p. oder extraneurale Schutzprobe (Sawyer, 1931a, b, c; Mahaffy u. a., 1933; Berghe, 1939; Schüffner, 1939). Das Testvirus muß eine gleichbleibende Pathogenität für Mäuse haben. Man benutzt am besten getrocknetes infektiöses Mäusegehirn, dessen konstanter Virusgehalt bekannt ist. Die richtige Virusverdünnung muß eine Gruppe von gleich empfänglichen Mäusen gleichzeitig in 100\% töten. Lépine und SoHIer (1954) geben folgendes Verfahren zur Herstellung des Testvirus an: eine Anzahl von Mäusen wird i.cer. mit neurotropem Virus (französischer Stamm Dakar) infiziert; die Tiere werden im Lähmungsstadium getötet. Die steril entnommenen Gehirne werden mit der 20 fachen Menge normalen inaktivierten Pferdeserums im gekühlten Mörser verrieben und die erhaltene Suspension 20 Min mit 3200 U/Min zentrifugiert. Die überstehende Flüssigkeit wird sofort in Mengen von je $0,5 \mathrm{ml}$ in Glasröhrchen getrocknet und bei $-20^{\circ} \mathrm{C}$ aufbewahrt, damit der Infektiositätstiter monatelang auf gleicher Höhe bleibt. Bei Gebrauch wird der Inhalt der Röhrchen auf sein ursprüngliches Volumen durch Zusatz von 0,5 ml Aqua dest. gebracht und mit 9,5 ml physiol. NaCl-Lösung verdünnt, wodurch sich eine Gehirnverdünnung von 1: 200 ergibt. Diese dient als Ausgang für die fallenden Virusverdünnungen, welche mit 10\% Pferdeserum enthaltender NaCl-Lösung hergestellt werden: $1: 1000$ bis $1: 10$ Millionen, um die $\mathrm{LD}_{50}$ des Materials festzustellen. Mit jeder 
Virusverdünnung werden 6 Mäuse i.cer. infiziert $(0,03 \mathrm{ml}$ je Maus). Gewöhnlich findet man die $\mathrm{LD}_{50}$ bei der Verdünnung 1:1 Million, d. h. $0,03 \mathrm{ml}$ der Verdünnung $10^{-6}$ enthalten eine für $50 \%$ der Tiere tödliche Dosis.

Zur Ausführung der direkten i.cer. Mäuseschutzprobe (Durieux und Koerber, 1956) wird $0,1 \mathrm{~g}$ Gehirnpulver mit 2,0 ml einer $10 \%$ igen Normalserumverdünnung verrieben. Man erhält dann eine Verdünnung $1: 5$, da die verwandte Virusmenge $0,4 \mathrm{~g}$ des frischen Gehirns entspricht. Nach dem Zentrifugieren werden $0,5 \mathrm{ml}$ der überstehenden Flüssigkeit zu 4,5 ml 10\% igen Normalserums gegeben, so daß sich eine Verdünnung von 1:50 ergibt. Von dieser Ausgangsverdünnung werden solche von 1:500 bis 1:50000 für die NR und solche von 1:1 Million und 1:2 Millionen zur Titrierung des Virus hergestellt. $0,5 \mathrm{ml}$ jeder Verdünnung werden mit gleichen Mengen des zu prüfenden Serums in Röhrchen sorgfältig unter Schütteln gemischt. Steht nicht genügend Serum zur Verfügung, so ändert man die Mengen in je 0,25 ml. Als Kontrollen dienen hyperimmunes Serum (Esel) und normales Affenserum. Damit ein guter Kontakt zwischen Virus und AK entsteht, wird das Gemisch $1 / 2$ St. bei 25-30 $\mathrm{C}$ stehen gelassen; dann werden von jedem Röhrchen 3 Mäuse mit je $0,03 \mathrm{ml}$ VirusSerumgemisch i.cer. infiziert. Außerdem erhalten je 3 Mäuse die Verdünnung 1:1 Million und 1:2 Millionen. Vor dem 5. Tage gestorbene Mäuse werden nicht zur Beurteilung benutzt. Die Beobachtungsdauer beträgt 10 Tage.

Bleiben zwischen dem 5. und 10. Tag alle Mäuse am Leben, so bedeutet dies einen guten Schutzkörpergehalt des betreffenden Serums; sterben alle Mäuse, dann muß mit dem Fehlen von Schutzstoffen gerechnet werden. Zwischen diesen beiden äußersten Werten lassen sich die Immunitätsgrade nach Zahl und Zeit der erkrankten und gestorbenen Mäuse berechnen.

Zur Beurteilung des erzielten Schutzgrades dient folgendes Schema:

\begin{tabular}{|c|c|c|c|c|c|}
\hline \multicolumn{4}{|c|}{$\begin{array}{l}\text { Verhältnis der überlebenden Mäuse } \\
\text { zur Gesamtzahl der benutzten Mäuse }\end{array}$} & \multirow[t]{3}{*}{$\begin{array}{l}\text { Ausfall } \\
\text { der Probe }\end{array}$} & \multirow[t]{3}{*}{ Beurteilung } \\
\hline \multicolumn{3}{|c|}{ Virusverdünnungen } & \multirow{2}{*}{ insgesamt } & & \\
\hline $1: 500$ & $1: 5000$ & $1: 50000$ & & & \\
\hline $\begin{array}{l}3 / 3 \\
2 / 3\end{array}$ & $\begin{array}{l}3 / 3 \\
3 / 3\end{array}$ & $\begin{array}{l}3 / 3 \\
3 / 3\end{array}$ & $\begin{array}{l}9 / 9 \\
8 / 9\end{array}$ & +++ & sehr guter Schutz \\
\hline $\begin{array}{l}1 / 3 \\
0 / 3 \\
0 / 3\end{array}$ & $\begin{array}{l}3 / 3 \\
3 / 3 \\
2 / 3\end{array}$ & $\begin{array}{l}3 / 3 \\
3 / 3 \\
3 / 3\end{array}$ & $\begin{array}{l}7 / 9 \\
6 / 9 \\
5 / 9\end{array}$ & ++ & guter Schutz \\
\hline $\begin{array}{l}0 / 3 \\
0 / 3\end{array}$ & $\begin{array}{l}1 / 3 \\
0 / 3\end{array}$ & $\begin{array}{l}3 / 3 \\
3 / 3\end{array}$ & $\begin{array}{l}4 / 9 \\
3 / 9\end{array}$ & + & geringer Schutz \\
\hline $\begin{array}{l}0 / 3 \\
0 / 3\end{array}$ & $\begin{array}{l}0 / 3 \\
0 / 3\end{array}$ & $\begin{array}{l}2 / 3 \\
1 / 3\end{array}$ & $\begin{array}{l}2 / 9 \\
1 / 9\end{array}$ & $?$ & nicht beweisend \\
\hline $0 / 3$ & $0 / 3$ & $0 / 3$ & $0 / 9$ & 0 & kein Schutz \\
\hline
\end{tabular}

Bei nicht beweisenden oder widersprechenden Ergebnissen muß die Probe wiederholt werden.

Gear u. a. (1953) ersetzten das neurotrope Virus durch 17D-Virus, um eine etwaige Einschleppung des ersteren in die südafrikanische Bevölkerung zu vermeiden, da das 17D-Virus nicht durch Mücken übertragen wird. Die Ergebnisse mit diesem Virus waren gut, doch war eine längere Beobachtungsdauer der Mäuse infolge des langsameren Infektionsablaufes erforderlich.

Collier u. a. (1959a, c) haben eine neue Technik der i.cer. Mäuseschutzprobe unter Verwendung des 17D-Impfstoffvirus und des neurotropen 17D-Stammes angegeben. Von dem Virus werden Verdünnungen von 1: 90, 1:900, 1:9000 und 1:90000 hergestellt. $\mathrm{Zu} \mathrm{0,9} \mathrm{ml}$ 
jeder dieser Verdünnungen wird 0,1 $\mathrm{ml}$ Serum gegeben, und zwar unverdünnt, 1:10 und 1: 100 verdünnt. In jeder Probe sind dann die Endverdünnungen des Virus 1: 100 bis $1: 100000$ und die des Serums 1:10 bis 1:1000. Die Röhrchen werden geschüttelt, 30 Min bei Zimmertemperatur $\left(20^{\circ} \mathrm{C}\right)$ gehalten und dann in ein Eisbad gebracht. $0,2 \mathrm{ml}$ jeder Verdünnung werden 5 oder 6 Mäusen i.cer. eingespritzt, die 3 Wochen beobachtet werden.

Die Berechnung des Immunitätsgrades erfolgt an Hand einer graphischen Darstellung mittels einer Virulenzkurve. Die $\mathrm{LD}_{50}$ wird täglich aus der $\mathrm{Zahl}$ der toten Mäuse berechnet und die Zahlen auf eine Kurve eingetragen. Die graphischen Darstellungen zeigen, daß die Immunität des Serums desto stärker ist, je größer der Abstand zwischen den Virulenzkurven der Kontrollen und jenen der Virus-Serumgemische ist. Collier u. a. glauben, daß die Darstellung des Immunitätsgrades mittels dieser Kurven entschieden klarer ist als die übliche Berechnung der $\mathrm{LD}_{50}$ am Ende des Testes und die aus ihr ermittelte Immunität (s. auch SmithbuRN, 1956).

SmithbuRn u. a. (1951) geben folgendes Vorgehen für die indirekte i.p. Mäuseschutzprobe an:

Eine 1\%ige Verdünnung des Virus (Mäusegehirnpassagevirus) in 10\%iger Serum-NaClLösung wird mit dem zu prüfenden Serum im Verhältnis 1: 2 gemischt. Dann erfolgt die i.p. Infektion von 6 Mäusen entweder mit $0,06 \mathrm{ml}$ des Gemisches bei Mäusen von 8 oder 10 , höchstens 14 Tagen oder 0,6 ml bei erwachsenen Mäusen (35-42 Tage), die mit Stärke vorbehandelt worden sind. Zur Kontrolle werden Titrierungen des Virus in nicht immunem Serum und in einem bekannten Immunserum mit 1\%igen Virusverdünnungen vorgenommen. Mit der i.p. Methode werden bei jungen Mäusen höhere AK-Titer erhalten. Im ganzen gesehen, ist dieses Verfahren aber weniger empfindlich als die i.cer. Probe, so daß viel größere Virusmengen erforderlich sind. Die verwandte Virusmenge ist überhaupt ausschlaggebend für den Ausfall der Reaktion. Zu große Virusmengen machen die Neutralisierung unmöglich (PANTHIER, 1956 b, 1958; Panthier u. a., 1957; Panthier und Carteaud, 1958). Dieses Verfahren wurde mit besonders gutem Erfolg zur Immunitätsbestimmung bei Menschen nach Erkrankung und Schutzimpfung sowie bei wilden Tieren in Ostafrika verwandt (Smithburn und Mahaffy, 1945; Haddow u. a., 1947; Dick und Smithburn, 1949; Smithburn u. a, 1949a).

Schließlich sind noch die Versuche einer subkutanen Mäuseschutzprobe von KERR und Bugher (zit. Smithburn, 1951) zu erwähnen. Sie benutzten 3-5 Tage alte Mäuse, die für eine s.c. Gelbfieberinfektion etwa ebenso empfänglich sind wie erwachsene Mäuse für eine i.cer. Infektion. Diese Modifikation erwies sich zwar als brauchbar, hat aber keine Einführung ertahren.

Maccallum und Findlay (1938), Bugher (1940) und Koprowski (1946) wiesen auf gelegentlich vorkommende falsch positive Ausfälle der NR besonders mit Tierseren hin.

Zur Bestimmung neu isolierter pantroper Virusstämme kommt nur die i.cer. Schutzprobe in Frage, da für eine extraneurale Applikation die Mäusepathogenität noch zu gering sein kann (SмithbuRN, 1951).

Eine genaue quantitative Bestimmung der N-AK ist in Einschichtzellkulturen von Hühnerembryofibroblasten mit der Plaque-Hemmungs-Probe (PHP) möglich. Porterfield (1959 c) benutzte hierzu mit Agar überschichtete Kulturen von Hühnerfibroblasten, die mit 10000 PBE des Gelbfiebervirus (neurotroper Stamm) beimpft wurden. Immunserum, das an Fischgrätenperlen haftete, wurde auf die Agarschicht gebracht, so daß die AK diffundierten, die darunter liegenden Zellen erreichten und die Ausbreitung des Virus hemmten. Wurden die Kulturen 5 Tage p. i. mit Neutralrot gefärbt, so wurde ein Gebiet von überlebenden Zellen sichtbar, welche die mit dem Immunserum beladenen Perlen umgaben. Die Größe dieser geschützten Zellzonen richtete sich nach der AK-Konzentration des Immunserums. Nach PorTerfield (1961 d) ist diese PHP weniger empfindlich als der Plaque-Neutralisationstest und der PlaqueReduzierungstest, aber weniger zeitraubend. Im Vergleich mit der i.cer. Mäuseschutzprobe war die Empfindlichkeit der Plaque-Neutralisation etwa 20 mal, die Plaque-Reduzierung: 2-4mal höher und die hier angegebene PHP etwa 5-10 mal niedriger. Seren von Personen, welche 1-3 Jahre zuvor Gelbfieber überstanden haben, setzen die Zahl der Plaques auf $20 \%$ herab; Rekonvaleszentenseren ergeben fast vollständige Neutralisierung. Uganda-S- und WN-Hyperimmunseren bedingten 50\% ige Abnahme, Zika- und WEE-Antiseren dagegen keine solche (Porterfield, 1960). 
Lemos Monteiro und Travassos $(1930,1931,1932,1933)$ stellten Reihenuntersuchungen in einem endemischen Gelbfiebergebiet Brasiliens an und fanden bei $50 \%$ der eingeborenen Bevölkerung $K B-A K$, keine jedoch bei Einwanderern. Sie wiesen die Spezifität der KBR mit Menschen- und Affenseren und gleichzeitig auch die antigene Identität von aus Afrika und Amerika stammenden Gelbfiebervirusstämmen nach.

Fox u. a. (1942a) beobachteten, daß die Impfung mit dem 17D-Virus gewöhnlich nicht zur Bildung von KB-AK führt, sondern diese nur auftreten, wenn die Impflinge encephalitische Erscheinungen bekamen bzw. mit bestimmten Impfstoffchargen infiziert worden waren. Nach Lennette und Perlowagora (1943) ist mit der KBR eine Unterscheidung einer Erkrankungs- und einer Impfimmunität möglich, da sich nach der Impfung keine KB-AK nachweisen lassen. Es ergab sich, daß die KB-AK am Ende der 2. Infektionswoche erschienen. Der höchste Titer war im Verlauf der 3. Woche erreicht, um dann wieder so stark abzunehmen, daß am Ende von 4 Monaten nur noch Spuren vorhanden waren.

Wassermann-positive Seren ergeben manchmal unspezifische Reaktionen; diese können in vielen Fällen durch Erhitzen aufgehoben werden (s. aueh Frobisher, $1931 \mathrm{a}, \mathrm{b}$ ).

Davis, G. E. (1931) fand unter den Seren von 21 Personen, die einen positiven Affenschutztest ergaben, nur 6 Seren mit KB-AK, davon 5 mit solchen in nur sehr geringer Menge. In einer Bevölkerungsgruppe, in welcher $40 \%$ einen positiven Affenschutztest zeigten, fanden sich keine Seren mit KB-AK (s. auch Hudson, 1931, 1932, Frobisher, 1931 d). Soper u. a. (1932) verglichen in einer postepidemischen Serumüberprüfung die KBR mit dem Affenschutztest. Sie kamen zu dem Ergebnis, daß alle Seren mit positiver KBR auch eine Schutzwirkung ausübten, umgekehrt aber von den Seren mit Schutzwirkung nur 13\% KB zeigten. Soper und De Andrade (1933) fanden 6-10 Wochen nach der Erkrankung mehr Seren mit KB-AK. FabiYi (1961) stellte in einer Gelbfieberepidemie den Wert der KBR zur Bestimmung der Durchseuchung einer Bevölkerung fest. In Verbindung mit der Mäuseschutzprobe ergab diese Reaktion einen hohen Anteil von Personen mit Gelbfieber-AK sowie mit AK gegen verwandte Antigene.

Sabin (1949) konnte bei Personen, die eine experimentelle Dengue (Typ 1, Hawaii)-Infektion durchgemacht hatten, KB-AK nicht nur gegen dieses Virus, sondern auch gegen andere Viren der Arbor-Gruppe, u. a. auch gegen Gelbfiebervirus nachweisen. Rhesus-Affen, die mit neurotropem oder viscerotropem bzw. beiden Viren infiziert worden waren, entwickelten KB-AK nicht nur gegen Gelbfieber mit Titern von 1:64 bis 1:256, sondern regelmäßig auch solche gegen JE und WN-Fieber mit Titern von 1:4 bis 1:32 sowie gelegentlich solche gegen Dengue (Typ 1, Hawaii), aber nicht gegen SLE, WEE und Rifttal-Fieber. JE-Virus mit homologen KB-AK-Titern von 1: 256 hatten einen Gelbfieber-AK-Titer von $1: 32$.

Allgemeine Anweisungen zur Durchführung der KBR bei Gelbfieber bestehen nicht, da sie bei weitem nicht die diagnostische und epidemiologische Bedeutung wie die Mäuseschutzprobe hat.

Aragao de Beaurepaire (1928a) unternahm die ersten allerdings erfolglos gebliebenen Versuche des Nachweises von KB-AK in Rekonvaleszenten- und Patientenseren vom 1. und 2. Krankheitstag mit einem Antigen aus phenolisiertem Extrakt infizierter Affenlebern. Moses (1929) konnte bei Verwendung eines aus Affenlebern bereiteten Kochantigens KB-AK nachweisen. Frobisher (1931 a, b, d) erhielt ein wirksames Antigen, indem er mit NaClLösung verriebene Lebern infizierter Affen über Schwefelsäure trocknete und dann mit Äther extrahierte. Das getrocknete entfettete Material wurde wieder mit physiol. NaCl-Lösung aufgeschwemmt und filtriert. Das Filtrat ergab ein wirksames mehrere Monate haltbares Antigen. Ein weiteres Antigen wurde durch abwechselndes Gefrieren und Wiederauftauen von Lebersuspensionen erhalten (s. auch Frobisher, 1929). Hudson und Davis (1929) sahen, daß infektiöses Affenserum als Antigen ein stärkeres Bindungsvermögen besitzt als Organextrakte. Die antigene Eigenschaft blieb erhalten, wenn das Serum in gefrorenem Zustand getrocknet und auf diese Weise aufgehoben wurde. Antigenverdünnungen von 1:20 bis 1:1000 wurden gegen eine Serumverdünnung von 1:5 ausgewertet. Für den Ausfall der Reaktion war die Einwirkung des Serums auf das Antigen über Nacht bei $5^{\circ} \mathrm{C}$ erforderlich. Positive KBR wurden sowohl mit menschlichem als auch mit Affenrekonvaleszentenserum erhalten. 
C. E. Davis (1931) bekam ein gutes Antigen aus Citratplasma (1:96 verdünnt) eines Affen zu Beginn der Fieberperiode (s. auch Hudson und Davis, 1929; Lennette und Perlowagora, 1943).

Perlowagora und Lennette (1944) führten die Antigenität des Serums nicht auf die Gegenwart von Virus allein, sondern auf eine Substanz zurück, die in den Wirtszellen unter der Wirkung des Virus gebildet wird. In Fällen, in denen die histologische Diagnose mißlang, erwies sich der Nachweis des spezifischen Antigens als zuverlässigeres diagnostisches Hilfsmittel. Zwischen der Schwere der Infektion und der Menge des gebildeten Antigens scheint eine Beziehung zu bestehen (Lennette und Perlowagora, 1945).

Frobisher (1933) erhielt aus infektiösem Mäusegehirn (neurotropes Virus) ein Antigen, das dem aus viscerotropem Virus noch überlegen war. Mit diesem Antigen wurden spezifische KB-AK in Menschen- und Affenseren ungefähr vom 5. Krankheitstag an nachgewiesen. Lennette und Perlowagora (1943) gewannen ein Antigen aus einer 10\% igen infektiösen Mäusegehirnemulsion nach dem Verfahren von CaSals und Palacios (1941), der 2\% inaktiviertes Meerschweinchenserum zugefügt wurden. Nach 24 St. Stehen im Eisschrank wurde zentrifugiert und die überstehende Flüssigkeit $5 \mathrm{mal}$ abwechselnd tiefgefroren (in Alkohol$\mathrm{CO}_{2}$-Schneegemisch) und wieder aufgetaut. Dadurch wurden weitgehende Gewebszerstörungen und Freiwerden großer Antigenmengen erzielt. Perlowagora und Hughes (1947, 1948) stellten aus einer Globulinfraktion ätherextrahierter infektiöser Mäusegehirne (neurotropes Virus) ein Antigen her, das den bisher gebrauchten Antigenen überlegen zu sein schien. Sie konnten nämlich mit diesem auch in den Seren von Jeichten und subklinisch verlaufenen Infektionen KB-AK nachweisen, was vorher noch nicht gelungen war. Sie bestätigten damit die Brauchbarkeit der Reaktion zur Feststellung kürzlich abgelaufener Infektionen. Sie beobachteten außerdem ebenfalls regelmäßig den Verlust der KB-AK im Serum experimentell infiziert gewesener Affen innerhalb 1 Jahres.

Hudson und Davis (1929) konnten aus durch Berkefeld-Kerzen filtrierten NaCl-Emulsionen infizierter Mücken ein KB-Antigen herstellen.

Der $H A H$ - $A K$ ist nicht mit dem KB-AK identisch. Die Resultate der HAHR mit Serumverdünnungen von $1: 10$ und mehr zeigten Übereinstimmung mit der Mäuseschutzprobe nach natürlicher Infektion und Schutzimpfung (Porterfield, 1956). Porterfield (1953, 1954) stellte für die HAHR ein Antigen aus einem Aceton-Ätherextrakt des Serums von RhesusAffen her, die mit dem Asibi-Virus infiziert worden waren. Die Verdünnungen des Antigens bis zu einem Titer von 1: 3200 und 1:6400 agglutinierten eine 0,5\% ige Hühnererythrozytensuspension.

Unspezifische Hemmstoffe der HA konnten aus menschlichen Seren durch Acetonextraktion entfernt werden. CASALS und BRown (1954) entfernten sie mittels Filtration durch SeitzEK-Scheiben sowie Clarke und Casals (1955) durch Adsorption der Seren an Bentonit (stark quellendes Al-silikat mit kräftiger Adsorptionsfähigkeit), ohne daß der AK-Titer beeinträchtigt wurde.

In der HAHR ergab sich eine Zugehörigkeit des Gelbfiebererregers zur Gruppe B der ArborViren. Sein Antigen wies Kreuzreaktionen mit Dengue-, Ilhéus-, Ntaya-, WN-, JE-, SLEund REFSE-Antiseren auf. Allerdings waren die homologen Reaktionen stärker als die heterologen.

Theiler und Casals (1958) verglichen die serologische Reaktionstähigkeit von 29 Gelbfi eberkranken mittels der HAHR, KBR und NR. Die Antigene für die HAHR und KBR wurden durch Aceton-Ätherextraktion infektiöser Gehirne von Mäusesäuglingen gewonnen. Für die KBR und HAHR wurden 8 Antigen Einheiten verwandt.

Nach Entfernung unspezifischer Hemmstoffe durch Adsorption mit Bentonit für die HAHR wurden die Seren in einer Serie zunehmend doppelter Verdünnungen, beginnend mit 1:4 bzw. 1: 10 geprüft. Die NR wurde durch i.cer. Injektion eines Virus-Serumgemisches auf junge erwachsene Mäuse ausgeführt. Das Gemisch enthielt etwa $100 \mathrm{LD}_{50}$ Virus in $0,03 \mathrm{ml}$ un d wurde vor der Einspritzung $1 \mathrm{St}$. bei $37^{\circ} \mathrm{C}$ bebrütet. Außerdem wurden die Seren gegen folgende Viren geprüft: Dengue (Typ 1 und 2), Ilhéus, SLE, WN. 17 Fälle konnten als primäre und $12 \mathrm{Fälle}$ als sekundäre Gelbfieberinfektionen, die zuvor bereits mit anderen 
Viren der B-Gruppe infiziert waren, ermittelt werden. Bei den Primärinfektionen traten zunächst die spezifischen HAH-AK auf, denen dann schnell die AK gegen andere B-Viren folgten. Die homologen HAH-AK waren immer gleich hoch oder höher als die heterologen. $\mathrm{KB}-\mathrm{AK}$ wurden über einen langen Zeitraum gebildet und nahmen noch zu, wenn die HAHAK bereits wieder abnahmen. Bei den Primärinfektionen schwankte der Beginn des KB-AKNachweises erheblich. Das KB-AK-Muster war bemerkenswert spezifisch. Übergreifen auf andere Antigene traten nur bei hohen homologen KB-AK auf. In den Primärinfektionen erschien die Bildung der N-AK ziemlich spezifisch; heterologe AK dieser Art traten nur in beschränktem Ausmaß auf. Bei den Sekundärinfektionen war die Bildung der HAH-AK und KB-AK stark und sehr schnell. Hier fand sich aber kein besonders spezifisches AK-Muster; die höchsten Titer von HAH-AK und KB-AK waren sogar heterolog. Bei Sekundärinfektionen wurde die Bildung heterologer N-AK in höherem Maß als die der Primärinfektion angeregt. In 11 von 12 dieser Fälle konnte die genaue Krankheitsdiagnose mittels der NR nicht erbracht werden.

Ein wichtiges Ergebnis der verschiedenen immunologischen Untersuchungen ist die Feststellung, daß es nur eine einzige antigene Gelbfieber-Virusform gibt. Der GelbfieberErreger weicht also in dieser Hinsicht von vielen anderen Virusarten ab. Dadurch gestaltet sich die Immunbiologie der Krankheit erheblich einfacher als jene z. B. der Poliomyelitis oder Influenza. Auch während der künstlichen Züchtung des Virus im Tier, in der Gewebekultur oder im embryonierten Hühnerei tritt keine Antigenveränderung ein. Alle Gelbfieber-Virusstämme ergeben Neutralisations-Kreuzreaktionen. Die Beobachtung, daß der abgeschwächte Kulturstamm 17D keine KB-AK zu bilden scheint, ist noch kein Beweis für eine antigene Abwandlung.

Collier u. a. (1959a) unternahmen kreuzweise Testinfektionsversuche mit den verschiedenen Gelbfieber-Virusstämmen bei Mäusen und stellten dabei fest:

17 D-Kulturvirus i.p. verabfolgt schützt Mäuse gegen eine i.cer. Infektion mit 17D-Kulturvirus, aber nicht gegen eine solche mit Asibi-Virus und nur nach mehreren Dosen gegen eine solche mit mäuseadaptiertem $17 \mathrm{D}$-Virus.

17D-Kulturvirus in kleinen unschädlichen Dosen i.cer. verabfolgt schützt gegen eine i.cer. Infektion mit mäuseadaptiertem $17 \mathrm{D}$-Virus.

Mäuseadaptiertes $17 D$-Virus i.p. verabfolgt schützt gegen eine i.cer. Infektion sowohl mit 17D-Kulturvirus als auch mit mäuseadaptiertem $17 \mathrm{D}$-Virus, nicht aber mit Asibi-Virus.

Asibi-Virus i.p. verabfolgt schützt gegen eine i.cer. Infektion mit allen 3 Stämmen (s. auch Coldier u. a., 1958).

Aus diesen Versuchen geht hervor, daß zwischen dem 17D-Kulturvirus, dem mäuseadaptierten $17 \mathrm{D}$-Virus und dem mäuseadaptierten Asibi-Virus gewisse Unterschiede bestehen könnten, obwohl sie den gleichen Ursprung im viscerotropen Asibi-Virus haben. Die Unterschiede dürften aber nicht allgemeiner antigener Natur sein, sondern vielmehr nur auf einer Unterdrückung von Teileigenschaften des Antigens speziell für die Maus beruhen, da alle diese Virusstämme noch voll immunogen für den Menschen sind.

Bereits 1930 untersuchte Frobisher das etwaige Präzipitationsvermögen von Immunseren gegen verschiedene Antigene gelbfieberinfizierter Affen (Urin, alkoholische Leber- und Herzextrakte, acetonun]ösliche Leber- und Herzextrakte, Kochsalzextrakte von Leber und Milz), ohne jedoch eine Reaktion zu erzieJen. Später versuchte Frobisher (1932), präzipitierende Kaninchenseren für das Virus zu gewinnen. Die Kaninchen wurden zu diesem Zwecke wiederholt mit aktivem Virus vorbehandelt. Es gelang ihm jedoch auch hier nicht, den geringsten Anhalt für das Vorhandensein von P-AK zu finden.

Erst Hughes $(1933,1934)$ kam zu einem positiven Ergebnis. Er zeigte, da.ß Affen-Immunserum $P-A K$ enthält, die mit einem im Serum an Gelbfieber sterbenden Affen vorhandenen Präzipitinogen reagieren, das an die Serum-Albuminfraktion gebunden sein soll. Auch das Serum schwer gelbfieberkranker Menschen enthältgroße Mengen eines löslichen Antigens, das sich in seiner Antigenität spezifisch von dem Virus selbst unterscheidet und aJs Präzipitinogen für ein ebenfalls im Menschenserum vorhandenes Präzipitin wirkt. Virushaltiges Serum, das 
solange aufbewahrt wird, bis kein aktives Virus mehr nachweisbar ist, enthält weiter Präzipitinogen, das bei Affen zur Bildung von Präzipitin (P-AK) führt. Dieses Präzipitinogen ist also ein echtes Antigen, das mit dem Virus selbst nicht identisch sein kann, da keine unmitte]bare Beziehung zwischen Virusmenge und Präzipitinogengehalt der Seren vorhanden ist. Hughes nahm dagegen an, daß das Präzipitinogen ein besonderes Zellprodukt sein könnte, das unter der Wirkung des Virus entsteht und in den Kreislauf abgegeben wird. Es tritt vom ersten Tage nach Fieberbeginn auf und vermehrt sich bis zum Ende bzw. Schwererwerden der Infektion, um aber schon während der Genesung wieder abzunehmen. Das Präzipitinogen bleibt nach Erwärmung des Serums aktiv, wird jedoch durch Kochen zerstört. Durch halbgesättigtes Ammoniumsulfat wird es nicht, durch voll gesättigtes dagegen ausgefällt.

Die präzipitierenden Antikörper ( $P-A K)$ scheinen mit den KB-AK identisch zu sein; es dürfte auch eine ähnliche Beziehung des Präzipitinogens zu dem KB-Antigen bestehen. Hughes $(1933,1934)$ stellte in Affenversuchen fest, daß alle Seren, welche eine Präzipitationsreaktion $(P R)$ ergaben, auch KB aufwiesen. Eine Beziehung zur NR bestand dagegen nicht. Die P-AK sind im Affenserum nicht sehr lange feststellbar.

Neurotropes Virus scheint bei Affen weder Präzipitinogen noch P-AK zu bilden. Ein gegen neurotropes Virus immunisierter Affe, dessen Serum kein Präzipitin aufwies, entwickelte solches nach Einspritzung präzipitinogenhaltigen Serums.

Die Präzipitationsreaktion wird folgendermaßen ausgeführt: das Serum eines an Gelbfieber sterbenden Affen wird durch ein Seitz-Filter geschickt. Das Filtrat wird mit einem AsibiAntiserum gemischt und nach 2 St. Stehen bei $37^{\circ} \mathrm{C}$ auf Trübung geprüft. Besser scheint die Ringmethode zu sein: in ein Röhrchen von $2 \mathrm{~mm}$ Durchmesser wird konzentriertes Antiserum und auf dieses vorsichtig mittels Kapillarpipette unter Vermeidung von Vermischung Serum von einem kranken bzw. infizierten Affen gegeben. Die Ablesung der Reaktion erfolgt wieder nach 2 St. Aufenthalt bei $37^{\circ} \mathrm{C}$ mit künstlichem Licht vor einem schwarzen Hintergrund. Im positiven Falle kommt es zu Bildung eines trüben Ringes an der Berührungsstelle beider Seren infolge Ausfällung des Präzipitogens durch das Präzipitin. Die Flockungsreaktion ist demnach einfach auszuführen und bedarf keiner kostspieligen Laboratoriumseinrichtungen. Eine kräftige Präzipitation kann in fraglichen Fällen die Diagnose sichern.

\section{Prophylaxe}

Das Gelbfieber gehört zu den allgemeingefährlichen Krankheiten, die der internationalen Seuchenüberwachung unterworfen sind. Es besteht Meldepflicht für Erkrankung, Verdachts- und Todesfälle.

Die Prophylaxe des Gelbfiebers besteht hauptsächlich in 3 Maßnahmen: Isolierung der Kranken in mückensicheren Räumen, Bekämpfung der Gelbfiebermücken und Schutzimpfung.

Die Isolierung der Kranken stellt eine wichtige Maßnahme zur Verhütung weiterer Erkrankungen durch Fernhaltung der Gelbfiebermücken vom Kranken während der virämischen Phase dar. Kann der Kranke nicht transportiert werden, so sollte er unter ein Zelt von mückensicherer Gaze gebracht werden.

\section{0-1. Mückenbekämpfung}

Um die Ansammlung und den Vermehrungszyklus der A.aegypti-Mücken unmöglich zu machen, müssen alle, aber auch die kleinsten Wasserbehälter aus den menschlichen Wohnstätten und ihrer nächsten Umgebung entfernt werden. Ist dies nicht möglich, so verschließt man die Wasserbehälter mit mückendichter Gaze und bedeckt die Wasseroberfläche von Brunnen, Teichen und anderen kleinen Gewässern mit Öl oder setzt in diesen larvenfressende Fische aus. Die beste Maßnahme ist die Anlage zentraler Wasserversorgungsanlagen und die Bekämpfung der Mücken in den Wohnungen durch insekticide Mittel wie DDT (Dichlor-diphenylTrichloräthan) und $\boldsymbol{\gamma}$-Hexachlorcyclohexan (Cyclohexan-Lindan). Neghme (1950) berichtete, 
daß in chilenischen Ortschaften der A. aegypti-Index ${ }^{1}$ ) durch Einbringung von DDT in Verdünnungen von $1: 1$ Million in die städtischen Wasserversorgungsanlagen schnell auf 0 gebracht wurde. Eine Bestäubung der Wände mit $1 \mathrm{~g}$ DDT/qm erbrachte eine 13 Wochen anhaltende Mückenfreiheit der Häuser. In Ecuador wurde von 1948-1952 eine intensiveA. aegypti-Bekämpfung durch wiederholte Bestäubung aller Wohnstätten mit 75\% igem DDT-Puder in genügender Menge, um eine Konzentration von $5 \%$ zu erhalten, vorgenommen; es kam zu einem vollständigen Verschwinden dieser Mücken (Garcia, 1953). In Häusern, deren Innenwände, Türen etc. mit einer 5\% igen DDT-Emulsion und einer Dosis von $168 \mathrm{mg}$ Quadratfuß gesprüht wurden, sank der A.aegypti-Index von 69 auf 17\%, was als Erfolg bezeichnet wird (Tota]spray). Beschränkte sich die DDT-Besprühung auf potentielle Brutplätze und die angrenzenden Wände ("perifokaler Spray"), die zum großen Teil außerhalb der Häuser lagen, wurde ein Abfall des Index nach 2 Sprühungen auf 4\% erzielt. Trotzdem blieben einige Herde bestehen. 1 Jahr nach dem 2. Spray lag der Index bei nur 3\%. Mit 1\% Dieldrin (einmaliger Perifokalspray) fiel der Index auf $3 \%$; 4 Wochen und 8 Monate später wiederholte Sprühungen führten zu einem Index unter $1 \%$. Es scheint, als ob nach einer Abnahme des A. aegyptiIndex unter 1\% Vermehrung und Ausbreitung dieser Mückenart nur sehr langsam vor sich gehen; sie können überhaupt verhütet werden, wenn die Brutplätze, nach denen jährlich oder sogar halbjährlich gesucht werden sollte, sofort besprüht werden (MACDonald, 1957; s. auch Pinto Severo, 1955; Fontan und Fauran, 1960; Surtees, 1960; Bransky, 1961; Fox, 1961; Khan und Brown, 1961).

Durch die Mückenvertilgungsmaßnahmen des Panamerican Sanitary Bureau auf dem amerikanischen Kontinent seit 1947 ist eine vollständige Ausrottung des A.aegypti in Bolivien 1948, in Französ. Guyana und den Bermudas 1953 gelungen. Seit 1955 sind auch in Brasilien keine A.aegypti mehr gefunden worden (Franco, 1957). Ende 1959 gab es noch Restherde in den USA, Mexiko, Argentinien, Surinam, Venezuela und Westindien.

Um die Waldmücken, welche zum großen Teil Baumkronenbrüter sind, zu vertilgen, bedarf es der Versprayung großer Mengen von DDT aus der Luft durch Flugzeuge, eine Maßnahme, die an sich auch über große Gebiete durchgeführt werden könnte, da das DDT verhältnismäßig billig ist.

Zur Entmückung von Flugzeugen und anderen schnellen Verkehrsmitteln, die aus Gelbfiebergebieten kommen, bilden DDT und Pyrethrum als Aerosol oder Spray, am besten kombiniert, die besten insekticiden Mittel (Madden u. a., 1945, 1946). Doch hat die Erfahrung bereits gezeigt, daß es besonders gegen die DDT-Präparate resistente Aedes-Stämme gibt (s. auch Gilkes u. a., 1956; Buswine, 1957; Shidrawi, 1957; Brown, 1958; Buswine und Cocker, 1958; Qutubuddin, 1958; RafFaele u. a., 1958).

Der Vermeidung der Gelbfieberverschleppung mit Flugzeugen dienen die verschiedenen internationalen Sanitätsabkommen für Luftfahrt $(1933,1944)$ sowie die internationalen Sanitätsvorschriften derWeltgesundheitsorganisation (1949,1952). (Näheres siehe Sмттн 1951).

Angesichts der Tatsache, daß eine Ausrottung der Waldzyklen (Wirtstiere und Überträger) unmöglich ist, und daß das Gelbfieber eine stete Wanderungsneigung zeigt, gewinnt die aktive Schutzimpfung aller Menschen, welche im Gelbfiebergürtel leben oder sich in diesen begeben, zunehmende Bedeutung.

\section{Die wichtigste Bekämpfungsmaßnahme ist heute die Impfpficht.}

Alle Personen, die in ein endemisches Gelbfiebergebiet einreisen, sollen 10 Tage vor ihrem Eintreffen geimpft werden. Die Impfbescheinigung wird erst 10 Tage nach der

1) Unter Aedes aegypti-Index versteht man das prozentuale Verhältnis der Zahl der Häuser in einem bestimmten, genau umschriebenen Gebiet, auf dessen Grundstücken Brutstätten von A.aegypti festgestellt worden sind, zur Gesamtzahl der Häuser, die in diesem Gebiet geprüft worden sind (WHO, 1961b). Auf eine wichtige Arbeit von Chiang und ReEves (1962) zur statistischen Schätzung der Virusinfektionshäufigkeit in einer MückenüberträgerPopulation und die mathematischen Berechnungsmethoden sei an dieser Stelle hingewiesen. 
Impfung gültig. Sie gilt 6 Jahre. Dem Impfzwang unterliegen auch Personen, die aus einem endemischen in ein gelbfieberfreies Gebiet, in dem aber die Vorbedingungen für den Ausbruch der Krankheit erfüllt sind, einreisen. Die Impfungen dürfen nur mit geprüften und von einer internationalen Kommission zugelassenen Impfstoffen an besonders hierzu autorisierten Instituten vorgenommen werden. Personen mit einer gültigen internationalen Impfbescheinigung ("International Certificate of Vaccination») werden keinen Quarantänemaßnahmen unterworfen. Personen, die Gelbfieber durchgemacht haben und mittels Schutzprobe festgestellte Immunkörper aufweisen, brauchen nicht geimpft zu werden.

In Übereinstimmung mit KerR (1957) glaubt Meers (1958), daß ein Anstieg der Immunitätshäufigkeit auf $85 \%$. erforderlich ist, um eine Epidemie zu verhindern. Die Schutzimpfung vermindert nicht nur die Zahl der Empfänglichen und gleichzeitig die der Zwischenträger ("Brücken«) vom Dschungel in die Städte, sondern verhütet auch den Ausbruch einer Stadtepidemie durch vorhandene Virusträger, da sie eine genügende Herdimmunität erzeugt. Es gelang aber noch nicht, die 15\%-Grenze der Nichtimmunen zu unterschreiten, ohne daß Gründe dafür gefunden werden konnten.

\section{0-2. Schutzimpfung}

Die ersten Versuche einer aktiven Immunisierung mit lebendem Virus dürften die von Finlay (1886) gewesen sein, der versuchte, durch Biß einer Mücke eine leichte Erkrankung beim Menschen zu erzeugen. Es vergingen aber noch über 40 Jahre, bis der erste Impfstoff, der als ungefährlich gelten konnte, hergestellt wurde. Nachdem HindLE (1928) erkannt hatte, daß mit einem abgetöteten Virus (Leber und Milz infizierter Affen) keine Immunisierung erzielt wurde, versuchte man die Herstellung von Lebendimptstoffen (s. auch Collier und DE Wit, 1960).

Heute unterscheidet man 2 grundlegend verschiedene Impfstoffe, nämlich den Mäusegehirnimpfstoff und den Kulturimpfstoff.

Die Übertragung des Gelbfiebervirus auf das Mäusegehirn und die Gewinnung eines neurotropen Virus fixe führte zur EntwickJung eines hochwertigen Impfstoffes durch SAWYER u. a. (1931, 1932). Einen Beweis für die verhältnismäßige Ungefährlichkeit des neurotropen Virus konnte man darin erblicken, daß die mit ihm im Laboratorium infizierten Personen nur einen milden Gelbfieberanfall bekamen und stets genasen. Zunächst wurden aber trotzdem Simultanimpfungen vorgenommen, indem s.c. getrennte Einspritzungen von Virus $(0,5 \mathrm{ml}$ einer 10\% igen Gehirnemulsion bzw. die aus ihr sich ergebende durch Berkfeld-N- oder Seitz-Filter geschickte Virusmenge) und, um eine etwaige Manifestation des Virus zu vermeiden, von 0,3-0,6 ml Immunserum je kg Körpergewicht erfolgte. Nach der 2. Woche konnten in der Regel Immunkörper im Blut nachgewiesen werden. Bereits nach einigen Wochen war der höchste Impfschutz erzielt. Obwohl schon bald eine dauernde, wenn auch nur langsame Abnahme der Serumschutzkörper stattfand, blieb die Immunität doch jahrelang kräftig genug, um vor einer Infektion zu bewahren. Da bereits 24 St. nach der Impfung Virus im Blut nicht mehr nachzuweisen war, kamen die Impflinge als etwaige Virusquellen für A. aegypti und damit als Verbreiter des Gelbfiebers praktisch nicht in Frage. Nachteil dieser Methode war die große Serummenge, die zur Impfung erforderlich war (je nach Körpergewicht 50,0 ml und mehr), und die damit verbundene Unmöglichkeit, die für die Simultanimpfung eines großen Personenkreises erforderlichen Mengen menschlichen Immunserums zu beschaffen. Pettit und Stefanopoulo $(1933,1934)$ sowie Stefanopoulo (1936) ersetzten aus diesem Grunde das menschliche Immunserum durch Pferdeimmunserum, von dem nur etwa $1 / 5$ des menschlichen erforderlich war, um eine sichere Neutralisierung des eingespritzten Virus zu gewährleisten. Theiler und Sмiтн (1936) benutzten später aus dem gleichen Grund Affenhyperimmunserum (s. auch Seltards, 1937). Vorteilhaft bewährte sich die Verwendung eines in gefrorenem Zustand getrockneten Gemisches von Immunserum und virushaltigem Mäuse- 
gehirn. Ein derartig getrockneter und im Kühlschrank aufbewahrter Impfstoff blieb monatelang am Leben.

NICOLLE (1935) stellte fest, daß je nachdem, ob Virus oder AK überwiegen, verschiedene Ergebnisse erzielt werden. Wird das Virus vollständig durch das Serum neutralisiert, so entsteht eine nur vorübergehende passive Immunität; bei einem Virusüberschuß dagegen verläuft die Immunisierung wie ohne Serumzusatz (s. auch Nicolle und LaIgert, 1935; LaIgret u. a., 1937).

Grad und Dauer des Impfschutzes wurden durch quantitative Bestimmung der Blut-AK festgestellt. SAWY ER (1935) fand Schutzkörper noch 4 Jahre nach der Impfung. Während der Schutzkörpertiter auf der Höhe der Immunität (gemessen an der Serumverdünnung, welche Mäuse noch zu schützen vermochte) $64-128$ betrug, lag er nach 4 Jahren nur noch zwischen 2-8. SAwyer kam daher zu der Auffassung, daß es angebracht wäre, Personen, die dauernd einer Infektion ausgesetzt wären, alle 2-3 Jahre auf ihren Schutzkörpertiter zu prüfen und nachzuimpfen, falls der Serumschutz stark gesunken oder sogar erloschen war. Nach BoIRoN (1956) wird bei immunen Personen eingespritztes Gelbfiebervirus schnell neutralisiert; es vermag aber trotzdem den Abwehrorganismus des Körpers anzuregen.

Aragao de Beaurepaire (1933a, b) benutzte als Virus zur Simultanimpfung Gehirn von brasilianischen Hausratten (Camondongos). Er nahm zunächst eine i.m. Einspritzung von, $3,0 \mathrm{ml}$ menschlichen Immunserums in den Oberarm und 6 St. später eine i.m. Einspritzung von $2,0 \mathrm{ml}$ Immunserum gemischt mit $0,001 \mathrm{~g}$ frischen infektiösen Gehirns vor.

Die ersten Impfungen ohne Immunserum wurden mit dem französischen neurotropen Virus vorgenommen (Sellards und Laigret, $1932 \mathrm{a}, \mathrm{b}, \mathrm{c}$; LaIGRet, $1933 \mathrm{a}, \mathrm{b}, 1934 \mathrm{a}, \mathrm{b}, \mathrm{c}, \mathrm{d}$; Aragao de Beaurepaire, 1933 b). Mathis u. a. $(1934,1936)$ nahmen die ersten derartigen Massenimpfungen in Afrika vor. Die Impfung bestand in 3 Injektionen von Virus in Abständen von je 20 Tagen. Das Virus war durch 24 St. Stehen bei Zimmertemperatur abgeschwächt worden. Lloyd und MaHAFFy (1934) erhielten bei Rhesus-Affen nach wiederholten s.c. Impfungen mit neurotropem Virus in monatlichen Intervallen keine signifikanten AK-Veränderungen mehr.

Sellards und LaIGReT $(1932 \mathrm{~b}, \mathrm{c})$ stellten außerdem einen in Eigelb eingehüllten Impfstoff her: infektiöses Mäusegehirn wurde 24 St. lang in Glyzerin bei $20^{\circ} \mathrm{C}$ gehalten, dann in Phosphatpuffer zerrieben und $24 \mathrm{St}$. bei $5^{\circ} \mathrm{C}$ getrocknet. Darauf erfolgten erneute Zerkleinerung und Mischung mit 4,0 ml frischen Hühnereigelbs, Trocknung und Pulverisierung. Die Sterilität des Impfstoffs sowie seine Virulenz wurden geprüft. Letztere galt als ausreichend, wenn Suspensionen von $1 / 100$ und $1 / 1000$ die i.cer. infizierten Mäuse töteten, aber eine solche von ${ }^{1} / 10000$ die Mäuse am Leben ließ. Die für eine Impfung ausreichende Menge von $0,05 \mathrm{~g}$ wurde in Ampullen aufbewahrt. Zum Gebrauch wurde die Trockensubstanz mit 1,0 ml Aqua dest. aufgeschwemmt. Nach Nicolle und LAIGRET (1935) genügt eine einmalige s.c. Impfung mit diesem Impfstoff.

SELLaRds und Laigret $(1936 \mathrm{a}, \mathrm{b})$ prüften die Wirksamkeit des Impfstoffes an einer Versuchsperson, welche 7 Monate nach der Impfung durch den Biß einer infektiösen Mücke nicht experimentell infiziert werden konnte.

Als Vorteil des in Eigelb eingehüllten Virus wird angegeben, daß es nicht zu schweren Reaktionen führt, wie dies manchmal bei dem zu schnell absorbierten wäßrigen Impfstoff der Fall ist; es kommt vielmehr nur zu einer langsamen Ausbreitung des Virus und immer zu einer Virämie, die mindestens 3 Tage anhält. N-AK treten vom 5. Tage ab auf. Allgemeinreaktionen sind Temperatursteigerung, Kopf- und Rückenschmerzen am 5. und 6. Tage; sie halten 12 bis 24 St. nur selten 3-4 Tage an. Manchmal kommt es zu Spätreaktionen am 11.-21. Tage: Fieber mit meningoencephalitischen Symptomen, Drucksteigerung des Liquors, Eiweiß- und Zellvermehrung, Lymphozytose, motorische und psychische Störungen (Mathis, 1948; Durieux, 1956). Trotz schweren Krankheitsbildes erfolgt immer Genesung (DeZest, 1937). Mathis beobachtete unter 1000 Geimpften in 60\% keine Reaktion, in $17 \%$ leichte Reaktionen, in $13 \%$ mäßigstarke Reaktionen und in $9 \%$ anhaltende Reaktionen. Sie sind bei jungen Menschen selten, nehmen mit dem Alter und Kräftezerfall zu, so daß dann 30\% der Geimpften Reaktionen aufweisen können. Neger scheinen weniger stark als Weiße zu reagieren (DurIEux, 1956). Die Allgemeinreaktionen scheinen u. a. von der Vermehrung des Virus im Blutstrom abhängig 
zu sein, ohne daß dies aber absolute Regel wäre. Virus im Blute wird in etwa 60-70\% der Impflinge nachweisbar. Die postvaccinalen Reaktionen sind kein Zufall, sondern normale Manifestierung des experimentellen Gelbfiebers. Peltier u. a. (1937) benutzten statt Eigelb Galle im Verhältnis 1:40 als Zusatz zum Impfstoff.

Zur Herstellung von Trockenimpfstoff aus dem französischen neurotropen Virus gibt Durieux (1956) folgende Anweisung:

Jede Maus erhält etwa 20000 MDL des neurotropen Standardvirus i.cer. eingespritzt. Die Gehirne der gelähmten Tiere werden bei $-22^{\circ} \mathrm{C}$ bis $-25^{\circ} \mathrm{C}$ gesammelt und auf bakterielle Sterilität geprüft. Nach etwa 24 St. kommen sie in Röhrchen zur Trocknung in den VakuumGefriertrockenapparat $\left(-25^{\circ} \mathrm{C}\right)$, der mit Actigel, einem Siliciumgel (früher Chlorcalcium) beschickt ist. Die Trocknung ist am Ende des 3. Tages vollständig. Die Gehirne werden im Mörser pulverisiert. Je $2 \mathrm{~g}$ Gehirn werden mit $0,25 \mathrm{~g}$ Célite, einer gereinigten und getrockneten Infusorienerde, gemischt, wodurch das Volumen des Impfstoffes vergrößert wird. Die bakterielle Sterilität des Pulvers wird ebenfalls kontrolliert. Darauf erneut 24 St. Trocknung im Vakuum bei $-25^{\circ} \mathrm{C}$. Das Impfstoffpulver wird in Mengen, welche ${ }^{1 / 10}$ Gehirn entsprechen, auf Ampullen verteilt und nochmals $24 \mathrm{St}$. im Gefriertrockenapparat getrocknet. Die Ampullen werden im Vakuum zugeschmolzen und bei $4^{\circ} \mathrm{C}$ aufbewahrt. Der Impfstoff hat dann noch nach $1 \mathrm{Jahr}$ nichts von seiner Wirksamkeit verloren. Bei $28^{\circ} \mathrm{C}$ kommt es zu einem langsamen Virulenzverlust. Über die Herstellung des Peltier-Impfstoffes s. auch HaAgen und GraEFE (1943).

Eine gewisse Gefahr birgt der aus Mäusegehirn gewonnene Impfstoff insofern in sich, als er gelegentlich durch spontane im Mäusegehirn vorhandene saprophytische Viren, die aber für den Menschen pathogen sind, z. B. der lymphozytären Choriomeningitis (Armstrong) verunreinigt sein kann. MolLaReT (1948) hat bei einem Kranken, der mit neurotropem Mäusevirus geimpft worden war, ein solches Begleitvirus festgestellt, mit dem der zur Impfstoffherstellung verwandte LAIGRETsche Mäusestamm verseucht war, wie eine Überprüfung des letzteren ergab. Die durch dieses Virus bedingten gelegentlichen späten Meningoencephalitiden post vaccinationem stellen nach Mollaret aber auch das einzige Handicap des Mäusegehirnimpfstoffs dar.

Die Bedenken, die gegen die Verwendung lebenden neurotropen Virus als Impfstoff geäußert worden sind, nämlich daß das im Blut kreisende Virus durch Gelbfiebermücken weiter übertragen und dadurch künstliche Krankheitsherde geschaffen werden könnten (DAvis u. a., 1932; Roubaud und Stefanopoulo, 1933), sind durch Mathis u. a. (1934) sowie Peltier u. a. (1939a, 1940b) und Peltier u. (1947) widerlegt worden. Nach Hunderttausenden von Impfungen ist in Afrika noch keine einzige derartige Übertragung festgestellt worden (MAтнIS, 1948). Auch sind niemals Schäden, die auf einen Viscerotropismus des neurotropen Virus für den Menschen hinweisen, beobachtet worden. Von 1939-1954 wurden vom PasteurInstitut in Dakar über 84 Millionen Impfstoffdosen ausgegeben (s. auch Husson und KoERBER, 1953; BRETEAU, 1954).

Zum Gebrauch wird der Inhalt einer Ampulle in 2,0 ml steriler Gummi arabicum-Lösung ( $1 \mathrm{~kg}$ auf $1500 \mathrm{ml}$ Leitungswasser von $\mathrm{p}_{\mathrm{H}}$ 7,2-7,4), die in Ampullen bereit gehalten wird, aufgelöst. Der fertige Impfstoff ist innerhalb von 1 St. nach der Zubereitung zu verarbeiten.

PeLtier u. a. (1939b) führten die Skarifikationsimpfung mit dem neurotropen Virus ein, nachdem sie festgestellt hatten, daß das Virus nach leichter Ritzung der Haut wie bei der Pockenschutzimpfung in den Organismus eindringt und wie nach s.c. Impfung sich vermehrt und AK bildet. 3 Tropfen Impfstoff werden mit der Impflanzette in Abständen von wenigen cm auf die Außenseite des Oberarms gebracht und durch die Tropfen gehend 8-10 mm lange oberflächliche Impfschnitte angelegt; der Impfstoff wird mit der austretenden Flüssigkeit gemischt und 5 Min zum Trocknen gelassen. Nach Durieux (1956) ist für die Skarifikationsimpfung mit dem neurotropen Virus eine Mindestmenge von $5000 \mathrm{LD}_{50}$ für Mäuse zu verlangen, da bei dieser Impfung nur ein Teil des Virus in den Organismus gelangt. Dies entspricht einem Titer von wenigstens 250000 MLD.

Cannon und Dewhurst (1955) sind dazu übergegangen, ein 17D-Mäusegehirnvirus zur Skarifikationsimpfung zu verwenden. Die Überlegenheit dieses Impfstoffes über den neuro- 
tropen Mäusegehirnstamm muß noch bewiesen werden (s. auch De Roever-Bonnet und HoEKstra, 1958).

Als Kontraindikationen gelten schlechter Allgemeinzustand, Nieren- und Leberkrankheiten, Alter unter 2 Jahren wegen der großen Empfänglichkeit der Kleinkinder für neurotrope Viren, oder für Kinder in Gebieten mit Mumps, Masernencephalitis, Polio und anderen Krankheiten. Während der ersten Wochen nach der Impfung wird empfohlen, Ermüdungen und übermäßiges Essen zu vermeiden. Beim Auftreten von Reaktionen ist sofort für Ruhe und Diät zu sorgen. Im allgemeinen treten bei der Skarifikation weniger Reaktionen als bei der s.c. Impfung auf. Die Impfimmunität wird mit dem Mäuseschutzversuch geprüft. Im großen ausgeführt hat er in Afrika eine Immunität von durchschnittlich $90 \%$ der Geimpften ergeben (Peltier, 1946, 1948). Courtney (1952) kam in Panama zu demselben Resultat. Über die Dauer der Immunität mit dem Dakar-Impfstoff gibt folgende Aufstellung Auskunft (Durieux und Koerber, 1956, s. auch Boyer, 1936).

\begin{tabular}{c|c|c|c}
\hline $\begin{array}{c}\text { Anzahl der Jahre } \\
\text { nach der Impfung }\end{array}$ & $\begin{array}{c}\text { Anzahl der unter- } \\
\text { suchten Personen }\end{array}$ & $\begin{array}{c}\text { Anzahl der } \\
\text { immunen Personen }\end{array}$ & \% der Immunen \\
\hline 1 & 142 & 134 & 94,3 \\
2 & 89 & 81 & 91,0 \\
3 & 30 & 28 & 93,3 \\
4 & 17 & 17 & 100,0 \\
5 & 16 & 9 & 100,0 \\
6 & 10 & 3 & 90,0 \\
7 & 4 & 1 & \\
8 & 1 & 0 & \\
9 & 1 & 1 & \\
10 & 1 & 2 & \\
11 & 2 & & \\
12 & & & \\
\hline
\end{tabular}

Die Züchtung des Gelbfiebervirus in vitro hat dazu geführt, auch Kulturvirus für Impfzwecke heranzuziehen. Lloyd (1935) sowie Soper und Smith (1938a) stellten mit dem "17 E«-Stamm Simultanimpfungen an. Obwohl die Eigenschaften dieses Stammes etwa jenen des neurotropen Mäusegehirnvirus entsprechen, wagte man nicht, ihn als Impfstoff ohne Immunserumzusatz zu verwenden, da die Abschwächung des Viscerotropismus nicht genügend gesichert erschien. Die Prüfungen der Eigenschaften des Kulturstammes »17D« ließen seine Verwendbarkeit als Imptstoff ohne Zusatz von Immunserum möglich erscheinen. Als 17D-Impfstoff diente zunächst das Seitz-Filtrat der Kulturen, das im gefrorenen Zustand im Vakuum getrocknet und zum Gebrauch zunächst mit normalem Menschenserum aufgelöst wurde. Der getrocknete Impfstoff bleibt bei -9 bis $-32^{\circ} \mathrm{C}$ aufbewahrt 3 Jahre, bei -5 bis $-25^{\circ} \mathrm{C} 2$ Jahre wirksam. Bei $37^{\circ} \mathrm{C}$ gehen $90-99 \%$ seiner Wirksamkeit in 2-8 Wochen verloren (Burruss und Hargett, 1947). Hahn und Bugher (1953) fanden in dem ersten Jahr der Aufbewahrung des getrockneten 17D-Impfstoffes bei $0-4^{\circ} \mathrm{C}$ einen schnellen Titerverlust (etwa 1,5-2 des logarithmischen Titers unter dem des Ausgangsmaterials), in den folgenden 5 Jahren dagegen nur einen geringfügigen weiteren Titerverlust. Noch nach 6-7jähriger Aufbewahrung war der Impfstoff - vorausgesetzt, daß sein Ausgangstiter hinreichend hoch war - so wirksam, daßB er zu Impfzwecken brauchbar war.

Panthier und Hannoun (1960b) verglichen die Wirksamkeit der 17D- und DakarImpfstoffe in 7 Tage embryonierten Eiern. Nach Injektion einer Dosis von 8000 i.cer. Mäuse$\mathrm{LD}_{50}$ des Dakar-Virus starben 9 von 56 Embryonen 8-12 Tage nach der Impfung, aber nur $9 \%$ Küken schlüpften. Mit gleicher Dosis des 17D-Impfstoffes starben $94 \%$ von 63 Embryonen 3-12 Tage p. i., die meisten am 5. Tage. Kein Küken schlüpfte. Bei $39^{\circ} \mathrm{C}$ Bebrütung bekamen die Embryonen schwerere Schädigungen als bei $36^{\circ} \mathrm{C}$.

Die ersten Massenimpfungen mit dem 17D-Virus wurden in Brasilien von H. H. Sмiтн u. a. (1938) ausgeführt. Zu einer Virämie kam es bei etwa der Hälfte der Geimpften zwischen 
dem 4. und 10. Tage; die nachweisbaren Virusmengen im Blut waren jed och äußerst klein. Nach SweET u. a. (1962) wich die Virämiehäufigkeit nach Impfung mit 17D-Virus in einer Gruppe von Personen mit N-AK gegen JE-Virus nicht erheblich von der Virämiehäufigkeit in einer Gruppe von Personen ohne Arbor-Virus-AK ab; bei der ersten Gruppe war allerdings der Virustiter im Blut etwas niedriger. Wisseman und Sweet (1962) stellten fest, daß Personen ohne frühere Infektionen mit einem Virus der Arbor-Gruppe, welche mit dem 17D-Virus (106,1 i.cer. $\mathrm{LD}_{50}$ für Mäusesäuglinge) primär geimpft und 14 Monate später mit demselben Virus nachgeimpft worden waren, 4-7 Tage nach der Nachimpfung keine Virämie zeigten.

Soper und Sмiтн (1938b) impften fast 600000 Personen in einem Dschungelgelbfiebergebiet Brasiliens, wo es zu einem plötzlichen Abfall der Erkrankungsziffer kam. Unter den Geimpften traten nur 8 Gelbfieberfälle auf; wahrscheinlich handelte es sich aber hier um zur Zeit der Impfung bereits infiziert Gewesene. Ähnliche Erfolge wurden von Bugher und GAST-GALvis (1944) in Kolumbien erzielt. Ebenso wie der neurotrope Impfstoff ergab auch das 17 D -Virus in über $90 \%$ der Geimpften eine Immunität, die mindestens 3 Jahre unverändert blieb (Smithburn und Mahaffy, 1945). Nach Anderson und Gast-Galvis (1947) hält die Immunität lange genug vor, um nur alle 5 Jahre nachimpfen zu müssen (s. auch Fox u. a., 1948; Fox und Cabral, 1943; Dick und Smithburn, 1949). Dick und Gee (1952) fanden später eine Immunität noch 9 Jahre nach der Schutzimpfung mit $17 \mathrm{D}$-Virus bei $77,2 \%$, während in einem nichtgeimpften Gebiet die Immunität nur $17,5 \%$ betrug. Courtors $(1954,1956)$ stellte anschließend sogar noch nach 12 Jahren einen Impfschutz bei $96 \%$ der Geimpften fest. Dick und Gee sowie Courtors schlagen daher eine Gültigkeit von 9 Jahren für die Gelbfieberzeugnisse vor (s. auch Smithburn, 1956). Nach Bres (1961) soll die Immunität, die durch das Dakar-Virus erzeugt wird, größer sein und länger anhalten als die durch 17D-Virus.

$\mathrm{Zu}$ den Nachteilen des 17D-Impfstoffes in der bis 1942 geübten Anwendungsweise gehörte u. a., daß durch die Filtration große Virusmengen zurückgehalten wurden, daß der Zusatz von Menschenserum kostspielig war und vor allem, daß mit letzterem gelegentlich pathogene Keime in den Impfstoff gelangten, die zu schweren Komplikationen, insbes. Virus-Hepatitis führten. Auf diese wurde zum ersten Mal von Findlay und Maccallum (1937a, b, c), Findlay (1938), Stefanopoulo (1938) sowie Soper und Smith (1938a, b) hingewiesen. Unter 2000 Geimpften erkrankten 2-3\% 2-7 Monate später an Gelbsucht. In Brasilien kam es 1939 zu einer Hepatitis-Epidemie, welche die Einstellung der Impfungen notwendig machte (Fox u. a., 1942 b); hier erkrankten in einer Gruppe von 304 Geimpften $27 \%$, in einer anderen Gruppe von 19000 Geimpften etwa 6\% an Ikterus. Hepatitis trat aber nicht nur nach Injektion von normalen und immunen Menschenseren, sondern auch von Pferde- und Affenimmunseren auf. Die größte Hepatitis-Epidemie wurde von SAwY ER u. a. $(1944 \mathrm{a}, \mathrm{b})$ beobachtet; sie umfaßte 28000 Erkrankungen mit 62 Todesfällen an akuter oder subakuter Leberatrophie (s. auch Findlay und Martin, 1943; Turner u. a., 1944; Freeman, 1946). Brick (1953) fand bei einer Reihe von Personen, welche 10 Jahre zuvor infolge einer Gelbfieberimpfung an einer "Serumhepatitis" erkrankt waren, Leberzirrhosen und chronische Hepatitis, allerdings ohne mit Sicherheit angeben zu können, ob in der Tat ein ursächlicher Zusammenhang mit der postvaccinalen Hepatitis besteht. Bereits seit 1942 wird daher zur Aufarbeitung des 17D-Virus kein Menschenserum, sondern nur Aqua dest. verwandt (s. auch Macnamara, 1955). Mit dem wäßrigen Impfstoff wird keine Gelbsucht mehr beobachtet (Fox u. a., 1942 c).

Penna (1956) gibt eine genaue Vorschrift zur Herstellung von $1^{17}$ D-Impfstoff im embryonierten Hühnerei: Jedes embryonierte Ei soll $5000 \mathrm{LD}_{50}$ Virus erhalten. Die Bebrütungsdauer beträgt bei 37,5-38 $\mathrm{C}$ bis zu 4 Tage. Vor Entnahme der lebenden Embryonen kommen die Eier für mindestens $1 / 2$ St. in einen Tiefkühler $\left(-20^{\circ} \mathrm{C}\right)$. Alle Embryonen einer Kulturserie werden bei einer Temperatur unter $0^{\circ} \mathrm{C}$ im Waring-Blendor zerkleinert. Sterilitätsproben werden entnommen. Der Embryobrei kommt in alkalifreie Glasflaschen und wird bei $-80^{\circ} \mathrm{C}$ unter Rotieren eingefroren und aufgehoben, aber höchstens 48 St., bis zum Vorliegen der Sterilitätsprobe. Nach Auftauen erfolgt 1 St. Zentrifugieren mit 2000 U/Min bei $2-5^{\circ}$ C. Die klare überstehende Flüssigkeit dient ohne Filtration als Impfstoff; sie wird in Ampullen eingefroren und im Vakuum getrocknet. Nach Einleitung von Stickstoff werden die Röhrchen zugeschmolzen und bei $-25^{\circ} \mathrm{C}$ aufbewahrt. Von den Ampullen werden Proben zur Sterilitätsprüfung an Meerschweinchen entnommen; diese erhalten 4,0 $\mathrm{ml}$ des konzentrierten Impfstoffs i.p. 
Treten innerhalb von 15 Tagen bei den Tieren Reaktionen auf, wird die betreffende Impfstoffcharge eliminiert. Der Impfstoff soll einen Titer von mindestens 1: $6000 \mathrm{LD}_{50}$ haben; dies entspricht etwa $200000 \mathrm{LD}_{50} / \mathrm{ml}$ (s. auch H. H. SмIтH u. a., 1938; HARGETT u. a., 1943; LuMSDen, 1954; MeERs, 1960).

Die bei der Züchtung gewonnenen Virusstämme werden laufend an Affen auf etwaige Zunahme des Neurotropismus und auf Immunisierungsvermögen geprüft. Von je 6 Affen sollen nicht mehr als 2 an Encephalitis erkranken und nicht mehr als 1 Tier sterben (Fox u. a., 1943). Aüf diese Weise werden für die Virusaussaat Kulturserien gleicher Beschaffenheit erhalten (s. auch Epidemiological Information Bull., 1945, Standard-Herstellungsverfahren nach Artikel 1; IX. Internationales Luftfahrt-Sanit.-Abkommen, 1944 und UnRRA, 1945, zit. Bonnel, 1956; Sawyer u. a., 1944a, b; Stefanopoulo und Duvolon, 1947a). Die internationalen Vorschriften über Herstellung, Aufbewahrung, Verteilungszeit und Versand des Impfstoffes sind zu beachten (s. auch WHO, 1957, 1959).

Die Empfänglichkeit des Menschen für eine i.d. Impfung scheint größer zu sein als für eine s.c. Impfung (DIcK, 1956). Bei Verimpfung von etwa 8000 i.cer. Mäuse- $\mathrm{LD}_{50}$ wurde bei 85 von 91 Personen (93,4\%) eine nach 1 Monat durch den Mäuseschutzversuch nachweisbare Immunität erhalten. Die Häufigkeit der AK-Reaktionen nach i.d. Impfung mit 17D-Impfstoff $(0,1 \mathrm{ml})$ erreicht nur etwa die Hälfte jener nach s.c. Impfung mit $17 \mathrm{D}$ und etwa $1 / 10$ jener nach Skarifikation mit Dakar-Impfstoff. Bemerkenswert ist die Beobachtung, daß es bei einer Person, welche vor 10 Jahren mit $17 \mathrm{D}$-Virus geimpft worden war und noch AK besaß, nach i.d. Einspritzung von 0,1 ml 17D-Impfstoff zu erheblichem AK-Titeranstieg kam (PANTHIER u. a., 1958).

Die Brauchbarkeit des 17D-Virus zur Skarifikationsimpfung wurde von HaHN (1951), Dick (1952a) sowie Cannon und Dewhurst (1953) erstmalig erprobt, indem Verreibungen der infizierten Hühnerembryonen mit Gummi arabicum oder lediglich mit Wasser durch Skarifikation in die Haut des Oberarms eingebracht wurden. Die Ergebnisse waren an einer noch beschränkten Zahl von Impflingen gut. Ein Vorteil der Skarifikation mit dem $17 \mathrm{D}$-Virus liegt u. a. darin, daß nicht nur die überstehende Flüssigkeit der zerkleinerten Hühnerembryonen, sondern daß die Gesamtembryonen verwandt werden, sowie daß Massenimpfungen viel schneller vorgenommen werden können und auch weniger kostspielig sind. Bei Massenskarifikationensimpfungen in 2 Gebieten von Sierra Leone mit 17D-Impfstoff (2000-3200 bzw. 1500-2500 LD ${ }_{50}$ ) und in einem weiteren Gebiet mit Mäusegehirnimpfstoff (1500-2000 $\mathrm{LD}_{50}$ ) wurde eine gute Immunität erzielt, wie im i.p. Mäuseschutzversuch geprüft und bestätigt wurde (CANnon u. a., 1957; KerR, 1957; MeErs, 1957). Einmalige Impfung ergab einen Schutz bei $94,2 \%$, zweimalige Impfung einen solchen bei $98 \%$ der immunisierten Schulkinder (Meers, 1960). Sмітнвurn (1956) hatte nach zweimaliger Impfung im Abstand von 14 Tagen einen Schutz bei 94,2\% festgestellt (s. auch FabiYi und MacNamara, 1962). Meers (1960) verglich an 60000 Schulkindern in Lagos die Wirksamkeit der Skarifikationsimpfung mit 17D-Virus mit und ohne gleichzeitige Pockenschutzimpfung; er stellte fest, daß beide Impfstoffe ohne Abnahme ihrer Immunogenität an verschiedenen Stellen appliziert werden können. Bei 93,1\% verlief die Gelbfieberimmunisierung (Kontrolle mit der i.p. Schutzprobe an Mäusesäuglingen) und bei $94,5 \%$ die Pockenimmunisierung positiv.

Peltier u. a. (1939a, 1940a, b) führten zur Massenimmunisierung gegen Gelbfieber und Pocken die kombinierte Impfung ein. Diese Doppelimmunisierung verläuft ohne gesteigerte Reaktionen seitens des einen oder anderen Virus. Die Impfung wird von Säuglingen gut vertragen. Auch bei Kindern sind die Impfreaktionen leichter als bei Erwachsenen. Peltier u. a. beobachteten bei etwa 7-8\% der Geimpften geringfügige Allgemeinreaktionen, leichtes Fieber, Gelenkschmerzen, Übelkeit 5-6 Tage nach der Impfung. Bei etwa 900000 Impfungen wurde ein Gelbfieberschutz in $95,4-98,3 \%$ der Fälle festgestellt.

Blanchard (1941) ging zur kombinierten Gelbfieber-Pockenschutzimpfung mittels Skarifikation über. HAHN (1951) erzielte mit diesem Verfahren gute Immunität, während Dick und Horgan (1952) weniger gute Resultate hatten. Meers $(1959 \mathrm{a}$, b) erhielt nach kombinierter Skarifikationsimpfung mit Pockenlymphe und Gelbfieberimpfstoff $17 \mathrm{D}$ nur bei $2 / 3$ der Geimpften einen Gelbfieberschutz. Der Unterschied in der AK-Reaktion bei den mit kombiniertem Impfstoff einerseits und nur mit 17D-Virus andererseits geimpften Personen 
könnte darauf beruhen, daß in der Kombination beider Antigene eine lokale Interferenz an der Skarifikationsstelle stattfindet, die das Eindringen des $17 \mathrm{D}$-Virus bei manchen Menschen verhindert. Peptonzusatz wirkt während der Antrocknung auf der Haut schützend auf das Gelbfiebervirus. Bis abschließende Erfahrungen mit der Kombinationsimpfung vorliegen, wird weiter empfohlen, nach Pockenschutzimpfung (Erstimpfung, Wiederholungsimpfung mit Pustelbildung) bis zur Gelbfieberimpfung 6 Wochen, nach Wiederholungsimpfung mit Knötchenbildung 1 Woche zu warten. Nach oraler Immunisierung mit abgeschwächtem PolioLebendimpfstoff soll 4 Wochen und nach BCG-Impfung 3 Monate gewartet werden. Nach Immunisierung mit abgetötetem Salk-Polio-Impfstoff, Toxoiden u. ä. bestehen keine Wartezeiten.

\section{0-3. Impfreaktion}

MacNamara (1953c) unterscheidet bei der Skarifikationsimpfung mit neurotropem Virus milde viscerale und neurale Reaktionen, die 4-7 Tage nach der Impfung auftreten: Fieber mit geringer Virämie. Die visceralen Reaktionen sind schwer zu definieren und kommen offenbar nur selten vor. Die neuralen Reaktionen sind dagegen verhältnismäßig häufig: bei Kindern in $4 \%$ der Geimpften mit einer Letalität von $40 \%$; Erwachsene werden seltener betroffen. In den Gehirnen von 3 tödlich verlaufenen Fällen wurde neurotropes Virus nachgewiesen. Infolge der großen Zahl von schweren Impfreaktionen wird neurotropes Virus zur Impfung von Kindern und jüngeren Erwachsenen von Macnamara abgelehnt. Auch EkLund (1953) berichtete über tödlich verlaufene Encephalitis bei Kindern in Costa Rica und Honduras nach Impfung mit dem Dakar-Impfstoff (10 gesicherte und 5 mögliche Fälle) (s. auch KaPLAN und GLUCK, 1945).

Bei den Impfungen mit Kulturvirus gehören zu den Allgemeinreaktionen die gelegentlich gegen das artfremde Hühnereiweiß im Impfstoff auftretenden allergischen Reaktionen; sie sind sehr selten und meist milde. Sulzberger und Asher (1942) beschrieben 2 Fälle von Urtikaria- und Erythema multiforme-artigen Hautausschlägen. Swartz (1943) sowie Sprague und BARNARD (1945) sahen je eine besonders schwere Reaktion bereits wenige Minuten nach der Impfung: angioneurotische Ödeme, Urtikaria, schwere Atemnot und gastrointestinale Erscheinungen. Kouwenaar (1953) hält auf Grund seiner Erfahrungen an 1130 Personen, welche wäßrigen $17 \mathrm{D}$-Impfstoff erhalten hatten, und von denen 15 als Allergiker bekannte Personen waren, Reaktionen wie Urtikaria, Serumkrankheit, Heufieber, Asthma, Ekzem bekamen, das Risiko solcher Zwischenfälle für nicht unerheblich. BERGHE und Hargett (1942) stellten fest, daß bei Meerschweinchen die Sensibilisierung gegen Hühnereiweiß in Beziehung zum Alter der verwandten Embryonen stand (s. auch LaIgret, 1947; Becker und Lieske, 1957; Mazaud u. a., 1957a. b).

Panthier und Husson (1957) beobachteten, daß eine desensibilisierende i.d. Injektion von $0,1 \mathrm{ml} 17 \mathrm{D}$-Impfstoff 20 Min vor der eigentlichen s.c. Impfung mit $0,5 \mathrm{ml}$ die Häufigkeit der allergischen Reaktionen herabsetzt. Panthier u. a. (1958) empfahlen, bei Allergie gegen Hühnereiweiß zunächst $0,1 \mathrm{ml}$ 17D-Impfstoff i.d. einzuspritzen und nach 2 Monaten eine Skarifikationsimpfung mit Dakar-Impfstoff vorzunehmen. Bei fast 35000 Impfungen mit 17D-Impfstoff stellten PanthieR u. a. (1959) auf Grund der Häufigkeit der lokalen Hautreaktionen nach i.d. Vorimpfung fest, daß die Überempfindlichkeit gegen Hühnereiweiß mit dem Alter zunahm und nach dem 50 . Jahr etwa $14 \%$ betrug. Nach der Desensibilisierung verlief die 2. s.c. Impfung ohne Allgemeinreaktionen.

Noтter u. a. (1960) führen eine Plazentaablösung mit Tod des 6 Monate alten Foetus nach Impfung der Mutter mit Eikulturvirus 17D auf eine Allergie zurück.

$\mathrm{Zu}$ den schwersten postvaccinalen Reaktionen, die noch vorkommen und besondere Beachtung erfordern, gehören die Encephalitis sowie die Meningoencephalitis. Fox u. a. (1942a) fanden in einer Gruppe von 55000 Personen in Brasilien, welche mit einem 17D-Unterstamm geimpft worden waren, 273 Fälle $(0,5 \%)$ von Encephalitis mit 1 Todesfall (2jähriges Kind). Dieser Unterstamm hatte einen erhöhten Neuro- bzw. Encephalotropismus erworben. Von 60 mit ihm infizierten Rhesus -Affen erkrankten $28 \%$ an Encephalitis, während sonst nur 5,7\% dieser Tiere encephalitische Erscheinungen bekommen. Fox u. a. (1942a) glaubten, daß das 
Gelbfiebervirus selbst, nicht dagegen ein extrinsisches Virus die Encephalitis erzeugt. Nach Standardisierung des 17D-Impfstoffs (1942) scheinen postvaccinale Encephalitiden nur noch selten vorzukommen. So beobachtete LÉpIne (zit. STUART, 1956) unter 1800 im Jahre 1953 unter $1 \mathrm{Jahr}$ alten geimpften Kindern $5 \mathrm{Fälle}$, dagegen unter gleichzeitig mit demselben Impfstoff immunisierten Erwachsenen keinen einzigen Fall. LARTigaut und LARTigaut (1954) sowie Lartigaut und Couteau (1954) teilten je 1 Fall bei einem 3 und einem 4 monatigen Säugling in Frankreich, HaAs (1954), Sсотт (1954), J. H. Sмгтн (1954), Тномson (1955) und Beet (1955) je 1 Fall in England, De Castro Freire (1955) einen solchen in Portugal und Swift (1955) 1 Fall in Südafrika ebenfalls bei Säuglingen mit. Panthier (1956a) beobachtete bei 7 Kleinkindern von 4 Wochen bis 6 Monaten Meningoencephalititiden und empfiehlt daher, Kinder unter 1 Jahr nicht zu impfen. FeItel u. a. (1960) sahen den ersten Fall von Encephalitis in den USA bei einem 10 Wochen alten Kind nach Impfung mit 17D-Virus; das Kind genas nach 10 Tagen. Сомв escot De Marsaquet und Thomas (1961) beobachteten nach kombinierter Pocken-Gelbfieber-Schutzimpfung bei der städtischen Bevölkerung von Ponte Noire (Kongo) 1958 eine Reihe postvakzinaler Reaktionen meningoencephalitischer Art.

Weitere Literatur zur Prophylaxe:

Agramonte (1924); Sellards und Bennett (1937), Antunes (1948), Paoliello (1948), Edwards (1949), Espinoza (1953), Durieux (1954), Sautet und Aldighieri (1954), Aldighieri (1955), Arrangements for vaccination against yellow fever (1955); Severo (1955), Pinto Severo (1956), Bonnel (1957), Comité d'experts du vaccin amaril (1957), Courtois (1957), Lippelt (1957), Manso (1957), Hughes und Porter (1958), Pinto Severo (1958), Boyd (1959), Medvedeva (1960).

\section{IV. Zika-Fieber}

Dick u. a. (1952) isolierten bei einem Rhesus-Affen im Zika-Wald bei Entebe (Uganda) ein Virus durch i.cer. Verimpfung auf Mäuse, die erkrankten und starben (s. auch Dick, 1952 b). Ein weiteres Virus wurde aus Aedes africanus durch Beimpfung eines RhesusAffen mit einer Mückensuspension isoliert. Der Affe bekam Fieber. Sein Serum wurde 8 Tage p. i. auch auf Mäuse i.cer. übertragen. Beide Virusstämme erwiesen sich in der NR identisch. Mac Namara (1954) konnte das Virus auch aus dem Blut eines Fieberkranken isolieren.

Bearcroft (1956) infizierte Menschen experimentell mit Virus der 6. Mäusepassage. Die Inkubationszeit betrug 82 St. Nach 7 Tagen trat Genesung ein. Das Virus wurde während der Fieberphase im Blut gefunden. Eine Weiterübertragung vom Kranken auf Mäusesäuglinge durch A. aegypti-Bisse gelang nicht.

Affen bekamen nach s.c. Impfung mit Mäusegehirnvirus nur eine latente Infektion, die ihren Ausdruck in einer Virämie während der ersten. Woche und Bildung von AK 2 Wochen nach der Impfung fand. Mäuse im Alter von 2 Wochen waren nur für eine i.cer., nicht aber für eine i.p. Infektion empfänglich. Mäusesäuglinge ließen sich dagegen leicht i.p. infizieren. Das für Mäuse äußerst neurotrope Virus ließ sich in den Gehirnen passagenweise züchten. Es wurde nur im Gehirn gefunden (Titer von etwa $10^{-7}$ ). Die Mäusegehirne wiesen Degeneration der Nervenzellen, Zellinfiltrationen und Erweichungsherde auf. Bei jungen Mäusen waren die Veränderungen besonders ausgedehnt und enthielten Einschlüsse vom Typus A nach Cowdry. REAGAN u. a. (1954c) fanden syrische Hamster empfänglich. Kaninchen, Meerschweinchen und Baumwollratten erkrankten nicht manifest, erwarben aber Immunität.

Das Zika-Virus läßt sich in vitro in verschiedenen Zellarten züchten. In HeLa- und Menschenfibroblastenkulturen wurde ein ZE beobachtet (Moore, 1957). In Einschichtzellkulturen von Hühnerfibroblasten nach Dulbecco (1952), die mit Agar überschichtet waren, bildet das Virus nach 4-5 Tagen ähnliche Plaques wie das Gelbfiebervirus (PorTerfield, 1959a).

TAYlor (1952) übertrug das Zika-Virus der 144. Mäusepassage in den Dottersack embryonierter Eier; nach 3 Passagen ergab die Suspension des Gesamtembryos (7 Tage Bebrütung) 
einen Mäuseinfektiositätstiter von 10-5,5. Nach Beimpfung des Amnionsacks erreichte der Titer im Embryogehirn 10-5. In beiden Fällen war das Virus bereits nach 2 Tagen nachweisbar. Nach Impfung in den Allantoissack vermehrte sich das Virus im Embryo etwas langsamer; es wurde erst nach 4 Tagen nachweisbar. Der höchste Titer betrug $10^{-4,7}$. Bei direkter Infektion der CAM wurde in dieser ein Titer von nur 10 $10^{-3,8}$ erzielt. Trotz seiner hohen Infektiosität und Pathogenität für Hühnerembryonen tötete das Zika-Virus diese nicht. Besondere pathologische Veränderungen wurden im Embryo nicht angetroffen.

Die Teilchengröße des Virus wurde durch Membranfiltration auf 18-26 mu ermittelt (Smithburn und Bugher, 1953). Reagan und Brueckner (1953d) fanden in elektronenmikroskopischen Aufnahmen infektiöser Mäusegehirn- und -rückenmarksuspensionen runde Teilchen von $40 \mathrm{~m} \mu$ Durchmesser. Reagan u. a. (1955b) sahen 16 St. nach Gehirninfektion von Mäusen die Virusteilchen auch im Blut an oder in den Erythrozyten. Nur in Gegenwart dieser Teilchen waren die Erythrozyten für Mäuse infektiös. 24 St. p. i. und später entnommenes Blut wies elektronenoptisch kein Virus auf, was dem Fehlen einer Infektiosität für Mäuse entsprach.

Aus infektiösen Mäusesäuglingsgehirnen ließ sich ein Hämagglutinin isolieren (CASALs und Brown, 1954; CASALS, 1957). Es agglutinierte nicht nur Hühner-, sondern auch Gänseerythrozyten (Porterfield, 1957).

Das Virus ließ sich getrocknet und in der Kälte bei $-50^{\circ} \mathrm{C}$ jahrelang aufbewahren (B EARCROFT, 1956).

Beim Zika-Virus ist mit einem natürlichen Infektionszyklus Affe-Mücke (Aedes africanus)Affe zu rechnen, in den sich gelegentlich der Mensch einschalten kann. Unter experimentellen Bedingungen läßt sich auch der A. aegypti infizieren (Boorman und Porterfield, 1956).

Wie aus der Häufigkeit der N-AK (6-13\%) unter den Bewohnern von Uganda und Tanganyika hervorgeht, ist die Zika-Virusinfektion in diesen Gebieten weit verbreitet (Dick u. a., 1952; SмiтнвuRN, 1952a, b). Aber auch in Indien, Malaya und Borneo besteht offenbar eine hohe Endemizität (Sмiтhвurn u. a., 1954a; Smithburn, 1954a). Unter den Bewohnern des Amazonas-Tales (Brasilien) wurden bei $4 \%$ AK gefunden (Causey und Theiler, 1958). In Ägypten scheint eine Infektion nach den spärlichen AK-Titern in der Bevölkerung nur selten vorzukommen (SмithiuRN u. a., 1954b).

Nach den wenigen vorliegenden Beobachtungen handelt es sich beim Menschen um eine kurzdauernde fieberhafte Krankheit mit unbestimmten Allgemeinerscheinungen, Kopfschmerzen, Schwindel und Übelkeit, bei der vielleicht die Gelbsucht in manchen Fällen auf eine Beteiligung der Leber hinweisen könnte, wenn diese nicht auf eine Begleitinfektion mit einem anderen Erreger zurückführbar ist (OLITsky und ClaRke, 1959). Todesfälle sind nicht bekannt.

Bei experimentell infizierten Menschen ließen sich mittels der Serumschutzprobe (NR an der Maus) und der HAHR spezifische Antikörper gegen Zika-Virus feststellen (BEARCROFT, 1956). Die KBR hat eine größere antigene Verwandtschaft zum Gelbfiebervirus als zu anderen B-Viren ergeben, während solche in der NR und HAHR nur selten hervortritt (CASALS, 1959, zit. Olitsky und Clarke, 1959, s. auch Smithburn, 1952a).

\section{V. Kyasanurwald-Fieber}

\section{Einleitung}

Das Kyasanurwald-Fieber ist eine in Indien vorkommende hämorrhagische Krankheit des Menschen, die erstmalig im Staate Mysore entdeckt und beschrieben worden ist. Sie nimmt einen langdauernden fieberhaften Verlauf mit Erschöpfungszuständen und ziemlich hoher Sterblichkeit wahrscheinlich infolge einer schweren Leberschädigung. Die Krankheit des Menschen gleicht in vieler Hinsicht dem Omsker hämorrhagischen Fieber, 
das ohne manifeste Erscheinungen seitens des ZNS verläuft (Work und TraPIDo, 1957, 1959; Work u. a. 1957). Sie wird durch Zecken übertragen. Nach dem Ort der ersten Virusisolierung bei einem Schwarzgesichtaffen (Presbytis entellus) und 2 Rotgesichtaffen (Macaca radiata) aus Blut und Organsuspensionen und anschließend auch beim Menschen wurde die menschliche Krankheit "Kyasanurwald-Fieber« genannt (WoRK, 1958). Der Erreger gehört zu den Arbor-Viren der Gruppe B und ist eng mit dem REFSEVirus verwandt (WoRK u. a. 1959).

\section{2. Ätiologie}

\section{2-1. Übertragungsversuche}

Rhesus-Affen (Macaca mulatta) wurden i.cer. oder i.p. mit infektiösem Affenserum infiziert. Bei i.n. infizierten Affen kreiste das Virus mindestens vom 4.-7. Tag und bei den i.p. infizierten vom 6.-7. Tag p.i. im Blut. Die Seren der Affen wiesen nach 3 Wochen N-AK auf. Eine experimentelle Infektion von Affen gelang auch mit mäusegehirnadaptiertem Virus nach i.cer., i.p. und s.c. Infektion. Alle Affen bekamen eine Virämie von mindestens 7 tägiger Dauer; sie schienen nicht manifest zu erkranken, entwickelten aber erhebliche Mengen von $\mathrm{N}$-AK.

Eine Infektion 2tägiger Mäusesäuglinge und 3 Wochen alter Mäuse erfolgte zunächst durch i.cer. Verimpfung von Serum und Suspensionen von Herzmuskel, Skelettmuskel, Lunge, Leber, Milz, Nieren und Gehirn der Affen. In den ersten Passagen pflegten die Mäusesäuglinge nach einer Inkubationszeit von 3 Tagen zu erkranken und am 4. Tag zu sterben. Die 3 Wochen alten Mäuse hatten eine Inkubationszeit von 4-6 Tagen. Hauptsymptom war eine charakteristische spastische Lähmung der unteren Extremitäten. Der Mäusegehirntiter blieb durch 28 Passagen unverändert hoch $\left(10^{-8}\right.$ bis $\left.10^{-9}\right)$. Junge Mäuse konnten auch s.c. und i.p. infiziert werden. Thre Gehirntiter lagen dann aber nur bei $10^{-5}$ nach einer Inkubationszeit von 6-13 Tagen.

Infektiöses Affenvirus (Organsuspensionen des 1. untersuchten Affen) wurde ebenfalls i.cer. und i.p. auf Hamstersäuglinge und junge Baumwollratten übertragen. Die Hamstersäuglinge erkrankten und starben, während die Baumwollratten gesund blieben. Sie machten aber wie erwachsene Baumwollratten, die i.p. infiziert waren, eine latente Infektion durch, da sie später spezifische KB-AK und HAH-AK aufwiesen.

Meerschweinchen, die i.p. infiziert wurden, entwickelten keine AK.

\section{2-2. Züchtungsversuche}

Nach Buckley (1959) gelingt die Züchtung des Virus in Zellkulturen der HeLa-Stämme, S3 und Detroit unter Zusatz von Tryptose-Phosphatbouillon, außerdem in menschlichen Embryodarmzellen mit Auslösung eines ZE, der zur vollständigen Zerstörung der Zellen führte. In Ḧ̈hnerembryofibroblastenkulturen war der ZE weniger deutlich, obwohl sich große Virusmengen bildeten, wie aus Mäuseinfektionsversuchen hervorging. Внатт (zit. Worк, 1959) züchtete einen menschlichen Virusstamm in Affen- und Hamsternierenzellkulturen. Die GK$\mathrm{LD}_{50}$ der 35 . Affennierenpassage betrug $10^{-5}$ bis $10^{-6}$; die 45 . Hamsternierenpassage ergab etwa den gleichen Titer. Der Mäuse- $\mathrm{LD}_{50}$-Titer der 5. und 15. Affennierenpassagen lag unter $10^{-4}$; er stieg aber in späteren Passagen auf $10^{-6}$.

Bнатт versuchte, Menschen- und Affenvirusstämme durch direkte Übertragung auf Zellkulturen von Hamster-, Meerschweinchen- und Affennieren- sowie Hühnerembryofibroblastenkulturen zu isolieren. In den Affen- und Meerschweinchennierenkulturen wurden keine Veränderungen festgestellt; die Kulturflüssigkeiten waren für Mäuse nicht infektiös. In den Hühnerzellkulturen wurde vom 5. Züchtungstag an ein deutlicher ZE gesehen; die Kulturflüssigkeiten töteten alle geimpften Mäuse. Noch in der 11. Kulturpassage waren die Kulturflüssigkeiten mäusepathogen, während die Zellveränderungen minimal geblieben waren. Die Hamsternierenkulturen zeigten am 3. Tage nur einen undeutlichen ZE. Die Kulturflüssig- 
keiten wiesen sowohl am 3. als auch am 11. Bebrütungstag mäusepathogenes Virus auf. In der 2. Passage wurden deutliche ZE beobachtet.

\section{2-3. Hämagglutination}

Sowohl die von Menschen als auch von Affen isolierten Virusstämme ergaben eine gute HA bei Zimmertemperatur und $37^{\circ} \mathrm{C}$ in einem $p_{H}$ von 6-6,6. HA fand auch in Zellkulturen statt. Nach BuckLey (1959) wird die HAR in Zellkulturen folgendermaßen ausgeführt: Die Flüssigkeit der infizierten Einschichtzellkultur (Hühnerembryofibroblasten) wird entfernt und die Kultur mit Hanks'scher Salzlösung $\left(\mathrm{p}_{\mathrm{H}}\right.$ 7,4-7,6) gewaschen; dann werden je Kultur $0,2 \mathrm{ml}$ Borat-NaCl-Lösung $\left(\mathrm{p}_{\mathrm{H}} 9,0\right)$ zugegeben und 30 Min. bei $37^{\circ} \mathrm{C}$ bebrütet. Das Hämagglutinin wird in die Boratpufferlösung abgegeben, in der es sich gut hält. Zu jeder Kultur kommen $0,2 \mathrm{ml}$ einer Gänseerythrozytensuspension in virusadjustierender Verdünnungsflüssigkeit (End-p $p_{H} 6,4$ ); es wird gut gemischt. Um optimale Ergebnisse zu erzielen, muß die optische Dichte der Erythrozytensuspension 1,8 betragen, also höher sein als jene, wie sie für die HA benutzt wird. Sie entspricht einer Suspension von $8 \mathrm{Vol} \%$ für Gänsezellen und $10 \mathrm{Vol} \%$ für Hühnerzellen. Für Röhrchenteste wird eine optische Dichte der Gänseerythrozyten von 0,45 , für Plattenteste dagegen von 0,75 empfohlen. Gänsezellen sind Hühnerzellen überlegen (Clarke und CaSals, 1958). Nach einer zweiten 1stündigen Bebrütung bei $4^{\circ} \mathrm{C}$ werden die Röhrchen 5 Min gespült, worauf die Reaktion unter dem Mikroskop abgelesen wird. Spezifisch für die Gegenwart von Virushämagglutinin ist eine typische Agglutination der kernhaltigen Gänseblutzellen: 3-12 Zellen sind der Länge nach miteinander verbunden. Diese auffällige kettenförmige Anordnung der Erythrozyten findet man nur in infizierten Kulturen. Doppelte oder dreifache Ketten sind typisch. Die um Einzelzellen oder Zellgruppen der Kultur gelagerten Erythrozyten bilden Hufeisen- oder Rosettenformen. Die HA findet vor oder gleichzeitig mit Hämadsorption statt. In Vergleichsuntersuchungen an Mäusen wurde festgestellt, daß HA nur dann stattfindet, wenn infektiöses Virus vorhanden ist.

\section{Epidemiologie; Übertragung}

Bisher sind nur 2 epidemiehafte Ausbrüche des Kysanurwald-Fiebers unter Menschen bekannt geworden. In der 1957-Epidemie wurden von 124 verdächtigen Fällen 56 durch Laboratoriumsmethoden als Kyasanurwald-Fieber diagnostiziert. Mindestens 6 von diesen Fällen starben, was einer Letalität von etwa 10\% entsprechen dürfte. Im April-Mai hatte die Epidemie ihren Höhepunkt erreicht. In den meisten Fällen handelte es sich um junge Männer, die vorwiegend im Wald beschäftigt waren. Der Virusnachweis bei Menschen, Affen und Zecken auch in den Monaten Oktober-Januar 1957/58 deutet darauf hin, daß Infektionsmöglichkeiten auch in den anderen Jahreszeiten bestehen. Die menschlichen Erkrankungen treten allerdings meist in den trockenen Jahreszeiten auf, wenn die Zecken aktiv werden und an der Krankheit gestorbene Affen in den Wäldern gefunden werden. Mit Einsetzen des Monsuns gehen die Ausbrüche gleichzeitig mit der Zeckenabnahme zurück.

Sero-epidemiologische Untersuchungen in den Gebieten, wo menschliche Erkrankungen vorgekommen waren, und in Ortschaften in deren Umgebung ergaben folgendes: Unter den Seren von über 1200 Personen befanden sich 123, welche eine positive HAHR gegen ein oder mehrere der benutzten Antigene (Kyasanurwald, JE, WN und Dengue 2) aufwiesen. Von diesen reagierten in der KBR nur 51 Seren mit dem Kyasanurwald-Fiebervirus.

Die unmittelbare Beziehung der menschlichen Erkrankungen zu den Affenerkrankungen in den Wäldern weist auf eine epidemiologische Ähnlichkeit mit dem Gelbfieber hin. Auf jeden Fall scheinen die Affen eine bedeutende und vielleicht sogar ausschlaggebende Rolle für die Aufrechterhaltung der Infektion überhaupt wie auch für ihre Verbreitung zu spielen. Die Durchseuchung unter den Affen dürfte ganz erheblich sein. Dies geht aus serologischen Untersuchungen hervor. Von 37 gesunden Affen eines Gebietes, in dem Menschenerkrankungen vorkamen, wiesen $6 \mathrm{~N}-\mathrm{AK}$ auf, was auf eine frühere Infektion hindeutet. Bei 13 Affen aus einem Gebiet ohne menschliche Erkrankungen waren keine N-AK nachweisbar. 
Shama (1957, zit. Work, 1959) fand im Zusammenhang mit menschlichen Erkrankungen im Staate Mysore in den benachbarten Wäldern tote Affen, die Symptome eines enterischen Fiebers aufwiesen. In den Lebern dieser Affen wurden Herdnekrosen, die im allgemeinen schwerer als beim Menschen waren, und polymorphkernige Zellreaktionen gefunden. Neben einer granulären gelblichbraunen Pigmentierung wiesen die Leberzellen mitunter runde eosinophile Körper im Zytoplasma auf. Ebenso wie in den menschlichen Lebern fand sich auch hier ein leichtes Hervortreten der retikuloendothelialen Zellen, die zum Teil hypertrophisch oder vielzellig waren. Außerdem wurden Entzündungszellen angetroffen. Auch die Nieren waren verändert, und zwar besonders im unteren Nephron. Schwere und ausgedehnte Veränderungen bestanden in den Tubuli contorti der Rinde. Lokale entzündliche Infiltrate waren selten. Blutaustritte bestanden in und um die Tubuli der Medulla. Die Lungen wiesen ebenfalls Blutaustritte in den Alveolen auf. Das Herz war mit Herdnekrosen und kleinen herdförmigen Monozyteninfiltraten sowie Histiozyten im Myokard beteiligt. Die Veränderungen in den anderen Eingeweideorganen einschließlich Milz und Magendarmkanal entsprachen jenen beim Menschen. Bei 2 Affen wurden im Gehirn deutliche Veränderungen einer nichteitrigen Encephalitis mit disseminierender Herdnekrose angetroffen. Dieser Befund stand im Gegensatz zum Fehlen encephalitischer Veränderungen in 3 Menschengehirnen. Das Virus ist also neurotrop für Affen; es muß daher damit gerechnet werden, daß es auch für Menschen neurotrop werden könnte. Ebenso wie beim Menschen sind auch beim Affen die beiden parenchymatösen Organe Leber und Niere am schwersten betroffen (s. auch IYer u. a., 1960).

Die Tatsache, daß verschiedene kleine Säugetiere experimentell infiziert werden können und spezifische N-AK bilden, läßt daran denken, daß auch in der Wildnis diese Tiere natürlich infiziert sind und als Virusreservoire in Frage kommen. In den Waldgebieten, in denen menschliche Erkrankungen vorgekommen waren (Kyasanurwald und Nachbarwälder), wurden bei diesen Tieren auch N-AK gefunden, und zwar in $35 \%$ bei Eichhörnchen, bei Ratten weniger häufig. Mäuse (Mus booduga), Spitzmäuse (Suncus murinus), gestreifte Erdhörnchen, Tatera indica hartwickei, sowie Haustiere wie Rind und Wasserbüffel besaßen ebenfalls AK (s. auch Pandit, 1960). Schließlich wurden auch beim Dschungelhuhn (Gallus somerati), goldrückigen Waldspecht (Brachypernus benghalensis), Dschungelreiher und Pfau N-AK gefunden (VorK, 1959; s. auch Pandit, 1960).

Als Überträger der Infektion von Affe zu Affe und von Affe zu Mensch sind bisher Zecken (Haemaphysalis spinigera und H.turturis) ermittelt worden. In den Proben von Larven, Nymphen sowie erwachsenen Zecken aus dem Kyasanurwald wurde das Virus isoliert (TRAPIDo u. a., 1959). Ratten (Rattus wrouthenie, rufescens, blandfordi) sowie Eichhörnchen (Funambulus tristriatus tristriatus) wurden ebenfalls als Zeckenträger (Haemaphysalis und Ixodes) ermittelt. Auch Rindvieh war in starkem Maße mit Haemaphysalis infestiert. Larven dieser Zecken, die an Leghorn-Hühnern, welche mit Kyasnurwald-Virus geimpft waren, durch Blutsaugen infiziert worden waren, übertrugen die Infektion auf ihre Nymphen und erwachsene Zecken. Ein junges Büffelkalb, an dem die infizierten Zecken gefüttert worden waren, bekam eine Virämie und entwickelte N-AK sowie HAH-AK, aber keine KB-AK (VARMa u. a., 1960).

Über die Verbreitungsweise des Kyasanurwald-Fiebers bestehen noch keine eingehenden Kenntnisse. Als wichtigste, vorläufig allerdings noch hypothetische Verschlepper werden die überall hinfliegenden Vögel genannt. Zecken (Haemaphysalis, Ixodes) sind in Rußland bereits bei verschiedenen Vogelarten gesammelt worden.

Die Krankheit hat sich im Laboratorium als hochinfektiös für Menschen, die mit ihr arbeiten, erwiesen (Clarke, zit. Work, 1958; ANIKer, 1960). Morse u. a. (1962) teilten 3 Fälle von menschlichen Laboratoriumsinfektionen mit; in 2 Fällen gelang der Virusnachweis im Blut. Alle 3 Fälle wurden serologisch bestätigt.

\section{Klinik}

Die Klinik des Kyasanurwald-Fiebers wurde eingehend von Work u. a. (1957) beschrieben. Die Inkubationszeit wird auf 3-8 Tage angegeben. Der Beginn ist plötzlich mit Fieber, 
Kopf-, Rücken- und Gliederschmerzen sowie schwerer Erschöpfung; häufig findet man Entzündung der Augen, Erbrechen und Durchfall am 3. oder 4. Krankheitstage. Am 3. Tage beginnen auch bereits Blutungen aus Nase, Gaumen, Magen und Darm, wodurch der hämorrhagische Charakter der Krankheit hervortritt. Allerdings fehlen in vielen Fällen offen zutage tretende Blutungen. Es ergibt sich das Bild einer akuten Erkrankung mit Lustlosigkeit, Schwäche und Fieber bis zu 39, $4^{\circ}$ C, aber selten höher. Das Fieber dauert 5-14 Tage und verläuft manchmal biphasisch. Die zweite Phase tritt nach einem fieberfreien Intervall von verschieden langer Dauer auf (s. auch Pandit, 1960). Manchmal ist der Puls zur Temperaturhöhe zu langsam. Fast immer besteht eine Conjunctivitis palpebrae et sclerae, gelegentlich mit Lichtscheu. Die Halslymphdrüsen können vergrößert, weich und manchmal verfärbt sein. Auch die Achsellymphdrüsen werden vergrößert und weich gefunden. Der Nacken ist oft steif infolge schmerzhafter Hals- und Spinalmuskeln.

Häufig besteht ein papulo-vesikulöses Enanthem auf dem weichen Gaumen. Blutungen am Gaumen werden allerdings selten gefunden. Blutbrechen, rotes Blut im Stuhl oder Melaena weisen auf Magendarmblutungen hin; diese können noch viele Tage nach Fieberabfall weiter bestehen. Exantheme sind nicht beobachtet worden. Gelegentliche rötliche Papeln oder abblassende Flecke in der Axillargegend weisen auf Zeckenbefall hin. Trockene Haut ist ein Zeichen von Wasserverarmung des Körpers. Besondere Herzveränderungen werden nicht gefunden. Infolge der gastrointestinalen Blutungen können Leibschmerzen bestehen.

Leber und Nieren erscheinen nicht vergrößert. Die Milz kann tastbar sein, besonders wenn eine allgemeine Lymphdrüsenbeteiligung besteht.

Manche Kranke haben hartnäckigen Husten mit blutuntermischtem Auswurf und manchmal größeren Blutmengen; die Geräusche über den Lungen und die Blutungen zeigen eine ernst hafte Beteiligung dieses Organs an; es kann zu Pneumonie kommen.

Während des akuten Stadiums besteht eine ausgesprochene Leukopenie (2000-3500 Zellen), die bis zur Entfieberung anhält, worauf eine leichte Leukozytose auftritt. Das Differentialblutbild pflegt kaum verändert zu sein.

Eiweiß im Urin erscheint meistens am 3. oder 4. Krankheitstage und bleibt ebenfalls bis zur Entfieberung bestehen.

Fine leichte neurologische Manifestation findet ihren Ausdruck in pathologischen Veränderungen der CSF während der zweiten Krankheitsphase (PANDIT, 1960; WeBB und RAv, 1961). In 4 von 8 untersuchten Fällen wurde Virus aus der Rückenmarksflüssigkeit isoliert.

Als wichtiges Krankheitszeichen gilt eine Thrombozytopenie verschiedenen Grades. In den meisten Fällen findet man agglutinierende AK für Thrombozyten und Leukozyten (PANDIT, 1960).

Der Verlauf der Krankheit schwankt erheblich. Alle Symptome können solange bestehen bleiben, wie die erste Fieberperiode (5-14 Tage) anhält. Daraus ergeben sich schwere Erschöpfungszustände. Die Genesung findet nur langsam statt und kann Monate dauern (s. auch WERB und RAV, 1961),

\section{Pathologie}

Die Erfahrungen stützen sich bisher auf 3 post-mortem-Untersuchungen bei am 7., 8. oder 9. Tage gestorbenen Kranken. Bereits anatomisch fielen in 2 Fällen die schweren Hämorrhagien und Verdichtungen in den Lungen sowie massive Blutungen im Magendarmtraktus auf. Es handelte sich nicht um lokale, sondern diffuse generalisierte Blutungen in die Alveolarräume der Lungen und in den Magen, das Jejunum, Ileum und Colon. Gehirn und Gehirnhäute waren hyperämisch, ohne weitere sichtbare Veränderungen zu zeigen. Auch Leber, Milz und Nieren waren makroskopisch nicht verändert, abgesehen von relativen Vergrößerungen.

Die histologischen Veränderungen waren folgende: In der Leber wurden nur selten Herdnekrosen gefunden. Die Kupfferschen Sternzellen traten mäßig bis stark hervor und erschienen manchmal hypertrophisch oder vielkernig. Sie zeigten Erythrozytenphagozytose. In der verdickten Glissonschen Kapsel fanden sich mononukleäre Entzündungszellen in verschiedener 
Zahl. In einem Fall bestand entzündliche Infiltration der Gefäßwände, in einem anderen Fall leichte Koagulationsnekrose des Zytoplasmas. Die Leberzellkerne waren vakuolisiert; das Zytoplasma der Leberzellen enthielt körniges gelblich-braunes Pigment. In den Nieren fanden sich geschwollene und blutüberfüllte Glomeruli, welche die Bowmansche Kapsel ausfüllten, sowie degenerative Veränderungen der Tubuli contorti in der Rinde mit Verlust der zytoplasmatischen Begrenzungen, Erweiterung der Tubuli, Zerfall des tubulären Zytoplasmas und Abstoßung der Zelltrümmer in das Lumen der Tubuli. Die Kerne dieser Tubuli waren zum Teil pyknotisch oder verdrängt. Außerdem bestanden kleine Herde interstitieller Gruppen von Monozyten und pigmentbeladenen Makrophagen. Im Rindenmark fielen im wesentlichen bei einem Fall Blutungen in den Tubuli auf. In allen 3 Fällen waren die Lungen fleckig verdichtet mit Hervortreten der Septumkapillaren und eines hämorrhagischen Exsudates in die Alveolarlumina. Blutiges Exsudat mit abgeschilfertem Epithel bestand auch in den Bronchiallumina. Außerdem wiesen die Wände der Bronchioli fleckige entzündliche Infiltrationen auf. In der Milz waren die Malphigischen Follikel undeutlich und die rote Pulpa verstärkt. Die übrigen Bauch- und Brustorgane erschienen unbeteiligt. Im Gehirn wurden keine encephalitischen Veränderungen festgestellt.

Die Ursache der Hämorrhagien konnte durch die histologische Untersuchung nicht hinreichend geklärt werden. Das Fehlen erkennbarer makroskopischer und mikroskopischer Veränderungen in den Blutgefäßen und Geweben, in denen Blutungen bestanden, wies auf andere Störungen hin.

\section{Diagnose}

Sie beruht hauptsächlich auf Laboratoriumsuntersuchungen wie Virusnachweis und AKReaktionen.

Der Virusnachweis ist im Blut lange möglich, da eine verhältnismäßig lange Virämie besteht, die 2 Tage vor Krankheitsbeginn einsetzt und dann weitere 10 Tage anhält. Infolge der Haltbarkeit des Virus in gekühltem Zustand kann es über lange Entfernungen zur Unterchung versandt werden. Die Isolierung erfolgt durch Verimpfung des Serums auf Mäusesäuglinge und gelingt sehr häufig. Seltener ist der Virusnachweis in der Rückenmarksflüssigkeit.

Von den serologischen Untersuchungen hat die HAHR diagnostische Bedeutung, wenn in der betreffenden Gegend keine anderen Infektionen mit Arbor-Viren der Gruppe B bestehen. Die HAH-AK erscheinen einige Tage vor den KB-AK. Ausschlaggebend ist der Titeranstieg in Serumpaaren.

\section{\%. Prognose}

Bei der prognostischen Beurteilung der Erkrankungen stehen der Umfang und die Dauer der Blutungen im Vordergrund. Bei Blutungen in inneren Organen, wie den Lungen, ist die Prognose ernst. Die Austrocknung, welche durch die Scheu der Kranken, Flüssigkeit zu sich zu nehmen, noch gesteigert wird, kann so erheblich sein, daß sie das klinische Bild schwer gestalten. Sonst scheint das Kyasanurwald-Fieber gewöhnlich einen leichteren Verlauf zu nehmen und es bei guter symptomatischer Behandlung schließlich zur Genesung zu kommen. Immerhin ist unter der bisherigen Erkrankungsziffer eine ganz erhebliche Letalität zu verzeichnen.

\section{Behandlung}

Sie ist rein symptomatisch und erstreckt sich hauptsächlich auf Bekämpfung der Schmerzen, des Erbrechens und der Dehydration, Ersatz der Elektrolyte und der Blutverluste. Bei hämorrhagischen Komplikationen sind Vitamin K- und Eisendarreichung sowie Gesamtblutoder Plasmatransfusionen angezeigt. 


\section{Immunbiologie}

Im Verlauf der Infektion entstehen KB-AK, HAH-AK und N-AK. Aus den immunologischen Untersuchungen geht deutlich hervor, daß das Kyasanurwald-Fieber zum Komplex der REFSE gehört, obwohl der encephalitogene Charakter des Virus fehlt. KBR und NR mit dem Kyasanurwald-Virus und Affenimmunseren gegen die REFSE zeigten eine enge antigene Verwandtschaft dieser beiden Viren. Auch Mäuseimmunserum ergab ein KB mit hohen Titern mit dem Kyasanurwald-Virus. Umgekehrt reagierten auch Kyasanurwald-Fieber-Rekonvaleszentenseren sehr stark mit dem Virus der REFSE.

NR und KBR mit Kyasanurwald-Fiebervirus und Gelbfieberimmunseren und umgekehrt mit Gelbfiebervirus (17 D) und Kyasanurwald-Fieber-Rekonvaleszentenseren ergaben keine nähere Verwandtschaft dieser beiden Viren.

Die Zellkultur ist gut zur NR geeignet, wie aus Versuchen mit Hamsterantiseren hervorgeht. Zwischen der Zellkultur-NR und der Mäuseschutzprobe bestand gute Übereinstimmung (s. auch Liвiкova, 1961). Es wurde nicht nur die Infektiosität, sondern auch das HA-Vermögen des Virus neutralisiert, so daß die Hämadsorptionsreaktion negativ blieb. Auf diese Weise ist also eine Hämadsorptionshemmung möglich (BUCKLEY, 1959).

\section{Prophylaxe}

Über die Möglichkeit einer erfolgreichen Bekämpfung des Kyasanurwald-Fiebers liegen offenbar noch keine Erfahrungen vor. Bei den recht komplex erscheinenden Übertragungsund Ausbreitungsweisen dürfte sie sich schwierig gestalten. Schon die Zeckenbekämpfung ist bei den vielen Wirtsarten in der Wildnis, die sich vom kleinen Säugetier über den Affen bis zum Vogel erstrecken, ein praktisch unlösbares Problem. Das gleiche gilt für alle Ausrottungsversuche unter den im Walde wild lebenden Tieren, unter denen die verschiedenen möglichen Infektketten ebenfalls noch unbekannt sind.

Da die Zeckenbekämpfung mit chemischen Mitteln wegen der großen Räume schwierig ist, sollte nach Pandit (1960) eine Verringerung der Virusträger-Mensch-Kontakte im Vordergrund der Prophylaxe stehen.

Nachdem im Mäuseversuch festgestellt worden war, daß mit REFSE-Impfstoff dieselbe immunisierende Wirkung wie mit einem Kysanurwald-Fieber-Impfstoff erzielt wird, wurde ein solcher auch zur Impfung von Menschen verwandt. Der REFSE-Impfstoff hatte aber keine immunisierende Wirkung gegen das Kyasanurwald-Fieber, denn die Erkrankungshäufigkeit blieb in der geimpften und ungeimpften Bevölkerung etwa die gleiche. Es wurden auch keine KB-AK oder HAH-AK gegen Kyasanurwald-Virus gefunden (PANDIT, 1960; ANIKER u. a., 1962; Pavari u. a., 1962; Shah u. a., 1962).

\section{VI. Hämorrhagische Fieber}

Menschliche Viruskrankheiten, die mit spontanen Blutungen einhergehen, sind in verschiedenen Gegenden der Welt weit verbreitet. Verschiedene immunologisch selbständige Viren sind als Erreger dieser hämorrhagischen Fieber erkannt worden (s. auch PANDIT, 1960). Die zu den Arbor-Viren gehörenden Erreger können nicht in eine Gruppe zusammengefaßt werden. In die Arbor-Gruppe B lassen sich das Omsker und das argentinische hämorrhagische Fieber einordnen (Parodi u. a., 1959, 1960).

Das Omsker hämorrhagische Fieber wurde erstmalig von Chumakov u. a. (1947, zit. Theiler und Casals, 1959) beschrieben. Es wird im allgemeinen durch Zecken übertragen. Konstantinov u. a. (1961) weisen auf Fälle hin, die nicht durch Zeckenbiß, sondern durch Kontakt mit sterbenden Nagern zustande gekommen sein sollen.

In der Provinz Omsk wurde eine Epizootie unter Bisamratten beobachtet, die durch das Virus des Omsker hämorrhagischen Fiebers hervorgerufen worden war (Alinov u. a., 1961). 
Wasserratten ließen sich experimentell infizieren. Sie entwickelten Virämie und Immunität. Die Übertragung des Virus in der Natur von Wasserratten auf Bisamratten war durch beide Tierarten gemeinsame Ektoparasiten möglich, und zwar durch die Gamasiden-Milben Haemogamasus glasgoni und Hg.ambulans. Alinov u. a. konnten die Infektion von Bisamratten, welche Omsker Fieber hatten, auf gesunde Tiere mit diesen Gamasiden, die zuvor an ersteren gefüttert worden waren, übertragen. Demnach müssen auch Milben als natürliche Virusüberträger angesehen werden.

Das Virus erzeugt bei Rhesus-Affen nach i.p. Infektion Fieber und Immunität. Es vermehrt sich in Albinomäusen, die an einer tödlichen Encephalitis mit nur geringfügiger Beteiligung anderer Organe erkranken. Außerdem ist es für Katzen pathogen.

Eine Züchtung des Virus im embryonierten Ei ist möglich.

Das Virus passiert Berkefeld-V- und N-, Chamberland $\mathrm{L}_{3}$ - und Seitz-Filter. In getrocknetem Zustand ist das Virus mindestens 2 Jahre haltbar und glycerinresistent (s. auch MüLlerDietz, 1957).

Beim Menschen nimmt die Krankheit häufig einen diphasischen Verlauf. In der zweiten Phase tritt erneut Fieber auf mit Wiederholung der Symptome der ersten Phase ohne Beteiligung des ZNS. Die Krankheit beginnt plötzlich mit Fieber, Kopfschmerzen und gastrointestinalen Erscheinungen. Nasenbluten, Blutbrechen und Uterusblutungen sind gewöhnlich, aber selten profus. Charakteristisch und diagnostisch wichtig sind die hämorrhagischen Injektionen oder das Enanthem des Gaumens. Der lymphatische Apparat ist meist beteiligt, Meningismus nicht ungewöhnlich, aber eine echte Meningitis fehlt. Man findet stärkere Leukopenie und Thrombozytose. Der Urin bleibt normal. Die Rekonvaleszenz dauert lange; es tritt aber vollständige Genesung ein mit Immunität. Genaue Angaben über die pathologischen Veränderungen liegen nicht vor. Nach GAJduser (1953) findet man große Hämorrhagien im Magendarmkanal und kleine Hämorrhagien überall verstreut. Die Hauptveränderung scheint die Beteiligung der Kapillaren zu sein (s. auch Olitsky und Clanke, 1959; Kapitel F IV).

Zwischen dem hämorrhagischen Fieber der Bukowina und dem Omsker Fieber besteht kreuzweise Immunität (GERMER, 1955).

Beim argentinischen hämorrhagischen Fieber, das seit 1958 in Buenos Aires beobachtet wurde, ist aus Patientenblut ein Virus isoliert worden (PARodi u. a., 1960), das von Mettler u. a. (1961) als »Junin-Virus» bezeichnet wird.

Der Erreger erwies sich als pathogen für Mäusesäuglinge und Meerschweinchen (PARodI u. a., 1958; Pirorski u. a., 1959).

Mettler u. a. (1961) züchteten das Virus serienweise in HeLa-Zellkulturen in einem Gemisch von wachstumsförderndem und Erhaltungs-Medium mit häufigem Mediumwechsel während der Periode der Virussynthese. Schon in der ersten Passage trat ein charakteristischer ZE auf, der auch noch in der 10. Passage vorhanden war. Die Spezifität des ZE wurde durch Behandlung der Kulturen mit fluorescierenden AK sowie durch die NR mit Seren von Tieren, die mit dem in Mäusesäuglingen gezüchteten Virus immunisiert worden waren, bewiesen. In den Zellkulturen wurde das Virus wie andere Arbor-Viren durch $\mathrm{Na}$ desoxycholat inaktiviert. Nach 8 Mäusepassagen ließ sich das Virus in 7 und 11 Tage embryonierten Hühnereiern durch einmalige Verimpfung in die Amnionhöhle und durch weitere Passagen auf der CAM, auf der es Veränderungen hervorrief, züchten. Im Ei wurde das Virus durch Rekonvaleszentenserum neutralisiert.

Parodi u. a. (1960) stellten eine antigene Verwandtschaft des Junin-Virus mit dem Virus der REFSE fest; Immunserum gegen letzteres neutralisierte auch das Junin-Virus.

\section{VII. Wesselsbron-Virusinfektion}

Das Wesselsbron-Virus wurde erstmalig von WeIss u. a. (1956) in Südafrika bei einem an einer Rifttalfieber-ähnlichen Krankheit eingegangenen Lamm aus Leber und Gehirn isoliert. Es führt zu Abort und Tod trächtiger Schafe mit hoher Letalität der Lämmer. 
In den Lebern der gestorbenen Mutterschafe und Lämmer findet man degenerative Veränderungen (s. auch Le Roux 1959). Ein weiterer Virusstamm wurde in Natal aus menschlichem Blut und Mücken von SмттнвuRN u. a. (1957) isoliert.

Koкernot u. a. (1960b) gelang die Isolierung zahlreicher Stämme während einer Epizootie unter den Schafen des Distrikts Middelburg (Kapprovinz).

Aedes circumluteolus, A.caballus und Taeniorhynchus uniformis sind in Südafrika natürlich infiziert gefunden worden (Muspratt u. a., 1957).

KокеRNot u. a. (1960b) isolierten das Virus außerdem aus Aedes (Neomelaniconion) spp., Mansonia (Mansonioides) uniformis und Culex univittatus, die in Nord-Natal und der Kapprovinz gesammelt worden waren.

Menschen erkranken an einem vorübergehenden influenzaartigen Syndrom, wie aus Infektionen von 6 Laboratoriumsangestellten beim Arbeiten mit dem Virus hervorgeht (Shahan und Traum, 1958).

Besonders empfängliche Laboratoriumstiere sind Mäuse. Erwachsene Tiere sterben nach i.cer., Mäusesäuglinge nach i.cer. und i.p. Infektion. Der Virustiter im Gehirn erreicht 10-7,5. Experimentell infizierte trächtige Meerschweinchen und Kaninchen abortieren; ihre Jungen sterben. Nichtträchtige Meerschweinchen, Kaninchen und Cercopithecus-Affen erwerben nach einer stumm bleibenden Infektion Immunität. Nichtträchtige Rinder, Pferde und Schweine erkranken leicht fieberhaft und werden immun.

Porterfield (1959a) konnte in Einschichtzellkulturen von Hühnerembryofibroblasten nach Dulbecco (1952), die mit Agar überschichtet waren, einen ZE des Wesselsbron-Virus mit Plaquebildung nach 2-3 Tagen feststellen.

Das Virus vermehrt sich gut im embryonierten Hühnerei.

Es ist pantrop, hat aber einen ausgesprochenen Tropismus für Nerven- und Embryogewebe.

Die Größe des Virus wird auf etwa $30 \mathrm{~m} \mu$ geschätzt (WeIss u. a., 1956).

Infektiöses Mäusegehirn enthält ein Hämagglutinin.

Nach den Virus- und AK-Befunden in Mücken und Tieren (Rinder, Schafe, Ziegen) scheint die Infektion in der Südafrikanischen Union weitverbreitet zu sein (s. auch КокеRNoт u. a., 1961b). Auch bei Menschen wurden AK in dem untersuchten Gebiet von Nordost-Natal häufig angetroffen.

Die NR und KBR zeigten, daß das Wesselsbron-Virus antigen von dem Rifttalfieber zu unterscheiden ist. Die Krankheit tritt daher auch bei Mutterschafen auf, die gegen Rifttalfieber geimpft sind.

\section{VIII. Uganda - S-Virus}

Das Uganda-S-Virus wurde von Dick und Haddow (1952) aus Aedes-Mücken in Uganda isoliert. Es gehört zur B-Gruppe der CAsalsschen Einteilung der Arbor-Viren. Menschliche Erkrankungen sind noch nicht bekannt geworden. N-AK wurden jedoch im Blut von Menschen aus verschiedenen Gegenden der Welt nachgewiesen. Nach OLITsKy und Clarke (1959) soll das sog. Makonde-Virus mit dem Uganda-S-Virus identisch sein (s. auch Ross, 1956; Spence und Thomas, 1959). Das SAH 336-Virus, das von einem Menschen in Tongaland isoliert wurde (SmithbuRn u. a., 1959), ist mit dem Uganda-SVirus verwandt (s. auch McIntosh, 1961).

Das Virus läßt sich i.cer. auf erwachsene Mäuse übertragen, die an einer tödlichen Encephalitis erkranken. Es scheint sich nur im Gehirn zu vermehren, also neurotrop für Mäuse zu sein. Mäusesäuglinge bekommen sowohl nach i.cer. als auch i.p. Infektion eine Encephalitis. Bei fortlaufender Passage findet eine zunehmende Virusvermehrung statt, so daß Titer von $10^{-7}$ bis $10^{-8}$ erreicht werden (Dick und Haddow, 1952). Nach SmithbuRN (1952a, b) zeigte das Virus der 19. Mäusepassage nach i.cer. Infektion die höchste, nach i.n. Infektion eine geringere und nach i.p. und s.c. Infektionen überhaupt keine Pathogenität. Mäuse erkranken 
nach rektaler Infektion an ähnlichen Erscheinungen wie nach i.cer. Infektion (REAGAN u. a., 1954 e). Hamster können nach i.cer. Infektion an einer tödlichen Encephalitis erkranken (KERR, 1952; Reagan u. a., 1954c). Baumwollratten, Meerschweinchen und verschiedene Affenarten scheinen für eine experimentelle Infektion unempfänglich zu sein (Dick und HadDow, 1952). Verschiedene experimentell infizierte Nagetierarten bekamen Virämie und bildeten zum Teil AK (McIntosh, 1961).

Das Uganda-S-Virus wurde von Dick und Haddow (1952) aus einem Pool von 65 Baummücken (Aedes longipalpis Grünb., A.ingrami Edw. und A.natronicus Edw.) isoliert, ohne daß ermittelt wurde, in welcher dieser Mückenarten sich das Virus befand. Experimentell ließ sich A. aegypti infizieren, in welchem sich das Virus auch vermehrte (Whitman, zit. Olitsky und Clarke, 1959). Es konnte in der Hämolymphe schon 10 Min nach Fütterung der Mücke an infektiösem Mäuseblut nachgewiesen werden (Boorman, 1960), und zwar 2-92 Tage p.i.

Nach Moore (1957) sind Vermehrung und ZE in verschiedenen Zellkulturarten nur schlecht. Porterfield (1959) fand, daß das Virus in Einschichtzellkulturen von Hühnerembryofibroblasten, die mit Agar überschichtet sind, ähnliche Plaques wie das Gelbfieber bildet, und zwar schon nach 2-3tägiger Bebrütung.

Das im Mäusegehirn adaptierte Virus läßt sich im embryonierten Hühnerei züchten. Nach Infektion 6 Tage bebrüteter Eier in den Dottersack wurde im allgemeinen eine höhere Viruskonzentration im Gehirn als im Körper des Embryos erhalten. Nach 6 Eipassagen infizierte das Virus die Embryonen in höheren Verdünnungen als wie sie für eine tödliche Mäuseinfektion erforderlich waren. Die Embryonen, welche die Infektion gewöhnlich überlebten, wiesen keine besonderen pathologischen Veränderungen auf: Hyperämie und kleine Nadelstichblutungen vorwiegend im Gehirn. Nach Infektion in den Amnionsack 11 tägiger Embryonen wurden die maximalen Virustiter im Gehirn und Körper des Embryos zwischen dem 3. und 5. Tage erreicht. Nach Infektion in den Allantoissack wurde Virus im Gehirn und in der Allantoisflüssigkeit erst nach 5 Tagen nachweisbar. Infektion der CAM erzeugte Verdickung und diffuse graue Trübung derselben. Sie ergab aber nur Titer von 10-3 gegen Gehirntiter von $10^{-5,5}$ bis 10-7,0 nach Infektion in den Dotter- oder Amnionsack (TAYLOR, 1952). Auch im Hühnerembryo scheint das Uganda-S-Virus vorwiegend neurotrop zu sein.

Aus Ultrafiltrationsversuchen von SmithBuRn und BUGHER (1953) geht eine Teilchengröße des Virus von 15-22 mu hervor, womit es zu den kleinsten Viren der Arbor-Gruppe gehört.

Das Virus besitzt ein Hämagglutinin, das durch Aceton-Ätherextraktion infektiöser Mäusegehirne (CaSals und Brown, 1954) oder durch Züchtung des Virus in menschlichen Amnionzellkulturen (SALMineN, 1962b, c) gewonnen wird. Es agglutiniert Hühnererythrozyten bei $4^{\circ}$ und $22^{\circ} \mathrm{C}$ in einem $\mathrm{p}_{\mathrm{H}}$ von 7,0 und - sogar noch stärker - Gänseblutzellen (Porterfield, 1957).

Obwohl bei Menschen noch keine manifesten Erkrankungen beobachtet worden sind, scheint es Gebiete zu geben, in denen die Bevölkerung stark infiziert ist. So fanden Dick und HADDow (1952) in serologischen Untersuchungen bei Schulkindern in Südnigeria einen hohen Prozentsatz mit N-AK für Uganda-S-Virus. MacNamara $(1953 \mathrm{~b}, \mathrm{c})$ bestätigte dies, indem er im i.cer. Mäuseschutzversuch bei $88 \%$ der Kinder AK fand; $72 \%$ der Seren schützten Mäuse gegen 100 oder mehr Mäuse- $\mathrm{LD}_{50}$ und weitere 16\% gegen 50-100 LD. Gleichzeitig wurden bei $63 \%$ dieser Kinder Gelbfieber-AK nachgewiesen, obwohl in diesem Gebiet bis dahin Gelbfiebererkrankungen noch nicht bekannt waren. In Brasilien (Amazonas-Tal) kommt das Uganda-S-Virus ebenfalls vor: bei 2,1\% der Bevölkerung wurden AK angetroffen (Causey und Theiler, 1958; s. auch Smithburn, 1952 b; Smithburn u. a., 1954b). Auch in anderen Gegenden der Erde wurden ziemlich häufig N-AK in menschlichen Seren gefunden. so in Tanganyika (Afrika), Indien, Malaya und Borneo (Sмiтнвurn u. a., $1954 \mathrm{a}, \mathrm{b}$ ).

Bei einem Rhesus-Affen wurde nach Gelbfieberinfektion ein ausgesprochener Anstieg der N-AK gegen Uganda-S-Virus festgestellt. Ein ähnliches Verhalten scheint beim Menschen zu bestehen. Bei 6 Gelbfieberkranken wurde ein erheblicher Anstieg der N-AK-Titer auch für Uganda-S-Virus beobachtet (Macnamara, 1953b): Smitburn (1952b) fand aber in kreuzweisen Affenschutzversuchen (NR) mit verschiedenen Antiseren keine gemeinsamen Antigene des Uganda-S-Virus mit Gelbfiebervirus oder anderen Arbor-Viren. Immunität gegen Uganda-S-Virus schützte Affen auch nicht gegen Gelbfieber. 
Uganda - S-Antigen ergab nur mit homologem Antiserum eine KBR, nicht aber mit Gelbfieberantiserum. Umgekehrt reagierte Gelbfieberantigen nicht mit Uganda-S-Antiserum (KERR, 1952). Eine Kreuz-KBR fand auch mit zahlreichen anderen Arbor-Viren nicht statt.

Nach CASALS und Brown (1954) wird das gereinigte Hämagglutinin nur durch spezifisches Antiserum gehemmt (s. auch Clarke und Casals, 1958).

\section{IX. Ntaya-Virus}

Das Ntaya-Virus ist aus einem Pool in Uganda gefangener Mücken isoliert worden (Smithburn und Haddow, 1951).

Mäuse (Schweizer Stamm) lassen sich i.cer. infizieren; sie erkranken an Lähmungen der Extremitäten und sterben 48 St. nach deren Beginn. Das Gehirn-adaptierte Virus erreicht einen Titer von $10^{-6}$. REAGAN u. a. (1954c) fanden syrische Hamster sehr empfänglich. Für Rhesus-Affen scheint das Virus nicht pathogen zu sein; nur nach wiederholter Infektion mit großen Virusdosen kommt es zur Bildung nachweisbarer AK-Mengen. ReAGAN u. a. (1953b) übertrugen das Virus i.cer., i.p., i.m., i.n., intrakardial, intralingual, intraokulär und rektal auf 1 tägige Küken.

In Kulturen verschiedener Zellarten findet Virusvermehrung statt. In menschlichen Fibroblastenkulturen kommt es zu einem ZE (Moore, 1957).

Das Virus läßt sich im embryonierten Hühnerei nach Dotter- und Amnionsackbeimpfung züchten. Die Embryonen werden tödlich infiziert (TAYLOR, 1952).

Smithburn und Bugher (1953) fanden bei Filtration durch Gradocolmembranen eine Teilchengröße des Virus von $80-120 \mathrm{~m} \mu$; es scheint also erheblich größer als die anderen Viren der Arbor-Virusgruppe B zu sein.

CASALS und BROWN (1954) wiesen im infizierten Mäusesäuglingsgehirn ein Hämagglutinin nach.

Das Virus vermehrt sich in künstlich infizierten Mücken (Whiтman, zit. Olitsky und Clarke, 1959).

$N-A K$ sind in den Seren von Menschen aus verschiedenen Teilen der Welt, zum Teil in hohem Prozentsatz, nachgewiesen worden. Smithburn u. a. (1954b) fanden in Ägypten 34,5\% der untersuchten Seren AK-haltig. In keinem Fall konnte jedoch hier das Ntaya-Virus isoliert werden (TAYLOR u. a., 1956). Erschwerend bei der Differenzierung der serologischen Befunde kommt hinzu, daß die Ntaya-positiven Seren mindestens noch ein anderes B-Virus neutralisieren (in Ägypten WN-Virus). Umgekehrt neutralisieren Rekonvaleszentenseren von WN-Fieber auch das Ntaya-Virus. Eine immunologische Verwandtschaft scheint außerdem mit dem Dengue- und dem JE-Virus zu bestehen. Olitsky und Clarke (1959) sind der Meinung, daß bisher noch kein endgültiger Beweis dafür geführt ist, daß das Ntaya-Virus in der Tat Menschen zu infizieren vermag.

\section{X. Spondweni-Virus}

Das Spondweni-Virus wurde erstmalig von KoкeRnot u. a. (1957e) in Natal aus der Mücke Taeniorhynchus (Mansonioides) uniformis (Theobald) isoliert. McIntosh u. a. (1961a) gelang es, in Tongaland (Südafrika) 9 weitere Virusstämme aus Mückenweibchen zu isolieren: 4 Stämme von Aedes (Neomelaniconion) circumluteolus (Theobald), 3 Stämme von Mansonia (Mansonioides) africana (Theobald) und je ein Stamm von A. cummensi spp. mediopunctatus (Theobald) und Eretmapodites silvestris (Ingram und De Meillon). Anschließend wiesen McIntosh u. a. (1962) auch in einem Pool von Aedes ochlerotatus fryeri und/oder Aedes (Aedimorphus) fowleri-Weibchen in Lumbo, Mozambique, das Spondweni-Virus nach. 
2 Tage alte Mäuse konnten i.cer. infiziert werden (s. auch KoкеRnot u. a., 1957c); sie erkrankten und starben nach 6-11 Tagen. Adaptiertes Virus tötete die Mäusesäuglinge nach 4-5 Tagen. Das Virus ließ sich weiter i.cer. auf Mäusesäuglingen züchten. Auch erwachsene Mäuse starben 5-7 Tage nach i.cer. Infektion mit dem adaptierten Virus.

Affen (Cercopithecus aethiops), Meerschweinchen und Kaninchen erkrankten nicht, bildeten aber AK.

Beim Arbeiten mit dem Spondweni-Virus kam es zu 2 Laboratoriumsinfektionen: Diese verliefen mit Fieber-, Kopf- und Allgemeinschmerzen, Schwindel, Schwäche, Übelkeit und leichtem Nasenbluten. Genesung erfolgte nach einigen Tagen. Bei einem Patienten gelang der Virusnachweis im Blut durch Verimpfung auf kleine Mäuse. Die Identität des Isolats mit dem Spondweni-Virus wurde durch die NR bewiesen. Die Patienten entwickelten außerdem spezifische N-AK, HAH-AK und KB-AK (McIntosh u. a., 1961a).

Das Virus war durch Seitz-Filter filtrierbar.

Durch Zucker-Aceton-Extraktion von infizierten Mäusegehirnen wurde ein kräftiges Hämagglutinin erhalten (McINTosh u. a., 1962).

Immunologisch ist das Spondweni-Virus ein Erreger der Arbor-Virusgruppe B. In den Seren von Menschen, die in der Nähe des Gebietes mit den infizierten Mücken lebten, wurden N-AK nachgewiesen (КокеRNot u. a., 1957 c). Aus serologischen Reihen-Untersuchungen an Menschen geht hervor, daß das Spondweni-Virus wahrscheinlich in Afrika weit verbreitet ist (KOKERNOT u. a., 1960a).

Der natürliche Wirbeltierwirt ist noch nicht gefunden worden.

Weitere Viren der Gruppe B, die bisher isoliert worden sind, sind nach CASALS (1961b) das Modoc-Virus in Kalifornien (USA), das AMM 1775-Virus in Malaya, das zentraleuropäische Zeckenfieber- oder durch Milch übertragene diphasische Meningoencephalitis-Virus (Rußland, Balkan, Schweden) sowie das Puten-Meningoencephalitis-Virus in Israel.

\section{Arbor-Viren, Gruppe C}

In den Regenwäldern des Amazonas-Stromes sind in der Nähe von Belem (Para) von Causey (1955, 1957, zit. Theiler und Casals, 1959) Virusstämme aus dem Blut fieberhaft erkrankter Menschen, aus dem Blut von Schildwacht-Affen ${ }^{1}$ ) und aus in der Wildnis gefangenen Mücken isoliert worden, die mit keinem der bekannten Arbor-Viren serologisch verwandt waren. Bis 1959 kannte man 5 Stämme: "Apeú", "Caraparu», "Marituba», »Murutuku» und "Oriboka». Sноре и. a. (1961) fügten als 6. Prototyp das "Itaqui»-Virus hinzu, das allerdings noch nicht in Mücken nachgewiesen wurde. Es wurde erstmalig aus dem Blut eines Affen, der ebenfalls in der Gegend von Belem ausgesetzt worden war, isoliert. Seit 1956 wurde das Virus 22 mal im Blut isoliert, und zwar einmal von einem Menschen, sonst von ausgesetzten Affen, Mäusen und anderen wilden Nagern, darunter einer wilden Ratte (Proechimys). Die Isolierung des Virus aus der wilden Waldratte weist darauf hin, daß kleine Waldnagetiere als Virusquellen für Arthropoden in Frage kommen, die dann auch den Menschen infizieren können.

CASAlS (1957) faßte diese Viren als Gruppe C der Arbor-Viren zusammen (s. auch CaSals, 1958; Theiler und Casals, 1959; Casals und Whitman, 1961; Causey u. a., 1961; Shope u. a., 1961; Tab. 39).

1) Unter Schildwacht-Tieren ("sentinel animals") versteht man Locktiere (Affen, Mäuse, Vögel u. a. m.), die in einem Käfig in einem Gebiet ausgesetzt werden, um dort von Insekten, die etwaige Virusträger sind, gebissen und infiziert zu werden. Auf diese Weise ist es verhältnismäßig leicht möglich, durch Insekten übertragbare Viren und deren Überträger zu ermitteln sowie das Vorkommen bestimmter Virusinfektionen bei Menschen und Tieren festzustellen, ohne daß bei ihnen Erkrankungen bekannt geworden sind. 


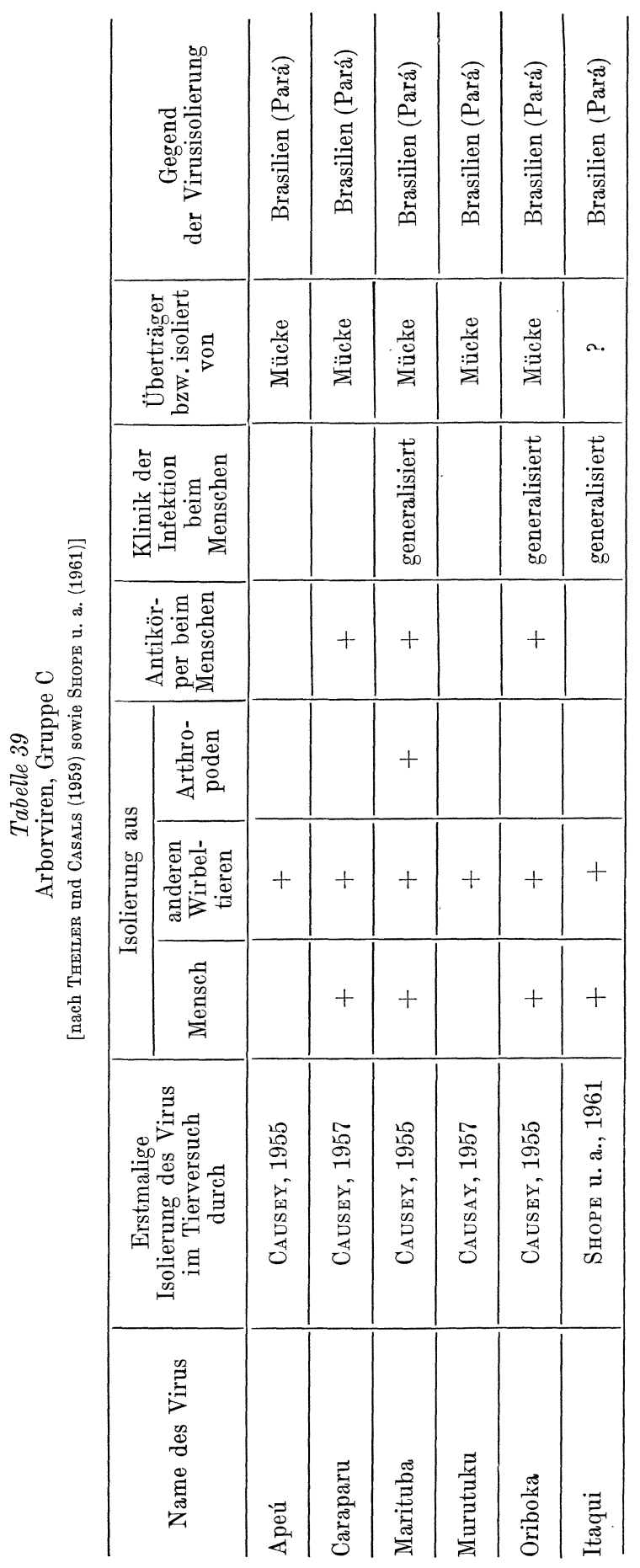


Die C-Viren vermehren sich in A. aegypti-Mücken. Diese lassen sich durch eine Blutmahlzeit an experimentell infizierten Tieren infizierten; sie vermögen die Infektion später durch Biß weiter auf andere Tiere zu übertragen (Whitman, zit. Theiler und Clarke, 1959).

Die Viren sind hochpathogen für Mäusesäuglinge nach i.cer. und parenteraler Infektion, dagegen weniger pathogen für erwachsene Mäuse. Im Blut und in der Leber der Mäusesäuglinge wurden innerhalb von 24 St. p. i. Virustiter von $10^{-8}$ und mehr gefunden, während sie im Gehirn meist nur $10^{-5}$ bis $10^{-7}$ betrugen (Casals und Whitman, 1961).

Das Oriboka-Virus tötet neugeborene Ratten nach i.cer. Injektion (BАBCock u. a., 1961).

Buckley und Shope (1961) züchteten das Apeú-Virus (An 848), das Caraparu-Virus (An 3994), das Marituba-Virus (An 15), das Murutuku-Virus (An 974) und das OribokaVirus (An 17) in HeLa-Zellkulturen (Originalstamm und verschiedene Klone) sowie in menschlichen Embryodarmkulturen. Vor der Infektion wurde das Vermehrungsmedium, das aus Hanks'scher Lösung (65\%), Tryptosephosphatbouillon, Difco (15\%) und Menschen-Normalserumgemisch (20\%), pH 7,4, bestand, durch ein Erhaltungsmedium ersetzt: EAGLE's Medium $(97 \%)$ und Kälberserum (3\%), pH 6,2-6,4. Zur Viruszüchtung wurde das $\mathrm{pH}$ durch Zusatz von Na bicarbonat oder Tris (hydromethylaminomethan) auf 7,2 erhöht. Das Erhaltungsmedium wurde gewöhnlich 3,7-10 Tage p. i. erneuert. Jedes Virus erzeugte einen deutlichen ZE, wenn die Zellen in einem wachstumsfördernden Medium (s. oben) und während der Periode der Virussynthese in EAGLE's Medium gezüchtet wurden. Das Oriboka-Virus wurde durch 10 Passagen gezüchtet. Der Infektiositätstiter der flüssigen Kulturpassage betrug 5,9-6,5 Mäuse- $\mathrm{LD}_{50} / \mathrm{ml}$, der ZE-Titer $\mathrm{ZE}_{50} / \mathrm{ml} 6,3-7$.

Infizierte Hühnerembryonen starben nicht.

Die Viren ließen sich in Gehirnemulsionen und Serum im $\mathrm{CO}_{2}$-Tiefkühler aufbewahren.

Aus den virushaltigen Seren der Mäusesäuglinge wurden durch Aceton- ̈̈ther-Extraktion Hämagglutinine gewonnen. Aus den Mäuselebern ließen sich $K B$-Antigene herstellen.

Wie häufig Infektionen bei Menschen sind, ist noch unbekannt. SHоре u. a. (1961) sahen eine menschliche Infektion mit dem Itaqui-Virus, die einen Waldarbeiter im Oriboka-Wald, ebenfalls in der Nähe von Bélem, betraf. Dieser war an Kopfschmerzen, Fieber, Lichtscheu, Schwindel, epigastrischem Unbehagen, mildem Schnupfen und Husten erkrankt. Serologische Untersuchungen im Amazonas-Tal haben aber ergeben, daß die Oriboka-Infektion unter den Bewohnern dieses Gebietes ziemlich häufig sein dürfte. Die HAHR mit Menschenseren aus Afrika ergab, daß C-Virusinfektionen wahrscheinlich auch in diesem Kontinent vorkommen (Theiler und Casals, 1959).

\section{Tabelle $39 a$}

Gruppenimmunitätsreaktionen (HAH) bei Meerschweinchen, die nacheinander mit 2 verschiedenen oder 2 gleichen Viren der Gruppe C infiziert worden waren (Nach CASALS, 1961 b)

\begin{tabular}{l|c|c|c|c}
\hline \multirow{2}{*}{$\begin{array}{c}\text { Antigen } \\
\text { (4 Einheiten) }\end{array}$} & \multicolumn{3}{|c}{ Titer der Meerschweinchen nach Infektion mit } \\
& $\begin{array}{c}\text { Caraparu } \\
\text { Ms 1/Ms 2 }\end{array}$ & $\begin{array}{c}\text { Caraparu + Oriboka } \\
\text { Ms 1 }\end{array}$ & $\begin{array}{c}\text { Caraparu + Caraparu } \\
\text { Ms 2 }\end{array}$ & Oriboka \\
\hline Oriboka & $20 / 20$ & 2560 & 20 & 640 \\
Caraparu & $640 / 1280$ & 5120 & 10240 & 0 \\
Apeú & $320 / 640$ & 2560 & 5120 & 0 \\
Marituba & $40 / 80$ & 640 & 320 & 0 \\
Murutuku & $40 / 80$ & 640 & 160 & 0 \\
\hline
\end{tabular}

$0=$ keine Reaktion mit der Verdünnung 1:10 
Mit Hilfe der HAHR und NR ist eine Differenzierung der verschiedenen C-Viren möglich. Die N-AK können im Mäuseschutzversuch nachgewiesen werden, für den nach BucKLEY und Sноре (1961) am besten Säuglinge genommen werden. Die NR in der Gewebekultur vermag den Mäuseschutzversuch und auch die HAHR für immunologische Untersuchungen zu ersetzen.

Nach Casals und Whitman (1961) sind die Murutuku- und Maritoba-Viren einerseits und die Apeu- und Caraparu-Viren andererseits eng mit einander verwandt, sie sind aber trotzdem leicht von einander sowie vom Oriboka-Virus zu unterscheiden (s. auch Tab. 39 a).

Casals und Whitman (1961) stellten mit der KBR fest, daß zwischen 4 der Prototypen Oriboka, Murutuku, Marituba und Apeú breite Kreuzreaktionen bestehen. Nur der CaraparuStamm An 3994 ergab keine Kreuz-KBR (s. auch BuckLey und Sноре, 1961), während der Caraparu-Stamm H 5546 sehr stark mit den anderen Prototypen, nicht aber mit An 3994 reagierte. Sноре u. a. (1961) fanden außerdem, daß der Itaqui-Stamm ein gemeinsames KB-Antigen mit dem Caraparu-Virus An 3994 hatte, dagegen keine signifikante Kreuzreaktion mit den anderen Prototypen ergab.

Die serologischen Beziehungen der Gruppe C-Viren gehen aus dem folgenden Schema (Abb. 40a) hervor.

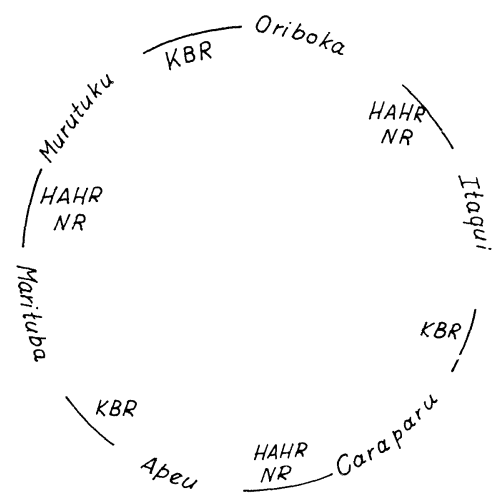

Abb. 40 a Serologische Beziehungen der Gruppe C-Viren

(nach Shope und Causey, 1962)

Von 200 untersuchten C-Virusstämmen reagierten 199 in der HAHR und KBR wie einer der 6 Prototypen. Durch diese serologische Verwandtschaft scheint es möglich zu sein, neue C-Virusstämme schnell zu identifizieren.

\section{E. Arbor-Viren, Gruppe D (Bunyamwera-Gruppe)}

Casals und Whitman (1960) konnten in immunologischen Kreuzreaktionen mit den noch nicht klassifizierten Viren (s. später) eine Gruppe zusammenstellen, die in sich wiederum besonders antigen verwandte Viren umfaßt. Sie nannten diese Gruppe nach ihrem Hauptvertreter Bunyamwera-Gruppe. 
Insgesamt gibt es zur Zeit 10 Virustypen: Bunyamwera-, Wyeomyia- und Simbu-Viren, die zuerst isoliert worden sind, ferner Oropouche-, Cache Valley-, Kairi-, Germiston'- und IleshaViren, die einzeln behandelt werden sollen. Außerdem sind noch folgende Viren, die zu dieser Gruppe gehören, isoliert worden: Chittor-Virus, das in Indien und Malaya gefunden worden ist, und das Guaroa-Virus, das in Columbien und Brasilien (Belem) isoliert worden ist (CAsals, 1961b). Die Gruppe dürfte sogar mindestens 18-20 Viren umfassen, die wiederum mehrere Untergruppen oder Komplexe bilden, was besonders beim Wyeomyia-Virus der Fall zu sein scheint. Mit Ausnahme der Wyeomyia- und Kairi-Viren haben alle diese Viren ein Hämagglutinin. Alle Viren, mit Ausnahme des Ilesha-Virus, sind aus Mücken isoliert worden, in denen sie sich auch vermehren. Aus Untersuchungen von Whitman (zit. Casals, 1961b) geht hervor, daß auch das California-Encephalitis-Virus mit der Bunyamwera-Gruppe verwandt sein könnte. CASALS und Whitman (1960) halten die i.cer. N-AKMäuseschutzprobe zum Nachweis eines Virus dieser Gruppe für spezifischer als die i.p. N-AK-Schutzprobe.

\section{E I, Bunyamwera-Virus}

Smithburn u. a. (1946) isolierten in einem unbewohnten Gebiet des Semlikiwaldes (WestUganda) aus einem Haufen von über 4000 Aedes aegypti ein Virus durch Verimpfung des Filtrates einer Mückensuspension auf einen Rhesus-Affen. Das Virus wurde nach seinem Fundort "Bunyamwera-Virus" genannt. KокеRnot u. a. (1957a) gewannen weitere Virusstämme aus A.circumluteolus, welche in Tongaland (Südafrika) gesammelt worden waren (s. auch Smithburn und De Meillon, 1957).

KoкeRnot u. a. (1958) isolierten das Virus auch aus dem Blut eines jungen Mannes, der beim Mückensammeln beschäftigt, aber nicht erkrankt war. In Aedes-Mücken wurde dasselbe Virus nachgewiesen.

Southam und Moore (1951) injizierten das Virus i.v. 4 Menschen mit inoperablen Tumoren. Von diesen erkrankte 1 Person (Leukämie) beinahe tödlich an einer schweren Encephalitis mit zurückbleibenden geistigen Schäden. Durch diesen Versuch scheint der Neurotropismus des Virus für den Menschen bewiesen zu sein. Bei der natürlichen Infektion des Menschen wird mit einer Virämie, schwerer Encephalitis und Tod zu rechnen sein. Über die Klinik der natürlichen Infektion ist aber noch nichts bekannt.

Das auf Rhesus-Affen s.c. übertragene Mückenvirus führte mitunter zu einer tödlich verlaufenden Fiebererkrankung mit Virämie. Das Virus ließ sich von Affen auf Mäuse i.cer., i.n., s.c. und i.p. übertragen. I.cer. war eine passagenweise Züchtung möglich. Die Mäuse erkrankten an Übererregbarkeit, Krämpfen und Lähmungen. Bei Beginn der Symptome bestand Virämie. Die Milz enthielt mehr Virus als die anderen visceralen Organe. Die durchschnittliche Zeit bis zum Tod der Mäuse betrug in der 14. Gehirnpassage 6,5 Tage. Die i.cer. und i.p. infizierten Mäuse wiesen Schutzstoffe auf. Mäuse, die rektal infiziert wurden, bekamen ähnliche nervöse Symptome wie nach i.cer. Infektion (REAGAN u. a., 1954d). Die Mäusegehirne wiesen Hyperämie, Hämorrhagien und Nekrosen der Nervenzellen in den seitlichen Ventrikeln auf. Die Degeneration dieser Zellen betraf vor allem das Ammonshorn und die Basalganglien. Große Cortisondosen erhöhten die Empfänglichkeit der Mäuse für eine tödliche Infektion erheblich (Southam und BАвсоск, 1951). AP-Virus schützte Mäuse gegen kleine i.cer. Dosen des Bunyamwera-Virus und verlängerte die Lebenszeit bei größeren Dosen (SPeIR und Southam, 1960). ReaGan u. a. (1954e) fanden Hamster für i.cer., i.n., i.d., i.m., intralinguale, intraorale, rektale und intrakardiale Infektionen empfänglich. Kaninchen erkrankten offenbar nicht, erwarben aber AK (Sмiтнinurn u. a., 1946). Die Höhlenfledermaus (Myotis lucifugus) ließ sich auf verschiedenen Wegen infizieren und erkrankte an nervösen Erscheinungen (REAGan u. a. 1954b). Bei dem wilden Nager Mystromys erzeugte das Virus eine schwache Virämie.

Das Virus wirkte onkolytisch und wachstumhemmend auf 2 östrogene Mäusesarkome (Wagner, Ridway) (Koprowski und NorTon, 1950) sowie auf Mäuse- und Rattenascitestumoren (Koprowska und Koprowski, 1953; Love u. a., 1953; Koprowski, 1956; Goldie u. a., 1958). 
Die sehr schnell auftretenden ersten Veränderungen in den Ehrlichschen Asciteskarzinomzellen waren Randständigwerden des Chromatins und Parachromatins, Vergrößerung des Kerns und Bildung eines feinen Chromatinnetzes, das die geschrumpften oder in bis zu 10 Fragmente aufgeteilten Kernkörperchen enthielt. Das Parachromatin schien sich zu verdichten und vielleicht zu vermehren, um einen oder mehrere Einschlüsse zu bilden. Diese waren zytochemisch nicht von RNS-Proteineinschlüssen in degenerierenden Zellen nichtinfizierter Tumoren zu unterscheiden. Die Bildung der zahlreichen intranukleären RNS-Proteineinschlüsse schien auf einer Veränderung des RN-Stoffwechsels zu beruhen. Die Azidophilie schien auf proteingebundene Aminosäuren zurückzuführen zu sein. In den Einschlüssen war keine DNS mit der Feulgen-Reaktion, aber RNS mit Toluidinblaumolybdat nachweisbar. Nach Zerfall des Kerns gelangten die RNS-Proteineinschlüsse in das Zytoplasma. Im Zytoplasma der Zellen mit Kernveränderungen waren die neutralen Lipidtröpfchen vermehrt. Das Golgi-Lipid und die Mitochondrien schienen jedoch bis zum Zellzerfall unverändert zu sein (Love, 1957, 1959).

Die Züchtung des Bunyamwera-Virus gelang Baron u. a. (1961) sowie IsaAcs u. a. (1961b) in Hühnerfibroblastenkulturen in einem agarhaltigen Nährmedium. Nach TAYLOR (1952) ist auch eine Züchtung des Virus im embryonierten Ei möglich.

Clarke und Theiler (1955) stellten aus infizierten Mäusesäuglingsgehirnen ein Hämagglutinin für Hühnererythrozyten her. PoRTERField (1957) fand auch Gänseerythrozyten zur HA geeignet.

Das Virus ließ sich durch Berkefeld-V-, N- und W-Kerzen sowie Seitz-EK-Scheiben filtrieren. Seine Teilchengröße wird auf 75-100 m $\mu$ geschätzt. Es ließ sich durch Gefriertrocknung haltbar machen und in Glyzerin aufbewahren (Sмтtнuren u. a., 1946).

Nach Нгтснсоск und IsaAcs (1960) schützt Interferon, das bei influenzainfizierten Mäusen in der Lunge entsteht und ins Blut übertritt, nach i.p. Injektion Mäuse gegen eine Bunyamwera-Infektion. Interferon aus Hühnerembryo- oder Kaninchenzellkulturen ergab in mit Bunyamwera-Virus infizierten Hühnerembryo-Einschichtzellkulturen eine Hemmung der Plaquebildung seitens des Virus. Die Begrenzung der Hemmzonen war besonders scharf. Thr Durchmesser stand im umgekehrten Verhältnis zur Virusdosis, aber im direkten Verhältnis zur Interferonkonzentration. Das Interferon hatte in einer Verdünnung von 1:125 keine Hemmwirkung mehr (Porterfield, 1959 d).

Als natürliche Virusreservoire können Affen angenommen werden, nachdem bereits Smithburn u. a. (1946) N-AK bei einem Colobus-Affen gefunden hatten. Die normale Übertragung dürfte durch Aedes-Mücken erfolgen.

In Uganda wurde der Anteil der Bevölkerung mit N-AK auf etwa 10\% (28 von 298 gesunden Personen) ermittelt. Aber auch in Südafrika wurden bei einem großen Teil der Bewohner sowie bei Tieren N-AK nachgewiesen (КокеRNot u. a., 1956, 1957a, 1958). AK sind ferner in der Bevölkerung von Nigeria und Tanganyika gefunden worden, so daß also auch die Bunyamwera-Infektion in Afrika weitverbreitet zu sein scheint. Dies geht auch aus serologischen Untersuchungen von КокекNот u. a. (1961b) mit Seren von Rindern, Ziegen und Schafen in Südafrika hervor.

Bunyamwera-Antiserum hemmte die HA des homologen Virus in der Verdünnung von 1: 1280, die HA des Germiston-Virus in der Verdünnung von 1:80, die HA des Ilesha-Virus in der Verdünnung von 1: 40 und die HA des Cache Valley-Virus ebenfalls in der Verdünnung von 1: 40 (Окимо, 1961). In der Kreuz-KBR reagierten die Bunyamwera- und Cache ValleyViren stark miteinander; die Kairi- und Wyeomyia-Viren zeigten dagegen nur geringfügige Kreuzreaktionen mit dem Bunyamwera-Virus (Casals und Whitman, 1960).

Durch Mäuseschutzversuche (NR) mit dem Bunyamwera-Virus und Antiseren gegen andere für Mäuse encephalotrope Arbor-Viren wurde festgestellt, daß ersteres mit den folgenden Viren nicht antigen verwandt zu sein scheint: Gelbfieber, Bwamba, WN, Semlikiwald, SLE, JE, EEE, WEE, Rifttal u. a. m.). Auch das von Smithburn u. a. (1946) im EntebeGelbfieber-Laboratorium isolierte »lot-Virus« ist nicht mit ihm verwandt.

Das Bunyamwera-Virus hat sich also in keine der Arbor-Gruppen einordnen lassen. 


\section{E II. Wyeomyia-Virus}

Bei Untersuchungen über das Dschungelgelbfieber in El Horizonte (Kolumbien) wurde von RocA-Garcia (1944) das »Wyeomyia-Virus« aus einer Gruppe von 160 Wyeomyia melanocephala-Mücken durch Verimpfung auf Mäusesäuglinge isoliert. Das Virus ist identisch mit dem Sabethine 1-Virus von Bugher u. a. (1944).

Junge Mäuse konnten i.cer. und i.n., Mäusesäuglinge auch s.c. passagenweise infiziert werden. Alle Tiere zeigten Lähmungen der hinteren Extremitäten. 2 Rhesus-Affen, die vorher für Gelbfieberversuche benutzt worden waren, zeigten weder Virus im Blut noch entwickelten sie AK. Auch bei Hamstern wurden weder Virus noch AK im Blut gefunden. Kaninchen blieben auch nach mehrmaligen Infektionen ohne AK.

Das Virus ließ sich weder in Gewebekulturen noch im embryonierten Ei passagenweise kultivieren.

Es war durch Berkefeld V-, N- und W- sowie Seitz-EK-Filter filtrierbar.

Eingefroren getrocknet hielt es sich mindestens 15 Monate; es konnte auch in $50 \%$ igem Glyzerin konserviert werden.

Bisher wurden weder bei Menschen noch Affen AK gefunden.

In der i.p. Mäuse-NR neutralisierte Wyeomyia-Antiserum sowohl das Bunyamwera- als auch das Kairi-Virus. In der Kreuz-KBR zeigten die Wyeomyia- und Kairi-Viren nur geringfügige Kreuzreaktionen untereinander (Casals und Whitman, 1960).

\section{E III. Simbu-Virus}

Weinbren u. a. (1957a) isolierten in Nord-Natal in der Nähe des Simbu-Sees aus Aedes (Banksinella) circumluteolus durch Verimpfung auf Mäuse das "Simbu-Virus». Dieses war für junge erwachsene Mäuse nach i.cer. Infektion und für Mäusesäuglinge nach jeder Infektionsart pathogen. Die Mäuse zeigten im Gehirn histopathologische Veränderungen. Das Virus erwies sich als hitze- und ätherempfindlich.

Nach experimenteller Infektion bildeten Kaninchen, Meerschweinchen und Affen (Cercopithecus aethiops) AK, ohne sichtbar zu erkranken. Verschiedene wilde Nagetiere (Mystromys, Arvicanthis, Saccostomus) sowie die Gerbillenart Tatera bekamen eine stärkere Virämie mit AK-Bildung, erkrankten aber nicht (McIntosh, 1961).

Weder bei Menschen noch bei Affen sind bisher in der Natur Virus oder AK angetroffen worden.

Das Virus ist antigen mit dem Bunyamwera-Virus verwandt.

\section{E IV. Oropouche-Virus}

Bei einem Köhler in Trinidad, der 3 Tage fieberhaft mit Rückenschmerzen und Husten erkrankt war, wurde in der akuten Phase aus dem Blut durch i.cer. Verimpfung von Serum auf 2 Tage alte sowie erwachsene Mäuse ein Virus isoliert, das nach dem Fundort "Oropouche-Virus" genannt wurde (Anderson u. a., 1961). Ein weiterer Virusstamm dieser Art wurde in einem Pool von Mansonia venezuelensis-Mücken nachgewiesen. In anderen in der Wildnis gefangenen Mückenarten konnte dagegen kein Virus festgestellt werden.

Das Oropouche-Virus ließ sich passagenweise in Mäusen weiterzüchten. 2 Tage alte i.cer. infizierte Mäuse starben nach 4 Tagen. Der Gehirnvirustiter der infizierten Mäusesäuglinge erreichte 10-7-10-8/0,02 ml. Er war etwa 100 mal höher als bei erwachsenen Mäusen, obwohl die Empfänglichkeit beider Altersgruppen etwa die gleiche war. Mäusesäuglinge waren für eine i.p. Infektion fast ebenso empfänglich wie erwachsene Mäuse für eine i.cer. Infektion. Hamster bekamen nach i.cer. Impfung Lähmungserscheinungen und starben innerhalb von 2-4 Tagen. Der Virustiter der Gehirne betrug $10^{-5}$ (i.cer. Injektion bei erwachsenen Mäusen). Bei einem 
Hamster wurde Virämie festgestellt. Der Blutvirustiter erreichte nach 4 Tagen 10-7. I.p. Infektion erzeugte eine ähnliche Erkrankung der Hamster wie i.cer. Infektion, allerdings mit einer längeren Inkubationszeit (5-20 Tage). Bei Meerschweinchen kam es nach i.cer. Injektion von $5000 \mathrm{LD}_{50}$ für Mäuse zu Lähmungen. Gehirnpassagen waren nicht möglich. Kaninchen erkrankten nach i.cer. Einspritzung von etwa 80000 und nach i.p. Einspritzung von etwa 1000-10000 LD 50 für Mäuse nicht, entwickelten aber N-AK. 2 Cebus-Affen (C. albifrons trinitatis Pusch) bekamen 3-5 Tage nach i.p. Infektion mit etwa $1000 \mathrm{LD}_{50}$ für Mäuse eine Virämie, erkrankten aber nicht.

Folgende Mückenarten ließen sich experimentell infizieren: Aedes scapularis, A.serratus, Culex fatigans, Psorophora ferrox. Die geglückte Infektion dieser Mücken wurde durch Beißen an 2 Tage alten Mäusesäuglingen 2 Wochen p. i. bewiesen, da dann das Oropouche-Virus von diesen wieder isoliert werden konnte.

Die Züchtung im embryonierten Hühnerei gelang nach Beimpfung des Dotter- oder Amnionsackes mit der 8. Mäusegehirnpassage. Mit zunehmender Eipassage wurde die Sterblichkeit der Embryonen regelmäßiger. Der Titer der Dottersäcke (tödliche Infektion) erreichte $10^{-6}$. Die NR mit der 14. Dottersackpassage und Oropouche-Immunserum ergab die Spezifität des gezüchteten Virus.

$\mathrm{Na}$ desoxycholat in Verdünnung von 1: 100 inaktivierte etwa $10^{3} \mathrm{LD}_{5_{0}}$ des Virus für Mäuse. Die Desoxycholatempfindlichkeit ist also erheblich.

Bei dem erkrankten Menschen wurden $N$ - $A K$ gegen das Virus nachgewiesen. Außerdem wurden im Blut von 3 weiteren Waldarbeitern, von 8 unter 26 untersuchten CebusAffen (C. albifrons trinitatis) und von 9 unter 26 Brüllaffen (Alouatta seniculus insularis) N-AK gefunden, was auf eine Infektion von Menschen und Affen hinweist.

Das Oropouche-Virus ließ in der KBR eine serologische Verwandtschaft mit dem in Südafrika isolierten Simbu-Virus, keine solche dagegen mit dem Bunyamwera-Virus erkennen.

\section{E V. Cache Valley -Virus}

Anläßlich von Routineuntersuchungen über das Vorkommen von Virus der WEE und SLE in Mücken im Staate Utah wurde von Holden und Hess (1959) ein bisher in Nordamerika unbekanntes Arbor-Virus aus einem Pool von 50 Culiseta inornata isoliert. Es wurde nach der Sammelstelle der Mücken "Cache Valley-Virus" genannt. Das Virus scheint nicht auf den Staat Utah beschränkt zu sein, denn Causey (zit. Casals und Whitman, 1960) fand ein ähnliches Virus im brasilianischen Staate Pará. Downs u. a. (1961) gelang die Isolierung des Virus in Trinidad aus einem Pool von Aedes scapularis durch i.cer. Verimpfung auf 2 Tage alte Mäusesäuglinge.

Wie die Erstisolierungen von Holden und Hess (1959) zeigten, erzeugte das Virus nach .cer. Injektion bei jungen Mäusen eine Encephalitis; die Tiere starben bis zum 13. Tage p. i. Der $\mathrm{LD}_{50}$-Titer der Mäusegehirne der 4. Passage betrug $10^{-4,6}$ und blieb bis zur 11. Passage auf der gleichen Höhe. Dann wurde das Virus 2-3 Tage alten Mäusen eingespritzt. Die 14. Mäusegehirnpassage hatte dann einen Infektiositätstiter von $10^{-7,7}$ auch für abgestillte Mäuse. Für Mäusesäuglinge war das Virus auch nach i.p. Injektion pathogen, für abgestillte Mäuse aber weder nach i.p. noch nach s.c. Infektion. Das Virus führte bei Kaninchen nach i.m. Injektion zur Bildung von AK. Für $1 / 2$ tägige Küken schien es nicht infektiös zu sein. Die Küken bekamen auch nach massiver Dosierung des Virus keine Virämie. N-AK waren auch nach 30 Tagen noch nicht vorhanden.

Es erzeugte in Hamsternierenzellkulturen einen ZE.

Das Virus war durch Seitz-Filter filtrierbar. Downs u. a. (1961) stellten aus einem NaClExtrakt infizierter Mäusegehirne ein KB-Antigen her.

Downs u. a. (1961) fanden spezifische N-AK in den Seren von 15 unter 46 Bewohnern von Trinidad, von 8 unter 26 Bewohnern Britisch-Guyanas und von 4 unter 11 Laboratoriums- 
angehörigen. In 3 von 28 Affenseren (Alouatta) in Trinidad wurden ebenfalls AK gefunden. Außerdem ergaben 20 von 26 untersuchten Pferdeseren in Britisch-Guyana sowie nach Holden und Hess (1959) auch 4 Pferdeseren aus dem Cache Valley N-AK.

Cache Valley-Antiserum neutralisierte in der i.p. Mäuse-NR sowohl Bunyamwera- als auch Kairi-Virus. Diese Reaktion war aber weniger stark als die i.cer. Mäuse-NR. Außerdem war sie mit homologem Virus stärker als mit den heterologen Viren (CaSals und Whitman, 1960). In der HAHR hemmte Cache Valley-Virus-Antiserum das homologe Virus in der Verdünnung von $1: 320$, die Bunyamwera-Ilesha- und Germiston-Viren in der Verdünnung von $1: 10$ (Okuno, 1961). Die KBR ergab Kreuzreaktionen mit den Bunyamwera- und Guaroa-Viren (Downs u. a., 1961).

\section{E VI. Kairi-Virus}

ANDERSon u. a. (1960) isolierten im Verlauf von Untersuchungen über das Vorkommen von Arbor-Viren in den Wäldern von Trinidad durch Verimpfung auf Mäusesäuglinge 31 Virusstämme aus Mücken. Ein neues Virus unter diesen scheint das "Kairi-Virus» zu sein. Casals und Whitman (1960) wiesen das Virus ebenfalls in Belém (Brasilien) in Aedes scapularis nach.

Es ließ sich i.cer. auf Mäusesäuglingen adaptieren, in denen es Titer von $10^{-6} \mathrm{LD}_{50}$ erreichte. Eine Übertragung auf Hamsternierenzellkulturen verlief negativ. Eine passagenweise Übertragung auf embryonierte Eier gelang auch nicht.

Alle Stämme passierten, Seitz-EK-Filter.

Gegen das Virus gerichtete $N-A K$ wurden sowohl bei Menschen als auch bei Affen in Trinidad gefunden.

Kairi-Antiserum hemmte die HA des Germiston-Virus in der Verdünnung von 1:160, die des Ilesha-Virus in der Verdünnung von 1:80 und die des Bunyamwera-Virus in der Verdünnung von $1: 40$, woraus die serologische Verwandtschaft des Kairi-Virus mit der Bunyamwera-Gruppe hervorgeht (OKUno, 1961).

\section{E VII. Germiston-Virus}

КокеRnot u. a. (1960) isolierten 2 Virusstämme aus Culex-Mücken bei Untersuchungen über die Ursache von Fiebern unbekannten Ursprungs in Germiston (Südafrika) durch i.cer. Infektion neugeborener und junger Mäuse. Während der Arbeit mit diesem Virus kam es zu 2 Laboratoriumsinfektionen; bei der einen Person wurde das Virus am 1. Tag der Erkrankung aus dem Blut durch i.cer. Verimpfung auf junge und erwachsene Mäuse isoliert. Das Virus ließ sich passagenweise auf Mäusen züchten. Neugeborene Ratten sind für eine i.cer. Infektion empfänglich und sterben (ВАвсоск u. a., 1961). Bei experimentell infizierten wilden Nagern, der Gerbillenart Tatera, kam es zu stärkerer Virämie und AK-Bildung (McInтosн, 1961).

Das Virus war durch Seitz-EK-Scheiben filtrierbar.

Ein Hämagglutinin wurde durch Aceton-Ätherextraktion aus den Seren der nach i.cer. Infektion erkrankten Mäuse, ein KB-Antigen aus Serum- und Gehirnextrakten der Mäuse gewonnen.

Die HAR ergab Titer von etwa 1:100. Das Hämagglutinin reagierte am besten bei $\mathrm{pH}$ von 6,0-6,2. Es ließ sich in getrocknetem Zustand bei $-20^{\circ} \mathrm{C}$ aufbewahren (OKuno, 1961).

Die Laboratoriumserkrankungen äußerten sich in Schüttelfrost, Fieber, Kopf-, Lenden- und Kreuzschmerzen und verschwanden bereits wieder nach 2 Tagen. Die Diagnose wurde in einem Fall, bei dem die Virusisolierung nicht gelungen war, nur durch die serologische Untersuchung gesichert. Es trat ein Anstieg der $N-A K$ und $H A H-A K$ auch für BunyamweraVirus und für die Viren der Gruppe B-, nicht dagegen für solche der Gruppe A und für RifttalFieber auf. In dem 2. Fall, in dem das Virus isoliert werden konnte, fanden sich im Rekonvaleszentenserum N-AK, KB-AK und HAH-AK für das homologe Virus und das Bunyamwera-Virus. 
Kreuz- $N R$ mit tierischen Immunseren ergaben eine antigene Verwandtschaft, aber keine Identität mit dem Bunyamwera-Virus, keine Verwandtschaft mit WN-, Rifttalfieber-, Sindbis-, Chikungunya- und Semlikiwald-Virus. Mäuse, die gegen Bunyamwera-Virus immunisiert worden waren, waren nicht gegen Germiston-Virus geschützt. ОкиNo u. a. (1961) bestätigten, daß das Germiston-Virus immunologisch zur Bunyamwera-Gruppe gehört. In der HAHR mit Germiston-Antiserum wurden das homologe Virus in der Verdünnung von 1: 2560, die Bunyamwera- und Ilesha-Viren in der Verdünnung von 1: 80 und das Cache Valley-Virus in der Verdünnung von 1:320 gehemmt. In der KBR ließ sich das Germiston-Virus scharf von anderen Viren der Gruppe unterscheiden. Das Fehlen von Kreuz-KBR ließ also keine antigene Verwandtschaft erkennen.

\section{E VIII. Ilesha-Virus}

Dieses Virus wurde von McNamara (1959, zit. Okuno, 1961) in Westnigeria isoliert. Es ließ sich auf Mäuse übertragen. Aus den Gehirnen infizierter Mäusesäuglinge wurden mittels der Zucker-Aceton-Extraktionsmethode ein Antigen für die KBR und ein Hämagglutinin gewonnen, das sich lyophilisiert bei $-20^{\circ} \mathrm{C}$ aufbewahren ließ. Der HA-Titer betrug bei $\mathrm{pH}$ $6,0-6,2 \quad 1: 200$.

Mit der NR wurde keine erkennbare Verwandtschaft des Ilesha-Virus mit den Gelbfieber-, Dengue 2-, Zika-, Uganda S-, Bwamba-, Pappataci-, Bunyamwera- und Coxsackie B 3-Viren gefunden.

Immunserum wurde von Mäusen gewonnen, die erst i.p. mit $0,2 \mathrm{ml}$ einer $10 \%$ igen virushaltigen Gehirnemulsion (inaktiviert mit $0,5 \% \beta$-Propiolacton 1 St. bei $37^{\circ} \mathrm{C}$ ) geimpft worden waren und 2 Wochen später eine weitere i.p. Injektion von $0,2 \mathrm{ml}$ einer $1 \%$ igen Suspension des vollaktiven Gehirnvirus erhalten hatten. Am 7., 15. und 23. Tag p. i. wurde Blut entnommen. Die jeweiligen Serumgemische wurden als "Primärserum» bezeichnet. Nach der letzten Blutentnahme wurde eine weitere i.p. Injektion einer frischen infektiösen 1\%igen Gehirnsuspension vorgenommen. Die 1-2 Wochen später entnommenen Seren wurden als »Hyperimmunserum " bezeichnet. Ilesha-Antiserum hemmte die HA des homologen Virus in der Verdünnung von 1: 1280, die des Cache Valley-Virus in der Verdünnung von 1:160, die des GermistonVirus nicht. In der KBR war eine enge Verwandtschaft nicht nur mit dem Cache Valley-, sondern auch mit dem Bunyamwera-Virus erkennbar (Окuno, 1961).

\section{F. Arbor-Viren, noch nicht gruppiert}

Casals (1961b) unterscheidet in der Gruppe noch nicht klassifizierter Viren folgende Untergruppen:

1. California Encephalitis, Trivittatus (USA), Melao (Trinidad), BeAR 8033 (Belém, Brasilien). Diese Untergruppe könnte aber noch zur Bunyamwera-Gruppe gehören.

2. Guamá, Catu (Belém,) Bimiti (Brasilien)

3. Bwamba (Uganda), Pongola (Südafrika)

4. Simbu (Südafrika), Oropouche (Trinidad), Sathuperi (Indien)

5. Turlock (USA), Umbre (Indien)

6. Anopheles A und B (Kolumbien), Tr 10076 (Trinidad)

7. AMM 2549 und 2325 (Malaya)

8. $\operatorname{Tr} 7994, \operatorname{Tr} 8762, \operatorname{Tr} 9223$ (Trinidad)

9. Quaranfil, Chenuda, Eg Ar 1304 (Ägypten)

Die Tab. 40 enthält außer den Viren der Bunyamwera-Gruppe einen Teil der bisher bekannten, aber noch nicht klassifizierten Arbor-Viren. 


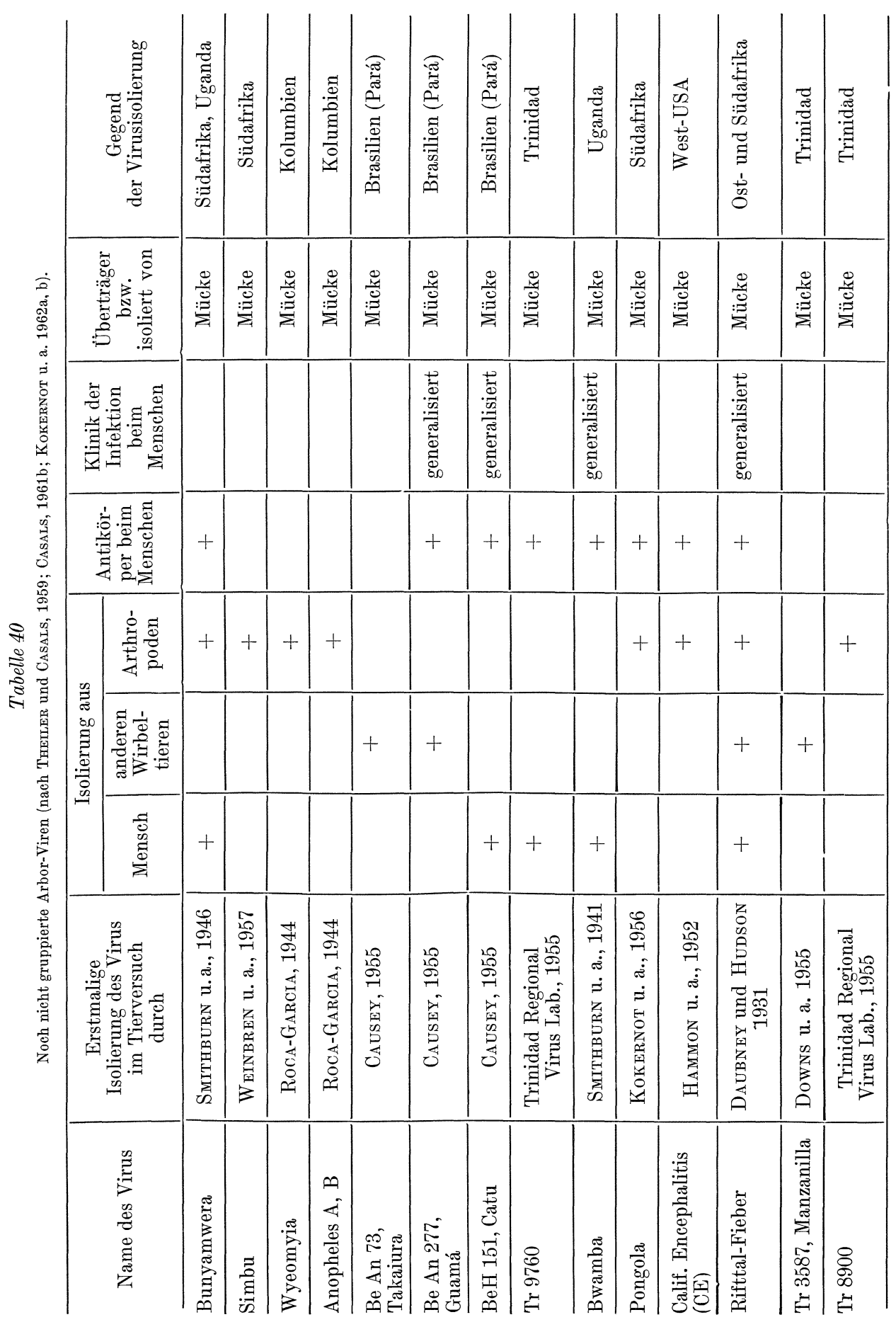




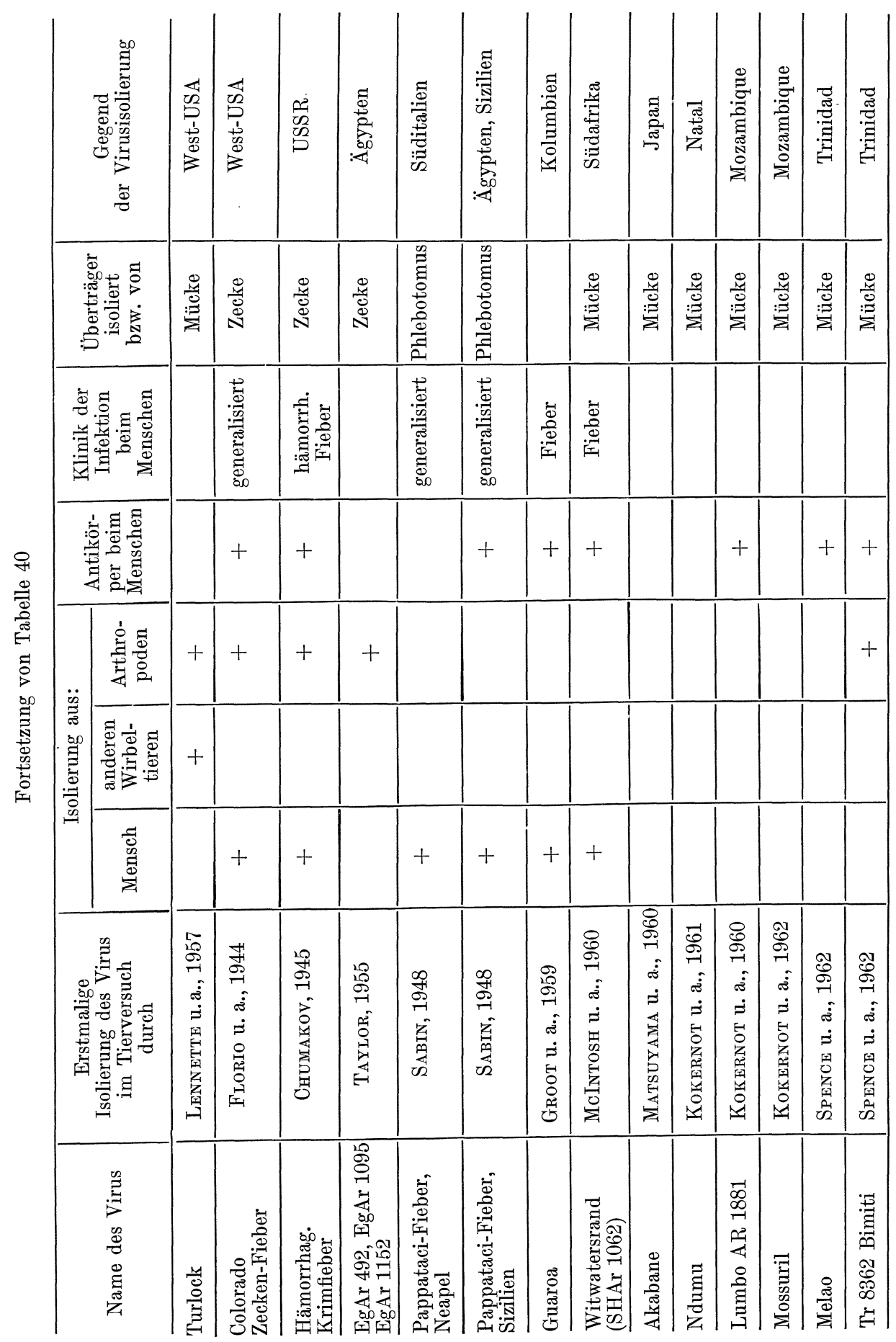


Die übrigen Viren dieser Gruppe scheinen weder untereinander noch mit anderen Viren verwandt zu sein. Nach Whitman und Shope (1962) scheint zu der 1. Untergruppe, dem California-Komplex, außerdem das in der Tschechoslowakei von Bardos und Danielova (1959) aus Mücken isolierte Tahyna-Virus zu gehören.

\section{F I. Bwamba-Fieber (einschl. Pongola-Virus)}

Anläßlich epidemiologischer Gelbfieberuntersuchungen im Bwamba-Kreis, WestUganda fanden Smithburn u. a. (1941) bei einer Reihe von Eingeborenen eine neue fieberhafte Krankheit unbekannter Ursache, welche als "Bwamba-Fieber» bezeichnet wurde. Das Virus wurde aus dem Blut (Serum) der Kranken durch i.cer. Injektion auf Mäuse isoliert (s. auch MaHAFfy u. a. 1943).

I.cer. und i.n. infizierte Mäuse erkrankten 4-6 Tage später zunächst an Übererregung und Exophthalmus und wurden dann wieder normal beweglich oder sogar träge. Sie zeigten Lichtscheu, dann encephalitische Erscheinungen. Es bestand Virämie. In den Gehirnen der Mäuse fanden sich mäßige bis starke Gefäßerweiterung und Hyperämie mit kleinen Hämorrhagien. Charakteristisch war die ausgedehnte diffuse Degeneration der Pyramidenzellen der Rinde. Die Kerne dieser Zellen waren geschwollen und schaumig oder blasig mit starker Schädigung der Chromatinanordnung und azidophilen Einschlüssen. Echte entzündliche Veränderungen waren nur geringfügig. Die Empfänglichkeit der Mäuse für eine i.cer. Infektion schien unabhängig vom Alter zu sein; sie nahm dagegen bei peripherer Infektion mit zunehmendem Alter der Tiere ab (Lennette und Koprowski, 1944a). Vilches und Hirst (1947) fanden, daß i.cer. injiziertes Influenzavirus mit der Vermehrung des in gleicher Weise zugeführten Bwamba-Virus bei Mäusen interferierte.

Bei Rhesus-Affen führte das Bwamba-Virus entweder zu einer stummen Infektion oder zu einer leichten fieberhaften Erkrankung. Es kam sowohl zu Virämie als auch zu Bildung von AK. Bei Cercopithecus-Affen fand sich eine ziemlich langdauernde Virämie (Dick, 1953b). Nach REAGAN u. a. (1954c) sollen Hamster für eine intrakardiale Infektion empfänglich sein. REAGAN u. a. (1953c) konnten ein in Mäusen adaptiertes Virus i.p. und i.cer. auf Hunde übertragen. Diese bekamen nervöse Krankheitserscheinungen nach 7-8 Tagen. Das Virus wurde durch Rückverimpfung auf Mäuse in den Hundegehirnen nachgewiesen. Junge Meerschweinchen erkrankten nach i.cer. Infektion fieberhaft und entwickelten AK. REAGAN u. a. (1953b) übertrugen das Virus außerdem i.cer., i.p., i.n., i.m., i.d., intrakardial, intraokulär, intralingual und rektal auf Eintagsküken. Kaninchen schienen nicht empfänglich zu sein.

Das Virus ließ sich in Kulturen verschiedener Zellarten einschließlich HeLa-Zellen unter Bildung eines ZE züchten (Moore, 1957). In Hühnerembryozellkulturen waren mehrere Passagen erforderlich, bis das Virus gut adaptiert war und Plaques sowie ein ZE erkennbar wurden (Buckley, 1959). Das Virus vermehrte sich im embryonierten Hühnerei, ohne den Embryo zu töten (TAYLOR, 1952).

Das Virus ließ sich durch Berkefeld- und Seitz-EK-Filter filtrieren. Filtration durch Gradocolmembranen ergab eine Größe der Virusteilchen von 75-113-150 m $\mu$ (SмIтнвuRN und BugheR, 1953). Elektronenmikroskopische Abbildungen von Gehirn und Rückenmark infizierter Mäuse ließen sphärische Teilchen mit unregelmäßigen Konturen und einem Durchmesser von 110 mu erkennen (REAGAN und BRUECKNER, 1954).

Das Virus war lyophilisierbar und bei $-70^{\circ} \mathrm{C}$ aufzubewahren.

Smithburn und Bugher (zit. Olitsky und Casals, 1952) sowie Smithburn und Mahaffy (1952) stellten mittels des AK-Nachweises (Mäuseschutzversuche) eine weite Verbreitung des Bwamba-Fiebers unter den Eingeborenen von Uganda und Tanganyika fest. MacNamara (1952) erhielt einen hohen Prozentsatz von AK in der Bevölkerung 3 verschiedener Gebiete von Nigeria (s. auch Sмiтнвurn u. a., 1941). Entsprechende Befunde erhob Dick (1953b) in Kenyia, Nord- und Südrhodesien; er fand außerdem AK in den Seren von 23,3\% der untersuchten Affen in Kenyia und Uganda. Tierische Virusreservoire sind noch nicht gefunden worden. Die Übertragung scheint unmittelbar von Mensch zu Mensch durch Mücken 
zu erfolgen. Das Virus vermehrt sich in Aedes aegypti, welche experimentell infiziert wurden. Es wird von diesen Mücken durch Biß auf Menschen übertragen (Whitman, zit. Theiler und Clarke, 1959).

Die Krankheit beginnt plötzlich und verläuft milde mit Fieber, Stirnkopfschmerz, Rückenund Gliederschmerzen, Schwäche und Konjunktivitis. Das Fieber dauert 2-5 Tage, Kopf- und Rückenschmerzen noch 2-3 Tage länger. Es besteht eine auffallende Bradykardie. Die Genesung verläuft schnell und ist vollständig.

In der Rekonvaleszenz lassen sich N-AK mittels des i.cer. Mäuseschutzversuches nachweisen. Das Bwamba-Virus wird durch Antiseren gegen WN- und Bunyamwera-Virus nicht neutralisiert (SMithburN u. a., 1946). Die AK sind mit radioaktivem Jod markierbar (Clarke und BLACK, 1955).

Das Pongola-Virus ist mit dem Bwamba-Fiebervirus antigen eng verwandt. Es wurde bisher in Tongaland (Südafrika) verschiedentlich von in der Wildnis gefangenen Aedes (Banksinella) circumluteolus-Mücken isoliert (КокеRnot u. a., 1957d). KокеRnot u. a. (1961b) wiesen bei zahlreichen Rindern, Schafen und Ziegen in Südafrika N-AK nach.

\section{F II. Rifttal-Fieber}

(Enzootische Hepatitis der Schafe).

Virus = Charon vallis, Holmes spec. nov.

Viscerophilus africanus, Zhdanov und Korenblit.

\section{Einleitung}

Das Rifttal-Fieber ist primär eine enzootische akute Hepatitis der Schafe, Ziegen und Rinder, die bisher nur in Afrika bekannt geworden ist. Sie ist wahrscheinlich erstmalig von Montgomery (1912-13) beschrieben worden, welcher in Kenyia (Ostafrika) unter den Lämmern eine Epizootie dieser Krankheit mit einer Sterblichkeit von $90 \%$ beobachtet hatte. Daubney u. a. (1931) isolierten den Erreger während eines großen Ausbruchs unter den Schafherden in Kenyia im Tal des Rift-Flusses, nach dem die Krankheit genannt worden ist (s. auch DaUbNey und Hudson, 1932, 1933). Die Übertragung scheint nicht nur durch Arthropodenbiß (Mücken), sondern auch durch Kontakt zu erfolgen, wodurch sich das RifttalFieber epidemiologisch grundsätzlich vom Gelbfieber unterscheidet.

Nachdem zahlreiche menschliche Erkrankungen, sowohl Laboratoriums- als auch natürliche Infektionen (Schafhirten), bekannt geworden sind, muß das Rifttal-Fieber in die große Gruppe der Zoo-Anthroponosen eingeordnet werden (s. auch STERN, 1958). Der Erreger gehört zu den ganz kleinen Viren, der in seiner Größe dem Gelbfiebervirus nahe kommt. Klinisch und pathologisch-histologisch hat das Rifttal-Fieber der Tiere mehr Ähnlichkeit mit dem menschlichen Gelbfieber als das menschliche Rifttal-Fieber, das ohne Beteiligung der Leber verläuft (s. auch Findlay und Howard, 1952). Findlay und Maccallum (1937) nahmen an, daß beide Viren auf einen gemeinsamen Erreger zurückgehen.

\section{2. Ätiologie}

\section{2-1. Übertragungsversuche}

Das Rifttal-Fieber läßt sich außer auf Schafe, Ziegen und Rinder, seine natürlichen Wirte, auf zahlreiche andere Tierarten, insbes. Affen und Nagetiere übertragen. EASTERDAY u. a. (1962 c) konnten Lämmer i.p., i.d., i.n. konjunktival, auf die Maulschleimhaut, durch Aerosole und infektiöse Mücken infizieren. Nach der Aerosolinfektion betrug die Sterblichkeit der unter 1 Woche alten Lämmer $90 \%$, die der über 1 Woche alten dagegen nur $20 \%$. Eine perorale oder 
Kontaktinfektion war nicht möglich. Bei Lämmern gelang die Infektion mit ganz geringen Virusmengen; erwachsene Schafe erforderten aber große Dosen. Fieber und Virämie setzten bei den Lämmern gewöhnlich früher als bei den Schafen ein; bei ersteren wurde auch ein höherer Blutvirustiter erhalten. Föten und fötale Membranen von abortierenden infizierten Schafen waren virushaltig (s. auch SHone, 1958). Weniger als 1 Woche alte Kälber ließen sich i.p. und i.d. mit virushaltigem Lammblut (Van Wyk-Stamm) ebenfalls infizieren. Die Tiere bekamen Fieber, Leukopenie und Virämie; die Sterblichkeit betrug 70\% (EASTERDAY u. a., 1962 b). Bei den gestorbenen Kälbern wurden ausgedehnte Leberveränderungen gefunden, die makroskopisch und mikroskopisch jenen der Lämmer entsprachen (EASTERDAY u. a., 1962 a). Ziegen erkrankten nach i.p. Infektion nicht so regelmäßig wie Lämmer und Kälber, bekamen aber auch Fieber, Leukopenie und Virämie, ältere später als junge. Das Virus wurde weder mit der Milch, der Galle noch dem Harn ausgeschieden (s. auch Daubney u. a., 1931; FindLAY, 1932).

Daubney u. a. (1931) übertrugen das Rifttal-Fieber experimentell auf eine Versuchsperson mit einem Filtrat infektiösen Schafgewebes. Die Erkrankung entsprach klinisch jener spontan infizierter Schafhirten. Der Kranke hatte eine Virämie, wie aus der Verimpfung von Blut auf Lämmer hervorging, und entwickelte spezifische N-AK.

Die Empfänglichkeit von Affen ist verschieden. Südamerikanische und indische Affenarten sind empfänglicher als afrikanische. Nach Findlay (1932) erkranken Cebus fatuellus, C. chrysopus, Hapale jacchus und H.penicillata nach einer Virusinfektion fieberhaft mit Virämie und lassen sich außerdem durch Beimpfung der Nasenschleimhaut und des Konjunktivalsacks infizieren. Die afrikanischen Affen Cercopithecus callitrichus, Erythrocebus patas und Cercocebus fulginosus erkranken nicht sichtbar, bekommen aber eine mehrtägige Virämie. Kapuzineraffen erwerben eine Immunität, die 14 Tage p. i. nachweisbar wird. Als empfänglich werden außerdem Macaca mulatta und M.inuus angegeben (Holmes, 1948). In den Lebern der empfänglichen Affen findet man ganz ähnliche pathologisch-histologische, insbes. intrazelluläre Veränderungen wie beim Gelbfieber (Findlay, 1933a): Councilmansche Körperchen und azidophile Kernveränderungen; dagegen bleiben die hyalinen Nekrosen beim RifttalFieber auf zentrale oder periportale Herde beschränkt. Die erkrankten Affen sterben nicht, erwerben aber einen mindestens 6 Monate anhaltenden Schutz gegen eine erneute Infektion.

Die Maus ist das empfänglichste Laboratoriumstier. Sie läßt sich auf allen Wegen infizieren und stirbt gewöhnlich nach 2-3 Tagen in fast 100\%. Die Vermehrung des Virus in den Mäuseorganen ist sehr stark; es werden Titer bis zu $10^{-8}$ erreicht. Obwohl in der Leber infizierter Mäuse während der Inkubationszeit keine signifikanten histopathologischen Veränderungen gefunden wurden, sahen Tsukada u. a. (1960) Zunahmen des Gesamt-P sowie der ${ }^{32} \mathrm{P}-$ Aufnahme in die RNS, der Menge der säurelöslichen organischen Phosphate und einen Anstieg der Atmungsaktivität. Diese Veränderungen wurden auf eine exponentielle Vermehrung des Virus in der Inkubationszeit zurückgeführt. Beim Einsetzen klinischer Erscheinungen wurde ein starkes Absinken des RNS-Stoffwechsels und der Atmung beobachtet, was aus der beginnenden Nekrose der Leberzellen erklärt wurde.

Das Rifttal-Fieber-Virus besitzt einen ausgesprochenen Neurotropismus für die Maus. Durch i.cer. Übertragung des Virus auf Mäuse, die kurz vorher spezifisches Immunserum i.p. erhalten hatten, konnte dieser Neurotropismus manifestiert werden (FindLaY und MAcKeNZIE, 1936; Findlay u. a., 1936; MacKenzie und Findlay, 1936). Nach 30 Gehirnpassagen war eine so weitgehende i.cer. Adaptierung erreicht, daß das Virus nur noch zu einerEM, aber nicht mehr zu einer Hepatitis führte, d.h. ein großer Teil seines ursprünglichen Viscerotropismus war verloren gegangen. Die neurotrope Variante vermehrte sich auch nicht mehr in den normalen Leberzellen der Maus nach s.c.oder i.p. Injektion(MacKenzIE u.a.,1936; Endo, 1951; s. auch FindLay und Howard, 1952). Daß es sich hier um eine Umwandlung im Sinne eines "Virus fixe«, also vielleicht sogar um eine Mutation handelt, scheint aus den Untersuchungen von SмiтнвuRN (1949b) hervorzugehen. Er erhielt ebenfalls durch passagenweise Züchtung des Virus in Mäusegehirnen einen neuen Virusklon, dessen Hepatotropismus ganz erheblich herabgesetzt war, ohne daß die Immunogenität verloren gegangen war. Nach s.c. Verimpfung wurden neugeborene Lämmer immunisiert, ohne daß Krankheitserscheinungen oder Virämie auftraten. Diese Tiere erwarben einen Schutz gegen das pantrope Virus, vorausgesetzt, daß die 
Infektion nicht i.cer. oder i.n. erfolgte. Матимото u. a. (1958) stellten dagegen bei einem neurotropen Virusstamm eine mehrere Tage anhaltende Virämie, die sogar noch nach Erscheinen von N-AK bestand, sowie eine Virusvermehrung in Leber und Milz fest. Nach 10 i.p. Passagen mit Milzgewebe wurde das Virus auch bei dieser Zuführungsweise gehirnpathogen wie nach i.cer. Passage. Kitchen (1950) fand, daß der primäre hepatotrope Charakter bis zur 15. i.cer. Mäusepassage erhalten blieb. Bis zur 20. Gehirnpassage waren beide Tropismen nachweisbar. Aus den Gehirnen der 20.-50. Passagen wurden durch Übertragung auf RhesusAffen ein neurotropes und ein hepatotropes Virus isoliert. Dasselbe wurde bei einer menschlichen Laboratoriumsinfektion mit der 68. Mäusepassage beobachtet. Bis zur 80. Mäusepassage trat dann immer mehr ein stabiler Neurotropismus hervor, während keine Leberveränderungen mehr erkennbar waren. Bei einem Affen, der mit der 81. Passage infiziert wurde, traten weder klinische Erscheinungen auf noch wurde das Virus isoliert. Der Affe war aber gegen eine anschließende Infektion mit hepatotropem Virus geschützt. Die 80.-90. Mäusegehirnpassagen zeigten keine hepatotropen Eigenschaften. Das neurotrope Virus dürfte demnach in ein irreversibles Virus fixe umgewandelt worden sein, das wahrscheinlich als Impfstoff für Schafe geeignet ist. Die Abwandlung oder Abschwächung des Mäusevirus schien sich allerdings nicht auf die ursprüngliche Menschenpathogenität zu erstrecken, denn auch nach mehr als 300 Mäusepassagen infizierte das Virus einen Laboratoriumsangestellten (SABIN und Blumberg, 1947). Nach i.p. Infektion erkranken die Mäuse an einer akuten nekrotisierenden Hepatitis mit Virämie und azidophilen Kerneinschlüssen (Findlay, 1932, s. auch später).

Nach Mıмs (1956a-d) sind erwachsene Mäuse für eine i.v. Infektion ebenso empfänglich wie für eine i.cer. Die Gehirntiter sind niedriger als die Bluttiter. Das Virus wird zunächst von den empfänglichen Zellen adsorbiert und der Bluttiter sinkt in der 1. St., um nach 5-9 St. wieder anzusteigen. Die Titerzunahme erfolgt schneller nach Infektion großer Inocula. Zwischen der Größe des Inoculums und dem Umfang der Adsorption bestehen insofern Beziehungen, als der log. der Menge des nicht adsorbierten Virus proportional dem log. der eingespritzten Menge ist. Es wurde berechnet, daß eine Maus mindestens $10^{10,2} \mathrm{LD}_{50}$ adsorbieren kann. Die Größe des "sättigenden« Inoculums wurde auf $10^{8,0}$ bis $10^{8,5} \mathrm{LD}_{50}$ berechnet. Das Virus, das im Blut adsorbiert wird, ist nirgends mehr nachweisbar. Nach i.v. Infektion mit sättigenden Virusdosen werden die ersten Kernveränderungen in den Leberze!len bereits nach 1 St. erkennbar; nach 3 St. sind alle Kerne einschlußhaltig. Schon nach $3^{1 / 2}$ bis $5^{1} / 2$ St. findet eine ausgedehnte Auflösung der Leberzellen statt, wobei zahlreiche Zelltrümmer in den Kreislauf gelangen. Auffällig sind die Blutansammlungen und Koagulationsstörungen nach 5 St. Gleichzeitig wird zunehmender Schwund des Leberglykogens bemerkbar, der nach 6 St. vollständig ist. In diesem Augenblick treten Krankheit und Tod ein. Dieselben histologischen Veränderungen sieht man, wenn die Mäuse infolge kleiner Virusdosen erst nach 40 St. sterben (Mrms, 1957a).

Kein oder nur wenig Virus wird im Mäuse-Urin nachweisbar, da es vielleicht durch $\mathrm{pH}$ des Urins neutralisiert wird. In der Galle kommt nur wenig Virus vor; es wird durch die Galle inaktiviert. Das Virus fehlt in der Milch der infizierten Mäuse. Möglicherweise findet Virusausscheidung durch die Nasenschleimhaut statt.

Niedrige Infektiositätstiter werden erhalten, wenn große Inocula serienweise von Maus zu Maus verimpft werden; dies wird durch die Bildung von nichtinfektiösem "inkomplettem" Virus erklärt.

Bei infizierten Mäusen wird die Entstehung von Lebernekrosen durch BAL, Aureomycin und Terramycin nicht verhindert (FIndlay und Howard, 1952). Phenoloxythiouracile schützen Mäuse nicht vor einer Infektion (Matтhews und Sмгтн, 1955). Atebrin (Mepacrin) scheint eine gewisse Schutzwirkung auszuüben, wenn die Mäuse kurz vor oder nach der Infektion behandelt werden (Hurst u. a., 1952; Hull und Hurst, 1961).

Frettchen erkranken nach einer Inkubationszeit von 1-3 Tagen an Lungenerscheinungen, Herdnekrosen der Leber und hämorrhagischer Enteritis gewöhnlich tödlich. Die Lungenerscheinungen, welche prädominieren, sind nur schwer von Influenza der Frettchen zu unterscheiden. Das Rifttal-Fiebervirus ist also bei Frettchen ausgesprochen pneumotrop (FraNcis und Magill, 1935). 
Für Hamster ist das Virus hochpathogen.

Holmes (1948) gibt als experimentell empfänglich an: graue Eichhörnchen (Sciurus carolinensis), Waldmaus (Apodemus sylvaticus), Feldmaus (Microtus agrestis), Haselmaus (Muscardinus avellaris). Bei einem Teil dieser Nager kommt es zu einer generalisierten, fast immer tödlichen Lebernekrose. McIntosh (1961) fand bei wilden Nagetieren (Mystromys, Mastomys, Aethomys, Saccostomus, Gerbillenart Tatera) eine stärkere Virämie mit AK-Bildung.

Rattensäuglinge sind empfänglicher als erwachsene Tiere. Die Sterblichkeit der Ratten beträgt etwa $50 \%$ (Francis und Magill, 1935). Weinbren und Mason (1957) sowie WeinBREN u. a. (1957 a) übertrugen das Virus auf wilde Ratten (Arvicanthis abyssinicus, niloticus, nubilans und tenebrosus), bei denen es zu Virämie kam. Das Virus vermehrte sich in ihnen, ohne daß die Tiere erkrankten.

Katzen erkranken nur an einem vorübergehenden Fieber.

Kaninchen und Meerschweinchen erkranken nicht; erstere bekommen eine Virämie und bilden N-AK (Findlay u. a., 1936; MacKenzie u. a., 1936). Pferde und Schweine scheinen nicht empfänglich zu sein (s. auch Weiss, 1957; Easterday u. a., 1962 b). Vögel, insbes. Hühner, Tauben, Kanarien und Wellensittiche, haben sich als unempfänglich erwiesen.

Bei empfänglichen' Tieren wird das Virus von der Mutter mit dem Plazentakreislauf auf den Foetus übertragen, welcher mitunter kleine Virusmengen enthält.

Eine zusammenfassende Beschreibung der pathologisch-histologischen Leberveränderungen bei den verschiedenen für Rifttalfieber empfänglichen Tieren (Schafe, Ziegen, Ratten, Mäuse, Affen, Eichhörnchen, Hamster) ist von FINDLAY (1933a) sowie später von vaN Rooy EN und RHODEs (1948) wie folgt gegeben worden:

Die ersten Veränderungen sind Herdnekrosen, welche bei Rhesus-Affen auf das Mittelzonengebiet der Leberläppchen beschränkt sind. Bei Lämmern, Mäusen, Ratten und anderen kleinen Nagetieren besteht keine solche Lokalisierung infolge der Schnelligkeit, mit welcher sich die Infektion über die ganze Leber entwickelt. Bei Mäusen findet man schon nach 48 St. so gut wie gar kein erkennbares Lebergewebe mehr. Die gesamte Läppchenstruktur ist zerstört, die Kerne zeigen Karyorrhexis, das Zytoplasma ist vakuolisiert und enthält nur noch Reste von Mitochondrien und Kernchromatin. Auch der Golgi-Apparat ist bereits nach $48 \mathrm{St}$. vollständig aus den Leberzellen verschwunden. Bei Rhesus-Affen sind die Prozesse weniger ausgedehnt; man findet lokalisierte hyaline Nekrosen, die durch runde hyaline azidophile Körperchen innerhalb des Zytoplasmas der Leberzellen charakterisiert sind; diese können von einem klaren Hof umgeben oder sogar von der Zelle ausgestoßen sein. Man findet sie weniger ausgeprägt in den hochempfänglichen Mäusen, besonders gut entwickelt dagegen in den am meisten resistenten Tieren wie erwachsenen Schafe und Ziegen. Nur gelegentlich sieht man bei Rhesus-Affen fettige Degeneration und Pigmentierung, welche bei allen anderen Tierarten zu fehlen scheinen. In den Zellkernen wird das Chromatin randständig; innerhalb des Nukleoplasmas erscheint azido (eosino-)-philes Material, das durch 0,1\%ige Essigsäure oder 1\% iges Ammoniak aufgelöst wird und Feulgen-negativ ist. HoRning (1934) versuchte eine physikalisch-chemische Analyse der Kernstrukturveränderungen mittels der Mikroinzineration von CowDRY (1933).

Das Rifttal-Fiebervirus vermehrt sich in vivo in Tumorzellen ganz erheblich. Auf die Zellen des EHRLichschen Asciteskarzinoms der Maus übt es eine deutliche onkolytische Wirkung aus (TAKEMORI u. a., 1954). Die pantropen und neurotropen Virusstämme zeigen in den Asciteshepatomzellen (7974) der Ratte, einem durch Azofarbstoff erzeugten Tumor, einen hohen Titer. Nach 11 Passagen des neurotropen Virus im Asciteshepatom und 8 Passagen mit niedrigen Verdünnungen sowie 5 Passagen mit Grenzverdünnungen im Mäusegehirn erhielten TAKEMORI u. a. (1955b) eine neue Variante mit s.c. Mäusepathogenität. Diese Variante wird mit dem D-O-Wechsel des Influenza-A-Virus verglichen und entsprechend als Mutation gedeutet. Bei der Vermehrung des ursprünglichen Virus soll jedes $10^{3}$. bis $10^{4}$. Teilchen eine Variante sein. Aber auch schon durch eine einmalige Passage des neurotropen Virus in EHRLICHschen Asciteszellen in vivo scheinen Varianten mit s.c. Mäusepathogenität zu entstehen. 


\section{2-2. Züchtungsversuche}

Saddington (1934) züchtete das Virus (Berkefeld-Filtrat von infektiöser Mäuseleber) in Maitland-Kulturen von Hühnerembryogewebe in Tyrode-Lösung. Die größte Virusvermehrung war nach 4-5 Bebrütungstagen erzielt. Es wurden 12 Passagen durchgeführt. MACKENZIE (1933) benutzte als Ausgangsmaterial infektiöses Mäuseblut; er züchtete das Virus durch 13 Passagen ohne Titerverlust oder sonstige Änderungen biologischer Eigenschaften. TAKEMORI u. a. (1954) beobachteten in Zellkulturen von embryonalen Menschen-, Schweine-, Mäuse- und Rattenfibroblasten einen starken ZE der pantropen und neurotropen Virusstämme. In Kulturen eines Mäusesarkoms (Tanizawa) fand eine starke Virusvermehrung mit schwerer Zelldegeneration statt. In der Kulturflüssigkeit wurden schon vor Erscheinen der Zellveränderungen Virustiter von $10^{-6}$ bis $10^{-7}$ erhalten. Durch Zusatz von Kaninchenimmunserum wurde die Zellzerstörung verhindert. Auch in Zellkulturen des Rattenasciteshepatoms (7974) vermehrten sich beide Virusstämme recht schnell mit einem Virustiter der Kulturflüssigkeit von $10^{-5}$ bis $10^{-7}$ wenige Tage vor Beginn der Zelldegeneration. Auch hier schienen wie in vivo Virusvarianten mit s.c. Mäusepathogenität zu entstehen (ТАкемоRI u. a., 1955b). Weitere Versuche von TaKemori u. a. (1955a) in Einschichtzellkulturen nach Dulbecco des Rhodamin-B-Rattensarkoms ergaben, daß das Virus (beide Stämme) makroskopisch sichtbare Plaques bildete. Dieser ZE wurde durch Vorbehandlung des Virus mit spezifischem Antiserum gehemmt.

Eine Züchtung im embryonierten Ei wurde von SADDINGTON (1934) auf der CAM 8-10tägiger Hühnerembryonen vorgenommen. Insgesamt erfolgten 5 Eipassagen. Das Virus wurde in der Leber, Eihaut und im Amnion der infizierten Embryonen gefunden. Die Leber zeigte pathologische Veränderungen in Form von gelblich-weißen Flecken, bei denen es sich um Hyperplasien und Nekrosen der Epithelzellen sowie entzündliche Veränderungen des benachbarten Bindegewebes handelte. Azidophile Kernveränderungen wie bei den infizierten Tieren wurden jedoch nicht gefunden. Die infizierte Eihaut zeigte ebenfalls Epithelhyperplasien und Entzündungsprozesse im Mesoderm. Nach Матимото u. a. (1959) vermehren sich pantropes und neurotropes Virus auch nach Verimpfung in das Blastoderm eintägiger Hühnerembryonen. Vom 2. oder 3. Tag mit zunehmendem Alter der Embryonen nimmt die Virusvermehrung ab. Serienweise Passagen in eintägigen Embryonen sind möglich. Kaschula (1953) stellte bei passagenweiser Züchtung des Virus in embryonierten Hühnereiern eine Abschwächung fest.

\section{2-3. Eigenschaften des Virus}

Der Erreger des Rifttal-Fiebers ist durch Berkefeld-V-, N- und W-Kerzen sowie Chamberland L2, 11, 13, 15, 17 filtrierbar (s. auch SARdou, 1935). Seine Teilchengröße wurde durch Ultrafiltration mit Gradocolmembranen auf 23-35 m $\mu$ geschätzt (FIndLAY, 1932; Broom und Findlay, 1933). Das Virus ist also nur wenig größer als das Gelbfiebervirus (s. auch DaUbNeY u. a., 1931).

Nach du NaudÉ u. a. (1954) enthält der neurotrope Stamm 2 infektiöse Komponenten verschiedener Größe (30,9 und 51,8 $\mathrm{m \mu}$ ), während das viscerotrope (pantrope) Virus nur aus Teilchen gleicher Größe bestehen soll (s. auch PoLson, 1953). Außerdem fanden Du NAUdÉ und Polson (zit. Hampton, 1955) keine KB-, aber nichtinfektiöse Teilchen von etwa $12 \mathrm{~m} \mu$ Durchmesser.

Bei Zimmertemperatur bleibt das Virus außerhalb des Organismus 1 Woche, bei $4^{\circ} \mathrm{C}$ (Blut) mehrere Wochen, in Glyzerin bei $4^{\circ} \mathrm{C}$ mindestens 8 Monate am Leben. Nach Finduay (1932) soll sich das Virus in Lammblut in einem Oxalat-Karbol-Glyzeringemisch 8 Monate und mit $0,5 \%$ Karbolzusatz bei $4^{\circ} \mathrm{C} 6$ Monate mäusepathogen erhalten. In getrocknetem Zustand (Mäuseblut, 1:10 mit normalem Serum gemischt im Vakuum getrocknet) hält sich das Virus etwa 8 Monate (Kitchen, 1934). Van Rooyen und Rhodes (1948) trockneten infektiöse Mäuseleber ebenfalls im Vakuum. Findlay und Howard (1952) beobachteten, daß neurotropes Virus (getrocknete infektiöse Mäusegehirne) durch Lagerung bei niedriger Temperatur wieder zu einem hepatotropen Virus werden kann. Durch i.p. Weiterzüchtung des Stammes entwickelte sich außerdem eine Encephalomyokarditis. 
Aus dem Blutplasma wird das Virus mit dem Fibrinogen, Euglobulin-, Pseudog]obulinund Albuminanteil ausgefällt.

Bei einem $P_{H}$ von 5,6 und 8 wird das Virus zerstört. Durch Erhitzen auf $56^{\circ} \mathrm{C}$ (Blut) wird das Virus in 40 Min abgetötet (Findlay, 1932). 25\% iger $\ddot{A} t h e r$ inaktiviert sowohl den hepatotropen als auch den neurotropen Stamm.

Die optimale Agglutination von Hühnererythrozyten wird bei $25^{\circ} \mathrm{C}$ und einem $\mathrm{p}_{\mathrm{H}}$ von 6,5 erhalten (Nims und MASON, 1956). Die HA erfolgt sowohl mit dem natürlichen unbehandelten Virus als auch mit dem durch Aceton-Ätherextraktion erhaltenen nichtinfektiösen Hämagglutinin. Beide Virusstämme werden schnell an die Erythrozyten adsorbiert und können nicht wieder eluiert werden. Unbehandeltes Virus ergibt höhere Titer, hat breitere $\mathrm{p}_{\mathrm{H}^{-}}$und Temperaturbereiche und agglutiniert ein größeres Erythrozytenspektrum.

Nach SAWA (1958) interferieren aktives und durch UV-Bestrahlung inaktiviertes Virus in der Maus bei gleichzeitiger Infektion miteinander, so daß es zu keiner Vermehrung und keiner N-AK-Bildung kommt (s. auch DU NAUdÉ und Polson, 1957). Inkomplettes Virus interferiert mit der visceralen Vermehrung von infektiösem Virus, indem es die Inkubationszeit verlängert und den Infektiositätstiter herabsetzt. Große Mengen inkompletten Virus vermögen mit der visceralen Vermehrung infektiösen Virus so weit zu interferieren, daß die Mäuse entweder am Leben bleiben, oder, wenn sie doch sterben, dies die Folge einer Vermehrung des Virus im Gehirn und nicht in der Leber ist. Daß die überlebenden Mäuse spezifische N-AK entwickeln, kann angenommen werden, da inkomplettes Virus seine Antigenität behalten hat. Eingehende Interferenzversuche wurden von МАтчмото и. а. (1959a-e) angestellt. Sie sahen, daß i.p. Injektion von neurotropem Virus die Infektion der Maus mit pantropem Virus zu verhindern vermag. N-AK, welche erst nach 3-4 Tagen erscheinen, verhindern die Interferenz nicht. Das i.p. injizierte Virus vermag mit dem pantropen Virus unabhängig von dessen Injektionsstelle zu interferieren. Das neurotrope Virus interferiert aber nicht mit dem pantropen, wenn beide s.c. eingespritzt werden. Damit es zu Interferenz kommt, muß das neutrope Virus vor dem pantropen injiziert werden. $10^{7}$ bis $10^{8} \mathrm{LD}_{50}$ des neurotropen Virus sind erforderlich, damit es zu einer deutlichen Interferenz mit $10^{3} \mathrm{LD}_{50}$ des pantropen Virus kommt. Die Vermehrung des Jetzteren in der Leber wird teilweise gehemmt, während das neurotrope Virus sich im Gehirn der Maus vermehrt. Durch UV-Bestrahlung inaktiviertes neurotropes Virus interferiert mit aktivem pantropem Virus.

Findlay und MacCallum (1937b) hatten gefunden, daß das Gelbfiebervirus in der Maus mit dem nicht verwandten Rifttal-Fieber-Virus interferiert bzw. eine antagonistische Wirkung ausübt, indem die Mäuse durch Infektion mit dem Gelbfiebervirus einen gewissen Schutz gegen eine Rifttal-Fieber-Infektion erwerben, während umgekehrt dies nicht der Fall zu sein scheint. Findlay und MacCallum wie auch später Theiler (1951) führten diese Schutzwirkung darauf zurück, daß das Gelbfiebervirus zwar eine gewisse Affinität für die Mäuseleberzellen habe, sich in diesen aber nicht zu vermehren vermöge, während das Rifttal-Fiebervirus sich in diesen Zellen so stark vermehrt, daß es zu Lebernekrose und Tod der Mäuse kommt; mit anderen Worten: das Gelbfiebervirus vermag die Mäuseleberzellen gegen das RifttalFiebervirus zu blockieren, ohne sie selbst zu schädigen. TheiLER nimmt an, daß das Gelbfiebervirus die Rezeptoren auf der Zelloberfläche besetzt, wodurch eine zweite Infektion mit dem Rifttal-Fieber-Virus unmöglich wird.Er glaubt, daß letzteres dagegen Affen vor Gelbfieber zu schützen vermag, sowie daß die pathogene Wirkung des Virus bei diesen Tieren weitgehend jener des Gelbfiebervirus entspricht. Bei der Maus bestehen jedoch grundlegende Unterschiede zwischen beiden Viren: erwachsene Mäuse, die extraneural mit natürlichem Rifttal-Fieber-Virus infiziert werden, sind außerordentlich empfänglich für dieses und sterben im Gegensatz zu den ebenfalls peripher mit Gelbfiebervirus infizierten Mäusen an schwerer Lebernekrose.

\section{Epidemiologie; $\ddot{\text { Übertragung }}$}

Das Rifttal-Fieber ist bisher nur in Afrika angetroffen worden. Ursprünglich in der Kenyia-Kolonie (Ostafrika) festgestellt erstreckt es sich heute über weite Teile des 
Kontinents (FIndlay u. a. 1936) vom englisch-ägyptischen Sudan bis in die Südafrikanische Union, in welcher es bei Schafen, Rindern und auch beim Menschen festgestellt worden ist (Joubert u. a. 1951; Gear u. a., 1951; Mundel und Gear, 1951; Henning, 1952; Williams u. a., 1962). Hier hat es in den Herden zu schweren Verlusten geführt (Alexander, 1951; s. auch Murphy und Easterday, 1961; Kaschula, 1957). Ferguson (1959) fanden Schafe auch in Nigeria infiziert. KoKernot u. a. (1956) wiesen das Vorkommen menschlicher Infektionen in Südafrika durch die positiven serologischen Reaktionen nach.

KокеRNot u. a. (1961b) fanden außerdem auch in den Seren von Rindern, Ziegen und Schafen N-AK.

Die primären Virusreservoire sind nicht die Horntiere, sondern verschiedene wild lebende Tiere, vor allen Dingen Nager, z. B. Rattenarten (Arvicanthis abyssinicus nairobae, Rattus rattus kijybis), bei denen AK gefunden wurden. Unter den Nagern scheint das Virus weit verbreitet zu sein und ebenfalls zu Erkrankungen mit hoher Letalität zu führen. Man hat beobachtet, daß den Epizootien in den Viehherden ein großes Sterben der Nager vorausgeht, sowie daß in den Gehöften mit starker Verrattung die Seuche besonders heftig wütet (FINDlay und Daubney, 1931). Gear u. a. (1955) stellten während einer Epizootie in einer Farm $\mathrm{N}$-AK bei einem Iltis (Ictonyx striatus) fest, der Schafkadaver gefressen und sich dabei vermutlich oral infiziert hatte. Hamster, Katzen und vor allen Dingen Affen können latent infiziert sein. Deshalb nahmen Sмгтнвurn u. a. (1948) an, daß im Urwald von Uganda (Semlikiwald) Baumaffen die Virusreservoire sind.

Bereits Daubney u. a. (1931) nahmen eine Übertragung der Krankheit von Nagern auf die Viehherden und ihre Verbreitung in diesen durch Insekten an, und zwar durch Stechmücken wie Aedesarten (A. aegypti, A. triseriatus; Easterday u. a., 1962 c), Mansonien (Taeniorhynchus fuscopennis, Th., T. microannulatus Th., T. versicolor) sowie durch Nymphen der Zecke Rhipicephalus appendiculatus. Diese Insekten nehmen während der Blutmahlzeit bei den infizierten Tieren während der virämischen Phase das Virus auf. BRUMPT (1949) nahm an, daß die Übertragung auf das Vieh durch Verschlucken oder Zerdrücken und Verreiben infektiöser Mücken auf der Haut und Eindringen in die Schleimhäute eine Rolle spielt. SмгтнBURN u. a. (1948) fanden anläBlich epidemiologischer Gelbfieberuntersuchungen verschiedene Mückenarten, unter ihnen Aedes tarsalis und deboerri sowie Eretmapodites chrysogaster, mit Rifttal-Fieber-Virus infiziert, wie die Verimpfung auf Affen und Mäuse zeigte (ВмттнBURN u. a., 1949 c). Weiter wurden infiziert gefunden: Aedes durbanensis (Muluigan, 1938, zit. Brumpt, 1949), A. circumluteolus (КокеRNot u. a., 1957a; W EINBRen u. a., 1957b) und A. africanus (WeINBREN u. a.. 1957b). Während einer Epizootie im südwestlichen OrangeFreistaat wurde das Virus in den Mücken Aedes caballus und Culex theileri festgestellt (Steyn und Schulz 1953, 1955). Das Virus soll sich mindestens 8 Tage im Mückenorganismus halten.

Nach Findlay und Howard (1952) kann das Rifttal-Fieber-Virus in parasitischen Würmern vorkommen, und zwar soll es in der Mäuseleber von den Larven der Taenia crassicollis aufgenommen werden.

Übertragungsversuche auf Menschen haben gezeigt, daß eine parenterale Infektion möglich ist. Dies würde bedeuten, daß in der Natur eine Übertragung durch Mücken von wild lebenden Tieren im Urwald erfolgen kann. Als natürlicher Überträger scheint nach SмIтнвURN u. a. (1949 c) Eretmapodites chrysogaster in Frage zu kommen. Hierauf wiesen schon die von FindLAY u. a. (1936) angestellten epidemiologisch-immunologischen Untersuchungen hin, welche im Blut der Eingeborenen von Uganda, Franz-Äquatorialafrika und dem damaligen angloägyptischen und französischen Sudan spezifische Schutzstoffe fanden. Dagegen stehen beim beruflichen Umgang mit verseuchtem Herdenvieh vielleicht Kontakt- und Inhalationsinfektionen im Vordergrund. Hier kommt also beim Arbeiten mit infektiösem Material (tierische Sekrete, Organe, Blut) das Eindringen des Virus durch die Haut (kleine Wunden) und Konjunktiva in Form von Schmier- und Schmutzinfektionen sowie durch die Schleimhäute der Respirations- und Verdauungswege in Form von Verschlucken oder Inhalation, in letzterem Falle auch von Kadaverstaub u. ä., in Frage. 
Das Rifttal-Fieber ist eine Berufskrankheit bei Schäfern, Landwirten, Schlächtern und Veterinären, welche mit kranken Tieren und infektiösen Kadavern in Berührung kommen (WeIss, 1957).

Nach TheIler (1951) weisen die bisherigen Untersuchungen auf einen Viruszyklus in Tieren der Wildnis und auch auf eine Dschungelform wie beim Gelbfieber hin, so daß also die Horntiere, insbes. Schafe, in der natürlichen Infektkette als sekundär infiziert betrachtet werden müssen und die Menschen, welche gewöhnlich erst von diesen infiziert werden, ein tertiäres, im allgemeinen letztes Glied in der Infektkette bilden. Gelegentlich kann auch eine Rückübertragung von infizierten Menschen während des virämischen Stadiums durch Mückenbiß auf das Hornvieh stattfinden.

Die Krankheit des Schafes geht mit Freßunlust, Erbrechen, blutigem Durchfall, Rückgang der Milchabsonderung, schleimig-eitrigem Nasensekret, schnellem Kräfteverfall, schwankendem Gang, Abort der trächtigen Tiere und Tod innerhalb von 24-48 St. einher. Die Sterblichkeit bei den Schafen erreicht 95\%. Die Lämmer sterben fast immer. Bei Ziegen und Rindern ist die Krankheit weniger schwer; die Letalität ist aber auch bei ihnen erheblich. Bei der Sektion findet man außer Prozessen in der Leber, welche mit den Gelbfieberveränderungen in der menschlichen Leber große Ähnlichkeit haben, hämorrhagische Enteritis, hämorrhagische Milznekrosen und Blutungsherde in der Niere (NAUck, 1952 b, s. auch SchUlz, 1951). vaN Rooyen und Rhodes (1948) geben außerdem subperikardiale Ecchymosen sowie Blutüberfülle und starke Injektion der Mesenterialgefäße und Vergrößerung der mesenterialen Lymphdrüsen mit Rindennekrose an. Die Krankheit der Horntiere, vorwiegend Schafe, Ziegen und Rinder ist nicht kontagiös. Das Virus wird offenbar nicht im Urin ausgeschieden (EASTERDAY, 1961).

\section{Klinik}

Die Inkubationszeit beträgt 4-6 Tage, manchmal weniger. Der Beginn ist plötzlich. Die wichtigsten Krankheitserscheinungen sind Schüttelfrost bei Beginn, Fieber, schlechtes Allgemeinbefinden, Appetitlosigkeit, Übelkeit, Erbrechen, Verstopfung, selten Durchfall, Schmerzen in Kopf, Gliedmaßen und Gelenken, die sehr schwer sein können. Häufig kommen Konjunktivitis mit Lichtscheu, starke Rötung des Gesichts und manchmal Nasenbluten vor. Akute Retinitis und Choroidoretinitis sind beschrieben worden (JouB ERT u. a., 1951). Die Temperatur steigt oft steil bis zu $40^{\circ} \mathrm{C}$, um aber nach 1-2 Tagen zur Norm zurückzukehren; nach 1-3 Tagen erfolgt ein neuer Anstieg auf $38-39^{\circ} \mathrm{C}$ (Sattelkurve) mit Verschlimmerung der klinischen Erscheinungen. Der Puls ist beschleunigt, der Blutdruck erniedrigt. Der zweite Anfall ist kürzer als der erste. Ein dritter und sogar vierter Temperaturanstieg mit erneuter Betonung der klinischen Symptome, aber ebenfalls kürzer und weniger ausgesprochen, kommen vor (s. Abb.41 und 42). Das Rifttal-Fieber des Menschen läßt also einen zyklischen Verlauf erkennen. Exantheme oder Nierenbeteiligung sind bisher nicht beobachtet worden. Im Gegensatz zur Zoonose fehlt beim Menschen der Viscerotropismus; insbes. bleibt die Leber unbeteiligt. Tastbare Vergrößerungen von Leber, Milz und Lymphdrüsen bestehen nicht, wohl aber Empfindlichkeit im Epigastrium und Druckgefühl oder Schmerzen im Abdomen oder in der Lebergegend. Schon zu Beginn besteht eine auffallende Leukopenie mit leichter relativer Lymphozytose und anschließender Agranulozytose. Findlay (1932) sah gelegentlich Myelozyten und Polynukleäre mit vakuolisierten Kernen.

Eine Beteiligung des ZNS geht aus den meningealen Symptomen (Schwindel, Nackensteifigkeit, Schlaflosigkeit und Delirien) hervor. Der Urin enthält gar keine oder nur geringe Mengen von Eiweiß, aber kein Virus. Die Krankheitsdauer richtet sich nach der Anzahl der Remissionen, ist aber meistens kurz. Die Heilung geht im allgemeinen ohne Komplikationen vor sich. Manchmal bleiben Kopfschmerzen, Myalgien und Schwäche bestehen und dehnen die Rekonvaleszenz über Wochen aus. Ebenso können Lymphopenie und relative Monozytose noch in der Rekonvaleszenz vorhanden sein.

Klinisch latent bleibende Infektionen scheinen vorzukommen. Wie aus einer tödlichen Laboratoriumsinfektion hervorgeht, kann die Krankheit auch beim Menschen einen schweren 


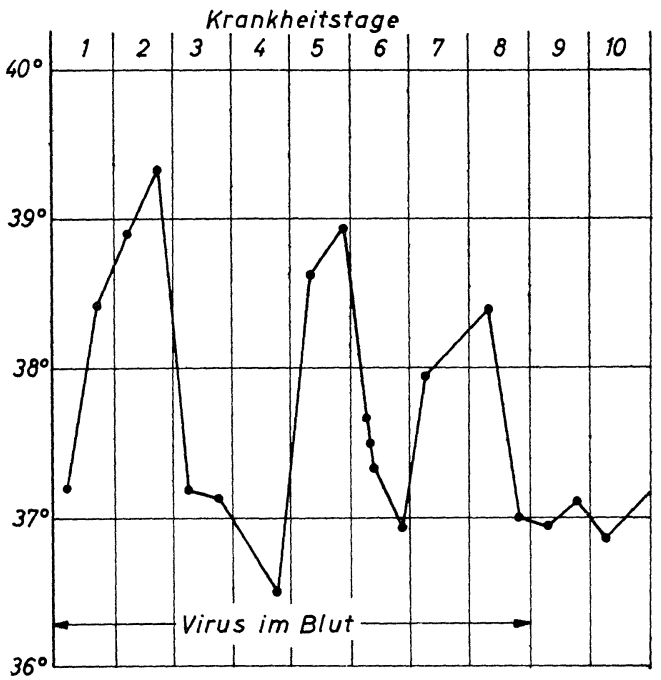

Abb. 41. Fieberkurve einer Rifftal-Fiebererkrankung des Menschen (nach Findlay, 1943)

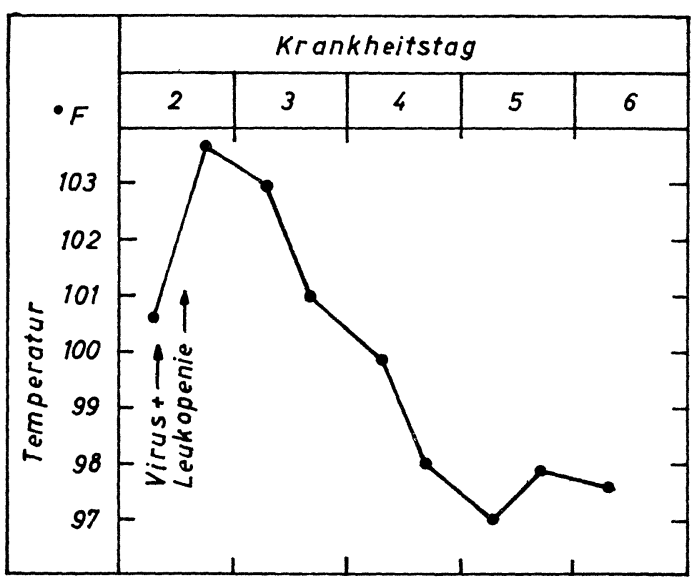

Abb. 42. Kurzdauerndes Fieber und Leukopenie einer Rifttal-Fiebererkrankung des Menschen (Laboratoriumsinfektion) (nach SmithburN u. a., 1949c) 
Verlauf nehmen, wobei dann Thromboseneigung besteht (Schwentier und Rivers, 1934). Rückfälle sind von Francis und Magill (1935) beobachtet worden (s. auch DaUbNeY u. a., 1931; van Rooy en und Rhodes, 1948; HöRIng, 1950; Joy eux und Sicé, 1950; Nauck, 1952 b; TheILER, 1952).

Curasson (1934) hielt eine in Französich-Sudan vorkommende zyklische Krankheit des Menschen für Rifttal-Fieber; es handelte sich um eine fieberhafte Erkrankung der warmen Jahreszeit, die mit Kopfschmerzen (Stirn- und Subokzipitalgegend), Gliederschmerzen, Übelkeit und Erbrechen einherging. Nach Rückgang des Fiebers kam es zu einem 2. Schub, der 4-6 Tage dauerte. Die Konjunktiven waren ikterisch verfärbt. Die Rekonvaleszenz dauerte lange. Gelbfieber konnte durch die negative Mäuseschutzprobe ausgeschlossen werden.

$\mathrm{Zu}$ den seltenen Komplikationen gehört ein zentraler seröser Befall der Retina, der gelegentlich von makulärer Schwellung und kleinen Hämorrhagien begleitet ist (ScHRIRE, 1951). Diese Retinaerkrankung beginnt einige Tage bis einige Wochen nach Fieberbeginn und geht mit Herabsetzung der Sehschärfe einher. Nach Rückbildung des Ödems pflegt letztere wieder hergestellt zu werden. In manchen Fällen beobachtete ScHRIRE jedoch eine dauernde Beeinträchtigung des Sehvermögens.

\section{Pathologie}

Da bisher nur ein tödlich verlaufener Fall von menschlichem Rifttal-Fieber beobachtet worden ist, sind die Kenntnisse seiner Pathologie noch nicht vollständig. Bei der tödlich verlaufenen Laboratoriumsinfektion, die von Schwentker und Rivers (1934) beschrieben worden ist, standen Thrombosen in der Vena cava, V. saphena und V.femoralis im Vordergrund. Ferner bestanden Pleuritis sowie Lungeninfarkte und -embolien beider Seiten. Die Leber erschien unverändert. Virus wurde in den Organen nicht gefunden. Während das Virus bei den empfänglichen Tieren ausgesprochen hepato- bzw. viscerotrop ist und hierin dem Gelbfiebervirus beim Menschen entspricht, scheint diese Eigenschaft des Rifttal-Fieber-Virus beim Menschen zu fehlen.

\section{Diagnose}

Die unbestimmten klinischen Erscheinungen, die auch an andere Krankheiten, z. B. Influenza, Malaria, Gelbfieber und Dengue denken lassen, gestatten die Diagnose des RifttalFiebers nur auf Grund anamnestischer und ätiologischer Erhebungen. Erkrankung im Anschluß an Kontakt mit verseuchten Schafen und anderen Tieren epidemiologisch in Frage kommender Gebiete ist bereits verdächtig. Gesichert wird die Diagnose durch den Tierversuch und die serologischen Untersuchungen. Blut, das während der ersten 3 Krankheitstage entnommen wird, ist virushaltig und erzeugt daher bei Mäusen besonders nach i.p. Injektion eine in 48 St. tödlich verlaufende nekrotisierende Hepatitis (Francis und Magill, 1935). Das in der Leber der infizierten Mäuse vorhandene Virus wird durch bekanntes Rifttal-Fieberimmunserum neutralisiert. Porterfield u. a. (1960) gelang der Virusnachweis in 2 Seren der akuten Phase mit der PBP in Hühnerembryo-Einschichtzellkulturen. Mit Rekonvaleszentenseren, die am 14. Tage oder später entnommen werden, kann zur Diagnose sowohl die NR als auch die KBR angestellt werden.

Serologisch lassen sich differentialdiagnostisch insbes. Gelbfieber und Dengue durch kreuzweise Immunisierungs- und Neutralisierungsversuche an Tieren (Affen, Mäuse) ausschließen (Findlay, 1932; Findlay und MacCallum, 1937b; van Rooyen und Rhodes, 1948). Außerdem ist auf die große epidemiologische und klinische Ähnlichkeit des Rifttal-Fiebers der Schafe, Rinder und Menschen mit der Wesselsbron-Infektion hinzuweisen (WeIss u. a., 1956). Das Wesselsbron-Virus gehört zu den Viren der Arbor-Gruppe B. 


\section{\%. Prognose}

Sie galt bis vor kurzem a]s durchaus gut. Bisher ist nur 1 Todesfall bekannt (Laboratoriumsinfektion, s. oben), bei dem eine multiple Thrombophlebitis am 45. Krankheitstage als Ursache anzunehmen war. Nach FREED (1951) sowie SCHRIRE (1951) können Dauerschäden vorkommen.

\section{Behandlung}

Sie ist rein symptomatisch. Im Vordergrund steht die Bekämpfung der Schmerzen. Zur Verhütung etwaiger Leberschäden wird eine intravenöse Schutzbehandlung mit großen Traubenzuckermengen empfohlen. FindLay (1936) hat bei einem schweren Fall mit Rekonvaleszentenserum, das er am 2. Krankheitstage einspritzte, eine schnelle Heilung erzielt.

\section{Immunbiologie}

Die menschliche Krankheit hinterläßt manchmal eine sehr lange anhaltende Immunität. Findlay und Howard (1952) gaben eine solche von mindestens 20 Jahren an, was praktisch einem dauernden Schutz entsprechen würde.

Das Virus entwickelt N-AK, KB-AK und HAH-AK (s. auch Schwentker und Rivers 1934; MacKenzie, 1935; Findlay, 1936). Sabin und Blumberg (1947) wiesen $N$ - $A K$ bereits am 4. Krankheitstag und bis zu 12 Jahren nach der Genesung nach. Im allgemeinen werden sie vom 14. Krankheitstag ab bis zum 5. Monat p.i. gefunden. Zur i.p. NR an der Maus werden nur 0,2 $\mathrm{ml}$ Serum-Virus (Blut oder Gewebe)-Gemisch benötigt.

Die $K B R$, die von Broom und FindLay (1933) angegeben worden ist, verläuft vom 14. Tage p.i. positiv.

Um die $H A H R$ mit infektiösem Mäuseserum als Antigen ausführen zu können, muß in diesem der bereits vorhandene Hemmstoff zerstört werden. Dies geschieht durch 3 tägige Aufbewahrung des infektiösen Serums bei $-24^{\circ} \mathrm{C}$ (Mrms und Mason, 1956).

Das Rifttal-Fiebervirus ist antigen bzw. immunbiologisch ein selbständiges Virus. Die serologischen Reaktionen zeigen kein Übergreifen auf Semlikiwald-Virus (Gruppe A) und Gelbfiebervirus (Gruppe B). Antigene Stammesunterschiede sind nicht gefunden worden.

\section{Prophylaxe}

Gefährdete Personen, welche mit infizierten Tieren oder sonstigem infektiösem Material Berührung haben, sollen mit Schutzhandschuhen arbeiten, um das Eindringen des Virus durch die Haut zu verhüten. Außerdem wird Schutz von Mund, Nase und Augen empfohlen, um das Eindringen des Virus in die Schleimhäute zu verhindern. In Ställen, Höfen und auf begrenzten Wiesen kommt außerdem Ausrottung der möglichen Virusreservoire (Nager) und Überträger (Arthropoden) in Frage. Hierdurch wird gleichzeitig ein Schutz des Viehs erzielt. Überführung der Herden in Höhen, wo es keine Mücken mehr gibt (1800-2500 m), bringt eine bestehende Zoonose zum Erlöschen.

$\mathrm{Ob}$ eine Schutzimpfung ganzer Bevölkerungen in den verseuchten Gebieten Afrikas praktische Bedeutung hat, ist noch unentschieden. Von um so größerer wirtschaftlicher Bedeutung könnte eine wirksame Schutzimpfung der Hornviehherden sein. FindLAY und Howard (1952) empfehlen für Schutzimpfungen der Tiere einen Mäusegehirnvirusstamm, der durch zahlreiche Passagen seinen Viscerotropismus verloren hat, aber noch immunisierend wirkt (s. auch Smithburn, 1949b; Steyn und Schulz, 1955; Henning, 1956). 


\section{F III. Colorado-Zecken-Fieber}

(Amerikanisches Gebirgs-Zecken-Fieber, Gebirgsfieber, nichtexanthematöses ZeckenFieber).

Virus $=$ Polyvectus, Becker spec nov.

Viscerophilus colorado Zhdanov und Korenblit.

\section{Einleitung}

Das Colorado-Zecken-Fieber (BEcker, 1926; 1930) oder amerikanische GebirgsZecken-Fieber (Toomey, 1931) ist seit über 100 Jahren im nordamerikanischen Felsengebirge bekannt. Noch Ende des 19. Jahrhunderts wurde angenommen, daß die Krankheit eine milde nichtexemathöse Form des Felsengebirgs-Fleckfiebers (Rocky Mountain Spotted Fever) wäre. Als klinische Einheit sui generis wurde sie erst von BEcKer beschrieben, der auch bereits die Übertragung durch den Biß der Zecke Dermacentor andersoni annahm, was von Toppisg u. a. (1940) bestätigt wurde. Die Krankheit ist gutartig und verläuft meist zyklisch mit einer biphasischen Fieberkurve.

Das Virus gehört zu keiner der bekannten Arbor-Virusgruppen nach TheILen und Casals (1959).

\section{2. Ätiologie}

Die ersten Isolierungen des Colorado-Zecken-Fiebervirus erfolgten durch Übertragung auf Menschen und Hamster.

Serienweise Infektionen von Menschen durch parenterale Einspritzung von Menschenblut oder -serum sind möglich. Die Inkubationszeit bei Versuchspersonen betrug gewöhnlich nur 3 Tage (Florio u. a., 1944, $1946 \mathrm{a}$, b, c; BLACK u. a., 1947). Sonst entsprach die experimentelle Erkrankung etwa der natürlichen. Die Hamsterpathogenität des Virus blieb während der Menschenpassagen unverändert.

Florio u. a. (1944, 1946a, b, c) übertrugen das Virus vom Menschen mit Blut oder Serum durch i.p. Infektion auf Goldhamster (Cricetus auratus). Die ersten Hamsterpassagen verliefen ohne Erscheinungen; erst von der 12. i.p. Passage ab begannen die Tiere zu sterben, allerdings ohne daß eine manifeste Erkrankung beobachtet wurde. Die Letalität betrug dann 25-50\% (s. auch Koprowski und Cox, 1946; Black u. a., 1947). Nur in der Milz wurden histologische Veränderungen gefunden, die bereits am 3. Tage p.i. ihren Höhepunkt erreicht hatten und sich auf Veränderungen des Zelltyps und des Aufbaus des lymphfollikulären Gewebes mit vollständiger oder teilweiser Aufhebung der sonst deutlichen Follikelbegrenzung erstreckten. In den großen mononukleären Zellen traten eosinophile und basophile Kerneinschlüsse auf. Die Hamster wiesen außerdem Leukopenie und im Zytoplasma abnorm großer Lymphozyten runde Körperchen von bis zu 500 mu Größe auf (BLACK u. a., 1947). Nach i.cer. Infektion kam es zu Virämie.

Koprowski und Cox $(1946,1947$ a) infizierten Mäuse (Schweizer Stamm) sowie braune Mäuse (Agouti) i.cer. Die Mäuse erkrankten 3-4 Tage p. i. mit Übererregbarkeit und struppigem Fell, dann Lähmungen der Beine und Erschöpfung. Der Tod trat etwa am 5.-7. Tag ein. Virus wurde im Blut, Gehirn und Rückenmark gefunden (s. auch DE BoeR u. a., 1947). 8 Tage alte Mäuse waren für eine i.p. Infektion ebenso empfänglich wie 28 Tage alte Mäuse für eine i.cer. Infektion (Koprowski und Cox, 1947a). Erhöhte Resistenz für eine i.p. Infektion wurde schon vom 14. Lebenstag beobachtet. OLIPHant und TibBs (1950) isolierten 10 Virusstämme aus dem Blut oder Serum Krankheitsverdächtiger durch i.p. Verimpfung auf 3-5 Tage alte Mäusesäuglinge (Schweizer Stamm). 5 Stämme erzeugten schon bei der Erstimpfung nach 5-8 Tagen zentralnervöse Erscheinungen. Die anderen 5 Stämme bedurften erst einer Blindpassage, indem das Gehirn der Mäuse am 5. Tage p. i. weitergeimpft wurde. 
Eine Adaptierung der in den Mäusesäuglingen gezüchteten Virusstämme auf über 16 Tage alte Mäuse war schwierig. Die Virusstämme verhielten sich antigen ähnlich wie der erste von Koprowski und Cox (1946) auf Mäusen adaptierte Stamm. Durch parenterale Injektion kleinster Virusmengen erwerben Mäuse eine Immunität gegen eine i.cer. Nachinfektion mit großen Mengen eines mäusegehirnadaptierten Virusstammes (Koprowski und Cox, 1947b). Durch mehrere i.p. Infektionen werden bei diesen Tieren Hyperimmunseren erhalten (DE Boer u. a., 1947). Burgdorfer und Lackman (1960), welche 3 Tage alte Mäusesäuglinge i.p. infizierten, stellten von Herz und Gehirn der nach $6 \rightarrow 8$ Tage erkrankten Tiere Gefrierschnitte her. Diese wurden mit Fluorescein isothiocyanat-markiertem Immunkaninchenglobulin gefärbt. Nur die infizierten Schnitte ergaben Fluorescenz.

HADLOW (1957) beschrieb bei Mäusesäuglingen, die mit Patientenblut oder Zeckensuspensionen infiziert worden waren, ausgebreitete Nekrose im Herzmuskel sowie mäßige Monozyteninfiltration mit anschließender Nekrose der Kleinhirnwindungen. Ferner traten geringfügigere entzündliche und degenerative Prozesse in der Gehirnrinde, dem Gehirnstamm und der Skelettmuskulatur, akute Thymusrückbildung, regressive Netzhautveränderungen und perizentrale Lebernekrose auf. Miller u. a. (1961) fanden bei i.cer. infizierten Mäusen und Hamstern ähnliche Gehirnprozesse, wie sie das Louping ill-Virus hervorruft: subkortikale Blutüberfüllung und petechiale Blutungen im Gehirn sowie Zerstörung der Purkinje-Zellen und der granulären Schicht im Kleinhirn. Lokale ischämische Nekrosen waren charakteristisch bei Mäusen, Hämorrhagien dagegen häufiger bei Hamstern. Außerdem bestanden intrazytoplasmatische fuchsinophile Einschlüsse in den Purkinje-Zellen und den Nervenzellen des Hippocampus und des Pons. Ähnliche Veränderungen traten bei Mäusen auch nach i.p. Infektion auf.

Gerloff und Larson (1959) gelang es, Rhesus-Affen mit einem mäuseadaptierten Virus i.v. und s.c. zu infizieren. Abgesehen von einer blutigen Diarrhöe bei einem Affen am 1. Tag p. i. und einer fieberhaften Reaktion bei 3 Affen blieben die Tiere ohne besondere Krankheitserscheinungen. Alle Affen bekamen aber eine Virämie, welche 15-50 Tage, im Durchschnitt 36 Tage dauerte, und eine Leukopenie mit Abnahme der Neutrophilen und relativer Vermehrung der Lymphozyten. Die makroskopischen und mikroskopischen Organuntersuchungen ergaben keine spezifischen Veränderungen. Nach 28 Tagen wurde geringe Virusmengen in Milz und Nieren, aber in keinen anderen Organen gefunden.

EkLuND u. a. (1958) fanden, daß Erdhörnchen (Citellus columbianus) für eine experimentelle Infektion empfänglich sind. Burgdorfer (1959) wies bei Stachelschweinen (Erethizon dorsatum), denen infizierte Zecken angesetzt oder eine infektiöse Zeckensuspension (D.andersoni) injiziert worden waren, Virämie nach. Diese hielt 23-50 Tage mit maximalen Virusmengen von $10^{3,8}$ bis $10^{5}$ Mäuse- $\mathrm{LD}_{50} \mathrm{ml}$ an. Bei Opossums und Baumwollratten wurde ebenfalls nach i.cer. Infektion Virus im Blut gefunden (Koprowski und Cox, 1947b).

Nach Miller u. a. (1961) sind Meerschweinchen für eine i.cer., nicht aber für eine i.p. Infektion empfänglich. Kaninchen und Lämmer ließen sich weder i.cer. noch i.p. infizieren.

Pickens und Luoto (1958) benutzten die KB-Zellkultur zur Isolierung und Züchtung des Virus. GerLoff und EKLund (1959) stellten in diesen Zellen nach Infektion mit dem Virus der 7. Hühnerembryopassage eine schnelle und komplette Zelldegeneration fest.

Passagenweise Kultivierung des Virus im Dottersack 7 Tage embryonierter Hühnereier ist möglich. Die Embryonen sterben nicht; es kommt aber zu einer generalisierten Infektion. In ihrem ZNS wird das meiste Virus gefunden. Da nach 4-5tägiger Bebrütung der höchste Titer erreicht ist, erfolgt dann Subkultivierung. Verdünnungen von $10^{-3,5}$ bis $10^{-4}$ sind nach i.cer. Injektion für Mäuse tödlich. Das Kulturvirus behält seine Mäuse- und Hamsterpathogenität (Koprowski und Cox, 1946, 1947b).

Das Colorado-Zecken-Fiebervirus läßt sich durch Berkefeld-N- und W-, sowie Seitz-EKFilter filtrieren (Koprowski und Cox, 1946). Florio u. a. (1946c) filtrierten das Virus durch Gradocolmembranen mit einer Porenweite von $24 \mathrm{~m} \mu$, woraus sie auf eine Teilchengröße von $10 \mathrm{~m} \mu$ schlossen. Koprowski und Cox (1947b) schätzten die Teilchengröße des im Mäusegehirn adaptierten Virus allerdings auf $35-50 \mathrm{~m} \mu$. Es gehört jedenfalls zu den kleinen Viren.

Die Widerstandsfähigkeit ist außerordentlich groß. Im gewöhnlichen Kühlschrank (Eisfach) bleibt es mindestens $3^{1} / 2$ Jahre am Leben, ebenso in der Tiefkühltruhe. Durch Gefrier- 
trocknung wird es ebenfalls haltbar gemacht. In Zeckensuspensionen scheint das Virus verhältnismäßig wenig haltbar zu sein (EkLund u. a., 1955). 30 Min Erhitzen auf $60^{\circ} \mathrm{C}$ zerstört das Virus.

\section{Epidemiologie; Übertragung}

Das Colorado-Zecken-Fieber schien bis vor kurzem auf die westlichen USA beschränkt zu sein, und zwar neben Colorado auf Utah, Wyoming und Idaho (Becker, 1930; ToppING u. a., 1940; Florio u. a., 1944, 1946 c). Es hat in den letzten Jahren ständig zugenommen. Es tritt nur dort auf, wo die Zecke Dermacentor andersoni vorkommt, die als einziger natürlicher Überträger auf den Menschen gelten muß, obwohl außerdem noch bei D. parumapertus (PHILIP und Hughes, 1953), D. occidentalis, D. albopictus und Otobius lagophilus (EkLund u. a., 1955) das Virus gefunden worden ist. Florio u. a. (1950) fanden natürlich infizierte D.andersoni in 3 verschiedenen Gebieten Colorados und konnten 9 Virusstämme durch Verimpfung von Zeckensuspensionen auf Hamster isolieren. EkLund (zit. Cox, 1952) sowie Ekuund u. a. (1955) wiesen das Virus auch im Bitterroot-Tal in Westmontana bei D.andersoni und Menschen durch Übertragung auf Mäusesäuglinge nach. Außerdem fanden FLoRIo u. a. (1950) natürlich infizierte Hundezecken (D. variabilis) in Staten Island im Staate New York, also im Osten der USA, ohne daß hier menschliche Erkrankungen bekannt geworden sind. Miller (1960) versuchte vergeblich, das Virus bei D. variabilis zu isolieren.

Wild lebende Tiere scheinen als Virusreservoire in Frage zu kommen. EkLund u. a. (1958) fanden serologisch einen Anhalt dafür, daß Erdhörnchen (Citellus columbianus columbianus) auch in der Natur infiziert sind. Die Goldmantelhörnchen, bei denen das Virus besonders häufig (28 Isolate von 61 Tieren) gefunden wurde, sind die bevorzugten Wirte der Zecke D. andersoni. In Gebieten, in denen diese Tierart heimisch ist, war die Infektionshäufigkeit der Zecken $16 \%$. Das Virus wurde bei ihnen in den Monaten März, Mai und Juni isoliert. N-AK wurden in den Seren der schwarzschwänzigen Jack-Kaninchen in Nevada nachgewiesen. Auf diesen Tieren parasitiert D. parumapertus, welcher auch den Menschen befällt. Burgdorfer und EkLund (1960a, b) wiesen das Virus in einem Erdhörnchen und einer Hirschmaus (Peromyscus maniculatus) 16-50 Tage lang nach. Die Hirschmaus zeigte Titer von $10^{2}-10^{3} \mathrm{LD}_{50} / \mathrm{ml}$ Blut für Mäuse. Backenhörnchen (Eutamias amoenus) zeigten Blutvirustiter von $10^{4,5}$ bis $10^{6,2}$ und Goldmantelhörnchen (Citellus lateralis tescorum) solche von $10^{3,5}$ bis $10^{5} \mathrm{LD}_{50} / \mathrm{ml}$ Blut für Mäuse. Auch Kiefernhörnchen (Tamiasciurus hudsonicus richardsoni) können infiziert sein.

Rozeboom und BURgdorfer (1959) infizierten Nymphen von D.andersoni durch Verfüttern von Blut, dessen Viruskonzentration $10^{1,5}$ bis $10^{4,5} \mathrm{LD}_{50}$ betrug. Die Zecken blieben bis ins Erwachsenenstadium Virusträger. Von der Verfütterung an blieb der Virustiter konstant, bis die Zecken sich zur Erwachsenenform häuteten, worauf die Konzentration zunahm, um 1,5-3,7 log höher als die verfütterte Viruskonzentration zu werden (s. auch BURGDORFER, 1959). Nach Burgdorfer und Ekuund (1960a, b) erwarben Nymphen und Larven von D. andersoni, die an infizierten Backenhörnchen und Goldmantelhörnchen gefüttert worden waren, eine permanente Infektion. Zeckenlarven, die an kolumbianischen Erdhörnchen gefüttert worden waren, bekamen eine vorübergehende Virämie; sie waren aber nicht mehr infektiös, wenn sie das Erwachsenenstadium erreicht hatten.

Nach Florio und Stewart (1947) sowie Florio und Miller (1948) wird die Infektion der Zecken transovariell von Generation zu Generation übertragen. Das Virus läßt sich im Larven-, Nymphen- und Erwachsenenstadium nachweisen, obwohl in den Eiern der ursprünglich infizierten Zeckenweibchen kein Virus gefunden wurde.

EKLUNd (1958) nahm dagegen an, daß das Virus bei den Zecken nicht transovariell übertragen wird. Das Überwintern des Virus scheint bereits genügend durch sein Fortleben in den blutsaugenden Stadien der Zecken allein und damit auch das Bestehenbleiben der Infektion in endemischen Gebieten erklärt zu sein (s. auch REEVES, 1961). Unter natürlichen Bedingungen wird das Virus in den überwinternden Nymphen und erwachsenen Zecken nachweisbar, sobald die klimatischen Bedingungen gestatten, sie zu sammeln (BURGDORFER und EkLund, 1959). 
Das Colorado-Zecken-Fieber ist jahreszeitlich gebunden, und zwar tritt es vorwiegend im Frühjahr und Herbst auf, während es in der trockenen Jahreszeit verschwindet. Es geht mit dem Auftreten der Zecken parallel und hat seinen Höhepunkt, wenn auch die Zeckenhäufigkeit am größten ist, was wiederum der Fall ist, wenn der Erdboden und die ihn bedeckende Vegetation feucht ist (Cox, 1959). Die Krankheit wird vorzugsweise bei männlichen Erwachsenen gefunden, die durch ihren Beruf häufiger und leichter Zeckenbissen ausgesetzt sind (Waldarbeiter, Viehhirten, Fischer). Die Krankheit wird mit zunehmendem Freiluftleben im Westen der USA häufiger (Johnson u. a. 1960). Bei Reisenden, die 4-5 Tage nach Verlassen des Colorado-Zecken-Fiebergebietes erkranken und Zeckenbißstellen aufweisen, sollte an eine Infektion gedacht werden.

\section{Klinik}

Florio u. a. (1944) beschreiben die Klinik des Colorado-Zecken-Fiebers folgendermaßen:

Es handelt sich um eine milde, nicht tödliche Infektion, die große Ähnlichkeit mit Dengue aufweist mit Ausnahme des Fehlens eines Exanthems. Die Inkubationszeit ist nur schwer zu bestimmen, da es meistens unmöglich ist, den Zeitpunkt des infizierenden Zeckenbisses zu ermitteln. 3-6 Tage werden angenommen. Prodromalerscheinungen fehlen. Die Krankheit beginnt plötzlich mit Frösteln. Es bestehen Kopf- und Rückenschmerzen, besonders der Lumbalgegend; allgemeine Schmerzhaftigkeit des ganzen Körpers, besonders der Muskeln und Sehnenansätze in den Gelenkgegenden und Retrobulbärschmerz mit leichter Lichtscheu sind Hauptsymptome. Charakteristisch sind ferner Appetitlosigkeit mit Übelkeit und gelegentlich Erbrechen. Mit Einsetzen der Symptome steigt das Fieber schnell auf gewöhnlich höchstens $39^{\circ} \mathrm{C}$ mit entsprechender Pulsbeschleunigung. Diese Erscheinungen halten gewöhnlich 24-72 Stunden an, worauf Temperatur und Puls schnell zur Norm zurückkehren und alle Symptome vollständig verschwinden. Die Patienten fühlen sich 24-60 Stunden wohl, wobei die Temperatur meist subnormal ist, und können ihrer gewohnten Beschäftigung nachgehen.

Die zweite Phase der Krankheit gleicht der ersten, kann aber 12-24 Stunden länger dauern. Allerdings sind die Erscheinungen und das Fieber weniger ausgesprochen, es sei denn, daß die erste Phase milde war, denn dann ist die zweite schwerer. Ein einziger, aber auch 3 Anfälle kommen vor. Nach Verschwinden der Erscheinungen fühlt sich der Kranke bereits ziemlich wohl, abgesehen von einer geringen Schlaffheit während 4-5 Tage.

Objektiv findet man gewöhnlich Fieber, beschleunigten Puls und gelegentlich leichte Konjunktivitis. Das Blutbild ergibt immer eine Abnahme der weißen Blutzellen: es kommt zu einer Leukopenie bis herab auf 2000 Zellen $/ \mathrm{mm}^{3}$ während des Rückfalles. Die Milz kann leicht vergrößert sein.

Nach LLOYd (1951) verlaufen über 90\% der Fälle zyklisch mit sattelförmiger Fieberkurve. Auch Meiklejohn (1957; zit. Cox, 1959) weist auf das Überwiegen dieser zyklischen Verlaufsform hin, während Cox (1959) die Zahl monophasischer Temperaturkurven für nicht so selten hält.

Meiklejohn (1957) sah in 3 Fällen Beteiligung des ZNS, von denen 2 das Bild einer Encephalitis boten, wie sie auch durch andere Viren, z. B., SLE- und WEE-Viren, hervorgerufen werden. Im 3. Falle bestand eine gutartige Meningitis ohne erkennbare Beteiligung des Gehirns mit Nacken- und Rückensteifigkeit und leichter Zellvermehrung in der Rückenmarksflüssigkeit. Nach Cox (1959) scheint eine klinische Beteiligung des Zentralnervensystems beim Colorado-Zeckenfieber aber nur selten zu sein. EkLund u. a. (1955) stellten allerdings fest, daß bei Beteiligung des Zentralnervensystems die Krankheit durchaus nicht einen so harmlosen Charakter hat, wie allgemein angenommen wird. Sie fanden ein Kind komatös und 2 Kinder delirös und desorientiert; ein Kind mit Encephalitissymptomen und Hämorrhagien starb (EkLund, 1957; zit. Cox, 1959; s. auch Silver u. a., 1961).

Zweiterkrankungen sind nicht bekannt. Eine Infektion erzeugt eine starke Immunität, wie Florio u. a. (1944) in Menschenversuchen fanden. 


\section{Pathologie}

Das pathologische Bild des Colorado-Zecken-Fiebers beim Menschen ist noch nicht bekannt.

\section{Diagnose}

Die Diagnose ist im wesentlichen eine Differentialdiagnose gegen Dengue und FelsengebirgsFleckfieber. Colorado-Zecken-Fieber und Dengue gleichen sich klinisch und hämatologisch (Simmons u. a., 1931 c; Florio u. a., 1946a) so weitgehend, daß man an die gleiche Krankheit denken könnte. Unterschiede bestehen in der Übertragungsweise: Colorado-Zecken-Fieber wird durch Zecken, Dengue durch Aedes-Mücken übertragen. Beim Colorado-Zecken-Fieber fehlen außerdem der Ausschlag und die meist lange Rekonvaleszenz, die beide für Dengue typisch sind. Biphasische Fieberkurve (Rückgang des Fiebers am 3. oder 4. Tag, erneuter Anstieg am 5. oder 6. Tag). Ein regelmäBiger Befund ist Granulozytopenie bei jedem Fieberanstieg mit schwerer toxischer Granulierung und Vermehrung der Jugendformen. Die Lymphozyten zeigen Abnormitäten vom Türk-Typ oder Virozytentyp. Im Knochenmark findet man entsprechend Aufhören des Myelozyten-Metamyelozytenstadiums (Johnson u. a., 1960).

Der Virusnachweis gelingt in der virämischen Phase am schnellsten durch Blutübertragung auf Hamster. Bei Dengue werden diese Tiere nicht infiziert. Serologische Teste (NR im Mäuseschutzversuch und in der Gewebekultur, KBR) gestatten ebenfalls eine Unterscheidung beider Krankheiten (O Liphant und Tibb, 1950; GrrlofF und EkLund, 1959). Nach EkLund (1957; pers. Mitt. an Cox, 1959) ist die NR beim Colorado-ZeckenFieber eine brauchbarere diagnostische Reaktion als bei den meisten anderen Viruskrankheiten. Die N-AK erscheinen allerdings u. U. erst 26 Tage nach Krankheitsbeginn. KB-AK werden nach 14-20 Tagen nachweisbar und bleiben dies bis zu 260 Tagen (Thomas und EkLund, 1960). Etwa 80\% der nach der 4. Krankheitswoche entnommenen Seren enthalten AK.

\section{Prognose}

Trotz der gelegentlich auftretenden zentralnervösen Lokalisation der Krankheit gilt die Prognose allgemein als gut. Die Letalität ist gleich 0 .

\section{Behandlung}

Sie ist rein symptomatisch. Bettruhe ist zu empfehlen.

\section{Immunbiologie}

Beim Menschen werden N-AK und KB-AK gebildet. Erstere bleiben etwa 3 Jahre bestehen. Thomas und EkLund (1960) fanden bei einer Reihe von Kranken wohl N-AK, aber keine $\mathrm{KB}-\mathrm{AK}$.

Die $N R$ wird meist an der Maus als Mäuseschutzprobe ausgeführt. GerLoff und EkLund (1959) empfehlen die NR in Kulturen von KB-Zellen. Das Serum-Virusgemisch wird 1 St. bei' $36^{\circ} \mathrm{C}$ gehalten, dann mit trypsinierten Zellsuspensionen in Kulturröhrchen gefüllt und weiter bei $36^{\circ} \mathrm{C}$ bebrütet. Nach 3 Tagen können die ersten Ergebnisse unter dem Mikroskop abgelesen werden. Dann wurde die Flüssigkeit ersetzt und nach nochmaliger 2 tägiger Bebrütung das Schlußresultat abgelesen. Das Immunserum verhinderte den ZE. Bei vergleichenden Untersuchungen mit 613 Menschenseren verdächtiger Fälle erwiesen sich beide NR- 
Formen als gleich spezifisch und empfindlich. Beide Reaktionen ergaben ferner, daß die AK nicht früher als am 7. Krankheitstag festgestellt werden konnten.

Für die KBR gewannen DE BoER u. a. (1947) brauchbare Antigene, indem sie infektiöse Mäusegehirne lyophilisierten und nach dem Verfahren von DE BoeR und Cox $(1946,1947)$ mit Benzol extrahierten. Antigenextraktionen waren auch mit Toluol und Dichloräthylen möglich. Thomas und EkLund (1960) bekamen gute Antigene durch Aceton-Äther-Extraktion der infizierten Mäusesäuglingsgehirne nach CASALS und BRowv (1954). Kreuzweise KBR zwischen Colorado-Zecken-Fieber-Immunseren und heterologen Antigenen (andere Viren und Rickettsien) ergaben eine Spezifität der Reaktion für das Colorado-Zecken-Fieber.

Die Ähnlichkeit von Colorado-Zecken-Fieber und Dengue führte bereits Florio u. a. (1946a) zu Immunitätsuntersuchungen an Menschen und Tieren: 4 mit Dengue-Virus immunisierte Menschen wurden mit Colorado-Zecken-Fieber-Virus (Hamster-MenschenPassage) nachinfiziert. 3 Personen erkrankten typisch. Umgekehrt erzeugte ColoradoZecken-Fieber-Virus auch keine Immunität gegen Dengue. Pollard u. a. $(1946 \mathrm{a}, \mathrm{b})$ fanden auch in Meerschweinchenversuchen keine immunologische Verwandtschaft beider Viren.

Colorado-Zecken-Fieber-Virus und Bullis-Fieber-Virus sind 2 verschiedene Erreger, denen nur gemeinsam ist, daß sie durch Zecken übertragen werden.

In der NR mit Mäusen (Koprowski und Cox, 1946, 1947a) sowie in der KBR (De BoeR u. a., 1947) wurde gezeigt, daß das Colorado-Zecken-Fieber auch mit folgenden Viren nicht antigen verwandt ist: REFSE, Springkrankheit, VEE, JE, SLE, LCM, Tollwut und Gelbfieber (s. auch Miller u. a., 1961).

\section{Prophylaxe}

Fernhaltung und rechtzeitige Entfernung der Zecken von der Haut sind die wichtigsten Verhütungsmaßnahmen. Geeignete Schutzkleidung (hohe Stiefel, Gamaschen, Socken, die über die Hosenbeine gezogen werden) wird empfohlen. Die Kleidung kann ferner mit insektiziden Mitteln behandelt werden (Dibutylphthalat, Dimethylphthalat) (s. auch Cox, 1959).

Eine Schutzimpfung mit lebendem Hühnerembryo-adaptiertem Virus ist von Koprowski und Cox (1947b) zunächst an 4 Personen vorgenommen worden; es entstand eine gute Immunität. Koprowski u. a. (1950) wiederholten diese Impfungen an weiteren 20 Personen; diese bekamen allerdings Reaktionen, die zum Teil dem Colorado-Zecken-Fieber glichen. Die Stärke der Reaktionen erlaubt noch keine Anwendung dieses Virus als Impfstoff in der Praxis.

\section{F IV. Epidemisches hämorrhagisches Fieber}

(Hämorrhagische Nephroso-Nephritis; fernöstliches hämorrhagisches Fieber; Jaroslavhämorrhagisches Fieber).

\section{Einleitung}

Im Sommer 1951 erkrankten auf dem koreanischen Kriegsschauplatz über 2000 Angehörige der UNO-Streitkräfte mit 122 Todesfällen an »epidemischem hämorrhagischem Fieber". Bis zum Abschluß der Kampfhandlungen 1954 war die Erkrankungsziffer auf etwa 3000 gestiegen. Das zunächst für eine neue Krankheit gehaltene Syndrom ist im Fernen Osten schon früher (1938-41) als "Kriegskrankheit» bekannt gewesen und somit von den Ärzten der UNO-Truppen in Korea nur wiederentdeckt worden. Das Krankheitsbild soll zum erstenmal 1930 von russischen Ärzten während einer Epidemie in Sibirien beschrieben worden sein (MaYer, 1952 b; Polonovski, 1953; GaJdusek, 1956a, b). Es ist dann alljährlich im Tal des Amur und dessen Nebenflüssen zu neuen Ausbrüchen gekommen. 
Shapiro und Barkagan (1960) weisen darauf hin, daß das hämorrhagische Fieber bereits 1110 in Zentralasien von dem persischen Arzt Dsurshoni beschrieben worden ist; dieser nahm bereits einen Gliederfüßler, offenbar eine Vogelmilbe, als Überträger an.

Die Russen bezeichneten die Krankheit teils nach den Gebieten ihres Auftretens, teils nach den am meisten hervortretenden Symptomen: Uzbekistan-Fieber, Omsker Fieber, Krim-Fieber, Fernost-Fieber, Bukowina-Fieber, später fernöstliche Nephroso-Nephritis, endemische hämorrhagische Nephroso-Nephritis (Smorodintsev u. a., 1944b; Chumakov, 1948 a, b; Bilibin, 1950). Letztere wird auch in Transkarpathien angetroffen (Avakian u. a., 1959).

Japanische Ärzte beobachteten die Krankheit im Amurgebiet sowie in der Mandschurei während der dortigen Feldzüge und auch später. Die Japaner sprachen von mandschurischem hämorrhagischem Fieber, mandschurischem Songo-Fieber, Korin-Fieber, Nidoko-Fieber, Kokuko-Fieber, Kokko-Fieber, Heiho-Fieber, Tayinshan-Krankheit, schließlich aber von epidemischem hämorrhagischem Fieber. Diese Bezeichnung wird neben der in Rußland gebräuchlichen "hämorrhagische Nephroso-Nephritis heute vielfach gebraucht (KITANo, 1944a, b; Hsiao, 1946; Takami, zit. Gauld und Craig, 1954; Marshall, 1954).

Der koreanische Typ der Krankheit ist neuerdings im Gebiet von Astrachan festgestellt worden (Zeitlenok u. a., 1957). Auch in Europa (Schweiz und Skandinavien), Afrika und Südamerika sind ähnliche Erkrankungen beobachtet worden (Мүгнам, 1951), so daß die verschiedenen Formen des hämorrhagischen Fiebers nicht als Tropenkrankheit bezeichnet werden können.

LeEdham (1953) definiert das epidemische hämorrhagische Fieber als eine akute einerseits fulminante, oft tödlich verlaufende, andererseits gutartige Krankheit, die durch schwere Toxämie, ausgebreiteten Kapillarschaden und hämorrhagische Diathese mit besonderer Beteiligung der Nieren gekennzeichnet ist (s. auch Symposium 1953, 1954).

Weitere Literatur zu Einleitung:

Smorodintsev (1948), Smadel (1953), Smorodintsev u. a. (1953), Höring (1954), Avakian und Lebedev (1955), Bieling (1955), Trencseni u. a. (1955), Chumakov (1956).

\section{2. Ätiologie}

ZhDaNov (1957) rechnet die Erreger der verschiedenen hämorrhagischen Fieberarten und die der Zecken-Encephalitiden zu einer gemeinsamen Virusfamilie, da das Virus des hämorrhagischen Fiebers in den fernöstlichen Bezirken Rußlands dem Zecken-Encephalitisvirus nahesteht.

PaNDIT (1960) teilt die hämorrhagischen Fieber ätiologisch in 4 Gruppen:

1. REFSE-Komplex unter besonderer Berücksichtigung des Omsker und des Kyasanurwald-Fiebers. Er glaubt, daß auch die biphasische (biundulante) Meningoencephalitis (= biphasisches Milchfieber) von Zentral- und Osteuropa, Louping ill (Springkrankheit) der britischen Schafherden und verschiedene Encephalitiden, die kürzlich in Skandinavien beschrieben worden sind, ferner das TP 21-Virus, das aus Zecken, die von Nagetieren in Malaya gesammelt worden waren, isoliert wurde, dazu gehören.

2. Hämorrhagisches Fieber von Philippinen und Thailand, das Halstead und Buescher (1961) inzwischen als zur Arbor-Virusgruppe A gehörig identifizierten.

3. Hämorrhagische Nephrosonephritis der russischen Literatur und das Korea-hämorrhagische Fieber der amerikanischen Literatur. Dieser Typ kommt aber nicht nur im Fernen Osten, sondern auch in Europa als Jaroslav-hämorrhagisches Fieber (Moskau, Bulgarien) vor.

4. Hämorrhagische Fieber verschiedener Ätiologie: hämorrhagische Fieber der Krim und von Uzbekistan, ein hämorrhagisches Fieber von Bulgarien, das immunologisch mit dem Omsker Fieber (Arbor-Virusgruppe B) verwandt zu sein scheint, und ein weiteres hämorrhagisches Fieber von Bulgarien, das nicht mit dem Jaroslav-Fieber identisch ist. 
Im allgemeinen erfolgt die Übertragung der Krankheiten dieser 4 Gruppen durch Zecken oder Mücken; nur beim biphasischen Milchfieber gibt es einen sekundären Übertragungszyklus durch virushaltige Ziegenmilch; auch Kuhmilch wurde infiziert gefunden. In der 3. Gruppe kommen Milben als Überträger in Frage. In der 4. noch am wenigsten definierten Gruppe bilden Zecken der Hyalomma-Art die Überträger beim Krim- und Uzbekistan-Fieber.

Japanische Autoren erzeugten beim Menschen durch Einspritzung einer Suspension von Milben, die von in der Mandschurei und Korea häufig vorkommenden Feldmäusen gesammelt worden waren, typisches hämorrhagisches Fieber. Die Krankheit konnte auf weitere Versuchspersonen mit Krankenserum i. v., s.c. und i.m. übertragen werden. Eine Infektion von Menschen war auch mit Berkefeld-N-Filtraten von Patientenserum und -urin möglich (SмoroDINTSEv u. a., 1944b; MAYER, 1952 a; GAJdusek, 1956b). Der Erreger war außerdem durch Chamberland $\mathrm{L}_{2},{ }_{3}, 5,8$-Kerzen, sowie. Seitz-EK-Filter filtrierbar und konnte 81 Tage bei $-70^{\circ} \mathrm{C}$ lebend erhalten werden (s. auch Kitano, 1944a; W. D. Hughes, 1952; Takami, zit. Gauld und Craig, 1954).

Die russischen Autoren unterscheiden nach MüLLER-Dietz (1957) folgende Viren:

1. Haemorrhagogenes crimae (Chumakov u. a., 1944), den Erreger des hämorrhagischen Fiebers der Krim oder Uzbekistans, der für Menschen, Katzen und junge Kaninchen pathogen ist. Er läßt sich auf Affen, Katzen und weiße Mäuse übertragen, bei denen es zu einem gutartigen hämorrhagischen Syndrom kommt. Er läßt sich im embryonierten Hühnerei züchten, passiert Berkefeld-V- und N- sowie Seitz-Filter. Im getrockneten Zustand hält er sich mindestens 2 Jahre lang.

2. Haemorrhagogenes sibiricus (Chumakov u. a., 1947), den Erreger des Omsker hämorrhagischen Fiebers, der nach neueren Untersuchungen (s. auch Olitsky und Clarke, 1959) zur Arbor-Virusgruppe B gehört (s. dort).

3. Haemorrhagogenes orientalis (MASAJI u. a., 1943), den Erreger des hämorrhagischen Fiebers in der Mandschurei, der für Affen und Mäuse pathogen ist.

4. Haemorrhagogenes nephritis (Smorodintsev, 1940), den Erreger der Nephroso-Nephritis, der für Katzen und verschiedene Mäusearten pathogen ist.

Zhdanov (1957) schließt als 5. Erreger dieser Gattung den "Haemorrhagogenes suis" an, den er für das Virus des hämorrhagischen Fiebers der Schweinehirten in der Schweiz hält.

Die Isolierungs-, Übertragungs- und Züchtungsversuche der japanischen und russischen Forscher konnten bisher noch nicht bestätigt werden.

Weitere Literatur zu Ätiologie:

Chumakov $(1956,1957)$.

\section{Epidemiologie; Übertragung}

Es wird vermutet, daß das epidemische hämorrhagische Fieber schon lange vor 1950 un* erkannt in Korea geherrscht hat. Die ersten Fälle wurden dort aber erst 1954 in der zivilen Landbevölkerung beobachtet, nachdem diese wieder seßhaft geworden war; es kam zu epidemischen Ausbrüchen; am häufigsten betroffen war das Alter von 30-49 Jahren. Todesfälle traten nur im Alter zwischen 10 und 39 Jahren auf. Die Sterblichkeit betrug 11,1\% der Erkrankten (Dodge u. a., 1956).

Über die bisher bekannte geographische Verteilung der hämorrhagischen Fiebergruppe gibt Abb. 43 Auskunft.

Als Wirtstiere des Erregers kommen Feldmäuse (Apodemus agrarius) ebenso wie die in Sibirien beheimatete Wühlmaus (Microtus michnoi s. fortis) in Frage. Es ist aber nicht ausgeschlossen, daß es noch andere Nager als natïrliche Virusreservoire gibt, z. B. die Wanderratte (Rattus norvegicus) und die Hausmaus (Mus musculus) (SсHмIDT, 1953; Dews und Marshall, 1954). Das epidemische hämorrhagische Fieber ist demnach pri- 
mär eine Zoonose der Nagetiere, die nur gelegentlich durch Arthropoden auf den Menschen übertragen und damit eine Zoo-Anthropronose wird.

Übertragung durch Kontaktinfektion kann ausgeschlossen werden, da noch keine Erkrankungen bei Ärzten und Pflegepersonal beobachtet worden sind. Auch Übertragung durch Lebensmittel und Wasser findet nicht statt (Sснміdт, 1953). GAJdusek (1956 b) weist darauf hin, daß infolge Auftretens des Fiebers auch im Winter fliegende Überträger, also in erster Linie Mücken, ausgeschieden werden können. Auf den infizierten Nagern parasitierende Arthropoden, die auch am Menschen Blut saugen, wie Flöhe, Läuse und Zecken, scheinen nur gelegentlich Überträger zu sein (Traub u. a., 1954; Germer, 1955), während Milben (Laeleps jettmari Vitzhum), die von GAuld und CraIg (1954) in epidemiologischen Untersuchungen (Korea) aufgestellten Bedingungen für den noch unbekannten Überträger erfüllen:

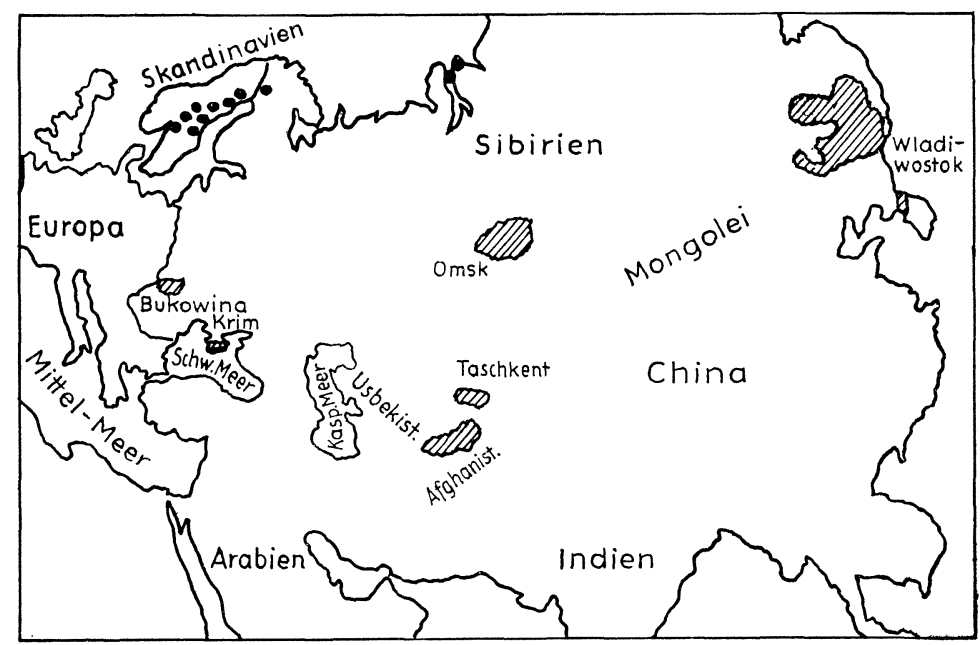

Abb. 43. Geographische Verbreitung der hämorrhagischen Fieber (nach GAJdusek, 1953)

1. größte Aktivität während der trockenen Frühjahrs- und Herbstmonate und geringe Aktivität während des übrigen Jahres; 2. weite Verbreitung über ländliche Teile des Endemiegebietes; 3. begrenzte Bewegungsmöglichkeit; 4. Infektiosität nur innerhalb umschriebener Plätze im Endemiegebiet; 5. Übertragung der Krankheit von einem Fokus auf den Menschen nur während einer kurzen Zeitspanne; 6. Fähigkeit, den Menschen zu infizieren, ohne Spuren über die Art und Weise der Übertragung zurückzulassen. Der Aktivitätsabfall der Milben in der Sommermitte entspricht in der Tat auch der Abnahme der Erkrankungshäufigkeit in dieser Jahreszeit. Andererseits wird auch durch große Regenfälle die Expositionsmöglichkeit der Menschen gegenüber Milben herabgesetzt. In Korea sind die Larven der Trombicula-Milben, welche ebenfalls Ektoparasiten der Feldmäuse sind, im ganzen Winter auf diesen zu finden. Traub u. a. (1954) stellten fest, daß sie besonders häufig an Orten vorkamen, wo auch Infektionen auftraten. Der Trombicula-Larven (Chigger)-Index, d. h. die Zahl der auf dem Nager gefundenen Larven entsprach etwa der Erkrankungshäufigkeit. Der Gipfel der Larvenhäufigkeit ging dem Gipfel der Erkrankungshäufigkeit um etwa 2-4 Wochen (Inkubationszeit) voraus. Es wird deshalb angenommen, daß die Larven und nicht die Milben selbst die Virusüberträger sind. Der Chigger-Index der beiden wichtigsten Seuchenreservoire, der Feld- und Wühlmäuse, fiel in den mittleren Sommermonaten und späten Herbstmonaten 2-4 Wochen vor dem plötzlichen Abfall der Erkrankungshäufigkeit (s. auch ToKUDA, 1941; 


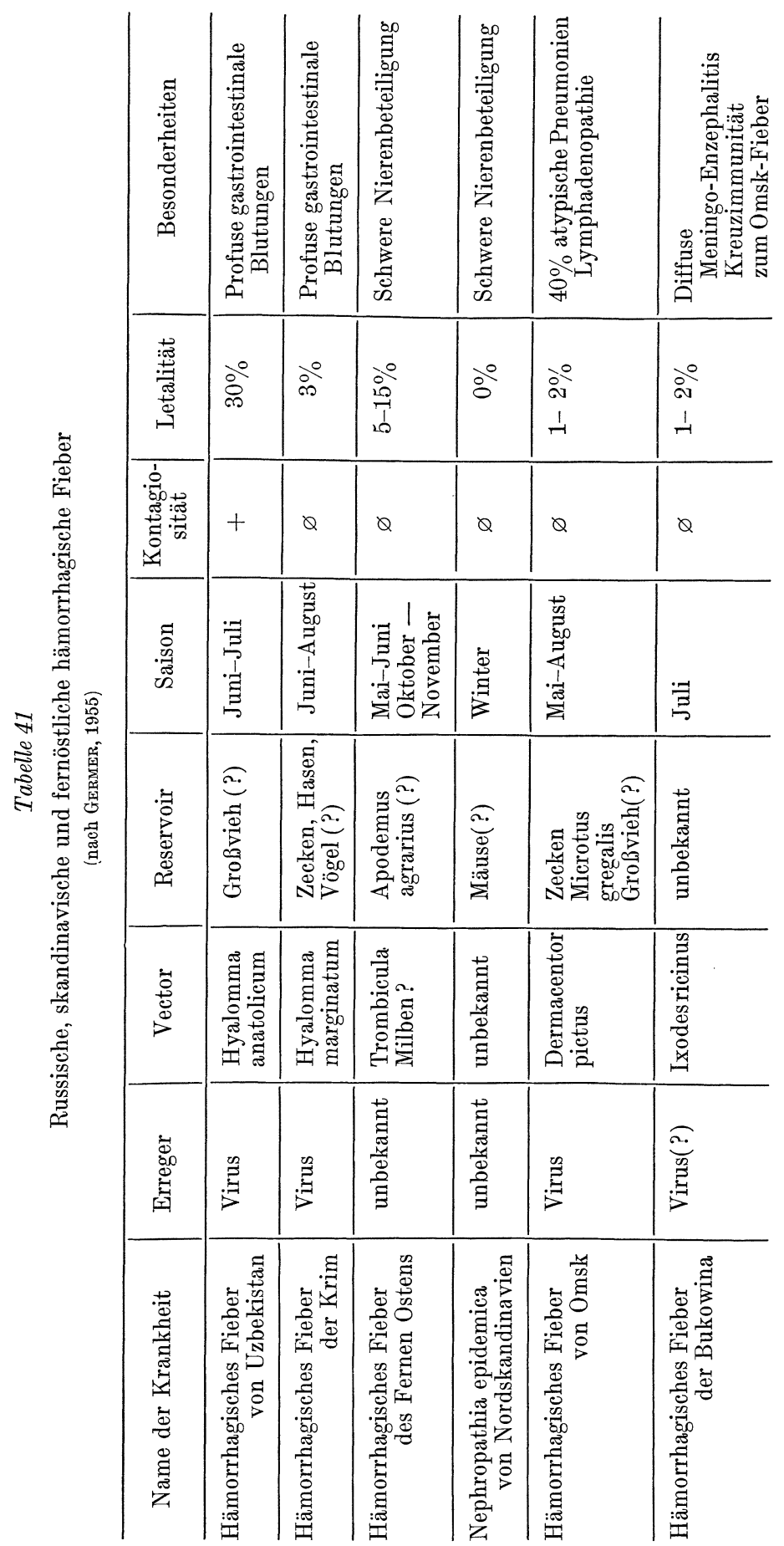


Lipovsky, 1951; Asamura, 1952; Wharton und Fuller, 1952; Barnett und Toshioka, zit. Marshall, 1954). Gajdusek (1956b) weist auf 2 Häufigkeitsgipfel innerhalb des Jahres hin: Ende Frühjahr - Anfang Sommer (Mai-Juni-Gipfel und Herbst Oktober-NovemberGipfel), die bereits den Russen und Japanern aufgefallen waren (s. auch Murovannyi, 1954; Dodge u. a., 1956; Smorodintsev u. a., 1957; Paul und McClure, 1958).

Germer (1955) spricht beim hämorrhagischen Fieber einerseits von einer "Platzkrankheit", da das Auftreten mehr oder weniger lokal begrenzt ist, andererseits von einer saisongebundenen "Aufsuchkrankheit", da meist landwirtschaftliche Waldarbeiter, Jäger und Soldaten auf vorgeschobenen Posten befallen werden, während Erkrankungen in den Städten nur selten vorkommen. Auch Miтtoff und DiмоғF (1962) fanden in Bulgarien das hämorrhagische Fieber meist bei Land- und Waldarbeitern im Alter von 20-40 Jahren, die gewöhnlich Kontakt mit Tieren hatten. In $60-70 \%$ bestand Zeckenbefall. Die Krankheit trat von April bis September, mit größter Häufigkeit im Juni und August auf (s. auch Tabelle 41).

\section{Weitere Literatur zu Epidemiologie, Übertragung:}

Azisbekian (1953), McNinch (1953) Plichet (1953); T. B. Med. 240 (1953); Brown (1954); Plank, und Rezucha, (1955); Trencseni u. a. (1955); Luger und Himes (1956); Angeloff und Panajotov (1960); Fjellström (1960); Lim u. a. (1961).

\section{Klinitk}

Die Schwere der Krankheit schwankt stark von so milden Verläufen, daß sie kaum erkennbar sind, bis zu tödlichen Fällen. Im Vordergrund stehen eine ausgesprochene Schädigung des Kapillarkreislaufs und Insuffizienz der Nierenfunktion (s. auch GERMER, 1955). MitTofF und Dimoff (1962) stellten beim bulgarischen hämorrhagischen Fieber Mattigkeit, Kopf- und Muskelschmerzen, Fieber, Kreislaufstörungen, etwa am 5. Tag hämorrhagische Diathese (Haut- und Zahnfleischblutungen, Epistaxis, Haematemesis, Melaena, Metrorrhagie) mit Leukopenie und Thrombozytopenie fest. Der Tod trat meist zwischen dem 4. und 9. Tag ein. In typischen Fällen lassen sich mindestens 5 Krankheitsstadien unterscheiden (T. B. Med 240, 1953; Germer, 1955; Gajdusek, 1956b):

1. Die Inkubationszeit beträgt 1-4, im Mittel 2-3 Wochen; mehrere Monate werden gelegentlich beobachtet.

\section{Invasions- oder Fieberphase}

Die Krankheit beginnt meistens plötzlich mit Temperaturanstieg, Schüttelfrost, Kopf- und Rückenschmerzen, schließlich Fieber bis zu $40^{\circ}$ C, das etwa 6 Tage anhält (»Sechstagefieber" in Sibirien) und dann kritisch, selten lytisch abfällt. Die Kopfschmerzen gehen oft mit retroorbitalen Schmerzen, die durch Augenbewegungen aggraviert werden, einher. Es besteht schweres Krankheitsgefühl mit Unruhe, Schlaflosigkeit, Schwäche und Myalgien, mitunter Schwindel und Ohnmacht. Appetitlosigkeit tritt schon früh auf und ist oft von Schluckauf, Übelkeit, Erbrechen am 3. oder 4. Tage sowie Durstgefühl und trockener Haut begleitet. Gesicht, Konjunktiven und Gaumen sind gerötet. Petechiale Blutungen und Ecchymosen treten gewöhnlich erst am 3. Tage auf, zunächst am weichen Gaumen und in den Achselfalten, anschließend in den Bindehäuten, auf der Brust, dem Rücken, der Taille, dem Gesäß und den Oberschenkeln. Am 3. oder 4. Tage sieht man ferner oft Ödeme der Konjunktiven und periorbitalen Gewebe sowie mäßige, nicht schmerzhafte Lymphdrüsenschwellungen. Leber- und Milzvergrößerungen bestehen. Schwere Rückenschmerzen können von Schmerzen in den Rippen-Wirbelsäulenwinkeln begleitet sein; ferner findet man heftige diffuse Leibschmerzen, gewöhnlich ohne Muskelspasmen. Flüchtiger Meningismus am 2. oder 3. Tage kommt vor. Am 4. oder 5. Tage setzt die Nierenschädigung mit plötzlich eintretender schwerer Albuminurie ein. 


\section{Hypotensive oder Schock-Phase}

Sie ist gekennzeichnet durch den Blutdruckabfall kurz vor oder nach dem Verschwinden des Fiebers. Bestehen beide gleichzeitig, so gilt dies als prognostisch ernstes Zeichen. Der Schock tritt gewöhnlich vom 5. oder 6. Tage, manchmal auch bereits vom 3. Tage an in Erscheinung und währt wenige Stunden bis 3 Tage. ${ }^{2} / 3$ der Todesfälle kommen dabei zwischen dem 3. und 10. Tage vor. Er geht mit Angst, Schweiß und Unruhe einher. Der Blick ist gewöhnlich verschwommen; in ganz schweren Fällen bestehen Verwirrung, Delirium, Koma und Krämpfe. Gleichzeitig treten außer Albuminurie, Mikrohämaturie und Zylindrurie auf. Die petechialen Blutungen nehmen infolge des schwerer werdenden Kapillarschadens zu. Man findet Hämorrhagien in den subkonjunktivalen Geweben, der Retina und dem Trommelfell sowie Nasenbluten, in schweren Fällen Bluthusten und -erbrechen sowie Blut im Stuhl und Urin, gelegentlich auch Blutungen im Zentralnervensystem. Im Falle der Genesung verschwinden alle diese Erscheinungen.

Der Puls kann relativ verlangsamt sein und trotz des hohen Fiebers nur 90-100 Schläge betragen. In schweren Fällen besteht aber Tachykardie mit fadenförmigem Puls. In der Rekonvaleszenz findet sich dagegen Pulsverlangsamung (40-60 Schläge). $\operatorname{In}^{3} / 4$ der Fälle bleibt jedoch der Blutdruckabfall unwesentlich; ebenso pflegen auch die Blutungen relativ selten zu sein oder fehlen ganz, so daß die Fieberphase unmittelbar in die Oliguriephase übergeht.

In schweren Fällen ist das Blutbild erheblich verändert. Es besteht Linksverschiebung mit Myelozyten. Anfangs kommt Leukopenie vor, der eine ausgesprochene Leukozytose, bis zu 100000 Zellen und mehr, mit leukämoider Reaktion und Eosinophilie sowie anschließend Lymphozytose mit atypischen Zellen folgen. Außerdem findet sich zu Beginn eine Thromozytopenie (30000-80000 Plättchen je $\mathrm{mm}^{3}$ ) zuweilen mit Riesenformen; nach 1 Woche sind die Werte aber wieder normal. Ferner bestehen Hypochlorämie und chlorarme Azotämie. Die Gerinnungszeiten schwanken mit Neigung zur Verkürzung bei Genesungsbeginn. Die Blutsenkung ist meistens nicht beschleunigt. Der Hämokritwert steigt ohne Veränderung des Gesamteiweißes. Bei schwerem Schock sind die kreisenden Blut- und Plasmamengen vermindert. Man findet in schweren Fällen Hyperkaliämie,Hyperphosphatämie sowie Abnahme der Serumnatrium- und -calciumwerte.

\section{Oliguriephase}

Die plötzlich einsetzende Verminderung der Harnausscheidung, die gelegentlich bis zur Anurie gesteigert ist, besteht 2-6 Tage und ist gewöhnlich von akuter Azotämie begleitet. Gleichzeitig steigt der Blutdruck wieder, und in manchen Fällen entwickelt sich eine ausgesprochene Hypertonie. Ferner findet man Bradykardie, Perikarditis, leichte Myokarditis, welche elektrokardiographisch erkennbar wird, urämisches Frieren, Durchfall oder Neigung zu Verstopfung. Germer (1955) weist auf ein merkwürdiges Syndrom in dieser Phase hin: Brechreiz, Erbrechen, Verwirrtheit, Benommenheit, Wahnideen, Zittern, Unruhe; dieses ist teils eine urämische Manifestation, teils aber auch auf eine relative Hypervolämie zurückzuführen. Außerdem wird oft ein Lungenödem angetroffen.

\section{Diuretische Phase}

Sie setzt gewöhnlich etwa am 10.-13. Krankheitstage ein, hält etwa 1 Woche an und ist gewöhnlich von schnellem Verschwinden der Krankheitserscheinungen begleitet.

\section{Rekonvaleszenz}

Sie beginnt mit Polyurie. Die Nierenstörungen gehen vielfach in 5-6 Wochen zurück; sei halten nur selten mehrere Monate an und äußern sich vor allem in mangelhaftem Konzentrationsvermögen der Nieren; endokrine Störungen sollen hier ebenfalls eine Rolle spielen können (Froeb und Mc Doweld, 1954; Zoeckler und Orbison, 1955).

Speers u. a. (1955) haben eine eingehende quantitative und qualitative Laboratoriumsanalyse bei 76 Kranken, von denen 6 starben, sowie 16 weiteren Gestorbenen vorgenommen, auf die hier hingewiesen wird.

Welche Spätfolgen das epidemische hämorrhagische Fieber hinterläßt, ist noch nicht im einzelnen bekannt. Störungen der endokrinen Funktionen, u. a. tödlicher Panhypopituitarismus, sind beobachtet worden (Zoeckler und Orbison, 1955, s. auch Giles u a., 1954). 
Weitere Literatur zu Klinit:

Hamasaki u. a. (1936, zit. Trencseni u. a., 1955), Mrrhman (1951); Tatarintzer und Bissiarina (1952); Andrew (1953); Barbero u. a. (1953); Pruitt und Cleve (1953); Schmidt (1953); Swift (1953); Blattner (1954); Earle (1954); Furth (1954); Hibbard u. a. (1954); Powell $(1953,1954)$; Sheedy u. a. (1954); Urban (1954); Trencseni u. a. (1955); Lancet (1960); Schapiro u. a. (1961a, b).

\section{Pathologie}

Die Infektion ist durch eine ausgedehnte, nicht entzündliche, offenbar toxisch bedingte funktionelle Gefäßerkrankung mit allgemeiner Erweiterung der Kapillaren, Permeabilitätssteigerung, Hyperämie und Blutungen in der Haut, den Schleimhäuten und fast allen Organen charakterisiert. Eine spezifische histologische Schädigung der Gefäßwandzellen scheint nicht vorhanden zu sein.

In der Fieberphase bestehen Erweiterungen der Arteriolen und Kapillaren, Plasmaaustritt durch die Kapillarwände und Erythrozytenanhäufungen in den Kapillaren, wodurch Kreislaufstörungen bedingt werden. Die Hämorrhagien gehen mit Brüchigkeit der Kapillaren und Thrombozytopenie einher. Todesfälle treten zwischen dem 3. und 10. Tage auf und sind fast regelmäßig von Schock begleitet. Dieser beruht gewöhnlich auf einer Verminderung der zirkulierenden Blutmenge infolge Austrittes von Serum aus den Gefäßen mit gleichzeitiger Kapillarerweiterung und Verlust des Arteriolentonus. Späterer Tod mit Schock tritt während der diuretischen Phase mit Dehydrierung der Gewebe und Störungen des Flüssigkeits- und Elektrolytgleichgewichtes während der Periode des Versagens der Nieren und des Hochdruckes sowie infolge von Blutungen in lebenswichtigen Gebieten ein. Nach GAJDUSEK (1956b) wird das klinische Bild auch durch Erscheinungen bestimmt, die auf der noch ungeklärten Rückkehr des ausgetreten gewesenen Plasmas in den Kreislauf beruhen. Durch diesen schnellen Zustrom des eiweißreichen Transudates in die Zirkulation kann ein Hochdruck entstehen. Das Auftreten der Hypervolämie ist von einem verminderten Blutvolumen begleitet, das trotz des zurückkehrenden Plasmas infolge der Dehydrierung und mäßigen Verminderung der kreisenden Erythrozyten bestehen bleibt. Eine relative Hypervolämie ergibt sich daraus, daß die Verringerung des funktionellen Gefäßraumes größer ist als die Abnahme der kreisenden Blutmenge (EARLE, 1953).

Bei den im Schock Verstorbenen findet man ein eiweißreiches gelatinöses Ödem in großer Menge im retroperitonealen, mesenterialen und mediastinalen Gewebe. Die Nieren sind vergrößert und zeigen eine blasse geschwollene Rinde, dunkelrotes blutreiches, häufig hämorrhagisches Mark, manchmal Nekroseherde im Zentrum der Pyramiden und sogar vollständige Nekrose aller Pyramiden; die Tubuli contorti, Henceschen Schleifen und Sammelröhren sind von verbreiterten und gestauten Gefäßen sowie blutigen Extravasaten umgeben. GERmer (1955) weist darauf hin, daß die Nierenveränderungen jenen des Gelbfiebers gleichen. SpeERS u. a. (1955) sprechen von einer »tieferen Nephronephrose«. Im Herzen bestehen außer diffuser hämorrhagischer Verfärbung des r. Vorhofes verstreute Petechien und Ecchymosen auf dem Epikard oder dem Endokard, ausgedehnte herdförmige Myokarditis vorwiegend im 1. Vorhof und beiden Kammern. Die Hämorrhagien sind häufig von Monozyteninfiltrationen umgeben. Bei nach dem 9. Tage Gestorbenen findet man Hyperämie und infarktartige Nekrosen des Vorderlappens der Hypophyse bis zum Infundibulum. In etwa der Hälfte der Fälle ist die Hypophyse vergrößert, rot, weich; bei starker Beteiligung des Vorderlappens sieht man Petechien in der Pars intermedia, im Infundubulum und in den benachbarten Gebieten des Hinterlappens. Bei etwa $1 / 4$ der Fälle sind die Nebennieren mit Petechien und gewöhnlich ausgedehnten einseitigen Blutungen oder hämorrhagischen Nekroseherden in der Rinde beteiligt. Die Leber ist häufig vergrößert und weist manchmal Nekroseherde in der Mittelläppchenzone sowie periportale Infiltrate und vermehrte Leukozytenzahlen in den Sinusoiden bei Fällen mit ausgesprochener leukämoider Leukozytose kurz vor dem Tode auf. Nach 
Schміdт (1953) besteht eine ausgesprochene fettige Degeneration der Leber mit intraparenchymaler Blutung. Das Pankreas zeigt in mehr als ${ }^{1} /{ }_{3}$ der Fälle eine mäBige diffuse interstitielle Entzündung mit oder ohne Blutungen. Gelegentlich kommt Herdnekrose mit Bevorzugung der LANG ERHansschen Inseln vor. Im Magendarmkanal bestehen gewöhnlich Ödem, Hyperämie und Blutungsherde, ferner manchmal Nekrosen der Submukosa. Die Milz ist vergrößert, hyperämisch, mit Blutungen besonders unter der Kapsel. Die Follikelzeichnung ist undeutlich; häufig findet man große megakaryozytenartige Zellen, selten andere Zeichen von Myelopoiese. Die Sinusoide sind reich an Leukozyten, welche teils granulozytenartig, teils großrundzellenartig wie bei entzündlichem Infiltrat sind. Die Lymphfollikel der Milz wie der Lymphknoten sind klein, frei von Keimzentren und inaktiv erscheinend. Das Knochenmark ist gewöhnlich hyperplastisch und zeigt oft eine megakaryozytäre Reaktion. In den Blutgefäßen besteht manchmal eine geringe perivaskuläre Infiltration der Vasa vasorum, selten eine milde diffuse Monozyteninfiltration der Aortenintima. Thromben und andere Zeichen von Gefäßverschluß fehlen. An den oberen Luftwegen beobachtet man Petechien, in den Lungen Hyperämie sowie kleine und größere konfluierende Blutungen, Ödem und Pleuraexsudat, ziemlich häufig auch durch bakterielle Sekundärinfektion bedingte Prozesse. Das ZNS ist frei von spezifischen Prozessen, die auf eine Virusgenese hinweisen; gelegentlich bestehen einzelne oder multiple kleine oder große Blutungen in der Dura mater, den Subarachnoidalräumen oder verschiedenen Groß- und Kleinhirnabschnitten sowie Hirnstamm (TB MED 240, 1953; Germer, 1955; Speers u. a., 1955; Gajdusek, 1956a).

\section{Weitere Literatur zu Pathologie:}

Honzin u. a. (1944); Smorodintsev u. a. (1944a); Tokoro (1944); Barbero u. a. (1953); Hullinghorst und Steer (1953); Kessler (1953); Knudsey (1954); Lukes (1954); Powell (1954); Greisman und Moe (1954) Work u. a. (1957); Ganong u. a. (1958).

\section{Diagnose}

Sie kann nur klinisch erfolgen, da es spezifische Laboratoriumsteste nicht gibt. Die charakteristische Rötung und Petechien bei einem fieberhaften Fall bilden in Endemiegebieten bereits einen Anhalt. Während der ersten beiden Krankheitstage sind die Erscheinungen aber so allgemein und vielen Infektionskrankheiten gemeinsam, daß eine Entscheidung nicht möglich ist.

BlattNer (1954) bezeichnet den Schüttelfrost als auffallendes Symptom der frühen Fieberphase (90\%); Kopfschmerzen sind mit $85 \%$ und Rückenschmerzen mit $78 \%$ ebenfalls hervorstechend. Der weitere Krankheitsverlauf sichert erst die Diagnose, vor allen Dingen in der 3. Phase mit der hämorrhagischen Diathese und der Nierenbeteiligung. Zu den wichtigsten Krankheiten, welche dem epidemischen hämorrhagischen Fieber ähneln können, und daher differentialdiagnostisch ausgeschlossen werden müssen, gehören Influenza, infektiöse Mononukleose, Masern, hämorrhagische Pocken, Scharlach, epidemisches Fleckfieber, Buschfleckfieber, Malaria, Rückfallfieber, Leptospirose, Virushepatitis, Nephritis, rheumatisches Fieber, Meningitis, Encephalitis, Infektionen der oberen und unteren Luftwege, allergische Purpura, Leukämie u. a. (TB MED 240, 1953; GAJDUSEK, 1956b).

Für die Diagnose wichtig ist die erhebliche Albuminurie gegen Ende der Fieberphase; ergänzend sind Blutdruckabfall, Schock, Thrombozytopenie, hoher Hämatokrit, Oligurie. Oliver und McDowell (1957) bezeichnen die Nierenveränderungen für so charakteristisch, daß sie allein schon die Diagnose gestatten. GERMER (1955) beobachtete bei 18 Fällen einen verhältnismäßig einförmigen Verlauf und bei der Sektion neben den multipel auftretenden Hämorrhagien tubulären Nierenschaden und Ausfall der Hypophysenvorderlappenfunktion. Als besonders auffallend gelten Sklerablutungen. GaNong u. a. (1958) heben besonders den Befund großer mononukleärer Zellen im Harnsediment und Lipidurie (Fetttröpfchen bis zu makroskopischer Größe, welche mit Äther extrahiert und mit Fettfärbung gefärbt werden können) hervor. 
Mayer $(1952 \mathrm{a}, \mathrm{b})$ beschrieb in einer Epidemie grippotyphöse Formen in 26,6\%, gastrointestinale Formen in 45,5\%, urämische Formen in 24,4\% und meningoencephalitische Formen in $5-6 \%$.

Weitere Literatur zu Diagnose:

Barbero u. a. (1953); Counts und Seltser (1953).

\section{Prognose}

Wenn die Krankheit überstanden wird, pflegt sie vollständig zu heilen. Ausnahmen bilden Fälle mit Blutungen im Zentralnervensystem und anderen lebenswichtigen Stellen. Die Todesfälle sind ziemlich gleichmäßig über die hypotensiven, oligurischen und diuretischen Phasen verteilt.

Als prognostisch ungünstig gelten verspätet einsetzende ärztliche Behandlung, schonungsloser Abtransport, langanhaltendes hohes Fieber, übermäßige Flüssigkeitszufuhr, langer oder erneuter Schock, anhaltende periphere leukämoide Blutreaktion, anhaltende Blutkonzentrierung, Anurie und fortschreitende schwere Elektrolytstörungen (TB MED 240, 1953; GAJDUSEK, 1956b).

Die Letalität beträgt etwa 5-15\%. Miтtoff und Dimoff (1962) fanden in Bulgarien eine solche von 10-36\%. Nach Germer (1955) stirbt 1/3 der Kranken an primärem Schock infolge des peripheren Gefäßkollapses, ein weiterer Teil an Lungenödem. Seltene Todesursachen sind profuse Blutungen in lebenswichtigen Organen oder Zentren.

\section{Behandlung}

Sie ist rein symptomatisch-unterstützend. Sulfonamide, Antibiotica, Hormone, Antihistaminica, Gesamtblut, Rekonvaleszentenserum u. a. haben sich als wirkungslos erwiesen. Frühzeitige Krankenhausbehandlung ist wichtig, und zwar möglichst schon vor Beginn der hypotensiven Phase und Blutungen. Wesentlich ist eine salzarme, kohlenhydratreiche Kost mit Flüssigkeitsbeschränkung. Milde Beruhigungsmittel sind bereits zu Beginn angezeigt. Größere Unruhe erfordert unter Umständen Barbiturate und Opiate. Bei stärkerem Erbrechen wird 5\%ige Traubenzuckerlösung i.v. und unter Umständen auch Salzlösung zugeführt, wobei aber übermäßige Flüssigkeitszufuhr und Ödembildung ebenso wie Austrocknung zu vermeiden sind. In der hypotensiven Phase empfiehlt sich möglichst frühe Noradrenalinzufuhr (Dauertropfeinlauf in die V.femoralis), bei starkem Schock und hohen Hämatokritwerten (über 55-60\%) salzarmes menschliches Albumin, wobei die Gefahr der Hypervolämie zu beachten ist. Bei drohendem oder bestehendem Lungenödem kann ein Aderla $B$ vorgenommen werden. Bluttransfusionen sind bei hohen Hämatokritwerten nicht angezeigt. Stärkere Retention harnpflichtiger Substanzen macht künstliche Niere erforderlich. Kochsalz- und Kaliumverluste in der diuretischen Phase werden unter ständiger Kontrolle der Elektrolyte ersetzt; die Flüssigkeitszufuhr ist der Harnmenge anzupassen. Hyperkaliämie soll durch intravenöse Zufuhr von Traubenzucker und Insulin bekämpft werden. In der Rekonvaleszenz ist körperliche Schonung wichtig (Germmer, 1955; GaJdusek, 1956 b).

Weitere Literatur zu Behandlung

KAtZ u. a. (1952); Woodward (1953); SAYer u. a. (1955).

\section{Immunbiologie}

$\mathrm{Ob}$ und wie lange eine wirksame Immunität besteht, ist noch unbekannt. In den Rekonvaleszentenseren sind keine AK gegen andere Krankheitserreger nachgewiesen worden. 


\section{Prophylaxe}

Für die Verhütung der Infektion ist der persönliche Schutz gegen die Milben die wirksamste Maßnahme. Man benutzt hierzu insektenabwehrende Verbindungen zur Imprägnierung der Kleidung, die aber verhältnismäßig häufig wiederholt werden muß (mindestens allmonatlich am besten nach der Wäsche). Empfohlen wird »M-1960«, ein emulgiertes Konzentrat, das n-Butylacetanilid (30\%), 2-Butyl-2-Äthyl-1: 3-propanediol (30\%), Benzylbenzoat (30\%) und einen Emulgierer (10\%) enthält. Anstelle von M-1960 kann auch folgendes Benzylbenzoatgemisch verwandt werden: Benzylbenzoat $(45 \%)$, Dimethylphthalat $(45 \%)$, Emulgierer $(10 \%)$.

Zum Fernhalten der Insekten von der unbedeckten Haut kann eine abweisende Flüssigkeit verwandt werden, z. B. die Verbindung »2020«: Dimethylphthalat (40\%), 2-Äthyl 1-3-Hexane$\operatorname{diol}(30 \%)$ und Dimethylearbat $(30 \%)$ oder die Verbindung $» 6-2-2 «$ : Dimethylphthalat (6 Teile) Indalon (2 Teile) und Äthylhexanediol (2 Teile).

Zur Insektenvernichtung im Gelände werden von den Amerikanern folgende Gifte angewandt: Dieldrin, Lindane (Gamma-Isomer des Benzolhexachlorids), DDT, das gegenüber Milben, Chigger und Flöhen im Terrain am wenigsten wirksam ist, so daß es weder Dieldrin noch Lindane zu ersetzen vermag. Gegen die Nagetiere werden außer Fallen zum Beispiel mit Warfarin vergiftete Köder in Unterstands- oder Lagernähe ausgelegt.

Weitere Literatur:

Chumakov, 1956, 1957

\section{F V. Pappataci-Fieber}

(Phlebotomus-Fieber, Sandfliegen-Fieber, Dreitage-Fieber, Sommer- oder Hundsfieber).

\section{Einleitung}

Das Pappataci-Fieber ist eine über die tropischen und subtropischen Länder verbreitete, durch die Mücke Phlebotomus pappatasii (= sticht schweigend - wegen des lautlosen Fluges) übertragbare, fieberhafte und virämische, aber nur kurzdauernde und prognostisch stets gutartige Krankheit, die endemisch und epidemisch auftritt. Als klinische Einheit wurde die Krankheit bereits 1804 von Pyм (zit. SABIN, 1959 c) auf Malta erkannt, aber die erste genaue klinische Beschreibung geht auf PrCK (1886) zurück; dieser bezeichnete die Krankheit als »Hundskrankheit» und hielt sie für eine Infektionskrankheit sui generis. Bereits Taussig (1905a, b, c), welcher im Gebiet der Adria epidemiologische Untersuchungen vornahm, glaubte, daß sie durch Phlebotomus pappatasii Scopoli übertragen wird. Der endgültige Nachweis der Überträgerrolle dieser Mücke erfolgte durch Doerr u. a. $(1909 a, b)$, welche gleichzeitig die Filtrierbarkeit des Erregers nachwiesen (s. auch DoERr, 1908).

Die Krankheit hat insofern praktische Bedeutung, als zum Beispiel Truppenteile, welche in Endemiegebiete verlegt werden, aber auch andere in diese einreisende Personen schwer betroffen werden. Nach Schilling (1939b) können bis zu $2 / 3$ der Zugezogenen erkranken. Sie sind während der oft langen Rekonvaleszenz arbeitsbeschränkt oder -unfähig.

Die im englischen Sprachgebiet vielfach gebräuchliche Bezeichnung "sandfly fever" ist nicht korrekt, da der Überträger nicht zu den Sandfliegen, sondern zu den Mücken gehört. 


\section{2. Ätiologie}

\section{2-1. Übertragungsversuche}

SABIN u. a. (1944a, b) isolierten einen Virusstamm ("Neapel ") durch Passage auf Versuchspersonen. Nach 8jähriger Aufbewahrung (lyophilisiertes Menschenserum) ließ sich das Neapel-Virus noch erfolgreich auf 2 Menschen übertragen. SABIN (1951a) stellte mit einem zweiten Virusstamm (»Sizilien«) weitere Untersuchungen an. Beide Stämme sind miteinander verwandt, unterscheiden sich aber antigen voneinander, so daß man von 2 Virustypen reden kann. Sie wurden durch kreuzweise Übertragungsversuche mit dem Phlebotomus pappatasiiVirus identifiziert. Menschen, welche experimentell infiziert wurden, wiesen Virus im Blut und Serum 24 St. vor und 24 St. nach Beginn des Fiebers auf, später jedoch nicht mehr. Die Viruskonzentration konnte aber auch so gering bleiben, daß 1 ml Serum keine Erkrankung mehr hervorrief; es wurden höchstens 1000 Menschen-ID (Stamm Sizilien) je ml erhalten. Virusmengen, welche nach i.d. oder i.v. Injektion zu einer Erkrankung führten, riefen nach s.c. oder i.m. Injektion bei 50-75\% keinerlei Krankheitserscheinungen hervor. Es entstand aber eine Immunität gegen i.d. und i.v. Nachinfektionen mit großen Virusmengen, so da.B eine latente Infektion stattgefunden hatte. Menschen, die i.d. oder i.v. mit so kleinen Virusmengen infiziert wurden, daß sie nicht mehr erkrankten, erwarben auch keine Immunität gegen eine Nachinfektion. Gegen eine i.d. oder i.v. Infektion erwiesen sich nur 5\% der Erwachsenen aus Pappataci-Fieber-freien Gegenden refraktär (SABIN, $1959 \mathrm{c}$; s. auch ANDERSon, 1941 a, b; Gontaeva, 1943; Fleming u. a., 1947). Lambelin und Elton (1961) beobachteten bei experimentell infizierten Personen unter Umständen nur ein subakutes Krankheitsbild, dessen einziges Symptom Fieberanstieg war.

Versuchspersonen, welche i.d. mit $10^{5,9}$ Mäuse $\mathrm{LD}_{50}$ der 30. Gehirnpassage des NeapelStammes oder der 10. und 20. Passage des mäuseadaptierten Sizilien-Stammes infiziert wurden, bekamen weder Fieber noch klinische Erscheinungen, entwickelten aber N-AK. Bei einer Nachinfektion von 4 Personen, die unmodifiziertes Neapel-Virus erhalten hatten, das bei Kontrollpersonen mäßiges Fieber hervorrief, waren 2 Personen vollständig geschützt; 2 andere bekamen leichtes vorübergehendes Fieber. Ihr Serum enthielt $10^{2}$ Mäuse-ID je ml, d. h. ihre Virämie war 200-1000 mal geringer als jene der infizierten Kontrollpersonen. Mit Sizilien-Virus nachinfizierte Personen entwickelten ebenfalls Immunität und AK (SABIN, $1959 \mathrm{c})$.

Tedeschi und Napolitani (1911a, b) erhielten bei Macacus cynomolgus-Affen nach Injektion von $0,5 \mathrm{ml}$ Berkenfeld-Filtrat von Krankenserum (Stamm Sizilien) eine leichte fieberhafte Krankheit mit einer Inkubationszeit von 7 Tagen. Sновтт u. a. (1934) fanden eine geringfügige Pathogenität für M.rhesus. 5 von 11 Affen, welche $10 \mathrm{ml}$ infektiöses Menschenblut erhalten hatten, bekamen 3-4 Tage später eine leichte fieberhafte Erkrankung von 1-5 tägiger Dauer. Mit dem Blut eines Affen konnten ein weiterer M.rhesus sowie 2 Menschen infiziert werden. Das Virus wurde im Affenblut bis zu 15 Tage nachgewiesen (Вновтт u. a., 1940). SabiN u. a. (1944a, b) versuchten vergeblich, Macacus rhesus, M.mulatta, M.radiata, junge Paviane (Papio hamadryas), Cercopithecus (griseoviridis, aethiops centralis, patas) i.cer., i.d., s.c., i.p., i.n. oder intratestal, sowie PAUL u. a. (1948) Schimpansen mit virushaltigem Menschenblut zu infizieren. Shortт u. a. (1934) sowie Jonescu-Minaiesi u. a. (1940) erzielten auch mit Filtraten von infektiösem Blut bei Affen eine fieberhafte Reaktion.

Während auch das mäuseadaptierte Sizilien-Virus bei Rhesus-Affen nach i.cer. Injektion keine Krankheitserscheinungen herbeiführte, sondern nur AK bildete, erzeugte das NeapelVirus bei 10 infizierten Affen, welche $10^{6}$ oder $10^{4} \mathrm{Mäuse-}-\mathrm{LD}_{50}$ der 30 . Mäusegehirnpassage erhalten hatten, nach 8-16 tägiger Inkubationszeit Fieber, aber keine Lähmungen oder andere encephalitische Symptome. Alle Affen wiesen jedoch interstitielle Infiltrationen und perivaskuläre Zellansammlungen in den Hinter- und Seitenhörnern des Rückenmarks, des Halsmarks, im Mittelhirn, Hypothalamus sowie gelegentlich in geringem Umfang auch in der parietalen und temporalen Gehirnrinde auf. Nur ein Affe entwickelte einen höheren Titer von N-AK.

SabiN (1955) gelang es zusammen mit SweEt, das Virus "Sizilien« aus infektiösem Menschenserum, das 9 Jahre gefroren aufbewahrt worden war, auf Mäusesäuglinge zu übertragen. 
Nach 3 Blindpassagen in 2-3 Tagen alten Mäusen mit Intervallen von 7 Tagen wurde ein Virus erhalten, das nach 11-12tägiger Inkubationszeit Encephalitis hervorrief. Pathologische Veränderungen fanden sich vor allem im Hypothalamus und Mittelhirn, aber nicht in Muskel, Fett, Pankreas und anderen Eingeweideorganen. Mit zunehmenden Mäusesäuglings-Gehirnpassagen wurde die Inkubationszeit kürzer. Nach 10 Passagen hatte das Virus einen Titer von bereits $10^{-5,4}$ je $0,01 \mathrm{ml}$, erzeugte aber noch keine Erkrankung bei großen abgestillten Mäusen. Erst nach 25 Gehirnpassagen in Mäusesäuglingen fing das Virus an, bei diesen wie auch bei 4 Wochen alten Tieren eine tödliche Encephalitis mit Titern von $10^{-7}$ je $0,01 \mathrm{ml}$, d. h. $10^{9} \mathrm{LD}_{50}$ je g Mäusesäuglingsgehirn zu erzeugen. Eine einmalige i.cer. Blindpassage mit Serum einer Versuchsperson, die mit dem Stamm "Neapel" infiziert worden war, in neugeborenen Mäusen ergab ein Virus, das nach 14 tägiger Inkubationszeit eine Encephalitis hervorrief. Nach 5 Gehirnpassagen in 2-4tägigen Mäusen wurde die Inkubationszeit auf 8 Tage verkürzt. Der Titer betrug $10^{-5,8}$ je $0,01 \mathrm{ml}$. Für 4 Wochen alte abgestillte Mäuse war das Virus auch nicht pathogen. Erst nach 35 Mäusesäuglingspassagen wurde es für ältere Tiere pathogen. In der 55. Gehirnpassage betrug der Titer für beide Altersgruppen etwa 10-5,9 mit 2 mal längerer Inkubationszeit der abgestillten Mäuse. Neugeborene und ältere Mäuse erkrankten nach i.n. Infektion mit klinischen Erscheinungen, nicht dagegen nach s.c. und i.p.Infektion.

Das Neapel-Virus gleicht dem Sizilien-Virus darin, daß es regelmäßig erwachsene Mäuse des PRI-Stammes tötet, der resistent gegen Dengue und andere antigen mit letzterem verwandte Arbor-Viren ist.

SabiN u. a. (1944a, b) versuchte ohne Erfolg, graue Mäuse, syrische Hamster, Meerschweinchen, Baumwollratten, ägyptische Wüstenratten (Jeroboas), und Kaninchen mit dem SizilienVirus vom Menschen zu infizieren, während der hochpathogene mäuseadaptierte Stamm nach i.cer. Injektion bei 5-6 tägigen Ratten eine tödliche Encephalitis erzeugte. Bei Hamstersäuglingen, Meerschweinchen und Kaninchen entstanden $\mathrm{AK}$, so daß eine latente Infektion stattgefunden haben mußte. Mit dem mäuseadaptierten Neapel-Virus kam es nach i.cer. Infektion von jungen Kaninchen, Meerschweinchen und Hamstern zu keiner erkennbaren Erkrankung. Bei Meerschweinchen und Hamstern wurde aber die Bildung von N-AK beobachtet.

\section{2-2. Züchtungsversuche}

Sabin (1955) konnte weder das Mäuse-adaptierte Sizilien- noch das Neapel-Virus in Zellkulturen von Affennieren züchten. HeNderson und TAY LOR (1960) gelang jedoch die Züchtung beider Stämme in Kulturen von Menschen- und Mäusesäuglingsnieren. Zur Beimpfung diente Mäusesäuglingspassagevirus. In den Menschennierenkulturen traten nach einer Bebrütungsdauer von 23 Tagen (Neapel-Virus) Plaques auf. Ein ZE wurde oft erst nach der 3.-4. Flüssigkeits- oder Plaque-Passage erhalten, und zwar nur, wenn Kulturen von Rindernieren verwandt wurden. In den Kulturen der Mäusesäuglingsnieren kam es schon in der 1. Passage zu einem ZE. Das Virus vermehrte sich in diesen Zellen reichlicher als in den Menschenzellen. Schon 2-3 Tage p. i. waren die höchsten Titer erreicht.

Beide Virusstämme sind noch nicht mit Sicherheit im embryonierten Ei gezüchtet worden. Versuche von Sновтт u. a. (1936b, 1938, 1939), die das Virus durch 60 Passagen auf der CAM gezüchtet haben wollen, sind unbestätigt geblieben (s. auch Demina und Levitanskaja, 1940; Demina, 1941b). Sabin (1955) gelang es nicht, die beiden mäuse-adaptierten Stämme im Hühnerembryo zur Vermehrung zu bringen.

\section{2-3. Hämagglutination}

Bei infizierten Meerschweinchen (Sizilien-Virus) ließ sich eine geringe Menge Hämagglutinin nachweisen, das Hühnererythrozyten maximal bei $37^{\circ} \mathrm{C}$ zwischen einem $\mathrm{p}_{\mathrm{H}}$ von 5,5 und 6,5 agglutinierte (SABIN, 1955). Niedrigere Titer wurden auch bei Zimmertemperatur und $4^{\circ} \mathrm{C}$ in einem breiten $\mathrm{p}_{\mathrm{H}}$-Bereich $(5,5-8,0)$ gefunden. Zur HA eigneten sich auch Gänseerythrozyten (Porterfield, 1957). Merthiolat 1: 10000 inaktivierte das Hämagglutinin des SizilienStammes, was im Gegensatz zu vielen Arbor-Viren steht. In normalem Serum ist ein Hemmstoff der HA vorhanden, der mit Alkohol, nicht aber mit Äther und Aceton extrahierbar war. 
Cotaesco und Badensini (1958) fanden, daß Serum und Plasma von Kranken Menschenerythrozyten der Gruppe 0 bei $4^{\circ} \mathrm{C}$, nicht dagegen bei $20^{\circ}$ und $37^{\circ} \mathrm{C}$ agglutinierten. Im Serum kam ein Titer von 1: 256 und im Plasma ein solcher von 1: 512 vor. Nach 30 Min Inaktivierung bei $56^{\circ} \mathrm{C}$ fiel der Titer von Serum und Plasma auf 1:,64. Nach 30-72tägiger Aufbewahrung bei $10^{\circ} \mathrm{C}$ war das HA-Vermögen erhalten geblieben. Auch Meerschweinchenerythrozyten wurden durch Krankenserum und -plasma bei $4^{\circ}$ und $20^{\circ} \mathrm{C}$ mit Titern von 1:2048 bzw. 1: 1024 und bei $37^{\circ} \mathrm{C}$ mit solchen von 1: 512 agglutiniert.

\section{2-4. Eigenschaften des Virus}

Schon DoerR (1908) stellte in Menschenversuchen fest, daß der Erreger des PappataciFiebers durch Berkefeld- und Chamberland-Kerzen filtrierbar ist (s. auch BIRT, $1910 \mathrm{a}, \mathrm{b}, \mathbf{c}$; Tedeschi und Napolitani, 1911a, b; Graham, 1915; Lépine, 1927; Kligler und Ashner, 1928). Shortt u. a. (1934) sowie Jonescu-Minaiesti u. a. (1940) erzeugten mit Filtraten von infektiösem Blut bei Menschen Pappataci-Fieber und bei Affen eine fieberhafte Reaktion. Versuche von SABIN u. a. (1944a, b) sowie SabiN (1951a) ergaben, daß das Virus in infektiösem Menschenblut Gradocol-Membranen mit einer durchschnittlichen Porenweite von $200 \mathrm{m \mu}$ und mehr passierte, nicht dagegen solche von nur $100 \mathrm{~m} \mu$. Dies ließ auf eine Teilchengröße des Virus von 40-60 m $\mu$ schließen (s. auch DoERR und RUss, 1909, 1914). Untersuchungen von SABIN (1955) ergaben jedoch für die mäuse-adaptierten Virusstämme Teilchengrößen von·nur etwa 17-25 mu, was etwa der Größe des Gelbfiebervirus entspricht. Beide Virusstämme haben denselben Filtrationsendpunkt.

Das Virus ist noch nicht elektronenoptisch dargestellt worden.

Die Haltbarkeit des Virus ist sehr groß. In festem $\mathrm{CO}_{2}$ tiefgekühlt bleibt es im Menschenserum mindestens 9 Jahre am Leben und infektiös. Lyophilisiert hielt es sich im gewöhnlichen Kühlschrank mindestens 8 Jahre (SABIN, 1955; s. auch Shortt u. a., 1936 a; Demina, 1941 a; SABIN u. a., 1944a, b). Durch Erhitzen auf $56^{\circ} \mathrm{C}$ wurde das Virus in 10 Min abgetötet (LÉPINe, 1927). Galle und Phenol töteten das Virus ab (Moskovsky u. a., 1936). In $2 \%$ iger Na citratLösung und in 50\%igem Glycerin blieb es 14 Tage am Leben (SHоRтт u. a., 1934).

\section{Epidemiologie; Übertragung}

Das Pappataci-Fieber kommt nur beim Menschen vor und wird nur durch Plebotomus (Sand)-Mücken, meist P.pappatasii Scopoli übertragen. Es tritt zwischen dem 20. und 45. ${ }^{\circ}$ nördl. Breite auf, also in den Ländern des Mittelmeers, der Adria, des Schwarzen und des Kaspischen Meeres, im Kaukasus, in Indien, China und anderen subtropischen und tropischen Ländern, in denen der Phlebotomus beheimatet ist. In Amerika ist die Krankheit bisher noch nicht festgestellt worden. In Madagaskar gilt der P.squamipleuris als Überträger (LE GAc, 1937). Als weitere verdächtige Überträger gelten Phlebotomus caucasicus, P. sergenti, P.perniciosus, P. major, P. chinensis und P. minutus (PIEKarsKI, 1954; KrIEg, 1961). Andere Mückenarten wie Aedes- und Culexarten sowie Flöhe kommen nach den Untersuchungen von SABIN u. a. (1944a, b) sowie SABIN (1951 a) nicht in Frage, ebenso auch nicht Bettwanzen (DoERR u. a. 1909b).

Der Phlebotomus gehört zu den Schmetterlingsflüglern (Psychodidae). Er gleicht einem kleinen Nachtfalter und ist nur 2-3 mm lang; er hat einen gedrungenen, kurzen, durchsichtigen hellbraun bis sandfarben gefärbten Körper (daher die Bezeichnung Sandmücke oder fälschlich Sandfliege), der ebenso wie die Flügel stark behaart ist. Die relativ breiten, am Außenrand in eine Spitze auslaufenden Flügel, welche an der Ansatzstelle abgeknickt sind, werden beim Sitzen nicht über dem Körper, der stark gekrümmt ist, zusammengelegt, sondern leicht erhoben gehalten ("Engefflügelstellung») (s. Abb. 44).

Behaarung und Flügelhaltung sowie die sprunghaften Flüge zur Seite bei der Verfolgung unterscheiden die Sandmücke von anderen Mückenarten. Sie hat lange 16 gliedrige Antennen und einen kurzen Stechrüssel mit langen Tastern. Die Mücke lebt vorwiegend in den Niede- 
rungen und Gebieten unter $600 \mathrm{~m}$, vor allem an der Küste sowie in den tiefen Flußtälern. Sie ist ein Dämmerungs- und Nachtinsekt, das nur in dieser Zeit beißt, tagsüber aber an dunklen windgeschützten und feuchten Stellen ruht. Die Eiablage erfolgt nicht im Wasser, sondern in feuchtem Boden, verwesendem Laub, Müll, Schutt, Küchenabfällen, Dung, Mauer- und Felsspalten, Löchern von Nagetieren, Blumentöpfen, Ställen, verwahrlosten Wohnungen u. a. m. Die Mücke legt keine großen Entfernungen zurück, sondern ist ortsgebunden. Sie fliegt lautlos. Man unterscheidet 4 Entwicklungsstadien: Ei, Larve, Nymphe und erwachsene Mücke. Aus den Eiern schlüpfen in 6-12 Tagen die Larven, die kaum 0,5 mm messen und sich von tierischen und pflanzlichen Zersetzungsprodukten nähren; sie häuten sich 4 mal. Die Puppe wird mit der letzten Larvenhaut auf der Unterlage befestigt. Das Puppen- und Nymphenstadium dauert 6-16 Tage. Unter günstigen Bedingungen beträgt die Gesamtentwicklungsdauer mindestens 4 Wochen. Während der Überwinterung bleibt die Entwicklung im Nymphenstadium stehen. Nur die Weibchen sind Blutsauger: sie werden 6-10 Tage nach der

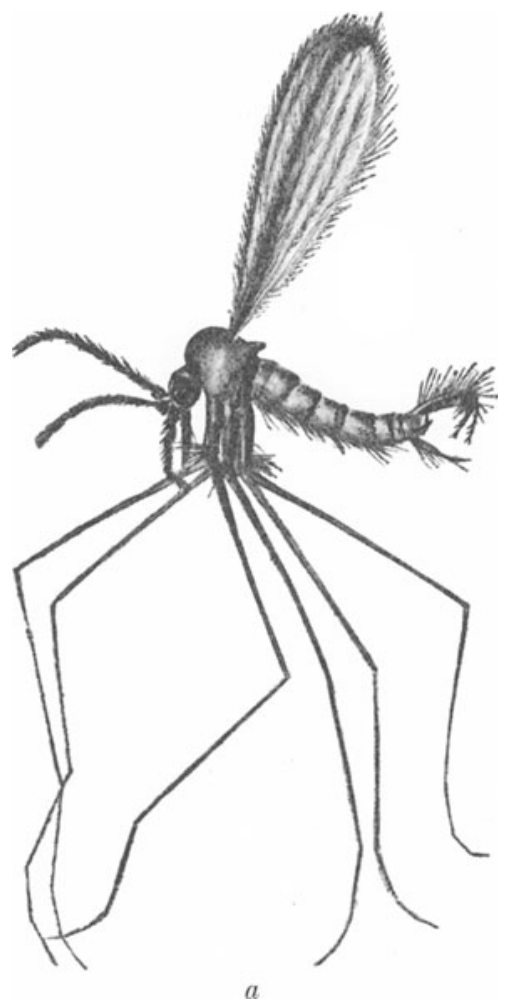

Abb. 44. Phlebotomus pappatasii. a) Männchen (nach Piekarski, 1954)

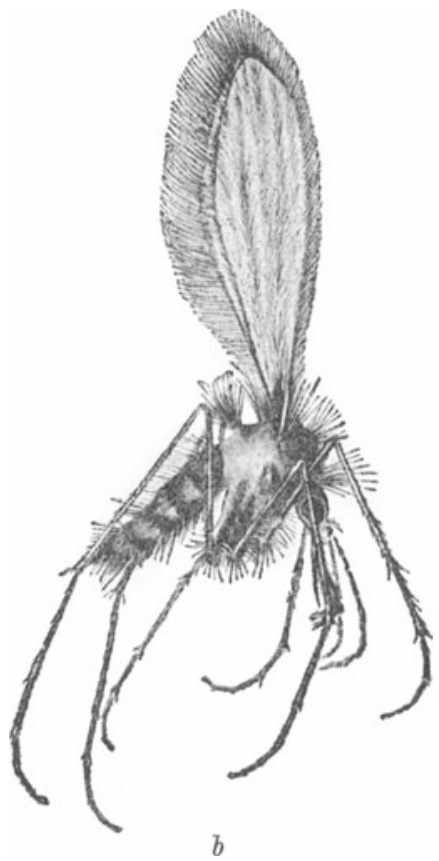

b) Weibchen

virushaltigen Blutmahlzeit infektiös. Ihre Bisse sind schmerzhaft und führen unter Umständen zu mehrere Tage bestehenden stark juckenden Quaddeln und bei durch mehrere Bisse sensibilisierten Menschen zu urtikariellen Papeln. Die erwachsenen geflügelten Mücken überwintern nicht. Infolge ihrer Kleinheit werden die Phlebotomen leicht übersehen. Sie leben nicht nur in den Häusern und in der Umgebung von Menschen und Haustieren, sondern auch im Freien. Man findet sie häufig in Baumhöhlen und -stümpfen (Ferguson und Graham, 1948; Romana u. a., 1949; BarnetT und Suy emoto, 1961). Häufig handelt es sich um Niststätten von Tieren, 
die als Wirte verschiedener Viruskrankheiten bekannt sind: Wölfe, Füchse, Schakale, Erdhörnchen, Hamster, Gerbillen, Merionen, Kaninchen, Hunde, Fledermäuse, Vögel (s. auch Grassi, 1907; Hoare, 1944; Dolmotova, 1946; Petrisheva, 1946; Wanson und Lebied, 1946; Herting und Fairschild, 1948; Parrot und Durand-Delarcre, 1948; Lewis und KIRK, 1951.

Die einzige Phlebotomenart, die sich dauernd in den Wohn- und Schlafräumen von Menschen aufhält, ist P.pappatasii. Die übrigen Arten fliegen erst nachts in die menschlichen Wohnungen, beißen aber auch im Freien (Piekarski, 1954).

Im Mittelmeergebiet ist das Pappataci-Fieber eine Sommerkrankheit; in anderen Gegenden der Tropen beginnt es mit Einsetzen der Regenzeit aufzutreten. Die Epidemien erreichen schnell ihren Höhepunkt und gehen mit Einsetzen der kühleren Temperaturen mehr oder weniger schnell zurück. Die Mücken bevorzugen Temperaturen von 26-27 $\mathrm{C}$, P.pappatasii gleichzeitig trockene Luft, andere Phlebotomusarten dagegen relative Luftfeuchtigkeit. $\mathrm{Da}$ die Mücken also vorwiegend in den heißen Monaten schwärmen, treten während dieser Zeit auch die meisten Erkrankungen auf. Entsprechend den 2 Mückengenerationen im Jahr in Südeuropa ist hier die Krankheitshäufigkeitskurve zweigipflig. Es gibt nur eine MenschMücke-Mensch-Infektkette. Die Mücke infiziert sich bei einer Blutmahlzeit bei einem Kranken im virämischen Stadium.

In endemischen Gebieten erfolgt die Infektion der Bevölkerung offenbar bereits im Kleinkindes- und Kindesalter. Die Krankheitsverläufe sind zu Beginn eines Ausbruchs leicht; während der Epidemie werden sie aber - was ziemlich charakteristisch ist - schwerer. Nach Doerr u. a. (1909) beruht dies darauf, daß der während der Überwinterung in den Larven abgeschwächte Erreger im Verlauf der Mücke-Mensch-Passagen seine Pathogenität wieder steigert. Nach BarnetT und Suy emoto (1961) waren bei einer Epidemie in Serbien im Jahre 1946 90\% der Bevölkerung erkrankt (s. auch Guelmino und Jeotic, 1955).

DoerR und Russ $(1909,1914)$ waren der Meinung, daß die Phlebotomen sich generationsweise zu infizieren vermögen (s. auch Moshкоvsкy u. a., 1937b). In Pakistan wurde Virus auch aus Sandmückenmännchen isoliert. Es wird daher angenommen, daß eine transovarielle Übertragung des Virus stattfindet (Barnett und Suy emoto, 1961). Sabin u. a. (1944a, b) stellten dagegen fest, daß eine Übertragung der Infektion von Mückengenerationen zu Mückengeneration nicht stattfindet. Whittingham (1924) lehnte die Mücke-Ei-, d. h. also transovarielle Infektion ebenfalls ab, nahm aber an, daß das Virus von einer Generation zur anderen indirekt dadurch übertragen werden kann, daß in den Brutplätzen Larven die infektiösen Ausscheidungen oder toten Körper ihrer Eltern fressen. Young u. a. (1926) konnten dies nicht bestätigen, denn unter normalen Bedingungen pflegen die P.pappatasii-Weibchen nach der Eiablage an den Brutplätzen nicht zu sterben und die jungen Larven zeigen keine Neigung, tote Mückenleiber zu fressen. Sie nahmen dafür an, daß als Zwischenträger oder Reservoire Akarinen (Milben wie Raphignarhus ypungi Hirst und Trombidium hindustanicum Hirst), welche auf den Mücken parasitieren, in Frage kommen. In welchen Wirten das Virus in den Herbst- und Wintermonaten in Abwesenheit der Phlebotomen überlebt, ist also noch nicht geklärt. Der Mensch ist auszuschließen, da das Virus schnell wieder aus dem Blut verschwindet.

Sснмidт u. a. (1960) gelang die Virusisolierung von P.pappatasii, die aus menschlichen Wohnungen in einem Vorort von Kairo gefangen worden waren. Es handelte sich um den Sizilien-Stamm. Außerdem wurde in wild gefangenen P.pappatasii, die Blut gesaugt hatten, AK gegen den Sizilien-Stamm gefunden. In Pakistan vorgenommene Felduntersuchungen ergaben bei 34\% der Sandmücken Virusisolate, was auf eine hohe Infektiositätsziffer in diesem Gebiet hinweist. Außerdem wurde Virus in Weibchen der Sandmückengruppe Sergentomyia gefunden (BARNett und SuYemoto, 1961).

\section{Klinik}

Die Inkubationszeit beträgt 3-6 Tage, manchmal mehr. Die Krankheit beginnt plötzlich mit steilem Fieberanstieg bis $40^{\circ} \mathrm{C}$ und Frösteln oder Schüttelfrost. Innerhalb weniger 
Stunden ist die Krankheit bereits voll entwickelt mit Störung des Allgemeinbefindens, starkem subjektivem Krankheitsgefühl, heftigen Kopfschmerzen, Lichtscheu, Augenschmerzen, Rücken-, Interkosta]- und Wadenschmerzen mit Wadenkrämpfen sowie Gelenkschmerzen, dabei Nacken- und Rückensteifigkeit. Auffallend ist die Rötung des gleichzeitig geschwollenen Gesichtes. Die Konjunktiven zeigen stark injizierte Gefäße, die oft streifenförmig in der Lidspalte lokalisiert sind (Picksches Zeichen), und brennen heftig. Der Rachen ist gerötet und manchmal von einem vesikulösen Enanthem überzogen. Außerdem beobachtet man an der Haut besonders des Gesichtes und anderer unbedeckter Körperteilen rötelnartige Erytheme, und zwar besonders bei Menschen, die zuvor noch nicht Phlebotomenbissen ausgesetzt gewesen sind; hier handelt es sich um durch den Mückenspeichel hervorgerufene Sensibilisierungserscheinungen, die nach wiederholten Bissen verschwinden, um einer Desensibilisierung oder Immunisierung Platz zu machen. Von den stark juckenden Bißstellen geht ein pruritusartiger Ausschlag aus, der infolge des Kratzens in Pyodermatitis übergehen kann. Dieses allein durch die Mückenbisse hervorgerufene Hautsymptom, das nichts mit der eigentlichen Infektion zu tun hat, wird vielfach als »Harara» bezeichnet.

Nach 2 Tagen hat die Temperatur ihren Höhepunkt erreicht. Meistens stellen sich Übelkeit und Erbrechen, beim Aufsitzen Schwindel sowie in 20-30\% Durchfälle ein; sonst besteht Verstopfung und die Zunge ist belegt. Nasen-, Zahnfleisch-, Magen- und Darmblutungen, Harnbluten und Metrorrhagien, ferner petechiale Blutungen in den Bindehäuten kommen gelegentlich vor. Charakteristisch ist die am 2. Tage beginnende im Vergleich zur Fieberhöhe relative Bradykardie (40-60 Schläge), die durch den erhöhten Lumbalflüssigkeitsdruck bedingt ist. Sie tritt manchmal erst nach der Entfieberung auf. Das Blutbild zeigt anfangs Leukozytose, dann deutliche Leukopenie mit relativer Lympho- und Monozytose, später Zunahme der Neutrophilen und Eosinophilen. Leber und Milz sind nur selten vergrößert; ganz selten entwickelt sich Gelbsucht. Der Fieberverlauf ist nicht ganz regelmäBig; die Temperatur fällt gewöhnlich nach 3 Tagen, so daß am 4. Tage Entfieberung besteht ("Dreitagefieber《). Mitunter läßt sich ein zyklischer Fieberverlauf mit Dromedarkurve erkennen; nach mehreren fieberfreien Tagen steigt die Temperatur wieder an und die Allgemeinerscheinungen stellen sich - wenn auch weniger heftig - erneut ein.

Eine Fieberkurve von Pappataci-Fieber mit Rückfall gibt die Abb. 45

$\begin{array}{llllllllllllll}1 & 2 & 3 & 4 & 5 & 6 & 7 & 8 & 9 & 1011 & 121314151617 & 1819\end{array}$

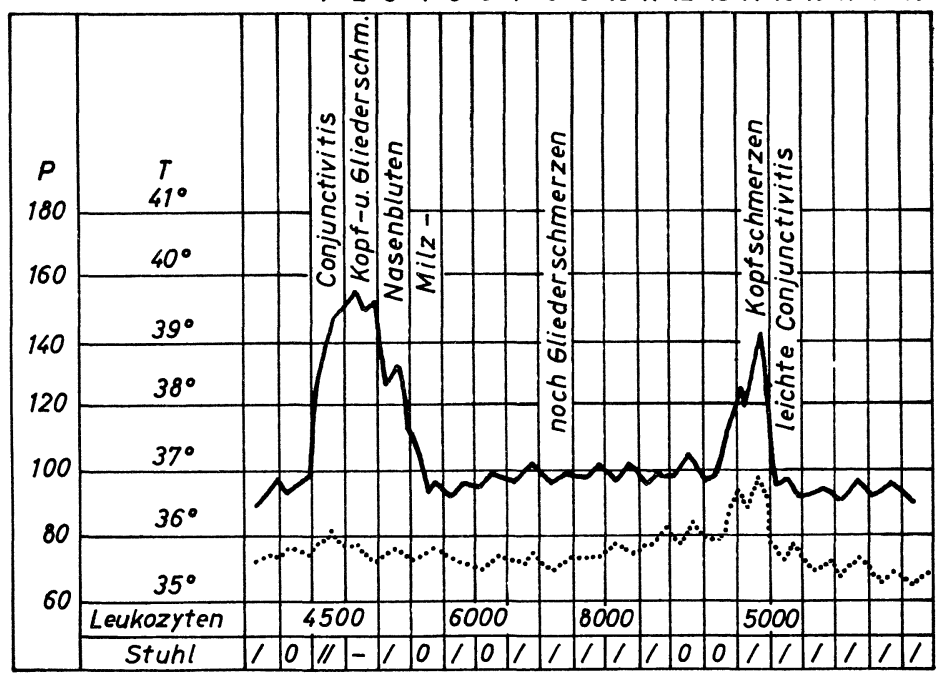

Abb. 45. Pappataci-Fieber mit Rückfall (nach Höring, 1950) 
In den schwereren Spätfällen hält das Fieber 10-12 Tage an und ist manchmal von einem flüchtigen Exanthem an Brust und Bauch begleitet. Mitunter entwickeln sich meningeale Erscheinungen. Als Regelbefund gilt eine Veränderung der Lumbalflüssigkeit: erhöhter Druck, vermehrter Eiweiß- und Zellgehalt (10-20 Lymphozyten). Die nervösen Erscheinungen stehen manchmal stark im Vordergrund.

Der Urin enthält kein oder nur ganz wenig Eiweiß.

Die Rekonvaleszenz dauert verschieden lange; sie erfordert manchmal erhebliche Zeit bis zur völligen Wiederherstellung; neben allgemeiner Schwäche bestehen nervöse Störungen, Schlaflosigkeit sowie Depression (s. auch NAUCK, 1956).

\section{Pathologie}

Besondere pathologische Veränderungen werden nicht beobachtet.

\section{Diagnose}

Sie erfolgt im allgemeinen bereits auf Grund der klinischen und epidemiologischen Beobachtungen (SABIN, 1959c). In Phlebotomus-Gebieten ist in der Schwarmzeit der Mükken bei fieberhaften Erkrankungen mit den genannten Symptomen stets an PappataciFieber zu denken, insbes. wenn es sich um zugezogene Personen, Reisende oder verlegte Truppenteile in endemischen Gebieten handelt.

Differentialdiagnostisch kommen Influenza, Gastroenteritis, Malaria, Maltafieber, Rückfallfieber, Gelbfieber, Fleckfieber, Rifttal-Fieber, Hepatitis u. a., in erster Linie aber Dengue in Frage. Die Abgrenzung gegen Malaria geschieht durch die Blutuntersuchung. Dengue ist durch das ausgesprochene Exanthem und Auftreten im Herbst vorwiegend in Städten und Siedlungen charakterisiert, während das Pappataci-Fieber mehr eine rurale Krankheit ist. Im Gegensatz zum kontinuierlichen Fieber bei Dengue fällt die Temperatur beim Pappataci-Fieber täglich; bei letzterem erleichtert die Bradykardie die Diagnose.

Eine spezifische Diagnose ist durch den Virusnachweis im Krankenserum im Frühstadium möglich: i.cer. Injektion des Krankenserums auf 1-3tägige Mäusesäuglinge. Außerdem kommt der Nachweis von AK im Rekonvaleszentenserum in Frage. Zur Serodiagnose eignet sich bisher nur der Nachweis von N-AK, die innerhalb von 2 Wochen nach Fieberbeginn auftreten. Zur NR sind beide Virusstämme zu verwenden.

\section{\%. Prognose}

Sie ist stets gut, selbst bei zunächst bedenklich erscheinenden schweren Symptomen des Zentralnervensystems. Rückfälle können eintreten. Schwäche und schnelle Ermüdbarkeit verhindern noch längere Zeit die Wiederaufnahme der normalen körperlichen und geistigen Tätigkeit, Todesfälle kommen nicht vor.

\section{Behandlung}

Sie beschränkt sich auf die Bekämpfung der Symptome. Hier kommen Pyramidon und Aspirin oder andere Analgetika, bei hartnäckigem Fortbestehen der Schmerzen auch stärkere Mittel in Frage (zum Beispiel Opiumtinktur). Außerdem werden Bettruhe, leicht verdauliche Kost, auch reichlich Obstsäfte verordnet und die Verstopfung mit milden Abführmitteln behoben. Beachtung erfordert die Gefahr etwaiger Darmblutungen. Bei starken zentralnervösen Erscheinungen werden Lumbalpunktionen zur Druckentlastung empfohlen. In der Rekonvaleszenz ist eine Kräftigungskur angebracht. 


\section{Immunbiologie}

Das Pappataci-Fieber erzeugt eine Immunität; wie Zweiterkrankungen zeigen, ist der Schutz aber nicht lebenslänglich.

Livshiтz (1937) beobachtete einen nur kurzen Schutz bei relativ vielen Menschen, da 20\% natürlich oder experimentell Erkrankter in derselben Saison noch einmal erkrankten.

Die einheimische Bevölkerung der endemischen Gebiete zeigt eine gewisse Feiung oder Durchseuchungsimmunität. Da der Rhythmus der Epidemien etwa 20 Jahre beträgt, ist also damit zu rechnen, daß die Immunität solange anhält.

Nach einer einmaligen experimentellen Infektion mit menschlichem Virus (Stamm Sizilien) traten $N-A K 2$ Wochen nach der Entfieberung auf. Sie wurden im allgemeinen noch nach 4-5 Monaten, aber sogar noch nach 9 Jahren gefunden.

Eine antigene Verwandtschaft mit Dengue-, WN-, JE- und SLE- sowie Gelbfieber-Virus wurde nicht gefunden (SaBIN, 1952c).

Wie bereits besprochen, kennt man zur Zeit 2 antigen verschiedene Virusstämme: Sizilien und Neapel. Die Differenzierung beider Stämme gelang in kreuzweisen Immunitätsversuchen bei Menschen außerdem auch mit der NR und mit der KBR mit menschlichen Rekonvaleszentenseren. Der Befund wurde dann mit Mäusehyperimmunseren beider Stämme bestätigt (SABIN, 1955).

\section{Prophylaxe}

Im Vordergrund aller Bekämpfungsmaßnahmen steht die Vernichtung der Phlebotomen. Diese gestaltet sich allerdings schwierig, da die Mücken oft an unzugänglichen Orten brüten und die Larven im Erdboden von den chemischen insektiziden Mitteln verschont bleiben. Den sichersten persönlichen Schutz gewähren mückensichere Kleidung und Fernhaltung der Phlebotomen von den Wohnstätten durch feinmaschige Mückengaze (Maschenweite 1-1,5 mm). Auch Schließen der Fenster und Türen mit Beginn der Dämmerung ist wichtig, falls keine Gazefenster und -türen vorhanden sind. Durchzug oder Ventilatoren vertreiben die Mücken.

Die Vernichtung der Mücken in den Häusern und deren Umgebung erfolgt durch Besprühen der Wände und Decken und außerhalb der Häuser der in Frage kommenden Brutstätten mit DDT oder Hexachlorocyclohexan (s. auch Konolev u. a., 1954). Auch die Mückennetze können mit DDT-haltigen Spritzmitteln u. ä. imprägniert werden, wodurch etwa eingedrungene Mücken noch getötet werden. Durch die DDT-Behandlung wird eine äußerst starke, aber lokalisiert bleibende Herabsetzung des Phlebotomusvorkommens erzielt, welche 12-19 Monate anhält (Herting und Fairchild, 1948; Hertig, 1949; s. auch Hertig und Fisher, 1945). Daß auch Phlebotomen eine DDT-Resistenz erwerben können, scheint aus den Beobachtungen von Brown u. a. (1951) hervorzugehen.

Wichtige Abwehrmittel sind allgemeine Sauberkeit, Instandhaltung der Wohnstätten und Ställe, häufiges Kalken der Wände, Entfernung allen Schuttes, Mülles und sonstiger Abfälle, welche den Mücken als Schlupfwinkel und Brutstätten dienen können, im Radius von 100 bis $200 \mathrm{~m}$ von den Wohnungen entsprechend der gewöhnlichen Fluglänge.

Zur persönlichen Prophylaxe kommen ferner insektenabweisende Präparate, zum Beispiel Dimethylphthalat, in Frage.

Die Isolierung der Kranken hat nur Wert in den ersten Krankheitstagen, solange das virämische Stadium besteht.

Allgemein anerkannte Impfstoffe sind noch nicht im Gebrauch. Da die Mäuse-adaptierten Virusstämme ihre Antigenität behalten, besteht die Möglichkeit, aus diesen brauchbare Impfstoffe herzustellen. Massenimpfungen wären von besonderem Wert für militärische Formationen vor ihrer Verlegung in Endemiegebiete. Von älteren Immunisierungsversuchen (Simultanimpfungen) sind vor allem jene von Моsснкоwsкy и. а. (1937a) in Rußland zu erwähnen. Sie verwandten allerdings keinen echten Impfstoff, sondern »virulentes" Krankenserum; kurz vor- oder hinterher wurde außerdem "viruzides" Rekonvaleszentenserum eingespritzt. Während von 493 so immunisierten Personen in einem Epidemiegebiet in der Folge 
nur 30,9\% erkrankten, war dies bei 726 Kontrollpersonen in 70,9\% der Fall. Ähnliche Ergebnisse mit demselben Verfahren erzielten Pirumov und Ananyan (1939). Ob ein in Rußland von Ananyan (1953) benutzter Lebendimpfstoff wirksam war, ist nach Sabin (1959c) schwer zu entscheiden.

\section{F VI. Guaroa-Fieber}

Groot u. a. (1959) fanden im Blut in einer Bevölkerungsgruppe in Kolumbien ein Virus, das zu leichtem Fieber und Immunität führte. Von insgesamt 110 untersuchten Menschen wiesen $48(43,6 \%)$ spezifische N-AK auf. Es scheint sich um ein neues Virus zu handeln. Es wurde "Guaroa-Virus» genannt.

Das Virus war für Mäuse jeden Alters, wenn es i.cer. eingespritzt wurde, pathogen. Nach s.c. Infektion starben nur Mäusesäuglinge. Die i.cer. infizierten Mäuse erkrankten zwischen 4 und 6 Tagen mit Lähmungen der Beine und starben zwischen 5 und 8 Tagen. In serienweisen Gehirnübertragungen bei Mäusesäuglingen betrugen die Virustiter $10^{-5}$ bis $10^{-6,8}$ je $0,03 \mathrm{ml}$. Bei erwachsenen Mäusen waren sie geringer. Für neugeborene Ratten war das Virus tödlich (BaBCock u. a., 1961).

Das Virus war auf Macacus-rhesus- und M.mulatta-Affen übertragbar. Nach s.c. oder i.d. Injektion von virushaltigem Menschenblut bekamen diese Affen eine Virämie und entwickelten N-AK. Aotus trivirgatus ließ sich i.cer. mit Mäusegehirn (8. Passage) infizieren, ebenso einer von 2 Gelbfieber-immunen Affen. Er bekam Lähmungen beider Beine nach 14 Tagen, genas aber wieder.

Das Virus war leicht durch Seitz-EK-Scheiben filtrierbar. Es blieb bei $-70^{\circ} \mathrm{C}$, nicht aber bei $-20^{\circ} \mathrm{C}$ am Leben und ließ sich lyophilisieren.

Es bestand keine immunologische Verwandtschaft des Virus mit 36 verschiedenen ArborViren. Das Virus wurde nicht neutralisiert durch Immunseren von Gelbfieber, Dengue 2, Ilhéus und VEE. Hyperimmunseren von Mäusen, Meerschweinchen und Affen gegen GuaroaVirus enthielten keine N-AK gegen Gelbfieber-, Dengue 2-, Ilhéus-Virus und keine HAH-AK gegen VEE, Gelbfieber-, Dengue 2-, Ilhéus- und Anopheles A und B-Virus. Affenimmunseren ergaben ferner keine HAHR mit Antigenen der Gruppe A (Mayaro, VEE-, EEE, WEE), der Gruppe B (Gelbfieber, SLE, Dengue 2, Ilhéus), der Gruppe C (Apéu, Marituba, Oriboka) sowie Bunyamwera-Virus. Mäuse-Immunserum enthielt nur KB-AK für das homologe Virus, nicht aber für die Viren der Gruppe A, B, C. In der HAHR wurden noch folgende Immunseren gegen das Guaroa-Virus geprüft: Bunyamwera, Bwamba, CE, Colorado-Zecken-Fieber, Rifttal-Fieber, Pappataci-Fieber (Neapel, Sizilien), Simbu, Turlock und Wyeomyia. Nur ein CE-Virus-Antiserum reagierte in Verdünnung von 1: 80, während homologes Serum in Verdünnung 1:640 hemmte. WhitMan und ShOPe (1962) fanden antigene Verwandtschaft des Guaroa-Virus mit dem California-Komplex in der HAHR und KBR.

Spence (Mitt. an Whitman und Shope, 1962) stellte mittels der KBR antigene Verwandtschaft mit der Bunyamwera-Gruppe fest.

\section{F VII. Witwatersrand-Fieber}

1958 beobachteten McIntosh u. a. (1960) unter den Bewohnern von Germiston bei Johannesburg (Südafrika) den Ausbruch einer fieberhaften Krankheit. Ein Pool von in dieser Gegend gefangenen Culex rubinotus-Mücken wurde 2 Tage alten Mäusesäuglingen und erwachsenen Mäusen injiziert. Erstere erkrankten oder starben am 4.-5., letztere am 9.-11. Tag p. i. Gehirn und Blut waren virushaltig.

Das Virus ließ sich auf Mäusen passagenweise züchten. Gehirn und Blut ergaben Titer von 7,5 und 7,7 $\log$ für Mäusesäuglinge. Infizierte Meerschweinchen erkrankten nicht, entwickelten aber AK.

Das Virus passierte Gradocolmembranen von $275 \mathrm{~m} \mu$ durchschnittlicher Porenweite. Es war $\mathrm{Na}$ desoxycholat-empfindlich und ließ sich gut lyophilsieren. 
Durch Zucker-Aceton-Extraktion von infektiösen Mäusesäuglingsgehirnen und ÄtherAceton-Extraktion von Mäusesäuglingsseren wurde ein Hämagglutinin mit optimalem Titer bei $\mathrm{pH} 6,0$ erhalten.

Witwatersrand-Antiseren ergaben mit dem homologen Virus eine HAHR mit einem Titer von 2500. Nưr bei wenigen Personen wurden bisher AK nachgewiesen.

Das Witwatersrand-Virus wird als neues noch nicht klassifiziertes Arbor-Virus angesehen, da es nur schwach durch Antiseren gegen 31 Arbor-Viren neutralisiert wurde. Die KBR mit Antigen, das aus infektiösen Gehirnen durch Zucker-Aceton-Extraktion gewonnen worden war, verlief mit Antiseren gegen 17 Arbor-Viren negativ. Es wurde auch keine Kreuz-HAHR mit zahlreichen Arbor-Viren erhalten.

\section{F VIII. Guamá-Virus-Gruppe}

Diese Gruppe besteht aus mindestens 3 Viren: Guamá, Catu und Bimiti. Die Guamáund Bimiti-Viren wurden gleichzeitig mit C-Viren im Waldgebiet von Belém (Amazonastal, Brasilien) isoliert. 7 Isolate stammten aus dem Blut von Menschen, über 100 aus dem Blut von Schildwacht-Affen, wilden Nagern und Mücken wie Sabethini (u. a. Trichoprosopon digitatum), Culicini (u. a. Haemagogus sp. Culex melanoconion), Aedes scapularis und A.serratus, die an Menschen Blut gesaugt hatten. Die Virusisolierungen erfolgten durch i.cer. Verimpfung des verdächtigen Materials auf 2-4tägige Mäusesäuglinge (Causey u. a., 1961).

Weiße Schildwacht-Mäuse, die im Urwald einer Mückenbißinfektion (Culex melanoconion) ausgesetzt worden waren, wurden ebenfalls befallen gefunden, so daß zahlreiche Virusstämme gewonnen werden konnten. Schildwacht-Affen bekamen nach experimenteller Infektion durch Mückenbiß eine bis zu 12 Tage dauernde Virämie, während diese bei natürlich infizierten Affen bis zu 83 Tage lang bestand. Der N-AK-Titer bei den infizierten Affen blieb im Vergleich zu den immunisierten Mäusen gering.

Der Prototypstamm des Guamá-Virus ist der Be An 277-Stamm, der von einem Affen im Oriboka-Wald isoliert worden war. Dasselbe Virus wurde auch in einem Pool von Culex melanoconion-Mücken angetroffen, die zusammen mit wilden Mäusen gefangen worden waren. Alle Virusstämme ließen sich durch i.cer. Passagen auf neugeborenen Mäusen züchten, die nach 2-6 Tagen erkrankten und starben. Der $\mathrm{LD}_{50}$-Titer für 4 Tage alte Mäuse betrug $10^{-6,5}$. Das Virus war auch für kleine Mäuse nach s.c. und i.p. Infektion pathogen. Es bestand aber auch nach i.cer. Infektion nur eine beschränkte Pathogenität für erwachsene Mäuse, die nur in bis zu $50 \%$ mit Lähmungen starben. Das Virus ließ sich im Mäusegehirn bei $24^{\circ} \mathrm{C}$ im getrockneten Zustand aufheben.

2 Menschen, die mit dem Guamá-Virus infiziert waren, erkrankten an Fieber, Schwindel, Lichtscheu, Übelkeit sowie Kopf-, Rücken-, Muske]- und Gelenkschmerzen, die 4 Tage anhielten. Im Rekonvaleszentenblut wurden nach 6-8 Wochen N-AK gegen die isolierten Virusstämme gefunden.

Als Prototyp des Catu-Virus gilt der Stamm BeH 151, der aus dem Blut eines Waldarbeiters (Oriboka-Wald), ferner von Schildwacht-Affen und -Mücken, die in den benachbarten Wäldern ausgesetzt worden waren, isoliert wurde. Das Virus wurde ferner bei wilden Tieren, nicht aber bei frei lebenden Mücken nachgewiesen (CAUSEY u. a., 1962). Es ließ sich ebenfalls durch i.cer. Passagen auf neugeborenen Mäusen züchten, die auch für eine s.c. und i.p. Infektion empfänglich waren. Der Stamm BeH 5056 erfuhr durch Gehirnpassagen auf erwachsenen Mäusen eine Modifikation im Sinne einer Pathogenitätssteigerung, so daß schon mäßig hohe Titer regelmäßig töteten.

Der mit Catu-Virus infizierte Mensch war an Fieber, das 5 Tage dauerte, Kopfschmerzen, Schmerzen im ganzen Körper und Schwäche erkrankt. Das Virus war vor dem Auf- 
treten von Symptomen isoliert worden. Es wurde bisher bei 4 Personen nachgewiesen. Rekonvaleszentenserum zeigte nach etwa 3 Wochen N-AK-Titeranstieg gegen das Virus.

Das Bimiti-Virus (bimiti = indianisches Wort für Kolibri) wurde in Trinidad, dem Land der Kolibris, aus einem Pool von Culex melanoconion spissipes Theob. und 33 nicht identifizierten Culex-Mücken durch i.cer. Verimpfung auf 2 Tage alte Mäusesäuglinge, die am 10. Tag erkrankten, isoliert. Als Prototypvirus gilt der Stamm Tr 8362 (Spence u. a., 1962). In weiteren Gehirnpassagen tötete das Virus die Mäusesäuglinge in 4-5 Tagen, von der 5. Passage ab in 3-4 Tagen. Die Tiere bekamen eine Virämie. Mäusesäuglinge ließen sich auch i.p. und s.c. infizieren. Meerschweinchen und Hamster erkrankten nicht nach i.cer. Infektion, entwickelten aber N-AK. Eintagsküken erschienen resistent gegen eine s.c. Infektion; in ihrem Blut wurden weder Virus noch N-AK nachgewiesen.

In Hamsternierenzellen erzeugte das Bimiti-Virus keinen ZE und vermehrte sich offenbar auch nicht. Es wurde durch Verimpfung in den Dottersack durch 10 Hühnerembryopassagen gezüchtet, ohne die Embryonen zu töten. Eine Züchtung in der Amnion- oder Allantoishöhle gelang nicht.

Das Bimiti-Virus ist $\mathrm{Na}$ desoxycholat-empfindlich.

Versuche, das Bimiti-Virus von 2500 Fieberkranken in Trinidad zu isolieren, verliefen negativ. Die KBR mit dem Virus und Rekonvaleszentenseren von 80 Fieberkranken blieb ebenfalls negativ. Nur bei sehr wenigen Menschen aus der Nachbarschaft der Mückenisolate, u. a. bei Mückenfängern, wurden N-AK gefunden. Menschliche Bimiti-Infektionen scheinen demnach sehr selten zu sein.

Die $K B R$ mit einem Antigen, das durch Aceton-Äther-Extraktion aus infektiösen Mäusegehirnen gewonnen worden war, und Mäusehyperimmunseren gegen 30 verschiedene Viren, die nicht aus Trinidad stammten, ergab einen positiven Ausfall mit einem Antiserum gegen das Catu-Virus, jedoch keinen mit Antiserum gegen Guama-Virus. Kreuzweise KBR und $N R$ mit Mäuseimmunseren zeigten, daß das Virus keine antigene Verwandtschaft mit folgenden Viren hat: EEE, VEE, Mayaro (Gruppe A), Ilhéus, SLE, Dengue, Gelbfieber (Gruppe B), Oropouche, Manzanilla, Wyeomyia, Cache Valley und Kairi. Da kein Hämagglutinin aus infektiösen Mäusegehirnen gewonnen werden konnte, wurden hämagglutinierende Antigene aus MayaroVirus sowie Ilhéus-, SLE- und Gelbfieber-Viren gegen Bimiti-Mäusehyperimmunseren in der $H A H R$ geprüft, die negativ ausfiel.

Die Viren der Guama-Gruppe lassen sich in Mücken nach der Inokulationsmethode von Whitman züchten (Whitman und Casals, 1961). Zur Differenzierung dieser neuen Viren eignete sich die HAHR nicht. Die KBR ergab auch nur Gruppenzusammengehörigkeit, aber keine antigene Trennung der einzelnen Stämme. Nur mit der NR an der Maus (Schutzprobe) waren die 3 Viren voneinander zu unterscheiden (Causey u. a., 1961; Whitman und CaSals, 1961).

\section{F IX. Tacaiuma-Virus}

Dieses Virus mit dem Prototyp An 73 war von Affen, die im Oriboka-Wald ausgesetzt worden waren, isoliert worden. Es war für Mäusesäuglinge und erwachsene Mäuse pathogen (CAUSeY u. a., 1961).

\section{F X. Manzanilla-Virus}

Während einer Gelbfieberepidemie in Trinidad wurden die Seren einer Reihe von tot aufgefundenen oder erschossenen Brüllaffen (Alouatta seniculus insularis) auf Mäusesäuglinge verimpft. Aus dem Serum eines Affen aus der Nähe von Manzanilla wurde ein neues Virus (Stamm Tr 3587) isoliert (Downs u. a., 1955a), das serologisch keine Verwandtschaft mit einer großen Zahl von Arbor-Viren erkennen ließ. Es war pathogen für Mäusesäuglinge nach i.cer. Infektion und ergab Titer von $10^{-5}$ bis $10^{-7} / 0,03 \mathrm{ml}$ sowie nach i.p. Infektion Titer von $10^{-4}$ bis $10^{-6}$. 2 Tage nach i.p. Infektion trat Virämie auf, nicht dagegen nach i.cer. Impfung. Erwachsene 
Mäuse waren für eine i.cer. Infektion empfänglich und erkrankten unter meningealen Erscheinungen. Der Gehirntiter erreichte $10^{-5}$ bis $10^{-8} \mathrm{LD}_{50} / 0,03 \mathrm{ml}$. Erwachsene Mäuse erkrankten nicht nach i.p. Injektion von etwa $10^{6}$ i.cer. $\mathrm{LD}_{50}$. Hamster ließen sich i.cer. infizieren. Der Virustiter in den Gehirnen erreichte $10^{-5} \mathrm{LD}_{50} / 0,03 \mathrm{ml}$ für Mäuse. Meerschweinchen erkrankten nicht, entwickelten aber AK. Cebus-Affen waren sowohl für eine i.cer. als auch für eine i.p. Infektion unempfänglich. Kaninchen und Eintagsküken waren ebenfalls unempfänglich und entwickelten auch keine AK. Hühnerembryonen waren dagegen hochempfänglich. Nach Infektion in den Dottersack betrug die Inkubationszeit 3-7 Tage. Das Virus ließ sich durch 34 Eipassagen züchten.

Die Mücken Aedes scapularis, A.serratus und Culex fatigans vermochten nach künstlicher Infektion das Virus nicht zu übertragen; dieses wurde bei den Mücken 2-3 Wochen lang nachgewiesen.

Die Seren von 47 Personen aus Waldgebieten neutralisierten das Virus nicht. 8 von 37 Brüllaffenseren neutralisierten das Virus erst, nachdem sie 30 Min. auf $56^{\circ} \mathrm{C}$ erhitzt worden waren.

\section{F XI. Akabane-Virus}

In Japan wurden bei Untersuchungen auf JE-Virus aus Mückensuspensionen (Aedes vexans und Culex tritaeniorhynchus) durch i.cer. Verimpfung auf Mäusesäuglinge, die nach einer Inkubationszeit von 2-5 Tagen erkrankten, 6 neue identische Virusstämme isoliert. Das Virus wurde »Akabane" genannt (Matsuyama u. a., 1960).

OyA u. a. (1961) züchteten einen Virusstamm in Hamsternierenzellkulturen.

Das Virus war Na desoxycholat-empfindlich und wurde durch Protaminsulfat nicht präzipitiert. Es agglutinierte Erythrozyten von Eintagsküken und Gänsen. Aus der 5. Mäusegehirnpassage wurde durch Zucker-Aceton-Extraktion ein allerdings nur geringtitriges Hämagglutinin $(1: 160)$ erhalten. Die HAHR mit diesem Hämagglutinin und Antiseren gegen 36 ArborViren zeigten keine serologische Verwandtschaft. Auch die HAHR mit Akabane-Virus-Antiserum und Hämagglutinin von $7 \mathrm{~A}$ - und 4 B-Arbor-Viren ließ keine Verwandtschaft erkennen. Die Kreuz-KBR mit 3 durch Zucker-Aceton-Extraktion aus infizierten Mäusesäuglingsgehirnen gewonnenen Antigenen ergaben serologische Identität der 3 Stämme. Die KBR mit Akabane-Virus-Antiserum und verschiedenen Arbor-Virusantigenen verlief negativ.

Menschliche Infektionen scheinen noch nicht bekannt geworden zu sein. Ob das AkabaneVirus durch Arthropoden übertragen wird, ist auch noch unbekannt.

\section{F XII. Ndumu-Virus}

Ein weiteres Virus, das »Ndumu«-Virus, und zwar die beiden Stämme AR 2204 und Ar 2211 wurden im nördlichen Natal aus einem Pool von 19 Mansonia (Mansonioides) uniformis Theob. und einem Pool von 278 Aedes (Neomelanoconion) circumluteolus Theob. isoliert (KoKernot u. a., 1961b).

Neugeborene und erwachsene Mäuse waren für eine i.cer. Infektion empfänglich. Die Überlebenszeit betrug bei den neugeborenen Mäusen durchschnittlich 3, bei den älteren Mäusen 7,5 Tage. Die Pathogenität für erwachsene Mäuse nach peripheren Infektionen war nur gering. Die Gehirnprozesse bei den i.cer. infizierten Mäusen waren die einer typischen Virus-Encephalitis und durch Rundzelleninfiltrationen im perivaskulären Gewebe mit verstreuten Herden von degenerierenden und nekrotisierenden Zellen charakterisiert.

Ein Vervet-Affe (Cercopithecus aethiops pygerythrus F. Cuvier), der i.cer. mit 4000 i.cer. $\mathrm{LD}_{50}$ für erwachsene Mäuse infiziert worden war, bekam eine Virämie. Meerschweinchen bildeten nach i.cer. Infektion N-AK.

Das Ndumu-Virus ist $\mathrm{Na}$ desoxycholat-empfindlich. Es ließ sich in einem Medium aus $5 \%$ Lactose, 1\% Pepton, M/25 Phosphatpuffer in Wasser ohne Titerverlust lyophilisieren.

Die NR und KBR ergaben immunologische Gleichartigkeit der beiden isolierten Virusstämme. NR, KBR und HAHR zeigten keinerlei Verwandtschaft beider Stämme mit zahlreichen Arbor-Viren. Wie die NR (i.cer. Mäuseschutzprobe) ergab, ist das Virus unter den Bewohnern Südafrikas weit verbreitet. Es scheint endemisch vorzukommen. 


\section{F XIII. Lumbo-Virus}

In Lumbo (Mozambique) wurden 12 bisher unbekannte identische Virusstämme aus Aedes (Skusea) pembaesis-Mücken isoliert. Als Sammelname wurde "Lumbo-Virus" gewählt.

Das Virus ließ sich passagenweise i.cer. von primär infizierten und erkrankten Mäusen auf neugeborene und erwachsene Mäuse mit durchschnittlicher Überlebenszeit von 4 Tagen weiterverimpfen. Erwachsene Mäuse konnten i.cer., aber nicht i.p. infiziert werden. Die Gehirne der infizierten Mäuse zeigten encephalitische Veränderungen. Hamster ließen sich i.cer., aber nicht i.p. infizieren. Vervet-Affen (Cercopithecus aethiops pygerythrus) bekamen am 3. und 4. Tag p. i. eine Virämie. Diese Affen wie auch Paviane (Papio cynocephalus), Buschbabys (Galagos crassicaudatus) und Meerschweinchen bildeten nach experimenteller Infektion AK, ohne Krankheitserscheinungen zu zeigen.

Das Lumbo-Virus ließ sich filtrieren und lyophilisieren. Es war $1 \mathrm{Jahr}$ bei $-20^{\circ}$. a aufbewahrt haltbar und Na desoxycholat-empfindlich. 30 Min Erhitzen auf $60^{\circ} \mathrm{C}$ tötete es nicht vollständig ab. Ein Hämagglutinin konnte bisher nicht gewonnen werden.

Mit der i.cer. Mäuseschutzprobe ließ sich eine gewisse Verwandtschaft des Prototypvirus AR 1881 mit dem Bwamba-Virus erkennen. In der HAHR und KBR ergab sich aber die Unabhängigkeit des Lumbo-Virus von diesem. Mit zahlreichen anderen Arbor-Viren wurde keine antigene Verwandtschaft festgestellt.

Von 128 Menschenseren aus der Gegend von Lumbo und Ndumu (Nord-Natal) enthielten 16 N-AK. 175 Seren aus Angola und einer anderen Gegend Afrikas waren dagegen negativ (s. auch КокеRNot u. a., 1960 a; Worth u. a., 1961).

\section{F XIV. Mossuril-Virus}

Außer dem Lumbo-Virus wurde in Lumbo ein weiteres neues Virus »Mossuril aus einem Pool von 15 Culex sitiens-Mücken isoliert. Dieses Virus war nur für neugeborene Mäuse und nur nach i.cer. Infektion pathogen. Es ließ sich leicht in ihnen adaptieren. Die Gehirne der infizierten Mäusesäuglinge zeigten encephalitische Veränderungen. Das Virus ließ sich durch Membranfilter mit mittlerer Porenweite von $275 \mathrm{~m} \mu$ filirieren und war lyophilisierbar. Es war $\mathrm{Na}$ desoxycholat-empfindlich und wurde durch $50 \mathrm{Min}$ Erhitzen auf $50^{\circ} \mathrm{C}$ vollständig inaktiviert. In der HAHR, KBR und NR wurde keine Verwandtschaft mit anderen Arbor-Viren festgestellt. Aus Mäuseschutzversuchen geht hervor, daß das Mossuril-Virus nur eine geringe Rolle für Infektionen von Säugetieren zu spielen scheint (КокеRNoт u. a., 1962a, b).

\section{F XV. Melao-Virus}

Aus den in einem Wald von Trinidad gesammelten Aedes scapularis-Mücken wurde ein weiteres Arbor-Virus »Melao« isoliert, das mit dem CE-Virus immunologisch verwandt zu sein schien.

Das Virus vermehrte sich gut in Aedes aegypti-Mücken und ließ sich in ihnen passageweise züchten.

Im Blut von über 2500 Menschen mit nichtdiagnostizierten Fiebern gelang der Virusnachweis nicht. Im Serum eines Menschen aus der Gegend der gesammelten Mücken wurden N-AK nachgewiesen (SPence u. a., $1962 \mathrm{a}, \mathrm{b}$ ).

Nach CaSals (1961b) gehören außerdem in die Gruppe der noch nicht gruppierten Arbor-Viren durch Culicoides übertragbare Viren, nämlich das in Afrika und dem östlichen Mittelmeergebiet isolierte Virus der afrikanischen Pferdekrankheit und das in Nordamerika, Spanien, Portugal und Israel isolierte Blauzunge-Virus, ferner das durch Mücken übertragbare in Kalifornien (USA) isolierte Hart Park-Virus sowie das in Afrika isolierte, durch Zecken übertragene Virus der Nairobi-Schlafkrankheit. 


\section{Literatur zu Kapitel V}

Agramonte, A., J. Trop. Med. 27, 285 (1924)

Airken, T. H. G., Mosquito News 20, 1 (1953); Artken, T. H. G., West Ind. Med. J. 6, 229 (1957); Artken, T. H. G. \& C. R. Anderson, Amer. J. Trop. Med. Hyg. 8, 41 (1959); Artken, T. H. G., W. G. Downs \& C. R. Anderson, Proc. Soc. Exper. Biol. 99, 635 (1958; Aitken, T. H. G., W. G. Downs, C. R. Anderson, L. Spence \& J. Casals, Science 131, $986(1960)$

Aldighieri, R., Med. Trop. 14, 286 (1954); Rev. Hyg. Med. Soc. 3, 314 (1955)

Alexander, R. A., J. South Afric. Vet. Med. Ass. 22, 105 (1951)

Alinov, V. J., T. N. Zakorkina, G. I. Nedkil \& V. G. Fedorova, Med. Parazit. (russ) 1, 24 (1961)

Aluison, A. C., F. E. Buckland \& C. H. Andrewes, Virology 17, 171 (1962)

Ananyan, S. A., Z. Mikrobiol. (russ), Nr. 1, 32 (1953)

Anderson, C. R., T. H. G. Aitken \& W. G. Downs, Amer. J. Trop. Med. Hyg. 5, 621 (1956a); Anderson, C. R., T. H. G. Aitken, L. P. Spence \& W. G. Downs, Amer. J. Trop. Med. Hyg. 9, 70 (1960); Anderson, C. R.\& W. G. Downs, Amer. J. Trop. Med. Hyg. 4, 662 (1955); Anderson, C. R., W. G. Downs \& A. E. Hill, Science 124, 224 (1956 b); ANderson, C. R., W. G. Downs, G. H. Watthey, N. W. Ahin \& A. A. Reese, Amer. J. Trop. Med. Hyg. 6, 1012 (1957); ANderson \& A. Gast-Galvis, Amer. J. Hyg. 45, 302 (1947); Anderson, C. R. \& J. Osorno-Mesa, Amer. J. Trop. Med. 26, 613 (1946); Anderson, C. R. \& M. Roca-Garcia, Amer. J. Trop. Med. 27, 161 (1947); Anderson, C. R., L. Spence \& W. G. Downs, Carribbean Med.J. 16, 68 (1954); Anderson, C. R., L., Spence W. G. Downs \& T. H. G. Aitken, Amer. J. Trop. Med. Hyg. 10, 574 (1961) Anderson, C. R. \& G. H. WatTley, Trans. Roy. Soc. Trop. Med. 49, 580 (1955)

Anderson, S. G. \& G. L. Ada, Virology 8, 270 (1959); Nature 188, 876 (1960)

Anderson, W. M. E., J. Roy. Army Med. Corps 14, 236 (1941 a), 15, 140 (1941 b)

ANDrew, R., Brit. Med. J. 1953 II, 1063

Andrewes, C. H. \& D. M. Horstmann, J. Gen. Microbiol. 3, 260 (1949)

Angeloff, St. \& P. Panajotov, Arch. Exper. Vet. Med. 14, 521 (1960)

Angilillio, B. \& G. F. Masca, Igiene moderna 52, 449 (1959)

Angulo, J. J., O. W. Richards \& A. L. Roque, J. Bact. 57, 297 (1949)

Aniker, S. P., Sympos. Diamond Jubilee Haffkine Inst. Proc. 62 (1960); Aniker, S. P., T. H. Work, T. Chandraseikharaiya, D. P. Narasimha Murthy, F. M. Rodrigues, R. Amed, K. G. Kulkarni, S. H. Rahman, H. Mansharamani \& H. A. Prasanna, Indian J. med. Res. 50, 147 (1962)

Antunes, P. C. A., Intern. Kongr. Tropenmed. Malaria 1, 498 (1948); Antunes, P. C. A. \& L. Whitman, Amer. J. Trop. Med. 17, 825 (1937)

Antunes, W. \& A. Castro, Bol. Ofic. San. Panameric. 24, 972 (1945)

Apostolopoulos, K. G., Münch. med. Wschr. 72, 265 (1930)

Aragao de Beaurepaire, H., Compt. rend. Soc. Biol. 99, 1341 (1928a); Mem. Inst. Oswaldo Cruz, Rio., Suppl. 2, 35 (1928b); Brasil. Med. 43, 849 (1929 a), 43, 885 (1929b); Compt. rend. Soc. Biol. 102, 476 (1929 c); Brasil. Med. 47, 75 (1933a); Compt. rend. Soc. Biol. 112, 1471 (1933 b), 114, 137 (1933c); Aragao de Beaurepaire, H. \& A da Costa lima, Compt. rend. Soc. Biol. 102, 53 (1929 a), 102, 477 (1929b), 102, 478 (1929c); Mem. Inst. Oswaldo Cruz 8, Suppl. 101 (1929 d), 9, 133 (1929e), 9, 139 (1929f), 9, 142 (1929 g); Compt. rend. Soc. Biol. 104, 619 (1930)

Arrangements for Vaccination against yellow Fever; Weekly Epidemiol. Rec. League of Nations 30, Suppl. 2, 1 (1955)

Armstrong, C., Publ. Health Rep. 38, 1750 (1923)

Asamura, K., Miscellaneus Rep. Res. Inst. Nat. Resources 86 (1952)

Ast, J. E., in: Pathogenesis and Pathology of Virus Diseases von Kidd 134 (New York 1950)

Ashburn, P. M. \& C. F. CraIG, J. Infect. Dis. 4, 440 (1907 a); Philippine J. Sci..2, 93 (1907 b), J. Amer. Med. Assoc. 48, 692 (1907 e)

Assumpcao, L. DE, Bol. Inst. Hig. Sao Paulo Nr. 71 (1940)

Audy, J. R., Trans. Roy. Soc. Trop. Med. 52, 308 (1958)

Avakian, A. A. \& A. D. Lebedev, Z. Mikrobiol (russ). Nr. 4, 20 (1955); Avakian, A. A., S. B. Shemshilewich \& V. M. Meschchenko, Probl. Virol. 4, Nr. 1, 87 (1959)

Azevedo, J. F. de, F. J. C. Cambournac \& M. R. Pinto, Ann. Inst. Med. Trop. Lissabon 4, $17(1947)$

AzisbeKIaN, G. A., Kriegsmed. (russ) 2, 41 (1953) 
BaBCoCK, V. I., D. B. Doris \& C. M. Southam, Fed. Proc. 20, 443 (1961)

Bablet, J., Bull. Off. Intern. Hyg. Publ. 27, 2360 (1935), 28, 1267 (1936 a), 28, 1313 (1936 b), 28, 2329 (1936 c), 28, 2346 (1936 d); Paris Med.1936 e, 500; Arch. Inst. Pasteur Indochine 7, 177 (1937 a); Bull. Off. Intern. Hyg. Publ. 29, 1139 (1937b); La Fièvrejaune (Paris, 1945); Bablet, J. \& F. Bloch, Ann. Inst. Pasteur 89, 492 (1937)

Bailey, S. F. \& R. M. BoharT, J. Econom. Entomol. 45, 947 (1952)

Balfour, A., Lancet, 1914 II, 1176; Trans. Roy. Soc. Trop. Med. 8, 75 (1915)

Bancroft, T. L., Austral. Med. Gaz. 25, 17 (1906)

Banta, J. E., Amer., J. Hyg. 67, 286 (1957)

Barbareschi, G., Rev. Biol. 5, 201 (1957)

Barbero, G. J., S. Katz, H. Kraus \& C. L. Leedham, Arch. Intern. Med. 91, 177 (1953)

Bardos, V.\& V. Damielovê, J. Hyg. Microbiol. Epid. 3, 264 (1959)

Barnett, H. C. \& W. Suy emoto, Transact. N. Y. Acad. Sci. 23, 609 (1961)

Baroian, O. B. \& T. M. Lozinskaia, Prob. Virol. 3, 1 (1958)

Baron, S.\& A. Isaacs, Nature 191, 98 (1961); Baron, S., J. S. Porterfield \& A. Isaacs, Virology 14, 444 (1961)

BarraUd, G., Clio en Epidaure (Paris, 1954)

Baruch, E., Exper. Cell Res. 1962 im Druck

Bates, M., Amer. J. Trop. Med. 24, 83 (1944a), 24, 91 (1944b); Ecology 25, 159 (1944c); Ann. Entomol. Soc. 40, 1 (1947); Bates, M. \& M. Roca-Garcia, Amer. J. Trop. Med. 25, 203 (1945), 26, 437 (1946a), 26, 585 (1946 b), 26, 607 (1946 c); Bates, M. \& J. Weir, Amer. J. Trop. Med. 24, 35 (1944)

Bauer, D. J., Nature 159, 438 (1947); Bauer, D. J. \& P. L. Bradley, Brit. J. Exper. Path. 37, 447 (1956); in: Biochemistry of Viruses von Broda \& Frisch-Niggemeyer 143 (Basel, New York 1959)

Bauer, J. H., Amer. J. Trop. Med. 8, 261 (1928), 11, 337 (1931); Brit. J. exper. Path. 32, 7 (1951); Bauer, J. H. \& N. P. Hudson, Amer. J. Trop. Med. 8, 371 (1928a); J. exper. Med. 48, 147 (1928b); J. Prev. Med. 4, 177 (1930); Bauer, J. H. \& T. P. Hughes, J. Gen. Physiol. 18, 143 (1934); Amer. J. Hyg. 21, 101 (1935); Bauer, J. H. \& A. F. MahafFy, Amer. J. Hyg. 12, 155 (1930)

BAYER, M. E. \& G. Nielsen, Arch. Virusforschg 11, 303 (1961)

Bearcroft, W. G. C., Transact. Roy. Soc. Trop. Med. 50, 442 (1956); J. Path. Bact. 74, 295 (1957), 80, 19 (1960), 80, 421 (1960 b), 83, 59 (1962)

Beasley, A. R., W. Lichter \& M. M. Sigel, Arch. Virusforschg. 10, 672 (1961); Beasley, A. R. \& M. M. SigeL, Bact. Proc. 61, 144 (1961)

Beck, C. E. \& R. W. G. Wyckoff, Science 88, 530 (1938)

BECKER, F. E., J. Infect. Dis. 39, 81 (1926); Colorado Med. 27, 36 (1930)

Becker, H. \& H. Lieske, Z. Tropenmed. 8, 4 (1957)

BeET, E. A., Brit. Med. J. 1955 I, 2266

Beeuwhes, H. A., J. H. Bauer \& A. F. Mahaffy, Amer. J. Trop. Med. 30, 305 (1930); Beeuwkes, H. A. \& T. B. Hayne, Transact. Roy. Soc. Trop. Med. 25, 107 (1932); Beeuwkes, H. A., J. A. Kerr, A. A. Weathersbee \& A. W. Taylor, Transact. Roc. Soc. Trop. Med. 26, 39 (1933); Beeuwkes, H. A. \& A. F. Mahaffy, Transact. Roy. Soc. Trop. Med. 28, 38 (1935)

Bejarano, J. F. R., Rev. San. Mil. Argent. 55, 129 (1956 a), 55, 281 (1956 b)

Bennett, B. L., F. C. Baker \& A. W. Sellards, Amer. J. Trop. Med. 33, 101 (1939)

Berdonneau, R., S. Serié, R. Panthier, C. Hannoun, S. C. Papaiocannou \& P. GeorgiETT, Bull. Soc. Path. Exot. 54, 276 (1961)

Berge, T. O.\& M. V. Hargett, Publ. Health Rep. 57, 652 (1942)

Berghe, L. van, Ann. Soc. Belge Méd. Trop. 19, 91 (1939)

Bergold, G. H. \& J. WeIBeL, Virology 17, 554 (1962)

Bernkopf, H., S. Levine \& R. Nerson, J. Infect. Dis. 93, 207 (1953)

BerRy, G. P.\& S. F. Kitchen, Amer. J. Trop. Med. 11, 365 (1931)

Bertram, D. S. \& R. G. Bird, Transact. Roy. Soc. Trop. Med. 55, 302 (1961a), 55, 404 (1961b); Bertram, D. S., E. R. Nye, R. G. Bird \& M. G. R. VARUa, Verhdl. 11. Intern. Kongr. Entomologie (Wien 1960)

Bieling, R., Dtsch. med. Wschr. 80, 125 (1955)

Bilibin, A. F., Moskov Med. Giz. 197 und 200, (1950)

BIRCH, F. M., Amer. J. Vet. Res. 2, 221 (1941)

Birt, C., Brit. Med. J. 1910a II, 875; J. Roy. Army Med. Corps 14, 236 (1910b), 15, 140 $(1910 \mathrm{c})$

Black, W. C., L. Florio \& M. O. Stewart, Amer. J. Path. 23, 217 (1947) 
Blanc, G., Presse Méd. 1609 (1932); in: Les Ultravirus des Maladies humaines von Levaditi \& Lépine 2. Aufl. 2, 945 (Paris, 1948); Blanc, G. \& J. Caminopetros, Arch. Inst. Pasteur Hellénique 2, 176 (1928a), 2, 199 (1928b), 2, 277 (1928c); Compt. rend. Acad. Sci. 187, 1081 (1928 d), 187, 1083 (1928 e), 188, 1273 (1929 a), 189, 594 (1929 b); Compt. rend. Soc. Biol. 100, 31 (1929 c), 100, 393 (1929d); Presse Méd.915 (1929e); Ann. Inst. Pasteur 44, 367 (1930); Blanc, G., J. Caminopetros, J. Dumas \& A. Saenz, Compt. rend. Acad. Sci. 188, 468 (1929a); Blanc, G., J. Caminopetros \& P. Giroud, Bull. Acad. Méd. 101, 1 $(1929$ b); Blanc, G., J. Caminopetros \& E. Manoussakis, Bull. Soc. Path. exot. 21, 525 (1928a); Presse Méd. 1162 (1928b)

Blanchard, E., Bull. Off. Intern. Hyg. Publ. 33, 407 (1941)

Blattiner, R. J., J. Pediatr. 45, 362 (1954)

Boer, C. J. De \& H. R. Cox, J. Bact. 51, 613 (1946); J. Immunol. 55, 193 (1947); Boer, C. J. DE, L. J. Kunz, H. Koprowski \& H. R. Cox, Proc. Soc. exper. Biol. 64, 202 (1947)

Botron, H., Compt. rend. Soc. Biol. 150, 2219 (1956); Borron, H. \& R. Camain, Bull. Mém. École Nat. Méd. Pharm. (Dakar) 5, 272 (1957); Compt. rend. Soc. Biol. 152, 69 (1958)

BoNnEL, P. H., WHO Monogr. Ser. 30, 193 (1956); Bol. Of. San. panamer. 43, 356 (1957); Bonnel, P. H. \& Z. Deutschamn, Bull. WHO 11, 325 (1954)

Boorman, J. P. T., Ann. Trop. Med. Parasit. 54, 8 (1960a); Trans. Roy. Soc. Trop. Med. 54, 362 (1960b); Boorman, J. P. T. \& J. S. Porterfield, Transact. Roy. Soc. Trop. Med. 50, 238 (1956), 51, 439 (1957)

Bosheld-Manrique, J., in: Yellow Fever, Symposium in Commemoration of Finlay 1955, Bol. Of. San. Panamer. 40, 400 (1956); Bull. WHO 16, 431 (1957); Boshell-ManRIQUe, J. \& G. A. Bevier, Amer. J. Trop. Med. Hyg. 7, 25 (1958); Boshell-Manrique, J. \& H. Groot, Bol. Of. San. Panamer. 43, 309 (1957); Boshell-Manrique, J. \& E. Osorno Mesa, Amer. J. Hyg. 40, 170 (1944)

Boyd, J. S. K., J. Roy. Inst. Publ. Health 22, 11 (1959)

Boye, J., Bull. Off. Intern. Hyg. Publ. 28, 1309 (1936)

BransBy, W. R., Bull. WHO 24, 541 (1961)

Bres, P. Bull. Soc. Path. Exot. 54, 995 (1961)

BRETEAU, H., Bull. WHO 11, 453 (1954)

Briceno Rossi, A. L., Gac. Med. Caracas 68, 45 (1960)

BricK, I. B., Arch. Int. Med. 92, 221 (1953)

Broom, J. C. \& G. M. Findlay, Brit. J. exper. Path. 14, 179 (1933)

Brown, A. W., Bull. WHO 18, 309 (1958); Brown, A. W., S. S. Sarkaria \& R. P. Thompson, Bull. Entomol. Res. 42, 105 (1951)

Brown, K. P., Transact. Roy. Soc. Trop. Med. 48, 105 (1954)

Bruce-Chwatt, L. J., J. Trop. Med. 58, 71 (1950)

Brumpt, E., Précis der Parasitologie (Paris 1949)

Bruno-Lobo, G., M. Bruno-Lobo, J. Travassos, F. Pinheiro \& I. P. Pazin, Ann. Microbiol. 9A, 183 (1961)

Buckland, F. E., Nature 188, 768 (1960); Buckland, F. E. \& D. A. J. Tyrell, Nature 195, $1063(1962)$

BuckleY, S. M., Ann. N. Y. Acad. Sci. 81, 172 (1959); Nature 192, 778 (1961); Buckley, S. M. \& R. S. Sноре, Amer. J. Trop. Med. 10, 53 (1961)

Bugher, J. C., Amer. J. Trop. Med. 20, 809 (1940), 21, 299 (1941), in: Yellow Fever von Strode 137 (New York 1951a); in: Yellow Fever, Symposium in Commemoration of Finlay (1955); Bugher, J. C., J. Boshell-Manrique, M. Roca-Garcia \& R. Gilmore, Amer. J. Trop. Med. 21, 309 (1941); Bugher, J. C., J. Boshell-Manrique, M. Roca-Garcia \& E. OsornoMeSA, Amer. J. Hyg. 39, 16 (1944); Bugher, J. C.\& A. GAst-Galvis, Amer. J. Hyg. 39, $58(1944)$

Bundes-Gesundh. Blatt 5, 292 (1962)

Burgdorfer, W., J. Infect. Dis. 104, 101 (1959); Burgdorfer \& C. M. Ekuund, Amer. J. Hyg. 69, 127 (1959); J. Infect, Dis. 107, 379 (1960a), 107, 384 (1960b); BURGDoRFER, W. \& D. Lackman, J. Bact. 80, 131 (1960)

Burke, A. W., Amer. J. Trop. Med. 17, 313 (1937)

Burnet, F. M., Principles of Animal Virology (New York 1955); Burnet, F. M. \& D. Lush, Austral. J. Exper. Biol. 18, 141 (1940)

Burns, H. F. \& C. J. FARINACCI, Science 123, 227 (1956)

Burruss, H. W. \& M. V. Hargett, Publ. Health Rep. 62, 940 (1947)

Bustamente, M. E., Gac. Méd. Mexico 87, 357 (1957), 88, 225 (1958), La Fiebre amarilla en Mexico y su Origen en America (1958b) 
Buswine, J. R., Transact. Roy Soc. Trop. Med. 51, 11 (1957); Buswine, J. R. \& W. Z. COOKER, Bull. WHO 18, 651 (1958)

Buxton, A. P., J. Anim. Ecology 20, 31 (1951)

Cambournac, F. C., A. F. Gandara, A. J. Pena \& W. L. Teixeira, Ann. Inst. Med. Trop. Lisboa 12, 101 (1955)

Cannelu, D. E., Amer. J. Path. 4, 431 (1928)

Cannon, D. A. \& F. Dewhurst, Ann. Trop. Med. Liverpool 47, 381 (1953); Cannon, D. A., F. Dewhurst \& P. D. Meers, Ann. Trop. Med. Liverpool 51, 256 (1957)

Cardamatis, J. P., Presse Méd. 671 (1929)

CANTELL, K., Arch. Virusforschg. 10, 510 (1961)

Carter, H. R., New Orleans Med. Surg. J. 52, 617 (1900); Med. Rec. 59, 361 (1901a), 59, 933 (1901b); Yellow Fever. An Epidemiological and historical Study of its Place of Origine (Baltimore 1931)

Carver, D. H. \& K. Naficy, Proc. Soc. Exper. Biol. 111, 356 (1962)

Casals, J., J. exper. Med. 79, 341 (1944), Transact. N. Y. Acad. Med. Ser. 2 19, 219 (1957); 6. Intern. Congr. Trop. Med. Malaria (1958); Abstr. Sympos. Papers 10. Pacific Sci. Congr. 458 (Honolulo 1961 a); Bull. WHO 24, 723 (1961 b); CASAls, J. \& L. V. Brown, Proc. Soc. exper. Biol. 83, 170 (1953); J. exper. Med. 99, 429 (1954); Casals, J. \& R. Palacios, J. exper. Med. 74, 409 (1941); Casals, J. \& L. Whitman, Amer. J. Trop. Med. Hyg. 6, 1004 (1957), 9, 73 (1960), 10, 250 (1961)

Castro Freire, L. De, Rev. Portug. Pediatr. 18, 65 (1955)

Catsaras, J., Arch. Schiffs. Tropenhyg. 35, 278 (1931)

Causey, O. R., C. E. Causey, O. M. Maroja \& D. G. Macedo, Amer. J. Trop. Med. Hyg. 10, 227 (1961); Causey, O. R. \& H. W. Kumm, Amer. J. Trop. Med. 28, 469 (1948); Causey, O. R., H. W. Kumm \& H. W. La emmert, Amer. J. Trop. Med. 30, 301 (1950); Causey, O. R., H. W. Laemmert \& G. S. Hayes, Amer. J. Hyg. 47, 304 (1948); Causey, O. R. \& O.Maroja, Amer. J. Trop. Med. Hyg. 6, 1017 (1957), 8, 368 (1959); Causey, O. R. \& M. Theiler, Amer. J. Trop. Med. Hyg. 7, 36 (1958)

Cerqueira, N. L. \& J. Boshell-Manrique, Rev. Appl. Entomol. (London) 33, 143 (1949)

Chabaud, M. A. \& M. Ovazza, Bull. WHO 19, 7 (1958)

Chagas, E. \& L. De Freitas, Mem. Inst. Oswaldo Cruz Suppl. 7, 72 (1929)

Chamberlain, R. W. \& W. D. Sudia, Ann. Rev. Entomol. 6, 371 (1961)

Chandler, A. C. \& L. Rice, Amer. J. Trop. Med. 3, 233 (1923); Indian Med. Gaz. 60, 460 (1925)

Chaniotis, N. \& E. Scordombellis, Presse Méd. 419 (1929)

Chany, C., Compt. rend. Acad. Sci. 250, 3903 (1960)

Cheng, P. Y., Biochem. Biophys. Acta 22, 433 (1956); Nature 181, 1800 (1958); Virology 6, 129 (1958b); Fed. Proc. 18, 203 (1959); Biochem. Biophys. Acta 53, 235 (1961 a); Virology 14, 124 (1961 b), 14, 132 (1961 c); Biochem. Biophys. Acta 61, 318 (1962 a); Fed. Proc. 21, $462(1962 \mathrm{~b})$

Chew, A., H. Yen, L. Y. Kiat, G. A. Leng, K. O. Teik, L. C. Hong \& R. Wells, Lancet $1961 \mathrm{I}, 307$

Chiang, C. L. \& W. C. Reeves, Amer. J. Hyg. 75, 376 (1962)

Christopher, S. R., Aedes aegypti L., The Yellow Fever Mosquito, its life, history, bionomics and structure (London 1960)

Chumakov, M. P., Encyclop. Milit. Med. (russ) 3, 268 (1948a); Vestn. Acad. Med. Nauk, USSR 19 (1948b); US-USSR. Med. Exchange Mission (1956); Publ. Health Monogr. Nr. 50, 19 (1957)

Chwatт, L. J., Nature 163, 808 (1949)

Clark, H. C., Amer. J. Trop. Med. Hyg. 1, 789 (1952)

Clarke, D. H., Ann. Rep. Rockefeller Found. Virus labor (New York 1960a); J. Exper. Med. 111, 21 (1960b); Clarke, D. H. \& F. L. Black, Proc. Soc. exper. Biol. 85, 391 (1955); Clarke, D. H. \& J. Casals, Proc. Soc. exper. Biol. 88, 96 (1955); Amer. J. Trop. Med. Hyg. 7, 561 (1958); Clarke, D. H. \& M. Theiler, J. Immunol. 75, 470 (1955)

Cleland, J. B., Rev. Prat. Mal. Pays Chauds 8, 509 (1928); in: A System of Bacteriology 7, 376 (London 1930); Cleland, J. B., B. Bradley \& W. Mac Donald, Med. J. Austral. 1916 a II, 179 ; Rep. Director Gen. Publ. Health N. S. Wales, Sydney $185(1916$ b); J. Hyg. 16, 317 (1918), 18, 217 (1919)

Cleland, R. \& J. Y. Sugg, J. Immunol. 85, 539 (1960)

Collier, W. A., Trop. Geogr. Med. (Amsterdam) 10, 316 (1958); Collier, W. A., H. DE 
Roever-Bonnet \& J. Hoekstra, Trop. Geogr. Med. 10, 261 (1958); A. v. Leeuwenhoek 25, 113 (1959); Trop. Geogr. Med. 11, 75 u. 80 (1959a), 11, 167 (1959 b), 11, 261 (1959 c); Collier, W. A. \& M. J. De Wit, Trop. Geogr. Med. 11, 281 (1959), 11, 339 (1959b), 12, 258 (1960); A. v. Leeuwenhoek 26, 209 (1961); Trop. Geogr. Med. 13, 2 (1961 b)

Colter, J. S. \& K. A. O. Ellem, Amer. Rev. Microbiol. 15, 229 (1961a); Fed. Proc. 20, 650 (1961b)

Combescot de Marsaquet, G. \& J. Thomas, Méd. trop. 21, 115 (1961)

Comité d'Experts du Vaccin amaril, WHO. Techn. Rep. Ser. 136 (1957)

Corbet, P. S., M. C. Williams \& J. D. Gillet, Transact. Roy. Soc. Trop. Med. 55, 463 (1961)

Costa-Cruz, J. Da, Brasil. Med. 44, 220 (1930a); Compt. rend. Soc. Biol. 104, 623 (1930b); Mem. Inst. Oswaldo Cruz 23, 109 (1930 c)

Cotansco, E. \& G. Badenski, Arch. Roum. Path. Exper. Microbiol. 17, 151 (1958)

Counts, E. F. \& R. Seltser, Ann. Intern. Med. 38, 67 (1953)

Courtney, K. O., Amer. J. Publ. Health 40, 417 (1950); 1. Interamer. Congr. Publ. Health, (Havana 1952)

Courtois, G., Ann. Soc. Belge Méd. trop. 34, 9 (1954); WHO, Monogr. Ser. Nr. 30, 105 (1956); Bol. Of. San. panamer. 43, 335 (1957); Courtois, G., P. Osterrieth \& G. B. Ridaura, Ann. Soc. belge Méd. trop. 40, 29 (1960)

Couto, M. \& H. da Rocha-Lima, in: Handb. Tropenkrankheiten von Mense, 5. Aufl. 729 (Leipzig 1935)

Cowdry, E. V., Amer. J. Path. 9, 149 (1933); Cowdry \& S. F. Kitchen, Science 69, 252 (1929); Amer. J. Hyg. 11, 227 (1930)

Cox, H. R., in: Viral and Rickettsial Infections of Man von Rivers, 2. Aufl. 526 (Philadelphia 1952), von Rivers \& Horsfall, 3. Aufl., 384 (Philadelphia 1959)

Curasson, G., Bull. Soc. Path. Exot. 27, 599 (1934)

DAGGY, R. H., War Med. 5, 292 (1944)

Daniels, J. B., Fed. Proc. 17, 508 (1958)

Darns, W. G., C. R. Anderson \& M. Theiler, Amer. Trop. Med. 5, 626 (1956)

Daubney, R. \& J. R. Hudson, Lancet, 1932 I, 611; East Afric. Med. J. 10, 2 (1933); Daubney, R, J. R. Hudson \& P. C. Garnham, J. Path. Bact. 34, 545 (1931)

Davies, A. M., J. Fendrich, Y. Yoshpe-Purer \& Y. Nir, J. Trop. Med. Hyg. 58, 12 (1955); Davis, A. M. \& Y. Yoshpe-Purer, Ann. Trop. Med. Parasit. 48, 46 (1954a); J. Trop. Med. Hyg. 57, 273 (1954b)

Davis, G. E., Amer. J. Hyg. 13, 79 (1931)

Davis, N. C., J. exper. Med. 49, 885 (1929); Amer. J. Hyg. 11, 321 (1930a); J. exper. Med. 51, 703 (1930b), 52, 405 (1930c); Amer. J. Trop. Med. 11, 31 (1931a), 11, 113 (1931 b); Brasil Med. 45, 378 (1931 c); Amer. J. Hyg. 16, 163 (1932a), 16, 177 (1932b); J. Parasitol. 19, 209 (1932 c); Amer. J. Trop. Med. 13, 547 (1933 a); Ann. Entomol. Soc. Amer. 26, 491 (1933 b); Amer. J. Trop. Med. 14, 343 (1934a); J. Immunol. 26, 361 (1934b); Davis, N. C. \& A. W. Burke, J. exper. Med. 49, 975 (1929); Davis, N. C., M. Frobisher \& W. Lloyd, J. exper. Med. 58, 211 (1933); Davis, N. C., W. Lloyd \& M. Frobisher, J. exper. Med. 56, 853 (1932); Davis, N. C. \& R. C. Shannon, J. exper. Med. 50, 81 (1929a), 50, 803 (1929 b); Amer. J. Hyg. 11, 335 (1930), 14, 715 (1931 a); Amer. J. Med. 11, 21 (1931 b)

Demina, N. A., Med. Parasitol. Moskau 10, 28 (1941a), 10, 271 (1941 b); Demina, N. A. \& P. B. Levitanskaja, Med. Parasitol. Moskau 9, 272 (1940)

Derrick, E. H. \& V. A. Bicks, Austral. Ann. Med. 7, 102 (1958)

Dews, S. C. \& I. H. Marshall, Amer. J. Trop. Med. Hyg. 3, 601 (1954)

Dezest, G., Bull. Soc. Path. Exot. 30, 253 (1937)

Dick, G. W. A., Ann. Trop. Med. Parasit. 44, 319 (1950); Amer. J. Hyg. 55, 140 (1952 a); Transact. Roy. Soc. Trop. Med. 46, 97 (1952 b); Brit. Med. Bull. 9, 215 (1953a); Transact. Roy. Soc. Trop. Med. 47, 13 (1953b); WHO Monogr. Ser. 30, 97 (1956); Dick, G. W. A. \& F. W. Gee, Transact. Roy. Soc. Trop. Med. 46, 449 (1952); Dick, G. W. A. \& A. J. HADDow, Transact, Roy. Soc. Trop. Med. 46, 600 (1952); Dick, G. W. A. \& E. S. Horgan, J. Hyg. 50, 376 (1952); Dick, G. W. A., S. F. Kitchen \& A. J. Haddow, Transact. Roy. Soc. Trop. Med. 46, 509 (1952; Dick, G. W. A. \& K. C. Smithburn, Amer. J. Trop. Med. 29, 57 (1949); Dick, G. W. A. \& R. M. TAY loR, J. Immunol. 62, 311 (1949)

Diercks, F. H., Amer. J. Trop. Med. Hyg. 8, 488 (1959); Diercks, F. H. \& W. McD. Hammon, Proc. Soc. exper. Biol. 96, 290 (1957), 97, 627 (1958), 100, 840 (1959); Dienks, F. H., W. D. Kundin \& T. J. Porter, Amer. J. Hyg. 73, 164 (1961)

Dinger, J. E., Zbl. Bakt. I, Orig. 121, 194 (1931); Ned. Tschr. Geneeskd. 98, 2206 (1954); Dinger, J. E., W. Schüffner \& E. P. Snijders, Zbl. Bakt. I. Orig. 119, 1 (1930); Ned. 
Tschr. Hyg. 6, 200 (1931); Dinger, J. E., W. Schüffner, E. P. Snijders \& N. H. SwelLengrebel, Ned. Tschr. Geneeskd. 73, 5982 (1929); Dinger, J. E. \& E. P. Snijders, Arch. Schiffs. Tropenhyg. 85, 497 (1931)

Dodge, H. J., H. E. Griffin, R. L. Gauld \& Y. S. Kim, Amer. J. Hyg. 63, 38 (1956)

Doerr, R., Bln. klin. Wschr. 45, 1847 (1908), in: Handb. der pathogenen Mikroorganismen von Kolle, Kraus, Uhlenhuth 3. Aufl. 8, 1, 522 (Jena u. Berlin 1930) in: Handb. der Virusforschung von Doerr \& Hallauer Ergbd. 1, 93 (Wien 1944); Doerr, R., K. Franz \& S. Taussig, Das Pappatacifieber (Leipzig 1909a); Wien. klin. Wschr. 22, 609 (1909b); Doerr, R. \& V. K. Russ, Arch. Schiffs. Tropenhyg. 13, 693 (1909); in: Handbuch der Tropenkrankheiten von Mense 388 (Leipzig 1914)

Doherty, R. L., Med. J. Austral. 1954 I, 753 ; Virology 6, 575 (1958); Doherty, R. L. \& J. G. Carley, Austral. J. Exper. Biol. 38, 427 (1961)

Dolmatova, A. V., Med. Parasitol. Moskau 15, 47 (1946)

Dominguez, F., Bull. Acad. Méd. Paris 120, 303 (1938)

Downs, W. G., T. H. G. Aitken \& C. R. Anderson, Amer. J. Trop. Med. Hyg. 4, 837 (1955 a); Downs, W. G. \& C. R. Anderson, West Indian med. J. 8, 101 (1959); Downs, W. G., C. R. Anderson, T. H. Aitken \& K. A. Delpeche, Caribbean Med. J. 18, 74 (1956a); Downs, W. G., C. R. Anderson \& L. Spence, Transact. Roy. Soc. Trop. Med. 49, 577 (1955 b); Downs, W. G., C. R. Anderson \& M. Theiler, Amer. J. Trop. Med. Hyg. 5, $626(1956$ b); Downs, W. G., L. Spence, T. H. G. Aitken \& L. Whitman, West Indian med. J. 10, 13 (1961)

Dulbecco, R., Proc. US Nat. Aacad: Sci. 38, 747 (1952); Dulbecco, R., M. Vogt \& A. G. R. STRICKLAND, Virology 2, 162 (1956)

Dunn, L. H., Bull. Entomol. Res. 17, 183 (1926), 18, 139 (1927a), 18, 145 (1927b), 18, 247 $(1927 \mathrm{c})$

Durieux, C., Bull. Acad. Nat. Méd. 118, 438 (1937); Essor Méd. Paris Nr. 9,9 (1954); WHO Monogr. Ser. 30, 31 (1956); Durieux, C., H. Boiron \& R. Koerber, Bull. Soc. Path. Exot. 40, 111 (1947); Durieux, C. \& R. Koerber, WHO Monogr. Ser. 30, 51 (1956)

Eagle, H., K. Habel, A. P. Rowe \& R. J. Huebner, Proc. Soc. Exper. Biol. 91, 361 (1956)

EARLe, D. P., Med. Bull. US Army, Far East 1, 58 (1953); Amer. J. Med. 16, 190 (1954)

Easterday, B. C., M. H. MoGavran, J. R. Rooney \& L. C. Murphy, Amer. J, vet. Res. 23, 470 (1962 a); Easterday, B. C., L. C. Murphy \& D. G. Bennett, Amer. J, Vet. Res. 23, $1224(1962 \mathrm{~b}), \mathbf{2 3}, 1231(1962 \mathrm{c})$

EDwaRDs, F. W., British Museum Natural History (London 1941)

EDwards, J. C., J. Roy. Soc. San. Inst. 69, 718 (1949)

Eklund, C. M., Bol. Ofi. San. Panamer. 35, 505 (1953); Ber. 6. Intern. Kongr. Trop. Med. Malaria 168 (1958); Ekrund, C. M., G. M. Kohls \& J. M. Brennan, J. Amer. Med. Assoc. 157, 335 (1955); Eklund, C. M., G. M. Kohls \& W. L. Jelloson, Science 128, 413 (1958)

Elmerndorf, J. E. \& H. H. Smith, Proc. Soc. exper. biol. 36, 171 (1937)

Elton, N. W., Amer. J. Publ. Health 42, 170 (1952 a), 42, 1527 (1952 b); Amer. J. Trop. Med. Hyg. 1, 436 (1952 c); Milit. Surg. 111, 157 (1952 d); Amer. J. Publ. Health 45, 19 (1955 a), 45, 923 (1955b), 46, 1259 (1956); Elton, N. W.\& C. M. Johnson, US Armed Forces Med. J. 1, 596 (1950); Elton, N. W., A. Romero \& A. Trejos, Amer. J. Clin. Path. 25, 135 (1955)

Endo, M., Virus 1, 42 (1951)

Entenman, C., F. K. Lorenz \& I. L. Chatkoff, J. Biol. Chem. 134, 495 (1940)

EspinozA, A. A., Sanidad El Salvador 4, 164 (1953)

Fabiyi, A., Ann. Trop. Med. Hyg. 55, 235 (1961); Fabiyi, A. \& F. N. MacNamara, Amer. J. Trop. Med. Hyg. 11, 817 (1962)

Favared, R., Bull. Soc. Path. Exot. 38, 77 (1945)

Fegali, A., Presse Méd. 59, 1481 (1951)

Feitel, M., E. H. Watson \& K. W. Cochran, Pediatr. 28, 965 (1960)

Fendrich, J., Y. NiR \& R. Goldman, J. Infect. Dis. 100, 141 (1957)

Ferguson, M. S. \& O. H. Graham, Transact. Roc. Soc. Trop. Med. 41, 679 (1948)

Ferguson, W., Bull. Epizoot. Dis. 7, 319 (1959)

FirTh, S., Diss. (1804)

Findlay, G. M., Transact. Roy. Soc. Trop. Med. 25, 229 (1932); Brit. J. Exper. Path. 14, 207 (1933 a); J. Path. Bact. 38, 1 (1934 a); Transact. Roy. Soc. Trop. Med. 27, 437 (1934 b); Brit. J. Exper. Path. 17, 89 (1936); 3. Conv. Trop. Morbis 1, 314 (1938); Transact. Roy. Soc. Trop. Med. 35, 51 (1942); in: Les Ultravirus des Maladies Animales von LÉvaditi und 
Lépine 892 (Paris 1943); Findlay, G. M. \& R. W. Brookfield, Transact. Roy. Soc. Trop. Med. 37, 95 (1944); Findlay, G. M. \& J. C. Broom, Brit. J. exper. Path. 14, 391 (1933); Findlay, G. M. \& L. P. Clarke, J. Path. Bact. 40, 55 (1935a); Transact. Roy. Soc. Trop. Med. 28, 193 (1935 b), 28, 335 (1935c), 28, 579 (1935 d); Findlay, G. M. \& T. A, Cockburn, Nature 152, 245 (1943); Findlay, G. M. \& R. Daubury, Lancet 1931 II, 1350; Findlay, G. M., T. F. Hewer \& L. P. Clarke, Transact. Roy. Soc. Trop. Med. 28, 413 (1935); Findlay, G. M. \& E. Hindle, Lancet 1930 I, 678; Findlay, G. M. \& E. M. Howard, Ann. Trop. Med. Paras. 45, 220 (1951); Arch. Virusforschg. 4, 411 (1952); Findlay, G. M. \& F. O. MacCallum, Bull. Off. Intern. Hyg. Publ. 29, 1145 (1937a); J. Path. Bact. 44, 405 (1937b); Transact. Roy. Soc. Trop. Med. 30, 507 (1937 c); Brit. J. exper. Path. 19, 384 (1938a); Transact. Roy. Soc. Trop. Med. 31, 103 (1938b); J. Path. Bact. 49, 53 (1939); Lancet 1940 II, 163; Findlay, G. M. \& R. D. MacKenzie, Brit. J. exper. Path. 17, 441 (1936); Findlay, G. M., R. D. MacKenzie \& R. O. Stern, Brit. J. exper. Path. 17, 431 (1936); Findlay, G. M. \& A. F. MahafFy, Transact. Roy. Soc. Trop. Med. 29, 417 (1936); Findlay, G. M. \& N. H. Martin, Lancet 1943 678; Findlay, G. M., G. J. Stefanopoulo, T. H. Davey \& A. F. Mahaffy, Transact. Roy. Soc. Trop. Med. 29, 419 (1936); Findlay, G. M., G. J. Stefanopoulo \& F. O. MacCallum, Bull. Soc. Path. Exot. 29, 986 (1936); Findlay, G. M. \& R. O. Stern, J. Path. Bact. 40, 311 (1935a), 41, $431(1935 \mathrm{~b})$

Finlay, C., An. Acad. Cienc. Med. Habana 17, 449 (1881 a), 17, 482 (1881b), 18, 147 (1881c); Amer. J. Med. Sci. 92, 395 (1886)

FJellströM, K. E., Acta med. scand. 167, 111 (1960)

Fleming, J., J. R. Bignetti \& A. N. Blades, Lancet 1947 I, 443

Floch, H., Arch. Inst. Pasteur Guyana Nr. 278 (1953); Floch, H., C. Durieux \& R. KoerBER, Ann. Inst. Pasteur 84, 495 (1953)

Florio, L., W. McD. Hammon, A. Laurent \& M. O. Stewart, J. exper. Med. 83, 295 (1946a); Florio, L. \& M. S. Miller, Amer. J. publ. Health 38, 211 (1948); Florio, L., M. S. Milier \& E. R. Mugrage, J. Immunol. 64, 265 (1950); Florio, L., E. R. Mugrage \& M. 0. Stewart, Ann. Int. Med. 25, 466 (1946b); Florio, L. \& M. O. Stewart, Amer. J. Publ. Health 37, 293 (1947); Florio, L., M. O. Stewart \& E. R. Mugrage, J. exper. Med. 80, $165(1944) ; 88,1(1946 \mathrm{c})$

FonseCA, F. DA, Compt. rend. Soc. Biol. 129, 1132 (1938a), 129, 1146 (1938b)

Fontan, R. \& P. Fauran, Bull. Soc. Path. Exot. 53, 892 (1960)

Fox, J. P., J. exper. Med. 77, 507 (1943); Amer. J. Hyg. 46, 1 (1947); Bull, WHO 24, 489 (1961); Fox, J. P. \& A. S. Cabral; Amer. J. Hyg. 37, 93 (1943); Fox, J. P., J. FonseCA da Cunha \& S. L. Kossobudzki, Amer. J. Hyg. 47, 14 (1948); Fox, J. P. \& S. Gard, Amer. J. Trop. Med. 20, 447 (1940); Fox, J. P., S. L. Kossobudzkr \& J. Fonseca DA Cunha, Amer. J. Hyg. 38, 113 (1943); Fox, J. P. \& H. W. La emmert, Amer. J. Hyg. 46 21, (1947); Fox, J. P., E. H. Lennette, C. Manso \& J. R. Souza Aguiar, Amer. J. Hyg. 36, 117 (1942 a); Fox, J. P., C. Manso, H. A. Penna \& M. Para, Amer. J. Hyg. 36, 68 (1942 b); J. Amer. Med. Assoc. 120, 51 (1942 c)

Francis, T. \& T. P. Magill, J. exper. Med. 62, 433 (1935)

Franco, O., Rev. Brasil Malar. 9, 567 (1957)

Franco, R., Acad. Med. Sez. Cient. Bogota 1, 169 (1911)

Frederiksen, H., Amer. J. Trop. Med. Hyg. 4, 483 (1955)

Freed, I., South African Med. J. 25, 930 (1951)

Freeman, G. Amer. J. Trop. Med. 26, 15 (1946)

French, E. L., Med. J. Austral. 1952 I, 100

Froeb, H. F. \& N. E. MacDoweld, Amer. J. Med. 16, 671 (1954)

Frobisher, M., Proc. Soc. exper. Biol. 26, 846 (1929), Amer. J. Hyg. 11, 300 (1930), 13, 585 (1931a), 14, 147 (1931b); J. exper. Med. 54, 733 (1931c); J. Prev. Med. 5, 65 (1931d); Amer. J. Hyg. 15, 485 (1932), 18, 354 (1933); Frobisher, M., N. C. Davis \& R. C. Shannon, Amer. J. Hyg. 14, 142 (1931)

Frothingham, T. E., Amer. J. Trop. Med. Hyg. 4, 863 (1955); Proc. Soc. exper. Biol. 100, $505(1959)$

Fulton, F., J. Gen. Microbiol. 22, 416 (1960)

FurTh, F. W., Amer. J. Med. 16, 651 (1954)

Gajdusek, D. C., Army Med. Serv. Graduate School, Med. Sci. Publ. Nr. 2 (1953); Washington, Geographical Rev. 41, 20 (1956a); Klin. Wschr. 34, 769 (1956b)

Galindo, P., Amer. J. Trop. Med. Hyg. 7, 429 (1958); Galindo, P., S. J. Carpenter \& H. Trapido, Amer. J. Trop. Med. 31, 98 (1951); Ann. Entomol. Soc. Amer. 45, 529 (1952); 
Galindo, P. \& E. De Rodaniche, Amer. J. Trop. Med. Hyg. 10, 395 (1961); Galindo, P., E. De Rodaniche \& H. Trapido, Amer. J. Trop. Med. Hyg. 5, 1022 (1956 a); Galindo, P. \& H. Trapido, Amer. J. Trop. Med. Hyg. 4, 543 (1955); Proc. Entomol. Soc. Washington 58, 288 (1956); Amer. J. Trop. Med. Hyg. 6, 145 (1957); Galindo, P., H. Trapido \& S. J. Carpenter, Amer. J. Trop. Med. 30, 533 (1950); Galindo, P., H. Trapido, S. J. Carpenter \&. F. S. Blanton, Ann. Entomol. Soc. Amer. 49, 543 (1956 b)

Ganong, W. F., E. Zucker, C. K. Chawson, E. C. Voss, M. L. Klotzbach \& K. A. Platt, Ann. Int. Med. 38, 61 (1958)

Garcia, E., Bol. Of. San. Panamer. Washington 31, 340 (1951), 34, 221 (1953)

GARD, S., in: Die Infektionskrankheiten des Menschen und ihre Erreger von Grumbach \& KIKUTH 1405 (Stuttgart 1958)

Garnham, P. C. C., J. O. Harper \& R. B. Highton, Bull. Entomol. Res. 36, 473 (1946)

Gast Galvis, A., Bol. Of. San. Panamer. Washington 44, 10 (1958); Gast Galvis, A. \& M. Bates, Rev. Fac. Med. Bogota 14, 243 (1945)

Gauld, R. L. \& J. P. CraIg, Amer. J. Hyg. 59, 32 (1954)

GaY, D. M. \& A. W. Sellards, Ann. Trop. Med. Parasit. 21, 321 (1927)

Gear, J. H. S., B. De Meillon \& D. H. S. Davis, Bureau Reg. OMS Afrique. Col. Afric. sur la Fièvre jaune 1953, 259; Gear, J. H. S., B. De Meillon, V. Measroch, R. Harwan \& D. H. S. Davis, South Afric. Med. J. 25, 980 (1951); Gear, J., B. De Meillon, A. F. Le Roux, R. Kofsky, R. Rose-Innes, J. J. Steyn, W. D. Oliff \& K. H. Schulz, South Afric. med. J. 29, 54 (1955); GEAR, J. H. S. \& F. P. REID, South Afric. Med. J. 31, 253 (1957)

Gerloff, R. K. \& E. M. Ekrund, J. Infect. Dis. 104, 174 (1959); Gerloff, R. K. \& C. L. Larson, Amer. J. Path. 35, 1043 (1959)

Germer, W. D., Dtsch. med. Wschr. 80, 1717 (1955)

Gibbins, E., Ann. Trop. Med. Parasit. 36, 151 (1942)

GIERER, A. \& G. Schramm, Z. Naturforschg. 11b, 138 (1956)

GiLb ERTSON, W. E., Amer. J. Publ. Health 35, 261 (1945)

Giles, R. B., J. A. Sheedy, C. N. Ekman \& \&, Amer. J. Med. 16, 629 (1954)

Gilkes, C. D., F. R. S. Kellett \& H. P. S. Gillette, West Indian Med. J. 5, 73 (1956)

GILL, W. D., Arch. Ophthalm. 57, 628 (1928)

Gillett, J. D., Ann. Trop. Med. Parasit. 45, 110 (1951); Transact. Roy. Soc. Trop. Med. 52, 269 (1958); East afric. Virus Res. Inst. Rep. (July 1960-June 1961); GiLletT, J. D.\& R. W. Ross, Ann. Trop. Med. Parasit. 47, 367 (1953), 49, 63 (1955); Gillett, J. D., R. W. Ross, G. W. A. Dick, A. J. Haddow \& L. E. HewitT, Ann. Trop. Med. Parasit 44, $342(1950)$

Gillette, H. P. S., Mosquito News 16, 121 (1956)

Giltner, L. T. \& M. S. Shahan, North Amer. Vet. 14, 25 (1933)

Ginder, D. R. \& W. F. Friedewald, Proc. Soc. exper. Biol. 77, 272 (1951), 79, 615 (1952)

Goldie, H., J. W. Joyner \& B. S. Brown, Z. Immun. Forschg. 115, 284 (1958)

Goldwasser, R. A. \& A. M. Davies, Transact. Roy. Soc. Trop. Med. 47, 336 (1953)

Gontaeva, A. A., Med. Parazitol. Moskva 12, 64 (1943)

Goodmann, G. T. \& H. Koprowski, J. Cellular comp. Physiol. 59, 333 (1962)

Goodpasture, E. W., J. Path. Bact. 8, 137 (1932)

Graham, G. F., Brit. Med. J. 1915 II, 169

Graham, H., J. Trop. Med. 6, 209 (1903)

Grassi, G. B., Ricerche sui flebotomi (Rom 1907)

Greisman, S. \& G. K. Mok, Rep. Com. Haemoorhagic Fever, Armed Forces Epidem. Board, (Washington 1954)

Gresser, I., Proc. Soc. Exper. Biol. im Druck 1962; Gresser, I. \& J. F. Enders, Virology 13, 420 (1961), 16, 428 (1962)

Groot, C. J. De, F. F. Metzger, C. W. Smith \& M. D. Hoggen, Virology 12, 317 (1960)

Groot, H., J. A. Herr, C. Samatin \& H. Vidales, Amer. J. Trop. Med. Hyg. 8, 175 (1959a); Groot, H., A. Morales \& H. Vidales, Amer. J. Trop. Med. Hyg. 10, 397 (1961); Groot, H., A. Oya, C. Bernal \& P. Barreto-Reyes, Amer. J. Trop. Med. 8, 604 (1959)

Grossberg, S. E. \& W. F. Scherer, Amer. J. Hyg. 69, 60 (1959)

Guelmino, D. \& M. Jeotic, Acta tropica 12, 179 (1955)

Guiseppe, F. DI, Policlinico 44, 610 (1937)

HaAgen, E., Zbl. Bakt. I. Orig. 128, 13 (1933a), 129, 237 (1933b); Arch. Exper. Zellfg. 15, 405 (1934a); Arch. Schiffs. Tropenhyg. 41, 188 (1937); HaAgen, E. \& H. Graefe, Zbl. Bakt. I. Orig. 150, 275 (1943); HAagen, E. \& M. Theiler, Proc. Soc. exper. Biol. 29, 435 (1932 a); Zbl. Bakt. I. Orig. 125, 145 (1932 b) 
HaAs, L., Brit. Med. J. 1954 II, 992

HadDow, A. J., Bull. Entomol. Res. 36, 33 (1945 a), 36, 297 (1945 b); Proc. Zool. Soc. London 115, 1 (1945 c); Bull. Entomol. Res. 37, 57 (1946); Ann. Trop. Med. Parasit. 44, 238 (1950), 46, 135 (1952); Ann. Rep. Virus Res. Inst. Entebe, East Africa (1953); Haddow, A. J., C. W. Davies \& A. J. Walker, Transact. Roy. Soc. Trop. Med. Hyg. 54, 517 (1960); HadDow, A.J. \& G. W. A.Dick, Ann. Trop. Med.Parasit. 42, 271 (1948); HadDow, A. J., G. W. A. Dick, W. H.R.Lumsden \& K. C. Smithburn, Transact. Roy. Soc. Trop. Med.45,189(1951); Haddow, A. J., J. D. Gillett \& P. S. Corbet, Ann. Trop. Med. Parasit. 53, 123 (1959a); Haddow, A. J., J. D. Gillett \& R. B. Highton, Bull. Entomol. Res. 37, 301 (1946); Haddow, A. J., A. F. Mahaffy, Bull. Entomol. Res. 40, 169 (1949); Haddow, A. J., K. C. Smithburn, G. W. A. Dick, S. F. Kitchen \& W. H. R. Lumsden, Ann. Trop. Med. Parasit. 42, 218 (1948); Haddow, A. J., K. C. Smithburn, A. F. Mahaffy \& J. C. Bugher, Transact. Roy. Soc. Trop. Med. 40, 677 (1947)

HadLOW, W. J., J. Infect. Dis. 101, 158 (1957)

Hahn, R. G., Amer. J. Hyg. 54, 50 (1951); Hahn, R. G. \& J. C. Bugher, J. Immunol. 70, $352(1953)$

Halcrow, J. G., Proc. Roy. Entomol. Soc. 30, 40 (1955)

Hallauer, C., in: Handb. der Virusforschung von Doerr \& Hallauer, Ergbd. 2, 189 (Wien 1950); Arch. Virusforschg. 9, 428 (1959); Hallauer, C. \& G. Kronauer, Arch. Virusforschg. 10, 267 (1960)

Halstead, S. B. \& E. L. Buescher, Science 134, 475 (1961)

Hamlin-HarRis, R., Ann. Trop. Med. Parasit. 25, 21 (1931)

Hammon, 'W. McD,, 6. Intern. Congr. Trop. Med. Malaria 163 (1958); Sem Méd. 118, 870 (1961); Hammon, W. McD., A. Rudnick \& G. E. Sather, Science 131, 1102 (1960a); Hammon, W. McD., A. Rudnick, G. E. Sather, K. D. Rogers \& L. J. Morse, Transact. Assoc. Amer. Phys. 73, 140 (1960 b); Hammon, W. McD. \& G. E. Sather, Proc. Soc. Exper. Biol. 91, 521 (1956); Hammon, W. MoD., W. D. Schrack \& G. E. Sather, Amer. J. Trop. Med. Hyg. 7, 323 (1958)

HaMpton, J. W. F., Biochem. biophys. Acta 18, 446 (1955)

Hannoun, C. \& R. Panthier, Bull. Soc. Path. Exot. 53, 424 (1960)

Hanson, R., Amer. J. Trop. Med. 16, 371 (1936)

Hardy, J. L. \& W. F. Scherer, Fed. Proc. 20, 444 (1961)

Hargett, M. V., H. W. Burruss \& A. Donovan, Publ. Health Rep. 58, 505 (1943)

Harris, W. H. \& C. W. Duval, J. exper. Med. 40, 817 (1924 a), 40, 835 (1924b)

Hayes, G. R.\& M. E. TinkeR, Mosquito News 18, 253 (1958)

Henderson, J. R., Yale J. Biol. Med. 33, 350 (1961); Henderson, J. R. \& R. M. Taylor, Proc. Soc. Exper. Biol. 101, 257 (1959); Henderson, J. R. \& R. M. TAYlor, Amer. J. Trop. Med. Hyg. 9, 32 (1960); Fed. Proc. 19, 402 (1960a); J. Immunol. 84, 590 (1960b); Virology 13, 477 (1961)

Henning, M. W., J. South Afric. Vet. Med. Ass. 23, 65 (1952); Animal Diseases in South Africa (Johannesburg 1956)

Herrera, G. \& V. Pardo, Arch. Path. 44, 393 (1947)

Herrera, J. M., N. W. Elton \& J. Nicosia, Arch. Hosp. Santo Tomas 4, 1 (1949 a), 4, 69 $(1949 \mathrm{~b})$

Hertig, M., Amer. J. Trop. Med. 29, 773 (1949); Hertig, M. \& G. B. Fairchild, Amer. J. Trop. Med. 28, 207 (1948); Hertig, M. \& A. A. Fisher, Bull. US Army Med. Dep. Nr. 88, $97(1945)$

Hibbard, B. Z., V. Ballard \& D. M. Gibson, Ann. Int. Med. 40, 1005 (1954)

Hinde, E., Brit. Med. J. 1928, 976; Transact. Roy. Soc. Trop. Med. 22, 405 (1929); Lancet 1930 II, 835; Hindle, E. \& G. M. Findlay, Brit. J. exper. Path. 11, 134 (1930)

Hirsch, A., Handb. der historisch-geographischen Pathologie (Stuttgart 1881)

Hitchoock, G. \& A. Isaacs, Brit. med. J. 1960 II, 1268; Hitchcock, G. \& J. S. Porterfield, Virology 13, 363 (1961)

Ho, M., Fed. Proc. 20, 442 (1961 a); Proc. Soc. Exper. Biol. 107, 639 (1961b); Virology 17, 262 (1962); Ho, M. \& M. K. Braining, J. Immunol. 89, 177 (1962); Ho, M. \& J. F. End ers, Proc. Nat. Acad. Sci. US 45, 385 (1959a); Virology, 9, 446 (1959 b)

Hoare, C. A., Trop. Dis. Bull. 41, 331 (1944)

Höring, F. O., Transact. Roy. Soc. Trop. Med. 32, 597 (1939); Klinische Infektionslehre 2. Aufl. (Berlin 1948); Exotische Krankheiten und Krankheitsverläufe (Stuttgart 1950); Med. Klin. 49, 713 (1954)

Hoffmann, J. M., Ned. Tschr. Geneeskd. 75, 5384 (1931)

HoffmanN, W. H., Dtsch. med. Wschr. 174 (1920); Amer. J. Trop. Med. 8, 563 (1928a); 
J. Trop. Med. Hyg. 31, 1 (1928b); Virchows Arch. 266, 769 (1928c); Arch. Schiffs. Tropenhyg. 33, 411 (1929); in: Handb. der pathogenen Mikroorganismen von Kolle, KraUs \& Unlenhuth 8, 419 (Berlin 1930a); Med. J. Rec. N. Y. 131, 299 (1930b); Ergeb. Med. 17, 113 (1931a); Rev. Med. Cir. Habana 36, 995 (1931b); Mundo Med. 14, 441 (1932); Arch. Schiffs. Tropenhyg. 41, 195 (1937)

Hold En, P. \& A. D. Hess, Science 130, 1187 (1959)

Holmes, F. O., in: Bergeys Manual of determinative Bacteriology Suppl. 2, 1267 (Baltimore 1948)

Holt, R. L., W. D. Fleming \& J. H. Kintner, Philipine J. Sci. 46, 601 (1931); Holt, R. L. \& J. H. Kintner, Amer. J. Trop. Med. 11, 103 (1931a); Philippine J. Sci. 46, 593 (1931 b)

Honzin, R., Y. Kurata \& K. Ikeda, Transact. Soc. Path. Jap. 34, 10 (1944)

Hoogstraat, H. P., US Naval Med. Res. Unit. Nr. 3 (Kairo 1958)

Horning, E. S., J. Roy. Microsc. Soc. 54, 9 (1934)

Hoskins, M., J. Immunol. 26, 391 (1934a); J. Parasitol. 20, 299 (1934b); Amer. J. Trop. Med. 15, 765 (1935)

Hотта, S., Nippon Igaku 34, 252 (1947), 35, 140 (1948); Tokyo Med. J. 67, 7 (1950); J. Infect. Dis. 90, 10 (1952); Acta Scholae Med. Univ. Kioto 31, 7 (1953a); J. Trop. Med. Hyg. 56, 83 (1953 b); Science 118, 225 (1953 c); Ann. Trop. Med. 47, 1 (1953 d); Acta Trop. 11, 97 (1954), 16, 188 (1959); Hotta, S. \& C. A. Evans, J. Infect. Dis. 98, 88 (1956 a); Proc. Soc. Exper Biol. 93, 153 (1956b); Virology 2, 704 (1956c); Hotтa, S., A. Ohyama, N. Fujita \& T. Yamada, Amer. J. Trop. Med. Hyg. 11, 811 (1962); Hotta, S., A. Ohyama, T. Yamada \& T. Awai, Jap. J. Microbiol. 5, 77 (1961); Hotta, S. \& T. Shiomi, Acta Scolae Med. Univ. Kioto 30, 11 (1952)

Hsiao, T. Y., Naval Med. 1289 (Washington 1946)

Hudson, N. P., Amer. J. Path. 4, 395 (1928a); 4, 407 (1928b); Proc. Soc. exper. Biol. 28, 937 (1931); Amer. J. Hyg. 15, 557 (1932); Hudson, N. P., J. H. Bauer \& C. B. Philip, Amer. J. Trop. Med. 9, 1 (1929a); Hudson, N. P. \& G. E. Davis, Amer. J. Trop. Med. 9, 223 (1929); Hudson N. P. \& S. F: Kitchen, J. Prev. Med. 4, 459 (1930); Hudson, N. P., C. B. Philip \& G. E. Davis, Amer. J. Trop. Med. 9, 223 (1929 b)

Hughes, J. H. \& J. E. Parker, Publ. Health Rep. 73, 1101 (1958)

Hughes, T. P., J. Immunol. 25, 275 (1933); J. Bact. 28, 401 (1934); Transact. Roy, Soc. Trop. Med. 36, 339 (1943); Hughes, T. P. \& A. Perlowagora, Amer. J. Trop. Med. 28, 101 (1948), 30, 835 (1950a); J. Immunol. 65, 155 (1950 b).

Hughes, W. D., Proc. Alumni Assoc. King Edward VII. Coll. Med. 5, 183 (1952)

Huld, R. \& E. W. Hurst, Nature 192, 806 (1961)

Hulinghorst, R. L. \& A. SteER, Ann. Intern. Med. 38, 77 (1953)

Hurst, E. W., J. M. Peters \& P. Meloni, Brit. J. Pharmacol. 7, 473 (1952)

Husson, R. A. \& R. Koerber, Ann. Inst. Pasteur 85, 735 (1953)

Inoki, S., S. Moriya \& R. Kobayashi, Med. J. Osaka Univ. 3, 347 (1952)

IsaAcs, A. \& S. G. Brown, Lancet 1960 II, 946; IsaAcs, A. \& G. Hitchcock, Lancet 1960 II, 69; Isaacs, A., H. G. Kemperer \& G. Hitchcock, Virology 13, 191 (1961 a); Isaacs, A., J. S. Porterfield \& S. Baron, Virology 14, 450 (1961 b)

IshII, N., Jap. Med. J. 1, 160 (1948); IshII, N., A. NAKaYAma \& Y. IshII, Yokohama Med. Bull. 5, 275 (1954)

Iyer, C. G. S., T. H. Work, D. P. Narashimha-Murthy, H. Trapido \& P. K. Rajagopalan, Ind. J. Med. Sci. 48, 276 (1960)

JAcoBs, H., Proc. Soc. exper. Biol. 57, 260 (1944)

JADIN, J., Ann. Soc. Belge Med. Trop. 17, 27 (1937)

JetTMar, H. M., Wien. klin. Wschr. 73, 21 (1961)

Johnson, C. M. \& S. F. Farnworth, Bol. Of. San. panamer. 41, 182 (1956)

Johnson, E. S., V. M. Napoli \& W. C. White, Amer. J. Clin. Path. 34, 118 (1960)

Johnson, W. B., Brit. Med. J. 1932 II, 285

Jonescu-Minaiesti, C., C. Popescu-Maleanu, G. Badenski \& E. Obogeanu, Acad. Roum. Bull. Sec. Sci. 22, 446 (1940)

Joubert, J. D. S., A. L. Ferguson \& J. H. S. Gear, South Afric. Med. J. 25, 890 (1951)

Joyeux, Ch. \& A. Sicé, Précis de Médicine des Pays chauds, 4. Aufl. 614 (Paris 1950)

Kalk, H. \& E. Wildhirt, in: Klinik der Gegenwart von Cobet, Gutzeit, Bock \& HartMaNN, 7, 377 (München 1958)

Kamal, H., Brit. Med. J. 1928 I, 1104 
Kamen, G. F., Nature 192, 986 (1961)

Kaplan, A. \& A. Lindgren, US Navy Med. Bull. 45, 506 (1945)

Kaplan, M. \& A. C. Gluck, Bull. Mém. Soc. Méd. Hôp. Paris 374 (1945)

Kasahara, S., R. Ueda, S. Yoshida, R. Hamano \& R. Yamada, Kitasato Arch. exper. Med. 13, 48 (1936)

Kaschula, V. R., Dissertation (Pretoria 1953)

Katz, S., C. L. Leedham \& W. H. KessleR, J. Amer. Med. Assoc. 150, 1363 (1952)

Kawamura, R., S. Fukusumi, T. IтоH, H. Ітон, S. Takagi \& Y. Obata, Kitasato Arch. exper. Med. 20, 1 (1943); Kawamura, R., M. Kodama, I. Ito, T. Yasaki \& Y. KobayaKAWA, Kitasato Arch. exper. Med. 13, 281 (1936)

Kerr, J. A., Amer. J. Trop. Med. 11, 139 (1931); Ann. Trop. Med. Parasit. 26, 119 (1932); Bull. Entomol. Res. 24, 493 (1933), in: Yellow Fever von Strode 385 (New York 1951); J. Immunol. 68, 461 (1952); Transact. Roy. Soc. Trop. Med. 51, 559 (1957); Bol. Of. San. Panamer. Wash. 44, 1 (1958); Kerr, J. A. \& T. B. Hayne, Amer. J. Trop. Med. 12, 255 (1932); Kerr, J. A., M. Roca-Garcia \& J. C. Bugher, Amer. J. Trop. Med. 9, 18 (1960)

KessleR, W. H., Ann. Int. Med. 38, 73 (1953)

Khan, N. M. \& A. W. H. Brown, Bull WHO 24, 519 (1961)

Kimura, R., N. Higashi \& H. Akazawa, Jap. J. Med. Sci. Bact. 2, 241 (1947); Kimura, R. \& S. Hотта, Nippon Igaku Nr. 3344, S. 1378 (1943)

Kingslay, C., At last: A christmas in the West Indies (New York 1871)

KIrK, R. \& M. A. HaseEb, Ann. Trop. Med. Parasit. 47, 225 (1953)

Kissling, R. E., Proc. Soc. exper. Biol. 96, 290 (1957); Ann. Rev. Microbiol. 14, 261 (1960)

Kitano, M., Manchukuo Med. J. 40, 191 (1944a); Nippon Dessenbyo Gakkai Zassi 18, 1 (1944)

KitAoka, M., Ann. Rep. Arbor virus study group. NIH Japan (Tokio 1959)

Kitchen, S. F., Amer. J. Trop. Med. 14, 547 (1934); Ann. Trop. Med. Parasit. 44, 132 (1950)

Kligler, I. J., Transact. Roy. Soc. Trop. Med. 28, 193 (1930); Kligler, I. J. \& M. Aschner, Ann. Trop. Med. Parasit. 22, 151 (1928)

KLotz, O., Yellow Fever in West Afrika (Baltimore 1927-1928); Kцотz, O.\& T. H. Belt, Amer. J. Path. 6, 655 (1930a), 6, 663 (1930b), 6, 689 (1930c); Amer. J. Trop. Med. 10, 299 (1930 d); Kцотz, O. \& W. Simpson, Amer. J. Trop. Med. 7, 271 (1927)

Knudsen, A., Transact. Roy. Soc. Trop. Med. 48, 112 (1954)

Koizumi, T., K. Yamaguchi \& K. Tonomura, J. Med. Assoc. Formosa Nr. 176, 399 (1917 a); Nr. 177, 432 (1917b); .China Med. J. as, 355 (1918)

Kokernot, R. H., C. S. Heyman, J. Muspratt \& B. Wolstenholme, South Afric. J. Med. Sci. 22, 71 (1957 a); Kokernot, R. H., B. M. McIntosh \& C. B. Worth, Amer. J. Trop. Med. Hyg. 10, 383 (1961a); Kokernot, R. H., B. M. McIntosh, C. B. Worth, T. DE Morais \& M. P. Weinbren, Amer. J. Trop. Med. Hyg. 11, 678 (1962a); Kokernot, R. H., N. M. McIntosh, C. B. Worth \& J. de Sousa, Amer. J. Trop. Med. Hyg. 11, 683 (1962 b); Kokernot, R. H., B. de Meillon, H. E. Paterson, C. S. Heyman \& K. C. Smithburn, South Afric. J. Med. Sci. 22, 145 (1957b); KoкERnot, R. H., K. C. Smithburn, A. F. Gandra, B. M. McIntosh \& C. S. Heyman, Ann. Inst. Med. Trop. 17, 201 (1960a); KoKernot, R. H., K. С. Smithburn \& E. Kluge, Ann. Trop. Med. Parasit. 55, 73 (1961b); Kokernot, R. H., K. C. Smithburn, B. de Meillon \& H. E. Paterson, Amer. J. Trop. Med. Hyg. 7, 579 (1958); Кokernot, R. H., K. C. Smithburn, J. Muspratt \& B. Hodgson, South Afric. J. Med. Sci. 22, 103 (1957 c); Kokernot, R. H., K. C. Smitmburn, H. E. Paterson \& B. M. Macintosh, Amer. J. Trop. Med. Hyg. 9, 62 (1960); KoKernot, R. H., K. C. Smithburn, H. E. Paterson \& B. de Meillon, South Afric. med. J. 34, 871 (1960 b); Kokernot, R. H., K. C. Smithburn \& M. P. Weinbren, J. Immunol. 77, 313 (1956); Kokernot, R. H., K. C. Smithburn, M. P. Weinbren \& B. de Meillon, South Afric. J. Med. Sci. 22, 81 (1957d)

Komp, W. H. W., Proc. Entomol. Soc. 38, 57 (1936); Amer. J. Trop. Med. Hyg. 1, 330 (1952); Proc. Entomol. Soc. 57, 181 (1955)

Konstantinov, V. P., Y. V. Vesdov \& L. S. Egonova, Sovet. Med. 25, 70 (1961)

Koprowska, J. \& H. Koprowski, Fed. Proc. 11, 420 (1952); Cancer Res. 13, 651 (1953)

Koprowski, H., J. Immunol. 54, 387 (1946); Ann. N. Y. Acad. Sci. 63, 895 (1956); KopRowski, H. \& H. R. Cox, Proc. Soc. exper. Biol. 62, 320 (1946); J. Immunol. 57, 239 (1947 a), 57, 255 (1947b); Koprowski, H. \& T. P. Hughes, J. Immunol. 54, 371 (1946); Koprowski, H. \& E. H. Lennette, Amer. J. Hyg. 40, 1 (1944a), 40, 14 (1944b); KopRowski, H. \& T. NoRTon, Cancer 3, 874 (1950)

Korolev, P. A., T. L. Markov \& N. I. Tikhomirova, Med. Parasit. Moskau Nr.4, 344 (1957)

Kotter, G. \& L. van den Berghe, Ann. Soc. Belge Méd. Trop. 15, 213 (1935) 
KouwenaAr, W., Trop. Geog. Med. (Amsterdam) 5, 75 (1953)

Krieg, A., Grundlagen der Insektenpathologie (Darmstadt 1961)

Kubes, V. \& F. A. Rios, Science 90, 20 (1939)

Kumm, H. W., Amer. J. Hyg. Monogr. Ser. 12 (1931 a); Bull. Entomol. Res. 22, 65 (1931b); Ann. Trop. Med. Parasit. 26, 207 (1932); Transact. Roy. Soc. Trop. Med. 43, 673 (1950); Amer. J. Trop. Med. Hyg. 1, 210 (1952); Kumm, H. W. \& N. L. Cerqueira, Bull. Entomol. Res. 42, 195 (1951); Kumm, H. W. \& M. Frobisher, Amer. J. Trop. Med. 12, 349 (1932); Kumm, H. W. \& H. W. Laemmert, Amer. J. Trop. Med. 30, 749 (1950); Kumm, H. W. \& O. Novis, Amer. J. Hyg. 27, 498 (1938)

Kundin, W. D. \& F. H. Dierks, Virology 10, 153 (1960)

KuYp, E. van DeR, Trop. Geogr. Med. (Amsterdam) 10, 181 (1958)

LaAke, E. W., J. Econom. Entomol. 51, 743 (1958)

Lacorte, J. C. \& G. G. Villela, Mem. Inst. Oswaldo Cruz 1928 Nr. 2, 62

Laemmert, H. W., Amer. J. Trop. Med. 23, 227 (1943, 24, 71 (1944), 26, 33 (1946), 28, 231 (1948); Laemmert, H. W. \& R. M. Taylor, Amer. J. Trop. Med. 26, Suppl. 23 (1946); Laemmert, H. W. \& T. P. Hughes, J. Immunol. 55, 61 (1947); LaemmerT, H. M., T. P. Hughes \& O. R. Causey, Amer. J. Trop. Med. 19, 555 (1949); Laemmert \& H. W. Kumm, Amer. J. Trop. Med. 30, 723 (1950); Laemmert, H. W. \& H. Moussatché, J. Infect. Dis. 72, 228 (1943)

Laigret, J., Arch. Inst. Pasteur (Tunis) 21, 112 (1933a), 22, 198 (1933b); Compt. rend. Acad, Sci. 196, 508 (1933 c); Arch. Inst. Pasteur (Tunis) 23, 43 (1934a), 28, 413 (1934b); Bull. Off. Intern. Hyg. Publ. 26, 1078 (1934c); Bull. Soc. Path. Exot. 27, 813 (1934d); Bull. Acad. Nat. Méd. 131, 13 (1947); Laigret, J.,G. Saleun \& J. Ceccaldi, Bull. Soc. Path. Exot. 30, 8 (1937)

Lambelin, G. \& F. Elton, Ann. Soc. Belge Med. trop. 4, 45 (1961)

La Motтe, L. C., Amer. J. Hyg. 72, 73 (1960)

LANCET 1960 II, 1387

Lartigaut, M. \&. L. Couteau, J. Méd. Bordeaux 131, 506 (1954); Lartigaut, M. \& D. LarTIGAut, J. Med. Bordeaux 131, 1788 (1954)

Lavier \& G. J. Stefanopoulo, in: Encycl. Méd. Chir. (Paris 1946)

Lavillaudreix, J., Arch. Anat. 43, 1 (1960)

Leedhay, C. L., Ann. Int. Med. 38, 106 (1953)

LeGac, P., Bull. Soc. Path. Exot. 30, 536 (1937), 40, 336 (1947); LeGac, P. \& J. Servant, Bull. Soc. Path. Exot. 32, 888 (1939)

Legandre, J., Bull. Soc. Path. Exot. 4, 26 (1911); Presse Méd. 459 (1929)

Lemos-Monteiro, J., Brasil. Med. 43, 1037 (1929), 44, 409 (1930); Lemos-Monteiro, J. \& J. Travasso, Compt. rend. Soc. Biol. 104, 697 (1930); 6. Reunion Soc. Argentin Path. Reg. Norte, B. Aires 324 (1931); Brasil Med. 46, 597 (1932); Rev. Ann. Med. Panamer. 1, 31 (1933)

Lennette, E. H. \& H. Koprowski, J. Immunol. 49, 175 (1944); J. exper. Med. 83, 195 (1946); Lennette, E. H. \& A. Perlowagora, Amer. J. Trop. Med. 23, 481 (1943), 25, 11 (1945)

Lépine, P., Bull. Roy. Soc. Path. Exot. 20, 251 (1927); Lépine, P.\& R. Sohier, Techniques de Laboratorie appliquées au Diagnostic des Maladies à Virus (Paris 1954)

LeRoux, J. M. W., Onderstepoort. Vet. Med. 28, 237.(1959)

Levi Castillo, R. Z. Tropenmed. 316 (1951), 4, 254 (1953)

Lewis, D. J., Ann. Trop. Med. Parasit. 37, 65 (1943); Bull. Entomol. Res. 37, 543 (1947); Ann. Trop. Med. Parasit. 47, 51 (1953); Lewis, D. J., T. P. Hughes \& A. F. Mahaffy, Ann. Trop. Med. Parasit. 36, 34 (1942); Lewis, D. J. \& R. KIRK, Bull. Entomol. Res. 41, $563(1951)$

Lewis, P., J. exper. Med. 52, 113 (1930)

LiBikova, H., Acta virol. 5, 195 (1961)

Liegors, P., E. Rousseau \& C. Courtors, Ann. Soc. Belge Méd. Trop. 28, 247 (1948)

Lim, K. A., A. Rudnik \& Y. C. Chan, Singapore Med. J. 2, 158 (1961)

Linhares, H., Mem. Inst. Oswaldo Cruz 38, 187 (1943a), 38, 201 (1943b), 38, 209 (1943 c), $38,225(1943 \mathrm{~d})$

Lins, S. A., Arch. Hyg. Lisboa 3, 195 (1929)

Lipowsky, L. J., J. Cansas Entomol. Soc. 24, 151 (1951)

Lippelt, H., Zbl. Bakt. I. Ref. 163, 215 (1957)

LIPPI, M., Arch. Ital. Sci. Med. Col. 36, 415 (1955)

Livshitz, J. M., Med. Parasit. Moskau 6, 938 (1937) 
LLoyd, L. W., Med. Clin. North Amer. 35, 587 (1951)

Lioyd, W., Amer. Heart J. 6, 504 (1931); Bull. Off. Intern. Hyg. Publ. 27, 2365 (1935); Lloyd, W. \& A. F. Mahaffy, J. Immunol. 25, 471 (1933), 26, 313 (1934); Amer. J. Trop. Med. 15, 51 (1935), 16, 73 (1936); Lloyd, W. \& H. A. Penna, Amer. J. Trop. Med. 13, 1 (1933 a), 13, 243 (1933 b); Lloyd, W., H. A. Penna \& A. F. Mahaffy, Amer. J. Hyg. 18, 323 (1933); Lloyd, W., M. Theiler \& N. Ricci, Transact. Roy. Soc. Trop. Med. 29, 481 (1936)

Love, R., Nature 180, 1338 (1957); Ann. N. Y. Acad, Sci. 81, 101 (1959); Love, R., H. KoPRowski \& H. Cox, Cancer Res. 13, 350 (1953)

Low, G. C. \& N. H. FARLeY, Brit. Med. J. 1931 I, 125

Luger, N. M. \& H. Himes, Arch. Int. Med. 98, 112 (1956)

Lukes, R. J., Amer. J. Med. 16, 639 (1954)

Lumley, G. F., Med. J. Austral. 1943 II, 236

Lumsden, W. H. R., Bull. Entomol. Res. 42317 (1951a), 42, 721 (1951b); J. Animal Ecology 20, 11 (1951c); Bull. WHO 11, 403 (1954); Bull. Entomol. Res. 46, 149 (1955a); Transact. Roy. Soc. Trop. Med. 49, 33 (1955b); East Afric. Med. J. 35, 519 (1958)

Lynch, C. J. \& T. P. Hughes, Genetics 21, 104 (1936)

MacCallum, F. O. \& G. M. Findlay, Transact. Roy. So. Trop. Med. 31, 199 (1938)

MacCarthy, D. D. \& D. B. Wilson, Transact. Roy. Soc. Trop. Med. 42, 83 (1949)

MacClelland, G. A. H., Bull. Entomol. Res. 50, 227 (1959)

MacCollum, R. W. \& J. F. Foley, Proc. Soc. Exper. Biol. 94, 556 (1957)

MacDonald, W. W., Ann. Trop. Med. Parasit. 50, 385 (1956a), 50, 399 (1956b), 51, 175 (1957)

MacIntosh, B. M., Transact. Rov. Soc. Trop. Med. 55, 63 (1961); McIntosh, B. M., R. H. Kokernot \& H. E. Paterson, South Afric. J. med. Sci. 25, 33 (1960); McIntosh, B. M., R. H. Kokernot, H. E. Paterson \& B. De Meillon, South Afric. med. J. 35, 647 (1961a); McIntosh, B. M., M. P. Weinbren, C. B. Worth \& R. H. Koкernot, Amer. J. Trop. Med. Hyg. 11, 685 (1962); McIntosh, B. M., C. R. Worth \& R. H. Kokernot, Transact. Roy. Soc. Trop. Med. 55, 192 (1961 b)

MacKenzie, R. D., J. Path. Bact. 37, 75 (1933), 40, 65 (1935); MacKenzie \& F. M. Findlay, Lancet 1936 I, 140; MacKenzie, R. D., F. M. Findlay, \& R. O. Stern, Brit. J. exper. Path. 17, 352 (1936)

MacKerRas, I. M., Transact. Roy. Soc. Trop. Med. 40, 295 (1946)

MacLean, D. M. \& W. J. Margrath, Med. J. Austral. 1959 II, 719

MacNamara, F., Ann. Rep. Virus Res. Institut, Lagos (Nigeria) (1952); Ann. Trop. Med. Parasit. 47, 9 (1953 a); Brit. J. exper, Path. 34, 392 (1953 b); Transact. Roy. Soc. Trop. Med. 47, 199 (1953 c); Bull. WHO 11, 391 (1954a); Transact. Roy. Soc. Trop. Med. 48, 139 (1954b); West Afric. Med. J. 4, 124 (1955), 6, 137 (1957); MacNamara, F., D. W. HorN \& J. S. Porterfield, Transact, Roy. Soc. Trop. Med. 53, 202 (1959)

MacNinch, J. H., Ann. Int. Med. 38, 53 (1953)

Madden, A. H., A. W. Lind quist \& E. F. Knipling, J. Econ. Entomol. 38, 252 (1945); Trop. Dis. Bull. 43, 158 (1946)

Maeyer, E. De \& J. F. Enders, Proc. Soc. Exper. Biol. 107, 573 (1961)

Magalhaes, A. De Goday, Arch. Path. 11, 561 (1931)

MAgARA, M., Nippon Igaku 1942, Nr. 3306, 2286

MahaffY, A. F., Transact. Roy. Soc. Trop. Med. 42, 511 (1949); Bul. WHO 11, 319 (1954); Sem. Hôp. Paris 31, 861 (1955); Mahaffy, A. F., W. Lloyd \& H. A. Penna, Amer. J. Hyg. 18, 618 (1933); Mahaffy, A. F., K. C. Smithburn, H. R. Jacobs \& L. D. Gillett, Transact. Roy. Soc. Trop. Med. 36, 9 (1943)

Manoussakis, E., Bull. Soc. Path. Exot. 21, 200 (1928a); Presse Méd. 1928b, 458; Recherches sur la Fièvre Dengue (Paris 1928c); Rev. Hyg. Méd. 53, 18 (1931)

Manso, C. DE S., Bol. Of. San. panamer. 43, 341 (1957)

Manso Soto, A. E., A. Martinez \& A. F. Prosen, Mision Estud. Pat. Reg. Argent. (Univ. B. Aires) 24, 33 (1953)

Marchoux, E., A. Salimbeni \& P. Simond, Ann. Inst. Pasteur 17, 665 (1903); Marchoux, E. \& P. Simond, Ann. Inst. Pasteur 20, 16 (1906 a), 20, 104 (1906 b), 20, 161 (1960c)

Marselos, V., Z. Urol. 24, 246 (1930)

Marshall, I. H., Amer. J. Trop. Med. Hyg. 3, 587 (1954)

Martinez, A., R. V. Carcavallo \& A. F. Prosen, An. Inst. Med. Reg. Resis. (arg) 5, 63 (1960)

Martinez Baez, M., Gac. Med. Mexico 88, 258 (1958) 
Mason, P. J. \& A. J. Haddow, Transact. Roy. Soc. Trop. Med. 51, 238 (1957)

Mathis, C., in: Les Ultravirus des Maladies humaines von Levaditi \& Lépine, 2. Aufl. 2, 833 (Paris 1948); Mathis, C., C. Durieux \& M. Mathis, Bull. Acad. Méd. 116, 226 (1936); Mathis, C., J. Laigret \& C. Durieux, Compt. rend. Acad. Sci. 199, 742 (1934); Mathis, C., A. W. Sellards \& J. Laigret, Compt. rend. Acad. Sci. 186, 604 (1928)

Mathis, M., Bull. Soc. Path. Exot. 29, 703 (1936 a); Compt. rend. Acad. Sci. 203, 547 (1936 b); Bull. Soc. Path. Exot. 30, 525 (1937)

Matsuyama, T., A. Oya, T. Ogata, I. Kobayashi, T. Nakamura, M. Takahashi \& M. Kitaoka, Jap. J. med. Sci. Biol. 13, 191 (1960)

Matthews, R. E. F. \& J. D. Smith, in: Advances in Virus Research von Smith \& Lauffer 3, 134 (New York, 1955)

Mattingly, P. F., Bull. Entomol. Res. 40, 149 (1949); Ann. Trop. Med. Parasit. 52, 5 (1958); Trans. Roy. Soc. Trop. Med. Hyg. 54, 97 (1960)

Matumoto, M., I. Nishii \& Y. Saburi, Compt. rend. Soc. Biol. 152, 1623 (1958), 53, 1634 (1959a), 153, 1645 (1959b), 153, 1649 (1959c), 153, 1664 (1959d); Matumoto, M., I. Nishir, Y. Saburi \& T. Suzuki, Compt. rend. Soc. Biol. 153, 1657 (1959e); Matumoto, M. Y. SABURI \& I. IshiI, J. Immun. 82, 219 (1959)

MAYeR, C. F., Labor. Invest. 1, 291 (1952 a); Mil. Surg. 110, 276 (1952 b)

Mazaud, R., P. Giudicelli \& J. Mousinac, Sem. Hôp. Paris 33, 125 (1957a), 33, 135 (1957b)

Medvedeva, G. I., Probl. virol. 5, 476 (1960)

Meers, P. D., Transact. Roy. Soc. Trop. Med. 51, 338 (1957), 52, 188 (1958), 53, 196 (1959a), 53, 256 (1956b), 53, 445 (1959), 54, 493 (1960); West Afric. Med. J. 9, 29 (1960b)

Meiklejohn, G., B. England \& E. H. Lennette, Amer. J. Trop. Med. Hyg. 1, 51 (1952 a), 1, 59 (1952 b); Meiklejohn, G., T. W. Simpson \& I. B. Stacy, 7. Congr. Pacific Sci (1949)

Meillon, B. DE, Ann. Rep. South Afric. Inst. Med. Res. Johannesburg 21 (1946); Bull. WHO 11, 443 (1954)

Melnick, J. L., E. C. Curnen \& A. B. Sabin, Proc. Soc. exper. Biol. 68, 198 (1948)

Mercado, J. G. \& C. E. G. Smith, Virology, 9, 482 (1960)

Mettler, N., Compt. rend. Soc. Biol. 154, 2375 (1960); Mettler, N., S. M. Buckley \& J. CaSals, Proc. Soc. Exper. Biol. 107, 684 (1961)

Meyer, K. F., C. M. Haring \& B. F. Howitt, Science 74, 227 (1931)

Milanovic, M. V., J. F. Enders \& A. Mitus, Proc. Soc. Exper. Biol. 95, 120 (1957)

Miller, J. K., Publ. Health Labor. 18, 53 (1960); Miller, J. K., V. N. Tompkins \& J. C. Sieracki, Arch. Path. 72, 149 (1961)

Mıms, C. A., Brit. J. exper. Path. 37, 111 (1956 a), 37, 120 (1956b), 37, 129 (1956 c); Austral. J. exper. Biol. 35, 595 (1957 a); Brit. J. exper. Path. 38, 329 (1957b); Mrms, C. A. \& P. J. Mason, Brit. J. exper. Path. 37, 423 (1956)

Misao, T., Chiryo (jap.) 26, 199 (1944)

Mittoff, A. \& G. Dimoff, Zbl. Bakt. I. Orig. 183, 424 (1962)

Mollaret, P., in: Traité de Médicine von Ravina \& Patel 2, 574 (Paris 1948); Mollaret, P. \& G. J. Stefanopoulo, Compt. rend. Soc. Biol. 117, 1101 (1934)

Montestruc, E., Rev. Méd. Hyg. Outre Mer 28, 182 (1956)

Montgomery, R. E., Ann. Rep. Dep. Agricult. Kenya (1912-13)

Moore, A. E., Ann. Rev. Microbiol. 8393 (1954); Texas Rep. Biol. Med. 15, 588 (1957)

Morishita, K., J. Med. Assoc. (Formosa )Nr. 247 (1925)

Morse, L. J., S. B. Russ, C. F. Needy \& E. L. Buescher, J. Immunol. 88, 240 (1962)

Moses, A., Arch. Hyg. Rio 3, 27 (1929)

Moshkovsky, S. H., N. A. Demina, B. J. Melakov, E. A. Pavlova \& J. M. Livshitz, Med. Parasit. Moskau 6, 610 (1937a); Moshrovsky, S. H., N. A. Demina, V. D. Nossina, E. F. Epstein, M. L. Melikhan Shonina, B. S. Rasina, E. A. Pavlova \& M. A. Wunder, Med. Parasit. Moskau 5, 838 (1936); Moshrovsky, S. H., N. A. Demina, V. D. Nossina, E. A. Pavlova, J. L. Livshitz, H. J. Pels \&. V. P. Roubtzova, Med. Parasit. Moskau 6, $922(1937 \mathrm{~b})$

Muckenfuss, R. S., C. Armstrong \& H. I. MacCordock, Publ. Health Rep. 48, 1341 (1933)

Müller-Dietz, H., Zbl. Bakt. I. Ref. 163, 575 (1957)

Mundel, B. \& J. H. S. Gear, South Afric. Med. J. 25, 797 (1951)

Murovannyi, I. L., Z. Mikrobiol (russ.) 62 (1954)

Murphy, L. C. \& B. C. Easterday. Proc. US Livestock San. 1961, 397

Muspratt, J., K. C. Smithburn, H. E. Paterson \& R. H. Kokernot, South Afric. J. Med. Sci, 22, $121(1957)$ 
Mussgay, M., Zbl. Vet. Med. 4, 243 (1957)

Myhrman, H., Acta med. Scand. 140, 52 (1951)

Nakagawa, Y. \& M. Shingu, Kurume Med. J. 2, 157 (1955)

Nakamura, M., Nature 191, 624 (1961)

Nauck, E. G. in: Handbuch der inneren Medizin 4. Aufl. 1, I, 593 (Berlin 1952a), 1, I, 626 (Berlin 1952 b); Ann. Inst. Med. Trop. Lisboa 10, 485 (1953); Lehrbuch der Tropenkrankheiten 321 (Stuttgart 1956)

Naude, W. du, T. Madsen \& A. Polson, Nature 173, 1051 (1954); Naudé, W. Du \& A. Polson, J. Gen. Microbiol. 16, 491 (1957)

Neghme, A., Bol. Of. San. Panamer. 29, 389 (1950)

Nelson, E. R., J. Pediatr. 56, 101 (1960)

News \& Comment, Bull. US Army Med. Dep. Nr. 84, 1 (1945)

Nicolau, S., L. Kopciowska, G. Balmus \& M. Mathis, Compt. rend. Soc. Biol. 116, 944 (1934a); Nicolau, S., L. Kopciowska \& M. Mathis, Ann. Inst. Pasteur 53, 455 (1934b); Compt. rend. Acad. Sci. 198, 288 (1934c); Compt. rend. Soc. Biol. 116, 818 (1934d); Presse Méd. 42, 1101 (1934e); Nicolau, S., L. Kopciowska, M. Mathis \& O. Baffet, Compt. rend. Soc. Biol. 116, 820 (1934f); Nicolau, S., M. Mathis \& O. Baffet, Compt. rend. Soc. Biol. 122, 203 (1936); Bull. Soc. Path. Exot. 30, 615 (1937)

Nicolle, C., Arch. Inst. Pasteur (Tunis) 17, 356 (1928); Bull. Acad. Méd. 113, 254 (1935); Nicolle, C. \& J. Laigret, Compt. rend. Acad. Sci. 201, 312 (1935)

Nieisen, G. \& J. Marquardt, Arch. Virusforschg. 12, 335 (1962)

NiR, Y. D. \& R. Goldwasser, Amer. J. Hyg. 73, 294 (1961)

Notт, J. C., New Orleans Med. Sci. J. 1848

Notter, A., J. Viallier \& H. Gabriel, Presse Méd. 68, 1139 (1960)

Nye, E. R., Transact. Roy. Soc. Trop. Med. 55, 459 (1961); Nye, E. R. \& D. S. Bertram, Virology 12, 570 (1960); Nye, E. R. \& J. C. Lien, Transact. Roy. Soc. Trop. Med. 54, 263 (1960)

O'Connor, J. L., L. C. Rowan \& J. J. Lawrence, Nature 176, 472 (1955)

Ogden, C. J., Transact. Roy. Soc. Trop. Med. 55, 302 (1961)

O'Gower, A. K., Austral. J. exper. Biol. 38, 1 (1960)

Okuno, T., Amer. J. Trop. Med. Hyg. 10, 223 (1961)

Oliphant, J. W. \& R. O. Tibis, Publ. Health Rep. 65, 521 (1950)

Olitsky, P. K. \& J. Casals, in: Viral and Rickettsial Infections of Man von Rivers, 2. Aufl. 252 (Philadelphia 1952); dito. 3. Aufl. von Rivers \& Horsfall, 298 (Philadelphia 1959); Olitsky, P. K. \& D. H. Clarke, dito, 3. Aufl. 305 (1959)

Oliver, J. \& M. MacDowell, J. Clin. Invest. 36, 99 (1957)

Omardeen, T. A., Bull. WHO 24, 495 (1961)

Orsi, E. V., R. Love \& H. Koprowski, Cancer Res. 17, 306 (1957)

Osterrieth, P. M. \& G. Blanes-Ridaura, Ann. Soc. belge Méd. trop. 40, 199 (1960); Osterrieth, P. M. \& P. Delaplanque-Liegeois, Ann. Soc. belge Méd. trop. 41, 63 (1961a), 41, 163 (1961 b); Osterrieth, P. M., P. Delaplanque-Liegeois \& G. Blanes-Ridaura, G., Ann. Soc. belge Méd. trop. 40, 199 (1960); Osterrieth, P. M., P. DeleplanqueLiegois \& R. Renoirte, Ann. Soc. belge Méd. trop. 40, 205 (1960)

Otтo, M. \& R. O. Neumann, Z. Hyg. 51, 357 (1905)

Oya, A., T. OKuno, T. Ogata, I. Kobayashi \& T. Matsuyama, Jap. J. Med. Sci. 14, 101 (1961)

Ozawa, Y., Yokohama Med. Bull. 5, 72 (1954)

Pandit, C. G., Amer. J. publ. Health 50, Anh. 2, 46 (1960)

Panthier, R., Bull. Soc. Path. Exot. 49, 477 (1956a), 49, 759 (1956 b), 51, 183 (1958); Panthier, R., P. Bres, R. A. Husson \& C. Hannoun, Bull. Soc. Path. Exot. 51, 589 (1958); Panthier, R. \& A. J. Carteaud, Bull. Soc. Path. Exot. 51, 159 (1958); Panthier, R., A. J. Carteaud \& R. A. Husson, Bull. Soc. Path. Exot. 50, 282 (1957); Panthier, R. \& C. Hannoun, Bull. Soc. Path. Exot. 53, 25 (1960), 53, 100 (1960b); Panthier R. \& R. A. Husson, Bull. Soc. Path. Exot. 50, 23 (1957); Panthier, R., R. A. Husson \& C. Hannoun, Bull. Soc. Path. Exot. 52, 759 (1959); Panthier, R., C. Lucasse \& C. Hannoun, Ann. Soc. belge Méd. trop. 42, 65 (1962)

Paoliello, A., Bol. Of. San. Panamer. 27, 1005 (1948)

Papanicolau, B., Z. Tbk. 53, 107 (1929)

Para, M. \& F. Aviles Nugue, Rev. Brasil. Malariol. 5, 223 (1953) 
Parks; J. J., J. R. Ganaway \& W. H. Price, Amer. J. Hyg. 68, 106 (1958); Parks, J. J. \& W. H. PrICE, Amer. J. Hyg. 67, 187 (1958)

Parodi, A. S., D. J. Greenway, H. R. Rugiero, E. Rivero, M. Frigerio, J. M. de la Barrera, N. Mettler, F. Garzon, M. de Bozaca, L. Guerrero \& N. Nota, El Dia Medico 30, 2300 (1958); Parodi, A. S., N. Mettler \& M. De Bozaca, Compt. rend. Soc. Biol. 154, 828 (1960); Parodi, A. S., H. R. Rugiero, D. J. Greenway, N. Mettler, A. Martinez, M. de Bosaca \& J. M. de la Barrera, Presse méd. argent. 46, (1959)

Parrot, L. \& R. Durand-Delacre, Arch. Inst. Pasteur Alger. 26, 402 (1948)

Patino Camargo, L., Rev. Hig., Bogota 2, 63 (1933)

Pattyn, S. R., J. P. Delville \& J. Peel, Ann. Soc. Belge Méd. trop. 40, 215 (1960)

Paul, J. R. \& W. W. MacClure, Amer. J. Hyg. 68, 126 (1958); Paul, J. R., J. L. Melnick \& A. B. Sabin, Proc. Soc. Exper. Biol. 68, 193 (1948)

Pavri, K. M., T. Gokhale \& K. V. Shah, Indian J. med. Res. 50, 153 (1962)

Peller, S., Bull. History of Med. 33, 195 (1959)

Peltier, M., Epidemiol. Inform. Bull. UNRRA Health Dis. (Wash.) 2, 806 (1946); Amer. J. Publ. Health 37, 1026 (1947); Intern. Congr. Trop. Med. Malar. 1, 489 (1948); Peltier, M., C. Durieux, H. Jonchère \& E. Arquié, Bull. Acad. Méd. 118, 432 (1937), 121, 657 (1939 a); Rev. Immunol. 5, 172 (1939 b); Ann. Inst. Pasteur 65, 146 (1940a); Bull. Acad. Méd. 123, 147 (1940b)

Penido, J. C. N., Mem. Inst. Oswaldo Cruz Suppl. 2, 65 (1928)

Penna, H. A., Amer. J. Trop. Med. 16, 331 (1936); WHO Monogr. Ser. 30, 67 (1956); Penna, H. A. \& H. Moussatche, Brasil Med. 53, 903 (1939)

Penna, O. \& B. Figueiredo, Folha Med. 10, 229 (1929)

Pepper, O. H. P., Ann. Med. Histor. 3, 363 (1941)

Pereira, H. C., in: Advances in virus research von Smith \& LaufFer 8, 245 (New York 1961)

Perlowagora, A. \& T. P. Hughes, J. Immunol. 55, 103 (1947), 60, 67 (1948); Perlowagora, A. \& E. Lennette, Amer. J. Trop. Med. 24, 235 (1944)

Perry, V. P., V. J. Evans, W. R. Earle, G. W. Hyatt \& W. C. Bedell, Amer. J. Hyg. 67, 286 (1958)

Perry, W. J., Amer. J. Trop. Med. 28, 253 (1948)

Petrisheva, P. A., J. Gen. Biol. 7, 65 (1946)

Pettit, A., Biol. Méd. 19, 307 (1929 a); Pettit, A. \& G. J. Stefanopoulo, Compt. rend. Soc. Biol. 102, 56 (1929), 104, 63 (1930); Bull. Acad. Méd. 110, 67 (1933); Bull. Off. Intern. Hyg. Publ. 26, 1075 (1934); Pettit, A., G. J. Stefanopoulo \& V. Frasey, Compt. rend. Soc. Biol. 99, 841 (1928a); Pettit, A., G. J. Stefanopoulo \& C. Kolochine, Compt. rend. Soc. Biol. 99, 260 (1928b); Bull. Acad. Méd. 102, 98 (1929)

Philip, C. B., Amer. J. Trop. Med. 9, 267 (1929), 10, 1 (1930a); Ann. Trop. Med. Parasit. 24, 493 (1930b); Bull. Entomol. Res. 24, 483 (1933); Philip, C. B. \& L. E. Hughes, Intern. Congr. Microbiol. (Rom) 5, 541 (1953)

Рнотакis, B. A., Arch. Schiffs. Tropenhyg. 33, 333 (1929)

Pick, A., Wien. med. Wschr. 36, 1141 u. 1168 (1886)

Pickels, E. G. \& J. H. Bauer, J. exper. Med. 71, 703 (1940)

Pickens, E. G. \& L. Louto, J. infect. Dis. 103, 102 (1958)

Piekarski, G., Lehrbuch der Parasitologie (Berlin 1954)

Pinto, M. R., An. Inst. Med. Trop. (Lisboa) 8, 275 (1951)

Pinto Severo, O. Bol. Of San. Panamer. 38, 378 (1955); Mosquito News 16, 115 (1956); Bol. Of San. Panamer. 45, 375 (1958)

Piorsky, I., J. Zuccarni, E. A. Molinelli, A. Di Pietro, J. C. Barrera-Oro \& P. MarTINI, Orientacion Medica 8, 303 (1959)

Pirumov, K. N. \& S. A. Anamyan, Med. Parasit. Moskau 8, 235 (1939)

Piyaratn, D., Austral. J. Trop. Med. Hyg. 10, 767 (1961)

Plank, J. \& M. Rezucha, Zbl. Path. 94, 480 (1955)

Plichet, A., Presse Méd. 61, 946 (1953)

Pollard, M., H. R. Livesay, D. J. Wilson \& J. C. Woodland, Amer. J. Trop. Med. 26, 175 (1946a); Proc. Soc. exper. Biol. 61, 396 (1946b)

Polonovski, M., Sem. Hôp. (Paris) 29, 3329 (1953)

Polson, A., Nature 172, 1154 (1953); Proc. Soc. exper. Biol. 85, 613 (1954)

Pontano, T., Z. Immunforschg. 69, 146 (1930)

Pool, W. A., A. Brownlee \& D. R. Wilson, J. Comp. Path. 43, 253 (1930)

Porterfield, J. S., WHO Seminar Yellow Fever, Campala 529 (1953); Transact. Roy. Soc. Trop. Med. 48, 261 (1954), 50, 344 (1956); Nature 180, 1201 (1957), 183, 1069 (1959a); Transact. Roy. Soc. Trop. Med. 53, 458 (1959 b), 53, 310 (1959 c); Lancet 1959d II, 326; 
Bull. WHO 22, 373 (1960); Acta Virol. 5, 274 (1961a); Bull. WHO 24, 735 (1961 b); in: Colonial Research 1960-1961, 353 (London 1961c); Transact. Roy. Soc. Trop. Med. 55, 308 (1961 d); Porterfield, J. S. \& C. E. Rowe, Virology 11, 765 (1960); Porterfield, J. S., M. C. Williams \& J. P. Woodall, Nature 188, $252(1960)$

Powell, G. M., J. Amer. Med. Assoc. 151, 1261 (1953); Medicine 33, 97 (1954)

Powell, H. M., C. G. Culbertson, J. M. MacGuire, M. M. Hoenn \& L. A. Baker, Antibiotics, Chemother. 2, 432 (1952)

Price, W. H., Publ. Health Rep. 71. 125 (1956); Price, W. H., R. W. Lee, W. F. Gunkel \& W. O'Leary, Amer. J. Trop. Med. Hyg. 10, 403 (1961)

Pruitt, F. W. \& E.A. Cleve, Amer. J. Med. Sci. 225, 660 (1953)

Qutubuddin, M., Bull. WHO 19, 1109 (1958)

Raffael, G., A. Coluzzi \& J. de Zulueta, Bull. WHO 18, 464 (1958)

Raynal, J. H., Méd. Trop. (Marseille) 12, 385 (1952)

Reagan, R. L. \& A. L. Brueckner, J. Bact. 64, 233 (1952 a); J. Infect. Dis. 91, 145 (1952 b); Amer. J. Path. 29, 773 (1953 a), 29, 1157 (1953 b); Cornell Vet. 43, 493 (1953 c); Texas Rep. Biol. Med. 11, 2 (1953 d); Transact. Amer. Microscop. Soc. 72, 345 (1953e); Amer. J. Vet. Res. 15, 164 (1954); Reagan, R. L., S. Chang \& A. L. Brueckner, Texas Rep. Biol. Med. 13, 470 (1955a), 13, 934 (1955b); Reagan, R. L., W. C. Day, M. P. Harmon \& A. L. Brueckner, Proc. Soc. exper. Biol. 80, 210 (1952a); Reagan, R. L., E. C. Delaha, M. T. Stewart \& A. L. Brueckner, Amer. J. Vet. Res, 15, 466 (1954a); Cornell Vet. 44, 298 (1954b); Reagan, R. L., M. T. Stewart \& A. L. Brueckner, Texas Rep. Biol. Med. 11, 610 (1953a); Reagan, R. L., M. T. Stewart, E. C. Delaha \& A. L. Brueckner, Texas Rep. Biol. Med. 12, 524 (1954c); Reagan, R. L., N. Strand \& A. L. Brueckner, Cornell Vet. 43, 427 (1953b); Proc. Soc. exper. Biol. 82, 642 (1953 c); Amer. J. Vet. Res. 15, 153 (1954d), 15, 157 (1954e); Cornell Vet. 44, 60 (1954f); ReaGan, R. L., F. S. Yancey \& A. L. Brueckner, Amer. J. Trop. Med. Hyg. 5, 809 (1956a); Reagan, R. L., F. S. Yancey, S. C. Chang \& A. L. Brueckner, Amer. J. Trop. Med. Hyg. 5, 1032 (1956 b)

ReED, W., Med. Rec. 60, 201 (1901); USA Senate Doc. 822, 90 (1911); Reed, W. \& J. CARroll, Amer. Med. 3, 301 (1902); Reed, W., J. Carroll, A. Agramonte \& J. W. Lazear, Philadelphia Med. J. 6, 790 (1900)

Reeves, W. C., Ber. 6. Intern. Kongr. trop. Med. Malaria 161 (1958a); in: Handb. Virusforschg. von Doerr \& Hallauer Erg.-Bd. 3, 177 (Wien 1958b); Progr. med. Virol. 3, 59 (1961)

RHODes, A. J. \& C. F. van Rooyen, Textbook of Virology 3. Aufl. (New York 1958)

Rickard, E. R., Rockefeller Found. Quartely Bull. 5, 310 (1931); Amer. J. Trop. Med. 17, $163(1937)$

Robinson, G. G., East Afric. Med. J. 27, 284 (1950)

Robinson, M. C., Transact. Roy. Soc. Trop. Med. 49, 28 (1955); Central. Afric. J. Med. 2, $394(1956)$

Roca-Garcia, M., J. Infect. Dis. 75, 160 (1944)

Rocha Lima H. DA, Arch. Schiff. Tropenhyg. 16, 192 (1912a); Verh. Dtsch. Path. Ges. 15, 163 (1912b); Folha Med. 7, 169 (1926); Festschrift BerNHARD Nocht 497 (1937)

Rodaniche, E. DE, Amer. J. Trop. Med. Hyg. 5, 480 (1956 a), 5, 797 (1956 b), 6, 835 (1957); Rodaniche, E. de \& P. Galindo, Amer. J. Trop. Med. Hyg. 6, 232 (1957 a), 6, 686 (1957b); 10, 393 (1961); Rodaniche, E. DE, P. Galindo \& C. M. Johnson, Amer. J. Trop. Med. Hyg. 6, 681 (1957), 8, 190 (1959)

RODGER, L. M., South Afric. Med. J. 35, 126 (1961)

Rodhain, J., Compt. rend. Soc. Biol. 128, 1007 (1936)

Roever-Bonnet, H. De \& J. Hoekstra, Trop. Geogr. Med. Amsterdam 10, 289 (1958), 13, 171 (1961)

Rogers, L. \& J. W. D. Megaw, Tropical Medicine 4. Aufl. (1942)

Romana, C., Najera, M., M. Conejos \& J. W. Alvaros, An. Inst. Med. Reg. Tukuman 2, $283(1949)$

Rooyen, C. E. van \& A. J. Rhodes, Virus Diseases of Man 2. Aufl. 437 (New York 1948)

Rosen, L., Amer. J. Hyg. 68, 45 (1958a); Amer. J. Trop. Med. Hyg. 7, 403 u. 406 (1958b); Rosen, L., L. E. Rozeboom, B. H. Sweet \& A. B. Sabin, Amer. J. Trop. Med. Hyg. 3, 878 (1954)

Rosenberger, C. R. \& C. W. Shaw, Proc. Soc. exper. Biol. 106, 223 (1961)

Rosenau, M. J., H. B. Parker, E. Francis \& G. E. Beyer, Publ. Health Bull. 14, 109 (1905) 
Ross, R. W., Ann. Trop. Med. Parasit. 44, 299 (1950); Annual Rep. Res. Inst. Entebe (1953); J. Hyg. 54, 177 (1956); Ross, R. W. \& J. D. Gillett, Ann. Trop. Med. Parasit. 44, 351 $(1950)$

Roubaud, E., J. Colas-Belcour \& G. J. Stefanopoulo, Compt. rend. Acad. Sci. 205, 182 (1937), 207, 1944 (1938); Roubaud, E. \& G. J. Stefanopoulo, Bull. Soc. Path. Exot. 26, $305(1933)$

Rowan, L. C., Med. J. Austral. 1959 I, 323; Rowan, L. C. R \& J. L. O'Connor, Nature 179, 786 (1957)

Rozeboom, L. E. \& W. Burgdorfer, Amer. J. Hyg. 69, 138 (1959)

Rudnick, A. \& W. McD. Hammon, Mosquito News 20, 247 (1960); Rudnick, A., W. McD. Hammon \& G. E. Sather, Amer. J. Trop. Med. Hyg. 11, 546 (1962)

Russell, F. F., Annual Rep. Rockefeller Found. 1932, 31

Sabin, A. B., Fed. Proc. 8, 410 (1949); Bact. Rev. 14, 225 (1950); Arch. Virusforschg. 4, 367 (1951 a); Fed. Proc. 10, 573 (1951 b); Amer. J. Trop. Med. Hyg. 1, 30 (1952a); Ann. N. Y. Acad. Sci. 54, 936 (1952 b); Proc. Nat. Acad. Sci. 38, 540 (1952 c); in: Viral and Rickettsial Infections of Man von Rivers 2. Aufl. 556 (Philadelphia 1952 d); Ann. N. Y. Acad, Sci. 56, 180 (1953); Amer. J. Trop. Med. Hyg. 4, 198 (1955); in: Diagnostic Procedures for Virus and Rickettsial Diseases von Francis 2. Aufl. 383 (New York 1956); Arch. Virusforschg. 9, 1 (1959a); in: Viral an Rickettsial Infections of Man 3. Aufl. von Rivers \& Horsfall 361 (Philadelphia 1959b), 374 (1959c); Sabin, A. B. \& R. W. Blumberg, Proc. Soc. exper. Biol. 64, 385 (1947); Sabin, A. B., C. B. Philip \& J. R. Paul, J. Amer. Med. Assoc. 125, 603 (1944a), 125, 693 (1944b); Sabin, A. B. \& R. W. Schlesinger, Science 101, 640 (1945); Sabin, A. B. \& I. Young, Proc. Soc. exper. Biol. 69, 478 (1948)

Saddington, R. S., Proc. Soc. exper. Biol. 31, 693 (1934)

Sainz, C. C., F. Lopez Pintado \& J. D. Mucha Macias, Rev. Inst. Salut Enferm trop. Mexico 20, 277 (1960)

Salminen, A., Ann. Med. Exper. Fenn. 37, 400 (1959); in: Sympos. on biology of viruses of the tick-borne encephalitis complex (Pressburg 1960); Acta path. microbiol. Scand. Suppl. 154, 341 (1962 a), 154, 343 (1962 b); Ann. Med. Exper. Fenn. 40, 174 (1962 c); Nature 194, 1301 (1962 d); Virology 16, 201 (1962 e)

SANNA, A. \& B. AngiLlo, Ig. moderna 52, 667 (1959), 54, 249 (1961)

SARDOU, Dissertation (Marseille 1935)

Sautet, J., Presse Méd. 63, 339 (1955); Sautet, J.\& R. Aldighieri, Bull. Soc. Path. Exot. 47, 387 (1954)

SAWA, I., Compt. rend. Soc. Biol. 150, 835 (1956), 152, 692 (1958)

Sawyer, W. A., Bol. Of. San. Panamer., 10, 971 (1931a); J. Prev. Med. 5, 413 (1931b); Medicine, Baltimore 10, 509 (1931c); Transact, Assoc. Amer. Phys. 50, 64 (1935); SAwY ER, W. A. \& M. Frobisher, J. Exper. Med. 50, 713 (1929); 1. Intern. Congr. Microbiol 2, 476 (Paris 1930); SAwyer, W. A., S. F. Kitchen, M. Frobisher \& W. Lloyd, J. exper. Med. 51, 493 (1930); Sawyer, W. A., S. F. Kitchen \& W. Lloyd, Proc. Soc. exper. Biol. 29, 62 (1931); J. exper. Med. 55, 945 (1932); Sawyer, W. A. \& W. Lloyd, J. exper. Med. 54, 533 (1931); SAwyer, W. A., W. Lloyd \& S. F. Kitchen, J. exper. Med. 50, 1 (1929); Sawyer, W. A., K. F. Meyer, M. D. Eaton, J. H. Bauer, I. Putnam \& F. F. SchwentKER, Amer. J. Hyg. 39, 337 (1944a), 40, 35 (1944b)

Sayer, W. J., G. Entwhisle, P. Uyeno \& R. C. Bignall, Ann. Int. Med. 42, 839 (1955)

Schaeffer, M., D. C. Gajdusek, A. Brown \& H. Eichenwald, Amer. J. Trop. Med. Hyg. 8, $372(1959)$

SchERER, W. F., in: Virus meningoencephalitis, Ciba Found. Study Group Nr. 7, 37 (London 1961); Scherer, W. F., M. Funkenbusch, E. L. Buescher \& T. Izumi, Amer. J. Trop. Med. Hyg. 11, 255 (1962 a); Scherer, W. F., T. Izumi, J. McCown \& J. L. Hardy, Amer. J. Trop. Med. Hyg. 11, 269 (1962 b)

Schilling, C., in: Handbuch der Viruskrankheiten von Gildemeister, Haagen \& WaldMANN 1, 488 (Jena 1939a), 1, 499 (1939 b)

Schlesinger, R. W., in: Diagnosis of Viral and Rickettsial Infections von Horsfall 101 (New York 1949); Amer. J. Hyg. 51, 248 (1950); Schlesinger, R. W. \& J. W. Frankel, Amer. J. Trop. Med. Hyg. 1, 66 (1952); Schlesinger, R. W., I. Gordon, J. W. Frankel, J. W. Winter, P. R. Patterson \& W. R. Dorrance, J. Immunol. 77, 352 (1956)

Schmidt, J. R., D. C. Gajdusek, M. Schaeffer \& R. H. Gorrie, Amer. J. Trop. Med. Hyg. 3, 479 (1959); Schmidt, J. R., M. L. Schmidt \& J. G. McWilliams, Amer. J. Trop. Med. 9, 450 (1960)

Schmidt, V., Nord. Med. 49, 250 (1953) 
Schrire, L., South Afric. Med. J. 25, 926 (1951)

Schüffner, W., Transact. Roy. Soc. Trop. Med. 32, 587 (1939); Schüffner, W., A. Mochtar, L. S. Prokoemau \& L. Honig, Arb. Geb. Auslandskde (Hamburg) 26, 500 (1927); SchürfNER, W., E. SNIJders \& B. WALD-Sorgdrager, Transact. Roy. Soc. Trop. Med. 32, 595 (1939)

Schule, P. A., Amer. J. Trop. Med. 8, 203 (1928)

Schulz, K. H., Med. Proc. 24, 37 (1959)

Schulze, I. T. \& R. W. Schlesinger, Fed. Proc. 21, 455 (1962)

SchwentKeR, F. F. \& T. M. Rivers, J. exper. Med. 59, 305 (1934)

Scotт, H. H., History of Tropical Medicine (Baltimore 1939)

Scotт, L. G., Brit. Med. J. 1954 II, 1108

Seltards, A. W., South Med. J. 23, 121 (1930); Ann. Trop. Med. Parasit. 29, 55 (1935); New Engl. J. Med. 216, 455 (1937); Sellards, A. W. \& B. L. Bennett, Ann. Trop. Med. Parasit. 31, 373 (1937); Sellards, A. W. \& E. Hindle, Brit. Med. J. 1928 I, 713; SelLARDS, A. W. \& J. LAIGRET, Arch. Inst. Pasteur (Tunis) 21, 229 (1932a); Compt. rend. Acad. Sci. 194, 1609 (1932 b), 194, 2175 (1932 c); Arch. Inst. Pasteur (Tunis) 25, 424 (1936 a; Compt. rend. Acad. Sci 202, 1467 (1936 b); Sellards, A. W. \& W. S. MaccanN, US Navy Med. Bull. 43, 420 (1944)

Severo, A. P., in: Yellow Fever, Symposium in Commemoration of Finlay (1955)

Shah, K. V., S. P. Aniker, D. P. Narasimha Murthy, F. M. Rodrigues, M. S. Jay adeviah \& H. A. Prasanna, Indian J. Med. Res. 50, 162 (1962); Shah, K. V., G. Cole, S. B. Russ, C. F. NEEDY \& E. L. BuEsCher, in: Sympos. on biology of viruses of the tick-borne encephalitis complex (Pressburg 1960a); SHAH, K. V., H. N. JoHnson \& T. R. RAO, Indian J. Med. Res. 48, 300 (1960)

Shahan, M. S. \& J. Traum, Ann. N. Y. Acad. Sci. 70, 614 (1958)

Shanon, R. C., Proc. Entomol. Soc. 33, 125 (1931); Shanon, R. C., A. W. Burke \& N. C. Davis, Amer. J. Trop. Med. 10, 145 (1930); Shanon, R. C. \& N. C. Davis, Amer. J. Trop. Med. 10, 151 (1930); Shanon, R. C., L. Whitman \& M. Franca, Science 88, 110 (1938b)

Shapiro, S. E. \& Z. S. Barkagan, Vopros. Virus. 1960, Nr. 2, 245; Shapiro, S. E., A. D. Kalmykova \& M. A. Garbuzov, Z. Mikrobiol. (russ) Nr. 5, 116 (1961 a); Shapiro, S. E., A. A. Konstantinov, I. S. Zhdanov \& M. I. Zelenskaya, Sovet. Med. 25, 64 (1961 b)

Sharp, W. B. \& E. Hollar, Amer. J. Trop. Med. 15, 247 (1935)

Shattuck, G. C., Diseases of the Tropics (New York 1951)

Sheedy, J. A., H. F. Froer, H. A. Baston, C. C. Conley, J. P. Murphy, B. B. Hunter, D. W. Cugell, R. B. Giles, S. C. Bershadsky, J. W. Vester \& R. H. Yoe, Amer. J. Med. 16, 619 (1954)

Shelokov, A., J. E. Vogel \& L. Chi, Proc. Soc. exper. Biol. 97, 802 (1958)

Shidrawi, G. R., Bull. WHO 17, 377 (1957)

Shone, D. K., Central Afric. J. Med. 4, 284 (1958)

Shope, R., J. exper. Med. 97, 627 (1953), 113, 511 (1961); Shope, R. E., C. E. Causey \& O. R. Causey, Amer. J. Trop. Med. 10, 264 (1961); Shope, R. E. \& O. R. Causey, Amer. J. Trop. Med. 11, 283 (1962); Shope, R. E., L. G. McNamara \& R. Mangold, J. Exper. Med. 111, $155(1960)$

Shore, H., Transact. Roy. Soc. Trop. Med. 55, 361 (1961)

Shortr, H. E., C. G. Pandit \& W. M. E. Anderson, 3. Intern. Congr. Microbiol. 368 (New York 1939); Shortт, H. E. \& R. S. RAo, Indian. J. Med. Res. 26, 229 (1938); ShortT, H. E., L. T. Poole \& E. D. Stephan, Indian. J. Med. Res. 21, 779 (1934); J. Roy. Army Med. Corps 67, 246 (1936a); Shortt, H. E., R. S. Rao \& C. S. Swaminath, Indian J. Med. Res. 23, 865 (1936 b)

Sigel, M. M. \& A. R. Beasley, Texas Rep. Biol. Med. 17, 618 (1959); Siger, M. M., A. R. Beasley, F. M. Wellimgs, W. Lichter \& J. A. Williams, Fed. Proc. 20, 443 (1961)

Siler, J. T., M. F. Hall \& A. P. Hitchens, J. Amer. Med. Assoc. 84, 1163 (1925a); Proc̈. Soc. exper. Biol. 28, 197 (1925 b); Philippine J. Sci. 29, 1 (1926)

Silver, H. K., G. Meinlejohn \& C. H. Kempe, Amer. J. Dis. Child. 101, 30 (1961)

Simmons, J. S., Amer. J. Trop. Med. 11, 77 (1931); Simmons, J. S., J. H. St. John, R. L. Holt \& F. H. K. Reynolds, Amer. J. Trop. Med. 11, 199 (1931a); Simmons, J. S., J. H. Sr. John \& F. H. K. Reynolds, Amer. J. Trop. Med. 10, 17 (1930a); Philippine. Sci. 41, 215 (1930b), 44, 1 (1931b), 44, $128(1931 \mathrm{c})$

SkLjamkaja, E. I., Vopros. Virol. 6, 354 (1957)

SMAdeL, J. E., Amer. J. Publ. Health 43, 1327 (1953)

Smetana, N., Arch. Intern. Med. 63, 760 (1939)

Smith, C. E. G., J. Hyg. 54, 569 (1956 a); J. Trop. Med. Hyg. 59, 243 (1956b); Med. J. 
Malaya 10, 289 (1956 c); J. Hyg. 55, 207 (1957a); Transact. Roy. Soc. Trop. Med. 51, 237 (1958); 54, 113 (1960); Brit. Med. Bull. 15, 235 (1959); Sмiтн, C. E. G. \& D. Holt, Bull. WHO. 24, 749 (1961)

Smith, E. C., Transact. Roy. Soc. Trop. Med. 29, 413 (1936)

Sмiтн, H. H., Amer. J. Trop. Med. 18, 77 (1938); in: Yellow Fever von Strode 539 (New York 1951); Smith, H. H., G. Bevier \& J. C. Bugher, Amer. J. Trop. Med. 28, 505 (1943); Smith, H. H., H. A. Penna \& G. Paoliello, Amer. J. Trop. Med. 18, 437 (1938); Smith, H. H. \& M. Teiler, J. exper. Med. 65, 801 (1937)

Sмiтн, J. H., Brit. Med. J. 1954 II, 852

Smithburn, K. C., J. Immunol. 44, 25 (1942), 51, 173 (1945), 52, 309 (1946); Amer. J. Trop. Med. 29, 414 (1949a); Brit. J. exper. Path. 30,1 (1949b); in: Yellow Fever von STRodE 165 (New York 1951); J. Immunol. 68, 441 (1952 a), 69, 223 (1952 b); Fed. Proc. 12, 460 (1953); Amer. J. Hyg. 59, 157 (1954a); J. Immunol. 72, 376 (1954b); WHO Monogr. Ser. Nr. 30, 11 (1956); Smithburn, K. C. \& J. C. Bugher, J. Bact. 66, 173 (1953); Smithburn, K. C., K. Goodner, G. W. A. Dick, S. F. Kitchen \& R. W. Ross, Ann. Trop. Med. Parasit. 43, 182 (1949a); Smithburn, K. C.\& A. J. Haddow, J. Immunol. 49, 141 (1944); Amer. J. Trop. Med. 26, 261 (1946), 29, 389 (1949); Proc. Soc. exper. Biol. 77, 130 (1951); Sмгтнburn, K. C., A. J. Haddow \& J. D. Gillett, Brit. J. exper. Path. 29, 107 (1948); Smithburn, K. C., A. J. Haddow \& W. H. R. Lumsden, Ann. Trop. Med. Parasit. 43, 74 (1949 b); Brit. J. exper. Path. 30, 35 (1949c); Smithburn, K. C., A. J. Haddow \& A. F. MahafFy, Amer. J. Trop. Med. 26, 189 (1946); Smithiburn, K. C., T. P. Hughes, A. W. Burke \& J. H. Paul, Amer. J. Trop. Med. 20, 471 (1940); Smithburn, K. C., J. A. Kerr \& P. B. Gatne, J. Immunol. 72, 248 (1954a); Smithburn, K. C., R. H. Kokernot, W. P. Weinbren \& B. de Meillon, South Afric. J. Med. Sci. 22, 113 (1957); Smithburn, K. C. \& A. F. Mahaffy, Amer. J. Trop. Med. 25, 217 (1945); Ann. Trop. Med. Parasit. 46, 61 (1952); Sмiтhburn, K. C., A. F. Mahaffy \& A. J. Haddow, J. Immunol. 49, 159 (1944); Smithburn, K. C., A. F. Mahaffy, A. J. Haddow, S. F. Kitchen \& J. F. Smith, J. Immunol. 62, 213 (1949c); Smithburn, K. C., A. F. Mahaffy \& J. H. Paul, Amer. J. Trop. Med. 21, 75 (1941); Smithburn, K. C. \& B. De Meillon, South Afric. J. Med. Sci. 22, 41 (1957); Smithburn, K. C., H. E. Paterson, C. S. Heyman \& P. A. D. Winter, South Afric. Med. J. 33, 959 (1959) Smithburn, K. C., R. M. Taylor, F. Rizk \& A. Kader, Amer. J. Trop. Med. Hyg. 3, 9 (1954b)

Smorodintsev, A. A., Encyclop. Wörterbuch der Kriegsmedizin (Moskau 1948); Sмorodintsev, A. A., I. S. Altshulev, M. I. Dumaevskir, M. V. Kiselevv, A. U. Churilov \& V. Darkshevich, Moskau Medgiz. 38 (1944a); Smorodintsev, A. A., I. S. Altshulev, M. I. Dumaevskit, K. A. Kokhreidze, V. D. Neustroev \& A. U. Churilov, Moskau Medgiz. 26 (1944b); Smorodintsev, A. A., M. P. Chumakov \& A. V. Churilov', Haemorrhagische Nephro-Nephritis (Moskau 1953), ref. Publ. Health Monogr. 50, 19 (1957); Smorodintsev, A. A., A. J. Dobryshevishaja, V. J. Iliyenko, B. B. Aleksejev, V. P. Gulamova \& L. V. FEDORCHUK, Neurotropic Virus Infections (engl. Übersetz. 4, 7 (1953)

SniJders, E. P., Geneeskd. Tschr. Ned. Ind. 71, 241 (1931); SniJders, E. P., E. J. Dinger \& W. A. P. Schüffner, Amer. J. Trop. Med. 11, 171 (1931a); Geneeskd. Tschr. Ned. Ind. 71, 345 (1931b); Snijders, E. P., M. F. Polak \& J. Hoekstra, Transact. Roy. Soc. Trop. Med. 40, 861 (1947); Snijders, E. P., S. Postmus \& W. A. P. Schüfrner, Amer. J. Trop. Med. 14, 519 (1934a); Ned. Tschr. Geneeskd. 78, 3253 (1934d)

Soper, F. L., Rev. Hyg. Saude Publ. Rio 8, 37 (1934a), 8, 73 (1934b); Bol. Of. San. Panamer. 14, 204 (1935a); Rev. Hig. Bogota 4, 49 (1935 b); Bull. Health Organ. League Nat. 5, 19 (1936a); Amer. J. Publ. Health 27, 1 (1937 a); Amer. J. Trop. Med. 17, 457 (1937b); Bull. Off. Intern. Hyg. Publ. 30, 1205 (1938); Transact. Roy. Soc. Trop. Med. 32, 297 (1939); in: Clinic of tropical Medicine von Bercovitz (New York 1943); Bol. Of. San. Panamer. 32, 197 (1952); Amer. J. Trop. Med. Hyg. 4, 573 (1955); Mosquito News. 18, 203 (1958); Soper, F. L.\& A. De Andrade, Amer. J. Hyg. 18, 588 (1933); Soper, F. L., H. Beeuwhes, N. C. Davis \& J. A. Kerr, Amer. J. Hyg. 27, 351 (1938); Soper, F. L., M. Frobisher, J. A. Kerr \& N. C. Davis, J. Prev. Med. 6, 341 (1932); Soper, F. L., H. A. Penna, E. Cardozo, J. Serafim, M. Frobisher \& J. Pinheiro, Amer. J. Hyg. 18, 555 (1933); Soper, F. L., E. R. Rickard \& P. J. Crawford, Amer. J. Hyg. 19, 549 (1934); Soper, F. L. \& H. H. Smith, Amer. J. Trop. Med. 18, 111 (1938a); Acta 3. Conv. Trop. Malaria Morbis Amsterdam I, 295 (1938b)

Southam, C. M. \& V. I. Babcock, Proc. Soc. exper. Biol. 78, 105 (1951); Southam, C. M. \& A. E. Moore, Amer. J. Trop. Med. 31, 724 (1951); J. Immunol. 72, 446 (1954b)

Speers, R. W., S. Katz, T. V. Parran \& A. Steer, J. Labor. Clin. Med. 46, 28 (1955)

Speir, R. W.\& C. M. Southam, Ann. N. Y. Acad. Sci. 83, 551 (1960) 
Spence, L. P., C. R. Anderson, T. H. G. Aithen \& W. G. Down, Amer. J. Trop. Med. Hyg. 11, 414 (1962 a), 11, 687 (1962 b); Spence. L. P., W. G. Downs, C. Boyd \& T. H. G. Aitken, West Indian med. J. 9, 273 (1960); Spence, L. P. \& L. Thomas, Transact. Roy. Soc. Trop. Med. 53, 248 (1959)

Sprague, H. B. \& J. H. Barnard, US Navy Med. Bull. 45, 71 (1945)

Stansly, P. G. \& D. S. Ramsey, Proc. Soc. Exper. Biol. 103, 20 (1960)

Stefanopoulo, G. J., Bull. Soc. Path. Exot. 22, 538 (1929), 25, 866 (1932); Ann. Inst. Pasteur 52, 443 (1934a), 52, 553 (1934b); Bull. Soc. Path. Exot. 29, 359 (1936), 30, 523 (1937); Acta 3. Conv. Trop, Malaria Morbis, Amsterdam I, 379 (1939); Stefanopoulo, G. J. \& G. Callinicos, Compt. rend. Soc. Biol. 110, 1270 (1932); Stefanopoulo, G. J. \& S. Duvolon, Bull. Soc. Path. Exot. 36, 76 (1943); Bull. Mém. Soc. Méd. Hôp. Paris 63, 990 (1947a); Bull. Soc. Path. Exot. 40, 285 (1947b); Stefanopoulo, G. J., P. Laurent \& R. Wassermann, Compt. rend. Soc. Biol. 122, 915 (1936); Stefanopoulo, G. J., P. Mollaret \& E. Desnos, Bull. Soc. Path. Exot. 27, 816 (1934); Stefanopoulo, G. J. \& Y. Nagano, Compt. rend. Soc. Biol. 128, 334 (1937); Stefanopoulo, G. J. \& R. Wassermann, Bull. Soc. Path. Exot. 26, 557 (1933)

Stern, L., Central Afric. J. Med. 4, 281 (1958)

Stevenson, L. D., Arch. Path. 27, 249 (1939)

Stewart, F. H., US Naval Med. Bull. 42, 1233 (1944)

Steyn, J. J. \& K. H. Schulz, Annual Rep. South Afric. Inst. Med. Res. (1953); South Afric. Med. J. 29, $1114(1955)$

Sт. John, J. H. \& R. L. Holt, Amer. J. Trop. Med. 11, 325 (1931); Sт. John, J. H., J. S. Simons \& F. H. K. Reynolds, Amer. J. Trop. Med. 10, 23 (1930a); Philippine J. Sci. 41, $381(1930 \mathrm{~b})$

Stokes, A., J. H. Bauer \& N. P. Hudson, Amer. J. Trop. Med. 8, 103 (1928a); J. Amer. Med. Assoc. 90, $253(1928 \mathrm{~b})$

Strandström, H., K. Sandelin \& N. Oker-Blom, Virology 16, 384 (1962)

Stuart, G., WHO Monogr. Ser. 30, 143 (1956)

Sulkin, S. E. \& C. Zarafonetis, J. Exper. Med. 85, 559 (1947)

Sulzberger, M. B. \& C. Asher, US Navy Med. Bull. 40, 411 (1942)

Sunaga, H., R. M. Taylor \& J. R. Henderson, Amer. J. Trop. Med. Hyg. 9, 419 (1960)

Surtees, G., Bull. Entomol. Res. 50, 681 (1960)

Swartz, H. F., J. Labor. Clin. Med. 28, 1663 (1943)

Sweet, B. H., R. M. Chanock \& A. B. Sabin, Fed. Proc. 12, 462 (1953); Sweet, B. H. \& A. B. Sabin, Fed. Proc. 13, 573 (1954a); J. Immunol. 73, 363 (1954b); Sweet, B. H., C. L. Wisseman, M. Kitaoka \& T. Tamiya, Amer. J. Trop. Med. Hyg. 11, 562 (1962)

Swift, W. E., Ann. Intern. Med. 38, 102 (1953)

Swift, S., Brit. Med. J. 1955 II, 677

Symposium on Epidemic Hemorrhagic Fever, Ann. Int. Med. 38, 53 (1953); Amer. J. Med. 16, 617 (1954)

Takahara, M. \& S. Hotta, Science 134, 1878 (1961)

Takemori, N., M. Nakano, M. Hemmi, H. Ikeda, S. Yanagida \& M. Kitaoka, Nature 174, 698 (1954); Takemori, N., M. Nakano, M. Hemmi \& M. Kitaoka, Virology 1, 58 (1955 b)

Taniguchi, T., T. Fusino, S. Inoki \& OKuno, Med. J. Osaka Univ. 2, 1(1951); TANiguchi, T., M. Hosokawa \& S. Kuga, Jap. J. exper. Méd. 14, 185 (1936)

Tatarintzev, N. M., V. P. Bisyiazina \& R. M. Kverel, Pediatrija (Moskau) 6, 43 (1952)

Taussig, S., Wien. klin. Wschr. 18, 129 (1905a), 18, 163 (1905b), 18, 196 (1905 c)

TAYLoR, R. M., in: Yellow Fever von Strode 427 (New York 1951); J. Immunol. 68, 473 (1952); 6. Intern. Congr. Microbiol. Rom 3, 236 (1953 a); 5. Intern. Congr. Trop. Med. Malaria, Konstantinopel (1953b), Yale J. Biol. Med. 32, 16 (1959); Amer. J. Trop Med. Hyg. 11, 169 (1962); Taylor, R. M. \& J. Fonseca DA Cunha, Amer. J. Trop. Med. Suppl. 26, 1 (1946); Taylor, R. M., M. A. Haseeb \& T. H. Work, Bull. WHO 12, 711 (1955a); Taylor, R. M. \& H. S. Hurlbut, J. Egypt. Med. Assoc. 36, 199 (1953a), 36, 489 (1953b); Taylor, R. M., H. S. Hurlbut, J. R. Work, J. R. Kingston \& T. E. Frothingham, Amer. J. Trop. Med. Hyg. 4, 844 (1955b); Taylor, R. M. \& M. Theiller, 4. Intern. Congr. Tropenmed. Malaria, Washington 1, 506 (1948); TAYLOR, R. M., T. H. Work, H. S. Hurlbut \& F. Rizk, Amer. J. Trop. Med. Hyg. 5, 579 (1956)

T. B. Med. 240 Dep. Army Techn. Bull. Epidemic Hemorrhagic Fever Washington (1953)

Tedeschi, A. \& M. Napolitenni, Zbl. Bakt. I. Orig. 57, 208 (1911a), 61, 502 (1911b)

Teesdale, C., Bull. Entomol. Res. 46, 712 (1955)

Tenbroeck, C. \& M. H. Merill, Proc. Soc. exper. Biol. 31, 217 (1933) 
Thalhammer, O., Ann. Paediatr. Basel 181, 257 (1953)

Theiler, M., Ann. Trop. Med. Parasit. 24, 249 (1930a); Science 71, 367 (1930b); Amer. J. Trop. Med. 13, 399 (1933a); Ann. Trop. Med. Parasit. 27, 57 (1933b); in: Yellow Fever von Strode 38 (New York 1951); in: Viral and rickettsial Infections of Man von Rivers, 2. Aufl. 552 (Philadelphia 1952); Proc. Soc. exper. Biol. 96, 380 (1957); Theiler M. \& J. Casals, Amer. J. Trop. Med. Hyg. 7, 585 (1958); Klin. Wschr. 37, 59 (1959); Theiler, M., J. Casals \& C. Mouttousses, Proc. Soc. exper. Biol. 103, 244 (1960); Theiler, M., \& D. H. Clarke, in: Viral and Rickettsial Infections of Man von Rivers \& Horsfall, 3. Aufl. 391 (Philadelphia 1959); Theiler, M. \& T. P. Hughes, Transact. Roy. Soc. Trop. Med. 28, 481 (1935); Theiler, M. \& A. W. Sellards, Amer. J. trop. Med. 6, 383 (1926); Theiler, M. \& H. H. Sмith, Bull. Off. Intern. Hyg. Publ. 28, 2354 (1936); J. exper. Med. 65, 767 u. 787 (1937)

Thomas, H. W., Brit. Med. J. 1907 I, 138

Thomas, L. A.\& C. M. EkLund, J. Infect. Dis. 107, 235 (1960)

Thomas, T. C. E., West Afric. Med. J. 9, 163 (1960)

Thompson, R. K. \& A. R. Lavender, Proc. Soc. exper. Biol. 84, 483 (1953)

Thompson, W. O., Brit. Med. J. 1955 II, 182

Tiggert, W. D., Berge, T. O.\& W. S. Gouchenour, Trans. New. York Acad. Sci. 22, 323 (1960)

Tinker, M. E. \& G. R. Hayes, Mosquito News 19, 73 (1958)

Toda, T. \& Y. Nakagawa, Hukuoka Acta Med. 37, 663 (1944)

Tokoro, Y., Transact. Soc. Path. Jap. 34, 7 (1944)

TokUdA, M., Transact. Biogr. Soc. Jap. 4, 1 (1941)

Toomey, N., Ann. Int. Med. 5, 585 (1931)

Topping, N. H., J. S. Cullyford \& G. E. Davis, Publ. Health Rep. 55, 2224 (1940)

Torres, C. M., Mem. Inst. Oswaldo Cruz 19, 13 (1926); Brasil. Med. 42,1101 (1928a); Compt. rend. Soc. Biol. 99, 1344 (1928b), 99, 1655 (1928c), 99, 1660 (1928d), 99, 1669 (1928e), 99, 1671 (1928f); Mem. Inst. Oswaldo Cruz Suppl. 55, (1928g); Sci. Med. 6, 427 (1928h); Compt. rend. Soc. Biol. 100, 966 (1929a), 101, 951 (1929b), 101, 959 (1929c), 102, 410 (1929 d), 102, $414(1929 \mathrm{e}), 105,727$ (1930a), 105, 732 (1930b); Mem. Inst. Oswaldo Cruz 25, 81 (1931); Schweiz. Z. allgem. Path. 16, 522 (1953); Torres, C. M. \& J. Penna-Azevedo, Compt. rend. Soc. Biol. 99, 1673 (1928)

Trapido, H. \& P. Galindo, Amer. J. Trop. Med. Hyg. 4, 665 (1955); Exper. Parasitol. 3, 285 (1956); Science 123, 634 (1956 b); Amer. J. Trop. Med. Hyg. 6, 114 (1957) Trapido, H., P. Galindo \& S. J. Carpenter, Amer. J. Trop. Med. Hyg. 4, 525 (1955); Trapido, H., P. K. Rajagopalan, T. H., Work \& M. G. R. Varma, Indian H. med. Res. 47, 133 (1959)

Traub, R., M. Hertig, W. H. Lawrence \& T. T. Jarris, Amer. J. Hyg. 59, 291 (1954)

Treesdale, C:, Bull. Entomol. Res. 46, 712 (1955)

Trejos, A. \& A. Romero, Rev. Biol. Trop. 2, 69 (1954)

Trencseni, T. B., Kelcti, A. Kineses, J. Szabo, H. Szentesi \& F. Barcsay, Acta Med. Acad. Sci. Hung. 7, 59 (1955)

Tsukada, H., Y. Koseki, A. Inoue \& K. Shimpo, Jap. Med. J. 18, 419 (1960)

Turner, R. H., J. R. Snaveley, E. B. Grossmann, R. N. Buchanan \& S. O. Foster, Ann. Int. Med. 20, 193 (1944)

Urban, H. J., Medizinische 1954, 855

Usinger, R. L., Publ. Health Rep. 59, 423 (1944)

Uttley, K. H., West Indian Med. J. 9, 185 (1960)

Vargas-Mendez, O. \& N. W. Elton, Amer. J. Trop. Med. Hyg. 2, 850 (1953)

Varma, M. G. R., H. E. Webb \& K. M. Parvi, Transact. Roy. Soc. Trop. Med. 54, 909 (1960)

Vilches, A. \& G. K. Hirst, J. Immunol. 57, 125 (1947)

Villela, E., Arch. Path. 31, 665 (1941)

Voges, W. DA, Bull. Off. Intern. Hyg. Publ. 22, 282 (1930)

Waddell, M. B., Amer. J. Trop. Med. 25, 329 (1945), 29, 567 (1949); Waddel, M. B. \& H. W. KumM, Amer. J. Trop. Med. 28, 247 (1948); WADD́ELL, M. B. \& R. M. TAYLOR, Amer. J. Trop. Med. 25, 225 (1945), 26, 455 (1946), 27, 471 (1947); 28, 87 (1948)

WAGNER, R. R., Bact. Rev. 24, 151 (1960)

Wakeman, A. M. \& C. A. Morrelu, Arch. Intern. Med. 49, 826 (1932)

Walcott, A. M., E. Cruz, A. Paoliello \& J. Serafim, Amer. J. Trop. Med. 17, 677 (1937) 
Walker, A. S., E. Meyers, A. R. Woodhill \& R. N. MaCCulloch, Med. J. Austral. 1942 II, 223

Wanson, M. \& R. Lebiad, Arch. Inst. Pasteur Alger. 24, 153 (1946)

WARREN, A. J., in: Yellow Fever von Strode 1 (New York, 1951)

Webi, H. E. \& L. R. Rav, Transact. Roy. Soc. Trop. Med. 55, 284 (1961)

Webster, L. T. \& G. L. Fite, Science 78, 463 (1933)

WECKER, E., Virology 7, 241 (1959)

WeEKLY Epidem. Rec. Nr. 27, 333 (1962)

Weinbren, M. P., Transact. Roy. Soc. Trop. Med. 52, 259 (1958); Weinbren, M. P., A. J. Haddow \& M. C. Williams, Transact. Roy. Soc. Trop. Med. 52, 253 (1958a), 52, 258 (1958b); Weinbren, M. P., C. S. Heymann, R. H. Kokernot \& H. E. Paterson, South Afric. J. Med. Sci. 22, 93 (1957 a); Weinbren, M. P., R. H. Kokernot \& K. C. Smithburn, South Afric. Med. J. 30, 631 (1956); Weinbren, M. P. \& R. J. Mason, South Afric. Med. J. 31, 427 (1957), Weinbren, M. P., M. C. Williams, Trans. Roy. Soc. Trop. Med. 52, 263 (1958); Weinbren, M. P., M. C. Williams \& A. J. Haddow, South Afric. Med. J.. 31, $951(1957 \mathrm{~b})$

Weiss, K. E., Bull. Epizoot. Dis. Africa 5, 431 (1957); Weiss, K. E., D. Haig \& R. A. AleXANDER, Onderstep. J. vet. Res. 27, 183 (1956)

WHO: Regulations Nr. 2 (1952); Cronicles 10, Nr. 9/10 (1956 a); Monogr. Ser. Nr. 30 (1956b); Technical Rep. Ser. 136 (1957), 179 (1959); Chronicle 15, 141 (1961a); International San. Reg. 2. Aufl. (Genf 1961b); Technical Rep. Ser. 219, (1961c)

Wharton, G. W. \& H. S. Fuller, Mem 4. Entomol. Soc. Wash. 185 (1952)

Whitman, L., J. Immunol. 29, 99 (1935); J. exper. Med. 66, 133 (1937); Amer. J. Trop. Med. 19, 19 (1939), 23, 17 (1943); in: Yellow Fever von Strode 229 (New York, 1951); W Hiтman, L. \& P. C. A. Antunes, Amer. J. Trop. Med. 17, 803 (1937), 18, 135 (1938a); Proc. Soc. exper. Biol. 37, 664 (1938b); Whitman, L. \& J. Casals, Amer. J. Trop. Med. 10, 259 (1961); Whitman L. \& R. E. Shope, Amer. J. Trop. Med. 11, 641 (1962)

Whittingham, H., J. State Med. 32, 461 (1924)

WieB ENGA, N. H., Amer. J. Hyg. 73, 350 (1961 a), 73, 365 (1961 b)

Williams, M. C., Ann. Trop. Med. Parasit. 50, 150 (1956); Williams, M. C. \& J. P. Woodall, Transact. Roy. Soc. Trop. Med. 55, 135 (1961); Williams, M. C., J. P. Woodall \& J. S. Porterfield, Transact. Roy. Soc. Trop. Med. 56, 166 (1962)

Wisseman, C. L. \& B. H. Sweet, Amer. J. Trop. Med. Hyg. 11, 570 (1962); Wisseman, C. L., B. H. Sweet, M. Kitaoka \& T. Tamiya, Amer. J. Trop. Med. Hyg. 11, 550 (1962)

Woke, P. A., Amer. J. Hyg. 25, 372 (1937)

Wolff, J. W., W. A. Collier, H. de Roever-Bonnet \& J. Hoekstra, Trop. Geogr. Med.. Amsterdam 10, 325 (1958)

Woodall, J. P.\& D. S. Bertram, Transact. Roy. Soc. Trop. Med. 53, 440 (1959), 54, 263 (1960)

Woodward, T. E., Rep. Field Unit. Comm. on Hemorrhagic Fever Armed Forces Epidem. Board (1953)

Work, T. H., Progr. Med. Virol. 1, 248 (1958); Work, T. H., F. R. Roderiguez \& P. N. Bhatt, Amer. J. Publ. Health 49, 869 (1959); Work, T. H. \& H. Trapido, Indian J. Med. Sci. 11, 340 (1957); 9. Pacific Sci. Congr. (1959); Work, T. H., H. Trapido, D. P. N. Murthy, R. L. RaO, P. Bhatt \& G. KulKami, Indian J. Med. Sci. 11, 619 (1957)

Worth, C. B., J. de Sousa \& M. P. Weinbren, Bull. Entom. Res. 52, 257 (1961)

Yamafugi, K. \& A. Ueda, Enzymologica 14, 107 (1950)

YaoI, H. \& S. Arakawa, Jap. Med. J. 1, 4 (1948); Yaor, H., I. Tagaya \& Y. Ozawa, Yokohama Med. Bull. 5, 68 (1954)

Young, T. C. Mc., C. A. E. Richmond \& G. R. Brendish, Indian J. Med. Res. 13, 961 (1926)

Zeitlenok, N. A., K. A. Vanag \& E. R. Pille, Vopros. Virus. 2, 92 (1957)

Zhdanov, W. M., Viren bei Mensch und Tier (dtsch. Übersetzung) (Jena 1957)

ZoecKLeR, S. J. \& J. A. Orbison, Ann. Int. Med. 43, 1316 (1955)

ZüLzer, W., in: Handbuch der speziellen Pathologie von ZIemsSen 2, 482 (Leipzig 1874) 